\title{
Comparative Effectiveness of Analgesics To Reduce Acute Pain in the Prehospital Setting
}


Number 220

\section{Comparative Effectiveness of Analgesics To Reduce Acute Pain in the Prehospital Setting}

Prepared for:

Agency for Healthcare Research and Quality

U.S. Department of Health and Human Services

5600 Fishers Lane

Rockville, MD 20857

www.ahrq.gov

Contract No. 290-20-1500012-I

Prepared by:

University of Connecticut Evidence-based Practice Center

Storrs, CT

Investigators:

Diana M. Sobieraj, Pharm.D.

William L. Baker, Pharm.D.

Brandon K. Martinez, Pharm.D.

Benjamin Miao, Pharm.D.

Adrian V. Hernandez, M.D., Ph.D.

.Craig I. Coleman, Pharm.D.

Mark X. Cicero, M.D.

Richard A. Kamin, M.D.

AHRQ Publication No. 19-EHC021-EF

September 2019 


\section{Key Messages}

\section{Purpose of Review}

To evaluate effectiveness and harms of opioids compared to nonopioid analgesics as treatment of moderate to severe acute pain in the prehospital setting.

\section{Key Messages}

- As initial therapy in the prehospital setting:

- Nonsteroidal anti-inflammatory drugs provide similar pain relief to opioids and may cause fewer overall side effects and less drowsiness.

- Acetaminophen may provide similar pain relief to opioids, and may cause fewer side effects overall and less dizziness.

- Ketamine may provide similar pain relief to opioids. Ketamine may cause more dizziness or overall side effects, while opioids may cause more respiratory depression.

- Combining an opioid with ketamine may be more effective in reducing pain compared with opioids alone.

- If morphine does not adequately relieve pain, changing to ketamine may be more effective and more quickly reduce pain than giving additional morphine.

\section{Caveats}

- Few studies have been conducted in the prehospital setting; we relied on evidence from the emergency department.

- Analgesics were primarily administered intravenously; this was the only route studied for acetaminophen. The intranasal route was common in studies reporting adverse events for the comparison of opioids versus ketamine. 
This report is based on research conducted by the University of Connecticut Evidence-based Practice Center (EPC) under contract to the Agency for Healthcare Research and Quality (AHRQ), Rockville, MD (Contract No. 290-2015-00012-I). The findings and conclusions in this document are those of the authors, who are responsible for its contents; the findings and conclusions do not necessarily represent the views of AHRQ. Therefore, no statement in this report should be construed as an official position of AHRQ or of the U.S. Department of Health and Human Services.

\section{None of the investigators have any affiliations or financial involvement that conflicts with the material presented in this report.}

The information in this report is intended to help healthcare decision makers - patients and clinicians, health system leaders, and policymakers, among others-make well-informed decisions and thereby improve the quality of healthcare services. This report is not intended to be a substitute for the application of clinical judgment. Anyone who makes decisions concerning the provision of clinical care should consider this report in the same way as any medical reference and in conjunction with all other pertinent information, i.e., in the context of available resources and circumstances presented by individual patients.

This report is made available to the public under the terms of a licensing agreement between the author and the Agency for Healthcare Research and Quality. This report may be used and reprinted without permission except those copyrighted materials that are clearly noted in the report. Further reproduction of those copyrighted materials is prohibited without the express permission of copyright holders.

AHRQ or U.S. Department of Health and Human Services endorsement of any derivative products that may be developed from this report, such as clinical practice guidelines, other quality enhancement tools, or reimbursement or coverage policies, may not be stated or implied.

This report may periodically be assessed for the currency of conclusions. If an assessment is done, the resulting surveillance report describing the methodology and findings will be found on the Effective Health Care Program website at www.effectivehealthcare.ahrq.gov. Search on the title of the report.

People using assistive technology may not be able to fully access information in this report. For assistance contact EPC@ahrq.hhs.gov.

Suggested citation: Sobieraj DM, Baker WL, Martinez BK, Miao B, Hernandez AV, Coleman CI, Cicero MX, Kamin RA. Comparative Effectiveness of Analgesics To Reduce Acute Pain in the Prehospital Setting. Comparative Effectiveness Review No. 220. (Prepared by the University of Connecticut Evidence-based Practice Center under Contract No. 290-2015-00012-I.) AHRQ Publication No. 19-EHC021-EF. Rockville, MD: Agency for Healthcare Research and Quality; August 2019. Posted final reports are located on the Effective Health Care Program search page. DOI: https://doi.org/10.23970/AHRQEPCCER220. 


\section{Preface}

The Agency for Healthcare Research and Quality (AHRQ), through its Evidence-based Practice Centers (EPCs), sponsors the development of evidence reports and technology assessments to assist public- and private-sector organizations in their efforts to improve the quality of healthcare in the United States. The National Highway Traffic Safety Administration (NHTSA) requested this report from the EPC Program at AHRQ and provided funding for the report. AHRQ assigned this report to the following EPC: University of Connecticut Evidencebased Practice Center (Contract Number 290-20-1500012-I).

The reports and assessments provide organizations with comprehensive, evidence-based information on common medical conditions and new healthcare technologies and strategies. They also identify research gaps in the selected scientific area, identify methodological and scientific weaknesses, suggest research needs, and move the field forward through an unbiased, evidence-based assessment of the available literature. The EPCs systematically review the relevant scientific literature on topics assigned to them by AHRQ and conduct additional analyses when appropriate prior to developing their reports and assessments.

To bring the broadest range of experts into the development of evidence reports and health technology assessments, AHRQ encourages the EPCs to form partnerships and enter into collaborations with other medical and research organizations. The EPCs work with these partner organizations to ensure that the evidence reports and technology assessments they produce will become building blocks for healthcare quality improvement projects throughout the Nation. The reports undergo peer review and public comment prior to their release as a final report.

AHRQ expects that the EPC evidence reports and technology assessments, when appropriate, will inform individual health plans, providers, and purchasers as well as the healthcare system as a whole by providing important information to help improve healthcare quality.

If you have comments on this evidence report, they may be sent by mail to the Task Order Officer named below at: Agency for Healthcare Research and Quality, 5600 Fishers Lane, Rockville, MD 20857, or by email to epc@ahrq.hhs.gov.

Gopal Khanna, M.B.A.

Director

Agency for Healthcare Research and Quality

Stephanie Chang, M.D., M.P.H.

Director

Evidence-based Practice Center Program

Center for Evidence and Practice Improvement Agency for Healthcare Research and Quality
Arlene S. Bierman, M.D., M.S.

Director

Center for Evidence and Practice Improvement

Agency for Healthcare Research and Quality

David W. Niebuhr, M.D., M.P.H., M.Sc.

Task Order Officer

Center for Evidence and Practice

Improvement

Agency for Healthcare Research and Quality 


\section{Acknowledgments}

The authors gratefully acknowledge the contribution of the EPC librarian, Sharon Giovenale, for her contribution to the literature search and citation retrieval process. We would like to acknowledge the affiliations of our content experts:

University of Connecticut School of Medicine (Richard A. Kamin); Yale School of Medicine (Mark X. Cicero);

\section{Technical Expert Panel}

In designing the study questions and methodology at the outset of this report, the EPC consulted several technical and content experts. Broad expertise and perspectives were sought. Divergent and conflicted opinions are common and perceived as healthy scientific discourse that results in a thoughtful, relevant systematic review. Therefore, in the end, study questions, design, methodologic approaches, and/or conclusions do not necessarily represent the views of individual technical and content experts.

Technical Experts must disclose any financial conflicts of interest greater than $\$ 5,000$ and any other relevant business or professional conflicts of interest. Because of their unique clinical or content expertise, individuals with potential conflicts may be retained. The TOO and the EPC work to balance, manage, or mitigate any potential conflicts of interest identified.

The list of Technical Experts who provided input to this report follows:

Kathleen Brown, M.D.

Children's National Health System

Washington, D.C.

James J. Gasper, PharmD, B.C.P.P.

Psychiatric and Substance Use Disorder Pharmacist, Pharmacy Benefits Division

California Department of Health Care Services

Sacramento, CA

Marianne Gausche-Hill, M.D., FACEP, FAAP, FAEMS*

Medical Director, Los Angeles County EMS Agency

Professor of Emergency Medicine and Pediatrics, David Geffen School of Medicine at UCLA

Harbor-UCLA Medical Center

Torrance, $\mathrm{CA}$

Mark Gestring, M.D., FACS*

Kessler Trauma Center, University of Rochester School of Medicine

Rochester, NY

Richard Hunt, M.D., FACEP

U.S. Department of Health and Human Services

Washington, D.C. 
Douglas F. Kupas, M.D., FAEMS, FACEP, EMT-P*

Geisinger Health System

Danville, PA

Jennifer Nadel, M.D.*

U.S. Food and Drug Administration

Silver Spring, MD

P. Daniel Patterson, Ph.D., M.P.H., M.S., N.R.P.

University of Pittsburgh

Pittsburgh, PA

Col. Todd Rasmussen, M.D., FACS

U.S. Department of Defense

Fort Detrick, MD

Manish I. Shah, M.D., M.S.*

Baylor College of Medicine

Texas Children's Hospital

Houston, TX

J. Matthew Sholl, M.D.

State of Maine EMS

Augusta, ME

William Zempsky, M.D.*

Connecticut Children's Medical Center

Hartford, CT

*Provided input on Draft Report.

\section{Peer Reviewers}

Prior to publication of the final evidence report, EPCs sought input from independent Peer Reviewers without financial conflicts of interest. However, the conclusions and synthesis of the scientific literature presented in this report do not necessarily represent the views of individual reviewers.

Peer Reviewers must disclose any financial conflicts of interest greater than $\$ 5,000$ and any other relevant business or professional conflicts of interest. Because of their unique clinical or content expertise, individuals with potential nonfinancial conflicts may be retained. The TOO and the EPC work to balance, manage, or mitigate any potential nonfinancial conflicts of interest identified.

The list of Peer Reviewers follows: 
David Callaway, M.D., MPA

Carolinas Medical Center

Charlotte, NC

David Gerstner

City of Dayton Fire Department

Dayton, $\mathrm{OH}$

Julie C. Leonard, M.D., M.P.H.

Ohio State University College of Medicine

Columbus, $\mathrm{OH}$

James Robinson

Denver Health EMS-Paramedic Division

Denver, CO 


\section{Comparative Effectiveness of Analgesics To Reduce Acute Pain in the Prehospital Setting}

\section{Structured Abstract}

Objective. To assess comparative effectiveness and harms of opioid and nonopioid analgesics administered by emergency medical services for treatment of moderate to severe acute pain in the prehospital setting.

Data sources. MEDLINE ${ }^{\circledR}$, Embase $^{\circledR,}$ and Cochrane Central from earliest date through May 9, 2019; hand searches of references of relevant studies and study registries.

Review methods. Two investigators screened abstracts, reviewed full-text files, abstracted data, and assessed study-level risk of bias. We performed meta-analyses when appropriate and graded the strength of evidence (SOE) upon which conclusions were made for a priori determined comparisons and outcomes. We defined the following as clinically important differences: 2 points on a 0 to 10 pain scale; time to analgesia of 5 minutes; 10 -percent absolute risk difference for any adverse event; and 5-percent absolute risk difference for hypotension, respiratory depression, and mental status changes.

Results. We included 52 randomized controlled trials and 13 observational studies. Due to the absence or insufficiency of prehospital evidence we based conclusions for initial analgesia on indirect evidence from the emergency department setting. As initial analgesics, we found no evidence of a clinically important difference in the change of pain scores with opioids versus ketamine administered primarily intravenously (IV) (low SOE), IV acetaminophen (APAP) (low SOE), or nonsteroidal anti-inflammatory drugs (NSAIDs) administered primarily IV (moderate SOE). The combined use of an opioid and ketamine, administered primarily IV, may reduce pain more than an opioid alone at 15 and 30 minutes (low SOE), but we found no evidence of a clinically important difference at 60 minutes (low SOE). We found no evidence of a clinically important difference in time to analgesia with opioids compared with APAP, both administered IV. Opioids may cause fewer adverse events than ketamine (low SOE), primarily administered intranasally. Opioids cause less dizziness than ketamine (low SOE) but may increase the risk of respiratory depression compared with ketamine (low SOE), primarily administered IV. Opioids cause more dizziness (moderate SOE) and may cause more adverse events than APAP (low SOE), both administered IV, but we found no evidence of a clinically important difference in hypotension (low SOE). Opioids may cause more adverse events and more drowsiness than NSAIDs (low SOE), administered primarily IV. Evidence on comparative effects of nitrous oxide and on harms of combined opioid and ketamine is insufficient.

For patients whose pain is not adequately reduced by IV morphine initially, we found that giving IV ketamine may reduce pain more and may be quicker than giving additional IV morphine (low SOE, insufficient evidence to determine comparative harms).

Conclusion. As initial analgesia administered primarily IV, opioids are no different than ketamine, APAP, and NSAIDs in reducing acute pain in the prehospital setting. Opioids may cause fewer total side effects than ketamine, but more than APAP or NSAIDs. Differences in 
specific side effects vary between analgesics and can further inform treatment decisions. Combined administration of an opioid and ketamine may reduce acute pain more than an opioid alone, but comparative harms are uncertain. When initial morphine is inadequate in reducing pain, giving ketamine may provide greater and quicker acute pain relief than giving additional morphine, although comparative harms are uncertain. Due to indirectness, SOE is generally low, and future research in the prehospital setting is needed. 


\section{Contents}

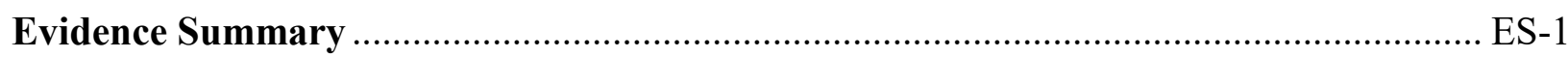

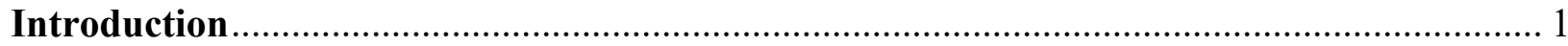

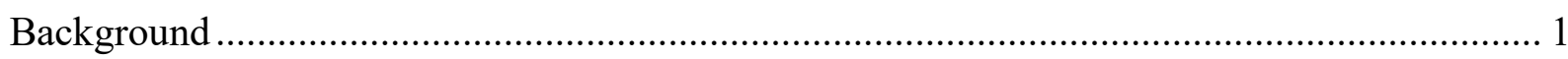

Management of Acute Pain in the Prehospital Setting ........................................................ 1

Impetus for the Review ................................................................................................ 3

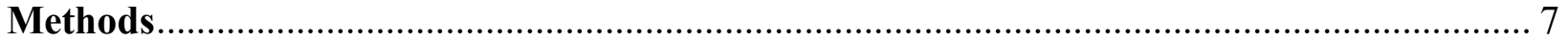

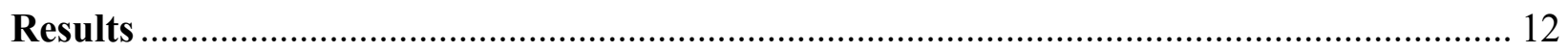

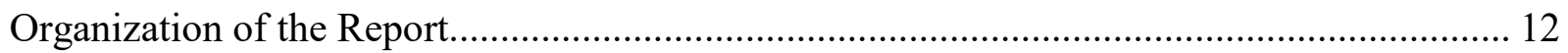

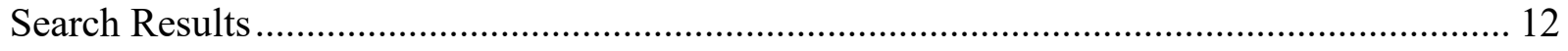

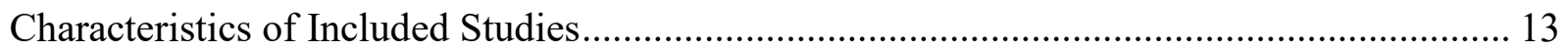

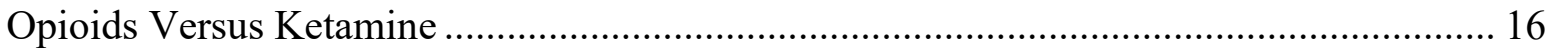

Combination of an Opioid and Ketamine Versus Opioid...................................................... 17

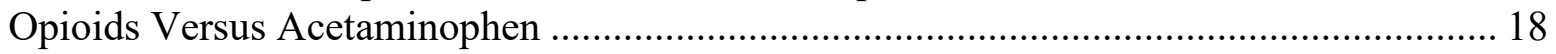

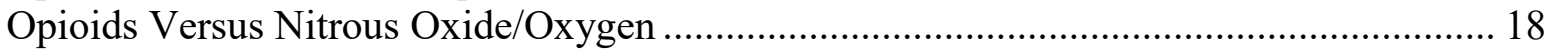

Opioids Versus Nonsteroidal Anti-Inflammatory Drugs ................................................... 18

Acetaminophen Versus Nonsteroidal Anti-Inflammatory Drugs ....................................... 19

Ketamine Versus Nonsteroidal Anti-Inflammatory Drugs .................................................... 19

Morphine Versus Fentanyl............................................................................................. 19

Combination of Opioid and Ketamine Versus Ketamine ..................................................... 20

Key Question (KQ) 1. What is the comparative effectiveness of the initial analgesic agent treatment for achieving reduction in moderate-to-severe acute-onset pain level when administered by EMS personnel in the prehospital setting? ................................................... 20

KQ 1a. How does effectiveness vary by patient characteristics? ........................................... 20

KQ 1 b. How does effectiveness vary by routes of administration, dosing, and timing?.......... 20

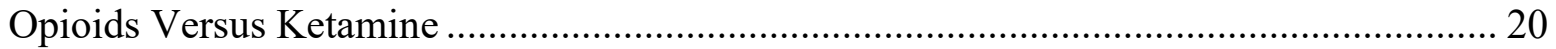

Combination of Opioid and Ketamine Versus Opioid............................................................. 24

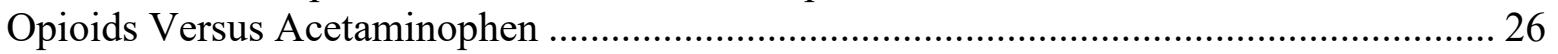

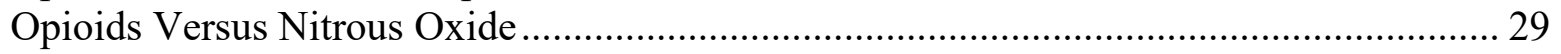

Opioids Versus Nonsteroidal Anti-Inflammatory Drugs ...................................................... 29

Acetaminophen Versus Nonsteroidal Anti-Inflammatory Drugs ............................................ 31

Ketamine Versus Nonsteroidal Anti-Inflammatory Drugs .................................................... 31

Morphine Versus Fentanyl............................................................................................. 32

KQ 2. What are the comparative harms of analgesic agents when administered by EMS personnel to control moderate-to-severe pain in the prehospital setting? ................................. 33

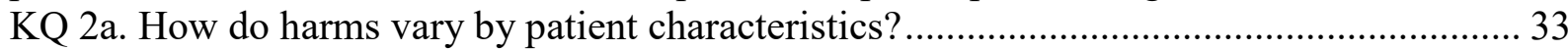

KQ 2b. How do harms vary by routes of administration, dosing, and timing? ........................ 33

KQ 2c. What are the comparative harms to EMS personnel who administer analgesics to patients for the control of moderate-to-severe pain in the prehospital setting? ......................... 33

Opioids Versus Ketamine ............................................................................................. 33

Combination of Opioids and Ketamine Versus Opioids..................................................... 38

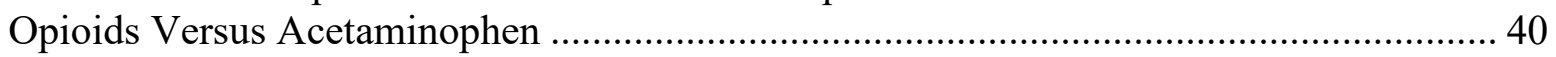

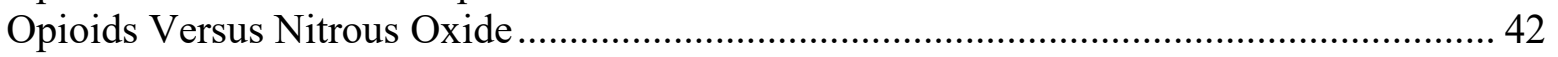

Opioids Versus Nonsteroidal Anti-Inflammatory Drugs ......................................................... 43

Acetaminophen Versus Nonsteroidal Anti-Inflammatory Drugs ........................................ 44 
Ketamine Versus Nonsteroidal Anti-Inflammatory Drugs .................................................. 44

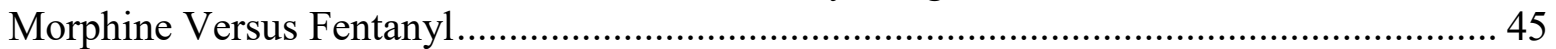

Combination of Opioid and Ketamine Versus Ketamine ................................................... 47

KQ 3. In patients whose moderate-to-severe acute-onset pain level is not controlled following initial analgesic treatment, what is the comparative effectiveness of switching the analgesic

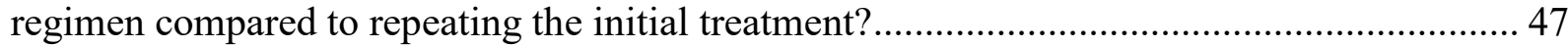

KQ 3a. How does effectiveness vary by patient characteristics? ........................................... 47

KQ 3b. How does effectiveness vary by timing of the second treatment administration? ....... 47

Additional Opioids Versus Ketamine ............................................................................ 47

KQ 4. In patients whose moderate-to-severe acute-onset pain level is not controlled following initial analgesic treatment, what are the comparative harms of switching to another analgesic

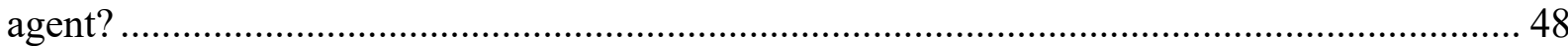

KQ 4a. How do harms vary by patient characteristics? ......................................................... 48

KQ 4b. How do harms vary by routes of administration, dosing, and timing? ....................... 48

Additional Opioids Versus Ketamine ………….............................................................. 48

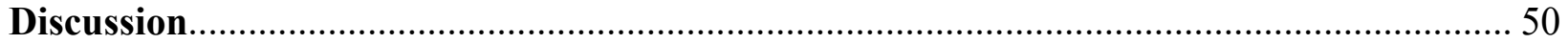

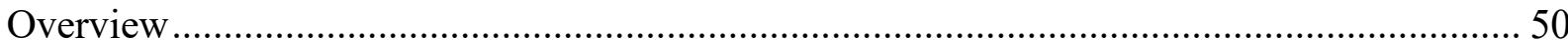

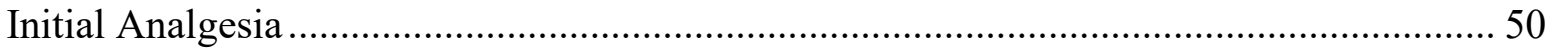

Inadequate Response to Initial Analgesia ........................................................................ 51

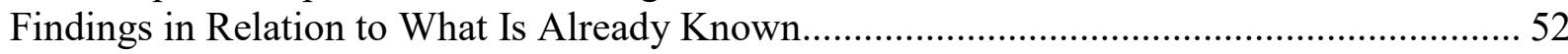

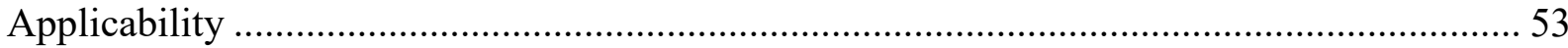

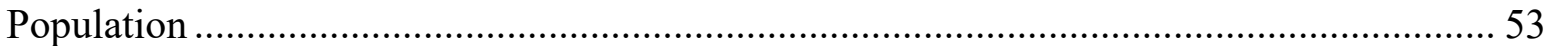

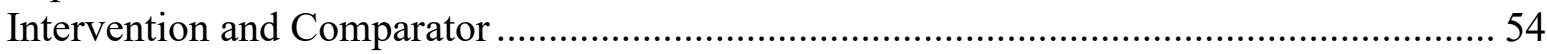

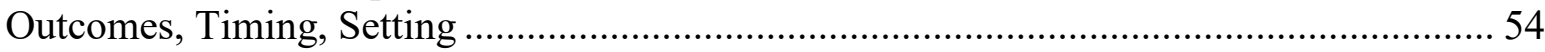

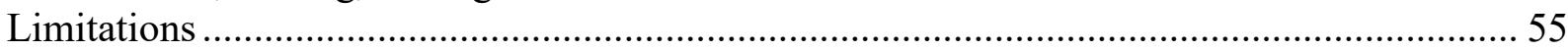

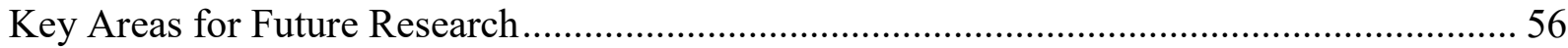

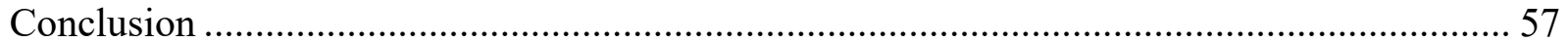

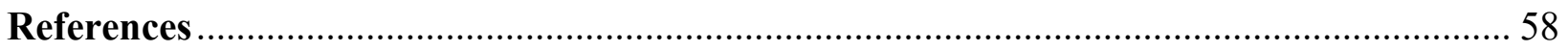

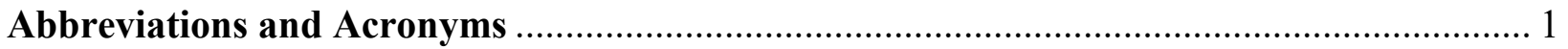

\section{Tables}

Table A. Characteristics of included studies for graded comparisons, per comparison.......ES-2

Table B. Summary of the comparative effectiveness and harms of initial analgesics in the

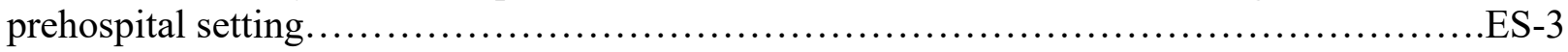

Table C. Summary of the comparative effectiveness and harms of subsequent analgesics in the

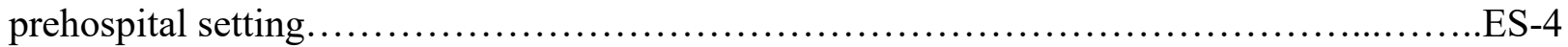

Table 1. Onset, duration, and typical initial doses for analgesics.............................................. 1

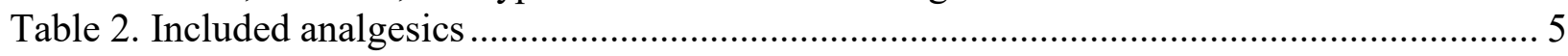

Table 3. Inclusion and exclusion criteria for Key Questions...................................................... 8

Table 4. Clinically important differences for graded outcomes .................................................. 10

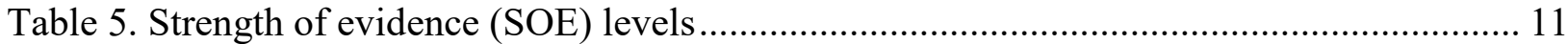

Table 6. Number of studies included in each Key Question, by comparison and study design ... 13

Table 7. Characteristics of included studies for graded comparisons, per comparison ................. 15

Table 8. Characteristics of included studies for comparisons not graded, per comparison........... 16

Table 9. Conclusions and strength of evidence for the comparison of opioids versus ketamine,

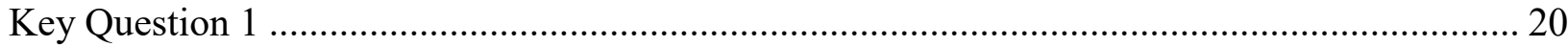


Table 10. Conclusions and strength of evidence for the comparison of combining an opioid and

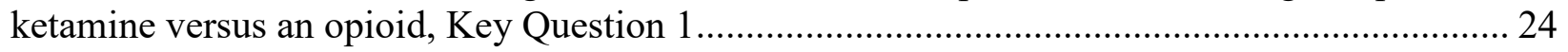
Table 11. Conclusions and strength of evidence for the comparison of opioids versus

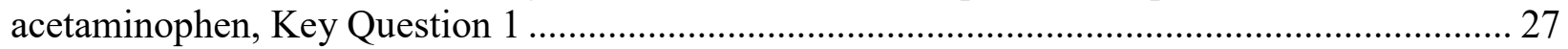

Table 12. Conclusions and strength of evidence for the comparison of opioids versus nitrous

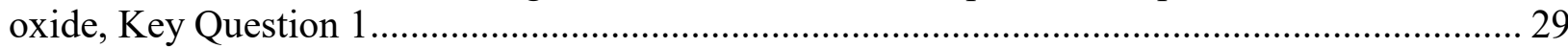

Table 13. Conclusions and strength of evidence for the comparison of opioids versus

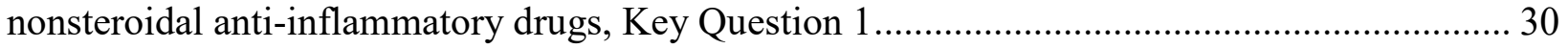

Table 14. Findings for the comparison of acetaminophen with nonsteroidal anti-inflammatory

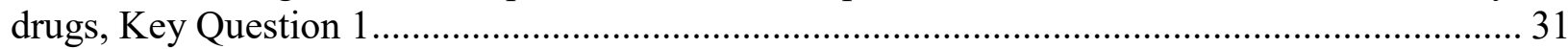

Table 15. Findings for the comparison of ketamine with nonsteroidal anti-inflammatory drugs,

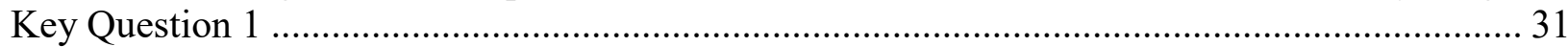

Table 16. Findings for the comparison of morphine versus fentanyl, Key Question 1 ............... 32 Table 17. Conclusions and strength of evidence for the comparison of opioids versus ketamine,

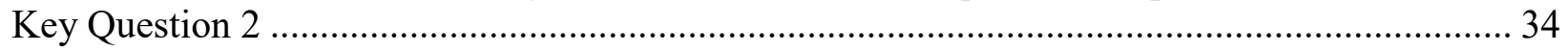

Table 18. Findings for the comparison of opioids versus ketamine, Key Question 2 ................ 37 Table 19. Conclusions and strength of evidence for the comparison of combination opioids and ketamine versus opioids, Key Question 2 .............................................................. 38 Table 20. Findings for the comparison of combination opioids and ketamine versus opioids, Key

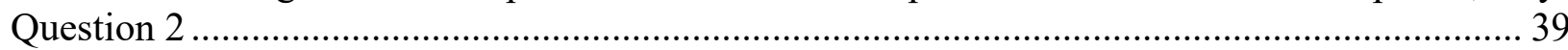

Table 21. Conclusions and strength of evidence for the comparison of opioids versus

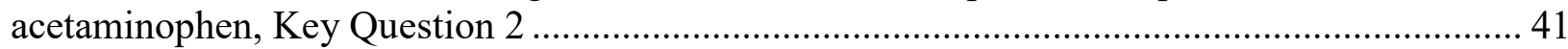

Table 22. Findings for the comparison of opioids versus acetaminophen, Key Question 2........ 42 Table 23. Conclusions and strength of evidence for the comparison of opioids versus nitrous

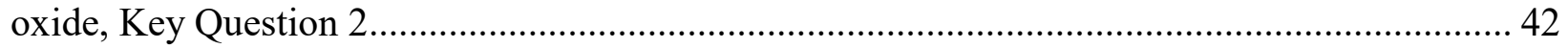

Table 24. Findings for the comparison of opioids versus nitrous oxide, Key Question 2........... 43 Table 25. Conclusions and strength of evidence for the comparison of opioids versus nonsteroidal anti-inflammatory drugs, Key Question 2 ............................................... 43

Table 26. Findings for the comparison of opioids versus nonsteroidal anti-inflammatory drugs,

Key Question 2 ............................................................................................... 44

Table 27. Findings for the comparison of acetaminophen with nonsteroidal anti-inflammatory

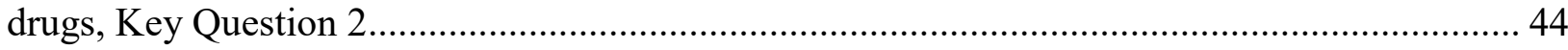

Table 28. Findings for the comparison of ketamine with nonsteroidal anti-inflammatory drugs,

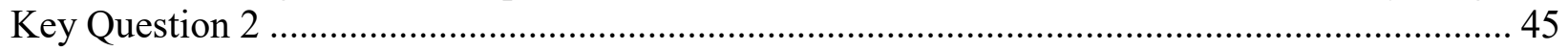

Table 29. Findings for the comparison of morphine versus fentanyl, Key Question 2 .............. 45

Table 30. Conclusions and strength of evidence for the comparison of additional opioids versus

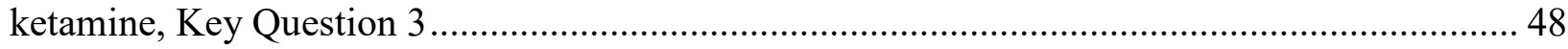

Table 31. Conclusions and strength of evidence for the comparison of additional opioids versus

ketamine, Key Question 4 ........................................................................................ 49

Table 32. Findings for the comparison of additional opioid versus ketamine, Key Question 4... 49

\section{Figures}

Figure A. Analytic framework .................................................................................... ES-1

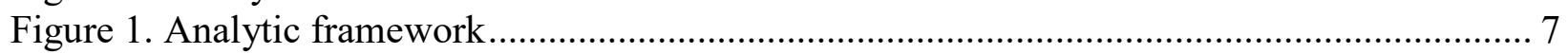

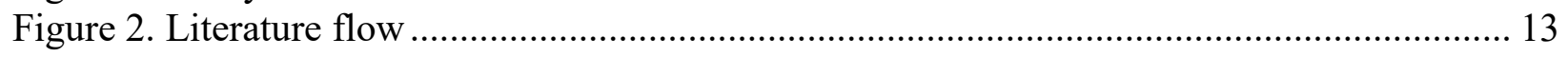

Figure 3. Change in pain scores at 15 minutes, opioids versus ketamine............................... 22

Figure 4. Change in pain scores at 30 minutes, opioids versus ketamine ............................... 22 
Figure 5. Change in pain scores at 60 minutes, opioids versus ketamine.

Figure 6. Change in pain scores at 15 minutes, combination of an opioid and ketamine versus opioid .....

Figure 7. Change in pain scores at 30 minutes, combination of an opioid and ketamine versus

opioid

Figure 8. Change in pain scores at 60 minutes, combination of an opioid and ketamine versus

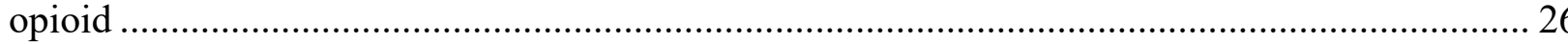

Figure 9. Change in pain scores at 15 minutes, opioids versus acetaminophen ........................ 27

Figure 10. Change in pain scores at 30 minutes, opioids versus acetaminophen ....................... 28

Figure 11. Change in pain scores at 60 minutes, opioids versus acetaminophen ....................... 28

Figure 12. Change in pain scores at 30 minutes, opioids versus nonsteroidal anti-inflammatory

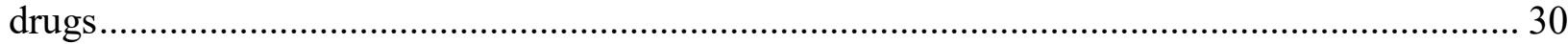

Figure 13. Change in pain scores at 60 minutes, opioids versus nonsteroidal anti-inflammatory drugs

\section{Appendixes}

Appendix A. Search Strategy

Appendix B. List of Excluded Studies

Appendix C. Evidence Tables

Appendix D. Risk of Bias Assessment

Appendix E. Strength of Evidence Assessments

Appendix F. Forest Plots 


\section{Evidence Summary}

\section{Objective and Rationale for the Review}

Appropriate management of acute pain is an integral part of patient management in the prehospital setting. The prevalence of pain specifically in the prehospital setting varies, with estimates ranging from 20-53 percent. ${ }^{1}$ Adequate pain relief is known to minimize anxiety and cardiac complications associated with acute pain. ${ }^{2}$ However, as many as 43 percent of adults ${ }^{3}$ and 85 percent of pediatric patients ${ }^{4}$ have insufficient prehospital pain relief.

For patients experiencing moderate to severe traumatic injury pain, current guidelines (based on moderate quality evidence) strongly recommend initial prehospital management with a weight-based opioid, either intravenous (IV) morphine or IV/intranasal (IN) fentanyl. ${ }^{5}$ Complicating the appropriate use of prehospital opioids is the fear of their abuse and the resulting epidemic in the United States. ${ }^{6,7}$ When combined with concerns of adverse events, such as vomiting and subsequent airway obstruction, respiratory depression, hypotension, and sedation, ${ }^{8}$ alternative analgesics have been sought. Nonopioid analgesics, including ketamine, acetaminophen (APAP), nitrous oxide/oxygen and nonsteroidal anti-inflammatory drugs (NSAIDs) (specifically ketorolac and ibuprofen) may provide adequate analgesia. This systematic review assesses the comparative effectiveness and harms of opioids compared to nonopioid analgesics for the prehospital management of acute pain (Figure A).

Figure A. Analytic framework

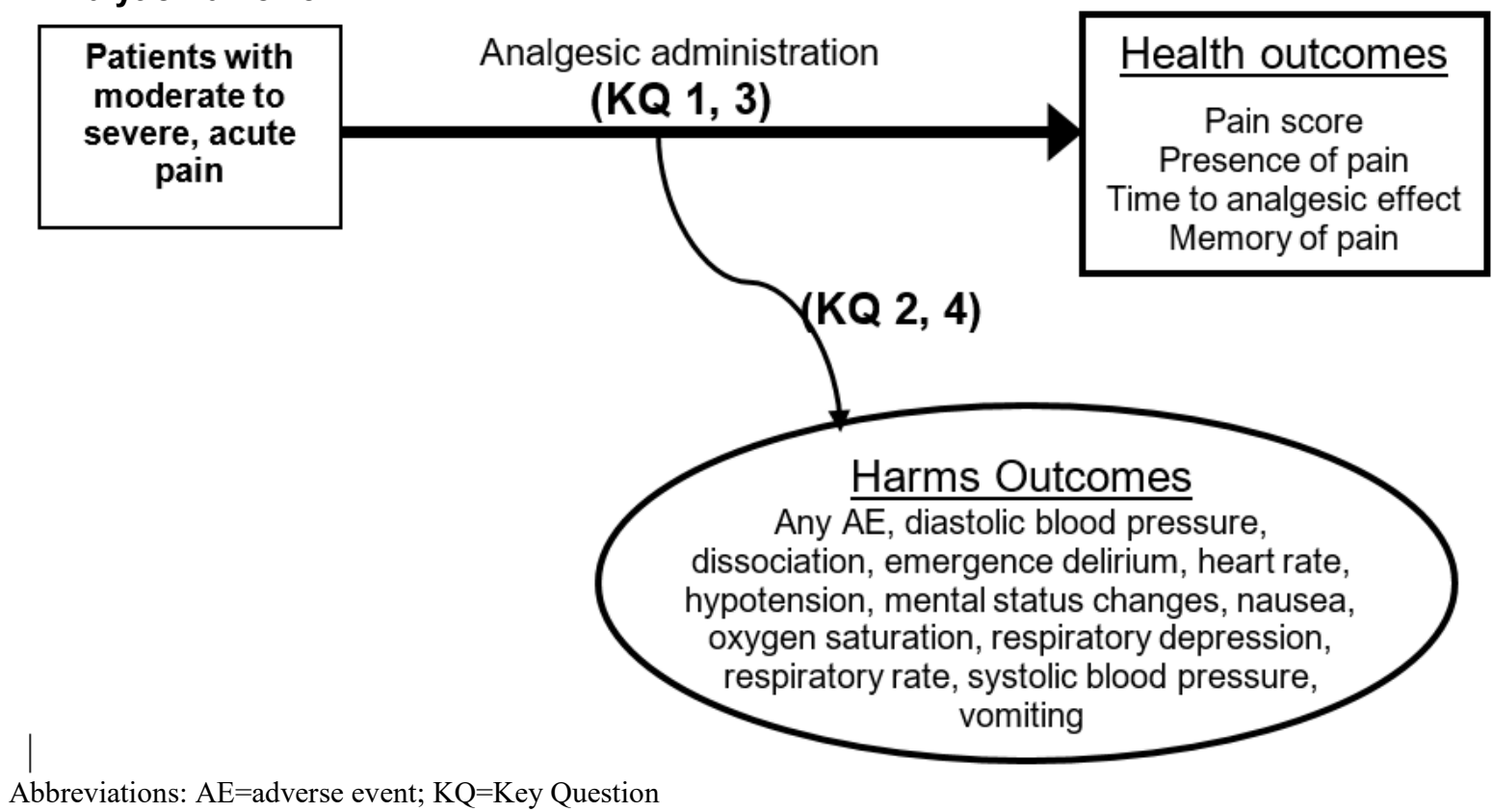

\section{Data Sources}

We searched MEDLINE ${ }^{\circledR}$, Embase ${ }^{\circledR}$ and Cochrane Central bibliographic databases from earliest date through May 9, 2019; hand searches of references of relevant studies; www.clinicaltrials.gov and the International Controlled Trials Registry Platform. The systematic review protocol is available in the full report. 


\section{Methods}

The protocol was registered in PROSPERO (CRD42018114959) and posted on the AHRQ website. The draft report will be posted for public and peer review and we will revise the report based on these comments. After input from the Technical Expert Panel (TEP), NHTSA, AHRQ and our EPC, we chose the following analgesic comparisons and outcomes upon which to formulate conclusions with graded strength of evidence (SOE): comparisons (opioids versus ketamine, opioids versus APAP, opioids versus nitrous oxide, opioids versus NSAIDs, combination opioid and ketamine versus opioids) and outcomes (pain severity, pain presence, time to analgesic effect, any adverse event, hypotension, mental status changes, and respiratory depression).

Conclusions are made in the context of clinically important differences that were established based on the input of NHTSA, AHRQ, the TEP, and our EPC. This includes 2 points on a 0 to 10 pain scale, 5 minutes for time to analgesia, 10 percent absolute difference for any adverse event and 5 percent absolute difference for hypotension, respiratory depression and mental status changes review. We judged the SOE for our conclusions in consideration of five domains: study limitations, consistency, directness, precision and reporting bias. ${ }^{9}$ The four levels of SOE include high $(+++)$, moderate $(++)$, low $(+)$, or insufficient.

The results for analgesics comparisons and outcomes that are not graded are reported in the full report.

\section{Results}

We included 52 randomized controlled trials (RCTs) and 13 observational studies, of which 37 RCTs and 4 observational studies provided evidence for graded comparisons and outcomes (Table A). ${ }^{10-74}$ We aimed to base conclusions on direct evidence from the prehospital setting, but this was not always possible because of a lack of studies. In the absence of sufficient prehospital evidence, we used evidence from the emergency department but downgraded strength of evidence for indirectness.

\begin{tabular}{|c|c|c|c|c|c|}
\hline Characteristic & $\begin{array}{l}\text { Opioids Versus } \\
\text { Ketamine }\end{array}$ & $\begin{array}{l}\text { Opioid+Ketamine } \\
\text { Versus Opioid }\end{array}$ & $\begin{array}{l}\text { Opioids } \\
\text { Versus } \\
\text { APAP }\end{array}$ & $\begin{array}{l}\text { Opioids } \\
\text { Versus } \\
\text { Nitrous } \\
\text { Oxide } \\
\end{array}$ & $\begin{array}{l}\text { Opioids } \\
\text { Versus } \\
\text { NSAIDs }\end{array}$ \\
\hline $\mathrm{N}$ of studies & $\begin{array}{l}17 \mathrm{RCT}^{\mathrm{R}} \\
3 \mathrm{OBS}^{\mathrm{a}}\end{array}$ & $\begin{array}{l}6 \text { RCT } \\
2 \text { OBS }^{a}\end{array}$ & $10 \mathrm{RCT}$ & $1 \mathrm{RCT}$ & $3 \mathrm{RCT}$ \\
\hline $\begin{array}{l}\text { Countries and } \mathrm{N} \text { of } \\
\text { studies }\end{array}$ & $\begin{array}{l}\text { Afghanistan } 2^{\text {b; }} \\
\text { Australia 1; Israel } \\
\text { 1; Iran 5; Sweden } \\
\text { 1; } 1 \text { New Zealand; } \\
\text { USA 8; Vietnam } 1\end{array}$ & $\begin{array}{l}\text { Afghanistan 1 }{ }^{\mathrm{b}} ; \\
\text { France 1; Iran 3; } \\
\text { Switzerland 1; } \\
\text { USA } 2\end{array}$ & $\begin{array}{l}\text { Iran 4; Turkey } \\
\text { 4; Qatar 1; } \\
\text { UK } 1\end{array}$ & Iran 1 & $\begin{array}{l}\text { Canada 1; } \\
\text { Iran 1; USA } 1\end{array}$ \\
\hline $\mathrm{N}$ of patients & 2,484 & 1,566 & 2,001 & 100 & 474 \\
\hline $\begin{array}{l}\text { Gender } \\
\text { (Range of males, \%) }\end{array}$ & 23.3 to 100 & 40 to 100 & 43 to 83 & 72 to 84 & 56.4 to 70.5 \\
\hline $\begin{array}{l}\text { Age } \\
\text { (Range of means, } y \text { ) }\end{array}$ & 7 to 77.3 & 23 to 51.58 & 29.1 to 44.6 & 35.8 to 37 & 11.7 to 39.3 \\
\hline $\begin{array}{l}\text { Pain Classification } \\
\text { ( } \mathrm{N} \text { studies) }\end{array}$ & $\begin{array}{l}\text { Traumatic: } 13 \\
\text { Nontraumatic: } 1 \\
\text { Mixed: } 6\end{array}$ & $\begin{array}{l}\text { Traumatic: } 3 \\
\text { Nontraumatic: } 2 \\
\text { Mixed: } 3\end{array}$ & $\begin{array}{l}\text { Traumatic: } 4 \\
\text { Nontraumatic: } \\
\text { 5; Mixed: } 1\end{array}$ & Traumatic: 1 & $\begin{array}{l}\text { Traumatic: } 1 \\
\text { Nontraumatic: } \\
\text { 1; Mixed: } 1\end{array}$ \\
\hline
\end{tabular}




\begin{tabular}{|c|c|c|c|c|c|}
\hline Characteristic & $\begin{array}{l}\text { Opioids Versus } \\
\text { Ketamine }\end{array}$ & $\begin{array}{l}\text { Opioid+Ketamine } \\
\text { Versus Opioid }\end{array}$ & $\begin{array}{l}\text { Opioids } \\
\text { Versus } \\
\text { APAP }\end{array}$ & $\begin{array}{l}\text { Opioids } \\
\text { Versus } \\
\text { Nitrous } \\
\text { Oxide }\end{array}$ & $\begin{array}{l}\text { Opioids } \\
\text { Versus } \\
\text { NSAIDs }\end{array}$ \\
\hline $\begin{array}{l}\text { Setting } \\
\text { (N studies) }\end{array}$ & $\begin{array}{l}\text { Prehospital: } 4 \\
\text { ED: } 14 \\
\text { Battlefield: } 2\end{array}$ & $\begin{array}{l}\text { Prehospital: } 2 \\
\text { ED: } 5 \\
\text { Battlefield: } 1\end{array}$ & ED: 10 & ED: 1 & ED: 3 \\
\hline 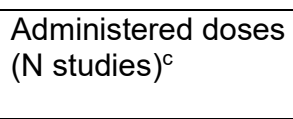 & $\begin{array}{l}\text { Single: } 11 \\
\text { Multiple: } 7 \\
\text { NR: } 2\end{array}$ & $\begin{array}{l}\text { Single: } 6 \\
\text { NR: } 2\end{array}$ & Single: 10 & Single: 1 & $\begin{array}{l}\text { Single: } 1 \\
\text { Multiple: } 2\end{array}$ \\
\hline $\begin{array}{l}\text { Dosage forms } \\
\text { ( } \mathrm{N} \text { of studies each) }\end{array}$ & $\begin{array}{l}\text { IV vs. IV: } 10 \\
\text { IN vs. IN: } 4 \\
\text { IV vs. IN: } 2^{\mathrm{d}} \\
\text { IM vs. IN: } 1^{\mathrm{d}} \\
\text { IM vs. IV: } 1 \\
\text { NEB vs. IV: } 1 \\
\text { Mixed/NR: } 2\end{array}$ & $\begin{array}{l}\text { IV+IV vs. IV: } 6 \\
\text { IV+IN vs. IV: } 1 \\
\text { NR: } 1\end{array}$ & IV vs. IV: 10 & $\begin{array}{l}\text { IV vs. inhaled: } \\
1\end{array}$ & $\begin{array}{l}\text { IV vs. IV: } 2 \\
\text { PO vs. PO: } 1\end{array}$ \\
\hline $\begin{array}{l}\text { Specific drugs } \\
\text { (N studies) }\end{array}$ & $\begin{array}{l}\text { Morphine: } 12 \\
\text { Fentanyl: } 6 \\
\text { Mixed: } 2\end{array}$ & $\begin{array}{l}\text { Morphine: } 6 \\
\text { Mixed: } 2\end{array}$ & $\begin{array}{l}\text { Morphine: } 9 \\
\text { Fentanyl: } 1\end{array}$ & Fentanyl: 1 & $\begin{array}{l}\text { Morphine: } 3 \\
\text { Ketorolac: } 2 \\
\text { lbuprofen: } 1\end{array}$ \\
\hline 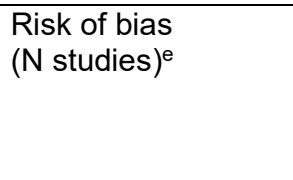 & $\begin{array}{l}\text { Low: } 12 \\
\text { Medium: } 2 \\
\text { High: } 2 \\
\text { Unclear: } 2 \\
\text { Low/medium: } 2\end{array}$ & $\begin{array}{l}\text { Low: } 7 \\
\text { Medium: } 1\end{array}$ & $\begin{array}{l}\text { Low: } 9 \\
\text { Unclear: } 1\end{array}$ & $\begin{array}{l}\text { Low/medium: } \\
1\end{array}$ & $\begin{array}{l}\text { Low: } 2 \\
\text { Medium: } 1\end{array}$ \\
\hline
\end{tabular}

Abbreviations: $\mathrm{APAP}=$ acetaminophen; $\mathrm{ED}=$ emergency department; $\mathrm{IM}=$ intramuscular; $\mathrm{IN}=$ intranasal; $\mathrm{IV}=$ intravenous; $\mathrm{NEB}=$ nebulized; $\mathrm{NR}=$ not reported; NSAIDs $=$ nonsteroidal anti-inflammatory drugs; $\mathrm{OBS}=$ observational; $\mathrm{PO}=\mathrm{oral}$; $\mathrm{RCT}=$ randomized controlled trial; UK=United Kingdom; USA=United States of American; vs=versus

aTwo observational studies included two comparisons: opioids vs. ketamine and morphine vs. fentanyl, one of these studies also compares opioids+ketamine vs. opioids.

${ }^{\mathrm{b}}$ These studies took place in Afghanistan but were US military forces

'Studies were classified according to the number of doses given of the randomized analgesic. Studies either allowed one dose or multiple doses.

${ }^{\mathrm{d}}$ One trial included 3 arms and thus has two comparisons: morphine IV vs. ketamine and morphine IM vs. ketamine

eSome studies had different risk of bias based on the individual outcome, and in these cases were listed as "low/medium" risk of bias

\section{Initial Analgesia}

Key Questions (KQ) 1 and 2 aimed to evaluate comparative effectiveness (KQ 1) and harms (KQ 2) of initial analgesics (Table B). Conclusions are based on indirect evidence from the emergency department setting. Opioids, ketamine and NSAIDs were primarily administered IV, and for APAP this was the only route studied. The IN route was also common in studies reporting adverse event outcomes for the comparison of opioids versus ketamine.

We found no evidence of clinically important differences in pain reduction between opioids and ketamine administered primarily IV, IV APAP or NSAIDs administered primarily IV. Combining opioids and ketamine may be more effective than opioids alone, administered primarily IV.

Opioids may cause fewer adverse events than ketamine, primarily administered IN. Based on subgroup analysis, this risk may be associated with age or route of administration. Opioids may cause more adverse events than NSAIDs, administered primarily IV. Opioids may cause more side effects than APAP, both administered IV. 
Table B. Summary of the comparative effectiveness and harms of initial analgesics in the prehospital setting

\begin{tabular}{|c|c|c|c|c|c|}
\hline Outcome & $\begin{array}{l}\text { Opioid }{ }^{\mathrm{a}} \text { Versus } \\
\text { Ketamine }^{\mathrm{a}}\end{array}$ & $\begin{array}{l}\text { Opioid+ketamine } \\
\text { Versus Opioida }^{a}\end{array}$ & $\begin{array}{l}\text { Opioid }^{\text {a Versus }} \\
\text { IV APAP }\end{array}$ & $\begin{array}{l}\text { Opioid }{ }^{\mathrm{a}} \text { Versus } \\
\text { Nitrous Oxide }\end{array}$ & $\begin{array}{l}\text { Opioid }{ }^{a} \text { Versus } \\
\text { NSAIDs }^{a}\end{array}$ \\
\hline $\begin{array}{l}\text { Pain severity } \\
\text { (continuous) }\end{array}$ & $\begin{array}{l}\text { No clinically } \\
\text { important } \\
\text { difference }(+)\end{array}$ & $\begin{array}{l}\text { Combination may } \\
\text { be more effective } \\
(+)\end{array}$ & $\begin{array}{l}\text { No clinically } \\
\text { important } \\
\text { difference }(+)\end{array}$ & Insufficient & $\begin{array}{l}\text { No clinically } \\
\text { important } \\
\text { difference }^{\mathrm{c}}(++)\end{array}$ \\
\hline $\begin{array}{l}\text { Pain presence } \\
\text { (dichotomous) }\end{array}$ & Insufficient & Insufficient & Insufficient & No data & Insufficient \\
\hline $\begin{array}{l}\text { Time to } \\
\text { analgesic effect }\end{array}$ & Insufficient & No data & $\begin{array}{l}\text { No clinically } \\
\text { important } \\
\text { difference }(+)\end{array}$ & No data & Insufficient \\
\hline $\begin{array}{l}\text { Any adverse } \\
\text { event }\end{array}$ & $\begin{array}{l}\text { Fewer with } \\
\text { opioids }(+)\end{array}$ & Insufficient & $\begin{array}{l}\text { More with } \\
\text { opioids }(+)\end{array}$ & Insufficient & $\begin{array}{l}\text { More with } \\
\text { opioids }(+)\end{array}$ \\
\hline Hypotension & Insufficient & Insufficient & $\begin{array}{l}\text { No clinically } \\
\text { important } \\
\text { difference (+) }\end{array}$ & No data & Insufficient \\
\hline $\begin{array}{l}\text { Mental status } \\
\text { changes }\end{array}$ & $\begin{array}{l}\text { Less dizziness } \\
\text { with opioids }^{\mathrm{d}}(+)\end{array}$ & Insufficient $^{e}$ & $\begin{array}{l}\text { More dizziness } \\
\text { with opioids }^{f} \\
(++)\end{array}$ & Insufficientg & $\begin{array}{l}\text { More } \\
\text { drowsiness with } \\
\text { opioids }^{\mathrm{h}}(+)\end{array}$ \\
\hline $\begin{array}{l}\text { Respiratory } \\
\text { depression }\end{array}$ & $\begin{array}{l}\text { More with } \\
\text { opioids (+) }\end{array}$ & Insufficient & Insufficient & No data & No data \\
\hline
\end{tabular}

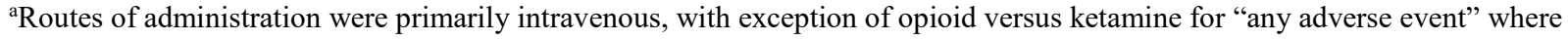
analgesics were primarily administered IN. (see table A, dosage form row).

Abbreviations: IV=intravenous

Strength of evidence: white $=$ no evidence; yellow $=$ insufficient; orange $(+)=$ low; blue $(++)=$ moderate. Conclusions of no clinically important difference are based on a priori determined thresholds of 2 points on a 0 to 10 pain scale, 5 minutes for time to analgesia, $10 \%$ absolute difference for any adverse event and 5\% absolute difference for hypotension, respiratory depression and mental status changes.

${ }^{\mathrm{b}}$ Change in 15 and 30 minutes; no clinically important difference at $60 \mathrm{~min}$

${ }^{\mathrm{c}}$ At 30 and $60 \mathrm{~min}$, inconclusive at $15 \mathrm{~min}$

dInsufficient for drowsiness, changes in RAAS, reduced GCS, sleepiness/tired, confusion, sedation, difficulty concentrating

eFor dizziness, sedation

Inconclusive for mild sedation

gFor dizziness

hInsufficient for depression (as a mental status change), dizziness

\section{Analgesia When Initial Choice Is Insufficient}

KQ 3 and 4 aimed to evaluate comparative effectiveness and harms of subsequent analgesia when initial analgesia is ineffective. Giving a patient ketamine IV instead of continuing to administer morphine IV when the initial morphine IV administration does not provide the patient with pain relief may reduce pain more and may reduce pain more quickly. This is based on direct evidence from the prehospital setting. Evidence of harms was either insufficient or nonexistent.

Table C. Summary of the comparative effectiveness and harms of subsequent analgesics in the prehospital setting

\begin{tabular}{ll}
\hline Outcome & $\begin{array}{l}\text { Additional Opioid Versus Switching to } \\
\text { Ketamine }\end{array}$ \\
\hline Pain severity (continuous) & Ketamine may be more effective $(+)$ \\
\hline Pain presence (dichotomous) & Insufficient \\
\hline Time to analgesic effect & Ketamine may be quicker $(+)$ \\
\hline Any adverse event & Insufficient \\
\hline Hypotension & Insufficient \\
\hline Mental status changes & Insufficient \\
\hline Respiratory depression & No data \\
\hline Strength of evidence: white $=$ no evidence; yellow $=$ insufficient; orange $(+)=$ low; blue $(++)=$ moderate
\end{tabular}




\section{Discussion}

Our review found that as an initial analgesic and primarily administered IV, opioids are no different than the nonopioid analgesics ketamine, APAP and NSAIDs in reducing pain. The combination of opioids and ketamine may be more effective in reducing pain, compared with opioids alone. When initial IV morphine is not effective, switching to IV ketamine may be better in reducing pain than continuing to administer morphine.

To put these findings in context there are key parameters concerning applicability to consider. The studies that compared the efficacy of opioids with ketamine mostly compare weight-based IV morphine $0.1 \mathrm{mg} / \mathrm{kg}$ with IV ketamine (variable weight-based dosing). Some studies evaluated IN fentanyl and IN ketamine, which were prepared from the IV formulations and delivered IN via an atomizer. The IN ketamine product on the US market is not approved for pain management and is specific to management of treatment-resistant depression. The doses of ketamine varied and too few studies were available to identify associations based on dose. When ketamine was studied in combination with opioids, a single IV dose was added to the opioid regimen. How administration of more than one ketamine dose impacts outcomes is unknown. Nine of the 10 trials that compared opioids with APAP compared IV morphine $0.1 \mathrm{mg} / \mathrm{kg}$ with IV APAP 1g, thus results cannot be extrapolated to other routes or doses. There were only three studies comparing opioids with NSAIDs with a mixed representation of oral and IV dosage forms. We were unable to draw conclusions about the efficacy of opioids compared with nitrous oxide (based on a single study with limitations).

Comparative harms of specific adverse events vary among analgesics and in the absence of clinically important differences in pain reduction, can inform individualized treatment decisions. The overall frequency of total adverse events in trials that compared opioids with ketamine suggests that at least 50 percent of treated patients will experience some type of adverse event but low-strength evidence suggests that opioids may cause fewer total adverse events than ketamine. These trials studied primarily IN analgesic administration and based on our subgroup analyses, the lower overall adverse event risk with opioids may be associated with either age or route of administration. Opioids may cause more respiratory depression while ketamine causes more dizziness. In contrast to the comparison of opioids with ketamine, opioids may cause more adverse events than IV APAP or NSAIDs when used as initial analgesics. In patients who do not adequately respond to initial morphine, comparative harms of giving ketamine compared with giving additional morphine are uncertain.

The focus of this report is to synthesize existing evidence. We do not make clinical recommendations. We encourage application of this evidence toward future work generating evidence-based clinical guidelines.

The major limitation of this review is the indirectness of evidence, which may have significant implications and led to our downgrading of conclusions. We believe the single most important future research need is addressing this evidence gap with pain management studies set in the prehospital environment. In addition, research is needed to explore subgroups, including patient and drug regimen characteristics and EMS personnel training and how these characteristics may modify comparative effectiveness and harms of analgesics.

\section{Conclusion}

As initial analgesia administered primarily IV, opioids are no different than ketamine, APAP, and NSAIDs in reducing acute pain in the prehospital setting. Opioids may cause fewer total side 
effects than ketamine, but more than APAP or NSAIDs. Differences in specific side effects vary between analgesics and can further inform treatment decisions. Combined administration of an opioid and ketamine may reduce acute pain more than an opioid alone but comparative harms are uncertain. When initial morphine is inadequate in reducing pain, giving ketamine may provide greater and quicker acute pain relief than giving additional morphine, although comparative harms are uncertain. Due to indirectness, strength of evidence is generally low, and future research in the prehospital setting is needed. 


\section{References}

1. McLean SA, Maio RF, Domeier RM. The epidemiology of pain in the prehospital setting. J Emerg Med. 2002;6(4):402-405. PMID: 12385606.

2. Thomas SH, Shewakramani S. Prehospital trauma analgesia. J Emerg Med. 2008 Jul:35(1):47-57. PMID: 17997072.

3. Albrecht E, Taffe P, Yersin B, et al. Undertreatment of acute pain (oligoanalgesia) and medical practice variation in prehospital analgesia of adult trauma patients: a $10 \mathrm{yr}$ retrospective study. Br J Anaesth. 2013 Jan;110 (1):96-106. PMID: 23059961.

4. Izsak E, Moore JL, Stringfellow K, Oswanski MF, Kindstrom DA, Stombaugh HA. Prehospital pain assessment in pediatric trauma. Prehosp Emerg Care 2008;12:182-6. PMID 18379914.

5. Gausche-Hill M, Brown KM, Oliver ZJ, et al. An evidence-based guideline for prehospital analgesia in trauma. Prehosp Emerg Care. 2014;18 Suppl 1:25-34. PMID: 24279813.

6. Clark DJ, Schumacher MA. America's opioid epidemic: supply and demand considerations. Anesth Analg. 2017 Nov;125(5):1667-1674. PMID: 29049112.

7. Hoppe JA, Nelson LS, Perrone J, et al. Opioid prescribing in the cross section of US emergency departments. Ann Emerg Med. 2015 Sep;66(3):253-259. PMID: 25952503.

8. Benyamin R AND Trescot AM, Datta S, et al. Opioid complications and side effects. Pain Physician. 2008 Mar;11(2 Suppl):S105-S120. PMID: 18443635.

9. Berkman ND, Lohr KN, Ansari M, et al. Grading the Strength of a Body of Evidence When Assessing Health Care Interventions for the Effective Health Care Program of the Agency for Healthcare Research and Quality: An Update, 2013. In: Methods Guide for Effectiveness and Comparative Effectiveness Reviews. AHRQ Publication No. 10(14)-EHC063-EF. Rockville MD: Agency for Healthcare Research and Quality; 2014. Chapters available at www.effectivehealthcare.ahrq.gov.

10. Deaton T, Auten J, Darracq MA. Nebulized fentanyl vs intravenous morphine for ED patients with acute abdominal pain: a randomized double-blinded, placebo-controlled clinical trial.
Am J Emerg Med. 2015 Jun;33(6):791-795. PMID: 25840767.

11. Farahmand S, Shiralizadeh S, Talebian MT, et al. Nebulized fentanyl vs intravenous morphine for ED patients with acute limb pain: a randomized clinical trial. Am J Emerg Med. 2014 Sep;32(9):1011-1015. PMID: 25027194.

12. Furyk JS, Grabowski WJ, Black LH. Nebulized fentanyl versus intravenous morphine in children with suspected limb fractures in the emergency department: a randomized controlled trial. Emerg Med Austral. 2009 Jun;21(3):203-209. PMID: 19527280.

13. Sub-dissociative ketamine for the management of acute pediatric pain. NCT01951963. https://clinicaltrials.gov/ct2/show/NCT01951963 ?term=NCT01951963\&rank=1. Accessed 11 March, 2019.

14. Galinski M, Dolveck F, Combes X, et al. Management of severe acute pain in emergency settings: ketamine reduces morphine consumption. Am J Emerg Med. 2007 May;25(4):385-390. PMID: 17499654.

15. Jalili M, Mozaffarpour Noori A, Sedaghat M, Safaie A. Efficacy of intravenous paracetamol versus intravenous morphine in acute limb trauma. Trauma Mon. 2016 Feb;21(1):e19649.

16. Tran KP, Nguyen Q, Truong XN, et al. A comparison of ketamine and morphine analgesia in prehospital trauma care: a cluster randomized clinical trial in rural Quang Tri province, Vietnam. Prehosp Emerg Care. 2014 AprJun;18(2):257-264. PMID: 24400915.

17. Verki MM, Mozafari J, Tirandaz F, Motamed H, Khazaeli A. Efficacy of nebulized fentanyl and low dose ketamine for pain control of patients with long bone fractures: a randomized, doubleblind, clinical trial. African Journal of Emergency Medicine. 2019; doi.org/10.1016/j.afjem.2019.02.003. [Epub ahead of print].

18. Quinn K, Kriss S, Drapkin J, et al. Analgesic efficacy of intranasal ketamine versus intranasal fentanyl for moderate to severe pain in children: a prospective, randomized, double-blind study. Pediatr Emerg Care. 2018 Jul 24; doi: 10.1097/PEC. 0000000000001556. [Epub ahead of print]. PMID: 30045355. 
19. Frey TM, Florin TA, Caruso M, et al. Effect of intranasal ketamine vs fentanyl on pain reduction for extremity injuries in children: the PRIME randomized clinical trial. JAMA Pediatr. 2019 Feb;173(2):140-146. PMID: 30592476.

20. Reynolds SL, Bryant KK, Studnek JR, et al. Randomized controlled feasibility trial of intranasal ketamine compared to intranasal fentanyl for analgesia in children with suspected extremity fractures. Acad Emerg Med. 2017 Dec;24(12):1430-1440. PMID: 28926159.

21. Graudins A, Meek R, Egerton-Warburton D, Oakley E. The PICHFORK (Pain in Children Fentanyl or Ketamine) Trial: a randomized controlled trial comparing intranasal ketamine and fentanyl in children with limb injuries. Ann Emerg Med 2015;65:248-254. PMID: 25447557.

22. Shimonovich S, Gigi R, Shapira A, et al. Intranasal ketamine for acute traumatic pain in the emergency department: a prospective, randomized clinical trial of efficacy and safety. BMC Emerg Med. 2016 Cov;16(1):43. PMID: 27829367.

23. Farnia MR, Jalali A, Vahidi E, et al. Comparison of intranasal ketamine versus IV morphine in reducing pain in patients with renal colic. AM J Emerg Med. 2017 Mar;35(3):434-437. PMID: 27931762.

24. Motov S, Mann S, Drapkin J, et al. Intravenous subdissociative-dose ketamine versus morphine for acute geriatric pain in the emergency department: a randomized controlled trial. Am J Emerg Med. 2019 Feb;37(2):220-227. PMID: 29807629.

25. Mahshidfar B, Mofidi M, Fattahi M, et al. Acute pain management in emergency department, low dose ketamine versus morphine, a randomized clinical trial. Anesth Pain Med. 2017 Dec;7(6):e60561. PMID: 29696126.

26. Motov S, Rockoff B, Cohen V, et al. Intravenous subdissociative-dose ketamine versus morphine for analgesia in the emergency department: a randomized controlled trial. Ann Emerg Med. 2015 Sep;66(3):222-229. PMID: 25817884.

27. Miller JP, Schauer SG, Ganem VJ, Bebarta VS. Low-dose ketamine vs morphine for acute pain in the ED: a randomized controlled trial. Am J Emerg Med. 2015 Mar;33(3):402-8. PMID: 25624076.

28. Majidinejad S, Esmailian M, Emadi M. Comparison of intravenous ketamine with morphine in pain relief of long bones fractures: a double blind randomized clinical trial. Emerg (Tehran). 2014 Spring;2(2):77-80. PMID: 26495351.

29. Jahanian F, Hosseininejad SM, Amini Ahidashti $\mathrm{H}$, et al. Efficacy and safety of morphine and low dose ketamine for pain control of patients with long bone fractures: a randomized, double-blind, clinical trial. Bull Emerg Trauma. 2018 Jan;6(1):31-36. PMID: 29379807.

30. Bronsky ES, Koola C, Orlando A, et al. Intravenous low-dose ketamine provides greater pain control compared to fentanyl in a civilian prehospital trauma system: a propensity matched analysis. Prehosp Emerg Care. 2018 May;1-8. doi: 10.1080/10903127.2018.1469704. [Epub ahead of print]. PMID: 29775117.

31. Schauer SG, Mora AG, MAddry JK, Bebarta VS. Multicenter, prospective study of prehospital administration of analgesia in the U.S. combat theater of Afghanistan. Prehosp Emerg Care. 2017 Nov-Dec;21(6):744-749. PMID: 28829661.

32. Schackelford SA, Fowler M, Schultz K, et al. Prehospital pain medication use by U.S. forces in Afghanistan. Mil Med. 2015 Mar;180(3):304309.PMID: 25735021.

33. Jennings PA, Cameron P, Bernard S, et al. Morphine and ketamine is superior to morphine alone for out-of-hospital trauma analgesia: a randomized controlled trial. Ann Emerg Med. 2012 Jun;59(6):497-503. PMID: 22243959.

34. Johansson P, Kongstad P, Johansson A. The effect of combined treatment with morphine sulphate and low-dose ketamine in a prehospital setting. Scand J Trauma Resusc Emerg Med. 2009 Nov;17:61. PMID: 19943920.

35. Clark E, Plint AC, Correll R, et al. A randomized, controlled trial of acetaminophen, ibuprofen, and codeine for acute pain relief in children with musculoskeletal trauma. Pediatrics. 2007 Mar;119(3):460-467. PMID: 17332198.

36. Oberholzer N, Kaserer A, Albrecht R, et al. Factors influencing quality of pain management in a physician staffed helicopter emergency medical service. Anesth Analg. 2017 Jul;125(1):200-209. PMID: 28489643.

37. Hosseininejad SM, Jahanian F, Erfanian Irankar $\mathrm{S}$, et al. Comparing the analgesic efficacy of morphine plus ketamine versus morphine plus placebo in patients with acute renal colic: a double-blinded randomized controlled trial. Am J Emerg Med. 2018 Sep 3. pii: S07356757(18)30733-2. doi: 
10.1016/j.ajem.2018.09.004. [Epub ahead of print]. PMID: 30201237.

38. Sin B, Tatunchak T, Paryavi M, et al. The use of ketamine for acute treatment of pain: a randomized, double-blind, placebo-controlled trial. J Emger Med. 2017 May;52(5):601-608. PMID: 28279542.

39. Beaudoin FL, Lin C, Guan W, Merchant RC. Low-dose ketamine improves pain relief in patients receiving intravenous opioids for acute pain in the emergency department: results of a randomized, double-blind, clinical trial. Acad Emerg Med. 2014 Nov;21(11):1193-1202. PMID: 25377395.

40. Abbasi S, Bidi N, Mahshidfar B, et al. Can lowdose of ketamine reduce the need for morphine in renal colic? A double-blind randomized clinical trial. Am J Emerg Med. 2018 Mar;36(3):376-379. PMID: 28821365.

41. Mohammadshahi A, Abdolrazaghnejad A, Nikzamir H, Safaie A. Intranasal ketamine administration for narcotic dose decrement in patients suffering from acute limb trauma in emergency department: a double-blind randomized placebo-controlled trial. Adv J Emerg Med. 2018;2(3):e30.

42. Vahdati S, Morteza Baghi HR, Ghobadi J, et al. Comparison of paracetamol (apotel $\AA$ ) and morphine in reducing post pure head trauma headache. Anesth Pain Med. 2014Jun;4(3):e14903. PMID: 25237630.

43. Pathan SA, Mitra B, Straney LD, et al. Delivering safe and effective analgesia for management of renal colic in the emergency department: a double-blind, multigroup, randomised controlled trial. Lancet. 2016 May;387(10032):1999-2007. PMID: 26993881.

44. Sotoodehnia M, Farmahini-Farahani M, Safaie A, Rasooli F, Baratloo A. Low-dose intravenous ketamine versus intravenous ketorolac in pain control in patients with acute renal colic in an emergency setting: a double-blind randomized clinical trial. Korean J Pain 2019;32:97-104. PMID: 31091508.

45. Serinken M, Eken C, Gungor F, et al. Comparison of intravenous morphine versus paracetamol in sciatica: a randomized placebo controlled trial. Acad Emerg Med. 2016 Jun;23(6):674-678. PMID: 26938140.

46. Eken C, Serinken M, Elicabuk H, et al. Intravenous pracetamol vesus dexketoprofen versus morphine in acute mechanical low back pain in the emergency department: a randomised double-blind controlled trial. Emerg Med J. 2014 Mar;31(3):177-181. PMID: 23407378.

47. Serinken M, Eken C, Turkcuer I, et al. Intravenous paracetamol versus morphine for renal colic in the emergency department: a randomised double-blind controlled trial. Emerg Med J. 2012 Nov;29(11):902-905. PMID: 22186009.

48. Craig M, Jeavons R, Probert J, Benger J. Randomised comparison of intravenous paracetamol and intravenous morphine for acute traumatic limb pain in the emergency department. Emerg Med J. 2012 Jan;29(1):37-39. PMID: 21362724.

49. Al B, Sunar MM, Zengin S, et al. Comparison of IV dexketoprofen trometamol, fentanyl, and paracetamol in the treatment of renal colic in the ED: a randomized controlled trial. Am J Emerg Med. 2018 Apr;36(4):571-576. PMID: 29029797.

50. Mollaei M, Esmailian M, Heydari F. Comparing the effect of intravenous acetaminophen

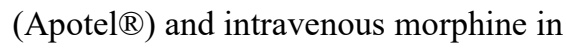
controlling the pain of forearm and leg fractures in adults. J Isfahan Med Sch. 2016;34(376):293298.

51. Masoumi K, Forouzan A, Asgari Darian A, et al. Comparison of clinical efficacy of intravenous acetaminophen with intravenous morphine in acute renal colic: a randomized, double-blind, controlled trial. Emerg Med Int. 2014;2014:571326. PMID: 25197573.

52. Masoumi B, Farzaneh B, Ahmadi O, Heidari F. Effect of intravenous morphine and ketorolac on pain control in long bones fractures. Adv Biomed Res. 2017 Jul;6:91. PMID: 28828342.

53. Safdar B, Degutis LC, Landry K, et al. Intravenous morphine plus ketorolac is superior to either drug alone for treatment of acute renal colic. Ann Emerg Med. 2006 Aug;48(2):173181. PMID: 16953530.

54. Le May S, Ali S, Plint AC, et al. Oral analgesics utilization for children with musculoskeletal injury (OUCH Trial): an RCT. Pediatrics. 2017 Nov;140(5): pii: e20170186. doi: 10.1542/peds.2017-0186. Epub 2017 Oct 11. PMID: 29021235.

55. Cenker E, Serinken M, Uyanik E. Intravenous paracetamol vs ibuprofen in renal colic: a randomised, double-blind, controlled clinical 
trial. Urolithiasis. 2018 Aug;46(4):369-373.

PMID: 28681267.

56. Cozzi G, Zanchi C, Chiaretti A, et al.

Adminsitering analgesia sublingually is a suitable option for children with acute abdominal pain in the emergency room. Acta Paediatr. 2019 Jan;108(1):143-148. PMID: 30043434.

57. Weldon ER, Ariano RE, Grierson RA. Comparison of fentanyl and morphine in the prehospital treatment of ischemic type chest pain. Prehosp Emerg Care. 2016;20(1):45-51. PMID: 26727338.

58. Smith MD, Wang Y, Cudnik M, et al. The effectiveness and adverse events of morphine versus fentanyl on a physician-staffed helicopter. J Emerg Med. 2012 Jul;43(1):69-75. PMID: 21689900.

59. Rickard C, O’Meara P, McGrail M, et al. A randomized controlled trial of intranasal fentanyl vs intravenous morphine for analgesia in the prehospital setting. Am J Emerg Med. 2007 Oct;25(8):911-917. PMID: 17920976.

60. Galinski M, Dolveck F, Borron SW, et al. A randomized, double-blind study comparing morphine with fentanyl in prehospital analgesia. Am J Emerg Med. 2005 Mar;23(2):114-119. PMID: 15765326.

61. Farahmand S, Shiralizadeh S, Talebian MT, et al. Nebulized fentanyl vs intravenous morphine for ED patients with acute limb pain: a randomized clinical trial. Am J Emerg Med. 2014 Sep;32(9):1011-1015. PMID: 25027194.

62. Mahar PJ, Rana JA, Kennedy CS, Christopher NC. A randomized clinical trial of oral transmucosal fentanyl citrate versus intravenous morphine sulfate for initial control of pain in children with extremity injuries. Pediatr Emerg Care. 2007 Aug;23(8):544-548. PMID: 17726413.

63. Borland M, Jacobs I, King B, O'Brien D. A randomized controlled trial comparing intranasal fentanyl to intravenous morphine for managing acute pain in children in the emergency department. Ann Emerg Med. 2007 Mar;49(3):335-340. PMID: 17067720.

64. Younge PA, Nicol MF, Kendall JM, et al. A prospective randomized pilot comparison of intranasal fentanyl and intramuscular morphine for analgesia in children presenting to the emergency department with clinical fractures. Emerg Med. 1999;11:90-94.
65. Scharonow M, Alberding T, Oltmanns W, Weilbach C. Project for the introduction of prehospital analgesia with fentanyl and morphine administering by specially trained paramedics in a rural service area in Germany. J Pain Res. 2017 Nov;10:2595-2599. PMID: 29158691.

66. Daoust R, Paguet J, Lavigne G, et al. Impact of age, sex and route of administration on adverse events after opioid treatment in the emergency department: a retrospective study. Pain Res Manag. 2015 Jan-Feb;20(1):23-28. PMID: 25664538.

67. Schacherer NM, Erikson Ramirez D, Frazier SB, Perkins AM. Expedited delivery of pain medication for long-bone fractures using an intranasal fentanyl clinical pathway. Pediatr Emerg Care. 2015 Aug;31(8):560-563. PMID: 25875994.

68. Wenderoth BR, Kaneda ET, Amini A, et al. Morphine versus fentanyl for pain due to traumatic injury in the emergency department. J Trauma Nurs. 2013 Jan-Mar;20(1):10-15. PMID: 23459426.

69. Bendall JC, Simpson PM, Middleton PM. Effectiveness of prehospital morphine, fentanyl, and methoxyflurane in pediatric patients. Prehosp Emerg Care. 2011 Apr-Jun;15(2):158165. PMID: 21294628.

70. Garrick JF, Kidane S, Pointer JE, et al. Analysis of the paramedic administration of fentanyl. J Opioid Manag. 2011 May-Jun;7(3):229-234. PMID: 21823553.

71. Fleischman RJ, Frazer DJ, Daya M, et al. Effectiveness and safety of fentanyl compared with morphine for out-of-hospital analgesia. Prehosp Emerg Care. 2010 Apr-Jun;14(2):167175. PMID: 20199230.

72. Vahedi HSM, Hajebi H, Vahidi E, Nejati A, Saeedi M. Comparison between intravenous morphine versus fentanyl in acute pain relief in drug abusers with acute limb traumatic injury. World J Emerg Med 2019;10:27-32. PMID: 30598715.

73. Griffioen MA, Ziegler ML, O'Toole RV, Dorsey SG, Renn CL. Change in pain score after administration of analgesics for lower extremity fracture pain during hospitalization. Pain Management Nursing 2019;20:158-163. PMID: 30442567.

74. Zhang M, Cowan T, Smiles JP, et al. Prehospital analgesic choice in injured patient does not impact on rates of vomiting: experience from a 
New South Wales primary retrieval service.

Emerg Med Australas. 2018 Jun;30(3):406-411.

PMID: 29205811. 


\section{Introduction}

\section{Background}

Appropriate management of acute pain is an integral part of patient management in the prehospital setting. The prevalence of pain specifically in the prehospital setting varies, with estimates ranging from 20-53 percent. ${ }^{1}$ Adequate pain relief is known to minimize the anxiety and cardiac complications associated with acute pain. ${ }^{2}$ However, as many as 43 percent of adults $^{3}$ and 85 percent of pediatric patients ${ }^{4}$ have insufficient prehospital pain relief. Reasons for this have included fear of adverse events with analgesic administration, unwanted masking of underlying pathology, and provider indifference to pain complaints, amongst others. ${ }^{5-7}$ Undertreatment of pain in the prehospital setting paired with the recent focus on optimizing opioid exposure creates a need for clinicians to have a thorough understanding of pain assessment tools and the comparative effectiveness and safety of analgesics for prehospital acute pain management.

Since pain cannot be adequately treated if not appropriately assessed, a careful evaluation of validated tools to measure pain in the prehospital setting is required. Current guidelines ${ }^{8}$ for the management of prehospital trauma pain recommend specific pain scales, broken into age-related categories. However, there is a dearth of studies comparing the diagnostic accuracy of pain assessment tools in the prehospital setting particularly in the absence of a gold standard assessment tool. ${ }^{9}$ Of particular interest is the evidence for use of these assessment tools in special populations including pediatrics, non-English speakers, and those with cognitive impairment or substance impairment.

\section{Management of Acute Pain in the Prehospital Setting}

For patients experiencing moderate to severe pain, current guidelines strongly recommend (based on moderate quality evidence) initial management with a weight-based opioid, either intravenous (IV) morphine or IV/intranasal (IN) fentanyl. ${ }^{8}$ Complicating the appropriate use of prehospital opioids is the fear of their abuse and the resulting epidemic in the United States. ${ }^{10,11}$ When combined with concerns of adverse events, such as vomiting and subsequent airway obstruction, respiratory depression, hypotension, and sedation, ${ }^{12}$ alternatives to opioid analgesia have been sought. Nonopioid analgesics, including ketamine, nitrous oxide/oxygen, acetaminophen, and non-steroidal anti-inflammatory drugs (NSAIDs) may be alternates to opioids in the prehospital setting and are a focus of this review (Table 1). A variety of nonpharmacologic modalities are also available (e.g. splinting, distraction, etc.), although they are not included in the current review.

Table 1. Onset, duration, and typical initial doses for analgesics ${ }^{a, 13-33}$

\begin{tabular}{|c|c|c|c|c|}
\hline $\begin{array}{l}\text { Analgesic - } \\
\text { Route }\end{array}$ & Onset & $\begin{array}{l}\text { Analgesic } \\
\text { Duration }\end{array}$ & $\begin{array}{l}\text { Typical Initial Adult Dosing } \\
\text { for Acute Pain }\end{array}$ & $\begin{array}{l}\text { Typical Initial Pediatric Dosing } \\
\text { for Acute Pain }\end{array}$ \\
\hline $\begin{array}{l}\text { Acetaminophen - } \\
\text { IV }\end{array}$ & $\begin{array}{l}5-10 \\
\text { minutes }\end{array}$ & 4-6 hours & $\begin{array}{l}<50 \mathrm{~kg}: 12.5 \mathrm{mg} / \mathrm{kg} \text { every } 4 \\
\text { hours or } 15 \mathrm{mg} / \mathrm{kg} \text { every } 6 \\
\text { hours; } \\
\geq 50 \mathrm{~kg}: 650 \mathrm{mg} \text { every } 4 \text { hours } \\
\text { or } 1,000 \mathrm{mg} \text { every } 6 \text { hours }\end{array}$ & $\begin{array}{l}\geq 2 \mathrm{y} \text { and adolescents; } \\
<50 \mathrm{~kg} \text { : refer to adult dosing; } \\
\text { >50kg: refer to adult dosing }\end{array}$ \\
\hline $\begin{array}{l}\text { Acetaminophen - } \\
\text { PO }\end{array}$ & $<1$ hour & 4-6 hours & $\begin{array}{l}\text { Regular strength: } 650 \mathrm{mg} \\
\text { every } 4-6 \text { hours; } \\
\text { Extra strength: } 1000 \mathrm{mg} \\
\text { every } 6 \text { hours; }\end{array}$ & $10-15 \mathrm{mg} / \mathrm{kg}$ every 4 to 6 hours \\
\hline
\end{tabular}




\begin{tabular}{|c|c|c|c|c|}
\hline $\begin{array}{l}\text { Analgesic - } \\
\text { Route }\end{array}$ & Onset & $\begin{array}{l}\text { Analgesic } \\
\text { Duration }\end{array}$ & $\begin{array}{l}\text { Typical Initial Adult Dosing } \\
\text { for Acute Pain }\end{array}$ & $\begin{array}{l}\text { Typical Initial Pediatric Dosing } \\
\text { for Acute Pain }\end{array}$ \\
\hline Fentanyl - IV & $\begin{array}{l}\text { Almost } \\
\text { immediate }\end{array}$ & $\begin{array}{l}30-60 \\
\text { minutes }\end{array}$ & $\begin{array}{l}0.35-0.5 \mathrm{mcg} / \mathrm{kg} \text { every } 30-60 \\
\text { minutes as needed }\end{array}$ & $\begin{array}{l}\text { Infant: } 1-2 \mathrm{mcg} / \mathrm{kg} \text {, may repeat at } \\
2 \text { to } 4 \text { hour intervals; } \\
\text { Children: } 1-2 \mathrm{mcg} / \mathrm{kg} \text {, may repeat } \\
\text { at } 30-60 \mathrm{~min} \text { intervals; } \\
\text { Adolescents }<18 \mathrm{y} \text { and }<50 \mathrm{~kg} \text { : } 0.5 \\
\text { to } 1 \mathrm{mcg} / \mathrm{kg} \text {, may repeat every } 1 \\
\text { to } 2 \text { hours; } \\
\text { Adolescents }<18 \mathrm{y} \text { and } \geq 50 \mathrm{~kg}: 25 \\
\text { to } 50 \mathrm{mcg} \text { every } 1 \text { to } 2 \text { hours }\end{array}$ \\
\hline Fentanyl - IM & 7-8 minutes & $1-2$ hours & $\begin{array}{l}0.35-0.5 \mathrm{mcg} / \mathrm{kg} \text { every } 30-60 \\
\text { minutes as needed }\end{array}$ & NA \\
\hline Fentanyl - IN & $\begin{array}{l}5-10 \\
\text { minutes }\end{array}$ & 1 hour & $\begin{array}{l}100 \text { mcg (one } 100 \mathrm{mcg} \text { spray } \\
\text { in one nostril) }\end{array}$ & $\begin{array}{l}\text { IV solution delivered via atomizer } \\
\text { at doses ranging from } 1-2 \mathrm{mcg} / \mathrm{kg} \\
\text { has been studied. }\end{array}$ \\
\hline Fentanyl -NEB & $\begin{array}{l}\text { Almost } \\
\text { immediate }\end{array}$ & $\begin{array}{l}30-60 \\
\text { minutes }\end{array}$ & $\begin{array}{l}\text { Studies used IV solution } \\
\text { delivered via nebulizer, doses } \\
\text { were either } 2 \mathrm{mcg} / \mathrm{kg} \text { or } \\
4 \mathrm{mcg} / \mathrm{kg} \text {. }\end{array}$ & NA \\
\hline $\begin{array}{l}\text { Fentanyl - } \\
\text { transmucosal } \\
\text { lozenge }\end{array}$ & $\begin{array}{l}5-15 \\
\text { minutes }\end{array}$ & $\begin{array}{l}\text { Related to } \\
\text { blood level }\end{array}$ & $\begin{array}{l}200 \text { mcg consumed over } 15 \\
\text { minutes }\end{array}$ & NA \\
\hline Ibuprofen - IV & $\begin{array}{l}30-60 \\
\text { minutes }\end{array}$ & $6-8$ hours & $\begin{array}{l}400 \text { to } 800 \mathrm{mg} \text { IV every } 6 \\
\text { hours as needed }\end{array}$ & $\begin{array}{l}6 \text { months to }<12 \mathrm{y}: 10 \mathrm{mg} / \mathrm{kg} \\
\text { every } 4 \text { to } 6 \text { hours; } \\
12-17 \mathrm{y}: 400 \mathrm{mg} \text { every } 4 \text { to } 6 \\
\text { hours }\end{array}$ \\
\hline Ibuprofen - PO & $\begin{array}{l}30-60 \\
\text { minutes }\end{array}$ & $6-8$ hours & 200 to $800 \mathrm{mg} \mathrm{3-4} \mathrm{times} \mathrm{daily}$ & $\begin{array}{l}\text { Infants and children }<50 \mathrm{~kg}: 4 \text { to } \\
10 \mathrm{mg} / \mathrm{kg} \text { every } 6 \text { to } 8 \text { hours }\end{array}$ \\
\hline Ketamine - IVC & $\begin{array}{l}\text { Within } 30 \\
\text { seconds }\end{array}$ & $\begin{array}{l}5-10 \\
\text { minutes }\end{array}$ & $\begin{array}{l}0.1-0.3 \mathrm{mg} / \mathrm{kg} \text { IV bolus over } \\
10-15 \text { minutes with option of } \\
\text { continuous infusion at } 0.15 \text { to } \\
0.2 \mathrm{mg} / \mathrm{kg} / \mathrm{hr}\end{array}$ & $\begin{array}{l}\text { Doses ranging from } 0.2 \text { to } \\
0.3 \mathrm{mg} / \mathrm{kg} \text { IV bolus have been } \\
\text { studied }\end{array}$ \\
\hline Ketamine - IN & $\begin{array}{l}\text { Within } 10 \\
\text { minutes }\end{array}$ & $\begin{array}{l}\text { Up to } 60 \\
\text { minutes }\end{array}$ & $0.5-1 \mathrm{mg} / \mathrm{kg}$ & $\begin{array}{l}\text { IV solution delivered via atomizer } \\
\text { has been studied at doses } \\
\text { ranging from } 1-1.5 \mathrm{mg} / \mathrm{kg}\end{array}$ \\
\hline Ketorolac - IV & $\begin{array}{l}\sim 30 \\
\text { minutes }\end{array}$ & 4-6 hours & $\begin{array}{l}\geq 50 \mathrm{~kg}: 30 \mathrm{mg} \text { IV as a single } \\
\text { dose or } 30 \mathrm{mg} \text { every } 6 \text { hours }\end{array}$ & $\begin{array}{l}<2 \mathrm{y}: 0.5 \mathrm{mg} / \mathrm{kg} \text { every } 6 \text { to } 8 \\
\text { hours; } \\
\geq 2 \mathrm{y} \text { and } \leq 16 \mathrm{y}: 0.5 \mathrm{mg} / \mathrm{kg} \text { every } 6 \\
\text { hours; } \\
\geq 17 \mathrm{y} \text { and }<50 \mathrm{~kg}: 15 \mathrm{mg} \text { as a } \\
\text { single dose or } 15 \mathrm{mg} \text { every } 6 \\
\text { hours; } \\
\geq 17 \mathrm{y} \text { and } \geq 50 \mathrm{~kg} \text { : refer to adult } \\
\text { dosing }\end{array}$ \\
\hline Ketorolac - PO & $\begin{array}{l}30-60 \\
\text { minutes }\end{array}$ & 4-6 hours & $\begin{array}{l}\geq 50 \mathrm{~kg}: 20 \mathrm{mg} \mathrm{PO}, \text { followed } \\
\text { by } 10 \mathrm{mg} \text { every } 4-6 \text { hours as } \\
\text { needed }\end{array}$ & $\begin{array}{l}\geq 2 \mathrm{y} \text { and } \leq 16 \mathrm{y}: 1 \mathrm{mg} / \mathrm{kg} \text { as a } \\
\text { single dose; } \\
\geq 17 \mathrm{y} \text { and }<50 \mathrm{~kg}: 10 \mathrm{mg} \text {, then } \\
10 \mathrm{mg} \text { every } 4 \text { to } 6 \text { hours; } \\
\geq 17 \mathrm{y} \text { and } \geq 50 \mathrm{~kg} \text { : refer to adult } \\
\text { dosing }\end{array}$ \\
\hline Morphine - IV & $\begin{array}{l}5-10 \\
\text { minutes }\end{array}$ & $4-5$ hours & $\begin{array}{l}2.5-5 \mathrm{mg} \text { every } 3-4 \text { hours as } \\
\text { needed }\end{array}$ & $\begin{array}{l}\leq 6 \text { months: } 0.025 \text { to } 0.03 \mathrm{mg} / \mathrm{kg} \\
\text { every } 2 \text { to } 4 \text { hours; } \\
>6 \text { months and }<50 \mathrm{~kg} \text { : } \\
0.05 \mathrm{mg} / \mathrm{kg} \text { every } 2 \text { to } 4 \text { hours; } \\
>6 \text { months and } \geq 50 \mathrm{~kg}: 2 \text { to } 5 \mathrm{mg} \\
\text { every } 2 \text { to } 4 \text { hours }\end{array}$ \\
\hline Morphine - IM & $\begin{array}{l}10-30 \\
\text { minutes }\end{array}$ & $4-5$ hours & $\begin{array}{l}\text { 5-10 mg every } 4 \text { hours as } \\
\text { needed }\end{array}$ & $\begin{array}{l}\text { Refer to pediatric IV morphine } \\
\text { dosing }\end{array}$ \\
\hline
\end{tabular}




\begin{tabular}{|c|c|c|c|c|}
\hline $\begin{array}{l}\text { Analgesic - } \\
\text { Route }\end{array}$ & Onset & $\begin{array}{l}\text { Analgesic } \\
\text { Duration }\end{array}$ & $\begin{array}{l}\text { Typical Initial Adult Dosing } \\
\text { for Acute Pain }\end{array}$ & $\begin{array}{l}\text { Typical Initial Pediatric Dosing } \\
\text { for Acute Pain }\end{array}$ \\
\hline Morphine - PO & $\begin{array}{l}\sim 30 \\
\text { minutes }\end{array}$ & $3-5$ hours & $\begin{array}{l}15-30 \mathrm{mg} \text { every } 4 \text { hours as } \\
\text { needed }\end{array}$ & $\begin{array}{l}\leq 6 \text { months: } 0.08 \text { to } 0.1 \mathrm{mg} / \mathrm{kg} \\
\text { every } 3 \text { to } 4 \text { hours; } \\
>6 \text { months and }<50 \mathrm{~kg}: 0.2 \text { to } \\
0.5 \mathrm{mg} / \mathrm{kg} \text { every } 3 \text { to } 4 \text { hours; } \\
>6 \text { months and } \geq 50 \mathrm{~kg}: 15 \text { to } \\
20 \mathrm{mg} \text { every } 3 \text { to } 4 \text { hours }\end{array}$ \\
\hline Nitrous Oxide & $2-5$ minutes & $\mathrm{N} / \mathrm{A}$ & $\begin{array}{l}25 \% \text { to } 50 \% \text { nitrous oxide } \\
\text { with oxygen }\end{array}$ & Refer to adult dosing \\
\hline
\end{tabular}

Abbreviations: IM=intramuscular; $\mathrm{IN}=$ intranasal; $\mathrm{IV}=$ intravenous; $\mathrm{kg}=\mathrm{kilogram}$; $\mathrm{mcg}=$ microgram; $\mathrm{mg}=$ milligram; $\mathrm{NA}=\mathrm{not}$ applicable; $\mathrm{NEB}=$ nebulizer; $\mathrm{PO}=$ by mouth

aThis table should be used in the context of understanding the findings of the report, as it relates to applicability of evidence. Please refer to drug dosing reference for maximal doses and additional clinical considerations when prescribing analgesics to treat acute pain, particularly because some routes for some analgesics are used off-label and established doses may be less clear.

ber FDA label for intranasal fentanyl approved for cancer breakthrough pain.

${ }^{\mathrm{c}}$ Ketamine is used off-label for acute pain management and doses may vary although use of sub-dissociative doses are general suggested for acute pain management.

\section{Impetus for the Review}

This systematic review will assess the comparative effectiveness and harms of opioid and nonopioid analgesics for the prehospital management of acute pain to support future work sponsored by the National Highway Traffic Safety Administration (NHTSA). The scope and Key Questions (KQs) for this topic were developed by the Agency for Healthcare Research and Quality in conjunction with the NHTSA and University of Connecticut Evidence-based Practice Center.

\section{Key Questions}

KQ1. What is the comparative effectiveness of the initial analgesic agent treatment for achieving reduction in moderate-to-severe acute-onset pain level when administered by emergency medical services (EMS) personnel in the prehospital setting?

$\mathrm{KQ}$ 1a. How does effectiveness vary by patient characteristics?

$\mathrm{KQ} 1 \mathrm{~b}$. How does effectiveness vary by routes of administration, dosing, and timing?

$K Q 2$. What are the comparative harms of analgesic agents when administered by EMS personnel to control moderate-to-severe pain in the prehospital setting?

KQ 2a. How do harms vary by patient characteristics?

$\mathrm{KQ} 2 \mathrm{~b}$. How do harms vary by routes of administration, dosing, and timing?

$K Q$ 2c. What are the comparative harms to EMS personnel who 
administer analgesics to patients for the control of moderate-tosevere pain in the prehospital setting?

$K Q 3$. In patients whose moderate-to-severe acute-onset pain level is not controlled following initial analgesic treatment, what is the comparative effectiveness of switching the analgesic regimen compared to repeating the initial treatment?

$K Q$ 3a. How does effectiveness vary by patient characteristics?

$K Q 3 b$. How does effectiveness vary by timing of the second treatment administration?

$\mathrm{KQ}$ 4. In patients whose moderate-to-severe acute-onset pain level is not controlled following initial analgesic treatment, what are the comparative harms of switching to another analgesic agent?

$\mathrm{KQ} 4 \mathrm{a}$. How do harms vary by patient characteristics?

$\mathrm{KQ} 4 \mathrm{~b}$. How do harms vary by routes of administration, dosing, and timing?

\section{Population, Intervention, Comparator, Outcome, Timing, Setting}

For this systematic review, the following population, intervention, comparator, outcome, timing, and setting (PICOTS) applies.

Populations: The population of interest is people with acute onset pain, moderate to severe in intensity, without restrictions on age. We determined pain intensity by 1) study inclusion/exclusion criteria, 2) reported baseline pain scores, or 3) in the absence of 1 or 2 , we assumed pain to have been at least moderate for trials studying opioids or ketamine. We did not exclude studies based on the specific tool or threshold used by the study to define moderate or severe pain. Studies that targeted patients with mild pain, non-zero pain or labor and delivery pain were excluded.

KQ 3 and 4 required patients to have had an inadequate responsive to a first analgesic. The definition of "inadequate response" was based on what was used in the study. We did not exclude studies based on the threshold or tool used by the study to determine adequacy of response.

Sub-KQ 1a, 2a, 3a and 4a targeted population characteristics that were potential modifiers of the original KQ including age, source of pain, severity of pain, medical condition (including chronic pain, chronically painful conditions or chronic opioid users), location of the pain, and vital signs. 
Sub-KQ 2c was specific to the population of EMS personnel that administer or handle analgesics in the care of patients with acute onset, moderate to severe pain, including emergency medical technicians, advanced emergency medical technicians, and paramedics.

Interventions: Interventions included in this report are listed in Table 2. We included studies regardless of the studied dose, frequency or route of administration (oral, subcutaneous, intravenous, intramuscular, intraosseous, intranasal, inhaled, or transdermal). We excluded other interventions such as nonpharmacologic treatments, placebo, no treatment, other combinations of interventions or complimentary/alternative medicine.

Table 2. Included analgesics

\begin{tabular}{l|l}
\hline Class & \multicolumn{2}{c}{ Analgesics } \\
\hline Opioid & Fentanyl, morphine \\
\hline Nonopioid & Acetaminophen, ketamine, nitrous oxide/oxygen, NSAIDs (ketorolac or ibuprofen) \\
\hline Combinations & Opioid (fentanyl or morphine) + ketamine \\
\hline Abbreviations: NSAIDs=nonsteroidal anti-inflammatory drugs
\end{tabular}

KQ 3 and 4 also evaluated the interventions in Table 2 but at a different dose that initially used or a different analgesic than the first, ineffective analgesic.

Sub-KQb 1-4 targeted characteristics of the analgesic regimen or training and background of the personnel that were potential modifiers of the original KQ. KQ $1 b, 2 b, 4 b$ explore route of administration, dose of analgesic and frequency of dose, EMS personnel training/background. KQ $3 \mathrm{~b}$ explored timing of the second analgesic.

Comparators: We were interested in comparing 1) opioid to nonopioid analgesics, 2) the combination of opioid plus ketamine to ketamine alone, 3) nonopioid to a different nonopioid analgesic, and 4) opioid to a different opioid analgesic (Table 2). We included studies regardless of the studied dose, frequency or route of analgesic administration (oral, subcutaneous, intravenous (IV), intramuscular (IM), intraosseous, intranasal (IN), inhaled, or transdermal). We excluded studies that did not have at least one comparator in Table 2.

KQ 3 and 4 required the study comparator to be the initial drug regimen studied to which the patient was determined to be inadequately responsive to.

\section{Outcomes:}

- KQ 1,3:

- Pain severity scores (continuous) and presence of pain (dichotomous), as defined by the tools and thresholds used in the included studies

$\circ$ Time to analgesic effect

$\circ$ Self-reported recall of pain episode

- $\mathrm{KQ} 2,4$ :

- Any adverse event (as in the total number of subjects that experienced an adverse event during the study)

- Blood pressure (systolic and diastolic)

- Dissociative experiences scale response

$\circ$ Emergence delirium

○ Heart rate

- Hypotension

- Mental status changes 
- Nausea

- Oxygen saturation

- Respiratory depression

- Respiratory rate

○ Vomiting

- KQ 2c:

○ Diversion

- Future risk of substance abuse or misuse

○ Needle sticks

Timing: There were no restrictions based on timing aside from studies from the ED setting for which we included pain related outcomes through 60 minutes.

Settings: The primary setting of interest was prehospital, and studies from the prehospital setting were considered to provide direct evidence. We also included studies from the ED and battlefield but these settings were considered to provide indirect evidence to the prehospital setting. See the methods section regarding the impact of evidence from indirect settings on strength of evidence grading.

Study Designs: We included randomized controlled trials, case-control, and cohort studies.

\section{Contextual Questions}

Two Contextual Questions (CQ) are addressed within this report. The intent of CQs is to enhance findings of the review and to ensure the findings are put into appropriate clinical or policy context. Contextual Questions are not systematically reviewed, and use a "best evidence" approach. Findings related to the CQs are presented in the Discussion chapter, within the Applicability subsection.

CQ 1: Which treatments are contraindicated for specific medical conditions or patient characteristics (e.g., dental pain, abdominal pain, depressed blood pressure, heart rate, and/or respiratory rate, altered mental status, agitation)?

CQ 2: What is the evidence regarding use of pain assessment tools in the prehospital setting for special populations including children, individuals with cognitive impairment, substance impaired individuals, and non-English speakers? 


\section{Methods}

The scope and Key Questions (KQs) for this topic were developed by the Agency for Healthcare Research and Quality (AHRQ) in conjunction with the National Highway Traffic Safety Administration (NHTSA) and the University of Connecticut Evidence-based Practice Center (UConn EPC). We (the UConn EPC) then drafted a protocol for the systematic review and recruited a panel of technical expert panelists (TEP) to provide high-level content and methodological expertise throughout the development of the review. The finalized protocol is posted on the Effective Health Care website at https://effectivehealthcare.ahrq.gov/topics/acutepain-ems/protocol. The PROSPERO registration is CRD42018114959.

We developed an a priori analytic framework to guide the systematic review process (Figure 1). The details of the analytic framework were determined in consultation with NHTSA and the TEP. We identified relevant literature by searching Ovid MEDLINE, Ovid MEDLINE InProcess \& Other Nonindexed Citations, EMBASE via Ovid and Cochrane Central Register of Controlled Trials from earliest date through May 9, 2019 using subject headings and natural language terms reflecting the settings and analgesics of interest (Appendix A). We supplemented the bibliographic database searches with backwards citation tracking of relevant publications. We searched the clinicaltrials.gov website and the World Health Organization International Controlled Trials Registry Platform for ongoing studies and those completed with reported results.

Figure 1. Analytic framework

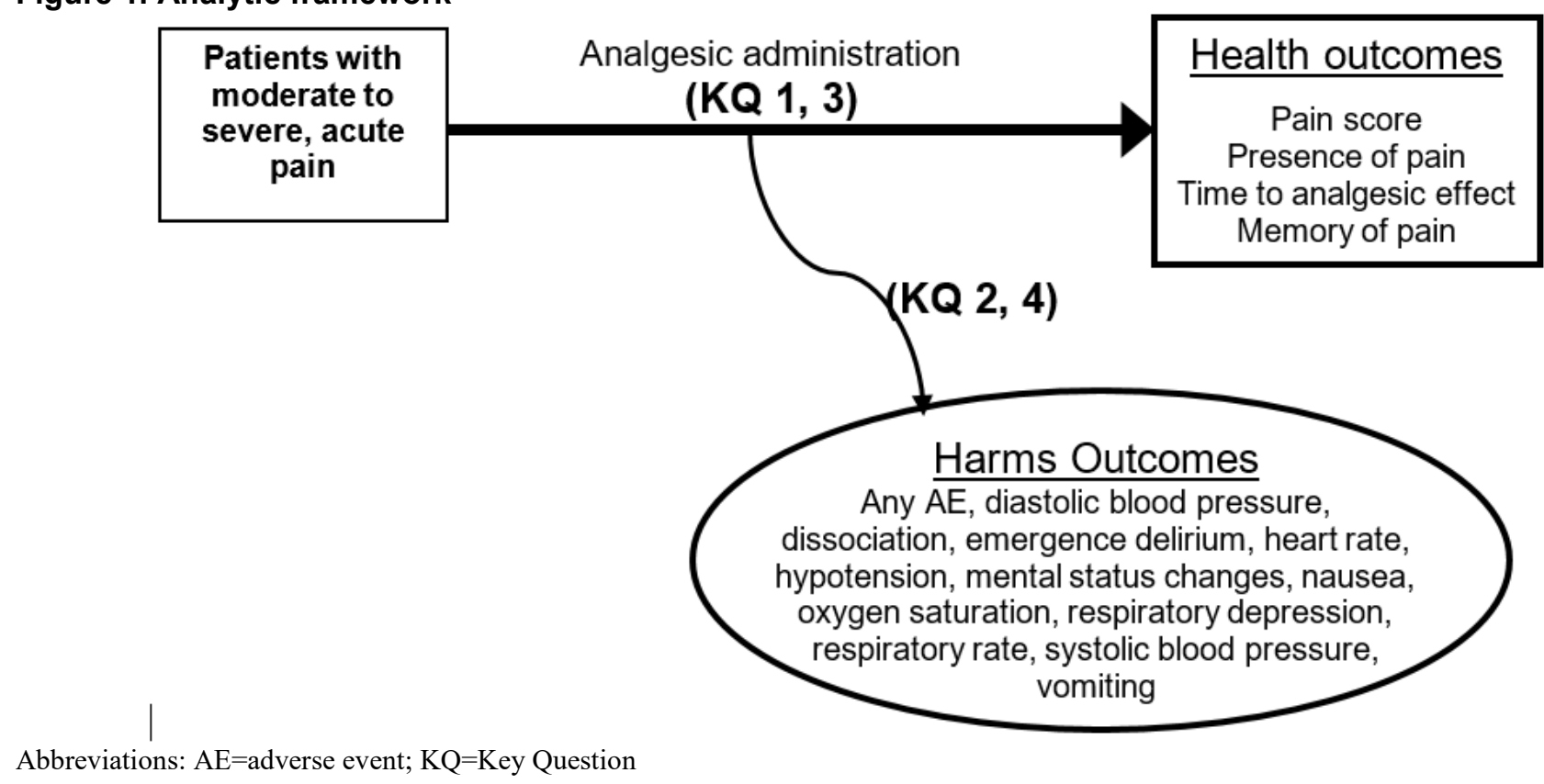

We managed citations using DistillerSR ${ }^{\circledR}$. We screened titles and abstracts using two independent reviewers to determine if the citation met inclusion/exclusion criteria (Table 3). When both reviewers agreed that a citation met inclusion criteria, we reviewed the full text for inclusion into the review. A third reviewer resolved disagreements. 
Table 3. Inclusion and exclusion criteria for Key Questions

\begin{tabular}{|c|c|c|}
\hline Category & Inclusion Criteria & Exclusion Criteria \\
\hline Population & $\begin{array}{l}\text { KQ 1-4: Any age with acute onset, moderate } \\
\text { to severe pain. } \\
\text { KQ 3, } 4 \text { : Above criteria plus considered } \\
\text { inadequately responsive to the initial } \\
\text { analgesic. }\end{array}$ & $\begin{array}{l}\text { KQ 1-4: Pain associated with labor and delivery; } \\
\text { mild or non-zero pain severity }\end{array}$ \\
\hline Intervention & $\begin{array}{l}\text { KQ 1-4: Opioids (morphine or fentanyl); } \\
\text { Nonopioids [ketamine, nitrous oxide/oxygen, } \\
\text { NSAIDs (ketorolac or ibuprofen), APAP]; } \\
\text { Opioids + ketamine } \\
\text { KQ 3, 4: Above criteria plus the analgesic } \\
\text { must vary in dose or drug, from the initial } \\
\text { analgesic the patient was determined } \\
\text { inadequately responsive to. }\end{array}$ & $\begin{array}{l}\text { KQ 1-4: Any other combination or single } \\
\text { interventions such as other analgesics, } \\
\text { nonpharmacological, placebo, no treatment or } \\
\text { complimentary alternative medicine. } \\
\text { KQ 3, 4: Administration of the same drug and } \\
\text { dose as the initial analgesic, which the patient } \\
\text { was determined to be inadequately responsive } \\
\text { to. }\end{array}$ \\
\hline Comparator & $\begin{array}{l}\text { KQ 1-4: Opioids (morphine or fentanyl); } \\
\text { Nonopioids [ketamine, nitrous oxide/oxygen, } \\
\text { NSAIDs (ketorolac or ibuprofen), APAP]; } \\
\text { Opioids + ketamine } \\
\text { KQ 3, 4: The initial analgesic regimen studied } \\
\text { to which the patient was inadequately } \\
\text { responsive. }\end{array}$ & $\begin{array}{l}\text { KQ 1-4: Any other single interventions such as } \\
\text { other analgesics, nonpharmacological, placebo, } \\
\text { no treatment or complimentary alternative } \\
\text { medicine. Any combinations of treatments that } \\
\text { are not specified in the inclusion criteria. } \\
\text { KQ } 3,4 \text { : Comparisons to analgesic regimens } \\
\text { other than the initial regimen to which the } \\
\text { patient was determined to be inadequately } \\
\text { responsive. }\end{array}$ \\
\hline Outcomes & $\begin{array}{l}\text { At least one outcome listed in PICOTS (see } \\
\text { Outcomes section above) }\end{array}$ & $\begin{array}{l}\text { Studies that do not include at least one } \\
\text { outcome }\end{array}$ \\
\hline Timing & All study durations and follow-ups & None \\
\hline Setting & Prehospital, battlefield, ED & All other settings. \\
\hline Study Design & $\begin{array}{l}\text { RCTs, nonrandomized controlled trials, } \\
\text { prospective or retrospective controlled cohort } \\
\text { studies, case-controlled studies }\end{array}$ & $\begin{array}{l}\text { Case series, case reports, studies without an } \\
\text { active comparator or non-active control group }\end{array}$ \\
\hline $\begin{array}{l}\text { Publication } \\
\text { Language, } \\
\text { Dates }\end{array}$ & No limits on publication date or language ${ }^{b}$ & Abstracts without published study manuscripts. \\
\hline
\end{tabular}

Abbreviations: APAP=acetaminophen; $\mathrm{ED}=$ =emergency department; KQ=Key Question; NSAIDs=nonsteroidal anti-inflammatory drugs; PICOTS=population, intervention, comparator, outcomes, timing, setting; $\mathrm{RCT}=$ randomized controlled trial

${ }^{a}$ Severity of pain was determined by study inclusion criteria, baseline pain scores, or if these data were not available severity was assumed to be moderate to severe in studies of opioids or ketamine.

${ }^{b}$ English language abstracts of non-English language articles will be reviewed at the abstract stage consistent with the process described by the Methods Guide. ${ }^{34}$

We contacted corresponding authors when needed for clarification related to inclusion criteria and to solicit data for outcomes that were reported in the methods of the paper but not reported as a numerical result. All authors were given a minimum of 7 days to acknowledge queries. We matched results posted in clinical trial registries, abstracts and meeting presentations to their corresponding full text publication, which was always used as the primary data source, and reviewed for supplemental data. We considered post-hoc and subgroup analyses of included studies when they provide data on the outcomes of interest.

One investigator extracted data into standardized collection forms and evidence and outcomes tables, followed by verification by a second investigator. Two independent reviewers assessed risk of bias using the Cochrane Collaboration's Risk of Bias Tool ${ }^{35}$ for randomized controlled trials (RCTs) and Newcastle Ottawa Scale ${ }^{36}$ for observational studies. We classified overall risk of bias for each study as low, moderate or high, according to the collective risk of bias per evaluated domain and the investigator's confidence in the study results given the identified limitations. ${ }^{37} \mathrm{~A}$ low rating implies lack of major or minor sources of bias that were 
likely to have influenced results. A medium rating implies some confidence that the results represented true treatment effect and although the study was susceptible to some bias, it was not sufficient to invalidate results. A high rating implies low confidence that results represented true treatment effects, due to significant flaws that implied biases of various types. Risk of bias was considered unclear if the majority of domains evaluated were unclear, meaning information was missing to permit judgements of possible bias. Studies with high risk of bias were not excluded from analyses rather their contribution to the evidence base was considered when grading strength of evidence for our conclusions.

To characterize the population, we classified the type of pain for each study as traumatic, nontraumatic or mixed. We synthesized all pain classifications together and when possible, we also analyzed and reported results for traumatic pain. We based synthesis on specific analgesic comparisons (i.e. opioid versus ketamine, opioid versus acetaminophen [APAP] etc.) and regimen characteristics including route, dose and frequency, were explored in subgroup analyses. Some studies, almost exclusively from the emergency department (ED) setting, reported outcomes at multiple specific time points over the course of the study. We collected and analyzed three times points: 15 minutes (post-drug administration through $15 \mathrm{~min}$ ), 30 minutes (20 to 30 minutes) and 60 minutes (40 to 60 minutes). These time points were selected in consideration of the pharmacokinetic profiles of the analgesics studied and time points that were decided to be most informative to the prehospital setting. When the time point of an outcome was not at 15, 30 or 60 minutes but fell within the given range of values considered acceptable for that time point, we included the data in our analysis (i.e. if a study reported pain at 20 minutes but not 30 minutes, we used the data from 20 minutes in the analysis of 30 minutes).

This review sought to address prehospital pain management although given the scarcity of studies, battlefield and ED settings were included to provide indirect evidence. We did not use meta-analysis across the three settings, only within each setting when applicable. However, when synthesizing the evidence we did consider data from the various settings. Battlefield data were qualitatively described and did not contribute to our conclusions.

We assessed clinical and methodological heterogeneity to determine appropriateness of metaanalysis. When there were two or more trials of similar pharmacologic comparisons and outcomes, we performed random-effects meta-analysis using inverse-variance weighting. Between-study variance was estimated using the Paule-Mandel estimator. ${ }^{38}$ The Hartung-Knapp method was used to adjust 95 percent confidence intervals (CI) when three or more studies were meta-analyzed; ${ }^{39,40}$ otherwise, a traditional DerSimonian-Laird random-effects model was used. ${ }^{41}$ Continuous outcomes are reported as mean differences and 95 percent CI. We pooled either mean change in continuous parameters from baseline (also referred to as the change score) for each arm or a difference in change scores, depending on what was reported in the studies. When necessary for parallel trials that did not report change scores individually for each arm, we calculated it from the available baseline and end-point values, as suggested by Follman et al. ${ }^{42}$ For continuous pain scales, we converted scores (e.g. 0-100 scale) to a 10-point scale using the methods of Thorlund, et al. ${ }^{43}$ When studies reported continuous parameters as medians and related variances, we converted the data to means and standard deviations according to the methods of Wan et al. ${ }^{44}$ For binary outcomes, risk differences (RD) and risk ratios (RR) are reported with corresponding 95 percent CI. For outcomes with zero events in one or both study arms, continuity correction was used. ${ }^{45,46}$ All studies, including those that were not amenable to pooling, are qualitatively summarized. 
When quantitative pooling of studies was possible, we assessed presence of statistical heterogeneity using the Cochrane $p$-value $(\mathrm{p}<0.10$ significant $)$ and the $\mathrm{I}^{2}$ statistic which represents the percentage ( $0-100$ percent) of variability in the treatment estimate that is attributable to heterogeneity. ${ }^{47}$ Small study effects were evaluated for through visual inspection of funnel plots. Tests for funnel plot asymmetry were conducted when 10 or more studies reported a given outcome. ${ }^{48} \mathrm{We}$ conducted subgroup analyses to evaluate for the presence of effect modifiers. Analyses were done for graded comparisons and outcomes, as previously specified. For individual outcomes, analyses were either stratified according to the subgroup or, when available, results from subgroup analyses reported in individual trials are summarized. All analyses were performed using the 'meta' package (version 4.9-4) in R (version 3.5.2; the R Project for Statistical Computing).

At the completion of the review, two reviewers independently constructed conclusions and graded each conclusion's strength of evidence (SOE). Conflicts were resolved either through consensus or third-party adjudication. Input from NHTSA, the TEP, AHRQ and our EPC led to a prioritized list of comparisons and outcomes for which conclusions were constructed and graded. Prioritized comparisons were opioids versus ketamine, opioids plus ketamine versus opioids, opioids versus APAP, opioids versus nitrous oxide and opioids versus nonsteroidal antiinflammatory drugs (NSAIDs). Prioritized outcomes were pain severity (continuous measures), presence of pain (dichotomous measures), time to analgesic effect, respiratory depression, hypotension, change in mental status, and "any adverse event".

Conclusions were constructed with consideration of the absolute effect estimates and their corresponding confidence intervals compared to clinically important differences (CID) established for this review (Table 4). These CIDs reflect input from our EPC and consultant experts, NHTSA, and the TEP. When the body of evidence generated a point estimate and confidence interval that exceeded the CID in one direction we concluded a difference exists between the analgesics compared for that outcome. When the point estimate and confidence interval suggested a CID may exist (confidence interval included both a CID and also a smaller difference, but overall was shifted towards a CID) we concluded there "may" be a difference between the two analgesics for that outcome. When the point estimate and confidence interval were entirely within the CID such that a CID in either direction was ruled out, we concluded "there was no evidence of a clinically important difference" for that analgesic comparison and outcome. We reserved use of "inconclusive" for when the confidence interval of the absolute measure was uninformative and included possibility of a CID in either direction or when the evidence base had multiple downgraded domains such that we were uncertain what the true effect was.

Table 4. Clinically important differences for graded outcomes

\begin{tabular}{ll}
\hline Outcome & Clinically Important Difference \\
\hline Pain score & 2 points on a continuous scale from 0 to 10 \\
\hline $\begin{array}{l}\text { Presence of pain, hypotension, respiratory } \\
\text { depression, mental status changes }\end{array}$ & ARD of $5 \%$ \\
\hline Time to analgesic effect & 5 minutes on a continuous scale \\
\hline Any adverse events & ARD of $10 \%$ \\
\hline
\end{tabular}

Abbreviations: $\mathrm{ARD}=$ absolute risk difference

The SOE of these conclusions was judged to be one of four levels (Table 5), in consideration of 5 domains: study limitations, consistency, directness (prehospital setting versus ED setting, the latter which is indirect evidence), precision and reporting bias. ${ }^{49}$ Conclusions based on RCTs 
started with a high SOE which could be downgraded based on the assessment of the 5 domains. Conclusions based on observational data began with a grade of low and may have been upgraded based on assessment of the 5 domains.

\section{Table 5. Strength of evidence (SOE) levels ${ }^{49}$}

\begin{tabular}{ll}
\hline SOE & Explanation \\
\hline High & We are very confident that the estimate of effect lies close to the true effect for this \\
& outcome. The body of evidence has few or no deficiencies. We believe that the findings \\
& are stable, i.e., another study would not change the conclusions \\
\hline Moderate & $\begin{array}{l}\text { We are moderately confident that the estimate of effect lies close to the true effect for } \\
\text { this outcome. The body of evidence has some deficiencies. We believe the findings are } \\
\\
\text { likely to be stable, but some doubt remains. }\end{array}$ \\
\hline Low & $\begin{array}{l}\text { We have limited confidence that the estimate of effect lies close to the true effect for this } \\
\text { outcome. The body of evidence has major or numerous deficiencies (or both). We } \\
\text { believe that additional evidence is needed before concluding either that the findings are } \\
\text { stable or that the estimate of effect is close to the true effect }\end{array}$ \\
\hline Insufficient & $\begin{array}{l}\text { We have no evidence, we are unable to estimate an effect, or we have no confidence in } \\
\text { the estimate of the effect for this outcome. No evidence is available or the body of } \\
\text { evidence has unacceptable deficiencies, precluding reaching a conclusion. }\end{array}$ \\
\hline
\end{tabular}

We assessed applicability of studies using the population, intervention, comparator, outcomes, timing, setting (PICOTS) framework. ${ }^{50}$ Characteristics that may have influenced applicability included but are not limited to age of patients, severity and type of pain, analgesic regimen characteristics (i.e. dose, route, frequency) and the timing of and definitions used for outcomes.

The Contextual Questions (CQ) were not based on a systematic review as the aim of the CQ were to provide a qualitative overview using the best evidence approach, without formal systematic review or analytic plans. Findings related to the CQs in this report are presented in the Discussion.

Experts in emergency medicine services, pain management and individuals representing stakeholder and user communities were invited to provide external peer review of this systematic review; AHRQ and an associate editor also provided comments. The draft report was posted on the AHRQ website for 4 weeks to elicit public comment. We addressed all reviewer comments, revising the text as appropriate, and documenting everything in a disposition of comments report to be made available three months after the Agency posts the final systematic review on the Effective Health Care website. 


\section{Results}

\section{Organization of the Report}

We begin by presenting the results of our literature search and citation screening. We provide an overview of study characteristics organized by unique analgesic comparisons.

Next we present the results for each Key Question (KQ). Results are organized by unique analgesic comparisons starting with graded comparisons (opioid versus ketamine, combination opioid and ketamine versus opioid, opioid versus acetaminophen [APAP], opioid versus nitrous oxide, opioid versus nonsteroidal anti-inflammatory drugs [NSAIDs]). Under the analgesic comparison, we present key messages followed by results and conclusions for the graded outcomes first, then results from subgroups of interest (the sub-KQs). After we conclude presentation of graded outcomes we provide "Additional Findings" which reflect results from outcomes that are not graded.

Supporting tables and figures relevant to the results appear in Appendixes C-F, including study and population characteristics, study level outcomes data, study risk of bias assessments, details regarding the strength of evidence (SOE) grading and forest plots.

\section{Search Results}

Our search identified 4907 nonduplicate records, of which 283 required full-text review after title and abstract screening, and 75 met eligibility criteria for inclusion in this review (Figure 2). These 75 citations reported results for 65 unique studies; ${ }^{16,17,19-21,27-30,51-106} 52$ randomized controlled trials (RCTs) and 13 observational studies. Citations excluded at the full text review stage are presented in Appendix B. As a result of searching trial registries, we found one study ${ }^{28}$ with results posted that has not been published in the peer reviewed literature. In addition, we received additional outcomes data from authors of 5 included studies. ${ }^{58,66,74,90,93}$ 
Figure 2. Literature flow

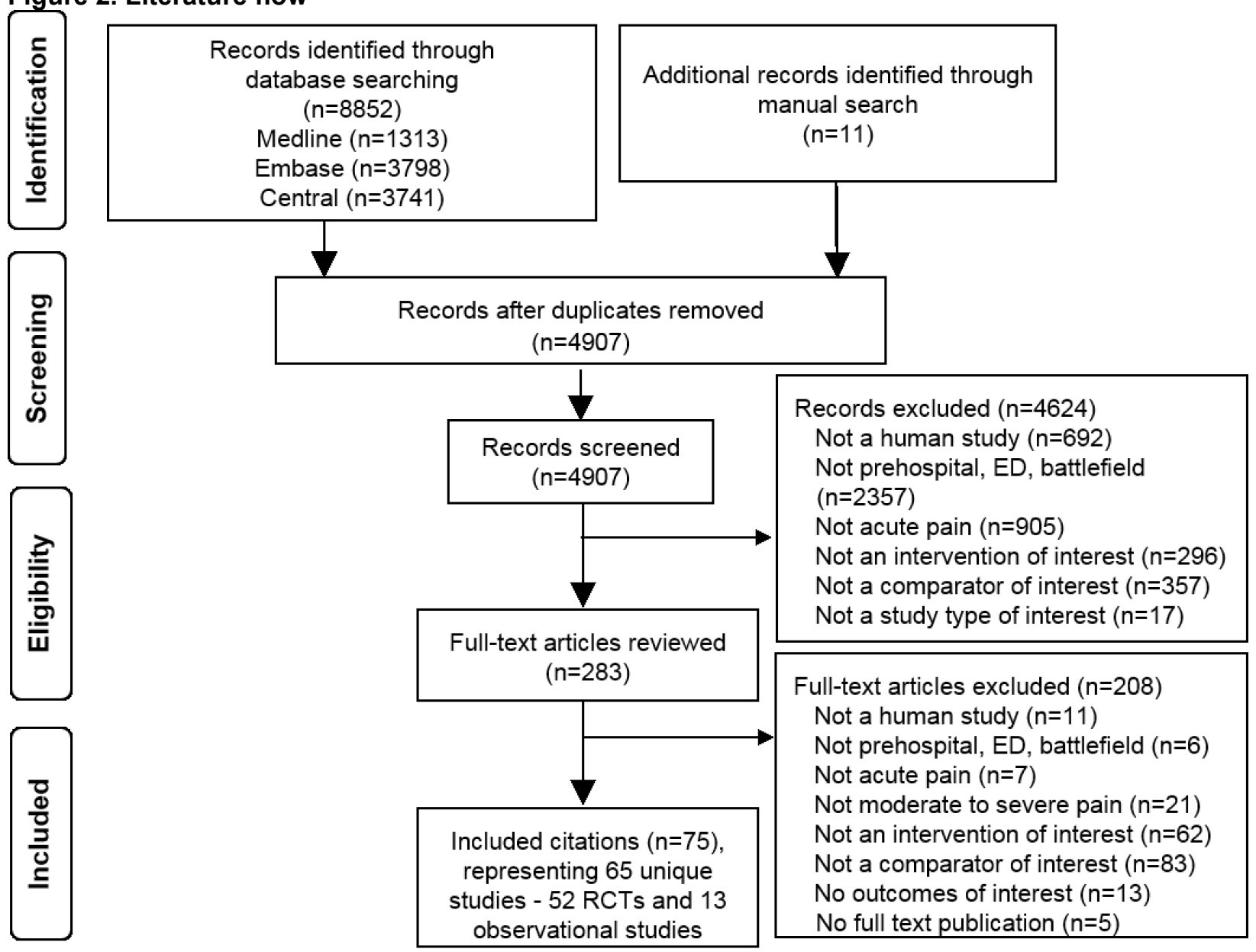

\section{Characteristics of Included Studies}

The distribution of studies per KQ, organized by comparison and study design, is presented in Table 6. Most of the literature answers KQ 1 and 2, whereas only 2 RCTs answer KQ 3 and 4. We present a summary of the characteristics of included studies in Table 7-8, followed by further details in the text, organized by comparison group.

Table 6. Number of studies included in each Key Question, by comparison and study design

\begin{tabular}{|c|c|c|c|c|c|c|}
\hline & Comparison & $\begin{array}{l}\text { Overall } \mathbf{N} \\
\text { Studies }\end{array}$ & KQ 1 & KQ 2 & KQ 3 & KQ 4 \\
\hline \multirow{5}{*}{$\begin{array}{l}\text { Graded } \\
\text { Strength of } \\
\text { Evidence }\end{array}$} & $\begin{array}{l}\text { Opioids vs. } \\
\text { Ketamine }\end{array}$ & $\begin{array}{l}17 \mathrm{RCT}^{\mathrm{RCT}} \\
3 \mathrm{OBS}^{\mathrm{a}}\end{array}$ & $\begin{array}{l}14 \mathrm{RCT} \\
2 \mathrm{OBS}\end{array}$ & $\begin{array}{l}14 \mathrm{RCT} \\
3 \mathrm{OBS}\end{array}$ & $2 \mathrm{RCT}$ & $2 \mathrm{RCT}$ \\
\hline & $\begin{array}{l}\text { Opioid + Ketamine } \\
\text { vs. Opioid }\end{array}$ & $\begin{array}{l}6 \text { RCT } \\
2 \text { OBS }^{a}\end{array}$ & $\begin{array}{l}6 \text { RCT } \\
1 \text { OBS } \\
\end{array}$ & $\begin{array}{l}6 \text { RCT } \\
1 \text { OBS }\end{array}$ & None & None \\
\hline & Opioid vs. APAP & $10 \mathrm{RCT}$ & $9 \mathrm{RCT}$ & $10 \mathrm{RCT}$ & None & None \\
\hline & $\begin{array}{l}\text { Opioid vs. Nitrous } \\
\text { Oxide }\end{array}$ & $1 \mathrm{RCT}$ & $1 \mathrm{RCT}$ & $1 \mathrm{RCT}$ & None & None \\
\hline & Opioid vs. NSAID & $3 \mathrm{RCT}$ & $3 \mathrm{RCT}$ & $3 \mathrm{RCT}$ & None & None \\
\hline
\end{tabular}




\begin{tabular}{|c|c|c|c|c|c|c|}
\hline & Comparison & $\begin{array}{l}\text { Overall N } \\
\text { Studies }\end{array}$ & KQ 1 & KQ 2 & KQ 3 & KQ 4 \\
\hline \multirow{4}{*}{$\begin{array}{l}\text { Strength of } \\
\text { Evidence Not } \\
\text { Graded }\end{array}$} & APAP vs. NSAID & $3 \mathrm{RCT}$ & $3 \mathrm{RCT}$ & $2 \mathrm{RCT}$ & None & None \\
\hline & Ketamine vs. NSAID & $1 \mathrm{RCT}$ & $1 \mathrm{RCT}$ & $1 \mathrm{RCT}$ & None & None \\
\hline & $\begin{array}{l}\text { Morphine vs. } \\
\text { Fentanyl }\end{array}$ & $\begin{array}{l}11 \text { RCT } \\
10 \text { OBS }^{a}\end{array}$ & $\begin{array}{l}9 \text { RCT } \\
8 \text { OBS }\end{array}$ & $\begin{array}{l}11 \mathrm{RCT} \\
7 \mathrm{OBS}\end{array}$ & None & None \\
\hline & $\begin{array}{l}\text { Opioid + Ketamine } \\
\text { vs. Ketamine }\end{array}$ & $1 \mathrm{OBS}$ & None & $1 \mathrm{OBS}$ & None & None \\
\hline
\end{tabular}

Abbreviations: $\mathrm{APAP}=$ acetaminophen; $\mathrm{ED}=$ emergency department; $\mathrm{KQ}=$ Key Question; NSAIDs= nonsteroidal antiinflammatory; OBS $=$ observational; $\mathrm{RCT}=$ randomized controlled trial; vs=versus

${ }^{a}$ Two observational studies include two comparisons: opioids vs. ketamine and morphine vs. fentanyl, one of these studies also compared opioid+ketamine vs. opioid 
Table 7. Characteristics of included studies for graded comparisons, per comparison

\begin{tabular}{|c|c|c|c|c|c|}
\hline Characteristic & $\begin{array}{l}\text { Opioids Versus } \\
\text { Ketamine }\end{array}$ & $\begin{array}{l}\text { Opioids + } \\
\text { Ketamine Versus } \\
\text { Opioid }\end{array}$ & $\begin{array}{l}\text { Opioids } \\
\text { Versus APAP }\end{array}$ & $\begin{array}{l}\text { Opioids } \\
\text { Versus } \\
\text { Nitrous } \\
\text { Oxide } \\
\end{array}$ & $\begin{array}{l}\text { Opioids } \\
\text { Versus NSAIDs }\end{array}$ \\
\hline $\mathrm{N}$ of studies & $\begin{array}{l}17 \mathrm{RCT} \\
3 \mathrm{OBS}^{\mathrm{a}}\end{array}$ & $\begin{array}{l}6 \text { RCT } \\
2 \text { OBS }^{a}\end{array}$ & $10 \mathrm{RCT}$ & $1 \mathrm{RCT}$ & $3 \mathrm{RCT}$ \\
\hline $\begin{array}{l}\text { Countries } \\
\text { (N studies) }\end{array}$ & $\begin{array}{l}\text { Afghanistan } 2^{\text {b; }} \\
\text { Australia 1; Israel } \\
\text { 1; Iran 5; Sweden } \\
\text { 1; } 1 \text { New Zealand; } \\
\text { USA 8; Vietnam } 1\end{array}$ & $\begin{array}{l}\text { Afghanistan } 1^{\mathrm{b}} ; \\
\text { France 1; Iran 3; } \\
\text { Switzerland 1; } \\
\text { USA } 2\end{array}$ & $\begin{array}{l}\text { Iran 4; Turkey 4; } \\
\text { Qatar 1; UK } 1\end{array}$ & Iran 1 & $\begin{array}{l}\text { Canada } 1 ; \text { Iran } \\
1 ; \text { USA } 1\end{array}$ \\
\hline $\mathrm{N}$ of patients & 2,484 & 1,566 & 2,001 & 100 & 474 \\
\hline $\begin{array}{l}\text { Gender } \\
\text { (Range of } \\
\text { males, \%) } \\
\end{array}$ & 23.3 to 100 & 40 to 100 & 43 to 83 & 72 to 84 & 56.4 to 70.5 \\
\hline $\begin{array}{l}\text { Age } \\
\text { (Range of } \\
\text { means, years) }\end{array}$ & 7 to 77.3 & 23 to 51.6 & 29.1 to 44.6 & 35.8 to 37 & 11.7 to 39.3 \\
\hline $\begin{array}{l}\text { Pain } \\
\text { Classification } \\
\text { (N studies) }\end{array}$ & $\begin{array}{l}\text { Traumatic: } 13 \\
\text { Nontraumatic: } 1 \\
\text { Mixed: } 6\end{array}$ & $\begin{array}{l}\text { Traumatic: } 3 \\
\text { Nontraumatic: } 2 \\
\text { Mixed: } 3\end{array}$ & $\begin{array}{l}\text { Traumatic: } 4 \\
\text { Nontraumatic: } 5 \\
\text { Mixed: } 1\end{array}$ & Traumatic: 1 & $\begin{array}{l}\text { Traumatic: } 1 \\
\text { Nontraumatic: } 1 \\
\text { Mixed: } 1\end{array}$ \\
\hline $\begin{array}{l}\text { Setting } \\
\text { (N studies) }\end{array}$ & $\begin{array}{l}\text { Prehospital: } 4 \\
\text { ED: } 14 \\
\text { Battlefield: } 2\end{array}$ & $\begin{array}{l}\text { Prehospital: } 2 \\
\text { ED: } 5 \\
\text { Battlefield: } 1\end{array}$ & ED: 10 & ED: 1 & ED: 3 \\
\hline $\begin{array}{l}\text { Administered } \\
\text { doses } \\
\text { (N studies) }^{\mathrm{c}}\end{array}$ & $\begin{array}{l}\text { Single: } 11 \\
\text { Multiple: } 7 \\
\text { Unknown: } 2\end{array}$ & $\begin{array}{l}\text { Single: } 6 \\
\text { Unknown: } 2\end{array}$ & Single: 10 & Single: 1 & $\begin{array}{l}\text { Single: } 1 \\
\text { Multiple: } 2\end{array}$ \\
\hline $\begin{array}{l}\text { Dosage forms } \\
\text { ( } \mathrm{N} \text { of studies } \\
\text { each) }\end{array}$ & $\begin{array}{l}\text { IV vs. IV: } 10 \\
\text { IN vs. IN: } 4 \\
\text { IV vs. IN: } 2^{\mathrm{d}} \\
\text { IM vs. IN: } 1^{\mathrm{d}} \\
\text { IM vs. IV: } 1 \\
\text { NEB vs. IV: } 1 \\
\text { Mixed/Unknown: } 2 \\
\end{array}$ & $\begin{array}{l}\text { IV+IV vs. IV: } 6 \\
\text { IV+IN vs. IV: } 1 \\
\text { Unknown: } 1\end{array}$ & IV vs. IV: 10 & $\begin{array}{l}\text { IV vs. inhaled: } \\
1\end{array}$ & $\begin{array}{l}\text { IV vs. IV: } 2 \\
\text { PO vs. PO: } 1\end{array}$ \\
\hline $\begin{array}{l}\text { Specific drugs } \\
\text { (N studies) }\end{array}$ & $\begin{array}{l}\text { Morphine: } 12 \\
\text { Fentanyl: } 6 \\
\text { Mixed: } 2 \\
\end{array}$ & $\begin{array}{l}\text { Morphine: } 6 \\
\text { Mixed: } 2\end{array}$ & $\begin{array}{l}\text { Morphine: } 9 \\
\text { Fentanyl: } 1\end{array}$ & Fentanyl: 1 & $\begin{array}{l}\text { Morphine: } 3 \\
\text { Ketorolac: } 2 \\
\text { Ibuprofen: } 1\end{array}$ \\
\hline $\begin{array}{l}\text { Risk of bias } \\
\text { (N studies) }^{\mathrm{e}}\end{array}$ & $\begin{array}{l}\text { Low: } 12 \\
\text { Medium: } 2 \\
\text { High: } 2 \\
\text { Unclear: } 2 \\
\text { Low/medium: } 2\end{array}$ & $\begin{array}{l}\text { Low: } 7 \\
\text { Medium: } 1\end{array}$ & $\begin{array}{l}\text { Low: } 9 \\
\text { Unclear: } 1\end{array}$ & $\begin{array}{l}\text { Low/medium: } \\
1\end{array}$ & $\begin{array}{l}\text { Low: } 2 \\
\text { Medium: } 1\end{array}$ \\
\hline
\end{tabular}

Abbreviations: APAP=acetaminophen; $\mathrm{ED}=$ emergency department; IM=intramuscular; $\mathrm{IN}=$ intranasal; IV=intravenous;

$\mathrm{NEB}=$ nebulized; NSAIDs=nonsteroidal anti-inflammatory drugs; $\mathrm{OBS}=$ observational; $\mathrm{PO}=\mathrm{oral} ; \mathrm{RCT}=$ randomized controlled trial; UK=United Kingdom; USA=United States of American; vs=versus

${ }^{a}$ Two observational studies included two comparisons: opioids vs. ketamine and morphine vs. fentanyl, one of these studies also compares opioids+ketamine vs. opioids.

${ }^{\mathrm{b}}$ These studies took place in Afghanistan but were US military forces

'Studies were classified according to the number of doses given of the randomized analgesic. Studies either allowed one dose or multiple doses.

${ }^{\mathrm{d}}$ One trial included 3 arms and thus has two comparisons: morphine IV vs. ketamine and morphine IM vs. ketamine

eSome studies had different risk of bias based on the individual outcome, and in this case were listed as "low/medium" risk of bias 
Table 8. Characteristics of included studies for comparisons not graded, per comparison

\begin{tabular}{|c|c|c|c|c|}
\hline Characteristic & $\begin{array}{l}\text { APAP Versus } \\
\text { NSAIDs }\end{array}$ & $\begin{array}{l}\text { Ketamine Versus } \\
\text { NSAIDs }\end{array}$ & $\begin{array}{l}\text { Morphine Versus } \\
\text { Fentanyl }\end{array}$ & $\begin{array}{l}\text { Opioid + Ketamine } \\
\text { Versus Ketamine }\end{array}$ \\
\hline $\mathrm{N}$ of studies & $3 \mathrm{RCT}$ & $1 \mathrm{RCT}$ & $\begin{array}{l}11 \text { RCT } \\
10 \text { OBS }^{a}\end{array}$ & $1 \mathrm{OBS}$ \\
\hline $\begin{array}{l}\text { Countries } \\
\text { (N studies) }\end{array}$ & $\begin{array}{l}\text { Canada } 1 \text {; Italy } 1 ; \\
\text { Turkey } 1\end{array}$ & Iran & $\begin{array}{l}\text { Afghanistan } 2^{\mathrm{b}} \text {; } \\
\text { Australia } 5 \text {; Canada } \\
\text { 2; France 1; Germany } \\
\text { 1; Iran 2; USA } 8\end{array}$ & Australia \\
\hline $\mathrm{N}$ of patients & 564 & 141 & 4,121 & 37 \\
\hline $\begin{array}{l}\text { Gender } \\
\text { (Range of males, \%) }\end{array}$ & 30 to 66.4 & 71 to 81.2 & 38 to 100 & NR \\
\hline $\begin{array}{l}\text { Age } \\
\text { (Range of means, } \\
\text { years) }\end{array}$ & 11.8 to 36 & 34.2 to 37.9 & 6.6 to 66.5 & NR \\
\hline $\begin{array}{l}\text { Pain Classification } \\
\text { (N studies) }\end{array}$ & $\begin{array}{l}\text { Traumatic: } 1 \\
\text { Nontraumatic: } 1 \\
\text { Mixed: } 1\end{array}$ & Nontraumatic: 1 & $\begin{array}{l}\text { Traumatic: } 12 \\
\text { Nontraumatic: } 2 \\
\text { Mixed: } 7\end{array}$ & Traumatic: 1 \\
\hline $\begin{array}{l}\text { Setting } \\
\text { (N studies) }\end{array}$ & ED: 3 & ED: 1 & $\begin{array}{l}\text { Prehospital: } 8 \\
\text { ED: } 11 \\
\text { Battlefield: } 2 \\
\end{array}$ & EMS: 1 \\
\hline $\begin{array}{l}\text { Administered doses } \\
\text { (N studies) }^{c}\end{array}$ & Single: 3 & Single: 1 & $\begin{array}{l}\text { Single: } 7 \\
\text { Multiple: } 10 \\
\text { Unknown: } 4\end{array}$ & Unknown: 1 \\
\hline $\begin{array}{l}\text { Dosage forms } \\
\text { ( } N \text { of studies each) }\end{array}$ & $\begin{array}{l}\text { IV vs. IV: } 1 \\
\text { SL vs. melt away: } 1 \\
\text { PO vs. PO: } 1\end{array}$ & IV vs. IV: 1 & $\begin{array}{l}\text { IV vs. IV: } 7 \\
\text { IV vs. NEB: } 3 \\
\text { IV vs. IN: } 4 \\
\text { IV vs. oral lozenge: } 1 \\
\text { IM vs. IN: } 1 \\
\text { Unknown: } 3 \\
\text { Mixed: } 2\end{array}$ & Unknown: 1 \\
\hline $\begin{array}{l}\text { Specific drugs } \\
\text { (N studies) }\end{array}$ & $\begin{array}{l}\text { Ibuprofen: } 2 \\
\text { Ketorolac: } 1\end{array}$ & Ketorolac: 1 & NA & $\begin{array}{l}\text { Morphine or } \\
\text { Fentanyl: } 1\end{array}$ \\
\hline 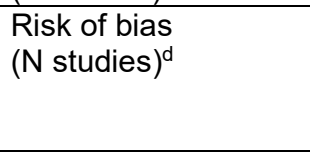 & Low: 3 & Low: 1 & $\begin{array}{l}\text { Low: } 9 \\
\text { Medium: } 7 \\
\text { High: } 3 \\
\text { Low/medium: } 2\end{array}$ & Medium: 1 \\
\hline
\end{tabular}

Abbreviations: APAP=acetaminophen; $\mathrm{ED}=$ emergency department; IM=intramuscular; $\mathrm{IN}=$ intranasal; IV=intravenous; $\mathrm{NA}=$ not applicable; $\mathrm{NEB}=$ nebulized; NSAIDs $=$ nonsteroidal anti-inflammatory drugs; $\mathrm{NR}=$ not reported; $\mathrm{OBS}=$ observational; $\mathrm{PO}=$ oral; $\mathrm{RCT}=$ randomized controlled trial; $\mathrm{SL}=$ sublingual; USA=United States of American; vs=versus

${ }^{a}$ Two observational studies included two comparisons: opioids vs. ketamine and morphine vs. fentanyl, one of these studies also compares opioids+ketamine vs. opioids.

${ }^{\mathrm{b}}$ These studies took place in Afghanistan but were US military forces

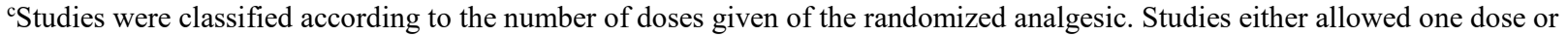
multiple doses.

"Some studies had different risk of bias based on the individual outcome, and in this case were listed as "low/medium" risk of bias

\section{Opioids Versus Ketamine}

We included 17 RCTs $(n=1831)$ and 3 observational studies $(n=653)$ that compared opioids with ketamine. ${ }^{17,27-30,51-65}$

\section{Effectiveness and Harms of Initial Analgesia (KQ 1 and 2)}

Fifteen RCTs $(n=1669)^{17,27-30,51-60}$ and 3 observational studies ( $\left.n=653\right)^{61-63}$ answer KQ 1 and 2. Two studies were in the emergency medical services (EMS) setting, ${ }^{27,61} 14$ were in the emergency department (ED) setting, ${ }^{17,28-30,51-60}$ and 2 were in the battlefield setting. ${ }^{62,63}$ One of 
these studies was only identified through a search on www.clinicaltrials.gov with posted results but has not been published in the peer reviewed literature; thus, it was not pooled with other studies. $^{28}$ The mean age ranged from 7 to 77 years. Five studies exclusively enrolled subjects under the age of 18 years, with lower age limits of 3, 4 and 8 years. In these trials mean or median age ranged from 7 to 13.3 years. One study exclusively enrolled older aged subjects, 65 years and older (mean age was 77 years). Baseline pain scores (mean or median) ranged from 7.4 to 9.2 on a 0 to 10 scale. Pain was classified as traumatic in 11 studies (road traffic injuries, blunt trauma, falls, assault, extremity fractures and soft tissue injuries, battlefield), ${ }^{17,27,29,53,56,59,60,62,63}$ nontraumatic in 1 study (renal colic), ${ }^{54}$ and mixed in 6 studies. ${ }^{28,52,55,57,58,61}$

Six studies compared fentanyl with ketamine, ${ }^{17,29,30,51,52,61}$ either as a single dose of analgesic ${ }^{17,30,51,52}$ or allowing multiple doses. ${ }^{29,61}$ Fentanyl intranasal (IN) was compared with ketamine IN in 4 studies; fentanyl doses were either $1.5 \mathrm{mcg} / \mathrm{kg}$ or $2 \mathrm{mcg} / \mathrm{kg}$ and ketamine doses were ether $1 \mathrm{mg} / \mathrm{kg}$ or $1.5 \mathrm{mg} / \mathrm{kg} .{ }^{17,29,51,52}$ One study compared fentanyl $2 \mathrm{mcg} / \mathrm{kg}$ intravenous (IV) with ketamine $0.3 \mathrm{mg} / \mathrm{kg}$ IV. ${ }^{61}$ One study compared nebulized fentanyl $4 \mathrm{mcg} / \mathrm{kg}$ with ketamine $0.4 \mathrm{mg} / \mathrm{kg} \mathrm{IV.}{ }^{51}$

Ten studies compared morphine with ketamine, ${ }^{27,28,53-60}$ either as a single dose ${ }^{28,52,53-57}$ of analgesic or allowing multiple doses. ${ }^{58-60}$ Seven of these studies compared morphine $0.1 \mathrm{mg} / \mathrm{kg}$ IV to ketamine; ketamine was administered IV at a dose of $0.2 \mathrm{mg} / \mathrm{kg}$ in 1 study, ${ }^{56} 0.3 \mathrm{mg} / \mathrm{kg}$ in 3 studies, ${ }^{55,57,58}$ or $0.5 \mathrm{mg} / \mathrm{kg}$ in 2 studies,${ }^{59,60}$ ketamine was administered $\mathrm{IN}$ at a dose of $1 \mathrm{mg} / \mathrm{kg}$ in 1 study. ${ }^{54}$ One study compared morphine $0.05 \mathrm{mg} / \mathrm{kg}$ with ketamine $0.3 \mathrm{mg} / \mathrm{kg} \mathrm{IV} .{ }^{28}$ One study compared age-based dosing of morphine 5 to $10 \mathrm{mg}$ IM with ketamine 0.2 to $0.3 \mathrm{mg} / \mathrm{kg} \mathrm{IV.}{ }^{27}$ One study had 3 arms and compared morphine $0.1 \mathrm{mg} / \mathrm{kg}$ IV, morphine $0.15 \mathrm{mg} / \mathrm{kg} \mathrm{IM}$ and ketamine $1 \mathrm{mg} / \mathrm{kg} \mathrm{IN} .^{53}$

Two studies compared either morphine or fentanyl with ketamine. ${ }^{62,63}$ One study did not report route or dose $\mathrm{e}^{62}$ and the other did not report dose but included IV and IM routes for opioids and ketamine. ${ }^{63}$

\section{Effectiveness and Harms of Subsequent Analgesia (KQ 3 and 4)}

The body of evidence for KQ 3 and 4 include 2 RCTs $(n=162)$ from the EMS setting, ${ }^{64,65}$ both evaluating continued titration of morphine IV versus switching to titrated ketamine IV in subjects inadequately responsive to initial morphine IV. These are the only two studies that qualify for KQ 3 and 4 in this review.

The mean age ranged from 41 to 74 years. Baseline pain scores (mean or median) ranged from 7.4 to 8.5 on a 0 to 10 scale and pain was classified as traumatic in both trials. One trial ${ }^{64}$ enrolled subjects whose pain score remained $\geq 5 / 10$ after morphine $5 \mathrm{mg}$ IV. Subjects received either titrated ketamine IV (10 to $20 \mathrm{mg}$ bolus, $10 \mathrm{mg}$ repeated every 3 minutes) or titrated morphine IV ( $5 \mathrm{mg}$ bolus repeated every $5 \mathrm{~min}$ ). The second trial ${ }^{65}$ enrolled subjects whose pain score was $\geq 4 / 10$ after morphine $0.1 \mathrm{mg} / \mathrm{kg}$ IV. Subjects received either ketamine $0.2 \mathrm{mg} / \mathrm{kg}$ or morphine $0.1 \mathrm{mg} / \mathrm{kg}$.

\section{Combination of an Opioid and Ketamine Versus Opioid}

We included 6 RCTs $(n=579)$ and 2 observational study $(n=987)$. Two studies were in the EMS setting, ${ }^{66,67} 5$ studies in the ED setting, ${ }^{68-72}$ and 1 study in the battlefield setting. ${ }^{62}$ The mean age ranged from 23 to 51.58 years. One study enrolled subjects as young as 15 years but the other studies used a lower limit of 18 years for enrollment. Baseline pain scores (mean or median) ranged from 7.5 to 8.7 on a 0 to 10 scale. Pain was classified as traumatic in 3 studies 
(traumatic limb, fracture, battlefield), ${ }^{62,66,72}$ nontraumatic in 2 studies (renal colic), ${ }^{68,71}$ and mixed in 3 studies. ${ }^{67,69,70}$ The trial by Beaudoin et al. was not pooled in meta-analysis of results related to this comparison. ${ }^{70}$ Unlike the other studies, this trial allowed enrollment of subjects that had previously failed analgesia for the acute pain episode, which reached 80 percent of the studied population.

In this body of evidence, all 6 RCTs added a single dose of ketamine to an initial dose of morphine IV and compared the combination to morphine alone. All trials also allowed titration of morphine IV after the initial dose but ketamine was not re-dosed. Morphine was dosed as $0.1 \mathrm{mg} / \mathrm{kg}$ in 5 trials and compared to IV ketamine. ${ }^{66,68-71}$ The doses of IV ketamine studied in these 5 trials were $0.15 \mathrm{mg} / \mathrm{kg}$ in 2 trials, ${ }^{70,71} 0.2 \mathrm{mg} / \mathrm{kg}$ in 2 trials, ${ }^{66,68}$ and $0.3 \mathrm{mg} / \mathrm{kg}$ in 2 trials. ${ }^{69,70}$ One trial had 3 arms such that two ketamine doses were evaluated. ${ }^{70}$ Morphine was dosed as $0.05 \mathrm{mg} / \mathrm{kg} \mathrm{IV}$ in 1 trial and compared to ketamine $1 \mathrm{mg} / \mathrm{kg} \mathrm{IN} .^{72}$

The 2 observational studies ${ }^{62,67}$ did not specify dosing strategies. One study evaluated either fentanyl or morphine in combination with ketamine, all delivered IV. ${ }^{67}$ One study from the battlefield setting did not report routes of administration for the opioids (morphine or fentanyl) or for ketamine. ${ }^{62}$

\section{Opioids Versus Acetaminophen}

We included 10 RCTs $(n=2,001)$, all of which were in the ED setting. ${ }^{73-82}$ The mean age ranged from 29.1 to 44.6 years old. All studies required subjects to be either 18 or 21 years of age for inclusion. All but 1 trial $^{74}$ applied an upper age limit, which was 55 to 65 years of age. Baseline pain scores (mean or median) ranged from 7.4 to 9.14 on a 0 to 10 scale. Pain was classified as traumatic in 4 trials ( 2 trials on fractures, ${ }^{79,81} 1$ on acute limb trauma, ${ }^{74}$ and 1 on post-trauma headache ${ }^{73}$ ), nontraumatic in 5 trials ( 4 renal colic, ${ }^{75,78,80,82} 1$ sciatic nerve pain $^{76}$ ) and 1 mixed population. ${ }^{77}$

Nine trials compared single doses of morphine $0.1 \mathrm{mg} / \mathrm{kg}$ IV with APAP $1 \mathrm{gm} \mathrm{IV} .^{73-79,81,82}$ One trial compared a single dose of fentanyl $2 \mathrm{mcg} / \mathrm{kg}$ IV with APAP $10 \mathrm{mg} \mathrm{IV} .^{80}$

\section{Opioids Versus Nitrous Oxide/Oxygen}

One RCT ( $\mathrm{n}=100)$ compared opioids with nitrous oxide/oxygen and this trial was in the EMS setting. ${ }^{83}$ The study enrolled subjects aged 15 to 85 years and the mean age was 35.8 to 37 years. Baseline pain scores (mean or median) were 9.0 on a 0 to 10 scale and the pain was classified as traumatic pain (isolated limb trauma). This trial compared fentanyl $2 \mathrm{mcg} / \mathrm{kg}$ IV with selfadministered nitrous oxide mixed with oxygen in a 50:50 ratio.

\section{Opioids Versus Nonsteroidal Anti-Inflammatory Drugs}

We included 3 RCTs ( $n=564)$, all of which were in the ED setting. ${ }^{84-86}$ The mean age ranged from 11.7 to 39.3 years. One trial ${ }^{86}$ enrolled subjects $6-17$ years of age while the other 2 trials ${ }^{84,85}$ enrolled subjects at least 18 years of age. Baseline pain scores (mean or median) ranged from 7.6 to 10.0 on a 0 to 10 scale. Pain was classified as traumatic in 1 trial $^{84}$ (long bone fracture), nontraumatic in 1 trial $^{85}$ (renal colic) and mixed in 1 trial. $^{86}$ Two trials ${ }^{84,85}$ compared morphine $5 \mathrm{mg}$ IV bolus with ketorolac (10mg or $15 \mathrm{mg}$ IV bolus) with second doses of morphine $5 \mathrm{mg}$ and ketorolac $5 \mathrm{mg}$ or $15 \mathrm{mg}$ if pain remained elevated. One trial compared a single dose of morphine $0.2 \mathrm{mg} / \mathrm{kg}$ by mouth with ibuprofen $10 \mathrm{mg} / \mathrm{kg}$ by mouth. ${ }^{86}$ 


\section{Acetaminophen Versus Nonsteroidal Anti-Inflammatory Drugs}

We included 3 RCTs ( $n=564)$, all of which we in the ED setting. ${ }^{87-89}$ The mean age ranged from 11.6 to 36 years. One trial ${ }^{87}$ enrolled subjects age 18 years and older while the other two trials enrolled children; 6 to 17 years old ${ }^{89}$ and 4 to 18 years old. ${ }^{88}$ Baseline pain scores (mean or median) ranged from 7 to 8 on a 0 to 10 scale. Pain was classified as traumatic in 1 trial (fractures), ${ }^{89}$ nontraumatic in 1 trial (renal colic), ${ }^{87}$ and mixed in 1 trial. ${ }^{88}$ APAP $1 \mathrm{~g}$ IV was compared to ibuprofen $800 \mathrm{mg}$ IV in 1 trial; ${ }^{87}$ acetaminophen $15 \mathrm{mg} / \mathrm{kg}$ by mouth was compared with ibuprofen $10 \mathrm{mg} / \mathrm{kg}$ by mouth in 1 trial; ${ }^{89}$ and ketorolac $0.5 \mathrm{mg} / \mathrm{kg}$ sublingual was compared with APAP $20 \mathrm{mg} / \mathrm{kg}$ melt away powder in 1 trial. $^{88}$

\section{Ketamine Versus Nonsteroidal Anti-Inflammatory Drugs}

One $\mathrm{RCT}^{90}(\mathrm{n}=141)$ compared ketamine with ketorolac in the ED setting. The study enrolled subjects over the age of 18 years, the mean was 34.2 to 37.9 years. Baseline pain scores (mean) were 8.4 to 8.7 on a 0 to 10 scale and the pain was classified as nontraumatic pain (renal colic). This trial compared ketamine $0.6 \mathrm{mg} / \mathrm{kg}$ IV with ketorolac $30 \mathrm{mg}$ IV.

\section{Morphine Versus Fentanyl}

We included 11 RCTs $^{16,19-21,91-97}(n=1405)$ and 10 observational studies ${ }^{62,63,98-105}(n=2716)$. Eight studies ${ }^{92-95,98,102-104}$ were in EMS, 11 studies ${ }^{16,19-21,96,97,99-101}$ were in the ED and 2 studies ${ }^{62,63}$ were in battlefield settings. The mean age ranged from 6.6 to 66.5 years. Five studies $16,21,96,97,102$ exclusively enrolled children, with inclusion criteria as young as 3 years and as old as 18 years. One study enrolled patients 6 months or older, ${ }^{103}$ and 1 study enrolled subjects 3 to 21 years old. ${ }^{100}$ The remaining trials enrolled subjects aged 15 years through adulthood. Baseline pain scores (mean or median) ranged from 5 to 10 on a 0 to 10 scale. Pain was classified as traumatic in 12 studies (blunt trauma, wound/soft tissue, fractures and battlefield), ${ }^{16,20,21,62,63,94,96,97,100,101}$ nontraumatic in two studies (ischemic chest pain, ab pain), ${ }^{19,92}$ and mixed in 7 studies. $^{93,95,98,99,102-104}$

In this body of evidence, morphine was administered IV in 16 studies, ${ }^{19-21,92-98,100-102,104}$ IM in 1 study, ${ }^{16}$ and mixed or unknown route in 4 studies. ${ }^{62,63,99,103}$ Fentanyl was administered IV in 8 studies, ${ }^{92-94,98,101,104}$ IN in 5 studies, ${ }^{95,97,16,100,102}$ nebulized IV solution in 3 studies, ${ }^{19-21}$ transmucosal lozenge in 1 study, ${ }^{96}$ and mixed or unknown routes in 4 studies. ${ }^{62,63,99,103}$

Eight studies compared single doses of morphine with fentanyl. ${ }^{16,19-21,96,101}$ Three studies compared a single dose of morphine $0.1 \mathrm{mg} / \mathrm{kg}$ IV with fentanyl delivered via nebulizer, at a dose of $4 \mathrm{mcg} / \mathrm{kg}^{20,21}$ or $2 \mathrm{mcg} / \mathrm{kg} .{ }^{19}$ One study compared a single dose of morphine $0.1 \mathrm{mg} / \mathrm{kg}$ IV with fentanyl $10-15 \mathrm{mcg} / \mathrm{kg}$ oral transmucosal lozenge. ${ }^{96}$ One study compared a single dose of morphine $0.2 \mathrm{mg} / \mathrm{kg}$ IM with fentanyl $1 \mathrm{mcg} / \mathrm{kg}$ IN.${ }^{16}$ One study compared a single dose of morphine $4 \mathrm{mg}$ IV with fentanyl $50 \mathrm{mcg}$ IV.${ }^{101}$ One study compared morphine $0.1 \mathrm{mg} / \mathrm{kg}$ IV with fentanyl $1 \mathrm{mcg} / \mathrm{kg} \mathrm{IV} .^{91}$

Nine studies compared multiple doses of morphine with fentanyl. ${ }^{92-95,97,102-104}$ One study compared weight and age based doses of morphine 2.5 to $5 \mathrm{mg}$ IV with fentanyl 25 to $50 \mathrm{mcg}$ IV. ${ }^{92}$ One study compared morphine $4 \mathrm{mg}$ IV with fentanyl $50 \mathrm{mcg}$ IV. ${ }^{94}$ Two studies compared age-based dosing of morphine IV with age-based dosing of fentanyl, IN in one study ${ }^{102}$ and IV in one study. ${ }^{104}$ One study compared morphine 2.5 to $5 \mathrm{mg}$ IV with fentanyl $180 \mathrm{mcg}$ IN. ${ }^{95}$ Two studies compared morphine $0.1 \mathrm{mg} / \mathrm{kg}$ IV with fentanyl, $1 \mathrm{mcg} / \mathrm{kg}$ IV in $1 \mathrm{study}^{93}$ and $1.4 \mathrm{mcg} / \mathrm{kg}$ IN in 1 study. ${ }^{97}$ One study compared fixed doses of morphine IV or IM with weight-based 
fentanyl IV or IM. ${ }^{103}$ One study compared morphine IV, without a specified dose, with fentanyl $1.5 \mathrm{mg} / \mathrm{kg} \mathrm{IN.}{ }^{100}$

In three studies dose of morphine was not specified ${ }^{62,63,99}$ and in 2 of these studies the route was not specified. ${ }^{62,99}$ In one study the dose and frequency of morphine and fentanyl were not specified. $^{105}$

\section{Combination of Opioid and Ketamine Versus Ketamine}

We included one observational study $(n=37)$ from the EMS setting studying traumatic pain. ${ }^{106}$ The age and gender for the cohort treated with analgesics was not reported in this study. Morphine plus ketamine, fentanyl plus ketamine, and ketamine alone were studied, although routes and doses were not provided.

Key Question (KQ) 1. What is the comparative effectiveness of the initial analgesic agent treatment for achieving reduction in moderate-to-severe acute-onset pain level when administered by EMS personnel in the prehospital setting?

$K Q 1$ 1a. How does effectiveness vary by patient characteristics?

$\mathrm{KQ} 1 \mathrm{~b}$. How does effectiveness vary by routes of administration, dosing, and timing?

\section{Opioids Versus Ketamine}

\section{Key Messages}

- There is no evidence of a clinically important difference between opioids and ketamine in the change of pain scores in 15, 30, or 60 minutes (low SOE). This conclusion is based on indirect evidence from the ED setting and primarily weight-based IV doses of morphine and ketamine.

- Evidence is insufficient for outcomes measuring full or partial resolution of pain or time to analgesic effect.

\section{Detailed Results}

We present the conclusions for the comparative effectiveness of opioids versus ketamine as initial analgesics in Table 9. The majority of this evidence base is indirect data from the ED setting and compares weight-based doses of morphine IV with ketamine IV.

Table 9. Conclusions and strength of evidence for the comparison of opioids versus ketamine, Key Question 1

\begin{tabular}{|c|c|c|c|}
\hline Outcome & $\begin{array}{l}\text { Study Design } \\
\text { and Sample } \\
\text { Size }\end{array}$ & $\begin{array}{l}\text { Conclusions } \\
\text { (Setting: Supporting Effect Estimates and } 95 \% \\
\text { Confidence Intervals) }\end{array}$ & $\begin{array}{l}\text { Strength of } \\
\text { Evidence } \\
\text { (Limitations) }\end{array}$ \\
\hline $\begin{array}{l}\text { Pain severity } \\
-15 \mathrm{~min}\end{array}$ & $\begin{array}{l}12 \\
\operatorname{RCTs}^{17,29,30,51,52-} \\
59 \\
(n=1128)\end{array}$ & $\begin{array}{l}\text { There is no evidence of a clinically important difference } \\
\text { between opioids and ketamine in the change of pain } \\
\text { scores in } 15 \text { min. } \\
\text { ED: Meta-analysis of } 12 \text { RCTs found MD } 0.35(-0.36 \text { to } \\
1.06) \text { at } 15 \text { min }\end{array}$ & $\begin{array}{l}\text { Low } \\
\text { (Inconsistent, } \\
\text { indirect) }\end{array}$ \\
\hline
\end{tabular}




\begin{tabular}{|c|c|c|c|}
\hline Outcome & $\begin{array}{l}\text { Study Design } \\
\text { and Sample } \\
\text { Size }\end{array}$ & $\begin{array}{l}\text { Conclusions } \\
\text { (Setting: Supporting Effect Estimates and 95\% } \\
\text { Confidence Intervals) }\end{array}$ & $\begin{array}{l}\text { Strength of } \\
\text { Evidence } \\
\text { (Limitations) }\end{array}$ \\
\hline $\begin{array}{l}\text { Pain severity } \\
-30 \text { min }\end{array}$ & $\begin{array}{l}12 \operatorname{RCTs}^{17,29,30,51-} \\
58,60 \\
(n=1153)\end{array}$ & $\begin{array}{l}\text { There is no evidence of a clinically important difference } \\
\text { between opioids and ketamine in the change of pain } \\
\text { scores in } 30 \text { min. } \\
\text { ED: Meta-analysis of } 12 \text { RCTs found MD } 0.26(-0.23 \text { to } \\
0.75) \text { at } 30 \text { min }\end{array}$ & $\begin{array}{l}\text { Low } \\
\text { (Inconsistent, } \\
\text { indirect) }\end{array}$ \\
\hline $\begin{array}{l}\text { Pain severity } \\
-60 \text { min }\end{array}$ & $\begin{array}{l}12 \\
\text { RCTs } 17,27,29,30,51- \\
53,55-58,60 \\
(n=1409) \\
1 \text { OBS }^{61}(n=158)\end{array}$ & $\begin{array}{l}\text { There is no evidence of a clinically important difference } \\
\text { between opioids and ketamine in the change of pain } \\
\text { scores in } 60 \text { min. } \\
\text { EMS: One trial }{ }^{27} \text { over prehospital period, MD }-0.4(-0.8 \text { to } \\
0.09) \text {. One observational study }{ }^{61} \text { favored ketamine vs. } \\
\text { morphine over the prehospital period [-5.5(3.1) vs. }-2.5 \\
(2.4), \text { p<0.001] } \\
\text { ED: Meta-analysis of } 11 \mathrm{RCTs} \mathrm{s}^{17,29,30,51-53,55-58,60} \text { found MD - } \\
0.36(-0.94 \text { to } 0.23) \text { at } 60 \text { min. }\end{array}$ & $\begin{array}{l}\text { Low } \\
\text { (Inconsistent, } \\
\text { indirect) }\end{array}$ \\
\hline $\begin{array}{l}\text { Pain } \\
\text { presence - } \\
\text { full resolution } \\
15 \text { min }\end{array}$ & $\begin{array}{l}1 \mathrm{RCT} \\
(\mathrm{n}=60)^{55}\end{array}$ & $\begin{array}{l}\text { Inconclusive. } \\
\text { ED: } 1 \text { RCT found AR } 16.7 \% \text { vs. } 50 \% \text {; RD }-33 \% \text { (-53 to }-9)\end{array}$ & $\begin{array}{l}\text { Insufficient } \\
\text { (Unknown } \\
\text { consistency, } \\
\text { indirect) }\end{array}$ \\
\hline $\begin{array}{l}\text { Pain } \\
\text { presence - } \\
\text { full resolution } \\
30 \text { min }\end{array}$ & $\begin{array}{l}3 \mathrm{RCT}^{52,55,57} \\
(\mathrm{n}=172)\end{array}$ & $\begin{array}{l}\text { Inconclusive. } \\
\text { ED: Meta-analysis of } 3 \text { RCTs found AR } 26.7 \% \text { vs. } 27.9 \% \text {; } \\
\text { RD }-1 \% \text { ( }-39 \text { to } 38)\end{array}$ & $\begin{array}{l}\text { Insufficient } \\
\text { (Indirect, very } \\
\text { imprecise) }\end{array}$ \\
\hline $\begin{array}{l}\text { Pain } \\
\text { presence - } \\
\text { full resolution } \\
60 \text { min }\end{array}$ & $\begin{array}{l}2 \mathrm{RCT}^{55,57} \\
(\mathrm{n}=146)\end{array}$ & $\begin{array}{l}\text { Inconclusive. } \\
\text { ED: Meta-analysis of } 2 \text { RCTs found AR } 23.3 \% \text { vs. } 21.9 \% \text {; } \\
\text { RD } 1 \%(-13 \text { to } 14)\end{array}$ & $\begin{array}{l}\text { Insufficient } \\
\text { (Indirect, very } \\
\text { imprecise) }\end{array}$ \\
\hline $\begin{array}{l}\text { Pain } \\
\text { presence- } \\
\text { partial } \\
\text { resolution - } \\
15 \text { min }\end{array}$ & $\begin{array}{l}5 \mathrm{RCT}^{30,52,55,57,59} \\
(\mathrm{n}=369)\end{array}$ & $\begin{array}{l}\text { Inconclusive. } \\
\text { ED: Meta-analysis of } 5 \text { RCTs found AR } 76.1 \% \text { vs. } 77.3 \% \text {; } \\
\text { RD } 2 \%(-25 \text { to } 28)\end{array}$ & $\begin{array}{l}\text { Insufficient } \\
\text { (Inconsistent, } \\
\text { indirect, very } \\
\text { imprecise) }\end{array}$ \\
\hline $\begin{array}{l}\text { Pain } \\
\text { presence- } \\
\text { partial } \\
\text { resolution - } \\
30 \text { min }\end{array}$ & $\begin{array}{l}4 \mathrm{RCT}^{29,30,55,57} \\
(\mathrm{n}=301)\end{array}$ & $\begin{array}{l}\text { Inconclusive. } \\
\text { ED: Meta-analysis of } 4 \text { RCTs found AR } 74.5 \% \text { vs. } 75.7 \% \text {; } \\
\text { RD }-1 \% \text { ( }-6 \text { to } 4)\end{array}$ & $\begin{array}{l}\text { Insufficient } \\
\text { (Indirect, } \\
\text { imprecise) }\end{array}$ \\
\hline $\begin{array}{l}\text { Pain } \\
\text { presence- } \\
\text { partial } \\
\text { resolution - } \\
60 \text { min }\end{array}$ & $\begin{array}{l}3 \mathrm{RCT}^{30,55,57} \\
(\mathrm{n}=208) \\
1 \mathrm{OBS}^{61}(\mathrm{n}=158)\end{array}$ & $\begin{array}{l}\text { Inconclusive. } \\
\text { EMS: One observational study }{ }^{61} \text { found more patients to } \\
\text { have partial resolution of pain with ketamine over the } \\
\text { prehospital period. } \\
\text { ED: Meta-analysis of } 3 \text { RCTs }{ }^{30,55,57} \text { found AR } 76.9 \% \text { vs. } \\
74.0 \% \text {; RD } 1 \%(-38 \text { to } 39)\end{array}$ & $\begin{array}{l}\text { Insufficient } \\
\text { (Inconsistent, } \\
\text { indirect, very } \\
\text { imprecise) }\end{array}$ \\
\hline $\begin{array}{l}\text { Time to } \\
\text { analgesic } \\
\text { effect - onset }\end{array}$ & $1 \mathrm{RCT}^{53}(\mathrm{n}=48)$ & $\begin{array}{l}\text { Inconclusive. } \\
\text { ED: } 13 \text {-arm trial found time to onset (min) favored IN } \\
\text { ketamine vs. IM morphine but was not different compared } \\
\text { with IV morphine. }\end{array}$ & $\begin{array}{l}\text { Insufficient } \\
\text { (High study } \\
\text { limitations, } \\
\text { inconsistent, } \\
\text { indirect, } \\
\text { imprecise) } \\
\end{array}$ \\
\hline $\begin{array}{l}\text { Time to } \\
\text { analgesic } \\
\text { effect - max } \\
\text { effect }\end{array}$ & $1 \mathrm{RCT}^{53}(\mathrm{n}=48)$ & $\begin{array}{l}\text { Inconclusive. } \\
\text { ED: } 13 \text {-arm trial found time to max effect (min) was not } \\
\text { different between IV morphine, IM morphine and IN } \\
\text { ketamine. }\end{array}$ & $\begin{array}{l}\text { Insufficient } \\
\text { (High study } \\
\text { limitations, } \\
\text { inconsistent, } \\
\text { indirect, } \\
\text { imprecise) }\end{array}$ \\
\hline
\end{tabular}

Abbreviations: $\mathrm{AR}=$ absolute risk; $\mathrm{ED}=$ emergency department; $\mathrm{EMS}=$ emergency medical services; $\mathrm{IM}=$ intramuscular; $\mathrm{IN}=$ intranasal; $\mathrm{IV}=$ intravenous; $\mathrm{MD}=$ mean difference; $\mathrm{min}=$ minutes; $\mathrm{OBS}=$ observational; $\mathrm{RCT}=$ randomized controlled trial; $\mathrm{RD}=$ risk difference 
There is no evidence of a clinically important difference in the reduction of pain scores when opioids are compared with ketamine at 15, 30 and 60 minutes (all low SOE) (Figure 3-Figure 5). These conclusions are each based on meta-analysis of the change in pain scores using indirect evidence from the ED setting and a clinically important difference of 2 points on a 0 to 10 scale. One RCT and one observational study from the EMS setting reported pain scores over the prehospital period. We considered these two studies in the conclusion for pain severity at $60 \mathrm{~min}$. because they did not report transport times and for studies that do, the majority of transport times exceed 30 minutes.

One observational study from the battlefield setting reported change in pain scores from 0 to 10 during the tactical evacuation period. ${ }^{63} \mathrm{We}$ did not consider battlefield data in formulating conclusion because the population and setting is too unlike the civilian population expected to access EMS services. This study found median (interquartile range) change in pain scores to be $3(-5$ to -1$)$ with morphine, -3 ( -4 to -2$)$ with fentanyl, and -4 ( -6 to -2$)$ with ketamine in 144 subjects.

Figure 3. Change in pain scores at 15 minutes, opioids versus ketamine

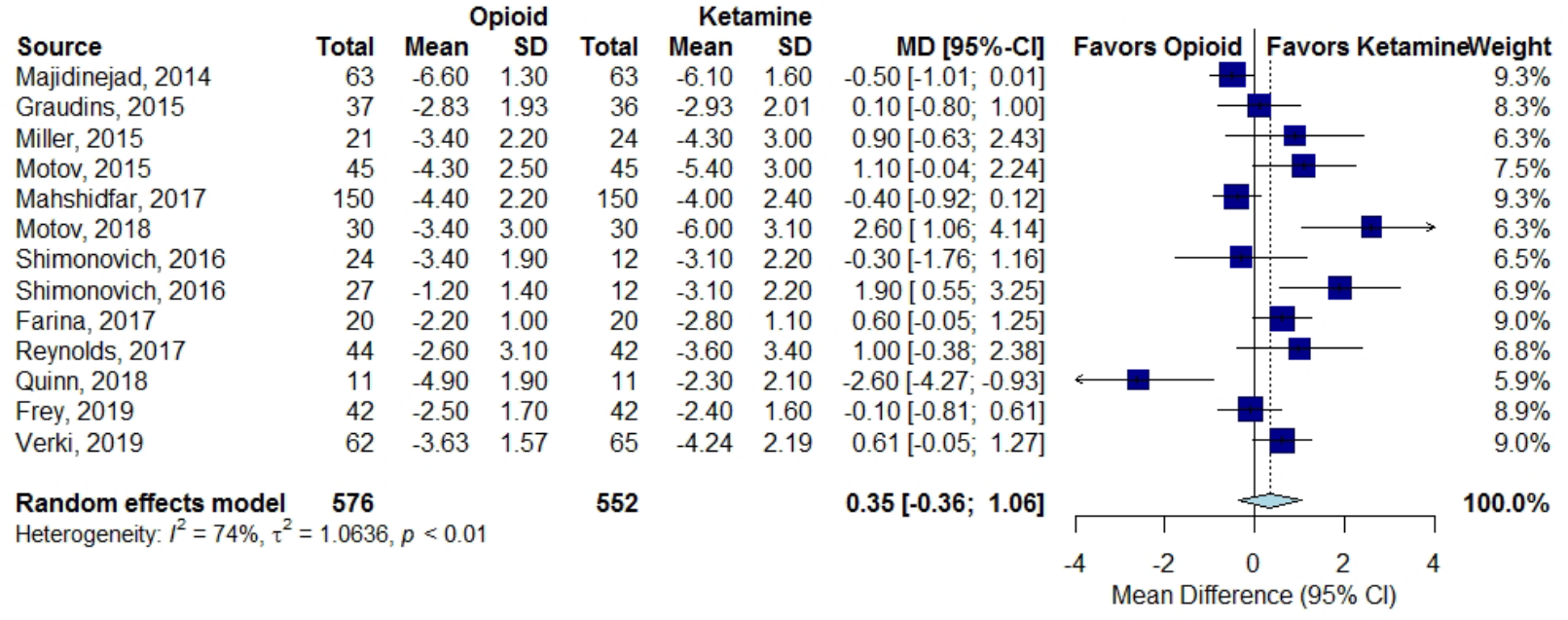

Abbreviations: $\mathrm{CI}=$ confidence interval; $\mathrm{MD}=$ mean difference; $\mathrm{SD}=$ standard deviation

Figure 4. Change in pain scores at $\mathbf{3 0}$ minutes, opioids versus ketamine

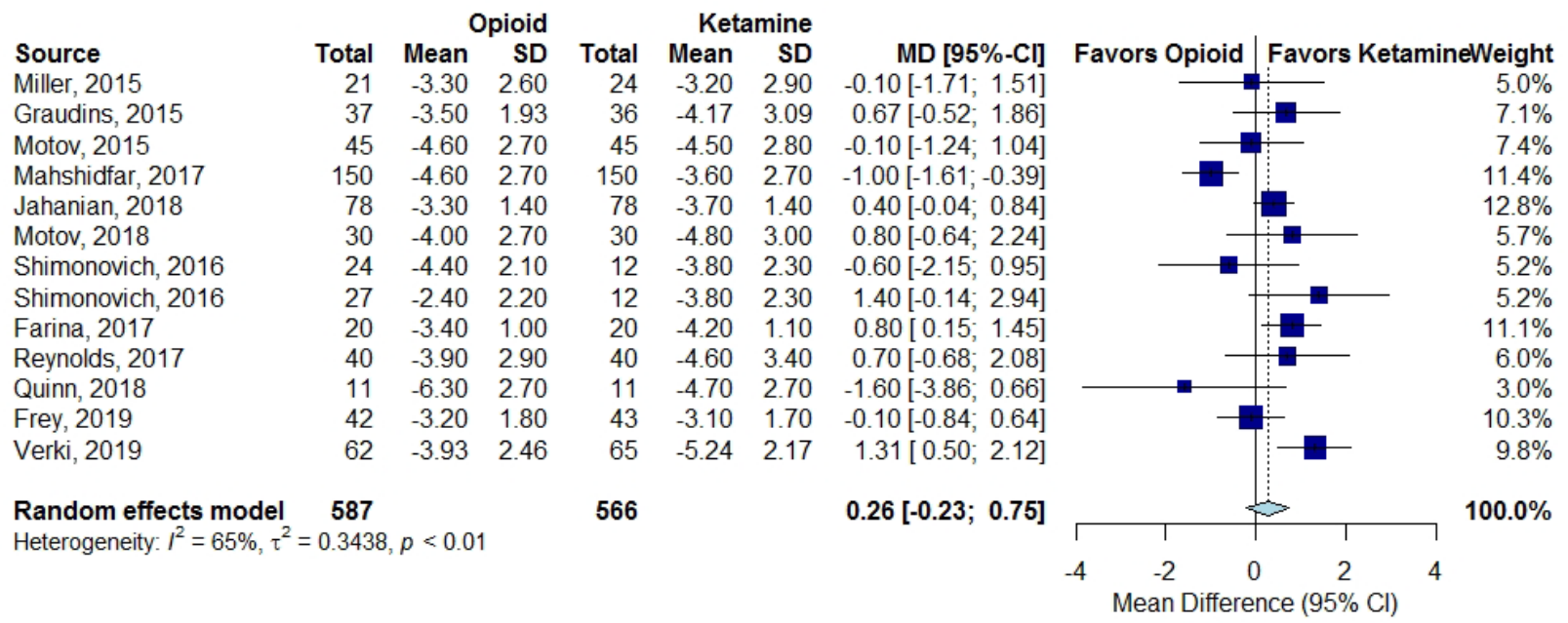

Abbreviations: $\mathrm{CI}=$ confidence interval; $\mathrm{MD}=$ mean difference; $\mathrm{SD}=$ standard deviation 


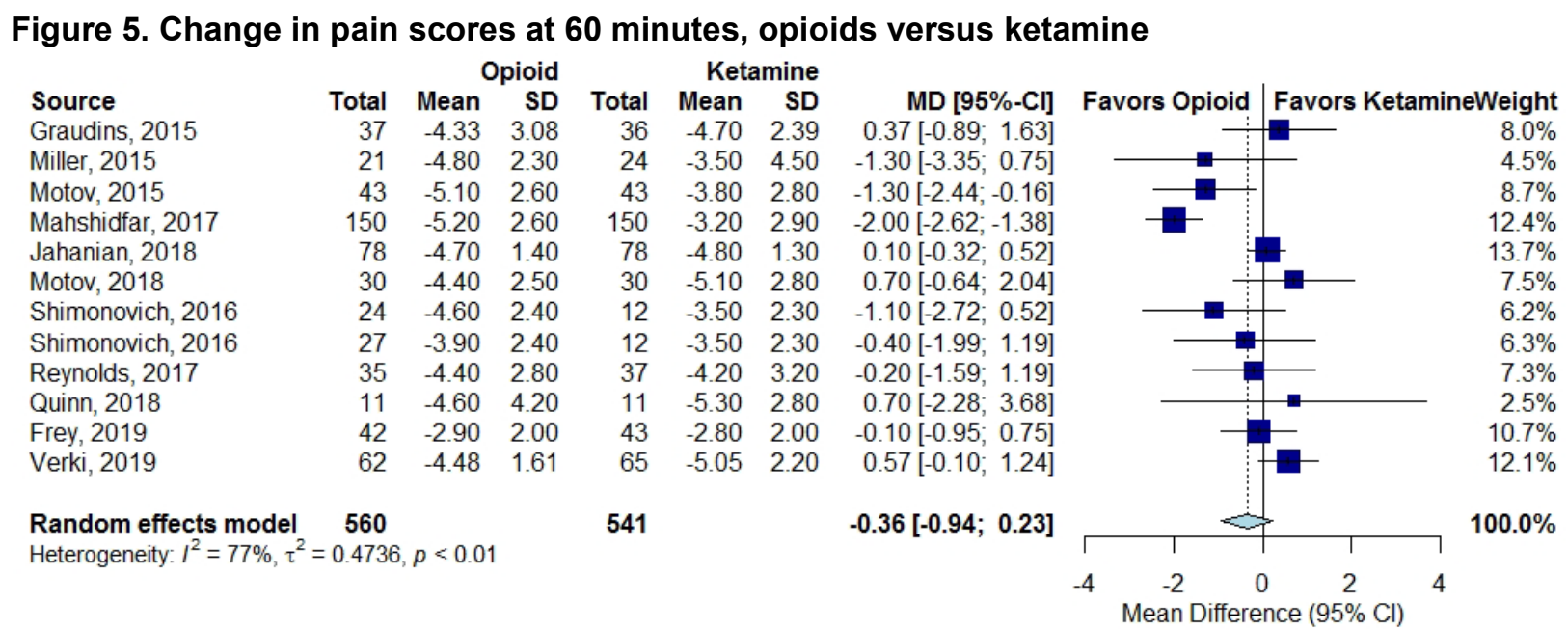

Abbreviations: $\mathrm{CI}=$ confidence interval; $\mathrm{MD}=$ mean difference; $\mathrm{SD}=$ standard deviation

There was insufficient evidence to conclude comparative effectiveness of opioids versus ketamine for the outcome of pain presence, either partial or full resolution of pain. In addition to indirectness of the data, effect estimates were very imprecise and included the possibility of clinically important differences favoring either analgesic. The single study ${ }^{61}$ from the EMS setting was observational and found more patients to achieve at least a 50 percent reduction in Numeric Rating Scale score with ketamine IV versus fentanyl IV (67 percent versus 19 percent, $\mathrm{p}=\mathrm{NR}$ ), after propensity score matching.

There was insufficient evidence to conclude comparative effectiveness of opioids versus ketamine on the time to analgesic effect. The single trial ${ }^{53}$ for this outcome had a high risk of bias because of inadequate randomization and allocation procedures, lack of blinding and high differential attrition between the morphine and ketamine arms.

No studies reported measures of the memory of a pain episode.

\section{Subgroups}

\section{Age}

Age ( $<18$ years old, $\geq 18$ years old) did not appear to be associated with differing effects of opioids versus ketamine for the outcome of change in pain at 15, 30 or 60 minutes (Appendix Figures F-6 to F-8).

\section{Type of Pain}

We analyzed studies that included traumatic pain only. Change in pain scores at 15, 30 and 60 minutes were similar to the main conclusion that there is no evidence of a clinically important difference in change of pain scores between opioids and ketamine (Appendix Figures F-9 to F11).

\section{Location of Pain}

We performed subgroup analysis by location of pain (extremity versus mixed/not reported). Location did not appear to be associated with differing effects of opioids versus ketamine for the outcome of change in pain at 15, 30 or 60 minutes (Appendix Figures F-12 to F-14). 


\section{Route of Analgesic Administration}

We performed a subgroup analysis of RCTs according to route of administration of opioid versus ketamine (IN versus IN, IV versus IN and IV versus IV). These route combinations did not appear to be associated with differing effects of opioids versus ketamine for the outcome of change in pain in 15, 30 or 60 minutes (Appendix Figures F-15 to F-17).

One 3-arm $\mathrm{RCT}^{53}$ was designed to route of morphine administration (IV vs IM) to ketamine IN. Time to onset was significantly faster with IN ketamine versus IM morphine (14.3 minutes [95 percent confidence interval 9.8 to 18.8 ) versus 26.0 minutes [20.3 to 31.7], $p=0.003$ ), but not compared to IV morphine [14.3 minutes [9.8 to 18.8 ] vs 8.9 minutes [6.6 to 11.2 ], $\mathrm{p}=0.30$ ). Time to maximal pain reduction and proportion of non-responders did not differ statistically.

\section{Frequency of Analgesic Administration}

Regardless of whether studies were comparing a single dose of opioids versus a single dose of ketamine or multiple doses of opioids versus multiple doses of ketamine, changes in pain scores at 15, 30 or 60 minutes were similar between opioids and ketamine (Appendix Figures F18 to $\mathrm{F}-20)$.

\section{Combination of Opioid and Ketamine Versus Opioid}

\section{Key Messages}

- Combining an opioid and ketamine may reduce pain more than an opioid alone in 15 and 30 minutes (low SOE) but there is no evidence of a clinically important difference at 60 minutes (low SOE). This is based mostly on indirect evidence from the ED setting comparing IV morphine and IV ketamine, where a single dose of ketamine was added to weight-based morphine.

- Evidence is insufficient for outcomes measuring pain presence or time to analgesic effect.

\section{Detailed Results}

We present the conclusions for the comparative effectiveness of the combination of an opioid and ketamine versus an opioid alone as initial analgesics in Table 10. The majority of this evidence base is indirect data from the ED setting and compares the combination of weightbased doses of morphine IV with a single weight-based dose of ketamine IV to weight-based morphine IV alone.

Table 10. Conclusions and strength of evidence for the comparison of combining an opioid and ketamine versus an opioid, Key Question 1

\begin{tabular}{|c|c|c|c|}
\hline Outcome & $\begin{array}{l}\text { Study Design } \\
\text { and Sample } \\
\text { Size }\end{array}$ & $\begin{array}{l}\text { Conclusions } \\
\text { (Setting: Supporting Effect Estimates and 95\% } \\
\text { Confidence Interval) }\end{array}$ & $\begin{array}{l}\text { Strength of } \\
\text { Evidence } \\
\text { (Limitations) }\end{array}$ \\
\hline $\begin{array}{l}\text { Pain severity } \\
-15 \mathrm{~min}\end{array}$ & $\begin{array}{l}4 \mathrm{RCT}^{66,69,71,72} \\
(\mathrm{n}=336)\end{array}$ & $\begin{array}{l}\text { Combining an opioid and ketamine may reduce pain } \\
\text { more than an opioid alone at } 15 \text { min. } \\
\text { EMS: } 1 \mathrm{RCT}^{66} \text { found } \mathrm{MD}-1.3(-2.6 \text { to } 0.02) \text { at } 15 \mathrm{~min} \text {. } \\
\text { ED: Meta-analysis of } 3 \mathrm{RCT} \mathrm{R}^{69,71,72} \text { found } \mathrm{MD}-1.04(-2.55 \text { to } \\
0.47) \text {. }\end{array}$ & $\begin{array}{l}\text { Low } \\
\text { (Inconsistent, } \\
\text { indirect, } \\
\text { imprecise) }\end{array}$ \\
\hline $\begin{array}{l}\text { Pain severity } \\
-30 \text { min }\end{array}$ & $\begin{array}{l}5 \\
\mathrm{RCT}^{66,68,69,71,72} \\
(\mathrm{n}=545)\end{array}$ & $\begin{array}{l}\text { Combining an opioid and ketamine may reduce pain } \\
\text { more than an opioid alone at } \mathbf{3 0} \text { min. } \\
\text { EMS: } 1 \mathrm{RCT} \mathrm{T}^{66} \text { found mean difference in the change of pain } \\
\text { scores to be MD }-1 \text { ( }-2.2 \text { to } 0.2) \text { at } 30 \text { min. } \\
\text { ED: Meta-analysis of } 4 \mathrm{RCT}^{68,69,71,72} \text { found MD }-0.59(-2.24 \text { to } \\
\text { 1.06). }\end{array}$ & $\begin{array}{l}\text { Low } \\
\text { (Inconsistent, } \\
\text { indirect, } \\
\text { imprecise) }\end{array}$ \\
\hline
\end{tabular}




\begin{tabular}{|c|c|c|c|}
\hline Outcome & $\begin{array}{l}\text { Study Design } \\
\text { and Sample } \\
\text { Size }\end{array}$ & $\begin{array}{l}\text { Conclusions } \\
\text { (Setting: Supporting Effect Estimates and 95\% } \\
\text { Confidence Interval) }\end{array}$ & $\begin{array}{l}\text { Strength of } \\
\text { Evidence } \\
\text { (Limitations) }\end{array}$ \\
\hline $\begin{array}{l}\text { Pain severity } \\
-60 \text { min }\end{array}$ & $\begin{array}{l}3 \mathrm{RCT}^{69,71,72} \\
(\mathrm{n}=241)\end{array}$ & $\begin{array}{l}\text { There is no evidence of a clinically important difference } \\
\text { between combining opioid and ketamine and opioid } \\
\text { alone in the change of pain scores in } 60 \text { min. } \\
\text { ED: Meta-analysis of } 3 \text { RCT found MD }-0.07(-1.14 \text { to } 1.00) \text {. }\end{array}$ & $\begin{array}{l}\text { Low } \\
\text { (Inconsistent, } \\
\text { indirect) }\end{array}$ \\
\hline $\begin{array}{l}\text { Pain } \\
\text { presence- } \\
\text { partial } \\
\text { resolution }\end{array}$ & $\begin{array}{l}\begin{array}{l}1 \mathrm{RCT}^{66} \\
(\mathrm{n}=65)\end{array} \\
1 \mathrm{OBS}^{67} \\
(\mathrm{n}=606)\end{array}$ & $\begin{array}{l}\text { Inconclusive. } \\
\text { EMS: } 1 \text { RCT found partial response in } 60.6 \% \text { vs. } 40.6 \% \text { of } \\
\text { patients, RD } 20 \% \text { (-4 to } 41) .1 \text { OBS study found the } \\
\text { proportion of sufficient response was } 69 \% \text { vs. } 70.9 \%, p=N R \text {. }\end{array}$ & $\begin{array}{l}\text { Insufficient } \\
\text { (Inconsistent, } \\
\text { imprecise) }\end{array}$ \\
\hline
\end{tabular}

Abbreviations: $\mathrm{ED}=$ emergency department; $\mathrm{EMS}=$ emergency medical services; $\mathrm{MD}=$ mean difference; $\mathrm{NR}=$ not reported; OBS $=$ observational; $\mathrm{RCT}=$ randomized controlled trial

Combining an opioid and ketamine compared with an opioid alone may reduce pain more than opioids alone, at 15 and 30 minutes (low SOE) (Figure 6-Figure 7). The clinically important difference was 2 points on a 0 to 10 scale. Data from the single trial ${ }^{66}$ in the EMS setting and from the meta-analyses of ED data agreed that a clinically important difference favoring the combination of analgesics was possible at both 15 and 30 minutes. At 60 minutes, there was no evidence of a clinically important difference between the combination of an opioid and ketamine and an opioid alone in the change in pain scores, based entirely in indirect evidence from the ED (low SOE) (Figure 8).

Figure 6. Change in pain scores at $\mathbf{1 5}$ minutes, combination of an opioid and ketamine versus opioid

\begin{tabular}{|c|c|c|c|c|c|}
\hline Source & MD & $95 \%-\mathrm{Cl}$ & Favors Op+Ket & Favors Opioic & Weight \\
\hline Sin, 2017 & -2.50 & {$[-4.48 ;-0.52]$} & & & $25.1 \%$ \\
\hline Abbasi, 2018 & -1.40 & {$[-2.56 ;-0.24]$} & & & $35.1 \%$ \\
\hline Mohammadshahi, 2018 & 0.20 & {$[-0.54 ; 0.94]$} & & & $39.8 \%$ \\
\hline Random effects model & -1.04 & {$[-2.55 ; 0.47]$} & & & $100.0 \%$ \\
\hline \multirow{2}{*}{\multicolumn{3}{|c|}{ Heterogeneity: $I^{2}=79 \%, \tau^{2}=1.3541, p<0.01$}} & | & 1 & \\
\hline & & & $\begin{array}{lr}-4 & -2\end{array}$ & $\begin{array}{lc}0 & 2 \\
\text { ance } & (95 \% \mathrm{Cl})\end{array}$ & \\
\hline
\end{tabular}

Abbreviations: $\mathrm{CI}=$ confidence interval; $\mathrm{MD}=$ mean difference; $\mathrm{Op}+\mathrm{Ket}=$ opioid plus ketamine

Figure 7. Change in pain scores at $\mathbf{3 0}$ minutes, combination of an opioid and ketamine versus opioid

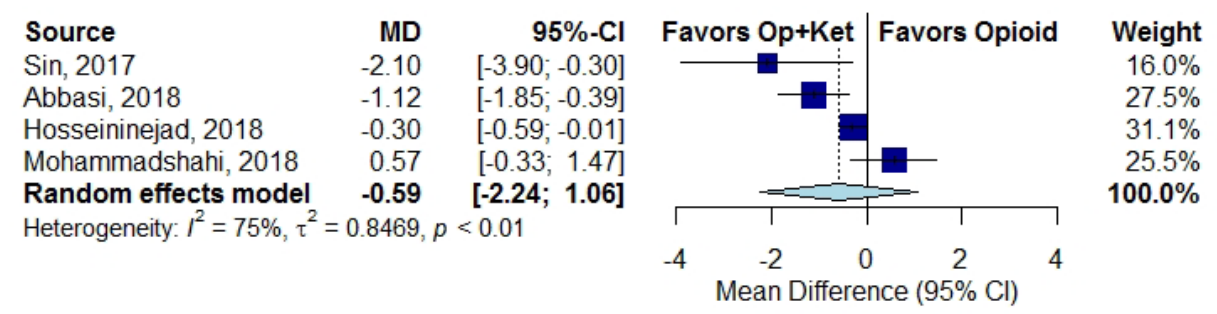

Abbreviations: $\mathrm{CI}=$ confidence interval; $\mathrm{MD}=$ mean difference; $\mathrm{Op}+\mathrm{Ket}=$ opioid plus ketamine 
Figure 8. Change in pain scores at 60 minutes, combination of an opioid and ketamine versus opioid

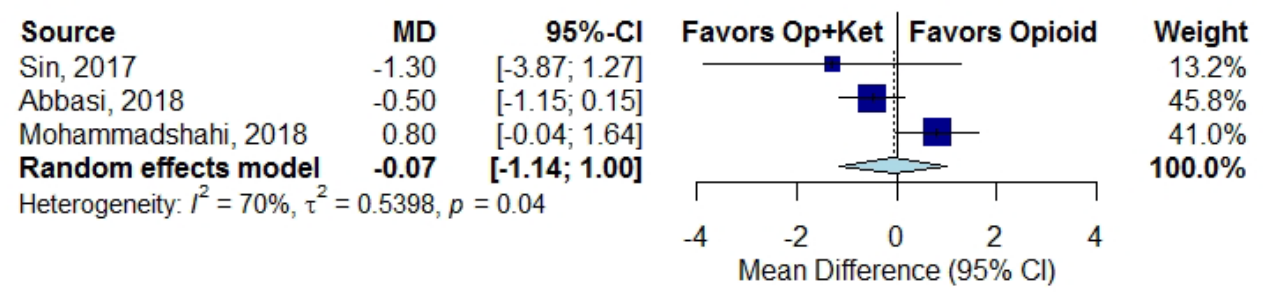

Abbreviations: $\mathrm{CI}=$ confidence interval; $\mathrm{MD}=$ mean difference; $\mathrm{Op}+\mathrm{Ket}=$ opioid plus ketamine

There is insufficient evidence to conclude the comparative effectiveness of combined opioid and ketamine versus opioid alone for the outcome of partial resolution of pain. Trial ${ }^{66}$ and observational study data ${ }^{67}$ were inconsistent and results from the trial did not exclude the possibility of no difference or a difference favoring the opioid alone. The 3-arm study by Beaudoin et al. was not pooled with others or considered in the conclusions made because 80 percent of the population enrolled had previously failed an analgesic; thus, this study was not answering comparative effectiveness of initial analgesia. ${ }^{70}$ The study used a summed painintensity difference (SPID) over 2 hours to measure changes in pain scores and the proportion achieving a SPID reduction of 33 percent or more were considered responders. There were more responders in the combination arm (morphine+ketamine $0.15 \mathrm{mg} / \mathrm{kg}$ versus morphine alone, 50 percent versus 25 percent $\mathrm{p}=0.19$; morphine + ketamine $0.3 \mathrm{mg} / \mathrm{kg}$ versus morphine alone, 70 percent versus 25 percent, $\mathrm{p}=0.01$ ).

No studies reported time to analgesic effect (insufficient SOE) or measures of the memory of pain.

\section{Subgroups}

\section{Analgesic Dose}

One $\mathrm{RCT}^{70}$ included 3 arms to compare two different doses of ketamine $(0.15 \mathrm{mg} / \mathrm{kg}$ or $0.3 \mathrm{mg} / \mathrm{kg})$ when added to morphine $(0.1 \mathrm{mg} / \mathrm{kg})$, versus morphine $0.1 \mathrm{mg} / \mathrm{kg}$ alone. The proportion achieving a SPID reduction of 33 percent or more were considered responders. The difference between the ketamine groups was not significant (50 percent versus 70 percent, $\mathrm{p}=0.33)$.

\section{Opioids Versus Acetaminophen}

\section{Key Messages}

- There is no evidence of a clinically important difference between IV opioids and IV APAP in the change of pain scores in 15, 30 or 60 minutes (low SOE), or in the time to analgesic effect (low SOE).

- These conclusions are based on indirect evidence from the ED setting comparing weightbased doses of morphine IV with fixed doses of APAP IV. 


\section{Detailed Results}

We present the conclusions of the comparative effectiveness of opioids versus APAP in Table 11. This evidence base is entirely indirect from the ED setting and compares morphine IV to APAP IV.

Table 11. Conclusions and strength of evidence for the comparison of opioids versus acetaminophen, Key Question 1

\begin{tabular}{|c|c|c|c|}
\hline Outcome & $\begin{array}{l}\text { Study } \\
\text { Design and } \\
\text { Sample Size }\end{array}$ & $\begin{array}{l}\text { Conclusions } \\
\text { (Setting: Supporting Effect Estimates and } 95 \% \\
\text { Confidence Intervals) }\end{array}$ & $\begin{array}{l}\text { Strength of } \\
\text { Evidence } \\
\text { (Limitations) }\end{array}$ \\
\hline $\begin{array}{l}\text { Pain severity - } \\
15 \text { min }\end{array}$ & $\begin{array}{l}7 \mathrm{RCT}^{73,74,76-} \\
79,82(\mathrm{n}=647)\end{array}$ & $\begin{array}{l}\text { There is no evidence of a clinically important difference } \\
\text { between IV opioids and IV APAP in the change of pain } \\
\text { scores in } 15 \text { min. } \\
\text { ED: Meta-analysis of } 7 \text { RCTs found MD } 0.18(-1.06 \text { to } 1.42) \text {. }\end{array}$ & $\begin{array}{l}\text { Low } \\
\text { (Inconsistent, } \\
\text { indirect) }\end{array}$ \\
\hline $\begin{array}{l}\text { Pain severity - } \\
30 \mathrm{~min}\end{array}$ & $\begin{array}{l}\mathrm{RCT}^{73-} \\
79,81,82 \\
(\mathrm{n}=1795)\end{array}$ & $\begin{array}{l}\text { There is no evidence of a clinically important difference } \\
\text { between IV opioids and IV APAP in the change of pain } \\
\text { scores in } 30 \text { min. } \\
\text { ED: Meta-analysis of } 9 \text { RCTs found MD } 0.30(-0.84 \text { to } 1.44) \text {. }\end{array}$ & $\begin{array}{l}\text { Low } \\
\text { (Inconsistent, } \\
\text { indirect) }\end{array}$ \\
\hline $\begin{array}{l}\text { Pain severity - } \\
60 \mathrm{~min}\end{array}$ & $\begin{array}{l}3 \mathrm{RCT}^{75,79,82} \\
(\mathrm{n}=1260)\end{array}$ & $\begin{array}{l}\text { There is no evidence of a clinically important difference } \\
\text { between IV opioids and IV APAP in the change of pain } \\
\text { scores in } 60 \text { min. } \\
\text { ED: Meta-analysis of } 3 \text { RCT found MD } 0.40(-1.01 \text { to } 1.81) \text {. }\end{array}$ & $\begin{array}{l}\text { Low } \\
\text { (Inconsistent, } \\
\text { indirect) }\end{array}$ \\
\hline $\begin{array}{l}\text { Pain presence- } \\
\text { partial } \\
\text { resolution - } 30 \\
\text { min }\end{array}$ & $\begin{array}{l}\text { 1 RCT }^{75} \\
(n=996)\end{array}$ & $\begin{array}{l}\text { Inconclusive. } \\
\text { ED: } 1 \mathrm{RCT} \text { found a partial response in } 81.8 \% \text { vs. } 78.1 \% \text { of } \\
\text { patients, RD }-4 \%(-8 \text { to } 1)\end{array}$ & $\begin{array}{l}\text { Insufficient } \\
\text { (Unknown } \\
\text { consistency, } \\
\text { indirect, } \\
\text { imprecise) }\end{array}$ \\
\hline $\begin{array}{l}\text { Time to } \\
\text { analgesic } \\
\text { effect }\end{array}$ & $\begin{array}{l}1 \mathrm{RCT}^{75} \\
(\mathrm{n}=1097)\end{array}$ & $\begin{array}{l}\text { There is no evidence of a clinically important difference } \\
\text { in the time to analgesia with IV opioids compared with IV } \\
\text { APAP. } \\
\text { ED: Median time to NRS<2 was } 60 \text { min in both arms, IQR } 30 \\
\text { to } 90 \text { min. }\end{array}$ & $\begin{array}{l}\text { Low } \\
\text { (Unknown } \\
\text { consistency, } \\
\text { indirect) }\end{array}$ \\
\hline
\end{tabular}

Abbreviations: $\mathrm{APAP}=$ acetaminophen; $\mathrm{ED}=$ emergency department; $\mathrm{IQR}=$ interquartile range; $\mathrm{IV}=$ intravenous; $\mathrm{MD}=$ mean difference; $\min =$ minutes; $\mathrm{NRS}=$ Numeric Rating Scale; $\mathrm{RCT}=$ randomized controlled trial; $\mathrm{RD}=$ risk difference

There is no evidence of a clinically important difference in the reduction of pain scores when IV opioids are compared to IV APAP at 15, 30 and 60 minutes (all low SOE) (Figure 9-Figure 11). These conclusions are each based on meta-analysis of the change in pain scores using indirect evidence from the ED setting and a clinically important difference of 2 points on a 0 to 10 scale.

Figure 9. Change in pain scores at 15 minutes, opioids versus acetaminophen

$\begin{array}{lrr}\text { Source } & \text { MD } & \mathbf{9 5 \%} \mathbf{- C l} \\ \text { Craig, 2012 } & 0.20 & {[-0.70 ; 1.10]} \\ \text { Serinken, 2012 } & -0.60 & {[-1.75 ; 0.55]} \\ \text { Eken, 2013 } & -1.10 & {[-2.15 ;-0.05]} \\ \text { Masoumi, 2014 } & 1.30 & {[0.50 ; 2.10]} \\ \text { Vahdati, 2014 } & 1.80 & {[1.00 ; 2.60]} \\ \text { Jalili, 2016 } & 1.30 & {[0.40 ; 2.20]} \\ \text { Serinken, 2016 } & -1.60 & {[-2.00 ;-1.20]} \\ \text { Random effects model } & \mathbf{0 . 1 8} & {[-\mathbf{1 . 0 6} ; \mathbf{1 . 4 2}]} \\ \text { Heterogeneity: } I^{2}=94 \%, \tau^{2}=1.5999, p<0.01\end{array}$

Abbreviations: $\mathrm{CI}=$ confidence interval; $\mathrm{MD}=$ mean difference

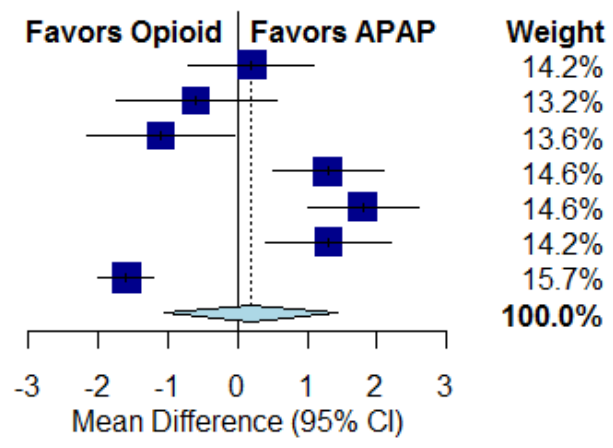


Figure 10. Change in pain scores at $\mathbf{3 0}$ minutes, opioids versus acetaminophen

\begin{tabular}{|c|c|c|c|c|c|}
\hline Source & MD & $95 \%-\mathrm{Cl}$ & Favors Opioid & Favors APAP & Weight \\
\hline Craig, 2012 & -0.30 & {$[-1.50 ; 0.90]$} & & & $10.2 \%$ \\
\hline Serinken, 2012 & 0.70 & {$[-0.40 ; 1.80]$} & & & $10.5 \%$ \\
\hline Eken, 2013 & -0.40 & {$[-1.40 ; 0.60]$} & & & $10.8^{\circ}$ \\
\hline Masoumi, 2014 & 1.70 & {$[0.80 ; 2.60]$} & & & $11.0^{\circ}$ \\
\hline Vahdati, 2014 & 2.30 & {$[1.40 ; 3.20]$} & & & $11.0^{\circ}$ \\
\hline Jalili, 2016 & 1.70 & {$[0.80 ; 2.60]$} & & & $11.0^{\circ}$ \\
\hline Mollaei, 2016 & -0.70 & {$[-1.30 ;-0.10]$} & & & $11.6^{\circ}$ \\
\hline Pathan, 2016 & 0.30 & {$[0.04 ; 0.56]$} & & 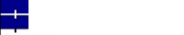 & $12.0^{\circ}$ \\
\hline Serinken, 2016 & -2.40 & {$[-2.85 ;-1.95]$} & & & $11.8^{\circ}$ \\
\hline Random effects model & 0.30 & {$[-0.84 ; 1.44]$} & & $=$ & $100.0^{\circ}$ \\
\hline \multirow{2}{*}{\multicolumn{3}{|c|}{ Heterogeneity: $I^{2}=95 \%, \tau^{2}=2.0130, p<0.01$}} & T & $T$ & \\
\hline & & & $\begin{array}{lc}-4 & -2 \\
\end{array}$ & $\frac{2}{2}$ & \\
\hline
\end{tabular}

Abbreviations: $\mathrm{CI}=$ confidence interval; $\mathrm{MD}=$ mean difference

Figure 11. Change in pain scores at 60 minutes, opioids versus acetaminophen

\begin{tabular}{|c|c|c|c|c|c|c|c|c|c|c|}
\hline Source & Total & Mean & $\begin{array}{r}\text { Opioid } \\
\text { SD }\end{array}$ & Total & Mean & $\begin{array}{r}\text { APAP } \\
\text { SD }\end{array}$ & $\operatorname{MD}[95 \%-\mathrm{Cl}]$ & Favors Opioid & Favors APAP & Weight \\
\hline Craig, 2012 & 27 & -2.60 & 2.0000 & 28 & -2.30 & 2.3000 & $-0.30[-1.44 ; 0.84]$ & & & $20.1 \%$ \\
\hline Masoumi, 2014 & 54 & -5.80 & 2.2000 & 54 & -6.80 & 1.8000 & $1.00[0.24 ; 1.76]$ & & & $31.0 \%$ \\
\hline Pathan, 2016 & 549 & -6.70 & 2.6800 & 548 & -7.00 & 2.2300 & $0.30[0.01 ; 0.59]$ & & & $48.9 \%$ \\
\hline \multirow{2}{*}{$\begin{array}{l}\text { Random effects model } \\
\text { Heterogeneity: } I^{2}=52 \%, \tau^{2}\end{array}$} & 630 & & & 630 & & & $0.40[-1.01 ; 1.81]$ & & $=$ & \multirow[t]{2}{*}{$100.0 \%$} \\
\hline & & & & & & & & $\begin{array}{l}-2 \quad-1 \\
\quad \text { Mean Diff }\end{array}$ & $\begin{array}{lc}0 & 1 \\
\text { ence } & (95 \% \mathrm{Cl})\end{array}$ & \\
\hline
\end{tabular}

Abbreviations: $\mathrm{CI}=$ confidence interval; $\mathrm{MD}=$ mean difference

There is insufficient evidence to conclude the comparative effectiveness IV opioids versus IV APAP on the outcome of partial responders at 30 minutes. One RCT found more patients achieved a reduction of 3 or more on the NRS with IV APAP versus IV opioids at 30 minutes. $^{75}$ The confidence interval did not exclude the possibility of a clinically important difference of 5 percent in favor of opioids; thus, this estimate was imprecise as well as indirect. We were unable to judge consistency with only one study and given additional downgraded domains, SOE was judged to be insufficient.

There is no evidence of a clinically important difference in the time to analgesia with IV opioids compared with IV APAP (low SOE). One trial ${ }^{75}$ reported the median time to NRS less than 2, as 60 minutes (IQR 30 to $90 \mathrm{~min}$ ) in both arms, suggesting no difference between these analgesics. We were unable to judge consistency with only one study and data were also indirect.

No studies reported measures of the memory of pain.

\section{Subgroups}

\section{Type of Pain}

We analyzed studies that included traumatic pain only. Change in pain scores at 15 and 30 minutes were similar to the main conclusion that there is no evidence of a clinically important difference in change of pain scores between IV opioids and IV APAP (Appendix Figures F-21 and F-22). 


\section{Opioids Versus Nitrous Oxide}

\section{Key Messages}

- Evidence is insufficient for the comparison of IV opioids with inhaled nitrous oxide, for outcomes measuring pain severity. No studies reported pain presence or time to analgesic effect.

\section{Detailed Results}

We present the conclusions of the comparative effectiveness of opioids versus nitrous oxide in Table 12. This evidence base included a single trial from the EMS setting comparing morphine IV with self-administered nitrous oxide/oxygen (50:50). ${ }^{83}$ This study had a medium risk of bias as it was open-label and we were unable to determine consistency without another study. Thus, evidence is insufficient to make conclusions regarding this comparison. No studies reported presence of pain or time to analgesic effect (insufficient SOE).

Table 12. Conclusions and strength of evidence for the comparison of opioids versus nitrous oxide, Key Question 1

\begin{tabular}{llll}
\hline Outcome & $\begin{array}{l}\text { Study } \\
\text { Design and } \\
\text { Sample Size }\end{array}$ & $\begin{array}{l}\text { Conclusions } \\
\text { (Setting: Supporting Effect Estimates and } \\
\text { 95\% Confidence Intervals) }\end{array}$ & $\begin{array}{l}\text { Strength of Evidence } \\
\text { (Limitations) }\end{array}$ \\
\hline $\begin{array}{l}\text { Pain severity }- \\
15 \text { min }\end{array}$ & $\begin{array}{l}\text { 1 RCT } \\
(\mathrm{n}=100)\end{array}$ & $\begin{array}{l}\text { Inconclusive. } \\
\text { EMS: 1 RCT found MD 0.8 (0.0 to 1.6) }\end{array}$ & $\begin{array}{l}\text { Insufficient } \\
\text { (Medium study limitations, } \\
\text { unknown consistency) }\end{array}$ \\
\hline $\begin{array}{l}\text { Pain severity }- \\
60 \text { min }\end{array}$ & $\begin{array}{l}\text { 1 RCT } 83 \\
(\mathrm{n}=100)\end{array}$ & $\begin{array}{l}\text { Inconclusive. } \\
\text { EMS: 1 RCT found MD 0.1 (-0.6 to 0.8) }\end{array}$ & $\begin{array}{l}\text { Insufficient } \\
\text { (Medium study limitations, } \\
\text { unknown consistency) }\end{array}$ \\
\hline
\end{tabular}

Abbreviations: EMS=emergency medical services; $\mathrm{MD}=$ mean difference; $\mathrm{RCT}=$ randomized controlled trial

\section{Opioids Versus Nonsteroidal Anti-Inflammatory Drugs}

\section{Key Messages}

- There is no evidence of a clinically important difference between opioids and NSAIDs administered IV and orally, in the change of pain scores in 30 or 60 minutes (moderate SOE).

- Evidence is insufficient for outcomes measuring pain severity at 15 minutes, partial or full resolution of pain, and time to analgesic effect.

\section{Detailed Results}

We present the conclusions of the comparative effectiveness of opioids versus NSAIDs in Table 13. This evidence base was entirely indirect evidence from the ED setting. Morphine IV was compared with ketorolac IV in two studies and oral morphine was compared to oral ibuprofen in one study. 
Table 13. Conclusions and strength of evidence for the comparison of opioids versus nonsteroidal anti-inflammatory drugs, Key Question 1

\begin{tabular}{|c|c|c|c|}
\hline Outcome & $\begin{array}{l}\text { Study } \\
\text { Design and } \\
\text { Sample Size }\end{array}$ & $\begin{array}{l}\text { Conclusions } \\
\text { (Setting: Supporting Effect Estimates and 95\% } \\
\text { Confidence Intervals) }\end{array}$ & $\begin{array}{l}\text { Strength of Evidence } \\
\text { (Limitations) }\end{array}$ \\
\hline $\begin{array}{l}\text { Pain severity - } \\
15 \text { min }\end{array}$ & $\begin{array}{l}1 \mathrm{RCT}^{84} \\
(\mathrm{n}=88)\end{array}$ & $\begin{array}{l}\text { Inconclusive. } \\
\text { ED: } 1 \text { RCT found MD } 0.2(-0.4 \text { to } 0.8)\end{array}$ & $\begin{array}{l}\text { Insufficient } \\
\text { (Medium study } \\
\text { limitations, unknown } \\
\text { consistency, indirect) }\end{array}$ \\
\hline $\begin{array}{l}\text { Pain severity - } \\
30 \text { min }\end{array}$ & $\begin{array}{l}3 \mathrm{RCT}^{84-86} \\
(\mathrm{n}=453)\end{array}$ & $\begin{array}{l}\text { There is no evidence of a clinically important } \\
\text { difference between opioids and NSAIDs in the } \\
\text { change of pain scores in } 30 \text { min. } \\
\text { ED: Meta-analysis of } 3 \text { RCT found MD } 0.01(-0.29 \text { to } \\
0.32)\end{array}$ & $\begin{array}{l}\text { Moderate } \\
\text { (Indirect) }\end{array}$ \\
\hline $\begin{array}{l}\text { Pain severity - } \\
60 \text { min }\end{array}$ & $\begin{array}{l}3 \mathrm{RCT}^{84-86} \\
(\mathrm{n}=453)\end{array}$ & $\begin{array}{l}\text { There is no evidence of a clinically important } \\
\text { difference between opioids and NSAIDs in the } \\
\text { change of pain scores in } 60 \text { min. } \\
\text { ED: Meta-analysis of } 3 \text { RCT found MD } 0.21(-0.10 \text { to } \\
0.51)\end{array}$ & $\begin{array}{l}\text { Moderate } \\
\text { (Indirect) }\end{array}$ \\
\hline $\begin{array}{l}\text { Pain presence- } \\
\text { partial } \\
\text { resolution - } 30 \\
\text { min }\end{array}$ & $\begin{array}{l}1 \mathrm{RCT}^{86} \\
(\mathrm{n}=227)\end{array}$ & $\begin{array}{l}\text { Inconclusive. } \\
\text { ED: } 1 \text { RCT found partial response in } 20.7 \% \text { vs. } \\
19.8 \%, \text { RD } 1 \%(-10 \text { to } 10)\end{array}$ & $\begin{array}{l}\text { Insufficient } \\
\text { (Unknown consistency, } \\
\text { indirect, very imprecise) }\end{array}$ \\
\hline $\begin{array}{l}\text { Pain presence- } \\
\text { partial } \\
\text { resolution - } 60 \\
\text { min }\end{array}$ & $\begin{array}{l}1 \mathrm{RCT}^{86} \\
(\mathrm{n}=243)\end{array}$ & $\begin{array}{l}\text { Inconclusive. } \\
\text { ED: } 1 \text { RCT found partial response in } 29.3 \% \text { vs. } \\
33.0 \%, R D-4 \%(-16 \text { to } 7)\end{array}$ & $\begin{array}{l}\text { Insufficient } \\
\text { (Unknown consistency, } \\
\text { indirect, very imprecise) }\end{array}$ \\
\hline $\begin{array}{l}\text { Pain presence- } \\
\text { full resolution - } \\
30 \mathrm{~min}\end{array}$ & $\begin{array}{l}1 \mathrm{RCT}^{85} \\
(\mathrm{n}=86)\end{array}$ & $\begin{array}{l}\text { Inconclusive. } \\
\frac{\text { ED: } 1 \text { RCT found } 16.3 \% \text { vs. } 11.6 \% \text {, RD } 5 \% \text { (-11 to }}{20)}\end{array}$ & $\begin{array}{l}\text { Insufficient } \\
\text { (Unknown consistency, } \\
\text { indirect, very imprecise) }\end{array}$ \\
\hline
\end{tabular}

There is no evidence of a clinically important difference in the reduction of pain scores when opioids are compared with NSAIDs at 30 and 60 minutes (all moderate SOE) (Figure 12-Figure 13). These conclusions are each based on meta-analysis of the change in pain scores using indirect evidence from the ED setting and a clinically important difference of 2 points on a 0 to 10 scale. Evidence is insufficient to conclude effects at 15 minutes. The single trial ${ }^{84}$ reporting 15 minutes data had a medium risk of bias due to inadequate randomization and allocation concealment procedures, we were unable to judge consistency with only 1 study, and data were indirect from the ED setting.

Figure 12. Change in pain scores at $\mathbf{3 0}$ minutes, opioids versus nonsteroidal anti-inflammatory drugs

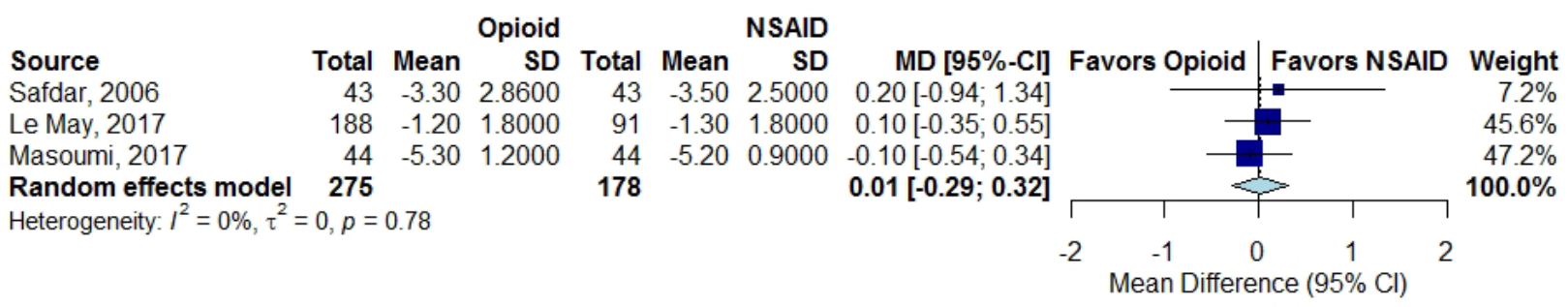

Abbreviations: $\mathrm{CI}=$ confidence interval; $\mathrm{MD}=$ mean difference; $\mathrm{NSAID}=$ nonsteroidal anti-inflammatory drug; $\mathrm{SD}=\mathrm{standard}$ deviation 
Figure 13. Change in pain scores at 60 minutes, opioids versus nonsteroidal anti-inflammatory drugs

$\begin{array}{lrr}\text { Source } & \text { MD } & \mathbf{9 5 \%} \mathbf{c} \mathbf{C l} \\ \text { Safdar, 2006 } & 0.40 & {[-1.15 ; 1.95]} \\ \text { Le May, 2017 } & 0.20 & {[-0.31 ; 0.71]} \\ \text { Masoumi, 2017 } & 0.20 & {[-0.19 ; 0.59]} \\ \text { Random effects model } & \mathbf{0 . 2 1} & {[-\mathbf{0 . 1 0} ; \mathbf{0 . 5 1}]} \\ \text { Heterogeneity: } I^{2}=0 \%, \tau^{2}=0, p=0.97 & \end{array}$

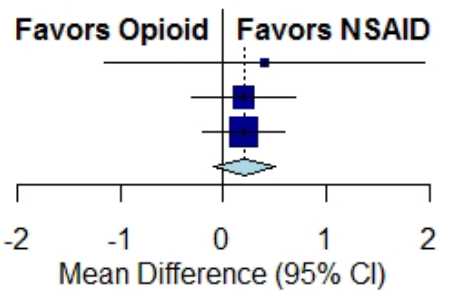

Weight

$3.9 \%$

$35.7 \%$

$60.4 \%$

$100.0 \%$

Mean Difference $(95 \% \mathrm{Cl})$

Abbreviations: $\mathrm{CI}=$ confidence interval; $\mathrm{MD}=$ mean difference; $\mathrm{NSAID}=$ nonsteroidal anti-inflammatory drug; $\mathrm{SD}=$ standard deviation

Evidence is insufficient to conclude comparative effectiveness of opioids versus NSAIDs on the outcomes of partial or full response because of very imprecise estimates that included a clinically important difference in favor of either analgesic.

No studies reported time to analgesic effects (insufficient SOE) or measures of memory of pain.

\section{Acetaminophen Versus Nonsteroidal Anti-Inflammatory Drugs}

We present results from studies that compared APAP versus NSAIDs in Table 14. This evidence base was entirely indirect evidence from the ED setting. One trial found pain to decrease less with APAP versus NSAIDs at 15 minutes. Otherwise, findings did not favor either analgesic significantly. No studies reported time to analgesic effect or memory of pain.

Table 14. Findings for the comparison of acetaminophen with nonsteroidal anti-inflammatory drugs, Key Question 1

\begin{tabular}{|c|c|c|}
\hline Outcome & $\begin{array}{l}\text { Study Design and } \\
\text { Sample Size }\end{array}$ & $\begin{array}{l}\text { Findings } \\
\text { (Setting: Effect estimates and } 95 \% \text { Confidence Interval) }\end{array}$ \\
\hline Pain severity - 15 min & $1 \mathrm{RCT}^{87}(\mathrm{n}=199)$ & ED: MD $1.0(0.5$ to 1.4$), p=0.000$ \\
\hline Pain severity $-30 \mathrm{~min}$ & $3 \mathrm{RCT}^{87-89}(\mathrm{n}=542)$ & ED: Meta-analysis of 3 RCTs MD 0.63 (-0.62 to 1.88$)$ \\
\hline Pain severity - 60 min & $2 \mathrm{RCT}^{88-89}(\mathrm{n}=340)$ & ED: Meta-analysis of 2 RCTs MD 0.53 (-0.87 to 1.92$)$ \\
\hline $\begin{array}{l}\text { Pain presence - } \\
\text { partial resolution } 30 \mathrm{~min}\end{array}$ & $1 \mathrm{RCT}^{88}(\mathrm{n}=92)$ & ED: AR $31.4 \%$ vs. $30.0 \% ;$ RD $1 \%(-14$ to 16$)$ \\
\hline $\begin{array}{l}\text { Pain presence - } \\
\text { partial resolution } 60 \mathrm{~min}\end{array}$ & $2 \mathrm{RCT}^{88,89}(\mathrm{n}=340)$ & $\begin{array}{l}\text { ED: Meta-analysis of } 2 \text { RCTs, AR } 44.7 \% \text { vs. } 52.4 \% \text {; RD }-6 \% \\
\text { (-26 to } 13)\end{array}$ \\
\hline
\end{tabular}

\section{Ketamine Versus Nonsteroidal Anti-Inflammatory Drugs}

We present results from a single trial that compared ketamine versus NSAIDs (ketorolac) in Table 15. The evidence base is indirect from the ED setting. Findings did not suggest a statistically significant difference in favor of either analgesic at 15 or 60 mins, but at 30 minutes the change in pain score was greater in subjects randomized to ketorolac. No studies reported presence of pain, time to analgesic effect or memory of pain.

Table 15. Findings for the comparison of ketamine with nonsteroidal anti-inflammatory drugs, Key Question 1

\begin{tabular}{lll}
\hline Outcome & $\begin{array}{l}\text { Study Design and } \\
\text { Sample Size }\end{array}$ & $\begin{array}{l}\text { Findings } \\
\text { (Setting: Effect estimates and 95\% Confidence Intervals) }\end{array}$ \\
\hline Pain severity $-15 \mathrm{~min}$ & 1 RCT $(n=126)^{90}$ & ED: 1 RCT MD 0.2 $(-0.8$ to 1.2$)$ \\
\hline Pain severity $-30 \mathrm{~min}$ & 1 RCT $(n=126)^{90}$ & ED: 1 RCT MD 1.3 (0.4 to 2.2) \\
\hline Pain severity $-60 \mathrm{~min}$ & 1RCT $(n=126)^{90}$ & ED: 1 RCT MD 0.7 $(-0.1$ to 1.5$)$ \\
\hline
\end{tabular}


Abbreviations: $\mathrm{ED}=$ emergency department; $\mathrm{MD}=$ mean difference; $\mathrm{RCT}=$ randomized controlled trial

\section{Morphine Versus Fentanyl}

We present results from RCTs that compared morphine versus fentanyl in Table 16 followed by a summary of findings from observational studies. Three trials are in the EMS setting ${ }^{93-95}$ and 5 trials ${ }^{19-21,91,97}$ are from the ED setting. Findings from the RCTs are not significant in favor of either analgesic (Table 16).

Table 16. Findings for the comparison of morphine versus fentanyl, Key Question 1

\begin{tabular}{|c|c|c|}
\hline Outcome & $\begin{array}{l}\text { Study Design and } \\
\text { Sample Size }\end{array}$ & $\begin{array}{l}\text { Findings } \\
\text { (Setting: Effect estimates and } 95 \% \text { Confidence Intervals) }\end{array}$ \\
\hline Pain severity -15 & $6 \mathrm{RCT}^{19-21,91,93,97}(\mathrm{n}=622)$ & EMS: $1 \mathrm{RCT}^{93}$ MD 0.5 (-0.7 to 1.7$), 1$ OBS see text ${ }^{102}$ \\
\hline $\min$ & $1 \mathrm{OBS}^{102}(n=612)$ & $\begin{array}{l}\text { ED: Meta-analysis of } 5 \text { RCTs }{ }^{19-21,91,97} \mathrm{MD} 0.25(-0.19 \text { to } \\
0.69)\end{array}$ \\
\hline $\begin{array}{l}\text { Pain severity }-30 \\
\text { min }\end{array}$ & $\begin{array}{l}8 \mathrm{RCT}^{19-21,91,93-95,97} \\
(\mathrm{n}=1049)\end{array}$ & $\begin{array}{l}\text { EMS: Meta-analysis of } 3 \mathrm{RCTs}^{93-95} \mathrm{MD}-0.17(-1.49 \text { to } 1.15) \\
\text { ED: Meta-analysis of } 5 \mathrm{RCTs}{ }^{19-21,91,97} \mathrm{MD} 0.64(-0.51 \text { to } \\
\text { 1.78) }\end{array}$ \\
\hline $\begin{array}{l}\text { Pain severity - } 60 \\
\text { min }\end{array}$ & $\begin{array}{l}3 \operatorname{RCT}^{19,20,91}(n=429) \\
3 \operatorname{OBS}^{98,103,104}(n=1036)\end{array}$ & $\begin{array}{l}\text { EMS: } 3 \text { OBS see text }{ }^{98,103,104} \\
\text { ED: Meta-analysis of } 3 \text { RCTs }{ }^{19,20,91} \text { MD } 1.10(-2.43 \text { to } 4.64)\end{array}$ \\
\hline $\begin{array}{l}\text { Pain presence - } \\
\text { partial resolution } 15 \\
\text { min }\end{array}$ & $\begin{array}{l}1 \operatorname{RCT}^{93}(n=54) \\
1 \operatorname{OBS}^{102}(n=612)\end{array}$ & $\begin{array}{l}\left.\text { EMS: } 1 \text { RCT }{ }^{93} \text { AR } 30.8 \% \text { vs. } 39.3 \% \text {; RD }-9 \% \text { (-32 to } 16\right), 1 \\
\text { OBS see text } 102\end{array}$ \\
\hline $\begin{array}{l}\text { Pain presence - } \\
\text { partial resolution } 30 \\
\text { min }\end{array}$ & $2 \mathrm{RCT}^{93,94}(\mathrm{n}=163)$ & $\begin{array}{l}\text { EMS: Meta-analysis of } 2 \text { RCTs AR } 62 \% \text { vs. } 66.4 \% ; \text { RD }-4 \% \\
(-18 \text { to } 10)\end{array}$ \\
\hline $\begin{array}{l}\text { Time to analgesic } \\
\text { effect }\end{array}$ & $3 \mathrm{OBS}^{100,101,103}(\mathrm{n}$ & $\begin{array}{l}\text { EMS: } 1 \text { OBS see text } \\
\text { ED: } 2 \text { OBS see text }{ }^{95,96}\end{array}$ \\
\hline
\end{tabular}

Abbreviations: $\mathrm{AR}=$ absolute risk; $\mathrm{ED}=$ emergency department; $\mathrm{EMS}=$ emergency medical services; $\mathrm{MD}=$ mean difference; $\mathrm{OBS}=$ observational; $\mathrm{RCT}=$ randomized controlled trial; $\mathrm{RD}=$ risk difference

Eight observational studies ${ }^{63,98,100-105}$ compared efficacy of morphine with fentanyl. Four studies are in the EMS setting. Bendall et al. ${ }^{102}$ found no difference in reduction of pain scores between morphine [median 5 (IQR 4 to 7)] and fentanyl [median 5 (IQR 3 to 7), p=not reported, stated no difference] or in the adjusted odds of $\mathrm{a} \geq 30$ percent reduction in pain score comparing morphine to fentanyl [adjust odds ratio 0.85 (95 percent confidence interval 0.50 to 1.35 ]. Fleischman et al. ${ }^{104}$ found no difference in the adjusted change in pain scores on a 0 to 10 scale comparing morphine with fentanyl $[0.23$ points $(-0.24$ to 0.71$)]$. Sharnow et al. ${ }^{98}$ found no significant difference in the decrease of pain scores between morphine and fentanyl (baseline and final mean scores, respectively, morphine 7.6 to 3.4, fentanyl 8 to 3.3). Garrick et al. ${ }^{103}$ found the average decrease in pain score was greater with fentanyl (3.62 points) versus morphine ( 2 points, $\mathrm{p}=\mathrm{NR}$ ) and that pain relief was more rapid with fentanyl based on the percent of subjects reporting pain relief within 1 minute (16.6 percent versus 2.0 percent), $1-2$ minutes (47.0 percent versus 14.0 percent), 2-3 minutes (19.9 percent versus 36.0 percent) and more than 3 minutes (16.6 percent versus 48 percent), $p=N R$.

Three studies were in the ED setting. Schacherer et al. ${ }^{100}$ reported nonsignificant findings for the number of patients with a pain score decrease by at least 2 point within 20 minutes of drug administration (morphine 14 percent versus fentanyl 26 percent, $\mathrm{p}=0.45$ ), the number of patients with a pain score decrease to 0 (morphine 45 percent versus 43 percent, $\mathrm{p}=0.89$ ) or for time to analgesic effect [morphine median 48 (IQR 20 to 65) versus fentanyl median 38 (IQR 15 to 100), $\mathrm{p}=0.99$ ]. Wenderoth et al. ${ }^{101}$ reported a nonsignificant difference in reduction of pain scores [morphine median -2 (IQR 1 to 4) versus fentanyl median -2 (IQR 1 to 4), p=0.76] but found a 
significant difference in the time to lowest pain score favoring fentanyl [morphine median 47 minutes (IQR 25 to 57) versus fentanyl median 22 minutes (IQR 12 to 34), $\mathrm{p}<0.001]$. Griffioen et al. reported the percent improvement in pain scores from pre- to post-analgesia administration to be 35 percent for fentanyl users versus 32 percent for morphine users, a finding stated to be not statistically significant $(\mathrm{p}=\mathrm{NR}) .{ }^{105}$

One study was in the battlefield setting and reported change in pain scores from 0 to 10 during the tactical evacuation period. ${ }^{63}$ The median (interquartile range) change in pain scores were $-3(-5$ to -1$)$ with morphine and $-3(-4$ to -2$)$ with fentanyl.

$K Q$ 2. What are the comparative harms of analgesic agents when administered by EMS personnel to control moderate-to-severe pain in the prehospital setting?

$\mathrm{KQ} 2 \mathrm{a}$. How do harms vary by patient characteristics?

$\mathrm{KQ} 2 \mathrm{~b}$. How do harms vary by routes of administration, dosing, and timing?

$K Q$ 2c. What are the comparative harms to EMS personnel who administer analgesics to patients for the control of moderate-to-severe pain in the prehospital setting?

\section{Opioids Versus Ketamine}

\section{Key Messages}

- Opioids may cause fewer total adverse events than ketamine (low SOE), primarily administered IN. Differences in adverse events may be associated with age, route, or type of pain.

- Opioids cause less dizziness than ketamine (low SOE), primarily administered IV. Differences in dizziness may be associated with age or route.

- Opioids may cause more respiratory depression than ketamine (low SOE), primarily administered IV.

- Evidence is insufficient for the outcome of hypotension and measures of mental status changes other than dizziness.

- Results from outcomes that were not graded for SOE suggest opioids lead to statistically lower values for heart rate, respiratory rate and systolic blood pressure compared with ketamine in 15 minutes; statistically lower systolic blood pressure versus ketamine in 30 minutes; statistically greater nausea/vomiting versus ketamine, administered primarily IV. Clinical relevance of these results is uncertain.

\section{Detailed Results}

We present the conclusions for the comparative harms of opioids versus ketamine as initial analgesics in Table 17. The majority of this evidence base is indirect data from the ED setting and compares weight-based doses of morphine IV or fentanyl IN with weight-based doses of ketamine IV or IN. 
Table 17. Conclusions and strength of evidence for the comparison of opioids versus ketamine, Key Question 2

\begin{tabular}{|c|c|c|c|}
\hline Outcome & $\begin{array}{l}\text { Study Design } \\
\text { and Sample } \\
\text { Size }\end{array}$ & $\begin{array}{l}\text { Conclusions } \\
\text { (Setting: Supporting Effect Estimates and } 95 \% \\
\text { Confidence Intervals) }\end{array}$ & $\begin{array}{l}\text { Strength of } \\
\text { Evidence } \\
\text { (Limitations) }\end{array}$ \\
\hline $\begin{array}{l}\text { Any adverse } \\
\text { event }\end{array}$ & $\begin{array}{l}8 \\
\operatorname{RCTs}^{17,29,30,52,54} \\
, 55,57,58(n=398)\end{array}$ & $\begin{array}{l}\text { Opioids may cause fewer total adverse events } \\
\text { than ketamine. } \\
\text { ED: Meta-analysis of } 6 \text { RCTs } \text { s }^{17,29,30,52,54,58} \text { over the } \\
\text { study period found AR } 50.0 \% \text { vs. } 82.4 \% \text {; RD }-30 \% \text { (- } \\
56 \text { to }-4 \text { ). Two RCTs }{ }^{55,57} \text { reported AEs at } 15 \text { and at } \\
30 \text { min are generally in agreement. }\end{array}$ & $\begin{array}{l}\text { Low } \\
\text { (Inconsistent, } \\
\text { indirect, } \\
\text { imprecise) }\end{array}$ \\
\hline Hypotension & $\begin{array}{l}4 \mathrm{RCTs}^{17,29,54,56} \\
(\mathrm{n}=508)\end{array}$ & $\begin{array}{l}\text { Inconclusive. } \\
\text { ED: Meta-analysis of } 4 \text { RCTs over the study period } \\
\text { found AR } 3.6 \% \text { vs. } 0 \% \text {; RD } 8 \%(-20 \text { to } 37)\end{array}$ & $\begin{array}{l}\text { Insufficient } \\
\text { (Inconsistent, } \\
\text { indirect, very } \\
\text { imprecise) }\end{array}$ \\
\hline $\begin{array}{l}\text { Mental status } \\
\text { changes - } \\
\text { dizziness }\end{array}$ & $\begin{array}{l}9 \text { RCTs }^{29,30,52,53-} \\
58(n=723)\end{array}$ & $\begin{array}{l}\text { Opioids cause less dizziness than ketamine. } \\
\text { ED: Meta-analysis of } 7 \text { RCTs }{ }^{29,30,52-54,56,58} \text { over the } \\
\text { study period found AR } 25.4 \% \text { vs. } 43.5 \% \text {; RD }-29 \% \text { (- } \\
52 \text { to }-6 \text { ). Two RCTs }{ }^{55,57} \text { reported dizziness at } 15 \\
\text { and } 30 \text { min and are generally in agreement. }\end{array}$ & $\begin{array}{l}\text { Low } \\
\text { (Inconsistent, } \\
\text { indirect) }\end{array}$ \\
\hline $\begin{array}{l}\text { Mental status } \\
\text { changes - } \\
\text { drowsiness }\end{array}$ & $\begin{array}{l}4 \mathrm{RCTs}^{29,30,58,60} \\
(\mathrm{n}=356)\end{array}$ & $\begin{array}{l}\text { Inconclusive. } \\
\text { ED: Meta-analysis of } 4 \text { RCTs over the study period } \\
\text { found } \\
\text { AR } 8.5 \% \text { vs. } 11.2 \% \text { RD }-2 \%(-19 \text { to } 15)\end{array}$ & $\begin{array}{l}\text { Insufficient } \\
\text { (Indirect, very } \\
\text { imprecise) }\end{array}$ \\
\hline $\begin{array}{l}\text { Mental status } \\
\text { changes - GCS }\end{array}$ & $\begin{array}{l}1 \mathrm{OBS}^{61} \\
(\mathrm{n}=158)\end{array}$ & $\begin{array}{l}\text { Inconclusive. } \\
\text { EMS: One OBS study found no difference in change } \\
\text { in GCS score } 0.03(0.4) \text { vs. }-0.1(0.8), p=0.16\end{array}$ & $\begin{array}{l}\text { Insufficient } \\
\text { (Unknown } \\
\text { consistency, } \\
\text { imprecise) }\end{array}$ \\
\hline $\begin{array}{l}\text { Mental status } \\
\text { changes - } \\
\text { sedation }\end{array}$ & $\begin{array}{l}2 \mathrm{RCT}^{30,52} \\
(\mathrm{n}=95)\end{array}$ & $\begin{array}{l}\text { Inconclusive. } \\
\text { ED: } 1 \text { RCT found sedation over the study period in } \\
18.2 \% \text { vs. } 63.6 \% \text { of patients, RD }-45 \%(-70 \text { to }-5) \text {. A } \\
\text { second trial found sedation scores to be similar } \\
\text { between groups. }\end{array}$ & $\begin{array}{l}\text { Insufficient } \\
\text { (Inconsistent, } \\
\text { indirect, } \\
\text { imprecise) }\end{array}$ \\
\hline $\begin{array}{l}\text { Mental status } \\
\text { changes - } \\
\text { confusion }\end{array}$ & $\begin{array}{l}1 \mathrm{RCT}^{53} \\
(\mathrm{n}=75)\end{array}$ & $\begin{array}{l}\text { Inconclusive. } \\
\text { ED: One 3-arm trial found confusion over the study } \\
\text { period in } 33.3 \% \text { vs. } 50 \% \text { of patients; morphine IV } \\
\text { RD }-38 \%(-58 \text { to }-11) \text {, morphine IM RD }-31 \%(-53 \text { to } \\
-5)\end{array}$ & $\begin{array}{l}\text { Insufficient } \\
\text { (High ROB, } \\
\text { unknown } \\
\text { consistency, } \\
\text { indirect) }\end{array}$ \\
\hline $\begin{array}{l}\text { Mental status } \\
\text { changes - } \\
\text { difficulty } \\
\text { concentrating }\end{array}$ & $\begin{array}{l}1 \mathrm{RCT}^{53} \\
(\mathrm{n}=75)\end{array}$ & $\begin{array}{l}\text { Inconclusive. } \\
\text { ED: One 3-arm trial found difficulty concentrating } \\
\text { over the study period in } 21.6 \% \text { vs. } 58.3 \% \text { of } \\
\text { patients; morphine IV RD }-38 \%(-58 \text { to }-10) \text {; } \\
\text { morphine IM RD }-36 \%(-57 \text { to }-9)\end{array}$ & $\begin{array}{l}\text { Insufficient } \\
\text { (High ROB, } \\
\text { unknown } \\
\text { consistency, } \\
\text { indirect) }\end{array}$ \\
\hline $\begin{array}{l}\text { Mental status } \\
\text { changes - } \\
\text { sleepiness/tired }\end{array}$ & $\begin{array}{l}1 \mathrm{RCT}^{29} \\
(\mathrm{n}=82)\end{array}$ & $\begin{array}{l}\text { Inconclusive. } \\
\text { ED: } 1 \text { RCT found sleepiness/tired to occur in } 36.6 \% \\
\text { vs. } 46.3 \% \text { of patients, RD }-2 \%(-22 \text { to } 18)\end{array}$ & $\begin{array}{l}\text { Insufficient } \\
\text { (Unknown } \\
\text { consistency, } \\
\text { indirect, very } \\
\text { imprecise) }\end{array}$ \\
\hline $\begin{array}{l}\text { Mental status } \\
\text { changes - } \\
\text { RASS }\end{array}$ & $\begin{array}{l}1 \mathrm{RCT}^{58} \\
(\mathrm{n}=36)\end{array}$ & $\begin{array}{l}\text { Inconclusive. } \\
\text { ED: } 1 \text { RCT evaluated RASS scores at various times } \\
\text { throughout the trial and found no significant } \\
\text { differences between groups. Median scores were } 0 \\
\text { in both arms at all evaluated times. }\end{array}$ & $\begin{array}{l}\text { Insufficient } \\
\text { (unknown } \\
\text { consistency, } \\
\text { indirect, } \\
\text { imprecise) }\end{array}$ \\
\hline $\begin{array}{l}\text { Respiratory } \\
\text { depression }\end{array}$ & $\begin{array}{l}4 \text { RCTs }^{17,55,56,58} \\
(n=491) \\
1 \text { OBS }^{61} \\
(n=158)\end{array}$ & $\begin{array}{l}\text { Opioids may cause more respiratory depression } \\
\text { than ketamine. } \\
\text { EMS: One OBS study }{ }^{61} \text { found } 2 \text { vs. } 0 \text { cases of } \\
\text { respiratory compromise that needed oxygen } \\
\text { supplementation - insufficient data, conclusion } \\
\text { based on ED data } \\
\text { ED: Meta-analysis of } 4 \text { RCTs }{ }^{17,55,56,58} \text { over the study } \\
\text { period found AR } 11.5 \% \text { vs } 2.4 \%, R D 4 \% \text { (-2 to } 11)\end{array}$ & $\begin{array}{l}\text { Low } \\
\text { (Inconsistent, } \\
\text { indirect, } \\
\text { imprecise) }\end{array}$ \\
\hline
\end{tabular}


Abbreviations: $\mathrm{AR}=$ absolute risk; $\mathrm{ED}=$ emergency department; $\mathrm{EMS}=$ emergency medical services; $\mathrm{GCS}=\mathrm{Glasgow}$ Comas Scale; $\mathrm{IM}=$ intramuscular; IV=intravenous; $\mathrm{MD}=$ mean difference; $\min =$ minutes; OBS=observational; RASS=Richmond Agitations Sedation Scale; $\mathrm{RCT}=$ randomized controlled trial; $\mathrm{RD}=$ risk difference

Opioids may cause fewer total adverse events than ketamine (low SOE). This conclusion is based on meta-analysis of indirect data from the ED setting and using the clinically important differences of 10 percent. The confidence interval included possibility of a difference less than clinically important; thus, this estimate is imprecise. Two trials by Motov et al. ${ }^{5,57}$ reported adverse events at 15 and 30 minutes and were not pooled with the other studies that reported adverse events over the study period. Risk differences for any adverse event at 15 and 30 minutes, using these two trials, were -39 percent ( -53 to -24$)$ and -19 percent ( -53 to 15$)$, respectively, and were considered to be in agreement with the overall analysis.

Opioids cause less dizziness than ketamine (low SOE). This conclusion is based on metaanalysis of indirect data from the ED setting and using the clinically important differences of 5 percent. Two trials by Motov et al. ${ }^{55,57}$ reported dizziness at 15 and 30 minutes and were not pooled with the other studies that reported dizziness over the study period. Risk differences for dizziness at 15 and 30 minutes, using these two trials, were -25 percent ( -40 to -10$)$ and -20 percent ( -63 to 23 ), respectively, and were considered to be in agreement with the overall analysis.

Opioids may cause more respiratory depression than ketamine (low SOE). One observational study ${ }^{61}$ from the EMS setting reported 2 versus 0 cases of respiratory depression in morphine versus ketamine treated subjects, both of which required oxygen supplementation. Data were considered insufficient to conclude comparative harms. Thus we considered meta-analysis of indirect data from the ED setting. Results did not rule out the possibility of a clinically important difference of respiratory depression, in favor of ketamine.

Evidence is insufficient for the outcomes of hypotension and other measures of mental status changes. One observational study ${ }^{62}$ from the battlefield setting was not considered in the conclusion of mental status changes because the population and setting were too unlike civilians expected to access EMS. This study reported Glasgow Coma Scale scores at (median, IQR) at the point of hospital admission for morphine (15, 15 to 15$)$, fentanyl $(15,14$ to 15$)$ and ketamine $(15,10$ to 15$)$.

\section{Subgroups}

\section{Age}

We performed a subgroup analysis of RCTs according to age ( $\geq 18$ years, $<18$ years). The comparative difference in dizziness between morphine and ketamine may be associated with age (Appendix Figure F-40). A greater difference in dizziness, favoring opioids, was found in subjects less than 18 years of age compared to 18 years of age and older $[<18$ years: risk difference (RD) -53 percent ( -72 to -33 ); $\geq 18$ years of age RD -15 percent ( -47 to 17 ). However, the $3 \mathrm{RCT}$ in the $<18$ years group are also the same $3 \mathrm{RCT}$ s that represent the IN route subgroup so it is unclear if age, route or both are potential modifiers of effect.

Age $(\geq 18$ years, $<18$ years) did not appear to be associated with differing effects of opioids versus ketamine for the outcome of hypotension (Appendix Figure F-41).

\section{Type of Pain}

We analyzed studies that included traumatic pain only. These results were in agreement with the main conclusions for the outcomes of dizziness, drowsiness, hypotension and respiratory 
depression (Appendix Figures F-42 to F-45). The analysis for any adverse event suggests that in traumatic pain, the difference between opioids and ketamine was greater than in the main analysis, favoring opioids (Main analysis RD -30 percent [-56 to -4$]$, traumatic pain only RD -41 percent [-52 to -30] (Appendix Figure F-46).

\section{Location of Pain}

We performed subgroup analysis by location of pain (extremity versus mixed/not reported). Location did not appear to be associated with differing effects of opioids versus ketamine for the outcome of any adverse event, dizziness, or respiratory depression (Appendix Figures F-47 to F49).

One RCT in the EMS setting reported the level of consciousness in a subset of head trauma patients to be similar before and after analgesia with opioids versus ketamine ( 96.4 percent versus 89.7 percent, $\mathrm{p}=\mathrm{NR}$ ).

\section{Route}

We performed a subgroup analysis of RCTs according to route of administration of opioid versus ketamine (IN versus IN, IV versus IN and IV versus IV). The comparative difference in dizziness between opioids and ketamine may be associated with route (Appendix Figure F-50). The difference in dizziness was more pronounced for the IN route, favoring opioids, (RD -53 percent [-65 to -41$]$ ) compared to the two other route combinations (IV versus IN: RD -9 [-47 to 29] and IV versus IV: RD -3 [-11 to 6]). However, the 3 RCTs in the IN vs IN group are also the same 3 RCTs that represent subjects $<18$ years of age so it is unclear if age, route or both are potential modifiers of effect.

One 3-arm $\mathrm{RCT}^{53}$ was designed to route of morphine administration (IV vs IM) to ketamine IN. Dizziness was more frequent with IN ketamine versus IM morphine (79.2 percent versus 22.2 percent, $\mathrm{p}<0.000)$ but not compared with IV morphine $(79.2$ percent versus 50 percent, $\mathrm{p}=0.092$ ). Confusion was more frequent with IN ketamine versus IV morphine (50 percent versus 12.5 percent, $p=0.027$ ) but not compared with IM morphine (50 percent versus 18.5 percent, $\mathrm{p}=0.061$ ). Difficulty concentrating was more frequent with ketamine IN compared to both IV morphine (58.3 percent versus 20.8 percent, $\mathrm{p}=0.034)$ and IM morphine (58.3 percent versus 22.2 percent, $\mathrm{p}=0.027$ ).

\section{Frequency of Analgesic Administration}

Regardless of whether studies were comparing a single dose of opioids versus a single dose of ketamine or multiple doses of opioids versus multiple doses of ketamine, frequency of dizziness (Appendix Figure F-51) or risk of having an adverse event (Appendix Figure F-52) was similar to the main conclusion.

\section{Additional Findings}

Additional findings for outcomes that are not graded with strength of evidence are in Table 18. Based on indirect data from the ED setting, vital sign changes at 15 minutes suggest statistically significant differences, including a lower heart rate with opioids versus ketamine [mean difference (MD) $-3.08(-5.23$ to -0.92$)$ ], a lower respiratory rate with opioids versus ketamine [MD -1.88 (-2.39 to -1.38)] and a lower systolic blood pressure with opioids versus ketamine [MD -8.26 (-16.22 to -0.31)]. The change in systolic blood pressure in 30 minutes was also significant, with a lower value in opioids versus ketamine [MD -6.26 (-11.28 to -1.23)]. One 
RCT from the EMS setting found a significantly higher number of patients experiencing nausea and/or vomiting with opioids versus ketamine [RD 15 percent (8 to 22)].

Table 18. Findings for the comparison of opioids versus ketamine, Key Question 2

\begin{tabular}{|c|c|c|}
\hline Outcome & $\begin{array}{l}\text { Study Design } \\
\text { and Sample Size }\end{array}$ & $\begin{array}{l}\text { Findings } \\
\text { (Setting: Effect Estimates and } 95 \% \text { Confidence Intervals) }\end{array}$ \\
\hline $\begin{array}{l}\text { Diastolic blood } \\
\text { pressure }-15 \text { min }\end{array}$ & $\begin{array}{l}3 \mathrm{RCT}^{17,57,60} \\
(\mathrm{n}=221)\end{array}$ & ED: Meta-analysis of 3 RCT MD $-4.24(-12.56$ to 4.08$)$ \\
\hline $\begin{array}{l}\text { Diastolic blood } \\
\text { pressure }-30 \text { min }\end{array}$ & $\begin{array}{l}3 \mathrm{RCT}^{17,57,59} \\
(\mathrm{n}=221)\end{array}$ & ED: Meta-analysis of $3 \mathrm{RCT}$ MD -0.30 (-4.76 to 4.16$)$ \\
\hline $\begin{array}{l}\text { Diastolic blood } \\
\text { pressure }-60 \text { min }\end{array}$ & $\begin{array}{l}2 \mathrm{RCT}^{17,58} \\
(\mathrm{n}=131) \\
1 \mathrm{OBS}^{61}(\mathrm{n}=158)\end{array}$ & $\begin{array}{l}\text { EMS: } 1 \mathrm{OBS}^{61} \text { mean (SD): }-2.6(14.7) \text { vs. }-1.6(15.0), \mathrm{p}=0.73 \\
\text { ED: Meta-analysis of } 2 \mathrm{RCT} \\
\end{array}$ \\
\hline Dissociation - 15 min & $1 \mathrm{RCT}^{17}(\mathrm{n}=86)$ & ED: 1 RCT AR 0\% vs. $2.3 \%$; RD -2\% (-12 to 7$)$ \\
\hline $\begin{array}{l}\text { Dissociation - study } \\
\text { duration }\end{array}$ & $\begin{array}{l}3 \mathrm{RCT}^{17,29,58} \\
(\mathrm{n}=213)\end{array}$ & ED: Meta-analysis of 3 RCT AR $0 \%$ vs. $0.9 \%$; RD $-1 \%$ (-4 to 3$)$ \\
\hline Emergence delirium & $\begin{array}{l}4 \mathrm{RCT}^{30,54,58,59} \\
(\mathrm{n}=287)\end{array}$ & ED: Meta-analysis of 4 RCT AR $0 \%$ vs. $8.4 \%$; RD $-7 \%$ (-27 to 12$)$ \\
\hline Heart rate -15 min & $\begin{array}{l}3 \mathrm{RCT}^{17,57,58} \\
(\mathrm{n}=221)\end{array}$ & ED: Meta-analysis of $3 \mathrm{RCT}$ MD $-3.08(-5.23$ to -0.92$)$ \\
\hline Heart rate $-30 \mathrm{~min}$ & $\begin{array}{l}3 \mathrm{RCT}^{17,57,58} \\
(\mathrm{n}=221)\end{array}$ & ED: Meta-analysis of 3 RCT MD 0.65 (-3.80 to 5.10) \\
\hline Heart rate $-60 \mathrm{~min}$ & $\begin{array}{l}2 \mathrm{RCT}^{17,58} \\
(\mathrm{n}=131) \\
1 \mathrm{OBS}^{61}(\mathrm{n}=158)\end{array}$ & $\begin{array}{l}\text { EMS: } 1 \text { OBS mean (SD) }-5.7(16.0) \text { vs. }-3.0(16.0), p=0.26 \\
\text { ED: Meta-analysis of } 2 \text { RCT MD }-0.06(-5.24 \text { to } 5.12)\end{array}$ \\
\hline Nausea - 15 min & $\begin{array}{l}2 \mathrm{RCT}^{55,57} \\
(\mathrm{n}=150)\end{array}$ & ED: Meta-analysis of 2 RCT AR $8 \%$ vs. $16 \%$; RD $-8 \%$ (-18 to 2$)$ \\
\hline Nausea - $30 \mathrm{~min}$ & $\begin{array}{l}2 \mathrm{RCT}^{55,57} \\
(\mathrm{n}=150)\end{array}$ & $\begin{array}{l}\text { ED: Meta-analysis of } 2 \text { RCT AR } 14.7 \% \text { vs. } 10.7 \% \text {; RD } 3 \% \text { (-7 to } \\
\text { 12) }\end{array}$ \\
\hline Nausea $-60 \mathrm{~min}$ & $1 \mathrm{RCT}^{55}(\mathrm{n}=60)$ & ED: 1 RCT AR $6.7 \%$ vs. $20 \%$; RD $-13 \%$ (-31 to 5$)$ \\
\hline Nausea - study period & $\begin{array}{l}5 \mathrm{RCT}^{29,30,54,56,58} \\
(\mathrm{n}=540)\end{array}$ & ED: Meta-analysis of 5 RCT AR $14.1 \%$ vs. $16.2 \%$; RD $-2 \%$ ( -9 to 5$)$ \\
\hline $\begin{array}{l}\text { Nausea and/or } \\
\text { vomiting }\end{array}$ & $\begin{array}{l}3 \mathrm{RCT}^{17,27,60} \\
(\mathrm{n}=527)\end{array}$ & $\begin{array}{l}\text { EMS: } 1 \mathrm{RCT}^{27} \text { AR } 19.4 \% \text { vs. } 4.7 \% \text {; RD } 15 \%(8 \text { to } 22) \\
\text { ED: } 2 \text { RCTs }{ }^{17,60} \text { found no difference; RD } 3(-9 \text { to } 16) \text { and } 4 \text { (-7 to }\end{array}$ \\
\hline $\begin{array}{l}\text { Oxygen saturation - } \\
15 \text { min }\end{array}$ & $\begin{array}{l}3 \mathrm{RCT}^{17,57,58} \\
(\mathrm{n}=221)\end{array}$ & ED: Meta-analysis of $3 \mathrm{RCT}$ MD $-0.19(-0.48$ to 0.11$)$ \\
\hline $\begin{array}{l}\text { Oxygen saturation - } \\
30 \mathrm{~min}\end{array}$ & $\begin{array}{l}3 \mathrm{RCT}^{17,57,58} \\
(\mathrm{n}=221)\end{array}$ & ED: Meta-analysis of 3 RCT MD 0.08 (-0.21 to 0.37$)$ \\
\hline $\begin{array}{l}\text { Oxygen saturation - } \\
60 \text { min }\end{array}$ & $\begin{array}{l}2 \mathrm{RCT}^{17,58} \\
(\mathrm{n}=131)\end{array}$ & ED: Meta-analysis of 2 RCT MD 0.18 (-0.16 to 0.52$)$ \\
\hline $\begin{array}{l}\text { Respiratory rate }-15 \\
\min \end{array}$ & $\begin{array}{l}3 \mathrm{RCT}^{17,57,58} \\
(\mathrm{n}=221)\end{array}$ & ED: Meta-analysis of $3 \mathrm{RCT}$ MD $-1.88(-2.39$ to -1.38$)$ \\
\hline $\begin{array}{l}\text { Respiratory rate }-30 \\
\text { min }\end{array}$ & $\begin{array}{l}3 \mathrm{RCT}^{17,57,58} \\
(\mathrm{n}=221)\end{array}$ & ED: Meta-analysis of $3 \mathrm{RCT}$ MD $-1.52(-4.13$ to 1.08$)$ \\
\hline $\begin{array}{l}\text { Respiratory rate }-60 \\
\min \end{array}$ & $\begin{array}{l}2 \mathrm{RCT}^{17,58} \\
(\mathrm{n}=131) \\
1 \mathrm{OBS}^{61}(\mathrm{n}=158)\end{array}$ & $\begin{array}{l}\text { EMS: } 1 \text { OBS }{ }^{61} \text { mean (SD) }-0.9(2.8) \text { vs. }-1.8(4.3), p=0.13 \\
\text { ED: Meta-analysis of } 2 \mathrm{RCT}^{17,58} \mathrm{MD}-1.97(-4.21 \text { to } 0.27)\end{array}$ \\
\hline $\begin{array}{l}\text { Systolic blood } \\
\text { pressure }-15 \text { min }\end{array}$ & $\begin{array}{l}3 \mathrm{RCT}^{17,57,58} \\
(\mathrm{n}=221)\end{array}$ & ED: Meta-analysis of 3 RCT MD -8.26 (-16.22 to -0.31$)$ \\
\hline $\begin{array}{l}\text { Systolic blood } \\
\text { pressure }-30 \text { min }\end{array}$ & $\begin{array}{l}3 \mathrm{RCT}^{17,57,58} \\
(\mathrm{n}=221)\end{array}$ & ED: Meta-analysis of 3 RCT MD $-6.26(-11.28$ to -1.23$)$ \\
\hline $\begin{array}{l}\text { Systolic blood } \\
\text { pressure }-60 \text { min }\end{array}$ & $\begin{array}{l}2 \mathrm{RCT}^{17,58} \\
(\mathrm{n}=131) \\
1 \mathrm{OBS}^{61}(\mathrm{n}=158)\end{array}$ & $\begin{array}{l}\text { EMS: } 1 \mathrm{OBS}^{61} \text { mean (SD) }-3.6(23.1) \text { vs. }-4.2(22.7), \mathrm{p}=0.87 \\
\text { ED: Meta-analysis of } 2 \mathrm{RCT}^{17,58} \mathrm{MD}-1.76(-8.58 \text { to } 5.05)\end{array}$ \\
\hline
\end{tabular}

Abbreviations: $\mathrm{AR}=$ absolute risk; $\mathrm{ED}=$ emergency department; $\mathrm{EMS}=$ emergency medical services; $\mathrm{MD}=$ mean difference; $\mathrm{RCT}=$ randomized controlled trial; $\mathrm{RD}=$ risk difference 
Two studies from the battlefield setting reported additional outcomes. ${ }^{62,63}$ Schauer et al. ${ }^{62}$ reported values at the point of admission comparing morphine, fentanyl and ketamine [median (IQR)]: systolic blood pressure [130 (106 to 144), 131 (114 to 143), 120 (91 to 140)], heart rate [93 (76 to 120$), 90$ (72 to 108$), 108$ (85 to 131$)$ ], respiratory rate [18 (16 to 22$), 18$ (14 to 22$), 20$ (16 to 25)], and oxygen saturation [99 (96 to 100), 97 (94 to 99), 99 (95 to 100)]. Shackelford et al. ${ }^{63}$ reported change in vital signs during tactical evacuation for morphine, fentanyl and ketamine treated subjects [mean change (SD)]: systolic blood pressure [-3 (13) versus 0 (14) versus $7(17)$ ], heart rate [-3 (23) versus $-3(14)$ versus $-5(20)]$, respiratory rate [-1 (2) versus -1 (2) versus -1 (4)], and oxygen saturation [4 (2) versus 1 (2) versus 2 (4)].

\section{Combination of Opioids and Ketamine Versus Opioids}

\section{Key Messages}

- Evidence is insufficient for the comparison of combination opioids and ketamine versus opioids alone, for the outcomes of any adverse event, hypotension, mental status changes and respiratory depression.

- Results from outcomes that were not graded for SOE suggest combination opioid and ketamine therapy leads to a statistically higher value for oxygen saturation and respiratory rate in 30 minutes and statistically less vomiting, compared to opioids alone, but clinical relevance is uncertain. Analgesics were administered primarily IV.

\section{Detailed Results}

We present the conclusions for the comparative harms of combination opioids and ketamine versus opioids as initial analgesics in Table 19. This evidence base includes data from both EMS and ED settings mostly comparing weight-based doses of morphine IV with ketamine IV. Evidence was insufficient for the outcomes of any adverse events, hypotension, mental status changes and respiratory depression. For some of these outcomes single studies didn't allow judging consistency and additional domains had limitations that led to downgrading. In other cases estimates are very imprecise where the confidence interval included the possibility of a clinically important difference in favor of either analgesic.

One observational study ${ }^{62}$ from the battlefield setting was not considered in the conclusion of mental status changes because the population and setting was too unlike civilians expected to access EMS. This study reported GCS scores (median, IQR) at the point of hospital admission for opioids plus ketamine (13, 8 to 14$)$, morphine (15, 15 to 15) and fentanyl $(15,14$ to 15$)$.

Table 19. Conclusions and strength of evidence for the comparison of combination opioids and ketamine versus opioids, Key Question 2

\begin{tabular}{|c|c|c|c|}
\hline Outcome & $\begin{array}{l}\text { Study } \\
\text { Design and } \\
\text { Sample Size }\end{array}$ & $\begin{array}{l}\text { Conclusions } \\
\text { (Setting: Supporting Effect Estimates and } 95 \% \\
\text { Confidence Intervals) }\end{array}$ & $\begin{array}{l}\text { Strength of } \\
\text { Evidence } \\
\text { (Limitations) }\end{array}$ \\
\hline $\begin{array}{l}\text { Any adverse } \\
\text { event }\end{array}$ & $\begin{array}{l}1 \mathrm{RCT}^{72} \\
(\mathrm{n}=80)\end{array}$ & $\begin{array}{l}\text { Inconclusive. } \\
\text { ED: } 1 \text { RCT found adverse events to occur in } 22.5 \% \text { vs. } \\
17.5 \% \text { of patients, RD } 5 \% \text { (-13 to } 22)\end{array}$ & $\begin{array}{l}\text { Insufficient } \\
\text { (Unknown } \\
\text { consistency, indirect, } \\
\text { very imprecise) }\end{array}$ \\
\hline Hypotension & $\begin{array}{l}\text { 1 RCT }^{71} \\
(n=106)\end{array}$ & $\begin{array}{l}\text { Inconclusive. } \\
\text { ED: } 1 \text { RCT found hypotension to occur in } 0 \% \text { vs. } 3 \% \text { of } \\
\text { patients, RD }-6 \% \text { ( }-16 \text { to } 3)\end{array}$ & $\begin{array}{l}\text { Insufficient } \\
\text { (Unknown } \\
\text { consistency, indirect, } \\
\text { imprecise) }\end{array}$ \\
\hline
\end{tabular}




\begin{tabular}{|c|c|c|c|}
\hline Outcome & $\begin{array}{l}\text { Study } \\
\text { Design and } \\
\text { Sample Size }\end{array}$ & $\begin{array}{l}\text { Conclusions } \\
\text { (Setting: Supporting Effect Estimates and } 95 \% \\
\text { Confidence Intervals) }\end{array}$ & $\begin{array}{l}\text { Strength of } \\
\text { Evidence } \\
\text { (Limitations) }\end{array}$ \\
\hline $\begin{array}{l}\text { Mental status } \\
\text { changes - } \\
\text { dizziness }\end{array}$ & $\begin{array}{l}2 \text { RCTs }^{66,68} \\
(n=265)\end{array}$ & $\begin{array}{l}\text { Inconclusive. } \\
\text { EMS: } 1 \mathrm{RCT}^{66} \text { found dizziness in } 18.2 \% \text { vs. } 0 \% \text { of } \\
\text { patients } 30 \text { min after the dose, RD } 18 \% \text { ( } 3 \text { to } 34) \text {. } \\
\text { ED: } 1 \text { RCT } 68 \text { found dizziness in } 22 \% \text { vs. } 11 \% \text { at } 20 \text { mins } \\
\text { [RD } 11 \%(1 \text { to } 21)] \text { and } 42 \% \text { vs. } 45 \% \text { at } 40 \text { min [RD }-3 \% \\
(-16 \text { to } 11) \text {. }\end{array}$ & $\begin{array}{l}\text { Insufficient } \\
\text { (Inconsistent, indirect, } \\
\text { imprecise) }\end{array}$ \\
\hline $\begin{array}{l}\text { Mental status } \\
\text { changes - } \\
\text { sedation }\end{array}$ & $\begin{array}{l}1 \mathrm{RCT}^{66} \\
(\mathrm{n}=65)\end{array}$ & $\begin{array}{l}\text { Inconclusive. } \\
\text { EMS: } 1 \text { RCT found sedation in } 21.2 \% \text { vs. } 6.3 \% \text { of } \\
\text { patients } 30 \text { min after the dose. RD } 15 \%(-2 \text { to } 32)\end{array}$ & $\begin{array}{l}\text { Insufficient } \\
\text { (Unknown } \\
\text { consistency, } \\
\text { imprecise) }\end{array}$ \\
\hline $\begin{array}{l}\text { Respiratory } \\
\text { depression }\end{array}$ & $\begin{array}{l}3 \mathrm{RCTS}^{66,69,71} \\
(\mathrm{n}=231)\end{array}$ & $\begin{array}{l}\text { Inconclusive. } \\
\text { EMS: } 1 \text { RCT }{ }^{66} \text { found respiratory depression to occur in } \\
0 \% \text { vs. } 3.1 \% \text { of patients, RD }-3 \%(-16 \text { to } 9) \\
\text { ED: Meta-analysis of } 2 \text { RCTs }{ }^{69,71} \text { found AR } 1.2 \% \text { vs. } \\
6.0 \%, \text { RD }-3 \%(-10 \text { to } 4)\end{array}$ & $\begin{array}{l}\text { Insufficient } \\
\text { (Indirect, very } \\
\text { imprecise) }\end{array}$ \\
\hline
\end{tabular}

Abbreviations: $\mathrm{AR}=$ absolute risk; $\mathrm{EMS}=$ emergency medical services; min=minutes; $\mathrm{OBS}=$ observational; $\mathrm{RCT}=$ randomized controlled trial; $\mathrm{RD}=$ risk difference; $\mathrm{vs}=$ versus

\section{Subgroups}

\section{Analgesic Dose}

One $\mathrm{RCT}^{70}$ included 3 arms to compare two different doses of ketamine $(0.15 \mathrm{mg} / \mathrm{kg}$ or $0.3 \mathrm{mg} / \mathrm{kg})$ when added to morphine $(0.1 \mathrm{mg} / \mathrm{kg})$, versus morphine $0.1 \mathrm{mg} / \mathrm{kg}$ alone. Dizziness was more common with ketamine $0.3 \mathrm{mg} / \mathrm{kg}$ ( 45 percent versus 0 percent, $\mathrm{p}<0.01$ ). Nausea occurred in 15 percent of both ketamine groups, and 2 subjects vomited in the ketamine $0.3 \mathrm{mg} / \mathrm{kg}$ group while none vomited in the $0.15 \mathrm{mg} / \mathrm{kg}$ group.

\section{Additional Findings}

Additional findings for outcomes that are not graded with strength of evidence are in Table 20. One RCT from the EMS setting found a statistically significant difference in the change of oxygen saturation in 30 minutes, suggesting a higher oxygen saturation with combination therapy versus opioids alone [MD 1 (0.2 to 1.8)]. Indirect evidence from RCTs in the ED setting found statistically significant difference in the change in respiratory rate in 30 minutes, suggesting a higher value with combination therapy versus opioids alone [MD $0.6(0.3$ to 0.9$)$ ]. Combination therapy was also found to have significantly less vomiting at 30 minutes compared with opioids alone [RD -10 percent $(-18$ to -2$)]$. No other findings were significant.

Table 20. Findings for the comparison of combination opioids and ketamine versus opioids, Key Question 2

\begin{tabular}{|c|c|c|}
\hline Outcome & $\begin{array}{l}\text { Study Design } \\
\text { and Sample Size }\end{array}$ & $\begin{array}{l}\text { Findings } \\
\text { (Setting: Effect Estimates and } 95 \% \text { Confidence Intervals) }\end{array}$ \\
\hline $\begin{array}{l}\text { Diastolic blood } \\
\text { pressure }-30 \text { min }\end{array}$ & $1 \mathrm{RCT}^{68}(\mathrm{n}=200)$ & ED: 1 RCT MD $1.2(-0.6$ to 3$)$ \\
\hline $\begin{array}{l}\text { Diastolic blood } \\
\text { pressure }-60 \mathrm{~min}\end{array}$ & $1 \mathrm{RCT}^{68}(\mathrm{n}=200)$ & ED: 1 RCT MD -1 (-4.6 to 2.5$)$ \\
\hline Dissociation & $1^{\text {RCT69 }}(n=60)$ & ED: No events occurred \\
\hline Emergence delirium & $1 \mathrm{RCT}^{69}(\mathrm{n}=60)$ & $\overline{\mathrm{ED}}$ : No events occurred \\
\hline Heart rate $-15 \mathrm{~min}$ & $1 \mathrm{RCT}^{72}(\mathrm{n}=80)$ & ED: 1 RCT MD 3.07 (-3.82 to 9.96$)$ \\
\hline Heart rate -30 min & $\begin{array}{l}2 \mathrm{RCT}^{67,72} \\
(\mathrm{n}=145)\end{array}$ & $\begin{array}{l}\text { EMS: } 1 R^{2} T^{67} \mathrm{MD}-2(-9.74 \text { to } 5.74) \\
\text { ED: } 1 \text { RCT }{ }^{72} \text { MD } 4.88(-2.01 \text { to } 11.77)\end{array}$ \\
\hline Heart rate $-60 \mathrm{~min}$ & $1 \mathrm{RCT}^{72}(\mathrm{n}=80)$ & $\overline{E M S}: 1 \mathrm{RCT}$ MD $4.82(-2.17$ to 11.81$)$ \\
\hline Nausea $-30 \mathrm{~min}$ & $1 \mathrm{RCT}^{68}(\mathrm{n}=200)$ & ED: 1 RCT AR $30 \%$ versus $34 \%$; RD $-4 \%$ (-17 to 9$)$ \\
\hline
\end{tabular}




\begin{tabular}{|c|c|c|}
\hline Outcome & $\begin{array}{l}\text { Study Design } \\
\text { and Sample Size }\end{array}$ & $\begin{array}{l}\text { Findings } \\
\text { (Setting: Effect Estimates and } 95 \% \text { Confidence Intervals) }\end{array}$ \\
\hline Nausea $-60 \mathrm{~min}$ & $1 \mathrm{RCT}^{68}(\mathrm{n}=200)$ & ED: 1 RCT AR $43 \%$ vs. $45 \%$; RD $-2 \%$ (-15 to 12$)$ \\
\hline Nausea - study period & $1 \operatorname{RCT}^{69}(\mathrm{n}=60)$ & ED: 1 RCT AR $10 \%$ vs. $3.3 \%$; RD $7 \%$ (-8 to 23$)$ \\
\hline $\begin{array}{l}\text { Nausea and/or } \\
\text { vomiting }-30 \mathrm{~min}\end{array}$ & $1 \mathrm{RCT}^{66}(\mathrm{n}=65)$ & EMS: 1 RCT AR $24.2 \%$ vs. $12.5 \%$; RD $12 \%$ (-8 to 30$)$ \\
\hline $\begin{array}{l}\text { Nausea and/or } \\
\text { vomiting - study } \\
\text { period }\end{array}$ & $1 \mathrm{RCT}^{71}(\mathrm{n}=106)$ & ED: 1 RCT AR $7.5 \%$ vs. $13.2 \%$; RD $-6 \%$ (-18 to 7 ) \\
\hline $\begin{array}{l}\text { Oxygen saturation - } \\
15 \mathrm{~min}\end{array}$ & $1 \mathrm{RCT}^{72}(\mathrm{n}=80)$ & ED: 1 RCT 0.7 (-8.1 to 9.5) \\
\hline $\begin{array}{l}\text { Oxygen saturation - } \\
30 \text { min }\end{array}$ & $\begin{array}{l}2 \mathrm{RCT}^{66,72} \\
(\mathrm{n}=145)\end{array}$ & $\begin{array}{l}\text { EMS: } 1 \mathrm{RCT}^{66} \mathrm{MD} 1(0.2 \text { to } 1.8) \\
\left.\text { ED: } 1 \mathrm{RCT}{ }^{72} \mathrm{MD} 0.8 \text { (-8 to } 9.6\right)\end{array}$ \\
\hline $\begin{array}{l}\text { Oxygen saturation - } \\
60 \mathrm{~min}\end{array}$ & $1 \mathrm{RCT}^{72}(\mathrm{n}=80)$ & ED: 1 RCT MD 0.8 (-8 to 9.6) \\
\hline $\begin{array}{l}\text { Respiratory rate }-30 \\
\min \end{array}$ & $1 \operatorname{RCT}^{68}(\mathrm{n}=200)$ & ED: 1 RCT MD 0.6 (0.3 to 0.9$)$ \\
\hline $\begin{array}{l}\text { Respiratory rate }-60 \\
\text { min }\end{array}$ & $1 \mathrm{RCT}^{68}(\mathrm{n}=200)$ & ED: 1 RCT MD 0.4 (-0.03 to 0.8$)$ \\
\hline $\begin{array}{l}\text { Systolic blood } \\
\text { pressure }-15 \text { min }\end{array}$ & $1 \mathrm{RCT}^{72}(\mathrm{n}=80)$ & ED: 1 RCT MD 0 (-8.5 to 8.5$)$ \\
\hline $\begin{array}{l}\text { Systolic blood } \\
\text { pressure }-30 \mathrm{~min}\end{array}$ & $\begin{array}{l}3 \mathrm{RCT}^{66,68,72} \\
(\mathrm{n}=345)\end{array}$ & $\begin{array}{l}\text { EMS: } 1 \mathrm{RCT}^{66} \mathrm{MD} 3(-6.7 \text { to } 12.7) \\
\left.\text { ED: Meta-analysis of } 2 \mathrm{RCT}^{68,72} \mathrm{MD} 1.35 \text { (-2.02 to } 4.72\right)\end{array}$ \\
\hline $\begin{array}{l}\text { Systolic blood } \\
\text { pressure }-60 \mathrm{~min}\end{array}$ & $\begin{array}{l}2 \mathrm{RCT}^{68,72} \\
(\mathrm{n}=280)\end{array}$ & ED: Meta-analysis of 2 RCT MD 4.35 (-3.51 to 12.21) \\
\hline Vomiting $-30 \mathrm{~min}$ & $1 \mathrm{RCT}^{68}(\mathrm{n}=200)$ & ED: 1 RCT AR 3\% vs. $13 \%$; RD $-10 \%$ (-18 to -2$)$ \\
\hline Vomiting $-60 \mathrm{~min}$ & $1 \mathrm{RCT}^{68}(\mathrm{n}=200)$ & ED: 1 RCT AR $32 \%$ vs. $38 \%$; RD $-6 \%$ (-19 to 7$)$ \\
\hline $\begin{array}{l}\text { Vomiting - study } \\
\text { period }\end{array}$ & $1 \mathrm{RCT}^{72}(\mathrm{n}=80)$ & ED: 1 RCT AR $12.5 \%$ vs. $10 \%$; RD $3 \%$ (-12 to 17$)$ \\
\hline
\end{tabular}

One study from the battlefield setting reported additional outcomes. ${ }^{62}$ Schauer et al. reported values at the point of admission comparing opioid plus ketamine, morphine and fentanyl [median (IQR)]: systolic blood pressure [121 (103 to 153), 130 (106 to 144), 131 (114 to 143)], heart rate [107 (88 to 131), 93 (76 to 120), 90 (72 to 108)], respiratory rate [18 (16 to 24), 18 (16 to 22), 18 (14 to 22)] and oxygen saturation [97 (89 to 100), 99 (96 to 100), 97 (94 to 99)].

\section{Opioids Versus Acetaminophen}

\section{Key Messages}

- Opioids cause more dizziness than APAP (moderate SOE) and may cause more adverse events than APAP (low SOE).

- There is no evidence of a clinically important difference in hypotension with opioids compared with APAP (low SOE).

- Evidence was insufficient for outcomes of mild sedation and respiratory depression.

- These conclusions are based on indirect evidence from the ED and comparing IV morphine with IV APAP.

\section{Detailed Results}

We present the conclusions for the comparative harms of opioids versus APAP as initial analgesics in Table 21. This evidence base is entirely indirect from the ED setting and compares IV morphine to IV APAP. 
Table 21. Conclusions and strength of evidence for the comparison of opioids versus acetaminophen, Key Question 2

\begin{tabular}{|c|c|c|c|}
\hline Outcome & $\begin{array}{l}\text { Study Design and } \\
\text { Sample Size }\end{array}$ & $\begin{array}{l}\text { Conclusions } \\
\text { (Setting: Supporting Effect Estimates and 95\% } \\
\text { Confidence Intervals) }\end{array}$ & $\begin{array}{l}\text { Strength of } \\
\text { Evidence } \\
\text { (Limitations) }\end{array}$ \\
\hline $\begin{array}{l}\text { Any adverse } \\
\text { event }\end{array}$ & $\begin{array}{l}6 \text { RCTs } 73,75,77-79,82 \\
(n=1,484)\end{array}$ & $\begin{array}{l}\text { Opioids may cause more adverse events than } \\
\text { APAP. } \\
\text { ED: Meta-analysis of } 5 \text { RCTs } 73,77-79,82 \text { over the } \\
\text { study period found AR } 35.4 \% \text { vs. } 5.6 \% \text {, RD } 30 \% \text { (- } \\
1 \text { to } 62 \text { ). } 1 \text { RCT } 75 \text { reporting total AEs "during acute" } \\
\text { management found } 3.5 \% \text { vs. } 1.3 \% \text {, RD } 2 \% \text { (0.4 to } \\
\text { 4). }\end{array}$ & $\begin{array}{l}\text { Low } \\
\text { (Inconsistent, } \\
\text { indirect, imprecise) }\end{array}$ \\
\hline Hypotension & $\begin{array}{l}5 \mathrm{RCTs}^{73,76-78,80} \\
(\mathrm{n}=624)\end{array}$ & $\begin{array}{l}\text { There is no evidence of a clinically important } \\
\text { difference in hypotension with opioids } \\
\text { compared to APAP. } \\
\text { ED: Meta-analysis of } 5 \text { RCTs found AR } 2.6 \% \text { vs. } \\
0 \% \text {, RD } 2 \%(0.00 \text { to } 4 \%) \text {. }\end{array}$ & $\begin{array}{l}\text { Low } \\
\text { (Indirect, } \\
\text { imprecise) }\end{array}$ \\
\hline $\begin{array}{l}\text { Mental status } \\
\text { changes - } \\
\text { dizziness }\end{array}$ & $\begin{array}{l}6 \\
\text { RCTs }{ }^{73,74,77,78,80,81} \\
(\mathrm{n}=539)\end{array}$ & $\begin{array}{l}\text { Opioids cause more dizziness than APAP. } \\
\text { ED: Meta-analysis of } 6 \text { RCTs found, AR } 7.8 \% \text { vs. } \\
0.3 \%, R D 7 \% \text { ( } 5 \text { to } 9 \text { ) }\end{array}$ & $\begin{array}{l}\text { Moderate } \\
\text { (Indirect) }\end{array}$ \\
\hline $\begin{array}{l}\text { Mental status } \\
\text { changes - } \\
\text { "mild" } \\
\text { sedation }\end{array}$ & $\begin{array}{l}1 \mathrm{RCT}^{77} \\
(\mathrm{n}=91)\end{array}$ & $\begin{array}{l}\text { Inconclusive. } \\
\text { ED: } 1 \text { RCT found mild sedation in } 2.2 \% \text { vs. } 0 \% \text { of } \\
\text { patients, RD } 2 \% \text { (-7 to } 12) \text {. }\end{array}$ & $\begin{array}{l}\text { Insufficient } \\
\text { (Unknown } \\
\text { consistency, } \\
\text { indirect, very } \\
\text { imprecise) }\end{array}$ \\
\hline $\begin{array}{l}\text { Respiratory } \\
\text { depression }\end{array}$ & $\begin{array}{l}1 \mathrm{RCT}^{78} \\
(\mathrm{n}=73)\end{array}$ & $\begin{array}{l}\text { Inconclusive. } \\
\text { ED: No events occurred in the } 1 \mathrm{RCT} \text {. }\end{array}$ & $\begin{array}{l}\text { Insufficient } \\
\text { (Unknown } \\
\text { consistency, } \\
\text { indirect) }\end{array}$ \\
\hline
\end{tabular}

Abbreviations: $\mathrm{APAP}=$ acetaminophen; $\mathrm{AR}=$ absolute risk; $\mathrm{ED}=$ emergency department; $\mathrm{RCT}=$ randomized controlled trial; $\mathrm{RD}=$ risk difference

Opioids may cause more adverse events than APAP (low SOE). This conclusion is based on meta-analysis of indirect data from the ED setting and the clinically important difference of 10 percent. Results did not rule out the possibility of a clinically important difference in favor of APAP. One RCT was not pooled with the others because it reported adverse events over an "acute" period of the study rather than the full study period but was in agreement with direction of effect from the pooled estimate.

There was no evidence of a clinically important difference in hypotension with opioids compared to APAP (low SOE). No subjects had hypotension in the APAP group and 8 (2.6 percent) had hypotension in the opioid group. Result from meta-analysis ruled out a clinically important difference of 5 percent in favor of either analgesic. However we considered the result imprecise because the confidence interval was shifted towards an increased risk with opioids.

Opioids cause more dizziness than APAP (moderate SOE). This conclusion is based on the meta-analysis of indirect data from the ED setting and a clinically important difference of 5 percent.

Evidence was insufficient for the outcomes of "mild" sedation and respiratory depression.

\section{Subgroups}

\section{Location of Pain}

We performed subgroup analysis by location of pain. Location (renal colic versus other/not reported) did not appear to be associated with differing effects of opioids versus APAP for the outcome of any adverse event (Appendix Figure F-79) or hypotension (Appendix Figure F-80). 
Location (extremity, renal colic, other/not reported) did not appear to be associated with differing effects of opioids versus APAP for the outcome of dizziness (Appendix Figure F-81).

\section{Type of Pain}

We analyzed studies that included traumatic pain only. These results did not suggest appreciable differences in effects for the outcomes of any adverse events and dizziness (Appendix Figures F-82 and F-83).

\section{Additional Findings}

Additional findings for outcomes that are not graded with strength of evidence are in Table

22. None of the results were statistically significant.

Table 22. Findings for the comparison of opioids versus acetaminophen, Key Question 2

\begin{tabular}{lll}
\hline Outcome & $\begin{array}{l}\text { Study Design and } \\
\text { Sample Size }\end{array}$ & $\begin{array}{l}\text { Findings } \\
\text { (Setting: Effect Estimates and 95\% Confidence Intervals) }\end{array}$ \\
\hline Nausea & $\begin{array}{l}\text { 4 RCT } \\
(\mathrm{n}=423,76,81,82\end{array}$ & ED: Meta-analysis of 4 RCT AR 10.4\% vs. 0.9\%; RD 12\% (-10 to 34) \\
\hline $\begin{array}{l}\text { Nausea and/or } \\
\text { vomiting }\end{array}$ & $2 \mathrm{RCT}^{77,78}(\mathrm{n}=164)$ & ED: Meta-analysis of 2 RCT AR 2.5\% vs. 4.8\%; RD -2\% (-8 to 3) \\
\hline Vomiting & $3 \mathrm{RCT}^{73,80,82}(\mathrm{n}=368)$ & ED: Meta-analysis of 3 RCT AR 7.1\% vs. 0.5\%; RD 9\% (-3 to 20) \\
\hline
\end{tabular}

Abbreviations: $\mathrm{AR}=$ absolute risk; $\mathrm{ED}=$ emergency department; $\mathrm{MD}=$ mean difference; $\mathrm{RCT}=$ randomized controlled trial; $\mathrm{RD}=$ risk difference

\section{Opioids Versus Nitrous Oxide}

\section{Key Message}

- Evidence is insufficient for the comparison of IV opioids versus inhaled nitrous oxide, for outcomes of any adverse event and dizziness. No studies reported hypotension or respiratory depression.

\section{Detailed Results}

We present the conclusions of the comparative harms of opioids versus nitrous oxide in Table 23. This evidence base included a single trial from the EMS setting comparing morphine IV with self-administered nitrous oxide/oxygen (50:50). ${ }^{83}$ This study had a medium risk of bias as it was opEn-label and we were unable to determine consistency without another study. Thus, evidence is insufficient to make conclusions regarding this comparison. No studies reported hypotension or respiratory depression (insufficient SOE).

Table 23. Conclusions and strength of evidence for the comparison of opioids versus nitrous oxide, Key Question 2

\begin{tabular}{llll}
\hline Outcome & $\begin{array}{l}\text { Study } \\
\text { Design and } \\
\text { Sample Size }\end{array}$ & $\begin{array}{l}\text { Conclusions } \\
\text { (Setting: Supporting Effect Estimates and } \\
\mathbf{9 5 \%} \text { Confidence Intervals) }\end{array}$ & $\begin{array}{l}\text { Strength of Evidence } \\
\text { (Limitations) }\end{array}$ \\
\hline Any adverse event & $\begin{array}{l}1 \mathrm{RCT}{ }^{83} \\
(\mathrm{n}=100)\end{array}$ & $\begin{array}{l}\text { Inconclusive. } \\
\text { EMS: 1 RCT found adverse events in 20\% vs. }\end{array}$ & $\begin{array}{l}\text { Insufficient } \\
\text { (Medium study limitations, } \\
\text { unknown consistency, } \\
\text { very imprecise) }\end{array}$ \\
\hline $\begin{array}{l}\text { Mental status } \\
\text { changes - dizziness }\end{array}$ & $\begin{array}{l}1 \mathrm{RCT} \text { of patients, RD } 6 \%(-9 \text { to 21) } \\
(\mathrm{n}=100)\end{array}$ & $\begin{array}{l}\text { Inconclusive. } \\
\text { EMS: 1 RCT found dizziness in 8\% vs. 4\% of }\end{array}$ & $\begin{array}{l}\text { Insufficient } \\
\text { (Medium study limitations, } \\
\text { unknown consistency, } \\
\text { very imprecise) }\end{array}$ \\
\hline
\end{tabular}

Abbreviations: EMS=emergency medical services; $\mathrm{RCT}=$ randomized controlled trial; $\mathrm{RD}=$ risk difference 


\section{Additional Findings}

Additional findings for outcomes that are not graded with strength of evidence are in Table 24. Subjects treated with opioids had a significantly higher heart rate compared to nitrous oxide. No other findings were significant.

Table 24. Findings for the comparison of opioids versus nitrous oxide, Key Question 2

\begin{tabular}{|c|c|c|}
\hline Outcome & $\begin{array}{l}\text { Study Design and } \\
\text { Sample Size }\end{array}$ & $\begin{array}{l}\text { Findings } \\
\text { (Setting: Effect Estimates and } 95 \% \text { Confidence Intervals) }\end{array}$ \\
\hline Diastolic blood pressure & $1 \mathrm{RCT}^{83}(\mathrm{n}=100)$ & ED: 1 RCT MD 1 (-1.7 to 3.7$)$ \\
\hline Heart rate & $1 \mathrm{RCT}^{83}(\mathrm{n}=100)$ & $\overline{\text { ED: }} 1$ RCT MD 4 (0.29 to 7.71) \\
\hline Oxygen saturation & $1 \mathrm{RCT}^{83}(\mathrm{n}=100)$ & ED: 1 RCT MD 0 (-0.9 to 0.9) \\
\hline Respiratory rate & $1 \mathrm{RCT}^{83}(\mathrm{n}=100)$ & ED: 1 RCT MD 0 (-0.5 to 0.5$)$ \\
\hline Systolic blood pressure & $1 \mathrm{RCT}^{83}(\mathrm{n}=100)$ & ED: 1 RCT MD 0 (-5.7 to 5.7) \\
\hline
\end{tabular}

\section{Opioids Versus Nonsteroidal Anti-Inflammatory Drugs}

\section{Key Messages}

- Opioids may cause more adverse events and more drowsiness than NSAIDs (low SOE), administered IV and orally.

- Evidence was insufficient for the outcomes of hypotension, dizziness and depression. No studies reported respiratory depression.

- Results from outcomes that were not graded for SOE suggest opioids lead to statistically higher risk of nausea compared with NSAIDs, administered IV and orally.

\section{Detailed Results}

We present the conclusions for the comparative harms of opioids versus NSAIDs as initial analgesics in Table 25. This evidence base was entirely indirect evidence from the ED setting. Morphine IV was compared with ketorolac IV in two studies and oral morphine was compared to oral ibuprofen in one study.

Table 25. Conclusions and strength of evidence for the comparison of opioids versus nonsteroidal anti-inflammatory drugs, Key Question 2

\begin{tabular}{|c|c|c|c|}
\hline Outcome & $\begin{array}{l}\text { Study } \\
\text { Design and } \\
\text { Sample Size }\end{array}$ & $\begin{array}{l}\text { Conclusions } \\
\text { (Setting: Supporting Effect Estimates and } 95 \% \\
\text { Confidence Intervals) }\end{array}$ & $\begin{array}{l}\text { Strength of } \\
\text { Evidence } \\
\text { (Limitations) }\end{array}$ \\
\hline $\begin{array}{l}\text { Any adverse } \\
\text { event }\end{array}$ & $\begin{array}{l}2 \mathrm{RCT}^{84,86} \\
(\mathrm{n}=367)\end{array}$ & $\begin{array}{l}\text { Opioids may cause more adverse events than } \\
\text { NSAIDs } \\
\text { ED: Meta-analysis of } 2 \text { RCTs found AR } 24.6 \% \text { vs. } 7.4 \% \text {, } \\
\text { RD } 21 \% \text { ( } 4 \text { to } 38 \text { ) }\end{array}$ & $\begin{array}{l}\text { Low } \\
\text { (Inconsistent, indirect, } \\
\text { imprecise) }\end{array}$ \\
\hline Hypotension & $\begin{array}{l}1 \mathrm{RCT}^{84} \\
(\mathrm{n}=88)\end{array}$ & $\begin{array}{l}\text { Inconclusive. } \\
\text { ED: } 1 \text { RCT found hypotension in } 6.8 \% \text { vs. } 0 \% \text { of } \\
\text { patients. RD } 7 \%(-3 \text { to } 18)\end{array}$ & $\begin{array}{l}\text { Insufficient } \\
\text { (Unknown } \\
\text { consistency, indirect, } \\
\text { imprecise) } \\
\end{array}$ \\
\hline $\begin{array}{l}\text { Mental status } \\
\text { changes - } \\
\text { drowsiness }\end{array}$ & $\begin{array}{l}2 \mathrm{RCT}^{84,86} \\
(\mathrm{n}=367)\end{array}$ & $\begin{array}{l}\text { Opioids may cause more drowsiness than NSAIDs } \\
\text { ED: Meta-analysis of } 2 \text { RCTs found AR } 3.9 \% \text { vs. } 0.7 \% \text {, } \\
\text { RD } 3 \%(0 \text { to } 6 \%)\end{array}$ & $\begin{array}{l}\text { Low } \\
\text { (indirect, imprecise) }\end{array}$ \\
\hline $\begin{array}{l}\text { Mental status } \\
\text { changes - } \\
\text { dizziness }\end{array}$ & $\begin{array}{l}1 \mathrm{RCT}^{85} \\
(\mathrm{n}=86)\end{array}$ & $\begin{array}{l}\text { Inconclusive. } \\
\text { ED: } 1 \text { RCT found dizziness in } 9.3 \% \text { vs. } 0 \% \text { of patients, } \\
\text { RD } 9 \%(-2 \text { to } 22)\end{array}$ & $\begin{array}{l}\text { Insufficient } \\
\text { (Unknown } \\
\text { consistency, indirect, } \\
\text { imprecise) }\end{array}$ \\
\hline
\end{tabular}




\begin{tabular}{llll}
\hline Outcome & $\begin{array}{l}\text { Study } \\
\text { Design and } \\
\text { Sample Size }\end{array}$ & $\begin{array}{l}\text { Conclusions } \\
\text { (Setting: Supporting Effect Estimates and 95\% } \\
\text { Confidence Intervals) }\end{array}$ & $\begin{array}{l}\text { Strength of } \\
\text { Evidence } \\
\text { (Limitations) }\end{array}$ \\
\hline $\begin{array}{l}\text { Mental status } \\
\text { changes }-\end{array}$ & $\begin{array}{l}\text { 1 RCT } \\
\text { (n=84) }\end{array}$ & $\begin{array}{l}\text { Inconclusive. } \\
\text { ED: 1 RCT found depression in 4.5\% vs. 0\% of patients, }\end{array}$ & $\begin{array}{l}\text { Insufficient } \\
\text { (Unknown } \\
\text { consistency, indirect, } \\
\text { very imprecise) }\end{array}$ \\
\hline
\end{tabular}

Abbreviations: $\mathrm{AR}=$ absolute risk; $\mathrm{ED}=$ emergency department; NSAIDs=nonsteroidal anti-inflammatory drugs;

$\mathrm{RCT}=$ randomized controlled trial; $\mathrm{RD}=$ risk difference

Opioids may cause more adverse events and may cause more drowsiness than NSAIDs (low SOE). These conclusions were each based on meta-analysis of indirect data from the ED setting. The confidence intervals of these estimates did not rule out the possibility of a difference that was less than clinically important, thus the estimates are considered imprecise.

Evidence is insufficient for the outcomes of hypotension, dizziness and depression. No studies reported respiratory depression (insufficient SOE).

\section{Additional Findings}

Additional findings for outcomes that are not graded with strength of evidence are in Table 26. Opioids significantly increase the risk of nausea compared to NSAIDs.

Table 26. Findings for the comparison of opioids versus nonsteroidal anti-inflammatory drugs, Key Question 2

\begin{tabular}{lll}
\hline Outcome & $\begin{array}{l}\text { Study Design and } \\
\text { Sample Size }\end{array}$ & $\begin{array}{l}\text { Findings } \\
\text { (Setting: Effect Estimates and 95\% Confidence Intervals) }\end{array}$ \\
\hline Nausea & 3 RCT $^{84-86}(n=453)$ & ED: Meta-analysis of 3 RCT AR 9.8\% vs. 1.7\%; RD 9\% (3 to 15) \\
\hline Vomiting & 2 RCT $^{84,85}(n=174)$ & ED: Meta-analysis of 2 RCT AR 4.6\% vs. 1.1\%; RD 3\% (-2 to 9) \\
\hline
\end{tabular}

Abbreviations: $\mathrm{AR}=$ absolute risk; $\mathrm{ED}=$ emergency department; $\mathrm{MD}=$ mean difference; $\mathrm{RCT}=$ randomized controlled trial; $\mathrm{RD}=$ risk difference

\section{Acetaminophen Versus Nonsteroidal Anti-Inflammatory Drugs}

We present results from studies that compared APAP versus NSAIDs in Table 27. This evidence base was entirely indirect evidence from the ED setting. Findings did not favor either analgesic significantly.

Table 27. Findings for the comparison of acetaminophen with nonsteroidal anti-inflammatory drugs, Key Question 2

\begin{tabular}{lll}
\hline Outcome & $\begin{array}{l}\text { Study Design } \\
\text { and Sample Size }\end{array}$ & $\begin{array}{l}\text { Findings } \\
\text { (Setting: Effect estimates and 95\% Confidence Intervals) }\end{array}$ \\
\hline Any adverse event & $\begin{array}{l}2 \mathrm{RCT}^{87,88} \\
(\mathrm{n}=340)\end{array}$ & ED: Meta-analysis of 2 RCT AR 4.7\% vs. 3.5\%; RD 1\% (-3 to 5) \\
\hline $\begin{array}{l}\text { Mental status changes } \\
\text { - dizziness }\end{array}$ & $\begin{array}{ll}\mathrm{RCT}^{88}(\mathrm{n}=140) \\
\text { Nausea }\end{array}$ & ED: No events occurred \\
\hline Vomiting & $1 \mathrm{RCT}^{88}(\mathrm{n}=140)$ & ED: 1 RCT AR 1.4\% vs. 0\%; RD 1\% (-5 to 8) \\
\hline $\begin{array}{l}2 \mathrm{RCT}^{87,88} \\
(\mathrm{n}=340)\end{array}$ & ED: Meta-analysis of 2 RCT AR 3.5\% vs. 1.8\%; RD 1\% (-2 to 4) \\
\hline
\end{tabular}

Abbreviations: $\mathrm{AR}=$ absolute risk; $\mathrm{ED}=$ emergency department; $\mathrm{MD}=$ mean difference; $\mathrm{RCT}=$ randomized controlled trial; $\mathrm{RD}=$ risk difference

\section{Ketamine Versus Nonsteroidal Anti-Inflammatory Drugs}

We present results from a single trail that compared ketamine to NSAIDs (ketorolac) in Table 28. This evidence base is indirect, from the ED setting. Several findings suggest statistically significant differences between ketamine and ketorolac. Total adverse events and 
dizziness were more frequent with ketamine versus ketorolac. Heart rate and systolic blood pressure were higher with ketamine versus ketorolac, at $15 \mathrm{~min}$ and $30 \mathrm{~min}$, but not $60 \mathrm{~min}$.

Table 28. Findings for the comparison of ketamine with nonsteroidal anti-inflammatory drugs, Key Question 2

\begin{tabular}{|c|c|c|}
\hline Outcome & $\begin{array}{l}\text { Study Design } \\
\text { and Sample Size }\end{array}$ & $\begin{array}{l}\text { Findings } \\
\text { (Setting: Effect Estimates and } 95 \% \text { Confidence Intervals) }\end{array}$ \\
\hline Any adverse event & $1 \mathrm{RCT}^{90}(\mathrm{n}=126)$ & ED: 1 RCT AR $62.9 \%$ vs. $14.1 \%$; RD $-49 \%$ (-62 to -33$)$ \\
\hline Heart rate $-15 \mathrm{~min}$ & $1 \mathrm{RCT}^{90}(\mathrm{n}=110)$ & $\overline{E D}: 1$ RCT MD 5.85 (2.99 to 8.71$)$ \\
\hline Heart rate $-30 \mathrm{~min}$ & $1 \operatorname{RCT}^{90}(n=110)$ & ED: 1 RCT MD 4.13 (1.35 to 6.91$)$ \\
\hline Heart rate $-60 \mathrm{~min}$ & $1 \mathrm{RCT}^{90}(\mathrm{n}=110)$ & ED: 1 RCT MD 2.59 (-0.14 to 5.32$)$ \\
\hline $\begin{array}{l}\text { Mental status changes } \\
\text { - dizziness }\end{array}$ & $1 \operatorname{RCT}^{90}(n=126)$ & ED: 1 RCT AR $40.3 \%$ vs. $0 \%$; RD $-40 \%(-52$ to -27$)$ \\
\hline Nausea & $1 \mathrm{RCT}^{90}(\mathrm{n}=126)$ & ED: 1 RCT AR $11.3 \%$ vs. $14.1 \% ;$ RD 3\% (-9 to 15$)$ \\
\hline $\begin{array}{l}\text { Systolic blood } \\
\text { pressure }-15 \mathrm{~min}\end{array}$ & $1 \operatorname{RCT}^{90}(\mathrm{n}=111)$ & ED: 1 RCT MD 9.19 (4.98 to 13.4$)$ \\
\hline $\begin{array}{l}\text { Systolic blood } \\
\text { pressure }-30 \mathrm{~min}\end{array}$ & $1 \mathrm{RCT}^{90}(\mathrm{n}=111)$ & ED: 1 RCT MD 8.38 (4.20 to 12.56) \\
\hline $\begin{array}{l}\text { Systolic blood } \\
\text { pressure }-60 \text { min }\end{array}$ & $1 \mathrm{RCT}^{90}(\mathrm{n}=111)$ & ED: 1 RCT MD 4.49 (0.34 to 8.64) \\
\hline
\end{tabular}

Abbreviations: $\mathrm{AR}=$ absolute risk; $\mathrm{ED}=$ emergency department; $\mathrm{MD}=$ mean difference; $\mathrm{RCT}=$ randomized controlled trial; $\mathrm{RD}=$ risk difference

\section{Morphine Versus Fentanyl}

We present results from RCTs that compared morphine versus fentanyl in Table 29 followed by a summary of findings from observational studies. Two findings from the evidence base were statistically significant. One $\mathrm{RCT}^{95}$ from the EMS setting found fewer adverse events with morphine versus fentanyl [RD -13 percent (-23 to-2)], although meta-analysis of indirect data from the ED did not support a statistically significant difference [RD -2 percent (-21 to 18)]. Based on a single trial from the EMS setting, sedation was significantly more common with morphine versus fentanyl [RD 42 percent (20 to 60)]. Meta-analysis of 2 RCTs suggest a statistically significant increase in nausea and/or vomiting with morphine versus fentanyl [RD 6 percent (1 to 11)]. Other findings were not significantly in favor of either analgesic.

Table 29. Findings for the comparison of morphine versus fentanyl, Key Question 2

\begin{tabular}{|c|c|c|}
\hline Outcome & $\begin{array}{l}\text { Study Design } \\
\text { and Sample } \\
\text { Size }\end{array}$ & $\begin{array}{l}\text { Findings } \\
\text { (Setting: Effect Estimates and } 95 \% \text { Confidence Intervals) }\end{array}$ \\
\hline Any adverse event & $\begin{array}{l}3 \mathrm{RCT}^{21,95,96} \\
(\mathrm{n}=391) \\
2 \mathrm{OBS}^{\mathrm{a}} \\
(\mathrm{n}=718)^{99,104}\end{array}$ & $\begin{array}{l}\text { EMS: } 1 \mathrm{RCT}^{95} \mathrm{AR} 14.9 \% \text { vs. } 27.5 \% \text {; RD }-13 \%(-23 \text { to }-2), 1 \mathrm{OBS}^{104} \\
\text { see text } \\
\text { ED: Meta-analysis of } 2 \mathrm{RCT}^{21,96} \mathrm{AR} 6.5 \% \text { vs. } 9.8 \% \text {; RD }-2 \%(-21 \text { to } \\
\text { 18), } 1 \mathrm{OBS}^{99} \text { see text }\end{array}$ \\
\hline Heart rate & $\begin{array}{l}3 \mathrm{RCT}^{16,92,93} \\
(\mathrm{n}=288)\end{array}$ & $\begin{array}{l}\text { EMS: } 1 \mathrm{RCT}^{16} \text { no events occurred, bradycardia } \\
\text { EMS: Meta-analysis of } 2 \mathrm{RCT}^{92,93} \mathrm{MD}-0.38(-6.49 \text { to } 5.73)\end{array}$ \\
\hline Hypotension & $\begin{array}{l}3 \mathrm{RCT}^{19,92,94} \\
(\mathrm{n}=419) \\
3 \text { OBS } \\
(\mathrm{n}=886)^{99,101,104 a}\end{array}$ & $\begin{array}{l}\text { EMS: Meta-analysis of } 2 \text { RCT }^{92,94} \text { AR } 2.5 \% \text { vs. } 0 \% \text {; RD } 2 \% \text { (-3 to } \\
\text { 7), } 1 \text { OBS see text }{ }^{104} \\
\left.\text { ED: } 1 \text { RCT } \text { RCT }^{19} \text { AR } 0 \% \text { vs. } 6.3 \% \text {; RD }-6 \% \text { (-29 to } 16\right), 2 \text { OBS see } \\
\text { text }{ }^{99,101}\end{array}$ \\
\hline $\begin{array}{l}\text { Mental status } \\
\text { changes - } \\
\text { lightheadedness, } \\
\text { loss of } \\
\text { consciousness }\end{array}$ & $1 \mathrm{RCT}^{20}(\mathrm{n}=90)$ & ED: 1 RCT AR $4.7 \%$ vs. 0\%; RD 5\% (-4 to 16$)$ \\
\hline $\begin{array}{l}\text { Mental status } \\
\text { changes - sedation }\end{array}$ & $\begin{array}{l}1 \operatorname{RCT}^{93}(n=54) \\
1 \mathrm{OBS}^{101} \\
(\mathrm{n}=718)\end{array}$ & $\begin{array}{l}\text { EMS: } 1 \text { RCT } 42.3 \% \text { vs. } 0 \% \text {; RD } 42 \% \text { (20 to } 60) \\
1 \text { OBS see text }\end{array}$ \\
\hline
\end{tabular}




\begin{tabular}{|c|c|c|}
\hline Outcome & $\begin{array}{l}\text { Study Design } \\
\text { and Sample } \\
\text { Size }\end{array}$ & $\begin{array}{l}\text { Findings } \\
\text { (Setting: Effect Estimates and } 95 \% \text { Confidence Intervals) }\end{array}$ \\
\hline Nausea & $\begin{array}{l}5 \mathrm{RCT}^{19,21,92,93,96} \\
(\mathrm{n}=432) \\
2 \mathrm{OBS}^{101,104} \\
(\mathrm{n}=886)\end{array}$ & $\begin{array}{l}\text { EMS: Meta-analysis of } 2 \mathrm{RCT}^{92,93} \text { AR } 16.8 \% \text { vs. } 14.7 \% \text {; RD } 0 \% \text { (- } \\
14 \text { to } 15), 1 \text { OBS see text }{ }^{104} \\
\text { ED: Meta-analysis of } 3 \mathrm{RCT}^{19,21,96} \text { AR } 10.8 \% \text { vs. } 5.1 \% \text {; RD } 9 \% \text { (-14 } \\
\text { to } 33), 1 \text { OBS see text }{ }^{101}\end{array}$ \\
\hline $\begin{array}{l}\text { Nausea and/or } \\
\text { vomiting }\end{array}$ & $\begin{array}{l}2 \mathrm{RCT}^{20,91} \\
(\mathrm{n}=397) \\
1 \mathrm{OBS}^{99} \\
(\mathrm{n}=\mathrm{NR})^{\mathrm{a}}\end{array}$ & $\begin{array}{l}\text { ED: Meta-analysis of } 2 \text { RCT AR } 15.4 \% \text { vs. } 8.4 \% \text {; RD } 6 \% \text { (1 to } 11 \text { ), } \\
1 \text { OBS see text }\end{array}$ \\
\hline Oxygen saturation & $\begin{array}{l}1 \operatorname{RCT}^{93}(n=54) \\
2 \operatorname{OBS}^{101,104} \\
(n=886)\end{array}$ & $\begin{array}{l}\text { EMS: MD } 0 \text { (-1.5 to } 1.5), 1 \text { OBS see text }{ }^{104} \\
\text { ED: } 1 \text { OBS see text }{ }^{101}\end{array}$ \\
\hline $\begin{array}{l}\text { Respiratory } \\
\text { depression }\end{array}$ & $\begin{array}{l}2 \operatorname{RCT}^{92,96} \\
(n=274) \\
3 \mathrm{OBS}^{98,99,101} \\
(\mathrm{n}=245)^{\mathrm{a}}\end{array}$ & $\begin{array}{l}\text { EMS: } 1 \text { RCT }^{92} \text { no events occurred, } 1 \text { OBS see text } \\
\text { ED: } 1 \text { RCT } \\
\text { E6 no events occurred, } 2 \text { OBS see text }{ }^{99,101}\end{array}$ \\
\hline Respiratory rate & $\begin{array}{l}2 \mathrm{RCT}^{92,93} \\
(\mathrm{n}=241) \\
1 \mathrm{OBS}^{104} \\
(\mathrm{n}=718)\end{array}$ & $\begin{array}{l}\left.\text { EMS: Meta-analysis of } 2 \mathrm{RCT}^{92,93} \mathrm{MD}-0.60 \text { (-1.55 to } 0.35\right), 1 \text { OBS } \\
\text { see text }\end{array}$ \\
\hline $\begin{array}{l}\text { Systolic blood } \\
\text { pressure }\end{array}$ & $1 \mathrm{RCT}^{93}(\mathrm{n}=54)$ & EMS: 1 RCT MD -3 (-14.2 to 8.2) \\
\hline Vomiting & $\begin{array}{l}6 \mathrm{RCT}^{16,92-94,96,97} \\
(\mathrm{n}=642)\end{array}$ & 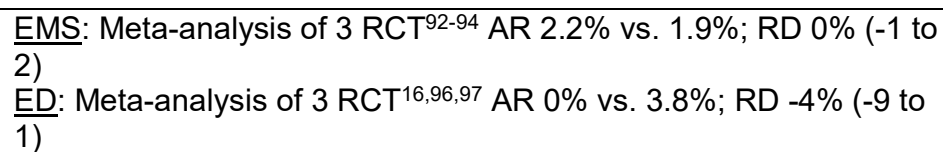 \\
\hline
\end{tabular}

Abbreviations: $\mathrm{AR}=$ absolute risk; $\mathrm{ED}=$ emergency department; $\mathrm{EMS}=$ emergency medical services; $\mathrm{MD}=$ mean difference; $\mathrm{OBS}=$ observational; $\mathrm{RCT}=$ randomized controlled trial; $\mathrm{RD}=$ risk difference

${ }^{a}$ Of the 31,742 subjects included in the analysis, the proportion per opioid was not reported thus the sample size from Daoust et al. is not factored into this total

Six observational studies ${ }^{62,63,98,99,101,104}$ compared harms of morphine with fentanyl. Two studies are in the EMS setting. Fleischman et al. ${ }^{104}$ reported frequencies of several harms comparing fentanyl with morphine, none of which reached statistically significant differences (fentanyl percent versus morphine percent, 95 percent confidence interval for difference): any adverse event 6.6 percent versus 9.9 percent, -0.8 percent to 7.3 percent), nausea or need for antiemetics (3.8 percent versus 7.0 percent, -0.1 percent to 6.5 percent), systolic blood pressure $<90$ $\mathrm{mmHg}$ (1.1 percent versus 1.7 percent, -1.1 percent to 2.3 percent $)$, respiratory rate $<12(0.3$ percent versus 0.9 percent, -0.5 percent to 1.7 percent), oxygen saturation $<92$ percent and 5 percent below baseline ( 1.1 percent versus 0.6 percent, -1.9 percent to 0.8 percent), sedation or decreased GCS (0.8 percent versus 1.1 percent, -1.1 percent to 1.7 percent). Sharonow et al. ${ }^{98}$ reported no patients to have respiratory depression requiring opioid antagonist or measures to secure airway; no patients had an oxygen saturation $<95$ percent.

Two studies are in the ED setting. Wenderoth et al. ${ }^{101}$ reported hypotension (systolic blood pressure $<90 \mathrm{mmHg}$ ) in 6.0 percent versus 0 percent $(p=N R)$; respiratory rate $<12$ in 2.4 percent versus 0 percent, $(\mathrm{p}=\mathrm{NR})$; oxygen saturation $<90$ percent in 1.2 percent versus 0 percent $(\mathrm{p}=\mathrm{NR})$, but in 3 of these 8 patients that experiences an adverse event, the event was reported as present at baseline. Nausea, in those without nausea at baseline, was significantly more frequent with morphine versus fentanyl 21.4 percent versus 0 percent, $\mathrm{p}=0.088$ ). Daoust et al. ${ }^{99}$ reported adjusted odds ratios (AOR) and 95 percent confidence intervals for harms with fentanyl referent to morphine and found less nausea/vomiting [AOR 0.80 (0.71 to 0.91)], fewer subjects with oxygen saturation $<92$ percent [AOR $0.73(0.64$ to 0.83$)$ ] and more subjects with systolic blood 
pressure $<90 \mathrm{mmHg}$ [AOR 2.50 (2.10 to 2.97)] with fentanyl. There was no significant difference in global adverse events [AOR 0.96 (0.88 to 1.04)].

Two studies are in the battlefield setting. Schauer et al. ${ }^{62}$ reported harms at the point of hospital admission in subjects treated with morphine versus fentanyl (median, IQR): systolic blood pressure (130, 106 to 144 versus 131,114 to 143$)$; heart rate $(93,76$ to 120 versus 90,72 to 108$)$; respiratory rate $(18,16$ to 22 versus 18,14 to 22$)$; oxygen saturation $(99,96$ to 100 versus 97, 94 to 99); Glasgow Coma Scale score (15, 15 to 15 versus 15, 14 to 15). Shackleford et al.$^{63}$ reported change in vital signs (mean, SD) during tactical evacuation in subjects treated with morphine versus fentanyl: systolic blood pressure [-3(13) versus $0(14), p=N R]$, heart rate [$3(23)$ versus $-3(14), p=N R]$, respiratory rate $[-1(2)$ versus $-1(2), p=N R]$ and oxygen saturation [4(2) versus $1(2), \mathrm{p}=\mathrm{NR}]$.

\section{Combination of Opioid and Ketamine Versus Ketamine}

One study compared vomiting in patients treated with either morphine or fentanyl in combination with ketamine versus etamine alone, in the EMS setting. ${ }^{105}$ There were more cases of vomiting in the fentanyl plus ketamine group ( $\mathrm{p}=$ not reported): morphine plus ketamine 0 percent; fentanyl plus ketamine 16.7 percent; ketamine alone 0 percent.

KQ 3. In patients whose moderate-to-severe acute-onset pain level is not controlled following initial analgesic treatment, what is the comparative effectiveness of switching the analgesic regimen compared to repeating the initial treatment?

\section{KQ 3a. How does effectiveness vary by patient characteristics?}

\section{$\mathrm{KQ} 3 \mathrm{~b}$. How does effectiveness vary by timing of the second treatment administration?}

\section{Additional Opioids Versus Ketamine}

\section{Key Messages}

- Giving ketamine may reduce pain more and may be quicker to reduce pain to a clinically important difference compared with giving additional opioids (low SOE).

- These conclusions are based on direct evidence from the EMS setting comparing IV morphine with IV ketamine when patients inadequately respond to initial morphine IV.

- Evidence is insufficient for the outcome of pain presence.

\section{Detailed Results}

We present the conclusions for the comparative effectiveness of giving additional opioids versus giving ketamine after inadequate initial analgesics in Table 30. Two RCTs ${ }^{64,65}$ from the EMS setting enrolled subjects who inadequately responded to morphine $(5 \mathrm{mg} \mathrm{IV}$ or $0.1 \mathrm{mg} / \mathrm{kg}$ IV) and compared giving additional morphine with switching to ketamine IV. 
Table 30. Conclusions and strength of evidence for the comparison of additional opioids versus ketamine, Key Question 3

\begin{tabular}{llll}
\hline Outcome & $\begin{array}{l}\text { Study } \\
\text { Design and } \\
\text { Sample Size }\end{array}$ & $\begin{array}{l}\text { Conclusions } \\
\text { (Setting: Supporting Effect Estimates and 95\% } \\
\text { Confidence Intervals) }\end{array}$ & $\begin{array}{l}\text { Strength of } \\
\text { Evidence } \\
\text { (Limitations) }\end{array}$ \\
\hline Pain severity & $\begin{array}{l}\text { 2 RCT64,65 } \\
(n=162)\end{array}$ & $\begin{array}{l}\text { Giving ketamine may reduce pain more than giving } \\
\text { additional opioids. } \\
\text { EMS: Meta-analysis of 2 RCTs found MD 1.99 (0.95 to 3.03) }\end{array}$ & $\begin{array}{l}\text { Low } \\
\text { (Medium study } \\
\text { limitations, } \\
\text { imprecise) }\end{array}$ \\
\hline $\begin{array}{l}\text { Over the prehospital period. } \\
\text { Time to } \\
\text { analgesic }\end{array}$ & $\begin{array}{l}\text { 1 RCT64 } \\
\text { effect }\end{array}$ & $\begin{array}{l}\text { Giving ketamine may be quicker to reduce pain to a } \\
\text { clinically important difference compared to giving } \\
\text { additional opioids. }\end{array}$ & $\begin{array}{l}\text { Low } \\
\text { (Medium study } \\
\text { limitations, }\end{array}$ \\
& & $\begin{array}{l}\text { EMS: 1 RCT found the median difference in the change of } \\
\text { pain score per minute to be -2.5 points per minute (-3.9 to - } \\
\text { 1.1) in favor of ketamine compared to opioids. }\end{array}$ & consistency) \\
\hline
\end{tabular}

Abbreviations: EMS=emergency medical services; $\mathrm{MD}=$ mean difference; $\mathrm{OBS}=$ observational; $\mathrm{RCT}=$ randomized controlled trial

Giving ketamine may reduce pain more than giving additional opioids in patients who have inadequate pain control after initial opioids (low SOE). This conclusion is based on metaanalysis of the change in pain scores using direct evidence from the EMS setting and a clinically important difference of 2 points on a 0 to 10 scale. The confidence interval did not exclude the possibility of a clinically important difference in favor of ketamine (an increase in the MD with morphine). In addition to inconsistency in the meta-analysis result, the studies had medium risk of bias for subject outcomes because they were open-label.

Giving ketamine may be quicker to reduce pain to a clinically important difference compared to giving additional opioids. This conclusion is based on a single trial and a clinically important difference of 5 minutes. The median difference in pain score change per minute was in favor of ketamine such that within 5 minutes, there likely would be at least a 2-point difference in pain scores on a 0 to 10 scale. This study was open-label thus medium risk of bias and we were unable to judge consistency with only 1 study.

No studies reported measure of pain presence (insufficient SOE) or memory of pain.

$\mathrm{KQ}$ 4. In patients whose moderate-to-severe acute-onset pain level is not controlled following initial analgesic treatment, what are the comparative harms of switching to another analgesic agent?

\author{
$\mathrm{KQ} 4 \mathrm{a}$. How do harms vary by patient characteristics?
}

$\mathrm{KQ} 4 \mathrm{~b}$. How do harms vary by routes of administration, dosing, and timing?

\title{
Additional Opioids Versus Ketamine
}

\section{Key Message}

- Evidence is insufficient for the comparison of giving additional opioids IV versus giving ketamine IV for the outcomes of any adverse event, hypotension, mental status changes and respiratory depression. 


\section{Detailed Results}

We present the conclusions for the comparative harms of additional opioids versus switching to ketamine after inadequate initial analgesics in Table 31 . Two RCTs ${ }^{64,65}$ from the EMS setting enrolled subjects who inadequately responded to morphine (5mg IV or $0.1 \mathrm{mg} / \mathrm{kg} \mathrm{IV}$ ) and compared giving additional morphine with switching ketamine IV. Evidence was insufficient for any adverse event, hypotension, sedation, GCS score $\leq 13$ and respiratory depression. Trials were open-label thus for subjective outcomes risk of bias was higher. Some estimates were very imprecise where the confidence interval included the possibility of a clinically important difference in favor of either analgesic. All outcomes were based on single studies thus consistency could not be judged. No studies reported respiratory depression (insufficient SOE).

Table 31. Conclusions and strength of evidence for the comparison of additional opioids versus ketamine, Key Question 4

\begin{tabular}{|c|c|c|c|}
\hline Outcome & $\begin{array}{l}\text { Study } \\
\text { Design and } \\
\text { Sample Size }\end{array}$ & $\begin{array}{l}\text { Conclusions } \\
\text { (Setting: Supporting Effect Estimates and 95\% } \\
\text { Confidence Intervals) }\end{array}$ & $\begin{array}{l}\text { Strength of Evidence } \\
\text { (Limitations) }\end{array}$ \\
\hline $\begin{array}{l}\text { Any adverse } \\
\text { event }\end{array}$ & $\begin{array}{l}1 \mathrm{RCT}^{64} \\
(\mathrm{n}=135)\end{array}$ & $\begin{array}{l}\text { Inconclusive. } \\
\text { EMS: } 1 \text { RCT found adverse events in } 13.8 \% \text { vs. } \\
38.6 \% \text { of patients, RD }-25 \%(-38 \text { to }-1)\end{array}$ & $\begin{array}{l}\text { Insufficient } \\
\text { (Medium study } \\
\text { limitations, unknown } \\
\text { consistency, imprecise) }\end{array}$ \\
\hline Hypotension & $\begin{array}{l}1 \mathrm{RCT}^{64} \\
(\mathrm{n}=135)\end{array}$ & $\begin{array}{l}\text { Inconclusive. } \\
\text { EMS: } 1 \text { RCT found hypotension in } 1.5 \% \text { vs. } 0 \% \text { of } \\
\text { patients, RD } 2 \%(-40 \text { to } 9)\end{array}$ & $\begin{array}{l}\text { Insufficient } \\
\text { (unknown consistency, } \\
\text { very imprecise) }\end{array}$ \\
\hline $\begin{array}{l}\text { Mental status } \\
\text { changes - } \\
\text { sedation }\end{array}$ & $\begin{array}{l}1 \mathrm{RCT}^{65} \\
(\mathrm{n}=27)\end{array}$ & $\begin{array}{l}\text { Inconclusive. } \\
\text { EMS: } 1 \text { RCT found no events in either arm. }\end{array}$ & $\begin{array}{l}\text { Insufficient } \\
\text { (medium study } \\
\text { limitations, unknown } \\
\text { consistency) }\end{array}$ \\
\hline $\begin{array}{l}\text { Mental status } \\
\text { changes - } \\
\text { GCS } \leq 13\end{array}$ & $\begin{array}{l}1 \mathrm{RCT}^{65} \\
(\mathrm{n}=135)\end{array}$ & $\begin{array}{l}\text { Inconclusive. } \\
\text { EMS: } 1 \text { RCT found reduced GCS score in } 1.5 \% \text { vs. } \\
4.3 \% \text { of patients, RD }-3 \% \text { ( }-10 \text { to } 5)\end{array}$ & $\begin{array}{l}\text { Insufficient } \\
\text { (Medium study } \\
\text { limitations, unknown } \\
\text { consistency, very } \\
\text { imprecise) }\end{array}$ \\
\hline
\end{tabular}

Abbreviations: EMS=emergency medical services; GCS=Glasgow Coma Scale; OBS=observational; $\mathrm{RCT}=$ randomized controlled trial; $\mathrm{RD}=$ risk difference; $\mathrm{vs}=$ versus

Additional finding for outcomes that are not graded for strength of evidence are in Table 32. There were no significant findings.

Table 32. Findings for the comparison of additional opioid versus ketamine, Key Question 4

\begin{tabular}{|c|c|c|}
\hline Outcome & $\begin{array}{l}\text { Study Design and } \\
\text { Sample Size }\end{array}$ & $\begin{array}{l}\text { Findings } \\
\text { (Setting: Effect Estimates and } 95 \% \text { Confidence Intervals) }\end{array}$ \\
\hline Heart rate & $2 \mathrm{RCT}^{64,65}(\mathrm{n}=162)$ & EMS: Meta-analysis of 2 RCT MD $1.10(-1.94$ to 4.14$)$ \\
\hline Oxygen saturation & $1 \mathrm{RCT}^{65}(\mathrm{n}=27)$ & EMS: MD $-3(-6.2$ to 0.2$)$ \\
\hline Respiratory rate & $2 \mathrm{RCT}^{64,65}(\mathrm{n}=162)$ & EMS: Meta-analysis of 2 RCT MD $-0.16(-1.46$ to 1.14$)$ \\
\hline $\begin{array}{l}\text { Systolic blood } \\
\text { pressure }\end{array}$ & $2 \mathrm{RCT}^{64,65}(\mathrm{n}=162)$ & EMS: Meta-analysis of 2 RCT MD -20.22 (-45.46 to 5.02) \\
\hline Nausea & $2 \mathrm{RCT}^{64,65}(\mathrm{n}=162)$ & $\begin{array}{l}\text { EMS: Meta-analysis of } 2 \text { RCT AR } 9.2 \% \text { vs. } 8.1 \% \text {; } \\
\text { RD }-1 \%(-20 \text { to } 17)\end{array}$ \\
\hline Vomiting & $2 \operatorname{RCT}^{64,65}(\mathrm{n}=162)$ & $\begin{array}{l}\text { EMS: Meta-analysis of } 2 \text { RCT AR } 0 \% \text { vs. } 4.7 \% \text {; } \\
\text { RD }-7 \%(-22 \text { to } 9)\end{array}$ \\
\hline $\begin{array}{l}\text { Emergence } \\
\text { delirium }\end{array}$ & $1 \operatorname{RCT}^{64}(\mathrm{n}=135)$ & EMS: 1 RCT AR 0\% vs. 5.7\%; RD -6\% (-14 to 2$)$ \\
\hline
\end{tabular}

Abbreviations: $\mathrm{AR}=$ absolute risk; $\mathrm{EMS}=$ emergency medical services; $\mathrm{MD}=$ mean difference; $\mathrm{RCT}=$ randomized controlled trial; $\mathrm{RD}=$ risk difference 


\section{Discussion}

\section{Overview}

Fifty-two randomized controlled trials (RCTs) and 13 observational studies constituted the evidence base for this review. Only 14 of these studies, 8 of which compared morphine to fentanyl, were from the prehospital setting. When mapped against the analgesic comparisons and outcomes, few prehospital studies were available per comparison. Therefore, our conclusions for Key Questions (KQ) 1 and 2 are based on indirect evidence from the emergency department (ED) setting. Conclusions for KQ 3 and 4 are based on direct evidence from 2 RCTs in the prehospital setting. The focus of this report is to synthesize existing evidence. We do not make clinical recommendations and encourage the application of this evidence to future work generating evidence-based clinical guidelines.

\section{Initial Analgesia}

As initial analgesics and primarily administered intravenously (IV), opioids are no different than ketamine, acetaminophen (APAP) and nonsteroidal anti-inflammatory drugs (NSAIDs) in reducing pain. These conclusions were all with low-strength evidence, except opioids versus NSAIDS which was moderate strength. The combination of opioids and ketamine may be more effective in reducing pain, compared with opioids alone. To put these findings in context there are some key parameters concerning applicability to consider. The studies that compared the efficacy of opioids with ketamine were mostly comparing weight-based IV morphine $0.1 \mathrm{mg} / \mathrm{kg}$ with IV ketamine (variable weight-based dosing). Some studies evaluated intranasal (IN) fentanyl and IN ketamine, which were prepared from the IV formulations and delivered IN via an atomizer. The IN ketamine product on the US market is not approved for pain management and is specific to management of treatment-resistant depression. The doses of ketamine varied and too few studies were available to identify associations based on subgroups of dose. When ketamine was studied in combination with opioids, a single IV dose was added to the opioid regimen. How administration of more than one ketamine dose impacts outcomes is unknown. Nine of the 10 trials that compared opioids with APAP compared IV morphine $0.1 \mathrm{mg} / \mathrm{kg}$ with IV APAP $1 \mathrm{gm}$, thus results cannot be extrapolated to other routes or doses. There were only three studies comparing opioids with NSAIDs with a mixed representation of oral and IV dosage forms.

We were unable to draw conclusions about the efficacy of opioids compared with nitrous oxide owning to a single study with limitations in design and inability to compare consistency of results with other studies. We did not grade outcomes for the comparisons of morphine versus fentanyl, APAP versus NSAIDs or ketamine versus NSAIDs. There were no statistically significant differences in pain scores between morphine and fentanyl. Pain decreased less with APAP versus NSAIDs at 15 minutes but the difference is smaller than what would be considered as clinically relevant. Pain decreased more with ketorolac compared with ketamine at 30 minutes but the difference as smaller than what would be considered clinically relevant. No studies, regardless of analgesic comparison, reported outcomes associated with the memory of pain (amnestic effect of the intervention).

Conclusions regarding comparative harms of initial analgesics were often inconclusive owing to insufficient data, with few studies per comparison and a lower frequency of events. Based on conclusions we were able to draw, the comparative harms of specific adverse events vary among 
analgesics and in the absence of clinically important differences in pain reduction and may inform individualized treatment decisions.

The overall frequency of total adverse events in trials that compared opioids with ketamine suggests that at least 50 percent of patients treated with either opioids or ketamine will experience some type of adverse event but low-strength evidence suggests that opioids may cause fewer total adverse events than ketamine. These trials studied analgesics primarily administered through the IN route. Based on subgroup analyses, effects may be modified by age ( $<18$ years versus 18 years and older), route and pain type, although because the same cohort of studies represented subjects $<18$ years old and IN routes, it is unclear what the true modifier is. Opioids may cause more respiratory depression while ketamine causes more dizziness, both based on low-strength evidence. Differences in dizziness may be associated with age or route but again, the same caveat applies as these subgroups were represented by the same studies. Results from outcomes that were not graded suggest opioids lead to statistically lower values for heart rate, respiratory rate and systolic blood pressure (SBP) compared with ketamine in 15 minutes; statistically lower SBP versus ketamine in 30 minutes; and statistically greater nausea/vomiting versus ketamine. Hemodynamic changes were mostly due to elevations with ketamine over reductions with opioids and these observations are consistent with known side effects of these drugs. We did not establish clinically important differences for these outcomes although the lower bound of the confidence interval for heart rate $(-5.23$ beats per minutes) and SBP $(-16.22$ $\mathrm{mmHg})$ at 15 minutes, for SBP at 30 minutes $(-11.28 \mathrm{mmHg})$, and upper bound for nausea/vomiting (risk difference 22 percent) suggest these findings may be clinically relevant changes.

In contrast to the comparison of opioids with ketamine, opioids may cause more adverse events than APAP or NSAIDs when used as initial analgesics, with low-strength evidence. Opioids cause more dizziness than APAP but there was no evidence of clinically important differences in hypotension, both based on low-strength evidence. Compared with NSAIDs, opioids were found to cause more drowsiness, based on low-strength evidence.

We were unable to conclude comparative harms of combination opioids and ketamine versus opioids alone. Results from single trials for outcomes that were not graded suggest combination therapy leads to a statistically higher oxygen saturation percentage and respiratory rate in 30 minutes and statistically fewer patients with vomiting. We did not establish clinically important differences for these outcomes although the observed differences may not be clinically relevant in the majority of patients. We did not grade outcomes for the comparisons of morphine versus fentanyl, APAP versus NSAIDs or ketamine versus NSAIDs. There were no significant differences between APAP and NSAIDs for the reported harms. Total adverse events and dizziness was more frequent with ketamine versus ketorolac. Heart rate and systolic blood pressure were higher with ketamine versus ketorolac at 15 and 30 minutes but not at 60 minutes. Some trial data suggested morphine has fewer adverse events and less sedation than fentanyl but observational data were not in agreement with these effects.

\section{Inadequate Response to Initial Analgesia}

In patients whose pain is inadequately responsive to initial morphine (KQ 3 and 4), giving ketamine IV may reduce pain more and may be quicker compared to giving more morphine IV, based on low-strength evidence. The evidence for this conclusion is directly from the prehospital setting, although conclusions were limited by the open-label nature of these trials and imprecise 
effect estimates. We were unable to conclude comparative harms of this comparison owning to infrequent reporting of harms, low events leading to imprecise estimates and study limitations.

\section{Findings in Relation to What Is Already Known}

For patients experiencing moderate to severe pain due to a traumatic injury, current guidelines (based on moderate quality evidence) strongly recommend initial prehospital management with a weight-based opioid, either IV morphine or IV/IN fentanyl. ${ }^{7}$ National model guidelines for pain management in the prehospital setting recommend either opioid or nonopioid analgesics but the specific drug and route of administration differs based on whether treatment is for moderate or severe pain. ${ }^{107}$ Our results are in support of the option of both opioid and nonopioid analgesics for patients with moderate to severe pain. Importantly, we found no evidence that opioids are better at reducing pain in this setting but are associated with more side effects than APAP or NSAIDs.

With the current opioid overdose epidemic and concerns about potential misuse of and addiction to opioids, recent interest in nonopioid alternatives has grown, specifically for ketamine. Ketamine, originally used as an anesthetic at higher doses, is used off-label for acute pain management. A position statement from The American College of Emergency Physicians (ACEP) and a joint guideline from the American Society of Regional Anesthesia and Pain Medicine, the American Academy of Pain Medicine and the American Society of Anesthesiologists are both in support of sub-dissociative doses of IV ketamine for acute pain management. ${ }^{108,109}$ Our conclusions support the efficacy of ketamine, and when compared to opioids there was no evidence of a clinically important differences in reducing pain. We found that initially combining ketamine with opioids may be more effective in reducing pain compared to opioids alone and when a patient inadequately responds to IV morphine, switching to ketamine may be more effective.

The expected side effect profile of sub-dissociative doses of IV ketamine includes dysphoria, dizziness and nausea that are typically short-term and self-limiting. ${ }^{108}$ Potential concerns regarding opioids (respiratory depression, hypoxemia, or hypotension) are not typical of subdissociative ketamine such that patients who are contraindicated to opioids may be candidates for ketamine. ${ }^{108}$ Although we found opioids may cause fewer total adverse events versus ketamine, opioids may cause more respiratory depression. Respiratory depression from opioids is a potentially fatal complication of both acute and chronic pain management. ${ }^{110,111}$

Elevations in blood pressure and heart rate with ketamine may also be common. ${ }^{112}$ Ketamine may cause more dizziness than opioids. We did not formulate conclusions for outcomes concerning hemodynamics or oxygenation but the observed changes are likely to be clinically important albeit consistent with the expected side effects. Experts describe emergence reactions to be uncommon at sub-dissociative ketamine doses. ${ }^{108}$ Four studies in our review explicitly reported emergence delirium, two studies of IV ketamine $0.5 \mathrm{mg} / \mathrm{kg}$ and $0.3 \mathrm{mg} / \mathrm{kg}$ and two studies of IN ketamine $1 \mathrm{mg} / \mathrm{kg}$. Collectively, 8.4 percent (12 of 143 subjects) of ketamine treated subjects were reported to experience emergence delirium. 


\section{Applicability}

\section{Population}

The population of this review was limited to those with moderate to severe, acute pain. Aside from labor and delivery, etiology or location of pain did not lead to exclusion. Generally, the mean ages of studies fell within the $3^{\text {rd }}$ to $4^{\text {th }}$ decade of life, with few studies specific to younger and older patients. Of studies that focused on pediatric or adolescents, the mean ages were closer to 10 years old, rather than very young pediatric patients. One study was specific to elderly, enrolling subjects over the age of 65 years, thus this evidence base is not applicable to older aged patients. Whether pain was traumatic, nontraumatic or mixed varied across comparisons. The most common type of traumatic pain, in general, was pain associated with limb fractures. Major injuries such as a crushed pelvis, major burns, or patients with multiple major traumatic injuries were not represented in this evidence base. The most common type of nontraumatic pain studied was pain associated with renal colic. Baseline pain scores were no less than 7 , representing more severe pain, with exception of studies comparing morphine with fentanyl where the lower bound was 5.

\section{Contraindications}

Contextual Question 1 is regarding contraindications to analgesics, which is also tied into the population related applicability of the evidence base constituting this review. The contraindications, precautions and warnings for the analgesics discussed in this report are presented in Appendix Table C-11, according to U.S. Food and Drug Administration. ${ }^{112-123}$ All analgesics are contraindicated in the presence of an allergy. Morphine and fentanyl are contraindicated within 14 days of monoamine oxidase inhibitors (MAOI). These opioids have common warnings related to risk of respiratory and central nervous system depression and characteristics that may predispose patients to these risks. Hypotension, cardiovascular instability and adrenal insufficiency are also warnings. Guidelines on analgesia for traumatic injuries and in the prehospital setting are in general agreement and recommend refraining from opioids with a Glasgow Coma Score (GCS) less than 15, hypoxia after maximal oxygen supplementation, signs of hypoventilation, hypotension, allergy or with MAOIs. ${ }^{8,107}$

As a comparison to labeled contradictions, we evaluated the exclusion criteria used by trials included in this review. Studies of opioids are mostly of morphine and the common exclusion criteria are consistent with the aforementioned label and guideline contraindications. They include: a history of respiratory disorders (e.g. chronic obstructive pulmonary disease or asthma), abnormal oxygen saturation (typically $<85$ percent to 95 percent), abnormal respiratory rate $(<8$ to 12 or $>20$ to 30 breaths per minute), cardiovascular disorders (e.g. ischemic heart disease, heart failure, and dysrhythmias), hemodynamic instability (SBP $<90 \mathrm{~mm} \mathrm{Hg}$ or $>160$ to $180 \mathrm{~mm}$ $\mathrm{Hg}$, heart rate $<50$ to 60 or $>100$ to 150 beats per minute), neurologic findings (e.g. decreased level of consciousness, GCS $<15$, cognitive impairment, altered mental status), head injury, and substance abuse (e.g. drug or opiate addiction or alcohol abuse). Unique to the use of intranasal fentanyl, subjects with nasal occlusion were excluded. As is typical in trials, patients with kidney or liver dysfunction or who were pregnant or lactating were commonly excluded.

Absolute and relative contraindications for ketamine in the setting of acute pain management are less agreed upon, related to the off-label use for this indication. The ACEP suggests ketamine for acute pain is contraindicated in infants less than 3 months of age and in those with stated adverse reactions or allergies to ketamine. ${ }^{108}$ Recent consensus guidelines from the American 
Society of Regional Anesthesia and Pain Medicine, American Academy of Pain Medicine, and American Society of Anesthesiologist provide differing suggestions. ${ }^{109}$ Ketamine should be avoided in pregnancy or psychosis (Grade B, moderate certainty); severe cardiovascular disease or poorly controlled hypertension, or severe cirrhosis (Grade C, moderate certainty); and patients with moderate cirrhosis or elevated intracranial and/or intraocular pressure (Grade $\mathrm{C}$, low certainty). ${ }^{109}$ Our review of the common exclusion criteria from studies investigating ketamine are generally consistent with these contraindications and what is reported above for opioids. Because these studies were always in comparison to an opioid, ketamine specific exclusions are unclear. Studies of intranasal ketamine also excluded patients with nasal occlusion. Like trials of other analgesics, pregnant or lactating patients were also excluded in most ketamine studies.

NSAIDs, ketorolac and ibuprofen, have a variety of contraindications and warnings that center around current bleeding or the risk of serious bleeding, presence or history of peptic ulcers or gastrointestinal bleeding, renal impairment or those at risk for renal impairment and cardiovascular effects related to prostaglandin inhibition. Prehospital specific guidelines suggest NSAID be avoided in patients with an allergy, aspirin sensitive asthma, renal insufficiency, peptic ulcer disease, hypotension (due to renal toxicity) or are pregnant. ${ }^{107}$ Studies of NSAIDs in our review excluded similar patient groups; mainly those with hemodynamic instability, liver or kidney disease, blood coagulation disorders, gastrointestinal bleeding, or peptic ulcer disease. One ibuprofen study also excluded patients with heart failure.

APAP warnings relate to concerns over liver disease or predisposition to hepatic toxicity and we found studies to commonly exclude patients with these characteristics. There appear to be few serious warnings for nitrous oxide. Suggested contraindications include patients with significant respiratory compromise or patients that cannot adequately breathe through their nose (upper respiratory tract infections, blocked sinuses, blocked nasal passages, and mouth breathers), in patients where gas expansion of body cavities could cause patient safety problems (pneumoencephalography, pneumothorax, air embolism, patients with colostomy bags or bowel obstruction, patients whom have undergone middle ear surgery, and cystic fibrosis), first trimester of pregnancy, patients undergoing treatment with bleomycin sulfate, vitamin B12 deficiency, severe emotional or psychiatric disturbances or drug related dependencies, and in patients who have received ocular surgery that included a gas bubble in the eye. ${ }^{124,125}$

\section{Intervention and Comparator}

Nonpharmacological management of acute pain was beyond the scope of this review and thus we cannot comment on how effectiveness and harms of these strategies compare to studied analgesics. As previously mentioned, most analgesics were delivered via the IV route, followed by IN routes for fentanyl and ketamine. Other routes were less common including nebulized IV fentanyl solution, sublingual ketorolac and oral ibuprofen. There were no studies of intraosseous delivery of analgesics which sometimes is employed in the prehospital setting. Doses for morphine and APAP were typically $0.1 \mathrm{mg} / \mathrm{kg}$ and $1 \mathrm{gm} \mathrm{IV}$, once, respectively. Ketamine IV dosing varied but was generally within the range of doses $(0.1$ to $0.3 \mathrm{mg} / \mathrm{kg})$ considered to be sub-anesthetic. ${ }^{108}$

\section{Outcomes, Timing, Setting}

Pain scores were mostly reported on a 0 to 10 scale and few studies used a $100 \mathrm{~mm}$ visual analog scale. Regardless, we were able to convert values such that all results are reported consistently in out review for a 0 to 10 scale, to enhance applicability of results. Many of the 
included studies were conducted in countries outside of the United States, which may contribute to different practice patterns in the prehospital setting.

Contextual Question 2 is regarding the evidence regarding use of pain assessment tools in the prehospital setting for special populations including children, individuals with cognitive impairment, substance impaired individuals, and non-English speakers. While current guidelines recommend formal assessment of pain in prehospital patients, a paucity of data exist evaluating pain scales in this setting. ${ }^{8,126} \mathrm{~A}$ number of pain scales have been developed and validated specifically for use in children. ${ }^{127,128}$ These pediatric-specific pain scales are important, given the subjective nature of pain and the likelihood for observers, such as parents or other caregivers, to over or underestimate a child's pain. ${ }^{129}$ Current guidelines ${ }^{8}$ recommend use of the FLACC (Faces, Legs, Arms, Cry, and Consolability) or CHEOPS (Children's Hospital of Eastern Ontario Pain Scale) in patients less than 4 years old, the Wong-Baker PACES Pain Scale or the Faces Pain Scale-Revised (FPS-R) for patients 4-12 years old, and the Numeric Rating Scale (NRS) in those over 12 years old. Subsequently published evidence in pediatric emergency departments support these recommendations, showing the FLACC scale to have high interrater reliability in patients 6 months to 5 years old. ${ }^{130}$ and that the FPS-R and Visual Analogue Scale (VAS) have strong properties in children 6-17 years old. ${ }^{131}$ Ultimately, the choice of scale in prehospital settings should be guided by the child's age, development, clinical status, and practitioner preference. Data exist for assessing pain in both pediatric ${ }^{132}$ and older adults with cognitive impairment, ${ }^{133}$ although none of it is in the prehospital setting. The inability of patients, young and old alike, with cognitive impairment to self-report pain make them susceptible to under treatment leading to a worsening of their underlying condition and worsening cognitive decline. In hospitalized children with cognitive impairment, the revised FLACC scale has been most studied in acute care settings. ${ }^{132}$ Within the emergency department, literature reports common use of the VAS combined with clinician's own intuition for assessing pain in elderly patients with cognitive impairment. ${ }^{134}$ A combination of observational and behavioral instruments has been recommended for pain assessment in older patients with dementia, although additional validation is required. ${ }^{133}$ No literature exists for specifically assessing pain severity in substance impaired individuals. Lastly, a number of these scales have been translated and validated for use in non-English speakers including (for example), but not limited to, Spanish, ${ }^{135,136}$ Finnish, ${ }^{137}$ Japanese, ${ }^{138}$ and Korean. ${ }^{139}$ Of note, none of these scales have been studied in the prehospital setting.

KQ 1 and 2 are answered based on indirect data from the ED.

\section{Limitations}

The major limitation of this review is the indirectness of evidence. Although our plan was to use prehospital data when possible, few studies were available for each unique comparison and outcome. Most of the literature from the prehospital setting is related to morphine versus fentanyl, which was not prioritized as a contemporary decisional dilemma for this evidence review and was not the focus of this report. With that said, we used the best available evidence to answer the KQs of this review.

The indirectness of evidence may have significant implications. The type and training of healthcare professionals administering analgesia in these two settings is different. Resources available to the medical team such as therapies, monitoring devices and diagnostic testing vary. The fact that the prehospital setting is mobile brings unique challenges not present in the ED. 
Given these differences, conclusions based on ED data were downgraded for indirectness, lowering the strength of evidence.

Subgroup analysis was not possible in many cases for various reasons, but these subgroups were important to the sponsor and experts in the field that constituted the Technical Expert Panel. Patient characteristics based on mean baseline parameters were aggregated around one extreme (e.g. severe but not moderate baseline pain, adult ages). In other cases a particular route, dose or pain type dominated the evidence base for a given comparison and outcome. No subgroup analyses were possible based on medical condition, including chronic pain. A single trial was performed in subjects with opioid addiction, but again comparing morphine to fentanyl and not informing contemporary analgesic comparisons. We found no evidence to describe comparative harms to EMS personnel during analgesic administration.

Use of ED data was associated with addition challenges. Pain, and usually cardiorespiratory monitoring parameters, were measured multiple times throughout the study period. Balancing analysis of the most appropriate time points against multiple hypothesis testing was a challenge. We chose to evaluate these outcomes at 15, 30 and 60 minutes. We based this decision on the expected pharmacokinetics of the analgesics studied, and the time points which would most likely encompass the typical transport time in the US.

We were challenged with the outcomes of mental status changes and emergence delirium. Many symptoms reported as harms in a trial could be considered a mental status change. We were quite liberal in what we allowed under this outcome, but kept analyses of distinct "symptoms" separate since within a study these outcomes may not have been mutually exclusive. Emergence delirium is a concern specific to ketamine. Several signs or symptoms may be associated with this phenomenon and we were strict in collecting data explicitly reported by the authors as emergence reactions, delirium or phenomenon. We did not assume a vaguely reported symptom may have been emergence delirium.

\section{Key Areas for Future Research}

The single most important future research need is addressing the gap of evidence of comparative effectiveness and harm of analgesics specifically in the prehospital setting. This stands for both initial analgesia and best approaches for when initial analgesia fails. Ideally such studies in the prehospital setting would be prospective in nature and optimally blinded to minimize the associated bias when the primary outcomes are subjective, as is pain. We found little evidence overall for subgroups in our review and many of them were left without data regardless of the analgesic, making these areas ideal for future research. Examples of these subgroups include special populations such as pediatrics, geriatrics and patients in shock. Similarly, evaluations of specific pain assessment tools in prehospital populations are lacking (particularly those in special populations).

Importantly, we found no evidence regarding how the level of emergency medical services (EMS) personnel training may impact outcomes. This may be most important for future research related to ketamine in the prehospital setting. Recent guidance ${ }^{109}$ for acute pain management suggests that healthcare providers that administer ketamine should hold the following qualifications: appropriately trained nurse with Advanced Cardiac Life Support training, with training in administration of moderate sedation, have knowledge of ketamine pharmacology, monitor for ketamine infusions at subanesthetic doses, and change doses based on directions from a responsible physician, who should be an anesthesiologist, intensive care physician, pain physician, or emergency medicine physician. No evidence was found for the outcomes of 
diversion or the future risk of substance abuse or misuse by EMS personnel, which also present an opportunity to evaluate in future studies.

Research is needed to explore analgesic regimen characteristics. The analgesics that form the basis of this review were mostly administered IV. Some studies of ketamine and fentanyl studied IN routes, but comparatively less than IV routes, and oral routes were rarely evaluated. There are times where IV access is not ideal or possible. Thus, research of routes that will provide quick and effective analgesia, other than IV, is needed. In addition, we were unable to evaluate how dose, frequency of administration, or timing of subsequent doses may modify effects. This may be less important for doses with longstanding drugs like morphine or APAP where almost all studies used the standard $0.1 \mathrm{mg} / \mathrm{kg}$ and $1 \mathrm{~g}$ dosing, respectively. However, even for these analgesics, we found no comparative evidence regarding timing for re-dosing. For ketamine, dose effects may be more important for future research given it is a newer option for acute pain and ideal dosing and administration methods are less certain for this indication. ${ }^{108}$

We recognize there are setting-related characteristics that may make it challenging to conduct rigorous, prospective trials in the prehospital setting. Alternative study designs can be informative and may be more practical. The National Highway Safety and Transportation Administration funds a National Emergency Services Information System (NEMSIS) to store data from EMS encounters in the US in an effort to improve patient care. ${ }^{140}$ Resources should be allocated to explore the feasibility of conducting rigorous observational studies that employ methods to minimize confounding and bias within this national database. Ideally, the database would include the name, dose, route and timing of administration of analgesics used during transport, transport time, hospital arrival time, re-dosing of analgesia or addition of analgesics, training of EMS personnel administering the analgesics, a pain score prior to administration of analgesia and again at the point of hospital arrival and presence of important adverse events.

\section{Conclusion}

As initial analgesia administered primarily IV, opioids are no different than ketamine, APAP and NSAIDs in reducing acute pain in the prehospital setting. Opioids may cause fewer total side effects than ketamine, but more than APAP or NSAIDs. Differences in specific side effects vary between analgesics and can further inform treatment decisions. Combined administration of an opioid and ketamine may reduce acute pain more than an opioid alone but comparative harms are uncertain. When initial morphine is inadequate in reducing pain, giving ketamine may provide greater and quicker acute pain relief than giving additional morphine, although comparative harms are uncertain. Due to indirectness, strength of evidence is generally low, and future research in the prehospital setting is needed. 


\section{References}

1. McLean SA, Maio RF, Domeier RM. The epidemiology of pain in the prehospital setting. J Emerg Med. 2002;6(4):402-405. PMID: 12385606.

2. Thomas SH, Shewakramani S. Prehospital trauma analgesia. J Emerg Med. 2008 Jul:35(1):47-57. PMID: 17997072.

3. Albrecht E, Taffe P, Yersin B, et al. Undertreatment of acute pain (oligoanalgesia) and medical practice variation in prehospital analgesia of adult trauma patients: a $10 \mathrm{yr}$ retrospective study. Br J Anaesth. 2013 Jan;110 (1):96-106. PMID: 23059961.

4. Izsak E, Moore JL, Stringfellow K, Oswanski MF, Kindstrom DA, Stombaugh HA. Prehospital pain assessment in pediatric trauma. Prehosp Emerg Care 2008;12:182-6. PMID 18379914.

5. McEachin CC, McDermott JT, Swor R. Few emergency medical services patients with lowerextremity fractures receive prehospital analgesia. Prehosp Emerg Care. 2002 Oct-Dec;6(4):406410. PMID: 12385607.

6. Fast M, Newton S. Assessment of pain in the transport environment: a review of the literature. J Emerg Nurs. 2008 Aug;34(4):301-304. PMID: 18640408.

7. Bounes V, Barniol C, Minville V, et al. Predictors of pain relief and adverse events in patients receiving opioids in a prehospital setting. Am J Emerg Med. 2011 Jun;29(5):512517. PMID: 20825821.

8. Gausche-Hill M, Brown KM, Oliver ZJ, et al. An evidence-based guideline for prehospital analgesia in trauma. Prehosp Emerg Care. 2014;18 Suppl 1:25-34. PMID: 24279813.

9. Jennings PA, Cameron P, Bernard S. Measuring acute pain in the prehospital setting. Emerg Med J. 2009 Aug;26(8):552-555. PMID: 19625547.

10. Clark DJ, Schumacher MA. America's opioid epidemic: supply and demand considerations. Anesth Analg. 2017 Nov;125(5):1667-1674. PMID: 29049112.

11. Hoppe JA, Nelson LS, Perrone J, et al. Opioid prescribing in the cross section of US emergency departments. Ann Emerg Med. 2015 Sep;66(3):253-259. PMID: 25952503.

12. Benyamin R AND Trescot AM, Datta S, et al. Opioid complications and side effects. Pain Physician. 2008 Mar;11(2 Suppl):S105-S120. PMID: 18443635.
13. Acteminophen. In: Lexi-drugs online [database on the Internet]. Hudson (OH): Lexicomp, Inc.; 2019 [updated 24 Jan 2019; cited 4 Feb 2019]. Available from: http://online.lexi.com. Subscription required to view.

14. Fentanyl. In: Lexi-drugs online [database on the Internet]. Hudson (OH): Lexicomp, Inc.; 2019 [updated 24 Jan 2019; cited 4 Feb 2019]. Available from: http://online.lexi.com. Subscription required to view.

15. Panagiotou I, Mystakidou K. Intranasal fentanyl: from pharmacokinetics and bioavailability to current treatment applications. Expert Rev Anticancer Ther. 2010 Jul;10(7):1009-1021. PMID: 20645689.

16. Younge PA, Nicol MF, Kendall JM, et al. A prospective randomized pilot comparison of intranasal fentanyl and intramuscular morphine for analgesia in children presenting to the emergency department with clinical fractures. Emerg Med. 1999;11:90-94.

17. Frey TM, Florin TA, Caruso M, et al. Effect of intranasal ketamine vs fentanyl on pain reduction for extremity injuries in children: the PRIME randomized clinical trial. JAMA Pediatr. 2019 Feb;173(2):140-146. PMID: 30592476.

18. Mather LE, Woodhouse A, Ward ME, et al. Pulmonary administration of aerosolized fentanyl: pharmacokinetic analysis of systemic delivery. Br J Clin Pharmacol. 1998 Jul;46(1):37-43. PMID: 9690947.

19. Deaton T, Auten J, Darracq MA. Nebulized fentanyl vs intravenous morphine for ED patients with acute abdominal pain: a randomized double-blinded, placebo-controlled clinical trial. Am J Emerg Med. 2015 Jun;33(6):791-795. PMID: 25840767.

20. Shervin F, Shiralizadeh S, Talebian MT, et al. Nebulized fentanyl vs intravenous morphine for ED patients with acute limb pain: a randomized clinical trial. Am J Emerg Med. 2014 Sep;32(9):1011-1015. PMID: 25027194.

21. Furyk JS, Grabowski WJ, Black LH. Nebulized fentanyl versus intravenous morphine in children with suspected limb fractures in the emergency department: a randomized controlled trial. Emerg Med Austral. 2009 Jun;21(3):203-209. PMID: 19527280.

22. Fentanyl Citrate. In Depth Answers [database on the Internet]. Greenwood Village (CO): Truven 
Health Analytics; 2019 [updated 1 Feb 2019; cited 2017 Jan 5]. Available from:

www.micromedexsolutions.com. Subscription required to view.

23. Ibuprofen. In: Lexi-drugs online [database on the Internet]. Hudson (OH): Lexicomp, Inc.; 2019 [updated 1 Feb 2019; cited 4 Feb 2019]. Available from: http://online.lexi.com. Subscription required to view.

24. Smith HS, Voss B. Pharmacokinetics of intravenous ibuprofen: implications of time of infusion in the treatment of pain and fever. Drugs. 2012 Feb;72(3):327-337. PMID: 22316349.

25. Cohen SP, Bhatia A, Buvanendran A, et al. Consensus guidelines on the use of intravenous ketamine infusions for chronic pain from the American Society of Regional Anesthesia and Pain Medicine, the American Academy of Pain Medicine, and the American Society of Anesthesiologists. Reg Anesth Pain Med. 2018 Jul;43(5):521-46.

26. American College of Emergency Physicians. Sub-dissociative dose ketamine for analgesia. Available at: https://www.acep.org/patientcare/policy-statements/sub-dissociative-doseketamine-for-analgesia/. Accessed $11 \mathrm{March}$, 2019.

27. Tran KP, Nguyen Q, Truong XN, et al. A comparison of ketamine and morphine analgesia in prehospital trauma care: a cluster randomized clinical trial in rural Quang Tri province, Vietnam. Prehosp Emerg Care. 2014 AprJun;18(2):257-264. PMID: 24400915.

28. Sub-dissociative ketamine for the management of acute pediatric pain. NCT01951963. https://clinicaltrials.gov/ct2/show/NCT01951963 ?term $=$ NCT01951963\&rank=1. Accessed 11 March, 2019.

29. Reynolds SL, Bryant KK, Studnek JR, et al. Randomized controlled feasibility trial of intranasal ketamine compared to intranasal fentanyl for analgesia in children with suspected extremity fractures. Acad Emerg Med. 2017 Dec;24(12):1430-1440. PMID: 28926159.

30. Graudins A, Meek R, Egerton-Warburton D, Oakley E. The PICHFORK (Pain in Children Fentanyl or Ketamine) Trial: a randomized controlled trial comparing intranasal ketamine and fentanyl in children with limb injuries. Ann Emerg Med 2015;65:248-254. PMID: 25447557.
31. Ketorolac. In: Lexi-drugs online [database on the Internet]. Hudson (OH): Lexicomp, Inc.; 2019 [updated 30 Jan 2019; cited 4 Feb 2019]. Available from: http://online.lexi.com. Subscription required to view.

32. Morphine. In: Lexi-drugs online [database on the Internet]. Hudson (OH): Lexicomp, Inc.; 2019 [updated 3 Feb 2019; cited 4 Feb 2019]. Available from: http://online.lexi.com. Subscription required to view.

33. Nitrous Oxide. In: Lexi-drugs online [database on the Internet]. Hudson (OH): Lexicomp, Inc.; 2019 [updated 31 Oct 2018; cited 4 Feb 2019]. Available from: http://online.lexi.com. Subscription required to view.

34. Agency for Healthcare Research and Quality. Methods guide for effectiveness and comparative effectiveness reviews. https://effectivehealthcare.ahrq.gov/topics/cermethods-guide/overview. Accessed 11 March, 2019.

35. Higgins JP, Altman DG, Gotzsche PC, et al. The Cochrane Collaboration's tool for assessing risk of bias in randomised trials. BMJ. 2011 Oct;343:d5928. PMID: 22008217.

36. Wells GA, Shea B, O'Connell D, et al. The Newcastle-Ottawa Scale (NOS) for assessing the quality of nonrandomized studies in metaanalyses. The Ottawa Hospital Research Institute. http://www.ohri.ca/programs/clinical_epidemiol ogy/oxford.asp. Accessed 11 March, 2019.

37. Viswanathan M, Ansari MT, Berkman ND, et al. Assessing the risk of bias of individual studies in systematic reviews of health care interventions; 2012. In: Methods Guide for Effectiveness and Comparative Effectiveness. AHRQ Publication No. 10(14)-EHC063-EF. Rockville, MD: Agency for Healthcare Research and Quality; 2014. Chapters available at www.effectivehealthcare.ahrq.gov.

38. Paule RC, Mandel J. Consensus values, regressions, and weighting factors. J Res Natl Inst Stand Technol. 1989 May-Jun;94(3):197203. PMID: 28053410.

39. Knapp G, Hartung J. Improved tests for a random effects meta-regression with a single covariate. Stat Med. 2003 Sep;22(17):26932701. PMID: 12939780.

40. Seide SE, Rover C, Friede T. Likelihood-based random-effects meta-analysis with few studies: 
empirical and simulation studies. BMC Med Res Methodol. 2019 Jan;19(1):16. PMID: 30634920.

41. DerSimonian R, Laird N. Meta-analysis in clinical trials revisited. Control Clin Trials. 2015 Nov;45(Pt A):139-145. PMID: 26343745.

42. Follmann D, Elliott P, Suh I, Cutler J. Variance imputation for overviews of clinical trials with continuous response. J Clin Epidemiol. 1992 Jul;45(7):769-773. PMID: 1619456.

43. Thorlund K, Walter SD, Johnston BC, et al. Pooling health-related quality of life outcomes in meta-analysis - a tutorial and review of methods for enhancing interpretability. Res Synth Meth. 2011 Sep;2(3):188-203. PMID: 26061786.

44. Wan X, Wang W, Liu J, Tong T. Estimating the sample mean and standard deviation from the sample size, median, range and/or interquartile range. BMC Med Res Methodol. 2014 Dec;14:135. PMID: 25524443.

45. Bradburn MJ, Deeks JJ, Berlin JA, Russell Localio A. Much ado about nothing: a comparison of the performance of metaanalytical methods with rare events. Stat Med. 2007 Jan;26(1):53-77. PMID: 16596572.

46. Cheng J, Pullenayegum E, Marshall JK, Iorio A, Thabane L. Impact of including or excluding both-armed zero-event studies on using standard meta-analysis methods for rare event outcome: a simulation study. BMJ Open. 2016 Aug;6(8):e010983. PMID: 27531725.

47. Higgins JP, Thomas SG, Deeks JJ, Altman DG. Measuring inconsistency in meta-analyses. BMJ. 2003 Sep;327:557-560. PMID: 12958120.

48. Sterne JAC, Sutton AJ, Ioannidis JPA, et al. Recommendations for examining and interpreting funnel plot asymmetry in metaanalyses of randomised controlled trials. BMJ. 2011 Jul;342:d4002. PMID: 21784880.

49. Berkman ND, Lohr KN, Ansari M, et al. Grading the Strength of a Body of Evidence When Assessing Health Care Interventions for the Effective Health Care Program of the Agency for Healthcare Research and Quality: An Update, 2013. In: Methods Guide for Effectiveness and Comparative Effectiveness Reviews. AHRQ Publication No. 10(14)-EHC063-EF. Rockville MD: Agency for Healthcare Research and Quality; 2014. Chapters available at www.effectivehealthcare.ahrq.gov.

50. Atkins D, Chang S, Gartlehner G, et al. Assessing the Applicability of Studies When Comparing Medical Interventions; 2010. In:
Methods Guide for Effectiveness and Comparative Effectiveness Reviews. AHRQ Publication No. 10(14)-EHC063-EF. Rockville, MD: Agency for Healthcare Research and Quality; 2014. Chapters available at www.effectivehealthcare.ahrq.gov.

51. Verki MM, Mozafari J, Tirandaz F, Motamed H, Khazaeli A. Efficacy of nebulized fentanyl and low dose ketamine for pain control of patients with long bone fractures: a randomized, doubleblind, clinical trial. African Journal of Emergency Medicine. 2019; doi.org/10.1016/j.afjem.2019.02.003. [Epub ahead of print].

52. Quinn K, Kriss S, Drapkin J, et al. Analgesic efficacy of intranasal ketamine versus intranasal fentanyl for moderate to severe pain in children: a prospective, randomized, double-blind study. Pediatr Emerg Care. 2018 Jul 24; doi: 10.1097/PEC. 0000000000001556. [Epub ahead of print]. PMID: 30045355.

53. Shimonovich S, Gigi R, Shapira A, et al. Intranasal ketamine for acute traumatic pain in the emergency department: a prospective, randomized clinical trial of efficacy and safety. BMC Emerg Med. 2016 Cov;16(1):43. PMID: 27829367.

54. Farnia MR, Jalali A, Vahidi E, et al. Comparison of intranasal ketamine versus IV morphine in reducing pain in patients with renal colic. AM J Emerg Med. 2017 Mar;35(3):434-437. PMID: 27931762.

55. Motov S, Mann S, Drapkin J, et al. Intravenous subdissociative-dose ketamine versus morphine for acute geriatric pain in the emergency department: a randomized controlled trial. Am J Emerg Med. 2019 Feb;37(2):220-227. PMID: 29807629.

56. Mahshidfar B, Mofidi M, Fattahi M, et al. Acute pain management in emergency department, low dose ketamine versus morphine, a randomized clinical trial. Anesth Pain Med. 2017 Dec;7(6):e60561. PMID: 29696126.

57. Motov S, Rockoff B, Cohen V, et al. Intravenous subdissociative-dose ketamine versus morphine for analgesia in the emergency department: a randomized controlled trial. Ann Emerg Med. 2015 Sep;66(3):222-229. PMID: 25817884.

58. Miller JP, Schauer SG, Ganem VJ, Bebarta VS. Low-dose ketamine vs morphine for acute pain in the ED: a randomized controlled trial. Am J Emerg Med. 2015 Mar;33(3):402-8. PMID: 25624076. 
59. Majidinejad S, Esmailian M, Emadi M. Comparison of intravenous ketamine with morphine in pain relief of long bones fractures: a double blind randomized clinical trial. Emerg (Tehran). 2014 Spring;2(2):77-80. PMID: 26495351.

60. Jahanian F, Hosseininejad SM, Amini Ahidashti $\mathrm{H}$, et al. Efficacy and safety of morphine and low dose ketamine for pain control of patients with long bone fractures: a randomized, double-blind, clinical trial. Bull Emerg Trauma. 2018 Jan;6(1):31-36. PMID: 29379807.

61. Bronsky ES, Koola C, Orlando A, et al. Intravenous low-dose ketamine provides greater pain control compared to fentanyl in a civilian prehospital trauma system: a propensity matched analysis. Prehosp Emerg Care. 2018 May;1-8. doi: 10.1080/10903127.2018.1469704. [Epub ahead of print]. PMID: 29775117.

62. Schauer SG, Mora AG, MAddry JK, Bebarta VS. Multicenter, prospective study of prehospital administration of analgesia in the U.S. combat theater of Afghanistan. Prehosp Emerg Care. 2017 Nov-Dec;21(6):744-749. PMID: 28829661.

63. Schackelford SA, Fowler M, Schultz K, et al. Prehospital pain medication use by U.S. forces in Afghanistan. Mil Med. 2015 Mar;180(3):304309.PMID: 25735021.

64. Jennings PA, Cameron P, Bernard S, et al. Morphine and ketamine is superior to morphine alone for out-of-hospital trauma analgesia: a randomized controlled trial. Ann Emerg Med. 2012 Jun;59(6):497-503. PMID: 22243959.

65. Johansson P, Kongstad P, Johansson A. The effect of combined treatment with morphine sulphate and low-dose ketamine in a prehospital setting. Scand J Trauma Resusc Emerg Med. 2009 Nov; 17:61. PMID: 19943920.

66. Galinski M, Dolveck F, Combes X, et al. Management of severe acute pain in emergency settings: ketamine reduces morphine consumption. Am J Emerg Med. 2007 May;25(4):385-390. PMID: 17499654.

67. Oberholzer N, Kaserer A, Albrecht R, et al. Factors influencing quality of pain management in a physician staffed helicopter emergency medical service. Anesth Analg. 2017 Jul;125(1):200-209. PMID: 28489643.

68. Hosseininejad SM, Jahanian F, Erfanian Irankar $\mathrm{S}$, et al. Comparing the analgesic efficacy of morphine plus ketamine versus morphine plus placebo in patients with acute renal colic: a double-blinded randomized controlled trial. Am J Emerg Med. 2018 Sep 3. pii: S0735-

6757(18)30733-2. doi: 10.1016/j.ajem.2018.09.004. [Epub ahead of print]. PMID: 30201237.

69. Sin B, Tatunchak T, Paryavi M, et al. The use of ketamine for acute treatment of pain: a randomized, double-blind, placebo-controlled trial. J Emger Med. 2017 May;52(5):601-608. PMID: 28279542.

70. Beaudoin FL, Lin C, Guan W, Merchant RC. Low-dose ketamine improves pain relief in patients receiving intravenous opioids for acute pain in the emergency department: results of a randomized, double-blind, clinical trial. Acad Emerg Med. 2014 Nov;21(11):1193-1202. PMID: 25377395.

71. Abbasi S, Bidi N, Mahshidfar B, et al. Can lowdose of ketamine reduce the need for morphine in renal colic? A double-blind randomized clinical trial. Am J Emerg Med. 2018 Mar;36(3):376-379. PMID: 28821365.

72. Mohammadshahi A, Abdolrazaghnejad A, Nikzamir H, Safaie A. Intranasal ketamine administration for narcotic dose decrement in patients suffering from acute limb trauma in emergency department: a double-blind randomized placebo-controlled trial. Adv J Emerg Med. 2018;2(3):e30.

73. Vahdati S, Morteza Baghi HR, Ghobadi J, et al. Comparison of paracetamol (apotel $\AA$ ) and morphine in reducing post pure head trauma headache. Anesth Pain Med. 2014Jun;4(3):e14903. PMID: 25237630.

74. Jalili M, Mozaffarpour Noori A, Sedaghat M, Safaie A. Efficacy of intravenous paracetamol versus intravenous morphine in acute limb trauma. Trauma Mon. 2016 Feb;21(1):e19649.

75. Pathan SA, Mitra B, Straney LD, et al. Delivering safe and effective analgesia for management of renal colic in the emergency department: a double-blind, multigroup, randomised controlled trial. Lancet. 2016 May;387(10032):1999-2007. PMID: 26993881.

76. Serinken M, Eken C, Gungor F, et al. Comparison of intravenous morphine versus paracetamol in sciatica: a randomized placebo controlled trial. Acad Emerg Med. 2016 Jun;23(6):674-678. PMID: 26938140.

77. Eken C, Serinken M, Elicabuk H, et al. Intravenous pracetamol vesus dexketoprofen versus morphine in acute mechanical low back 
pain in the emergency department: a randomised double-blind controlled trial. Emerg Med J. 2014 Mar;31(3):177-181. PMID: 23407378.

78. Serinken M, Eken C, Turkcuer I, et al. Intravenous paracetamol versus morphine for renal colic in the emergency department: a randomised double-blind controlled trial. Emerg Med J. 2012 Nov;29(11):902-905. PMID: 22186009.

79. Craig M, Jeavons R, Probert J, Benger J. Randomised comparison of intravenous paracetamol and intravenous morphine for acute traumatic limb pain in the emergency department. Emerg Med J. 2012 Jan;29(1):37-39. PMID: 21362724.

80. Al B, Sunar MM, Zengin S, et al. Comparison of IV dexketoprofen trometamol, fentanyl, and paracetamol in the treatment of renal colic in the ED: a randomized controlled trial. Am J Emerg Med. 2018 Apr;36(4):571-576. PMID: 29029797.

81. Mollaei M, Esmailian M, Heydari F. Comparing the effect of intravenous acetaminophen (Apotel $\AA$ ) and intravenous morphine in controlling the pain of forearm and leg fractures in adults. J Isfahan Med Sch. 2016;34(376):293298.

82. Masoumi K, Forouzan A, Asgari Darian A, et al. Comparison of clinical efficacy of intravenous acetaminophen with intravenous morphine in acute renal colic: a randomized, double-blind, controlled trial. Emerg Med Int. 2014;2014:571326. PMID: 25197573.

83. Kariman H, Majidi A, Amini A et al. Nitrous oxide/oxygen compared with fentanyl in reducing pain among adults with isolated extremity trauma: a randomized trial. Emergency Medicine Australia 2011;23:761-768.

84. Masoumi B, Farzaneh B, Ahmadi O, Heidari F. Effect of intravenous morphine and ketorolac on pain control in long bones fractures. Adv Biomed Res. 2017 Jul;6:91. PMID: 28828342.

85. Safdar B, Degutis LC, Landry K, et al. Intravenous morphine plus ketorolac is superior to either drug alone for treatment of acute renal colic. Ann Emerg Med. 2006 Aug;48(2):173181. PMID: 16953530.

86. Le May S, Ali S, Plint AC, et al. Oral analgesics utilization for children with musculoskeletal injury (OUCH Trial): an RCT. Pediatrics. 2017 Nov;140(5): pii: e20170186. doi: 10.1542/peds.2017-0186. Epub 2017 Oct 11. PMID: 29021235.

87. Cenker E, Serinken M, Uyanik E. Intravenous paracetamol vs ibuprofen in renal colic: a randomised, double-blind, controlled clinical trial. Urolithiasis. 2018 Aug;46(4):369-373. PMID: 28681267.

88. Cozzi G, Zanchi C, Chiaretti A, et al. Adminsitering analgesia sublingually is a suitable option for children with acute abdominal pain in the emergency room. Acta Paediatr. 2019 Jan;108(1):143-148. PMID: 30043434.

89. Clark E, Plint AC, Correll R, et al. A randomized, controlled trial of acetaminophen, ibuprofen, and codeine for acute pain relief in children with musculoskeletal trauma. Pediatrics. 2007 Mar;119(3):460-467. PMID: 17332198.

90. Sotoodehnia M, Farmahini-Farahani M, Safaie A, Rasooli F, Baratloo A. Low-dose intravenous ketamine versus intravenous ketorolac in pain control in patients with acute renal colic in an emergency setting: a double-blind randomized clinical trial. Korean J Pain 2019;32:97-104. PMID: 31091508.

91. Vahedi HSM, Hajebi H, Vahidi E, Nejati A, Saeedi M. Comparison between intravenous morphine versus fentanyl in acute pain relief in drug abusers with acute limb traumatic injury. World J Emerg Med 2019;10:27-32. PMID: 30598715.

92. Weldon ER, Ariano RE, Grierson RA. Comparison of fentanyl and morphine in the prehospital treatment of ischemic type chest pain. Prehosp Emerg Care. 2016;20(1):45-51. PMID: 26727338.

93. Galinski M, Dolveck F, Borron S et al. A randomized, double-blin study comparing morphine with fentanyl in prehospital analgesia. Am J Emerg Med. 2005;23:114-119. PMID: 15765326.

94. Smith MD, Wang Y, Cudnik M, et al. The effectiveness and adverse events of morphine versus fentanyl on a physician-staffed helicopter. J Emerg Med. 2012 Jul;43(1):69-75. PMID: 21689900.

95. Rickard C, O’Meara P, McGrail M, et al. A randomized controlled trial of intranasal fentanyl vs intravenous morphine for analgesia in the prehospital setting. Am J Emerg Med. 2007 Oct;25(8):911-917. PMID: 17920976.

96. Mahar PJ, Rana JA, Kennedy CS, Christopher NC. A randomized clinical trial of oral transmucosal fentanyl citrate versus intravenous 
morphine sulfate for initial control of pain in children with extremity injuries. Pediatr Emerg Care. 2007 Aug;23(8):544-548. PMID: 17726413.

97. Borland M, Jacobs I, King B, O'Brien D. A randomized controlled trial comparing intranasal fentanyl to intravenous morphine for managing acute pain in children in the emergency department. Ann Emerg Med. 2007 Mar;49(3):335-340. PMID: 17067720.

98. Scharonow M, Alberding T, Oltmanns W, Weilbach C. Project for the introduction of prehospital analgesia with fentanyl and morphine administering by specially trained paramedics in a rural service area in Germany. J Pain Res. 2017 Nov;10:2595-2599. PMID: 29158691.

99. Daoust R, Paguet J, Lavigne G, et al. Impact of age, sex and route of administration on adverse events after opioid treatment in the emergency department: a retrospective study. Pain Res Manag. 2015 Jan-Feb;20(1):23-28. PMID: 25664538.

100. Schacherer NM, Erikson Ramirez D, Frazier SB, Perkins AM. Expedited delivery of pain medication for long-bone fractures using an intranasal fentanyl clinical pathway. Pediatr Emerg Care. 2015 Aug;31(8):560-563. PMID: 25875994.

101. Wenderoth BR, Kaneda ET, Amini A, et al. Morphine versus fentanyl for pain due to traumatic injury in the emergency department. J Trauma Nurs. 2013 Jan-Mar;20(1):10-15. PMID: 23459426.

102.Bendall JC, Simpson PM, Middleton PM. Effectiveness of prehospital morphine, fentanyl, and methoxyflurane in pediatric patients. Prehosp Emerg Care. 2011 Apr-Jun;15(2):158165. PMID: 21294628.

103. Garrick JF, Kidane S, Pointer JE, et al. Analysis of the paramedic administration of fentanyl. $\mathrm{J}$ Opioid Manag. 2011 May-Jun;7(3):229-234. PMID: 21823553.

104.Fleischman RJ, Frazer DJ, Daya M, et al. Effectiveness and safety of fentanyl compared with morphine for out-of-hospital analgesia. Prehosp Emerg Care. 2010 Apr-Jun;14(2):167175. PMID: 20199230.

105. Griffioen MA, Ziegler ML, O'Toole RV, Dorsey SG, Renn CL. Change in pain score after administration of analgesics for lower extremity fracture pain during hospitalization. Pain
Management Nursing 2019;20:158-163. PMID: 30442567.

106.Zhang M, Cowan T, Smiles JP, et al. Prehospital analgesic choice in injured patient does not impact on rates of vomiting: experience from a New South Wales primary retrieval service. Emerg Med Australas. 2018 Jun;30(3):406-411. PMID: 29205811.

107. National Model EMS Clinical Guidelines. Version 2.1 June 2018. NASEMSO Medical Directors Council.

108. American College of Emergency Physicians. Sub-dissociative dose ketamine for analgesia. Available at: https://www.acep.org/patientcare/policy-statements/sub-dissociative-doseketamine-for-analgesia/. Accessed February 28, 2018.

109. Schwenk ES, Viscusi ER, Buvanendran A, et al. Consensus guidelines on the use of intravenous ketamine infusions for acute pain management from the American Society of Regional Anesthesia and Pain Medicine, the American Academy of Pain Medicine, and the American Society of Anesthesiologists. Reg Anesth Pain Med. 2018 Jul;43(5):456-466. PMID: 29870457.

110. Overdyk F, Dahan A, Roozekrans M, van der Schrier R, Aarts L, Niesters M. Opioidindiucuded respiratory dperssion in the acute care setting: a compendium of case reports. Pain Manag 2014;4:317-25. PMID: 25300390.

111.Dahan A, Overdyk F, Smith T, Assrts L, Niesters M. Pharmacovigilence: a review of opioidinduced respiratory depression in chronic pain patients. Pain Physician 2013;16:E85-94. PMID: 23511694.

112.Ketalar [package insert]. Par Pharmaceuticals, Inc. Chestnut Ridge, NY. August 2018.

113. Morphine sulfate [package insert]. Eatontown, NJ: West-Ward Pharmaceuticals Corp; 2016.

114.Morphine sulfate injection [package insert]. Lake Zurich, IL: Fresenius Kabi USA, LLC; 2016.

115. Fentanyl citrate injection solution [package insert]. Lake Forest, IL: Hospira Inc; 2018.

116.Lazanda ${ }^{\circledR}$ [package insert]. Bedminster, NJ: Archimedes Development Ltd; 2012.

117. Fentanyl citrate lozenge [package insert]. Webster Groves, MO: SpecGx LLC; 2017.

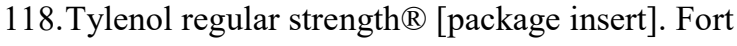
Washington, PA: Johnson \& Johnson Consumer Inc., McNeil Consumer Healthcare Division; 2017. 
119.Ofirmev® [package insert]. Hazelwood, MO: Mallinckrodt Hospital Products Inc; 2018.

120. Ketorolac tromethamine injection [package insert]. Rancho Cucamonga: Amphasatar Pharmaceuticals Inc; 2017.

121. Toradol® oral [package insert]. Nutley, NJ: Roche Laboratories Inc; 2008.

122. Caldolor ${ }^{\circledR}$ [package insert]. Nashville, TN: Cumberland Pharmaceuticals Inc; 2019.

123.Motrin ${ }^{\circledR}$ [package insert]. New York, NY: Pharmacia \& Upjohn Company, Division of Pfizer Inc; 2007.

124.American Academy of Pediatric Dentistry. Guideline on use of nitrous oxide for pediatric dental patients. Pediatr Dent. 2013 SepOct;35(5):E174-178. PMID: 24290547.

125.Clark M. In: Back to the future: An update on nitrous oxide/oxygen sedation. Hartley M, editor. Tulsa, Oklahoma: Craig Dickson; 2009. pp. 629.

126. Karcioglu O, Topacoglu H, Dikme O, Dikme O. A systematic review of the pain scales in adults: Which to use? Am J Emerg Med. 2018 Apr;36(4):707-14. PMID: 29321111.

127. Birnie KA, Hundert AS, Lalloo C, et al. Recommendations for selection of self-report pain intensity measures in children and adolescents: a systematic review and quality assessment of measurement properties. Pain. 2019 Jan;160(1):5-18. PMID: 30180088.

128. Tomlinson MN, von Baeyer CL, Stinson JN, Sung L. A systematic review of faces scales for the self-report of pain intensity in children. Pediatrics. 2010 Nov;126(5):e1168-98. PMID: 20921070.

129. Chambers CT, Reid GJ, Craig KD, et al. Agreement between child and parent reports of pain. Clin J Pain. 1998 Dec;14(4):336-42. PMID: 9874013.

130.Kichman A, Howell J, Sheridan M, et al. Reliability of the Faces, Legs, Activity, Cry, and Consolability Scale in assessing acute pain in the pediatric emergency department. Pediatr Emerg Care. 2017 Jan;33(1):14-7. PMID: 27977532.

131.Le May S, Ballard A, Khadra C, et al. Comparison of the psychometric properties of 3 pain scales used in the pediatric emergency department: Visual Analogue Scale, Faces Pain Scale-Revised, and Colour Analogue Scale. Pain. 2018 Aug;159(8):1508-17. PMID: 29608509.

132. Crosta QR, Ward TM, Walker AJ, Peters LM. A review of pain measures for hospitalized children with cognitive impairment. J Spec Pediatr Nurs. 2014 Apr;19(2):109-18. PMID: 24612473.

133.Hadjistavropoulos T, Herr K, Prkachin KM, et al. Pain assessment in elderly adults with dementia. Lance Neurol. 2014 Dec;13(12):121627. PMID: 25453461.

134.Jones J, Sim TF, Hughes J. Pain assessment of elderly patients with cognitive impairment in the emergency department: implications for pain management - a narrative review of current practices. Pharmacy (Besel). 2017 Jun;5(2):pii: E30. PMID: 28970442.

135.Carcia-Galicia A, Lara-Munoz Mdel C, Arechiga-Santamaria A, et al. Validity and consistency of a new scale (Faces Pain Scale) and of the Spanish version of the CHEOPS scale to evaluate postoperative pain in children. $\mathrm{Cir}$ Cir. 2012 Nov-Dec;80(6):510-5. PMID: 23336144.

136.da Silva FC, Santos Thuler LC, de LeoonCasasola OA. Validity and reliability of two pain assessment tools in Brazilian children and adolescents. J Clin Nurs. 2011 Jul;20(1314):1842-8. PMID: 21564357.

137. Repo JP, Tukiainen EJ, Roine RP, et al. Reliability and validity of the Finnish version of the Visual Analogue Scale Foot and Ankle (VAS-FA). Foot Ankle Surg. 2018 Dec;24(6):474-80. PMIS: 29409192.

138. Matsuichi Y, Hoshino H, Shimojo N, et al. Verifying the validity and reliability of the Japanese version of the Face, Legs, Activity, Cry, Consolability (FLACC) Behavioral Scale. PLoS ONE. 2018 Mar;13(3):e0194094. PMID: 29534083.

139. Moon Y, Kim YS, Lee J, Han SH. Validity of the Korean Version of the Face, Legs, Activity, Cry, and Consolability Scale for assessment of pain in dementia patients. J Korean Med Sci. 2017 Nov;32(11):1852-6. PMID: 28960040.

140.https://nemsis.org/what-is-nemsis/. Accessed 11 March, 2019. 


\section{Abbreviations and Acronyms}

$\begin{array}{ll}\text { Abbreviation } & \text { Definition } \\ \text { AHRQ } & \text { Agency for Healthcare Research and Quality } \\ \text { APAP } & \text { acetaminophen } \\ \text { CI } & \text { confidence interval } \\ \text { CID } & \text { clinically important difference } \\ \text { CQ } & \text { Contextual Question } \\ \text { ED } & \text { emergency department } \\ \text { EMS } & \text { emergency medical services } \\ \text { EPC } & \text { Evidence-based Practice Center } \\ \text { GCS } & \text { Glasgow Coma Scale } \\ \text { IM } & \text { intramuscular } \\ \text { IN } & \text { intranasal } \\ \text { IQR } & \text { interquartile range } \\ \text { IV } & \text { intravenous } \\ \text { Kg } & \text { kilogram } \\ \text { KQ } & \text { Key Question } \\ \text { Mcg } & \text { microgram } \\ \text { MD } & \text { mean difference } \\ \text { Mg } & \text { milligram } \\ \text { NEB } & \text { nebulizer } \\ \text { NHTSA } & \text { National Highway Traffic Safety Administration } \\ \text { NR } & \text { not reported } \\ \text { NSAID } & \text { nonsteroidal anti-inflammatory } \\ \text { PO } & \text { by mouth } \\ \text { RCT } & \text { randomized controlled trial } \\ \text { RD } & \text { risk difference } \\ \text { SD } & \text { standard deviation } \\ \text { SL } & \text { sublingual } \\ \text { SOE } & \text { strength of evidence } \\ \text { SPID } & \text { summed pain intensity difference } \\ \text { TEP } & \text { Technical Expert Panel } \\ \text { UK } & \text { United Kingdom } \\ \text { US } & \text { United States } \\ \text { VS } & \text { versus } \\ & \end{array}$




\section{Appendixes}

\section{Table of Contents}

Appendix A. Search Strategy $\quad$ A-1

Appendix B. List of Excluded Studies $\quad$ B-1

Appendix C. Evidence Tables $\quad$ C-1

Appendix D. Risk of Bias Assessment $\quad$ D-1

Appendix E. Strength of Evidence Assessments $\quad$ E-1

Appendix F. Forest Plots $\quad$ F-1 


\section{Appendix A. Search Strategy}

\section{Search in Medline, Cochrane Central, and Embase all via OVID}

1. Emergency Medical Services/

2. Emergency Medical Technicians/

3. Emergency Treatment/

4. Emergency Medicine/

5. AMBULANCES/ or AIR AMBULANCES/

6. First Aid/

7. prehospital.mp.

8. pre-hospital.mp.

9. paramedic*.mp.

10. ambulance*.mp.

11. out-of-hospital.mp.

12. out of hospital.mp.

13. ems.mp.

14. emt.mp.

15. emergency services.mp.

16. emergency medical service*.mp.

17. emergency technician*.mp.

18. emergency practitioner.mp.

19. emergency dispatch*.mp.

20. emergency despatch*.mp.

21. first responder*.mp.

22. emergency rescue*.mp.

23. emergency resus*.mp.

24. emergency triage.mp.

25. military medicine/

26. military medicine.mp

27. battlefield.mp

28. combat.mp

29. emergency department.mp

30. hospital/

31. morphine/

32. fentanyl/

33. ketamine/

34. nitrous oxide/

35. ketorolac/

36. ketorolac tromethamine/

37. ibuprofen/

38. acetaminophen/

39. morphine.mp

40. ketamine.mp

41. ketorolac.mp 
42. fentanyl.mp

43. nitrous oxide*.mp

44. ibuprofen.mp

45. acetaminophen.mp

46.31 or 32 or 33 or 34 or 35 or 36 or 37 or 38 or 39 or 40 or 41 of 42 or 43 or 44 or 45

47. 1 or 2 or 3 or 4 or 5 or 6 or 7 or 8 or 9 or 10 or 11 or 12 or 13 or 14 or 15 or 16 or 17 or 18 or 19 or 20 or 21 or 22 or 23 or 24 or 25 or 26 or 27 or 28 or 29 or 30

48. 46 and 47

49. epidemiologic studies/

50. exp cohort studies/

51. exp case-contol studies/

52. case control.tw.

53. (cohort adj (study or studies)).tw.

54. cohort analy\$.tw.

55. (follow up adj (study or studies)).tw.

56. (observational adj (study or studies)).tw.

57. longitudinal.tw.

58. retrospective.tw.

59. cross sectional.tw.

60. cross-sectional studies/

61. or $/ 49-60$

62. randomized controlled trials as topic/

63. randomized controlled trial/

64. random allocation/

65. double blind method/

66. single blind method/

67. clinical trial/

68. clinical trial, phase i.pt.

69. clinical trial, phase ii.pt.

70. clinical trial, phase iii.pt.

71. clinical trial, phase iv.pt.

72. controlled clinical trial.pt.

73. randomized controlled trial.pt.

74. multicenter study.pt.

75. clinical trial.pt.

76. exp clinical trials as topic/

77. or/ $62-76$

78. (clinical adj trial\$).tw.

79. (( $\operatorname{sing} 1 \$$ or doubl $\$$ or treb $\$$ or tripl $\$$ ) adj (blind $\$ 3$ or mask $\$ 3)$ ).tw.

80. placebos/

81. placebo\$.tw.

82. randomly allocated.tw.

83. (allocated adj2 random\$).tw.

84. or/78-83

85.77 or 84

86. case report.tw. 
87. letter/

88. historical article/

89. or/86-88

90.85 not 89

91. 61 or 90

92.91 and 48 


\section{Appendix B. List of Excluded Studies}

\section{Not a human study $n=11$}

1. Arora S, Wagner JG, Herbert M. Myth: parenteral ketorolac provides more effective analgesia than oral ibuprofen. CJEM. 2007 Jan;9(1):30-2. Review. PMID: 17391598.

2. Atkinson P, Chesters A, Heinz P. Pain management and sedation for children in the emergency department. BMJ. 2009 Oct 30;339:b4234. doi: 10.1136/bmj.b4234. Review. PMID: 19880530.

3. Brookoff D, Polomano R. Treating sickle cell pain like cancer pain. Ann Intern Med. 1992 Mar 1;116(5):364-8. PMID: 1736768.

4. Carpenter CR. In patients in the emergency department with acute pain, 10, 15, and 30 mg of ketorolac did not differ for pain relief. Ann Intern Med. 2017 Apr 18;166(8):JC44. doi: 10.7326/ACPJC-2017-166-8-044. PMID: 28418546.

5. Drake AB, Milne WK, Carpenter CR. Hot Off the Press: Subdissociative-dose Ketamine for Acute Pain in the Emergency Department. Acad Emerg Med. 2015 Jul;22(7):887-9. doi: 10.1111/acem.12705. PMID: 26130219.

6. Fournier-Charriere E. Analgesia in pediatric emergency. Medecine Therapeutique Pediatrie. 1999;2(5):381-394.

7. Gottlieb M, Ryan KW, Binkley C. Is Low-Dose Ketamine an Effective Alternative to Opioids for the Treatment of Acute Pain in the Emergency Department? Ann Emerg Med. 2018 Aug;72(2):133-134. doi: 10.1016/j.annemergmed.2017.10.028. PMID: 29229229.

8. Grimaldi D, Cortelli P. Migraine. Treating acute migraine in the emergency department. Nat Rev Neurol. 2009 Oct;5(10):529-31. doi: 10.1038/nrneurol.2009.155. PMID: 19794512.

9. Horowitz BZ, Hendrickson RG, Pizarro-Osilla C. Not so fast! Ann Emerg Med. 2006 Jan;47(1):122-3. PMID: 16387231.

10. Mesa M. From battlefield to backpack: Evolution of the auto-injector. Drug Delivery Technology. 2009;9(3):42-49.

11. Stratton SJ. The Hennepin Ketamine Study. Prehospital and Disaster Medicine. 2018;33:457.

\section{Not in the prehospital, ED or battlefield settings $n=6$}

1. Beaudoin FL, Gutman R, Merchant RC, et al. Persistent pain after motor vehicle collision: comparative effectiveness of opioids vs nonsteroidal anti-inflammatory drugs prescribed from the emergency department-a propensity matched analysis. Pain. 2017 Feb;158(2):289-295. doi: 10.1097/j.pain.0000000000000756. PMID: 28092325.

2. Hughes JM, McKinnon CJ, Taylor KM et al. Nonsteroidal anti-inflammatory drug prescriptions are associated with increased stress fracture diagnosis in the US army population. Journal of Bone and Minderal Research. 2019;34:429. 
3. Molokie RE, Montminy C, Dionisio C, et al. Opioid doses and acute care utilization outcomes for adults with sickle cell disease: ED versus acute care unit. Am J Emerg Med. 2018 Jan;36(1):88-92. doi: 10.1016/j.ajem.2017.07.037. PMID: 28802541.

4. Pollack CV Jr, Diercks DB, Thomas SH, et al. Patient-reported Outcomes from A National, Prospective, Observational Study of Emergency Department Acute Pain Management With an Intranasal Nonsteroidal Anti-inflammatory Drug, Opioids, or Both. Acad Emerg Med. 2016 Mar;23(3):331-41. doi: 10.1111/acem.12902. PMID: 26782787.

5. Poonai N, Bhullar G, Lin K, et al. Oral administration of morphine versus ibuprofen to manage postfracture pain in children: a randomized trial. CMAJ. 2014 Dec 9;186(18):1358-63. doi: 10.1503/cmaj.140907. PMID: 25349008.

6. Thornton JA, Fleming JS, Goldberg AD, et al. Cardiovascular effects of 50 per cent nitrous oxide and 50 per cent oxygen mixture. Anaesthesia. 1973 Sep;28(5):484-9. PMID: 4728154.

\section{Not acute pain $(n=7)$}

1. Adelgais KM, Brent A, Wathen J, et al. Intranasal Fentanyl and Quality of Pediatric Acute Care. J Emerg Med. 2017 Nov;53(5):607-615.e2. doi: 10.1016/j.jemermed.2017.05.027. PMID: 28967529.

2. Eshaya-Chauvin B, Nyffenegger E. Retrospective study of anesthesia for war injuries. Rev Med Suisse Romande. 1990;110(5):429-432.

3. Gharavifard M, Boroumand Reza Zadeh B, Zamani Moghadam H. A Randomized Clinical Trial of Intravenous and Intramuscular Ketamine for Pediatric Procedural Sedation and Analgesia. Emerg (Tehran). 2015 Spring;3(2):59-63. PMID: 26495383.

4. Nemeth M, Jacobsen N, Bantel C, et al. Intranasal Analgesia and Sedation in Pediatric Emergency Care-A Prospective Observational Study on the Implementation of an Institutional Protocol in a Tertiary Children's Hospital. Pediatr Emerg Care. 2019 Feb;35(2):89-95. doi: 10.1097/PEC.0000000000001017. PMID: 28121974.

5. Siriwardena AN, Asghar Z, Lord B, et al. Patient and clinician factors associated with prehospital pain treatment and outcomes: cross sectional study. Am J Emerg Med. 2019 Feb;37(2):266-271. doi: 10.1016/j.ajem.2018.05.041. PMID: 29861367.

6. Strong JM. Changing trends in drug overdose over a six-year period. Mil Med. 1984 Jan;149(1):17-20. PMID: 6422327.

7. Young S. Comparing the use of ketamine and midazolam in emergency settings. Emerg Nurse. 1999 Dec-2000 Jan;7(8):27-30. PMID: 10847007.

\section{Not moderate to severe pain $(\mathbf{n}=\mathbf{2 1})$}

1. Alexander J, Manno M. Underuse of analgesia in very young pediatric patients with isolated painful injuries. Ann Emerg Med. 2003 May;41(5):617-22. PMID: 12712027. 
2. Axeen S, Seabury SA, Menchine M. Emergency Department Contribution to the Prescription Opioid Epidemic. Ann Emerg Med. 2018 Jun;71(6):659-667.e3. doi: 10.1016/j.annemergmed.2017.12.007. PMID: 29373155.

3. Azizkhani R, Pourafzali SM, Baloochestani E, et al. Comparing the analgesic effect of intravenous acetaminophen and morphine on patients with renal colic pain referring to the emergency department: A randomized controlled trial. J Res Med Sci. 2013 Sep;18(9):772-6. PMID: 24381620.

4. Bektas F, Eken C, Karadeniz O, et al. Intravenous paracetamol or morphine for the treatment of renal colic: a randomized, placebo-controlled trial. Ann Emerg Med. 2009 Oct;54(4):568-74. doi: 10.1016/j.annemergmed.2009.06.501. PMID: 19647342.

5. Benini F, Castagno E, Barbi E, et al. Multicentre emergency department study found that paracetamol and ibuprofen were inappropriately used in $83 \%$ and $63 \%$ of paediatric cases. Acta Paediatr. 2018 Oct;107(10):1766-1774. doi: 10.1111/apa.14306. PMID: 29505669.

6. Bondarsky EE, Domingo AT, Matuza NM, et al. Ibuprofen versus acetaminophen versus their combination in the relief of musculoskeletal pain in the emergency setting. Ann Emerg Med. 2011;58(4 SUPPL. 1):S255.

7. Bondarsky EE, Domingo AT, Matuza NM, et al. Ibuprofen vs acetaminophen vs their combination in the relief of musculoskeletal pain in the ED: a randomized, controlled trial. Am J Emerg Med. 2013 Sep;31(9):1357-60. doi: 10.1016/j.ajem.2013.06.007. PMID: 23896011.

8. Donald C, Duncan R, Blair L, et al. Paediatric analgesia in the emergency department, are we getting it right? Eur J Emerg Med. 2007 Jun;14(3):157-9. PMID: 17473610.

9. Ehikhamenor EE, Aghahowa SE, Azodo CC. Retrospective evaluation of analgesics prescribing pattern in a tertiary hospital in Nigeria. Journal of Medicine and Biomedical Research. 2012;11(1):71-77.

10. Herd DW, Babl FE, Gilhotra Y, et al. Pain management practices in paediatric emergency departments in Australia and New Zealand: a clinical and organizational audit by National Health and Medical Research Council's National Institute of Clinical Studies and Paediatric Research in Emergency Departments International Collaborative. Emerg Med Australas. 2009 Jun;21(3):210-21. doi: 10.1111/j.1742-6723.2009.01184.x. PMID: 19527281.

11. Herd DW, Salehi B. Palatability of two forms of paracetamol (acetaminophen) suspension: A randomised trial. Paediatr Perinat Drug Ther. 2006;7(4):189-193.

12. Hung KKC, Graham CA, Lo RSL, et al. Oral paracetamol and/or ibuprofen for treating pain after soft tissue injuries: Single centre double-blind, randomised controlled clinical trial. PLoS One. 2018 Feb 6;13(2):e0192043. doi: 10.1371/journal.pone.0192043. PMID: 29408866.

13. Lambrinkakos-Raymond K, Ali S, Dubrovsky AS, Burstein B. Low useage of analgesics for pediatric concussion-related pain in US emergency departments between 2007 and 2015. J Pediatr. 2019 pii: S0022-3476(19)30267-7. doi: 10.1016/j.jpeds.2019.02.035. PMID: 30955787. 
14. LoVecchio F, Oster N, Sturmann K, et al. The use of analgesics in patients with acute abdominal pain. J Emerg Med. 1997 Nov-Dec;15(6):775-9. PMID: 9404792.

15. Morgenstern LB, Huber JC, Luna-Gonzales H, et al. Headache in the emergency department. Headache. 2001 Jun;41(6):537-41. PMID: 11437887.

16. Rainer $\mathrm{TH}$, Jacobs $\mathrm{P}, \mathrm{Ng} \mathrm{YC}$, et al. Cost effectiveness analysis of intravenous ketorolac and morphine for treating pain after limb injury: double blind randomised controlled trial. BMJ. 2000 Nov 18;321(7271):1247-51. PMID: 11082083.

17. Ruzek MA, Richman P, Eskin B, et al. Emergency department treatment of migraines has changed significantly since 1999-2000. Acad Emerg Med. 2017;24(Supplement 1):S194.

18. Ruzek M, Richman P, Eskin B, et al. ED treatment of migraine patients has changed. Am J Emerg Med. [Epub ahead of print 20 Aug 2018] doi: 10.1016/j.ajem.2018.08.051. PMID: 30170929.

19. Shavit I, Jacob R, Friedman N et al. Effect of patient and nurse ethnicity on emergency department analgesia for children with appendicitis in Israeli government hospitals. Eur J Pain. 2018;22:1711-1717. PMID: 29883525

20. Sheridan DC, Meckler GD, Spiro DM, et al. Diagnostic testing and treatment of pediatric headache in the emergency department. J Pediatr. 2013 Dec;163(6):1634-7. doi:

10.1016/j.jpeds.2013.07.006. PMID: 23968749.

21. Yates DW, Laing GS, Peters K, et al. Mild analgesics and the accident and emergency department--cost and safety more important than potency? Arch Emerg Med. 1984 Dec;1(4):197-203. PMID: 6399444.

\section{Not an intervention of interest $(n=62)$}

1. Aravamuthan B, Williams K, Mar S. Initial management of migraine headaches with oral medications in a pediatric emergency unit. Neurology. 2014;82(10 SUPPL. 1).

2. Baumann BM, Mills AM, Shofer FS, et al. Pregnancy status affects analgesia administration in pelvic pain patients. Acad Emerg Med. 2011;18(5 SUPPL. 1):S191S192.

3. Berben SA, Meijs TH, van Dongen RT, et al. Pain prevalence and pain relief in trauma patients in the Accident \& Emergency department. Injury. 2008 May;39(5):578-85. Epub 2007 Jul 20. PMID: 17640644.

4. Berben SA, Schoonhoven L, Meijs TH, et al. Prevalence and relief of pain in trauma patients in emergency medical services. Clin J Pain. 2011 Sep;27(7):587-92. doi: 10.1097/AJP.0b013e3182169036. PMID: 21505324.

5. Berger A, Wang Y, Chung B, et al. Racial disparities in analgesic use amongst patients presenting to the emergency department for acute renal colic in the united states: A population-based analysis. J Urol. 2018;199(4 Supplement 1):e676-e677.

6. Bijur PE, Mills AM, Chang AK, et al. Comparative Effectiveness of Patient-Controlled Analgesia for Treating Acute Pain in the Emergency Department. Ann Emerg Med. 2017 Dec;70(6):809-818.e2. doi: 10.1016/j.annemergmed.2017.03.064. PMID: 28601270. 
7. Bounes V, Vallé B, Concina F, et al. Treatment of Acute Renal Colic in US and French EDs: Simulated Cases and Real Cases in Acute Pain Management. Am J Emerg Med. 2016 Oct;34(10):1955-1958. doi: 10.1016/j.ajem.2016.06.107. PMID: 27431741.

8. Boyd RJ, Stuart P. The efficacy of structured assessment and analgesia provision in the paediatric emergency department. Emerg Med J. 2005 Jan;22(1):30-2. PMID: 15611538.

9. Carreira CR, Oliveira E, Marques A, et al. How pain is treated in an emergency department in a central hospital? A prospective study. Reg Anesth Pain Med. 2012;37(5 SUPPL. 1):E213-E214.

10. Chauny JM, Marquis M, Paquet J, et al. The simple query "Do you want more pain medication?" is not a reliable way to assess acute pain relief in patients in the emergency department. CJEM. 2018 Jan;20(1):21-27. doi: 10.1017/cem.2017.2. PMID: 28294095.

11. Chang AK, Meyer RH, Bijur PE, et al. Randomized clinical trial of an IV hydromorphone titration protocol versus usual care for management of acute pain in older emergency department patients. Acad Emerg Med. 2013;20(5 SUPPL. 1):S44.

12. Chen EH, Shofer FS, Dean AJ, et al. Gender disparity in analgesic treatment of emergency department patients with acute abdominal pain. Acad Emerg Med. 2008 May;15(5):414-8. doi: 10.1111/j.1553-2712.2008.00100.x. PMID: 18439195.

13. Cheng C-T, Law GTWM, Roman C, et al. Evaluation of the assessment and management of acute migraines in two Australian metropolitan emergency departments. Journal of Emergency Medicine, Trauma and Acute Care. 2016;2016(3):A6.

14. Curtis KM, Henriques HF, Fanciullo G, et al. A fentanyl-based pain management protocol provides early analgesia for adult trauma patients. J Trauma. 2007 Oct;63(4):819-26. PMID: 18090011.

15. Dattani ND, Tassone N, Costa A, et al. No difference in opioid administration to elderly patients between rural and urban emergency departments in Ontario. Canadian Journal of Emergency Medicine. 2015;17(Supplement 2):S59.

16. Davey N, O'Sullivan R. Intranasal fentanyl for paediatric orthopaedic injuries in the emergency department. Ir J Med Sci. 2016;185(SUPPL. 5):S280.

17. Decosterd I, Hugli O, Tamchès E, et al. Oligoanalgesia in the emergency department: short-term beneficial effects of an education program on acute pain. Ann Emerg Med. 2007 Oct;50(4):462-71. PMID: 17445949.

18. Delaney KM, Pankow A, Avner JR, et al. Appendicitis and Analgesia in the Pediatric Emergency Department: Are We Adequately Controlling Pain? Pediatr Emerg Care. 2016 Sep;32(9):581-4. doi: 10.1097/PEC.0000000000000573. PMID: 26466149.

19. Doherty S, Bennetts S, Knott J, et al. Improving pain management practices in Australian emergency departments. Acad Emerg Med. 2012;19(6):726.

20. Friedman DI, Fisher SG, Feldon SE, et al. Migraine treatment in the emergency department - What's really happening? Cephalalgia. 2009;29(SUPPL. 1):19. 
21. Furyk J, Sumner M. Pain score documentation and analgesia: a comparison of children and adults with appendicitis. Emerg Med Australas. 2008 Dec;20(6):482-7. doi: 10.1111/j.1742-6723.2008.01133.x. PMID: 19125826.

22. Galinski M, Picco N, Hennequin B, et al. Out-of-hospital emergency medicine in pediatric patients: prevalence and management of pain. Am J Emerg Med. 2011 Nov;29(9):1062-6. doi: 10.1016/j.ajem.2010.06.031. PMID: 20685056.

23. GhabeliJuibary A, Sasannejad P. Analysis of headache management in referral neurology emergency center in north eastern Iran. Cephalalgia. 2015;35(6 SUPPL. 1):170.

24. Guéant S, Taleb A, Borel-Kühner J, et al. Quality of pain management in the emergency department: results of a multicentre prospective study. Eur J Anaesthesiol. 2011 Feb;28(2):97-105. doi: 10.1097/EJA.0b013e3283418fb0. PMID: 21119516.

25. Hamdan A, Thompson M. Emergency analgesia administration in children: Retrospective analysis and recommendations. Arch Dis Child. 2012;97(SUPPL. 2):A458-A459.

26. Hoppe JA, Nelson LS, Perrone J, et al. Opioid Prescribing in a Cross Section of US Emergency Departments. Ann Emerg Med. 2015 Sep;66(3):253-259.e1. doi: 10.1016/j.annemergmed.2015.03.026. PMID: 25952503.

27. Hwang U, Belland LK, Handel DA, et al. Is all pain is treated equally? A multicenter evaluation of acute pain care by age. Pain. 2014 Dec;155(12):2568-74. doi: 10.1016/j.pain.2014.09.017. PMID: 25244947.

28. Hwang U, Richardson LD, Harris B, et al. The quality of emergency department pain care for older adult patients. J Am Geriatr Soc. 2010 Nov;58(11):2122-8. doi: 10.1111/j.1532-5415.2010.03152.x. PMID: 21054293.

29. Innes G, Andruchow J, McRae A, et al. Does gender influence renal colic management and outcome? Canadian Journal of Emergency Medicine. 2015;17(Supplement 2):S52.

30. Innes G, Scheuermeyer F, Boyda H, et al. Emergency Department management of renal colic: Does gender matter? Acad Emerg Med. 2016;23(SUPPL. 1):S252-S253.

31. Jones JS, Johnson K, McNinch M. Age as a risk factor for inadequate emergency department analgesia. Am J Emerg Med. 1996 Mar;14(2):157-60. PMID: 8924137.

32. Kariman H, Majidi A, Taheri S, Shahrami A, Hatamabadi HR. Analgesic Effects of Inhalation of Nitric Oxide (Entonox) and Parenteral Morphine Sulfate in Patients with Renal Colic; A Randomized Clinical Trial. Bull Emerg Trauma. 2015 Apr;3(2):46-52. PMID: 27162902.

33. Kaufmann J, Roth B, Engelhardt et al. Development and prospective federal state-wide evaluation of a device for height-based dose recommendations in prehospital pediatric emergencies: a simple tool to prevent most severe drug errors. Prehosp Emerg Care. 2018;22:252-259. PMID: 27925849.

34. Khemani K, Reddy L, Jain S, et al. Unanticipated consequences identified after implementation of a Pediatric Emergency Department (PED)-based Intranasal Fentanyl (INF) protocol for the treatment of Vaso-Occlusive Pain Episodes (VOE) in children with Sickle Cell Disease (SCD). Pediatr Blood Cancer. 2018;65(Supplement 1):S110-S111. 
35. Lord B, Bendall J, Reinten T. The influence of paramedic and patient gender on the administration of analgesics in the out-of-hospital setting. Prehosp Emerg Care. 2014 Apr-Jun;18(2):195-200. doi: 10.3109/10903127.2013.856502. PMID: 24401105.

36. Lord B, Bendall JC, Reinten-Reynolds T. Impact of paramedic and patient gender on prehospital pain management. Australasian Journal of Paramedicine. 2013;10(2):12.

37. Lord B, Jennings PA, Smith K. Effects of the Introduction of Intranasal Fentanyl on Reduction of Pain Severity Score in Children: An Interrupted Time-Series Analysis. Pediatr Emerg Care. 2017 Dec 1. doi: 10.1097/PEC.0000000000001376. PMID: 29200141.

38. Maddry J, Bebarta V. Out-of-hospital en route care and life-saving interventions of traumatically injured combat patients transported by medevac from point of injury. Ann Emerg Med. 2015;66(4 SUPPL. 1):S62-S63.

39. Maddry JK, Mora AG, Savell S, et al. Combat MEDEVAC: A comparison of care by provider type for en route trauma care in theater and 30-day patient outcomes. J Trauma Acute Care Surg. 2016 Nov;81(5 Suppl 2 Proceedings of the 2015 Military Health System Research Symposium):S104-S110. PMID: 27768659.

40. Madeira F, Ferreira P, Lapa T, et al. Prehospital pain management: Do we have to learn more about it? Eur J Anaesthesiol. 2013;30(SUPPL. 51):203-204.

41. Manzo UM, Fee C. The association of patient primary language and receipt of analgesics among emergency department patients presenting with headache, abdominal pain, or low back pain. Ann Emerg Med. 2014;64(4 SUPPL. 1):S131.

42. Mar S, Isbell S, Prensky A. The spectrum of diagnosis and management of headaches in a pediatric emergency department: A large retrospective study. Ann Neurol. 2011;70(SUPPL. 15):S165-S166.

43. Matthews R, McCaul M, Smith W. A description of pharmacological analgesia administration by public sector advanced life support paramedics in the City of Cape Town. Afr J Emerg Med. 2017 Mar;7(1):24-29. doi: 10.1016/j.afjem.2017.01.002. PMID: 30456102.

44. Mazer-Amirshahi ME, Mullins PM, Richards L, et al. Emergency department utilization of opioid analgesics vs. non-opioid therapies for abdominal pain. Acad Emerg Med. 2016;23(SUPPL. 1):S86.

45. Mura P, Serra E, Marinangeli F, et al. Prospective study on prevalence, intensity, type, and therapy of acute pain in a second-level urban emergency department. J Pain Res. 2017 Dec 12;10:2781-2788. doi: 10.2147/JPR.S137992. PMID: 29263692.

46. Netherton SJ, Lonergan K, Wang D, et al. Computerized physician order entry and decision support improves ED analgesic ordering for renal colic. Am J Emerg Med. 2014 Sep;32(9):958-61. doi: 10.1016/j.ajem.2014.05.002. PMID: 24997107.

47. Normansell D, Quattromani E, Storkan M, et al. Treating pain in geriatric blunt trauma patients. Acad Emerg Med. 2014;21(5 SUPPL. 1):S213-S214. 
48. Paquin H, Trottier ED, Pastore Y, et al. Evaluation of a protocol using intranasal fentanyl for treatment of acute pain crisis in sickle cell patients in the emergency department. the satisfi - Sickle cell analgesic treatment with in fentanyl solution for fast track intervention - Study. Pediatr Blood Cancer. 2017;64(Supplement 1):S19.

49. Pasquier M, Geiser V, De Riedmatten M, et al. Helicopter rescue operations involving winching of an emergency physician. Injury. 2012 Sep;43(9):1377-80. doi:

10.1016/j.injury.2011.06.196. PMID: 21762912.

50. Rehmani RS. Pain practices in a Saudi emergency department. Saudi Med J. 2010 May;31(5):539-44. PMID: 20464044.

51. Schlesinger N, Young TC, Radvanski DC, et al. Treatment of acute gout in the emergency department evaluated according to the 2012 american college of rheumatology guidelines. Arthritis Rheum. 2013;65(SUPPL. 10):S849.

52. Shill J, Taylor DM, Ngui B, et al. Factors associated with high levels of patient satisfaction with pain management. Acad Emerg Med. 2012 Oct;19(10):1212-5. doi: 10.1111/j.1553-2712.2012.01451.x. PMID: 23035970.

53. Siddiqui A, Belland L, Bagiella E, et al. The effect of analgesics on early ED pain outcomes. Acad Emerg Med. 2015;22(5 SUPPL. 1):S196.

54. Simpson PM, Bendall JC, Tiedemann A, et al. Provision of out-of-hospital analgesia to older fallers with suspected fractures: above par, but opportunities for improvement exist. Acad Emerg Med. 2013 Aug;20(8):761-8. doi: 10.1111/acem.12190. PMID: 24033618.

55. Steinberg PL, Nangia AK, Curtis K. A standardized pain management protocol improves timeliness of analgesia among emergency department patients with renal colic. Qual Manag Health Care. 2011 Jan-Mar;20(1):30-6. doi: 10.1097/QMH.0b013e31820429d9. PMID: 21192205.

56. Tanabe P, Artz N, Mark Courtney D, et al. Adult emergency department patients with sickle cell pain crisis: a learning collaborative model to improve analgesic management. Acad Emerg Med. 2010 Apr;17(4):399-407. doi: 10.1111/j.1553-2712.2010.00693.x. PMID: 20370779.

57. Tanabe P, Hafner JW, Martinovich Z, et al. Adult emergency department patients with sickle cell pain crisis: results from a quality improvement learning collaborative model to improve analgesic management. Acad Emerg Med. 2012 Apr;19(4):430-8. doi: 10.1111/j.1553-2712.2012.01330.x. PMID: 22506947.

58. Tanabe P, Martinovich Z, Buckley B, et al. Safety of an ED High-Dose Opioid Protocol for Sickle Cell Disease Pain. J Emerg Nurs. 2015 May;41(3):227-35. doi: 10.1016/j.jen.2014.07.014. PMID: 25241635.

59. Tanabe P, Myers R, Zosel A, et al. Emergency department management of acute pain episodes in sickle cell disease. Acad Emerg Med. 2007 May;14(5):419-25. PMID: 17389246.

60. Van Woerden G, Van Den Brand CL, Den Hartog CF, et al. Increased analgesia administration in emergency medicine after implementation of revised guidelines. Int $\mathrm{J}$ Emerg Med. 2016 Dec;9(1):4. doi: 10.1186/s12245-016-0102-y. PMID: 26860533. 
61. White LJ, Cooper JD, Chambers RM, et al. Prehospital use of analgesia for suspected extremity fractures. Prehosp Emerg Care. 2000 Jul-Sep;4(3):205-8. PMID: 10895913.

62. Wong MT, Ip M, Graham CA. Pain and pain management in a Hong Kong emergency department. Hong Kong Journal of Emergency Medicine. 2011;18(6):406-411.

\section{Not a comparator if interest $(n=83)$}

1. Akinsola BT, Hagbom R, Zmitrovich A, et al. More rapid delivery of parenteral analgesia by adding intranasal fentanyl to the management of sickle cell disease vaso-occlusive pain episodes at a pediatric emergency department. Blood. 2014;124(21).

2. Andolfatto G, Willman E, Joo D, et al. Intranasal ketamine for analgesia in the emergency department: a prospective observational series. Acad Emerg Med. 2013 Oct;20(10):1050-4. doi: 10.1111/acem.12229. PMID: 24127709.

3. Baumann BM, Mills AM, Smith N, et al. Discharge status improves timeliness of analgesia administration. Acad Emerg Med. 2011;18(5 SUPPL. 1):S200-S201.

4. Behzadnia MJ, Javadzadeh HR, Saboori F. Time of admission, gender and age: challenging factors in emergency renal colic - a preliminary study. Trauma Mon. 2012 Fall;17(3):329-32. doi: 10.5812/traumamon.6800. PMID: 24350118.

5. Beiter JL Jr, Simon HK, Chambliss CR, et al. Intravenous ketorolac in the emergency department management of sickle cell pain and predictors of its effectiveness. Arch Pediatr Adolesc Med. 2001 Apr;155(4):496-500. PMID: 11296078.

6. Bijur PE, Esses D, Chang AK, et al. Dosing and titration of intravenous opioid analgesics administered to ED patients in acute severe pain. Am J Emerg Med. 2012 Sep;30(7):1241-4. doi: 10.1016/j.ajem.2011.06.015. PMID: 21908134.

7. Birnbaum A, Esses D, Bijur PE, et al. Randomized double-blind placebo-controlled trial of two intravenous morphine dosages $(0.10 \mathrm{mg} / \mathrm{kg}$ and $0.15 \mathrm{mg} / \mathrm{kg})$ in emergency department patients with moderate to severe acute pain. Ann Emerg Med. 2007 Apr;49(4):445-53, 453.e1-2. PMID: 16978739.

8. Birnbaum A, Schechter C, Tufaro V, et al. Efficacy of patient-controlled analgesia for patients with acute abdominal pain in the emergency department: a randomized trial. Acad Emerg Med. 2012 Apr;19(4):370-7. doi: 10.1111/j.1553-2712.2012.01322.x. PMID: 22506940.

9. Blancher M, Dubie E, Favier I, et al. Evaluation of pain management in mountain rescue: A prospective observational study of 49 patients managed by physician-staffed helicopter emergency medical service (P-HEMS) during mountain rescue missions. High Alt Med Biol. 2014;15(2):A292-A293.

10. Borland M, Milsom S, Esson A. Equivalency of two concentrations of fentanyl administered by the intranasal route for acute analgesia in children in a paediatric emergency department: a randomized controlled trial. Emerg Med Australas. 2011 Apr;23(2):202-8. doi: 10.1111/j.1742-6723.2011.01391.x. PMID: 21489168. 
11. Bounes V, Barniol C, Minville V, et al. Predictors of pain relief and adverse events in patients receiving opioids in a prehospital setting. Am J Emerg Med. 2011 Jun;29(5):5127. doi: 10.1016/j.ajem.2009.12.005. PMID: 20825821.

12. Bounes $\mathrm{V}$, Charpentier $\mathrm{S}$, Houze-Cerfon $\mathrm{CH}$, et al. Is there an ideal morphine dose for prehospital treatment of severe acute pain? A randomized, double-blind comparison of 2 doses. Am J Emerg Med. 2008 Feb;26(2):148-54. doi: 10.1016/j.ajem.2007.04.020. PMID: 18272093.

13. Bowers KJ, McAllister KB, Ray M, et al. Ketamine as an Adjunct to Opioids for Acute Pain in the Emergency Department: A Randomized Controlled Trial. Acad Emerg Med. 2017 Jun;24(6):676-685. doi: 10.1111/acem.13172. PMID: 28177167.

14. Browne LR, Shah MI, Studnek JR, et al. Multicenter Evaluation of Prehospital Opioid Pain Management in Injured Children. Prehosp Emerg Care. 2016 Nov-Dec;20(6):759767. PMID: 27411064.

15. Burns BS, Fu R, Bailey J, et al. The treatment of oropharyngeal pain in the emergency department: Comparing a topical agent and opioids for clinically important outcomes. Acad Emerg Med. 2015;22(5 SUPPL. 1):S259-S260.

16. Cacciotti C, Vaiselbuh S, Romanos-Sirakis E. Pain Management for Sickle Cell Disease in the Pediatric Emergency Department: Medications and Hospitalization Trends. Clin Pediatr (Phila). 2017 Oct;56(12):1109-1114. doi: 10.1177/0009922816674521. PMID: 27798391.

17. DeVellis $\mathrm{P}$, Thomas SH, Wedel SK. Prehospital and emergency department analgesia for air-transported patients with fractures. Prehosp Emerg Care. 1998 Oct-Dec;2(4):293-6. PMID: 9799017.

18. Dhanjal S, Kent M, Lyons K, et al. Multimodal analgesia in polytrauma combat injured servicemembers: Why aren't we using NSAIDs? Reg Anesth Pain Med. 2016;41(5).

19. Dong L, Donaldson A, Metzger R, et al. Analgesic administration in the emergency department for children requiring hospitalization for long-bone fracture. Pediatr Emerg Care. 2012 Feb;28(2):109-14. doi: 10.1097/PEC.0b013e3182442c25. PMID: 22270501.

20. Ducasse J-L, Salvan D, Houze-Cerfon V, et al. Predictors of adverse events in patients receiving opioids in an emergency setting: A prospective large observational cohort study. Acad Emerg Med. 2011;18(5 SUPPL. 1):S32.

21. Furyk J, Levas D, Close B, et al. Intravenous versus oral paracetamol for acute pain in adults in the emergency department setting: a prospective, double-blind, double-dummy, randomised controlled trial. Emerg Med J. 2018 Mar;35(3):179-184. doi: 10.1136/emermed-2017-206787. PMID: 29247042.

22. Farsi D, Movahedi M, Hafezimoghadam P, et al. Acute pain management with intravenous $0.10 \mathrm{mg} / \mathrm{kg}$ vs. $0.15 \mathrm{mg} / \mathrm{kg}$ morphine sulfate in limb traumatized patients: a randomized double-blinded placebo-controlled trial. Ulus Travma Acil Cerrahi Derg. 2013 Sep;19(5):398-404. doi: 10.5505/tjtes.2013.86383. PMID: 24214779.

23. Freed J, Ender KL. Acute management of vaso-occlusive pain in pediatric sickle cell disease. Pediatr Blood Cancer. 2009;52(6):727. 
24. Galinski M, Hoffman L, Bregeaud D, et al. Procedural Sedation and Analgesia in Trauma Patients in an Out-of-Hospital Emergency Setting: A Prospective Multicenter Observational Study. Prehosp Emerg Care. 2018 Jul-Aug;22(4):497-505. doi: 10.1080/10903127.2017.1413464. PMID: 29384419.

25. Grandcolas N, Galéa J, Ananda R, et al. [Stonefish stings: difficult analgesia and notable risk of complications]. Presse Med. 2008 Mar;37(3 Pt 1):395-400. French. PMID: 18160253.

26. Grissa MH, Claessens YE, Bouida W, et al. Paracetamol vs piroxicam to relieve pain in renal colic. Results of a randomized controlled trial. Am J Emerg Med. 2011 Feb;29(2):203-6. doi: 10.1016/j.ajem.2009.09.019. PMID: 20934829.

27. Guillot O, Le Borgne P, Kauffmann P et al. Acute shoulder dislocation in the emergency department: a retrospective evaluation of pain management and a proposal for a standard operating procedure. Annales Francaises de Medicine d'Urgence. 2018;8:7.

28. Gülen B, Dur A, Serinken M, et al. Pain treatment in patients with acute pancreatitis: A randomized controlled trial. Turk J Gastroenterol. 2016 Mar;27(2):192-6. doi: 10.5152/tjg.2015.150398. PMID: 27015624.

29. Gunasekera L, Sun-Edelstein C, Heywood J, et al. Management of migraine in the australian emergency department. J Neurol Neurosurg Psychiatry. 2018;89(6):e8-e9.

30. Hebsgaard S, Mannering A, Zwisler ST. Assessment of acute pain in trauma-A retrospective prehospital evaluation. J Opioid Manag. 2016 Sep/Oct;12(5):347-353. doi: 10.5055/jom.2016.0351. PMID: 27844474.

31. Hewes HA, Dai M, Mann NC, Baca T, Taillac P. Prehospital Pain Management: Disparity By Age and Race. Prehosp Emerg Care. 2018 Mar-Apr;22(2):189-197. doi: 10.1080/10903127.2017.1367444. PMID: 28956669.

32. Holdgate A, Shepherd SA, Huckson S. Patterns of analgesia for fractured neck of femur in Australian emergency departments. Emerg Med Australas. 2010 Feb;22(1):3-8. doi: 10.1111/j.1742-6723.2009.01246.x. PMID: 20015246.

33. Jacob R, Krauss B, Twito G, et al. Emergency Department Pain Management in Children With Appendicitis in a Biethnic Population. Clin J Pain. 2017 Nov;33(11):1014-1018. doi: 10.1097/AJP.0000000000000485. PMID: 28177940.

34. Jennings PA, Lord B, Smith K. Clinically meaningful reduction in pain severity in children treated by paramedics: a retrospective cohort study. Am J Emerg Med. 2015 Nov;33(11):1587-90. doi: 10.1016/j.ajem.2015.06.026. PMID: 26186993.

35. Karlsen AP, Pedersen DM, Trautner S, et al. Safety of intranasal fentanyl in the out-ofhospital setting: a prospective observational study. Ann Emerg Med. 2014 Jun;63(6):699703. doi: 10.1016/j.annemergmed.2013.10.025. PMID: 24268523.

36. Lee JS, Stiell IG, Wells GA, et al. Adverse outcomes and opioid analgesic administration in acute abdominal pain. Acad Emerg Med. 2000 Sep;7(9):980-7. PMID: 11043991.

37. Lewis $\mathrm{P}$, Wright $\mathrm{C}$, Hooper C. Opioid analgesia on the battlefield: a retrospective review of data from Operation HERRICK. J R Army Med Corps. 2018 Sep;164(5):328-331. doi: 10.1136/jramc-2017-000897. PMID: 29626143. 
38. Lord B, Cui J, Kelly AM. The impact of patient sex on paramedic pain management in the prehospital setting. Am J Emerg Med. 2009 Jun;27(5):525-9. doi:

10.1016/j.ajem.2008.04.003. PMID: 19497456.

39. Man SY, Woo WK, Lam PKW, et al. Feasibility study comparing oral paracetamol and oral non-steroidal anti-inflammatory drugs for treating pain after musculoskeletal injury: A randomized, double blind, controlled trial. Hong Kong Journal of Emergency Medicine. 2004;11(2):78-84.

40. Masoudi Alavi N, Aboutalebi MS, Sadat Z. Pain management of trauma patients in the emergency department: a study in a public hospital in Iran. Int Emerg Nurs. 2017 Jul;33:53-58. doi: 10.1016/j.ienj.2016.10.005. PMID: 27956149.

41. Mazer-Amirshahi M, Mullins PM, Pines JM, et al. Trends in opioid prescribing for acute headache in US emergency departments. Journal of Medical Toxicology. 2014;10(1):6667.

42. MercadoDublin MF,Vaidotas M, Goncalves MF, et al. Acute renal pain treatment in emergency department. Eur J Pain Suppl. 2011;5(1):144.

43. Miner JR, Kletti C, Herold M, et al. Randomized clinical trial of nebulized fentanyl citrate versus i.v. fentanyl citrate in children presenting to the emergency department with acute pain. Acad Emerg Med. 2007 Oct;14(10):895-8. PMID: 17898251.

44. Mora A, Ervin A, Ganem V, et al. En route use of opioids, ketamine, and epidural analgesia to treat pain in awake patients transported out of combat zones by us air force critical care air transport teams. Ann Emerg Med. 2014;64(4 SUPPL. 1):S130.

45. Mora AG, Ganem VJ, Ervin AT, et al. En Route Use of Analgesics in Nonintubated, Critically Ill Patients Transported by U.S. Air Force Critical Care Air Transport Teams. Mil Med. 2016 May;181(5 Suppl):145-51. doi: 10.7205/MILMED-D-15-00194. PMID: 27168565.

46. Morris CR, Ahmad F, Bennett J, et al. Pediatric emergency department use of intranasal fentanyl to treat pain in children with sickle cell disease and its impact on discharge rates: A multicenter perspective. Blood. 2016;128(22).

47. Motov SM, Mai M, Pushkar I, et al. A prospective randomized, double-blind trial comparing intravenous push dose of low dose ketamine to short infusion of low dose ketamine for treatment of moderate to severe pain in the emergency department. Acad Emerg Med. 2017;24(Supplement 1):S39.

48. Motov S, Mai M, Pushkar I, et al. A prospective randomized, double-dummy trial comparing IV push low dose ketamine to short infusion of low dose ketamine for treatment of pain in the ED. Am J Emerg Med. 2017 Aug;35(8):1095-1100. doi: 10.1016/j.ajem.2017.03.004. PMID: 28283340.

49. Motov S, Yasavolian M, Likourezos A, et al. Comparison of Intravenous Ketorolac at Three Single-Dose Regimens for Treating Acute Pain in the Emergency Department: A Randomized Controlled Trial. Ann Emerg Med. 2017 Aug;70(2):177-184. doi: 10.1016/j.annemergmed.2016.10.014. PMID: 27993418. 
50. Neighbor ML, Puntillo KA. Intramuscular ketorolac vs oral ibuprofen in emergency department patients with acute pain. Acad Emerg Med. 1998 Feb;5(2):118-22. PMID: 9492131.

51. Nunn ML, Hayden JA, Magee K. Current management practices for patients presenting with low back pain to a large emergency department in Canada. BMC Musculoskelet Disord. 2017 Feb 23;18(1):92. doi: 10.1186/s12891-017-1452-1. PMID: 28228138.

52. Peche $\mathrm{S}$, Lenox $\mathrm{J}$, Isbell $\mathrm{S}$, et al. The spectrum of diagnosis and management of headaches in pediatric emergency department. Neurology. 2012;78(1 Meeting Abstract).

53. Pickering G, Moustafa F, Macian N, et al. A New Transmucous-Buccal Formulation of Acetaminophen for Acute Traumatic Pain: A Non-inferiority, Randomized, DoubleBlind, Clinical Trial. Pain Physician. 2015 May-Jun;18(3):249-57. PMID: 26000668.

54. Portis A, Jain N, Portis J, et al. Non-narcotic emergency management of renal colic improves length of stay and discharge rate. J Urol. 2018;199(4 Supplement 1):e19.

55. Regan L, Chapman AR, Celnik A, et al. Nose and vein, speed and pain: comparing the use of intranasal diamorphine and intravenous morphine in a Scottish paediatric emergency department. Emerg Med J. 2013 Jan;30(1):49-52. doi: 10.1136/emermed2011-200970. PMID: 22411597.

56. Risgaard O, Mikkelsen S. Fentanyl in a prehospital setting in Denmark: A retrospective study. Resuscitation. 2010;81(2 SUPPL. 1):S72.

57. Robb AL, Ali S, Poonai N, et al. Pain management of acute appendicitis in Canadian pediatric emergency departments. CJEM. 2017 Nov;19(6):417-423. doi: 10.1017/cem.2016.391. PMID: 27899166.

58. Rogovik AL, Goldman RD. Prehospital use of analgesics at home or en route to the hospital in children with extremity injuries. Am J Emerg Med. 2007 May;25(4):400-5. PMID: 17499657.

59. Schaefer JA, Mlekoday TJ. Time to opioid administration after implementation of an intranasal fentanyl protocol. Am J Emerg Med. 2015 Dec;33(12):1805-7. doi: 10.1016/j.ajem.2015.08.050. PMID: 26452510.

60. Schlesinger N, Radvanski D, ChangYoung T, et al. Diagnosis and treatment of acute gouty arthritis at a university hospital emergency department. Ann Rheum Dis. 2013;72(SUPPL. 3).

61. Schönenberg M, Reichwald U, Domes G, et al. Effects of peritraumatic ketamine medication on early and sustained posttraumatic stress symptoms in moderately injured accident victims. Psychopharmacology (Berl). 2005 Nov;182(3):420-5. PMID: 16012867.

62. Shrestha R, Pant S, Shrestha A, et al. Intranasal ketamine for the treatment of patients with acute pain in the emergency department. World J Emerg Med. 2016;7(1):19-24. doi: 10.5847/wjem.j.1920-8642.2016.01.003. PMID: 27006733.

63. Siddiqui A, Hwang UY. Ed pain care and its effects on short term hospitalization outcomes. Acad Emerg Med. 2013;20(5 SUPPL. 1):S62. 
64. Silka PA, Roth MM, Geiderman JM. Patterns of analgesic use in trauma patients in the ED. Am J Emerg Med. 2002 Jul;20(4):298-302. PMID: 12098176.

65. Singer AJ, Thode Jr. HC. Analgesia prescriptions for ED patients with low back pain: A national perspective. Acad Emerg Med. 2013;20(5 SUPPL. 1):S212.

66. Soleyman-Zomalan E, Motov S, Likourezos A, et al. Patterns of Ketorolac dosing by emergency physicians. World J Emerg Med. 2017;8(1):43-46. doi: 10.5847/wjem.j.19208642.2017.01.008. PMID: 28123620.

67. Solomon LR. Pain management in adults with sickle cell disease in a medical center emergency department. J Natl Med Assoc. 2010 Nov;102(11):1025-32. PMID: 21141290.

68. Stehouwer NR, Park B, Edge P, et al. Acute care in the emergency department differs before and after transition for adolescents and young adults with sickle cell disease. Blood. 2015;126(23):3267.

69. Taha HM, Rehmani RS. Pain management of children and adolescents with sickle cell disease presenting to the emergency department. Saudi Med J. 2011 Feb;32(2):152-5. PMID: 21301761.

70. Tichter AM, Anderson A, Suh E, et al. United States emergency department practice patterns for the treatment of sickle cell patients presenting with vaso-occlusive crisis. Acad Emerg Med. 2017;24(Supplement 1):S220.

71. Tornabene SV, Deutsch R, Davis DP, et al. Evaluating the use and timing of opioids for the treatment of migraine headaches in the emergency department. J Emerg Med. 2009 May;36(4):333-7. doi: 10.1016/j.jemermed.2007.07.068. PMID: 18280084.

72. Trichard S, Dantony E, Maucort-Boulch D, et al. A randomised trial of cryotherapy alone or in combination with analgesia on trauma pain. Annales Francaises de Medecine d'Urgence. 2016;6(6):395-402.

73. Turkcuer I, Serinken M, Eken C, et al. Intravenous paracetamol versus dexketoprofen in acute migraine attack in the emergency department: a randomised clinical trial. Emerg Med J. 2014 Mar;31(3):182-5. doi: 10.1136/emermed-2013-203044. PMID: 24394884.

74. Turturro MA, Paris PM, Seaberg DC. Intramuscular ketorolac versus oral ibuprofen in acute musculoskeletal pain. Ann Emerg Med. 1995 Aug;26(2):117-20. PMID: 7618770.

75. Van Zanden JE, Wagenaar S, Ter Maaten JM, Ter Maaten JC, Lightenberg JJM. Pain score, desire for pain treatment and effect on pain satisfaction in the emergency department: a prospective, observational study. BMC Emerg Med. 2018;8:40. MPID: 30409124.

76. Vanoye C, Lacroix G, Le Gonidec E, et al. Local-regional anesthesia in the management of stingray stings: Experience of the Bouffard medical-surgical hospital in Djibouti. Med Sante Trop. 2017 Feb 1;27(1):40-43. doi: 10.1684/mst.2016.0638. PMID: 28132951.

77. Wiel E, Zitouni D, Assez N, et al. Continuous Infusion of Ketamine for Out-of-hospital Isolated Orthopedic Injuries Secondary to Trauma: A Randomized Controlled Trial. Prehosp Emerg Care. 2015 January-March;19(1):10-16. PMID: 24932670. 
78. Wigley G. Nitrous oxide/oxygen in the London Ambulance Service. Br J Clin Pract. 1974 Dec;28(12):407-8. PMID: 4617591.

79. Woo WW, Man SY, Lam PK, et al. Randomized double-blind trial comparing oral paracetamol and oral nonsteroidal antiinflammatory drugs for treating pain after musculoskeletal injury. Ann Emerg Med. 2005 Oct;46(4):352-61. PMID: 16187469.

80. Wright JM, Price SD, Watson WA. NSAID use and efficacy in the emergency department: single doses of oral ibuprofen versus intramuscular ketorolac. Ann Pharmacother. 1994 Mar;28(3):309-12. PMID: 8193414.

81. Yan J, McLeod S, Edmonds M, et al. Analgesic use for the management of suspected acute renal colic in the emergency department. Acad Emerg Med. 2012;19(SUPPL. 1):S229.

82. Zempsky WT, Loiselle KA, McKay K, et al. Do children with sickle cell disease receive disparate care for pain in the emergency department? J Emerg Med. 2010 Nov;39(5):6915. doi: 10.1016/j.jemermed.2009.06.003. PMID: 19703740.

83. Zun LS, Downey LV, Gossman W, et al. Gender differences in narcotic-induced emesis in the ED. Am J Emerg Med. 2002 May;20(3):151-4. PMID: 11992331.

\section{No outcomes of interest $(n=13)$}

1. Bendall JC, Simpson PM, Middleton PM. Prehospital analgesia in New South Wales, Australia. Prehosp Disaster Med. 2011 Dec;26(6):422-6. doi: 10.1017/S1049023X12000180. PMID: 22559307.

2. Berger A, Wang Y, Chung B, Chang S, Haleblian G. Trends in regional narcotic and NSAID use in emergency department patients with acute renal colic. J of Endourology. 2018;32:A312.

3. Borland ML, Clark LJ, Esson A. Comparative review of the clinical use of intranasal fentanyl versus morphine in a paediatric emergency department. Emerg Med Australas. 2008 Dec;20(6):515-20. doi: 10.1111/j.1742-6723.2008.01138.x. PMID: 19125831.

4. Degrauwe S, Roffi M, Carbone F et al. Influence of intravenous fentanyl versus morphine on ticagrelor absorption and platelet inhibition in patients with ST-segment elevation myocardial infarction undergoing primary PCI. Eur Heart J. 2018;39:1236.

5. Jennings PA, Cameron P, Bernard S, et al. Long-term pain prevalence and health-related quality of life outcomes for patients enrolled in a ketamine versus morphine for prehospital traumatic pain randomised controlled trial. Emerg Med J. 2014 Oct;31(10):840-3. doi: 10.1136/emermed-2013-202862. PMID: 23851034.

6. Jokar A, Ahmadi K, Hajimaghsoodi L, Ketabi S. Use of fentany patch and intravenous morphine for treatment of leg bone fracture: tretment profile and clinical effectiveness. Open Access Maced J Med Sci. 2018;6:2301-2305. PMID: 30607180.

7. Melissa N, Jonathan K, Ian W, et al. The management and outcome of back pain presentations to the emergency department: A retrospective cohort study. Intern Med J. 2016;46(Supplement 2):13. 
8. Milani GP, Benini F, Dell'Era L, et al. Acute pain management: acetaminophen and ibuprofen are often under-dosed. Eur J Pediatr. 2017 Jul;176(7):979-982. doi:

10.1007/s00431-017-2944-6. PMID: 28600631.

9. Noviasky J, Candela C, Barbagallo D, et al. Intravenous opiate dosing in the geriatric population in the emergency department at a community hospital. Pharmacotherapy. 2017;37(12):e172-e173.

10. Petrelli T, Farrokhyar F, McGrath P, et al. The use of ibuprofen and acetaminophen for acute headache in the postconcussive youth: A pilot study. Paediatr Child Health. 2017 Mar;22(1):2-6. doi: 10.1093/pch/pxw011. PMID: 29483787.

11. Thaete J, Reyes L. No racial disparity in pain management of long bone fractures in a rural emergency department. Acad Emerg Med. 2017;24(Supplement 1):S243.

12. Winter S, Jootun R. Audit of morphine administration by east midlands ambulance service (EMAS). BMJ Open. 2017;7(Supplement 3):A3-A4.

13. Yeoh K. Babl F. Analgesia and sedation in pnuematic enema reduction for intussusception. A retrospective study at the Royal Children's Hospital, Melbourne. EMA-Emergency Medicine Australia. 2019;31:56.

\section{No full text publication $(n=5)$}

1. Berkman MR, Larsen J, Smith J, et al. Ketamine and morphine versus morphine alone for treatment of acute pain in the emergency department. Ann Emerg Med. 2014;64(4 SUPPL. 1):S131-S132.

2. DeLaney M, Lovely T, Davison P, et al. Low-dose ketamine compared to standard therapy for the treatment of acute pain in the emergency department. Acad Emerg Med. 2015;22(5 SUPPL. 1):S368-S369.

3. Mosaddegh R, Rezai M, Jalili F, et al. Comparison the efficacy of intravenous ketorolac versus morphine in the treatment of renal colic. Crit Care. 2018;22(Supplement 1).

4. Nouira N, Lahmer S, Jaouani S et al. Is intranasal fentanyl so effective than parenteral morphine for managing acute post traumatic pain in adults? Critical Care. 2019;23.

5. Rehmani R. A randomized controlled trial of paracetamol versus morphine for the treatment of acute painful crisis of sickle cell disease. Acad Emerg Med. 2013;20(5 SUPPL. 1):S149. 


\section{Appendix C. Evidence Tables}

Table C-1. Study and population characteristics, randomized controlled trials

\begin{tabular}{|c|c|c|c|c|}
\hline $\begin{array}{l}\text { Author, year } \\
\text { Country } \\
\text { Setting } \\
\text { Risk of Bias }\end{array}$ & Eligibility & Intervention and Comparator & Population Characteristics & Outcomes \\
\hline $\begin{array}{l}\text { Frey, } 2019^{17} \\
\text { United States } \\
\text { Setting: ED } \\
\text { Risk of bias: Low }\end{array}$ & $\begin{array}{l}\text { 8-17y old with acute extremity injury \& } \\
\text { VAS } \geq 35 / 100 \\
\text { Exclusions: Significant head, chest, } \\
\text { abdomen or spine injury, GCS }<15 \text { or } \\
\text { inability to report a VAS score, nasal } \\
\text { trauma or aberrant nasal anatomy, } \\
\text { active epistaxis, drug allergy, history } \\
\text { of psychosis, opioid administration } \\
\text { prior to arrival, non-English speaking, } \\
\text { in police custody, postmenarchal } \\
\text { without a negative pregnancy test }\end{array}$ & $\begin{array}{l}\text { A: Fentanyl } 2 \mathrm{mcg} / \mathrm{kg} \text { IN (max } 100 \\
\mathrm{mcg}, \text { median } 1.9 \mathrm{mcg} / \mathrm{kg} \text { IQR } 1.7 \\
\text { to } 1.9)(\mathrm{n}=42) \\
\text { B: Ketamine } 1.5 \mathrm{mg} / \mathrm{kg} \text { IN (max } \\
100 \mathrm{mg}, \text { median } 1.5 \mathrm{mg} / \mathrm{kg} \text { IQR } \\
1.5 \text { to } 1.5)(\mathrm{n}=44) \\
\text { Rescue: NR }\end{array}$ & $\begin{array}{l}\text { Age A:12.2(2.3) B:11.8(2.6) } \\
\text { Males A:74\% B:59\% } \\
\text { Weight A:50.8kg(22.8) } \\
\text { B:45.8kg(14.4) } \\
\text { Race/ethnicity A/B: White } \\
69 \% / 68 \% \text {, Black } 24 \% / 25 \% \text {, other } \\
7 \% / 7 \% \\
\text { Pain etiology/location A/B: } \\
\text { Fracture } 81 \% / 85 \% \text {, dislocation } \\
5 \% / 9 \%, \text { sprain/strain } 12 \% / 2 \% \text {, } \\
\text { other } 2 \% / 4 \% \\
\text { Pain Classification: Traumatic }\end{array}$ & $\begin{array}{l}\text { Any AE } \\
\text { Diastolic blood pressure } \\
\text { Dissociation } \\
\text { Heart rate } \\
\text { Hypotension } \\
\text { Oxygen saturation } \\
\text { Pain severity } \\
\text { Respiratory depression } \\
\text { Respiratory rate } \\
\text { Systolic blood pressure }\end{array}$ \\
\hline $\begin{array}{l}\text { Sotoodehnia, } \\
2019^{90} \\
\text { Iran } \\
\text { Setting: ED } \\
\text { Risk of bias: low }\end{array}$ & $\begin{array}{l}>18 y \text { old presenting to the ED with } \\
\text { acute renal colic } \\
\text { Exclusions: Sensitivity to ketamine or } \\
\text { ketorolac, ischemic heart disease, } \\
\text { hypertension, intracerebral vascular } \\
\text { abnormalities, fibromyalgia, chronic } \\
\text { pains managed with morphine, use of } \\
\text { analgesics within } 4 \text { h before } \\
\text { presenting to the ED, pregnancy, } \\
\text { lactation, renal or hepatic failure, } \\
\text { psychosis, trauma to the head or eye, } \\
\text { and unstable vital signs }\end{array}$ & $\begin{array}{l}\text { A: Ketamine } 0.6 \mathrm{mg} / \mathrm{kg} \text { IV }(\mathrm{n}=67) \\
\text { B: Ketorolac } 30 \mathrm{mg} \text { IV }(\mathrm{n}=74) \\
\text { Rescue: Morphine } 0.1 \mathrm{mg} / \mathrm{kg} \mathrm{IV} \\
\text { for intolerable pain }\end{array}$ & $\begin{array}{l}\text { Age A: } 34.2(9.9) \text { B: } 37.9(10.6) \\
\text { Males A:71\% B: } 81.2 \% \\
\text { Weight NR } \\
\text { Race/ethnicity NR } \\
\text { Pain etiology/location: Renal } \\
\text { colic } 100 \% \\
\text { Pain classification: Non-traumatic }\end{array}$ & $\begin{array}{l}\text { Any } \mathrm{AE} \\
\text { Heart rate } \\
\text { Mental status changes } \\
\text { Nausea } \\
\text { Pain severity } \\
\text { Systolic blood pressure }\end{array}$ \\
\hline
\end{tabular}




\begin{tabular}{|c|c|c|c|c|}
\hline $\begin{array}{l}\text { Author, year } \\
\text { Country } \\
\text { Setting } \\
\text { Risk of Bias }\end{array}$ & Eligibility & Intervention and Comparator & Population Characteristics & Outcomes \\
\hline $\begin{array}{l}\text { Vahedi, } 2019^{91} \\
\text { Iran } \\
\text { Setting: ED } \\
\text { Risk of bias: low }\end{array}$ & $\begin{array}{l}\geq 18 y \text { old and addicted to opioids, } \\
\text { presenting to the ED with acute pain } \\
\text { of } 6 \text { or more on a } 0 \text { to } 10 \text { scale, from } \\
\text { traumatic limb injury } \\
\text { Exclusions: history of allergic } \\
\text { reactions to fentanyl or morphine, } \\
\text { GCS }<14, N R S<5, S B P<90 \mathrm{mmHg}\end{array}$ & $\begin{array}{l}\text { A: Morphine } 0.1 \mathrm{mg} / \mathrm{kg} \mathrm{IV}(\mathrm{n}=152) \\
\text { B: Fentanyl } 1 \mathrm{mcg} / \mathrm{kg} \mathrm{IV} \mathrm{(} \mathrm{n}=155) \\
\text { Rescue: If pain remained } \geq 3 \text { or did } \\
\text { not decrease by at least } 50 \% \text { after } \\
60 \text { min, ketorolac } 60 \mathrm{mg} \text { IV was } \\
\text { administered }\end{array}$ & $\begin{array}{l}\text { Age A: 31.8(10.4) B: 31.0(10.7) } \\
\text { Males A:92.8\% B: } 89 \% \\
\text { Weight NR } \\
\text { Race/ethnicity NR } \\
\text { Pain etiology/location: Limb } \\
\text { injury } 100 \% \\
\text { Pain classification: Traumatic }\end{array}$ & $\begin{array}{l}\text { Diastolic blood pressure } \\
\text { Heart rate } \\
\text { Nausea } \\
\text { Pain severity } \\
\text { Respiratory rate } \\
\text { Systolic blood pressure } \\
\text { Oxygen saturation }\end{array}$ \\
\hline $\begin{array}{l}\text { Verki, } 2019^{51} \\
\text { Iran } \\
\text { Setting: ED } \\
\text { Risk of bias: low }\end{array}$ & $\begin{array}{l}\text { 18-55 years old with limb fracture, } \\
\text { VAS score higher than } 3 \\
\text { Exclusions: Consumed anti-psychotic, } \\
\text { sedative, TCA, MAOI, SSRI drugs, } \\
\text { opioid addicts, patients with underlying } \\
\text { acute or chronic renal and hepatic } \\
\text { disease, cardiac disease, upper } \\
\text { and/or lower respiratory infection, } \\
\text { asthma, COPD, or allergies, pregnant } \\
\text { or breast-feeding women, fentanyl- } \\
\text { prohibited patients, those with multiple } \\
\text { myeloma, a history of convulsion, } \\
\text { ketamine allergy, head injury, or } \\
\text { avulsion fractures, and patients with } \\
\text { unstable hemodynamic factors }\end{array}$ & $\begin{array}{l}\text { A: Fentanyl } 4 \mathrm{mcg} / \mathrm{kg} \text { nebulized } \\
(\mathrm{n}=62) \\
\text { B: Ketamine } 0.4 \mathrm{mg} / \mathrm{kg} \text { IV over } 10 \\
\text { min }(\mathrm{n}=65) \\
\text { Rescue: VAS }>3 \text { after } 60 \mathrm{~min}- \\
\text { treated with morphine } 0.1 \mathrm{mg} / \mathrm{kg} \\
\text { IV }\end{array}$ & $\begin{array}{l}\text { Age A: 34.5(11.97) B: } \\
\text { 36.28(10.73) } \\
\text { Males A:72.6\% B: } 66.2 \% \\
\text { Weight NR } \\
\text { Race/ethnicity NR } \\
\text { Pain etiology/location: Limb } \\
\text { fracture } 100 \% \\
\text { Pain classification: Traumatic }\end{array}$ & Pain severity \\
\hline
\end{tabular}




\begin{tabular}{|c|c|c|c|c|}
\hline $\begin{array}{l}\text { Author, year } \\
\text { Country } \\
\text { Setting } \\
\text { Risk of Bias }\end{array}$ & Eligibility & Intervention and Comparator & Population Characteristics & Outcomes \\
\hline $\begin{array}{l}\text { Abbasi, } 2018^{71} \\
\text { Iran } \\
\text { Setting: ED } \\
\text { Risk of bias: Low }\end{array}$ & $\begin{array}{l}\text { 18-65y old previously diagnosed with } \\
\text { nephrolithiasis or urinary stone by a } \\
\text { urologist w/VAS } \geq 6 / 10 \\
\text { Exclusions: Unstable vitals (SBP }<90 \\
\text { mmHg, HR }<60 \text { or }>120, \mathrm{RR}<8 \text { or } \\
>22 \text {, O2 saturation }<92 \% \text {, narcotic } \\
\text { analgesic before admission, history of } \\
\text { liver disease, kidney disease, chronic } \\
\text { respiratory, CVD, known blood } \\
\text { coagulation, chronic mental illness, } \\
\text { use of psychiatric drugs, addiction to } \\
\text { drugs and psychotropic substances, } \\
\text { drug allergy, inability to understand } \\
\text { the concept of VAS }\end{array}$ & $\begin{array}{l}\text { A: Morphine } 0.1 \mathrm{mg} / \mathrm{kg}+\text { ketamine } \\
0.15 \mathrm{mg} / \mathrm{kg} \text { IV }(\mathrm{n}=53) \\
\text { B: Morphine } 0.1 \mathrm{mg} / \mathrm{kg}+\text { placebo } \\
\text { IV }(\mathrm{n}=53) \\
\text { Rescue: Morphine IV continued } \\
\text { until a VAS } \leq 3 / 10,120 \text { min or } \\
30 \mathrm{mg} \text { of morphine max }\end{array}$ & $\begin{array}{l}\text { Age A: } 51.58 \text { (NR) B: } 49.42 \text { (NR) } \\
\text { Males total study } 67 \% \\
\text { Weight NR } \\
\text { Race/ethnicity NR } \\
\text { Pain etiology/location A/B: Renal } \\
\text { colic } 100 \% \\
\text { Pain Classification: Nontraumatic }\end{array}$ & $\begin{array}{l}\text { Hypotension } \\
\text { Nausea or vomiting } \\
\text { Pain severity } \\
\text { Respiratory depression }\end{array}$ \\
\hline $\begin{array}{l}\text { Al, } 2018^{80} \\
\text { Turkey } \\
\text { Setting: ED } \\
\text { Risk of bias: Low }\end{array}$ & $\begin{array}{l}\text { 16-65y old w/suspected renal colic } \\
\text { subsequently confirmed with imaging, } \\
\text { pain onset within } 12 \mathrm{~h}, \mathrm{VAS} \geq 4 / 10 \\
\text { Exclusions: Hx of direct blunt trauma } \\
\text { to the CVAT within the last week, drug } \\
\text { allergy, SBP<90, hx prostate, renal } \\
\text { and adrenal, and bladder malignancy } \\
\text { or surgery on these regions within the } \\
\text { last } 6 \mathrm{~m} \text {, hx chronic pain syndrome, } \\
\text { use of pain-killer, antidepressant, } \\
\text { anticonvulsant, muscle relaxant, or } \\
\text { steroid within } 12 \mathrm{~h}, \mathrm{hx} \text { of substance or } \\
\text { alcohol dependency, pregnant, } \\
\text { nursing mothers, PID }\end{array}$ & $\begin{array}{l}\text { A: Fentanyl } 2 \text { mcg/kg IV ( } n=100) \\
\text { B: Paracetamol 10mg IV ( } n=100) \\
\text { Rescue: Study drugs, diclofenac } \\
\text { or tramadol to those who needed } \\
\text { them, physician discretion }\end{array}$ & $\begin{array}{l}\text { Age NR } \\
\text { Males A: } 67 \% \text { B: } 67 \% \\
\text { Weight NR } \\
\text { Race/ethnicity NR } \\
\text { Pain etiology/location: Renal } \\
\text { colic } 100 \% \\
\text { Pain Classification: Nontraumatic }\end{array}$ & $\begin{array}{l}\text { Hypotension } \\
\text { Mental status changes } \\
\text { Vomiting }\end{array}$ \\
\hline
\end{tabular}




\begin{tabular}{|c|c|c|c|c|}
\hline $\begin{array}{l}\text { Author, year } \\
\text { Country } \\
\text { Setting } \\
\text { Risk of Bias }\end{array}$ & Eligibility & Intervention and Comparator & Population Characteristics & Outcomes \\
\hline $\begin{array}{l}\text { Burnett, } 2018^{28} \\
\text { USA } \\
\text { Setting: ED } \\
\text { Risk of bias: } \\
\text { Unclear }\end{array}$ & $\begin{array}{l}\text { 3-17y old with medical/traumatic } \\
\text { condition requiring IV opioid } \\
\text { analgesics } \\
\text { Exclusions: Trauma team activation, } \\
\text { drug allergy, inability to provide } \\
\text { informed consent, patient unwilling to } \\
\text { provide assent, high suspicion of } \\
\text { injury related to child abuse, } \\
\text { patient/family member is non-English } \\
\text { speaking, patient is incarcerated }\end{array}$ & $\begin{array}{l}\text { A: Morphine } 0.05 \mathrm{mg} / \mathrm{kg} \text { IV }(\mathrm{n}=32) \\
\text { B: Ketamine } 0.3 \mathrm{mg} / \mathrm{kg} \mathrm{IV}(\mathrm{n}=31) \\
\text { Rescue: Morphine given at the } \\
\text { discretion of the treatment team }\end{array}$ & $\begin{array}{l}\text { Age A:12.7(3.7) B:13.3(3.6) } \\
\text { Males A:72\% B:61\% } \\
\text { Weight NR } \\
\text { Race/ethnicity NR } \\
\text { Pain etiology/location NR } \\
\text { Pain Classification: Mixed }\end{array}$ & Nausea or vomiting \\
\hline $\begin{array}{l}\text { Cenker, } 2018^{87} \\
\text { Turkey } \\
\text { Setting: ED } \\
\text { Risk of bias: Low }\end{array}$ & $\begin{array}{l}\text { 18-60y old presenting w/flank pain } \\
\text { ultimately diagnosed as renal colic } \\
\text { Exclusions: Analgesic within } 6 \mathrm{~h} \text {, fever } \\
\text { or hemodynamically unstable, } \\
\text { peritoneal irritation signs, cardiac } \\
\text { failure, hx of renal or hepatic failure, } \\
\text { drug allergy, pregnancy, vision } \\
\text { problems. }\end{array}$ & $\begin{array}{l}\text { A: Ibuprofen } 800 \mathrm{mg} \text { IV }(\mathrm{n}=100) \\
\text { B: Paracetamol } 1 \mathrm{~g} \mathrm{IV}(\mathrm{n}=100) \\
\text { Rescue: Inadequate pain relief at } \\
\text { 30min received fentanyl } 1 \mathrm{\mu g} / \mathrm{kg} \\
\text { IV }\end{array}$ & $\begin{array}{l}\text { Age total study } 36(9) \\
\text { Males total study } 64.5 \% \\
\text { Weight NR } \\
\text { Race/ethnicity NR } \\
\text { Pain etiology/location: Renal } \\
\text { colic } 100 \% \\
\text { Pain Classification: Nontraumatic }\end{array}$ & $\begin{array}{l}\text { Any } \mathrm{AE} \\
\text { Pain severity } \\
\text { Vomiting }\end{array}$ \\
\hline $\begin{array}{l}\text { Cozzi, } 2018^{88} \\
\text { Italy } \\
\text { Setting: ED } \\
\text { Risk of bias: Low }\end{array}$ & $\begin{array}{l}\text { 4-18y old w/moderate to severe acute } \\
\text { abdominal pain and pain score of } \\
\geq 6 / 10 \text { (Wong-Baker } 4-7 y, \text { NRS } \geq 8 y \text { ) } \\
\text { Exclusions: drug allergy, analgesic } \\
\text { drugs in the } 8 \mathrm{~h} \text { before the medical } \\
\text { evaluation, hx nephropathy, liver } \\
\text { disease, metabolic or neurologic } \\
\text { disease and thrombocytopenia or } \\
\text { bleeding disorders, abdominal pain } \\
\text { was due to fecal stasis or severe } \\
\text { dehydration }\end{array}$ & $\begin{array}{l}\text { A: Ketorolac } 0.5 \mathrm{mg} / \mathrm{kg} \text { oral drops } \\
\mathrm{SL}(\mathrm{max} 30 \mathrm{mg})(\mathrm{n}=70) \\
\text { B: Paracetamol melt in the mouth } \\
\text { powder } 20 \mathrm{mg} / \mathrm{kg} \text { melt in the } \\
\text { mouth powder (max } 1 \mathrm{~g})(\mathrm{n}=70) \\
\text { Rescue: Pain score } \geq 6 / 10 \text { at } 2 \mathrm{~h} \text {, } \\
\text { rescue analgesic of ED } \\
\text { pediatrician's choice was given }\end{array}$ & $\begin{array}{l}\text { Age A:12(9-14) B:12(9-14.3) } \\
\text { Males A:30\% B:45.7\% } \\
\text { Weight NR } \\
\text { Race/ethnicity NR } \\
\text { Pain etiology/location A/B: } \\
\text { Appendicitis } 7.1 \% / 11.4 \% \text {, } \\
\text { gynecological } 12.9 \% / 14.3 \% \text {, } \\
\text { urological } 4.3 \% / 4.3 \% \text {, viral } \\
\text { infection } 45.7 \%, 41.4 \% \text {, colic } \\
22.9 \% / 21.4 \%, \text { functional } \\
0 \% / 2.9 \% \text {, other } 7.1 \% / 4.3 \% \\
\text { Pain Classification: Mixed }\end{array}$ & $\begin{array}{l}\text { Any AE } \\
\text { Mental status changes } \\
\text { Nausea } \\
\text { Pain severity } \\
\text { Presence of pain } \\
\text { Vomiting }\end{array}$ \\
\hline
\end{tabular}




\begin{tabular}{|c|c|c|c|c|}
\hline $\begin{array}{l}\text { Author, year } \\
\text { Country } \\
\text { Setting } \\
\text { Risk of Bias }\end{array}$ & Eligibility & Intervention and Comparator & Population Characteristics & Outcomes \\
\hline $\begin{array}{l}\text { Hosseininejad, } \\
2018^{68} \\
\text { Iran } \\
\text { Setting: ED } \\
\text { Risk of bias: Low }\end{array}$ & $\begin{array}{l}\text { 18-65y old w/kidney stones and } \\
\text { VAS } \geq 6 / 10 \\
\text { Exclusions: Unstable vital signs, drug } \\
\text { allergy, pregnancy, breastfeeding, } \\
\text { contraindications to morphine, history } \\
\text { of opium addiction, any } \\
\text { analgesic/narcotic within past } 6 \mathrm{~h}, \\
\text { peritoneal s/sx on abdominal exam, hx } \\
\text { chronic CV, liver, kidney diseases, } \\
\text { psvchosis }\end{array}$ & $\begin{array}{l}\text { A: Morphine } 0.1 \mathrm{mg} / \mathrm{kg}+\text { ketamine } \\
0.2 \mathrm{mg} / \mathrm{kg} \text { IV }(\mathrm{n}=100) \\
\text { B: Morphine } 0.1 \mathrm{mg} / \mathrm{kg} \mathrm{IV}(\mathrm{n}=100) \\
\text { Rescue: Morphine } 0.05 \mathrm{mg} / \mathrm{kg} \mathrm{IV}\end{array}$ & $\begin{array}{l}\text { Age A:35.29(7.12) B:35.91(9.13) } \\
\text { Males A:67\% B:70\% } \\
\text { Weight A:70.3kg(7.02) } \\
\text { B:69.86kg(8.56) } \\
\text { Race/ethnicity NR } \\
\text { Pain etiology/location: Renal } \\
\text { colic 100\% } \\
\text { Pain Classification: Nontraumatic }\end{array}$ & $\begin{array}{l}\text { Diastolic blood pressure } \\
\text { Mental status changes } \\
\text { Nausea } \\
\text { Pain severity } \\
\text { Respiratory rate } \\
\text { Systolic blood pressure } \\
\text { Vomiting }\end{array}$ \\
\hline $\begin{array}{l}\text { Jahanian, } 2018^{60} \\
\text { Iran } \\
\text { Setting: ED } \\
\text { Risk of bias: Low }\end{array}$ & $\begin{array}{l}\text { 18-65y old, upper or lower extremity } \\
\text { long bone fractures caused by blunt } \\
\text { trauma, pain score } \geq 7 / 10 \\
\text { Exclusions: Mental or neurological } \\
\text { disorders, liver, kidney, stroke, asthma } \\
\text { and other respiratory diseases, heart } \\
\text { diseases, }<45 \mathrm{~kg} \text { or }>155 \mathrm{~kg} \text {, pregnant } \\
\text { or lactating, SBP }>180 \text { or }<90 \mathrm{mmHg} \text {, } \\
\mathrm{HR}<50 \text { or }>150, \mathrm{RR}<10 \text { or }>30 \text {, } \\
\text { decreased LOC, blow to the head or } \\
\text { eyes, multiple trauma, drug allergy, } \\
\text { drug addiction/IV use, other fractures, } \\
\text { severe displacement, need of } \\
\text { reduction, open fracture, compartment } \\
\text { syndrome, analgesic before the study }\end{array}$ & $\begin{array}{l}\text { A: Morphine } 0.1 \mathrm{mg} / \mathrm{kg} \text { IV }(\mathrm{n}=80) \\
\text { B: Ketamine } 0.5 \mathrm{mg} / \mathrm{kg} \text { IV }(\mathrm{n}=79) \\
\text { Rescue: In the absence of pain } \\
\text { relief at any time of the study, half } \\
\text { of the previous doses of the same } \\
\text { group was administered. If the } \\
\text { pain score remains } 9 \text { or } 10 \text { out of } \\
10, \text { or more than } 2 \text { times to the } \\
\text { administered drug, fentanyl } 1 \\
\mu \mathrm{g} / \mathrm{kg} \text { IV was given. }\end{array}$ & $\begin{array}{l}\text { Age A:36.38(9.3) B:35.87(7.3) } \\
\text { Males A:70.5\% B:71.8\% } \\
\text { Weight NR } \\
\text { Race/ethnicity NR } \\
\text { Pain etiology/location: Road } \\
\text { traffic accidents } 71.8 \% / 69.3 \% \text {, } \\
\text { fall } 23.1 \% / 24.3 \% \text {, assault } \\
5.1 \% / 6.4 \% \\
\text { Pain Classification: Traumatic }\end{array}$ & $\begin{array}{l}\text { Mental status changes } \\
\text { Nausea or vomiting } \\
\text { Pain severity }\end{array}$ \\
\hline
\end{tabular}




\begin{tabular}{|c|c|c|c|c|}
\hline $\begin{array}{l}\text { Author, year } \\
\text { Country } \\
\text { Setting } \\
\text { Risk of Bias }\end{array}$ & Eligibility & Intervention and Comparator & Population Characteristics & Outcomes \\
\hline $\begin{array}{l}\text { Mohammadshahi, } \\
2018^{72} \\
\text { Iran } \\
\text { Setting: ED } \\
\text { Risk of bias: Low }\end{array}$ & $\begin{array}{l}>18 y \text { old w/limb pain resulting from } \\
\text { traumatic injuries within the last } 24 \mathrm{~h} \text {, } \\
\text { NRS } \geq 7 / 10 \\
\text { Exclusions: open fracture, closed } \\
\text { fracture in more than one site, fracture } \\
\text { plus dislocation, acute traumatic pain } \\
\text { in more than two limbs, BP }<90 / 60 \text { or } \\
>160 / 100, \mathrm{HR}>120 \text { or }<60, \mathrm{GCS}<15 \text {, } \\
\text { non-limb traumatic injuries, } \\
\text { pregnancy, drug allergy, patients } \\
\text { leaving the hospital for any reason } \\
\text { within } 3 \mathrm{~h} \text { of drug administration }\end{array}$ & $\begin{array}{l}\text { A: Morphine } 0.05 \mathrm{mg} / \mathrm{kg} \mathrm{IV} \mathrm{+} \\
\text { ketamine } 1 \mathrm{mg} / \mathrm{kg} \text { IN using a } \\
\text { dropper }(\mathrm{n}=40) \\
\text { B: Morphine } 0.05 \mathrm{mg} / \mathrm{kg} \mathrm{IV} \mathrm{+} 0.02 \\
\mathrm{ml} / \mathrm{kg} \text { distilled water IN using a } \\
\text { dropper ( } \mathrm{n}=40) \\
\text { Rescue: After } 10 \mathrm{~min} \text { if patient } \\
\text { requested more analgesics } \\
\text { morphine } 0.05 \mathrm{mg} / \mathrm{kg} \text { IV was } \\
\text { given }\end{array}$ & $\begin{array}{l}\text { Age A:31.42(10.3) B: } 31.75(8.2) \\
\text { Males total study } 54.9 \% \\
\text { Weight NR } \\
\text { Race/ethnicity: NR } \\
\text { Pain etiology/location: Traumatic } \\
\text { limb } 100 \% \\
\text { Pain classification: Traumatic }\end{array}$ & $\begin{array}{l}\text { Any AE } \\
\text { Heart rate } \\
\text { Oxygen saturation } \\
\text { Pain severity } \\
\text { Systolic blood pressure } \\
\text { Vomiting }\end{array}$ \\
\hline $\begin{array}{l}\text { Motov, } 2018^{55} \\
\text { USA } \\
\text { Setting: ED } \\
\text { Risk of bias: Low }\end{array}$ & $\begin{array}{l}\geq 65 y \text { old w/ acute pain (within } 7 d \\
\text { onset), NRS } \geq 5 / 10 \text { requiring opioid } \\
\text { analgesia, abdominal, flank, back, or } \\
\text { musculoskeletal pain } \\
\text { Exclusions: Altered mental status, } \\
\text { drug allergy, weight }<40 \text { or }>115 \mathrm{~kg} \text {, } \\
\text { SBP }<90 \text { or }>180, \mathrm{HR}<50 \text { or }>150 \text {, } \\
\mathrm{RR}<10 \text { or }>30, \text { hx of acute head or } \\
\text { eye injury, seizure, intracranial } \\
\text { hypertension, severe COPD, chronic } \\
\text { pain, renal or hepatic insufficiency, } \\
\text { alcohol or drug abuse, psychiatric } \\
\text { illness, or recent (4h before) opioid } \\
\text { use }\end{array}$ & $\begin{array}{l}\text { A: Morphine } 0.1 \mathrm{mg} / \mathrm{kg} \text { IV (mean } \\
6.8 \mathrm{mg}(1.5))(\mathrm{n}=30) \\
\text { B: Ketamine } 0.3 \mathrm{mg} / \mathrm{kg} \mathrm{IV} \mathrm{over} 15 \\
\text { min (mean } 21.0 \mathrm{mg}(6.2))(\mathrm{n}=30) \\
\text { Rescue: Fentanyl } 0.5 \mathrm{mcg} / \mathrm{kg} \text { if } \\
\text { NRS } \geq 5 / 10 \text { and requested by } \\
\text { patient }\end{array}$ & $\begin{array}{l}\text { Age A: } 77.1(8.5) \text { B: } 77.3(8.4) \\
\text { Males A:23.3\% B:23.3\% } \\
\text { Weight NR } \\
\text { Race/ethnicity NR } \\
\text { Pain etiology/location A/B: } \\
\text { Abdominal 33.3\%/46.7\%, cancer } \\
\text { 16.7\%/6.7\%, back 3.3\%/16.7\%, } \\
\text { musculoskeletal 10\%/3.3\%, } \\
\text { fracture } 23.3 \% / 16.7 \% \text {, flank } \\
13.3 \% / 10 \% \\
\text { Pain Classification: Mixed }\end{array}$ & $\begin{array}{l}\text { Any AE } \\
\text { Mental status changes } \\
\text { Nausea } \\
\text { Pain severity } \\
\text { Presence of pain } \\
\text { Respiratory depression }\end{array}$ \\
\hline
\end{tabular}




\begin{tabular}{|c|c|c|c|c|}
\hline $\begin{array}{l}\text { Author, year } \\
\text { Country } \\
\text { Setting } \\
\text { Risk of Bias }\end{array}$ & Eligibility & Intervention and Comparator & Population Characteristics & Outcomes \\
\hline $\begin{array}{l}\text { Quinn, } 2018^{52} \\
\text { USA } \\
\text { Setting: ED } \\
\text { Risk of bias: Low }\end{array}$ & $\begin{array}{l}\text { 3-17y old, moderate to severe pain } \\
\text { (NRS } \geq 6 / 10 \text { or equivalent Wong-Baker } \\
\text { FACES Pain Scale) } \\
\text { Exclusions: Weight }>64 \mathrm{~kg} \text {, insufficient } \\
\text { intensity to warrant opioid, facial } \\
\text { trauma or any abnormality of the nasal } \\
\text { anatomy, circulatory insufficiency, } \\
\text { developmental delay, head } \\
\text { trauma/increased intracranial } \\
\text { pressure/altered consciousness, drug } \\
\text { allergy, inability to provide pain scale } \\
\text { assessment, opioid pain medication } \\
\text { immediately before arrival to the ED }\end{array}$ & $\begin{array}{l}\text { A: Fentanyl } 1.5 \mu \mathrm{g} / \mathrm{kg} \mathrm{IN} \mathrm{(n=11)} \\
\text { B: Ketamine } 1 \mathrm{mg} / \mathrm{kg} \mathrm{IN} \mathrm{(}=11) \\
\text { Recue: Morphine } 1 \mathrm{mg} / \mathrm{kg} \mathrm{IV} \mathrm{if} \mathrm{a} \\
\text { patient or parents requested } \\
\text { additional pain relief }\end{array}$ & $\begin{array}{l}\text { Age A:9.58(2.92) B:9.77 (2.51) } \\
\text { Males A:73\% B:91\% } \\
\text { Weight NR } \\
\text { Race/ethnicity NR } \\
\text { Pain etiology/location A/B: } \\
\text { Musculoskeletal 73\%/73\%, } \\
\text { abdominal } 27 \% / 27 \% \\
\text { Pain Classification: Mixed }\end{array}$ & $\begin{array}{l}\text { Any AE } \\
\text { Mental status changes } \\
\text { Pain severity } \\
\text { Presence of pain }\end{array}$ \\
\hline $\begin{array}{l}\text { Farina, } 2017^{54} \\
\text { Iran } \\
\text { Setting: ED } \\
\text { Risk of bias: Low }\end{array}$ & $\begin{array}{l}\geq 15 y \text { old, renal colic pain and didn't } \\
\text { require surgical intervention } \\
\text { Exclusions: opioid addiction, prior use } \\
\text { of analgesics, pregnancy, drug allergy, } \\
\text { nasal occlusion, SBP }>180 \text { or }<90 \text {, } \\
\text { respiratory distress, altered level of } \\
\text { consciousness }\end{array}$ & $\begin{array}{l}\text { A: Morphine } 0.1 \mathrm{mg} / \mathrm{kg} \text { IV + } \\
\text { placebo IN }(n=20) \\
\text { B: Ketamine } 1 \mathrm{mg} / \mathrm{kg} \text { IN + placebo } \\
\text { IV }(n=20) \\
\text { Rescue: If no decrease in VAS at } \\
\text { 30min fentanyl } 1-2 \mathrm{mcg} / \mathrm{kg} \text { every } \\
5 \text { min was titrated to effect }\end{array}$ & $\begin{array}{l}\text { Age A:34.75(11.71) } \\
\text { B:39.25(10.75) Males A:85\% } \\
\text { B:40\% } \\
\text { Weight A:76.14(10.32) } \\
\text { B:74.10(9.98) } \\
\text { Race/ethnicity NR } \\
\text { Pain etiology/location: Renal } \\
\text { colic } 100 \% \\
\text { Pain Classification: Nontraumatic }\end{array}$ & $\begin{array}{l}\text { Any AE } \\
\text { Emergence delirium } \\
\text { Hypotension } \\
\text { Mental status changes } \\
\text { Nausea } \\
\text { Pain severity }\end{array}$ \\
\hline $\begin{array}{l}\text { Le May, } 2017^{86} \\
\text { Canada } \\
\text { Setting: ED } \\
\text { Risk of bias: Low }\end{array}$ & $\begin{array}{l}\text { 6-17y old w/musculoskeletal injury to } \\
\text { upper or lower limb, VAS }>29 / 100 \\
\text { Exclusions: drug or color allergy, } \\
\text { suspected child abuse, inability to self- } \\
\text { report pain, chronic pain requiring } \\
\text { daily analgesics, NSAIDs or opioid } \\
\text { use within 3h before triage, injury to } \\
>1 \text { limb, known hepatic or renal } \\
\text { disease and/or dysfunction, known } \\
\text { bleeding disorder, neurocognitive } \\
\text { disability precluding assent and } \\
\text { participation in the study, hx of sleep } \\
\text { apnea or loud snoring in the past } 5 \mathrm{~d}\end{array}$ & $\begin{array}{l}\text { A: Morphine } 0.2 \mathrm{mg} / \mathrm{kg} \mathrm{PO}, \text { max } \\
15 \mathrm{mg}(\mathrm{n}=201) \\
\text { B: Ibuprofen } 10 \mathrm{mg} / \mathrm{kg} \mathrm{PO}, \max \\
600 \mathrm{mg}(\mathrm{n}=99) \\
\text { Rescue: Eligible to receive rescue } \\
\text { analgesia at any time }\end{array}$ & $\begin{array}{l}\text { Age A:11.7(2.7) B:12.2(2.6) } \\
\text { Males A:56.4\% B:58.2\% } \\
\text { Weight NR } \\
\text { Race/ethnicity NR } \\
\text { Pain etiology/location: Fracture } \\
\text { 35.6\%/47.3\%, soft tissue } \\
62.2 \% / 52.74 \% \text {, missing } 2.1 \% / 0 \% \\
\text { Pain Classification: Mixed }\end{array}$ & $\begin{array}{l}\text { Any AE } \\
\text { Mental status changes } \\
\text { Nausea } \\
\text { Pain severity } \\
\text { Presence of pain }\end{array}$ \\
\hline
\end{tabular}




\begin{tabular}{|c|c|c|c|c|}
\hline $\begin{array}{l}\text { Author, year } \\
\text { Country } \\
\text { Setting } \\
\text { Risk of Bias }\end{array}$ & Eligibility & Intervention and Comparator & Population Characteristics & Outcomes \\
\hline $\begin{array}{l}\text { Mahshidfar, } \\
2017^{56} \\
\text { Iran } \\
\text { Setting: ED } \\
\text { Risk of bias: Low }\end{array}$ & $\begin{array}{l}\text { 18-70y old, musculoskeletal trauma, } \\
\text { NRS } \geq 5 / 10 \\
\text { Exclusions: instability in vital signs, } \\
\text { head trauma, GCS score }<15 \text {, opiate } \\
\text { users, psychiatric or cardiac problem, } \\
\text { drug allergy, pregnancy, breast- } \\
\text { feeding, renal or hepatic insufficiency, } \\
\text { contraindications to interventions }\end{array}$ & $\begin{array}{l}\text { A: Morphine } 0.1 \mathrm{mg} / \mathrm{kg} \text { IV (mean } \\
6.8 \mathrm{mg}(1.2))(\mathrm{n}=155) \\
\text { B: Ketamine } 0.2 \mathrm{mg} / \mathrm{kg} \mathrm{IV} \mathrm{(mean} \\
14.9 \mathrm{mg}(3.3))(\mathrm{n}=153) \\
\\
\text { Rescue: }<3 / 10 \text { point decrease in } \\
\text { pain score, morphine } 3 \mathrm{mg} \text { IV } \\
\text { every } 5 \text { minutes }\end{array}$ & $\begin{array}{l}\text { Age A:34.1(7.3) B:34.4(7.6) } \\
\text { Males A:82\% B:84\% } \\
\text { Weight A:68.4kg(12.9) } \\
\text { B:75.1kg(14.6) } \\
\text { Race/ethnicity NR } \\
\text { Pain etiology/location A/B: } \\
\text { Fracture } 24 \% / 28 \% \text {, soft tissue } \\
\text { injury } 76 \% / 72 \% \\
\text { Pain Classification: Traumatic }\end{array}$ & $\begin{array}{l}\text { Hypotension } \\
\text { Mental status changes } \\
\text { Nausea } \\
\text { Pain severity } \\
\text { Respiratory depression }\end{array}$ \\
\hline $\begin{array}{l}\text { Masoumi, } 2017^{84} \\
\text { Iran } \\
\text { Setting: ED } \\
\text { Risk of bias: Low }\end{array}$ & $\begin{array}{l}\geq 18 y \text { old w/long bone fractures } \\
\text { Exclusions: Asthma, COPD, } \\
\text { rheumatoid fever, peptic ulcer } \\
\text { disease, GI bleeding, drug allergy, } \\
\text { without complete consciousness, } \\
\text { hemodynamic instability and } \\
\text { symptoms of respiratory distress and } \\
\text { GIB during the pain relief injection }\end{array}$ & $\begin{array}{l}\text { A: Morphine } 5 \mathrm{mg} \text { IV bolus then } \\
2.5 \mathrm{mg} \text { q } 5 \mathrm{~min} X 20 \mathrm{~min} \text { if } \mathrm{VAS} \geq 4 / 10 \\
(\mathrm{n}=44) \\
\text { B: Ketorolac } 10 \mathrm{mg} \text { IV bolus then } \\
5 \mathrm{mg} \text { q5min } X 20 \mathrm{~min} \text { if } \mathrm{VAS} \geq 4 / 10 \\
(\mathrm{n}=44) \\
\text { Rescue: NR }\end{array}$ & $\begin{array}{l}\text { Age A:33.2(11.4) B:29.1(12.5) } \\
\text { Males A:70.5\% B:63.6\% } \\
\text { Weight NR } \\
\text { Race/ethnicity NR } \\
\text { Pain etiology/location: Long bone } \\
\text { fracture } 100 \% \\
\text { Pain Classification: Traumatic }\end{array}$ & $\begin{array}{l}\text { Any AE } \\
\text { Hypotension } \\
\text { Mental status changes } \\
\text { Nausea } \\
\text { Pain severity } \\
\text { Vomiting }\end{array}$ \\
\hline $\begin{array}{l}\text { Reynolds, } 2017^{29} \\
\text { USA } \\
\text { Setting: ED } \\
\text { Risk of bias: Low }\end{array}$ & $\begin{array}{l}\text { 4-17y old w/suspected fracture of any } \\
\text { single extremity requiring analgesia, } \\
\text { Wong-Baker FACES (4-10y) or VAS } \\
(11-17 y) \geq 3 / 10 \\
\text { Exclusions: GCS }<15 \text {, drug allergy, } \\
\text { pregnancy, intoxication, age-adjusted } \\
\text { hypotension at presentation (SBP }<70 \\
+2 x \text { age if }<10 y, \text { or }<90 \text { for those } \\
>10 y) \text {, weight }>70 \mathrm{~kg} \text {, opioid analgesia } \\
\text { administered prior to arrival, multiple } \\
\text { injuries, nonverbal from } \\
\text { developmental delay, or aberrant } \\
\text { nasal anatomy that precluded IN } \\
\text { medications }\end{array}$ & $\begin{array}{l}\text { A: Fentanyl } 1.5 \mathrm{mcg} / \mathrm{kg} \text { IN ( } \mathrm{n}=44) \\
\text { B: Ketamine } 1 \mathrm{mg} / \mathrm{kg} \mathrm{IN} \mathrm{(} \mathrm{n}=43) \\
\text { Rescue: } 2 \mathrm{nd} \text { dose } \geq 20 \mathrm{mins} \text { after } \\
\text { 1st dose of ketamine } 0.5 \mathrm{mg} / \mathrm{kg} \mathrm{IN} \\
\text { or fentanyl } 0.75 \mathrm{mcg} / \mathrm{kg} \mathrm{IN}\end{array}$ & $\begin{array}{l}\text { Age A: } 4-10 y \text { y3\%, 11-17y } 27 \% \\
\text { B: } 4-10 y 72 \%, 11-17 y 28 \% \\
\text { Males A: } 64 \% \text { B: } 61 \% \\
\text { Weight NR } \\
\text { Race/ethnicity NR } \\
\text { Pain etiology/location: Single } \\
\text { extremity fracture } 100 \% \\
\text { Pain Classification: Traumatic }\end{array}$ & $\begin{array}{l}\text { Any AE } \\
\text { Dissociation } \\
\text { Hypotension } \\
\text { Mental status changes } \\
\text { Nausea } \\
\text { Pain severity } \\
\text { Presence of pain }\end{array}$ \\
\hline
\end{tabular}




\begin{tabular}{|c|c|c|c|c|}
\hline $\begin{array}{l}\text { Author, year } \\
\text { Country } \\
\text { Setting } \\
\text { Risk of Bias }\end{array}$ & Eligibility & Intervention and Comparator & Population Characteristics & Outcomes \\
\hline $\begin{array}{l}\text { Sin, } 2017^{69} \\
\text { USA } \\
\text { Setting: ED } \\
\text { Risk of bias: Low }\end{array}$ & $\begin{array}{l}\geq 18 y \text { old w/chief complaint of acute } \\
\text { pain (w/in } 15 \mathrm{~d} \text { ), moderate to severe } \\
\text { (NRS } \geq 3 \text { ) } \\
\text { Exclusions: RR not within } 12-20, \mathrm{HR} \\
\text { not within } 60-110, \mathrm{BP}<90 / 50 \text { or } \\
>180 / 100, \mathrm{O} 2 \text { sat }<94 \% \text {, altered } \\
\text { mental status, weight }>166 \mathrm{~kg}, \\
\text { pregnancy or breastfeeding, drug } \\
\text { allergy, opioid use within } 4 \mathrm{~h} \text {, hx of } \\
\text { schizophrenia, depression, or } \\
\text { substance abuse, traumatic head } \\
\text { injury with or without LOC, myocardial } \\
\text { ischemia, headache, migraine, or } \\
\text { increase in intracranial or intraocular } \\
\text { pressure }\end{array}$ & $\begin{array}{l}\text { A: Morphine } 0.1 \mathrm{mg} / \mathrm{kg} \mathrm{IV} \mathrm{push,} \\
\text { max } 10 \mathrm{mg}(\mathrm{mean} 6.6 \mathrm{mg}(1.4))+ \\
\text { ketamine } 0.3 \mathrm{mg} / \mathrm{kg} \text { infused over } \\
15 \mathrm{~min}(\mathrm{n}=30) \\
\text { B: Morphine } 0.1 \mathrm{mg} / \mathrm{kg} \mathrm{IV} \mathrm{push,} \\
\text { max } 10 \mathrm{mg} \text { (mean } 5.9 \mathrm{mg}(1.7))+ \\
\text { placebo infusion ( } \mathrm{n}=30) \\
\text { Rescue: Morphine } 0.1 \mathrm{mg} / \mathrm{kg} \mathrm{IV} \\
\text { push (max } 10 \mathrm{mg}) \text { was offered at } \\
5,15,30,45,75,90,105 \text {, and } 120 \\
\text { after initial dose if the patients } \\
\text { reported NRS } \geq 4 / 10\end{array}$ & $\begin{array}{l}\text { Age A:41(16) B:48(17) } \\
\text { Males A:40\% B:40\% } \\
\text { Weight A: } 81 \mathrm{~kg}(22) \mathrm{B}: 85 \mathrm{~kg}(24) \\
\text { Race/ethnicity A/B: White } \\
\text { 10\%/16.7\%, African American } \\
60 \% / 60 \% \text {, Hispanic 30\%/16.7\%, } \\
\text { Asian/Pacific Islander } 0 \% / 6.7 \% \\
\text { Pain etiology/location: Abdominal } \\
63.3 \% / 73.3 \% \text {, musculoskeletal } \\
20 \% / 16.6 \% \text {, back } 6.6 \% / 0 \% \text {, } \\
\text { elbow fracture } 0 \% / 3.3 \% \text {, abscess } \\
0 \% / 3.3 \% \text {, hip 0\%/3.3\%, testicular } \\
3.3 \% / 0 \% \text {, renal colic } 6.6 \% / 0 \% \\
\text { Pain Classification: Mixed }\end{array}$ & $\begin{array}{l}\text { Dissociation } \\
\text { Emergence delirium } \\
\text { Nausea } \\
\text { Pain severity } \\
\text { Respiratory depression }\end{array}$ \\
\hline $\begin{array}{l}\text { Jalili, } 2016^{74} \\
\text { Iran } \\
\text { Setting: ED } \\
\text { Risk of bias: Low }\end{array}$ & $\begin{array}{l}\geq 18 y \text { old w/acute limb trauma and pain } \\
\text { score }>3 / 10 \\
\text { Exclusions: drug allergy or } \\
\text { contraindication, SBP }<90, \text { pregnancy, } \\
\text { any analgesic drug use within } 6 \mathrm{~h}, \\
\text { known pulmonary, cardiac, renal, or } \\
\text { hepatic failure }\end{array}$ & $\begin{array}{l}\text { A: Morphine } 0.1 \mathrm{mg} / \mathrm{kg} \mathrm{IV}(\mathrm{n}=30) \\
\text { B: Paracetamol } 1 \mathrm{~g} \mathrm{IV}(\mathrm{n}=30) \\
\text { Rescue: Morphine IV titrated to } \\
\text { effect at } 30 \mathrm{~min} \text { if NRS }>4 / 10\end{array}$ & $\begin{array}{l}\text { Age NR } \\
\text { Males NR } \\
\text { Weight NR } \\
\text { Race/ethnicity NR } \\
\text { Pain etiology/location: Acute limb } \\
\text { trauma } 100 \% \\
\text { Pain Classification: Traumatic }\end{array}$ & $\begin{array}{l}\text { Mental status changes } \\
\text { Pain severity }\end{array}$ \\
\hline
\end{tabular}




\begin{tabular}{|c|c|c|c|c|}
\hline $\begin{array}{l}\text { Author, year } \\
\text { Country } \\
\text { Setting } \\
\text { Risk of Bias }\end{array}$ & Eligibility & Intervention and Comparator & Population Characteristics & Outcomes \\
\hline $\begin{array}{l}\text { Mollaei, } 2016^{81} \\
\text { Iran } \\
\text { Setting: ED } \\
\text { Risk of bias: Low }\end{array}$ & $\begin{array}{l}\text { 15-60y old with forearm or leg } \\
\text { fractures, moderate to severe pain } \\
\text { (VAS }>4 / 10) \\
\text { Exclusions: GCS }<15 \text {, weight< } 60 \text { or } \\
>100 \mathrm{~kg}, \text { hemodynamic instability, lung } \\
\text { problems, previous use of pain killer } \\
\text { drugs and narcotics, addiction, } \\
\text { previous liver or kidney disease, } \\
\text { concussion, pregnancy, previous use } \\
\text { of monoamine oxidase, sleeping and } \\
\text { sedative drugs, phenobarbital and } \\
\text { isoniazid, multiple vomiting incidents } \\
\text { and nausea }\end{array}$ & $\begin{array}{l}\text { A: Morphine } 0.1 \mathrm{mg} / \mathrm{kg} \text { IV over } 10- \\
15 \mathrm{~min}(\mathrm{n}=28) \\
\text { B: Acetaminophen } 1 \mathrm{~g} \text { IV over } 10- \\
\text { 15min }(n=27) \\
\text { Rescue: VAS }>5 / 10 \text { after } 30 \mathrm{~min} \\
\text { morphine will be prescribed for } \\
\text { patient }\end{array}$ & $\begin{array}{l}\text { Age A:35(11.3) B:36.0(11.1) } \\
\text { Males A:60.7\% B:63\% } \\
\text { Weight A:65.0kg(3.0) } \\
\text { B:65.5kg(2.9) } \\
\text { Race/ethnicity NR } \\
\text { Pain etiology/location: Traffic } \\
\text { accident } 82.1 \% / 81.5 \% \text {, falling } \\
\text { from height 14.3\%/18.5\%, direct } \\
\text { injuries 3.6\%/0\% } \\
\text { Pain Classification: Traumatic }\end{array}$ & $\begin{array}{l}\text { Mental status changes } \\
\text { Nausea } \\
\text { Pain severity }\end{array}$ \\
\hline $\begin{array}{l}\text { Pathan, } 2016^{75} \\
\text { Qatar } \\
\text { Setting: ED } \\
\text { Risk of bias: Low }\end{array}$ & $\begin{array}{l}\text { 18-65y old w/renal colic and } \\
\text { NRS } \geq 4 / 10 \\
\text { Exclusions: drug allergy, hx of asthma, } \\
\text { known renal or liver failure or } \\
\text { impairment, pregnancy, pain caused } \\
\text { by a traumatic mechanism (in the } \\
\text { setting of injury, for example motor } \\
\text { vehicle crash, fall, or assault), or } \\
\text { previous use of analgesia within } 6 \mathrm{~h}\end{array}$ & $\begin{array}{l}\text { A: Morphine } 0.1 \mathrm{mg} / \mathrm{kg} \text { IV ( } \mathrm{n}=548) \\
\text { B: Paracetamol 1g IV ( } \mathrm{n}=549) \\
\text { Rescue: Morphine } 3 \mathrm{mg} \text { IV q5min } \\
\text { until NRS<2/10 or participant } \\
\text { refused further analgesia (starting } \\
\text { 30min after initial dose) }\end{array}$ & $\begin{array}{l}\text { Age A:34.4(28.6-41.5) B:34.7 } \\
(28.8-41.7) \\
\text { Males A:81\% B:83\% } \\
\text { Weight A:72kg(65-84.6) } \\
\text { B:74.6kg(65-84) } \\
\text { Race/ethnicity NR } \\
\text { Pain etiology/location: Renal } \\
\text { colic } 100 \% \\
\text { Pain Classification: Nontraumatic }\end{array}$ & $\begin{array}{l}\text { Any AE } \\
\text { Pain severity } \\
\text { Presence of pain } \\
\text { Time to analgesic effect }\end{array}$ \\
\hline $\begin{array}{l}\text { Serinken, } 2016^{76} \\
\text { Turkey } \\
\text { Setting: ED } \\
\text { Risk of bias: Low }\end{array}$ & $\begin{array}{l}\text { 21-65y old presenting w/pain radiating } \\
\text { along sciatic nerve, VAS } \geq 40 \\
\text { Exclusions: pain }>1 \mathrm{w} \text {, low back or leg } \\
\text { trauma within } 1 \mathrm{w}, \text { sensory or motor } \\
\text { deficit, drug allergy, unstable vital } \\
\text { signs, fever }>37.9^{\circ} \mathrm{C}, \mathrm{hx} \text { of malignancy, } \\
\text { cauda equina syndrome, chronic pain } \\
\text { syndromes, rheumatologic diseases, } \\
\text { drug or alcohol addiction, pregnancy } \\
\text { or lactation, analgesic, antidepressant, } \\
\text { anticonvulsant, muscle relaxant } \\
\text { medication, or steroid in past } 6 \mathrm{~h}\end{array}$ & $\begin{array}{l}\text { A: Morphine } 0.1 \mathrm{mg} / \mathrm{kg} \text { IV over 4- } \\
5 \mathrm{~min}(\mathrm{n}=100) \\
\text { B: Acetaminophen } 1 \mathrm{~g} \text { IV over 4- } \\
5 \mathrm{~min}(\mathrm{n}=100) \\
\text { Rescue: Fentanyl } 1 \mathrm{mcg} / \mathrm{kg} \text { at } \\
\text { 30min if needed }\end{array}$ & $\begin{array}{l}\text { Age A:44.6(10.2) B:43.7(9.8) } \\
\text { Males A:48\% B:43\% } \\
\text { Weight NR } \\
\text { Race/ethnicity NR } \\
\text { Pain etiology/location: Sciatic } \\
\text { nerve } 100 \% \\
\text { Pain Classification: Nontraumatic }\end{array}$ & $\begin{array}{l}\text { Hypotension } \\
\text { Nausea } \\
\text { Pain severity }\end{array}$ \\
\hline
\end{tabular}




\begin{tabular}{|c|c|c|c|c|}
\hline $\begin{array}{l}\text { Author, year } \\
\text { Country } \\
\text { Setting } \\
\text { Risk of Bias }\end{array}$ & Eligibility & Intervention and Comparator & Population Characteristics & Outcomes \\
\hline $\begin{array}{l}\text { Shimonovich, } \\
2016^{53} \\
\text { Israel } \\
\text { Setting: ED } \\
\text { Risk of bias: High }\end{array}$ & $\begin{array}{l}\text { 18-70y old w/mild-moderate blunt } \\
\text { trauma causing moderate to severe } \\
\text { pain (VAS } \geq 80 / 100) \\
\text { Exclusions: GCS }<15 \text {, weight }<50 \text { or } \\
>110 \mathrm{~kg}, \mathrm{HR}>100, \mathrm{SBP}<90 \text { or }>160 \text {, } \\
\text { American Society of Anesthesiologists } \\
\text { score other than } 1 \text { or } 2 \text {, regular use of } \\
\text { opiates, analgesia received within the } \\
\text { prior } 3 \mathrm{~h} \text {, drug allergy, a large meal } \\
\text { ingested within the previous hour, } \\
\text { pregnancy, deviated nasal septum or } \\
\text { trauma to the nose, hx of psychiatric } \\
\text { condition, head trauma, head injury } \\
\text { complaining of LOC, dizziness, } \\
\text { vomiting, or nausea }\end{array}$ & 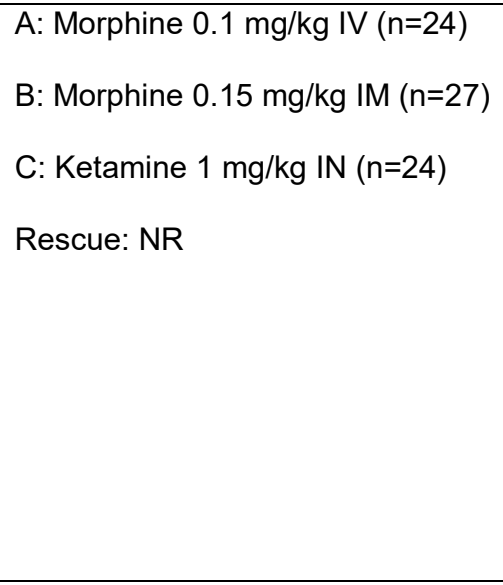 & $\begin{array}{l}\text { Age A:42.9(38.0-47.8) } \\
\text { B:37.7(32.8-42.6) C:37.9(32.3- } \\
\text { 43.5) } \\
\text { Males A:75\% B:59.3\% C:70.8\% } \\
\text { Weight NR } \\
\text { Race/ethnicity: NR } \\
\text { Pain etiology/location: NR } \\
\text { Pain Classification: Traumatic }\end{array}$ & $\begin{array}{l}\text { Emergence delirium } \\
\text { Mental status changes } \\
\text { Pain severity } \\
\text { Presence of pain } \\
\text { Time to analgesic effect }\end{array}$ \\
\hline $\begin{array}{l}\text { Weldon, } 2016^{92} \\
\text { Canada } \\
\text { Setting: EMS, } \\
\text { ambulance } \\
\text { transport in urban } \\
\text { system } \\
\text { Risk of bias: Low }\end{array}$ & $\begin{array}{l}\geq 18 y \text { w/ischemic type chest pain not } \\
\text { relieved by oxygen, ASA, and } \\
\text { nitroglycerin } \\
\text { Exclusions: SBP }<100,02 \text { sat }<95 \% \text {, } \\
\text { pregnancy, cognitive impairment, drug } \\
\text { allergy, traumatic injury, evidence of } \\
\text { right ventricular infarct identified by the } \\
\text { presence of ST segment elevation }\end{array}$ & $\begin{array}{l}\text { A: Morphine IV every } 5 \mathrm{~min} \text {, max } 4 \\
\text { doses }(\mathrm{n}=99) \\
<75 \mathrm{y} \text { and }>50 \mathrm{~kg}: 5 \mathrm{mg} \\
>75 \mathrm{y} \text { and/or } \leq 50 \mathrm{~kg}: 2.5 \mathrm{mg} \\
\text { B: Fentanyl IV every } 5 \mathrm{~min} \text {, max } 4 \\
\text { doses }(\mathrm{n}=88) \\
<75 \mathrm{y} \text { and }>50 \mathrm{~kg}: 50 \mathrm{mcg} \\
>75 y \text { and/or }<50 \mathrm{~kg}: 25 \mathrm{mcg} \\
\text { Rescue: NR }\end{array}$ & $\begin{array}{l}\text { Age A:66.1(15.8) B:64.5(16) } \\
\text { Males A:53\% B:53\% } \\
\text { Weight A:79.4kg(19.6) } \\
\text { B:78.43kg(17.6) } \\
\text { Race/ethnicity NR } \\
\text { Pain etiology/location: Ischemic } \\
\text { chest pain 100\% } \\
\text { Pain Classification: Nontraumatic }\end{array}$ & $\begin{array}{l}\text { Heart rate } \\
\text { Hypotension } \\
\text { Nausea } \\
\text { Respiratory depression } \\
\text { Respiratory rate } \\
\text { Vomiting }\end{array}$ \\
\hline
\end{tabular}




\begin{tabular}{|c|c|c|c|c|}
\hline $\begin{array}{l}\text { Author, year } \\
\text { Country } \\
\text { Setting } \\
\text { Risk of Bias }\end{array}$ & Eligibility & Intervention and Comparator & Population Characteristics & Outcomes \\
\hline $\begin{array}{l}\text { Deaton, } 2015^{19} \\
\text { USA } \\
\text { Setting: ED } \\
\text { Risk of bias: } \\
\text { Medium }\end{array}$ & $\begin{array}{l}\text { 18-65y old w/acute non-injury } \\
\text { abdominal pain } \geq 5 \\
\text { Exclusions: Drug allergy, impairment } \\
\text { in renal or hepatic function, } \\
\text { hypothyroidism, Addison disease, } \\
\text { prostatic hypertrophy, or urethral } \\
\text { stricture, taking monoamine oxides } \\
\text { inhibitors, tricyclic antidepressants, } \\
\text { sedative hypnotics, or known } \\
\text { cytochrome P450 3A4 inhibitors within } \\
\text { 14d, oral or IV or IM pain medications } \\
\text { before enrollment }\end{array}$ & $\begin{array}{l}\text { A: Morphine } 0.1 \mathrm{mg} / \mathrm{kg} \text { IV }(\mathrm{n}=16) \\
\text { B: Fentanyl } 2 \mathrm{mcg} / \mathrm{kg} \mathrm{NEB}(\mathrm{n}=16) \\
\text { Rescue: Available at any point } \\
\text { during the study according to } \\
\text { treating physician preference }\end{array}$ & $\begin{array}{l}\text { Age A:32.38(10.76) } \\
\text { B:30.19(10.7) } \\
\text { Males A:50\% B:38\% } \\
\text { Weight NR } \\
\text { Race/ethnicity A/B: White } \\
\text { 75\%/56\%, African American } \\
\text { 12.5\%/12.5\%, Hispanic } \\
6.25 \% / 25 \%, \text { Asian American } \\
6.25 \% / 6.25 \% \\
\text { Pain etiology/location: Abdomen } \\
\text { 100\% } \\
\text { Pain Classification: Nontraumatic } \\
\end{array}$ & $\begin{array}{l}\text { Hypotension } \\
\text { Nausea } \\
\text { Pain severity }\end{array}$ \\
\hline $\begin{array}{l}\text { Graudins, } 2015^{30} \\
\text { New Zealand } \\
\text { Setting: ED } \\
\text { Risk of bias: } \\
\text { Low }\end{array}$ & $\begin{array}{l}\text { 3-13y old w/acute limb injury with } \\
\text { moderate to severe pain of } 6 \text { or more } \\
\text { at triage } \\
\text { Exclusions: serotonergic } \\
\text { antidepressants; previous } \\
\text { administration of parenteral or IN } \\
\text { analgesics or opioid analgesia; opioid } \\
\text { antagonist use; allergy to ketamine, } \\
\text { fentanyl, or ibuprofen; aberrant nasal } \\
\text { anatomy or acute or chronic nasal } \\
\text { problems or nasal trauma that may } \\
\text { have precluded adequate intranasal } \\
\text { delivery; multiple trauma or head } \\
\text { injury with loss of consciousness or } \\
\text { cognitive impairment. }\end{array}$ & $\begin{array}{l}\text { A: Fentanyl } 1.5 \mathrm{mcg} / \mathrm{kg} \text { IN ( } \mathrm{n}=37) \\
\text { B: Ketamine } 1 \mathrm{mg} / \mathrm{kg} \text { IN ( } \mathrm{n}=36) \\
\text { Rescue: Additional IN fentanyl or } \\
\text { IV morphine, based on provider } \\
\text { preference }\end{array}$ & $\begin{array}{l}\text { Age A:9(6 to 11) B:7(6 to 9.5) } \\
\text { Males A:65\% B:61\% } \\
\text { Weight NR } \\
\text { Race/ethnicity } \\
\text { Pain etiology/location: Upper } \\
\text { limb fracture ( } 73 \% / 88.9 \%) \text {, upper } \\
\text { limb soft tissue injury } \\
\text { (13.5\%/8.3\%), lower limb fracture } \\
\text { (13.5\%/0\%), lower limb soft } \\
\text { tissue injury (0\%/2.8\%) } \\
\text { Pain classification: Traumatic }\end{array}$ & $\begin{array}{l}\text { Any adverse event } \\
\text { Emergence delirium } \\
\text { Mental status changes } \\
\text { Nausea } \\
\text { Pain presence } \\
\text { Pain severity }\end{array}$ \\
\hline
\end{tabular}




\begin{tabular}{|c|c|c|c|c|}
\hline $\begin{array}{l}\text { Author, year } \\
\text { Country } \\
\text { Setting } \\
\text { Risk of Bias }\end{array}$ & Eligibility & Intervention and Comparator & Population Characteristics & Outcomes \\
\hline $\begin{array}{l}\text { Miller, } 2015^{58} \\
\text { USA } \\
\text { Setting: ED } \\
\text { Risk of bias: Low }\end{array}$ & $\begin{array}{l}\text { 18-59y old w/abdominal, flank, low } \\
\text { back or extremity pain warranting IV } \\
\text { opioid treatment } \\
\text { Exclusions: O2 sat< }<95 \%, \text { SBP }<90 \text { or } \\
>180, \mathrm{HR}<50 \text { or }>120, \mathrm{RR}<10 \text { or }>30 \text {, } \\
\text { altered mental status, intoxication, } \\
\text { fibromyalgia or other chronic pain } \\
\text { condition requiring the use of opioids } \\
\text { or tramadol as an outpatient, ischemic } \\
\text { heart disease, heart failure or unstable } \\
\text { dysrhythmias, use of an opioid or } \\
\text { tramadol within } 4 \mathrm{~h} \text {, drug allergy, } \\
\text { required pain medication immediately, } \\
\text { pregnant or breast-feeding, history of } \\
\text { chronic oxygen-dependent pulmonary } \\
\text { disease, hepatic cirrhosis, or dialysis } \\
\text { dependent, presence of intracranial } \\
\text { mass, a history of psychosis, } \\
\text { weight< } 45 \mathrm{~kg} \text { or }>115 \mathrm{~kg}, \text { presence of } \\
\text { acute ocular or head trauma }\end{array}$ & $\begin{array}{l}\text { A: Morphine } 0.1 \mathrm{mg} / \mathrm{kg} \text { IV over } \\
5 \mathrm{~min} \text { (max } 8 \mathrm{mg} \text { ), second dose } \\
\text { could be given as early as } 20 \mathrm{~min} \\
\text { ( } \mathrm{n}=21 \text { ) } \\
\text { B: Ketamine } 0.3 \mathrm{mg} / \mathrm{kg} \text { IV infusion } \\
\text { over } 5 \mathrm{~min} \text { (max } 25 \mathrm{mg} \text { ), second } \\
\text { dose could be given as early as } \\
20 \mathrm{~min} \text { ( } \mathrm{n}=24 \text { ) } \\
\text { Rescue: If the patient requested a } \\
\text { third dose of pain medication the } \\
\text { data collection stopped and } \\
\text { patient was eligible for open label } \\
\text { pain medication of the providers } \\
\text { choosing. }\end{array}$ & $\begin{array}{l}\text { Age A:29(10) B:31(12) } \\
\text { Males A:43\% B:58\% } \\
\text { Weight NR } \\
\text { Race/ethnicity NR } \\
\text { Pain etiology/location: Abdomen } \\
71 \% / 65 \% \text {, back } 19 \% / 35 \% \text {, } \\
\text { extremity } 10 \% / 0 \% \\
\text { Pain Classification: Mixed }\end{array}$ & $\begin{array}{l}\text { Any AE } \\
\text { Diastolic blood pressure } \\
\text { Dissociation } \\
\text { Emergence delirium } \\
\text { Heart rate } \\
\text { Mental status changes } \\
\text { Nausea } \\
\text { Oxygen saturation } \\
\text { Pain severity } \\
\text { Respiratory depression } \\
\text { Respiratory rate } \\
\text { Systolic blood pressure } \\
\text { Vomiting }\end{array}$ \\
\hline $\begin{array}{l}\text { Motov, } 2015^{57} \\
\text { USA } \\
\text { Setting: ED } \\
\text { Risk of bias: Low }\end{array}$ & $\begin{array}{l}\text { 18-55y old w/acute (within } 7 \mathrm{~d} \text { ) } \\
\text { abdominal, flank, back or } \\
\text { musculoskeletal pain NRS } \geq 5 / 10 \text { and } \\
\text { required opioid analgesia } \\
\text { Exclusions: pregnancy, breast- } \\
\text { feeding, altered mental status, drug } \\
\text { allergy, weight }<46 \mathrm{~kg} \text { or }>115 \mathrm{~kg} \text {, } \\
\text { SBP }<90 \text { or }>180, \mathrm{HR}<50 \text { or }>150 \text {, } \\
\text { RR }<10 \text { or }>30 \text {, hx of acute head or } \\
\text { eye injury, seizure, intracranial } \\
\text { hypertension, chronic pain, renal or } \\
\text { hepatic insufficiency, alcohol or drug } \\
\text { abuse, psychiatric illness, or recent } \\
\text { (4h) opioid use }\end{array}$ & $\begin{array}{l}\text { A: Morphine } 0.1 \mathrm{mg} / \mathrm{kg} \text { IV push } \\
\text { over } 3 \text { to } 5 \mathrm{~min} \text { (mean } 7.7 \mathrm{mg}(1.6) \text { ) } \\
\text { (n=45) } \\
\text { B: Ketamine } 0.3 \mathrm{mg} / \mathrm{kg} \mathrm{IV} \mathrm{push} \\
\text { over } 3 \text { to } 5 \mathrm{~min} \text { (mean } 21.8 \mathrm{mg} \\
(4.9))(\mathrm{n}=45) \\
\text { Rescue: NRS } \geq 5 / 10 \text { and } \\
\text { requested additional pain relief, } \\
\text { fentanyl } 1 \mathrm{mcg} / \mathrm{kg} \text { was } \\
\text { administered }\end{array}$ & $\begin{array}{l}\text { Age A:36(10.5) B:35(9.5) } \\
\text { Males A:37.8\% B:33\% } \\
\text { Weight A:78kg(16.6) } \\
\text { B:74kg(15.9) } \\
\text { Race/ethnicity: NR } \\
\text { Pain etiology/location A/B: } \\
\text { Abdominal 69\%/73\%, flank } \\
\text { 20\%/16\%, back and } \\
\text { musculoskeletal 11\%/11\%, } \\
\text { Pain Classification: Mixed }\end{array}$ & $\begin{array}{l}\text { Any AE } \\
\text { Diastolic blood pressure } \\
\text { Heart rate } \\
\text { Mental status changes } \\
\text { Nausea } \\
\text { Oxygen saturation } \\
\text { Pain severity } \\
\text { Presence of pain } \\
\text { Respiratory rate } \\
\text { Systolic blood pressure }\end{array}$ \\
\hline
\end{tabular}




\begin{tabular}{|c|c|c|c|c|}
\hline $\begin{array}{l}\text { Author, year } \\
\text { Country } \\
\text { Setting } \\
\text { Risk of Bias }\end{array}$ & Eligibility & Intervention and Comparator & Population Characteristics & Outcomes \\
\hline $\begin{array}{l}\text { Beaudoin, } 2014^{70} \\
\text { USA } \\
\text { Setting: ED } \\
\text { Risk of bias: Low }\end{array}$ & $\begin{array}{l}\text { 18-65y old w/moderate to severe } \\
\text { acute pain (NRS } \geq 5 / 10 \text { ) determined to } \\
\text { require opioids by emergency } \\
\text { physician, still study eligible if they } \\
\text { received previous analgesics prior if } \\
\text { NRS was still } \geq 5 / 10 \\
\text { Exclusions: Neurologic, respiratory, or } \\
\text { hemodynamic compromise; drug } \\
\text { allergy, acute psychiatric illnesses, } \\
\text { history of stroke, renal impairment } \\
\text { (creatinine }>2 \mathrm{mg} / \mathrm{dL} \text { ), liver failure, or } \\
\text { history of cardiac disease (prior } \\
\text { myocardial infarction, angina, cardiac } \\
\text { stents, or bypass surgery); pregnant } \\
\text { or breastfeeding }\end{array}$ & 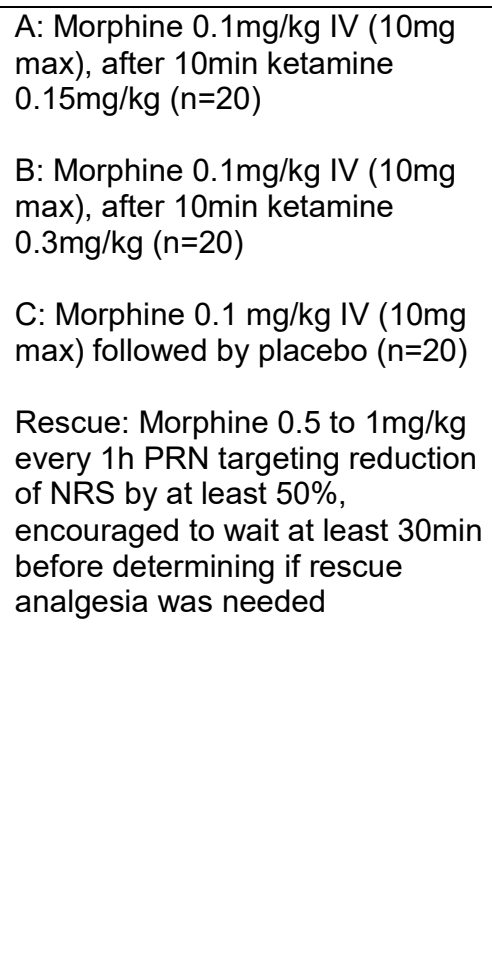 & 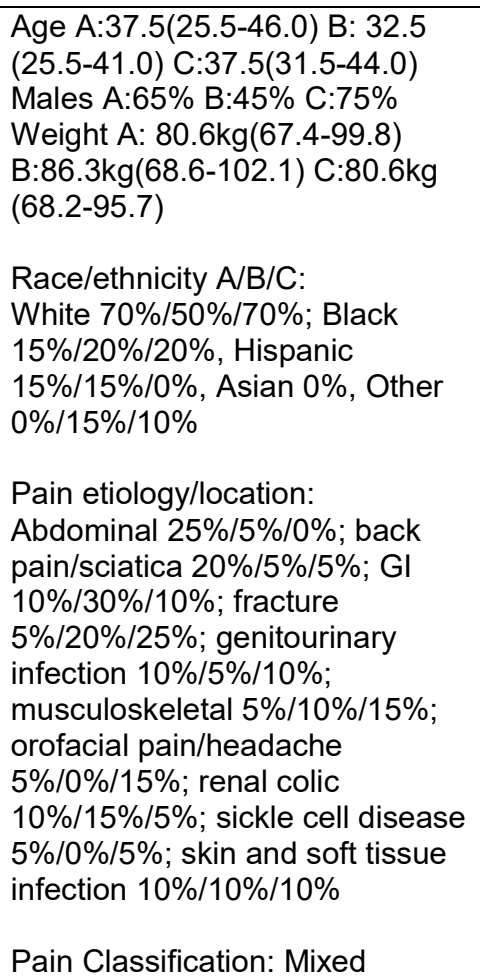 & $\begin{array}{l}\text { Respiratory depression } \\
\text { Hypotension } \\
\text { Mental status changes } \\
\text { Nausea } \\
\text { Pain severity } \\
\text { Presence of pain } \\
\text { Vomiting }\end{array}$ \\
\hline $\begin{array}{l}\text { Majidinejad, } \\
2014^{59} \\
\text { Iran } \\
\text { Setting: ED } \\
\text { Risk of bias: } \\
\text { Unclear }\end{array}$ & $\begin{array}{l}\text { 18-55y old w/long bone fracture } \\
\text { Exclusions: drug abuse, trauma to the } \\
\text { head, symptoms and signs of } \\
\text { increased intracranial pressure, } \\
\text { decrease LOC, respiratory problems, } \\
\text { hx of asthma, contraindications for } \\
\text { ketamine (hx of cardiac problems, } \\
\text { especially congestive heart failure, } \\
\text { ischemic cardiac conditions, HTN, } \\
\text { CVA) and morphine (asthma, } \\
\text { respiratory problems, hemodynamic } \\
\text { instability), drug allergy }\end{array}$ & $\begin{array}{l}\text { A: Morphine } 0.1 \mathrm{mg} / \mathrm{kg} \text { IV }(\mathrm{n}=63) \\
\text { B: Ketamine } 0.5 \mathrm{mg} / \mathrm{kg} \text { IV }(\mathrm{n}=63) \\
\text { Rescue: Half initial dose if } \\
\text { NRS } \geq 3 / 10 \text { after } 10 \mathrm{~min}\end{array}$ & $\begin{array}{l}\text { Age A: } 53.6(14.3) \text { B:35.1(13.5) } \\
\text { Males A:81\% B:71.4\% } \\
\text { Weight NR } \\
\text { Race/ethnicity NR } \\
\text { Pain etiology/location: Long bone } \\
\text { fracture } 100 \% \\
\text { Pain Classification: Traumatic }\end{array}$ & $\begin{array}{l}\text { Emergence delirium } \\
\text { Pain severity } \\
\text { Presence of pain }\end{array}$ \\
\hline
\end{tabular}




\begin{tabular}{|c|c|c|c|c|}
\hline $\begin{array}{l}\text { Author, year } \\
\text { Country } \\
\text { Setting } \\
\text { Risk of Bias }\end{array}$ & Eligibility & Intervention and Comparator & Population Characteristics & Outcomes \\
\hline $\begin{array}{l}\text { Masoumi, } 2014^{82} \\
\text { Iran } \\
\text { Setting: ED } \\
\text { Risk of bias: Low }\end{array}$ & $\begin{array}{l}\text { 18-55y old w/renal colic } \\
\text { Exclusions: drug allergy, fever }>38 \mathrm{C} \text {, } \\
\text { hemodynamic instability, evidence of } \\
\text { peritoneal inflammation, pregnancy, } \\
\text { proven or suspected aortic aneurysm } \\
\text { or dissection, use of any analgesic } \\
\text { drug up to 6h prior, heart failure, renal } \\
\text { failure, respiratory failure, liver failure, } \\
\text { kidney transplant and opioid addiction }\end{array}$ & $\begin{array}{l}\text { A: Morphine } 0.1 \mathrm{mg} / \mathrm{kg} \text { IV over } 5- \\
10 \text { min }(n=55) \\
\text { B: Acetaminophen } 1 \mathrm{~g} \mathrm{IV} \mathrm{over} 5-10 \\
\text { min }(n=55) \\
\text { Rescue: After } 30 \text { minutes, if } \\
\text { VAS } \geq 5 / 10 \text { fentanyl } 1 \mathrm{mcg} / \mathrm{kg} \mathrm{IV} \\
\text { was administered }\end{array}$ & $\begin{array}{l}\text { Age A: 34.96(8.94) B:36.07(9.7) } \\
\text { Males A:72.2\% B:79.6\% } \\
\text { Weight NR } \\
\text { Race/ethnicity NR } \\
\text { Pain etiology/location: Renal } \\
\text { colic } 100 \% \\
\text { Pain Classification: Nontraumatic }\end{array}$ & $\begin{array}{l}\text { Any AE } \\
\text { Nausea } \\
\text { Pain severity } \\
\text { Vomiting }\end{array}$ \\
\hline $\begin{array}{l}\text { Shervin, } 2014^{20} \\
\text { Iran } \\
\text { Setting: ED } \\
\text { Risk of bias: Low }\end{array}$ & $\begin{array}{l}15-50 y \text { old w/limb trauma in acute pain } \\
\text { with NRS }>5 / 10 \\
\text { Exclusions: opioid use or addiction, } \\
\text { recent or hx of TCA, SSRI, MAOI, } \\
\text { antipsychotics, and any nonspecified } \\
\text { sedative/hypnotic, acute or chronic } \\
\text { medical health problems w/ASA } \\
\text { classification > } 2 \text { including upper or } \\
\text { lower respiratory tract infection, acute } \\
\text { or chronic liver or kidney disease, } \\
\text { reactive airway disease, unknown } \\
\text { allergies, pregnancy, lactation }\end{array}$ & $\begin{array}{l}\text { A: Morphine } 0.1 \mathrm{mg} / \mathrm{kg} \text { IV }(\mathrm{n}=43) \\
\text { B: Fentanyl } 4 \mathrm{mcg} / \mathrm{kg} \text { NEB }(\mathrm{n}=47) \\
\text { Rescue: If } \mathrm{NRS} \geq 5 / 10 \text { after } 15 \mathrm{~min} \text {, } \\
\text { morphine } 1 \mathrm{mg} \text { IV every } 5 \text { min until } \\
\text { NRS }<5 / 10\end{array}$ & $\begin{array}{l}\text { Age A:26.86(7.73) B:26.8(7.45) } \\
\text { Males A:83.7\% B:83\% } \\
\text { Weight A:72.67kg(11.88) } \\
\text { B:75.53(13.04) } \\
\text { Race/ethnicity NR } \\
\text { Pain etiology/location A/B: } \\
\text { Wound/soft tissue 34.9\%/17\%, } \\
\text { fracture 41.9\%/48.9\%, } \\
\text { sprain/strain } 23.3 \% / 34 \% \\
\text { Pain Classification: Traumatic }\end{array}$ & $\begin{array}{l}\text { Mental status changes } \\
\text { Nausea or vomiting } \\
\text { Pain severity }\end{array}$ \\
\hline $\begin{array}{l}\text { Tran, } 2014^{27} \\
\text { Vietnam } \\
\text { Setting: EMS } \\
\text { transport for } \\
\text { protracted } \\
\text { evacuations in } \\
\text { low resource, } \\
\text { rural setting } \\
\text { Risk of bias: } \\
\text { Medium }\end{array}$ & $\begin{array}{l}\text { Trauma patients in need of analgesia, } \\
\text { at least } 30 \text { months old } \\
\text { Exclusions: objections to pain } \\
\text { treatment, coma, in-field anesthesia } \\
\text { for invasive life support, deep } \\
\text { unconsciousness upon first infield } \\
\text { contact, prehospital evacuation time of } \\
<10 \text { min }\end{array}$ & $\begin{array}{l}\text { A: Morphine } 5 \mathrm{mg} \text { (child) or } 10 \mathrm{mg} \\
\text { (adult) IM ( } \mathrm{n}=139) \\
\text { B: Ketamine } 0.2 \text { to } 0.3 \mathrm{mg} / \mathrm{kg} \text { slow } \\
\text { intermittent IV injection (mean } \\
\text { dose } 15 \mathrm{mg})(\mathrm{n}=169) \\
\text { Rescue: NR }\end{array}$ & $\begin{array}{l}\text { Age A:36.9(NR) B:35.5(NR) } \\
\text { Males A:80\% B:75\% } \\
\text { Weight NR } \\
\text { Race/ethnicity NR } \\
\text { Pain etiology/location: Road } \\
\text { traffic accident casualties } 61 \% \text {, } \\
\text { falls } 24 \% \text {, mine accidents } 9 \% \\
\text { Pain Classification: Traumatic }\end{array}$ & $\begin{array}{l}\text { Nausea or vomiting } \\
\text { Pain severity } \\
\text { Presence of pain }\end{array}$ \\
\hline
\end{tabular}




\begin{tabular}{|c|c|c|c|c|}
\hline $\begin{array}{l}\text { Author, year } \\
\text { Country } \\
\text { Setting } \\
\text { Risk of Bias }\end{array}$ & Eligibility & Intervention and Comparator & Population Characteristics & Outcomes \\
\hline $\begin{array}{l}\text { Vahdati, } 2014^{73} \\
\text { Iran } \\
\text { Setting: ED } \\
\text { Risk of bias: } \\
\text { Unclear }\end{array}$ & $\begin{array}{l}\text { 18-55y old complaining of headaches } \\
\text { due to trauma, VAS } \geq 40 \\
\text { Exclusions: GCS }<15 \text {, drug allergy or } \\
\text { contraindication, fever }\left(>38^{\circ} \mathrm{C}\right) \text {, } \\
\text { hemodynamic instability, neurological } \\
\text { findings, pregnancy, analgesic within } \\
6 \mathrm{~h} \text {, liver, renal, pulmonary or cardiac } \\
\text { disease, transplanted kidney or liver }\end{array}$ & $\begin{array}{l}\text { A: Morphine } 0.1 \mathrm{mg} / \mathrm{kg} \text { IV over } \\
\text { 10min }(\mathrm{n}=30) \\
\text { B: Paracetamol } 1 \mathrm{~g} \mathrm{IV} \mathrm{over} 10 \mathrm{~min} \\
(\mathrm{n}=30) \\
\text { Rescue: NR }\end{array}$ & $\begin{array}{l}\text { Age A:32.9(11.1) B:37.6(12.5) } \\
\text { Males A:80\% B:60\% } \\
\text { Weight NR } \\
\text { Race/ethnicity NR } \\
\text { Pain etiology/location: Post- } \\
\text { traumatic headache } 100 \% \\
\text { Pain Classification: Traumatic }\end{array}$ & $\begin{array}{l}\text { Any AE } \\
\text { Hypotension } \\
\text { Mental status changes } \\
\text { Nausea } \\
\text { Pain severity } \\
\text { Vomiting }\end{array}$ \\
\hline $\begin{array}{l}\text { Eken, } 2013^{77} \\
\text { Turkey } \\
\text { Setting: ED } \\
\text { Risk of bias: Low }\end{array}$ & $\begin{array}{l}\text { 18-55y old w/moderate to severe } \\
\text { acute mechanical low back pain } \\
\text { according to } 4 \text { point VRS } \\
\text { Exclusions: analgesic medications in } \\
\text { the last } 6 \mathrm{~h}, \text { pregnancy, peritoneal } \\
\text { irritation signs, hemodynamic } \\
\text { instability, renal transplantation, renal, } \\
\text { liver, cardiac or pulmonary failure, } \\
\text { malignancy, pain indicating sciatica, } \\
\text { positive Straight Leg Raise Test, } \\
\text { neurological deficit, known allergy to } \\
\text { study drugs, probable renal or biliary } \\
\text { colic, illiterate }\end{array}$ & 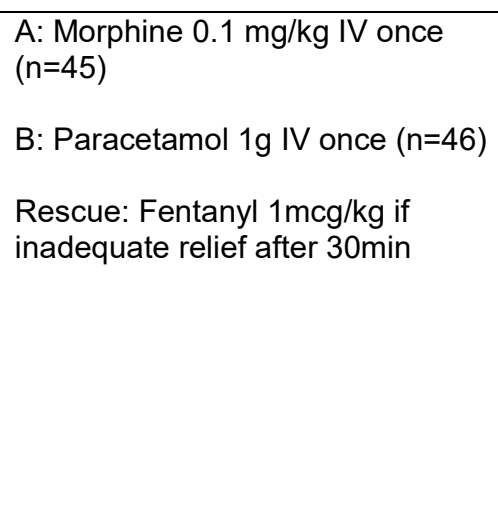 & $\begin{array}{l}\text { Age total study } 31.5(9.5) \\
\text { Males total study } 60.6 \% \\
\text { Weight NR } \\
\text { Race/ethnicity NR } \\
\text { Pain etiology/location: Acute, } \\
\text { mechanical low back pain } 100 \% \\
\text { Pain Classification: Mixed }\end{array}$ & $\begin{array}{l}\text { Any AE } \\
\text { Hypotension } \\
\text { Mental status changes } \\
\text { Nausea or vomiting } \\
\text { Pain severity }\end{array}$ \\
\hline $\begin{array}{l}\text { Craig, } 2012^{79} \\
\text { UK } \\
\text { Setting: ED } \\
\text { Risk of bias: Low }\end{array}$ & $\begin{array}{l}16-65 y \text { old } w / \text { isolated limb trauma and } \\
\text { pain score } \geq 7 / 10 \\
\text { Exclusions: Weight }<50 \mathrm{~kg} \text {, chest pain, } \\
\text { GCS }<15 \text {, drug allergy, liver disease, } \\
\text { or patient clinically jaundiced, major } \\
\text { trauma, pregnancy, breast feeding, } \\
\text { requiring an immediate limb-saving } \\
\text { procedure, extreme distress }\end{array}$ & $\begin{array}{l}\text { A: Morphine 10mg IV infusion } \\
\text { over 15min }(n=28) \\
\text { B: Paracetamol } 1 \mathrm{~g} \mathrm{IV} \mathrm{infusion} \\
\text { over 15min }(n=27) \\
\text { Rescue: Morphine IV titrated to } \\
\text { effect in after the initial infusion } \\
\text { the patient's pain relief was } \\
\text { judged to be inadequate }\end{array}$ & $\begin{array}{l}\text { Age A:35(16-62) B:38(16-64) } \\
\text { Males A:53.6\% B:55.6\% } \\
\text { Weight NR } \\
\text { Race/ethnicity NR } \\
\text { Pain etiology/location A/B: } \\
\text { Fracture } 50 \% / 59.2 \% \text {, soft tissue } \\
50 \% / 40.7 \% \\
\text { Pain Classification: Traumatic }\end{array}$ & $\begin{array}{l}\text { Any } \mathrm{AE} \\
\text { Pain severity }\end{array}$ \\
\hline
\end{tabular}




\begin{tabular}{|c|c|c|c|c|}
\hline $\begin{array}{l}\text { Author, year } \\
\text { Country } \\
\text { Setting } \\
\text { Risk of Bias }\end{array}$ & Eligibility & Intervention and Comparator & Population Characteristics & Outcomes \\
\hline $\begin{array}{l}\text { Jennings, } 2012^{64} \\
\text { Australia } \\
\text { Setting: EMS- } \\
\text { single out-of- } \\
\text { hospital } \\
\text { ambulance } \\
\text { provider } \\
\text { Risk of bias: } \\
\text { Low/medium }\end{array}$ & $\begin{array}{l}\geq 18 y \text { reporting traumatic pain with } \\
\text { VNRS } \geq 5 \text { after total dose of morphine } \\
5 \mathrm{mg} I \mathrm{IV} \text {, speaking and able to rate } \\
\text { their pain } \\
\text { Exclusions: Drug allergy, pregnant or } \\
\text { lactating, current ischemic chest pain } \\
\text { or acute pulmonary edema, SBP }>180 \\
\text { and evidence of a head injury, history } \\
\text { of LOC or GCS score }<15 \text {, inability to } \\
\text { obtain venous access, presumed } \\
\text { intoxication with alcohol/illicit } \\
\text { substances }\end{array}$ & $\begin{array}{l}\text { A: Ketamine } 10 \text { or } 20 \mathrm{mg} \text { bolus, } \\
\text { repeat } 10 \mathrm{mg} \text { every } 3 \mathrm{~min} \text { until pain } \\
\text { free or serious adverse event or } \\
\text { arrival at the } E D \text {, mean } 40.6 \mathrm{mg} \\
(25)(\mathrm{n}=70) \\
\text { B: Morphine } 5 \mathrm{mg} \text { bolus, repeat } 1 \\
\text { to } 5 \mathrm{mg} \text { every } 5 \mathrm{~min} \text { until pain free } \\
\text { or a serious adverse event or } \\
\text { arrival at the ED, mean } 14.4 \mathrm{mg} \\
(9.4)(n=65) \\
\text { Rescue: No therapies other than } \\
\text { those randomized were allowed }\end{array}$ & $\begin{array}{l}\text { Age A: 41(26-56) B:45(31-66) } \\
\text { Males A:64\% B:58\% } \\
\text { Weight NR } \\
\text { Race/ethnicity NR } \\
\text { Pain etiology/location A/B: } \\
\text { Extremity fracture } 37 \% / 45 \% \text {, soft } \\
\text { tissue injury } 24 \% / 23 \% \text {, fracture- } \\
\text { other } 20 \% / 20 \% \text {, dislocation } \\
16 \% / 11 \% \text {, burn } 3 \% / 1 \% \\
\text { Pain Classification: Traumatic }\end{array}$ & $\begin{array}{l}\text { Any AE } \\
\text { Emergence delirium } \\
\text { Heart rate } \\
\text { Hypotension } \\
\text { Mental status changes } \\
\text { Nausea } \\
\text { Pain severity } \\
\text { Respiratory rate } \\
\text { Systolic blood pressure } \\
\text { Time to analgesic effect } \\
\text { Vomiting }\end{array}$ \\
\hline $\begin{array}{l}\text { Serinken, } 2012^{78} \\
\text { Turkey } \\
\text { Setting: ED } \\
\text { Risk of bias: Low }\end{array}$ & $\begin{array}{l}\text { 18-55y old w/acute renal colic, } \\
\text { moderate to severe pan on the 4-point } \\
\text { verbal scale } \\
\text { Exclusions: analgesics within } 6 \mathrm{~h}, \\
\text { presented with fever or were } \\
\text { hemodynamically unstable, signs of } \\
\text { peritoneal irritation or cardiac failure, } \\
\text { hx of renal failure, hepatic failure or } \\
\text { drug allergy, pregnant, vision } \\
\text { problems, ultimately diagnosed with } \\
\text { other renal pathology }\end{array}$ & $\begin{array}{l}\text { A: Morphine } 0.1 \mathrm{mg} / \mathrm{kg} \text { IV }(\mathrm{n}=35) \\
\text { B: Paracetamol } 1 \mathrm{~g} \mathrm{IV} \mathrm{(n=38)} \\
\text { Rescue: Fentanyl } 1 \mathrm{mcg} / \mathrm{kg} \text { IV if } \\
\text { inadequate pain relief }\end{array}$ & $\begin{array}{l}\text { Age A:31.3(9.0) B:29.1(8.2) } \\
\text { Males A:65.7\% B:73.7\% } \\
\text { Weight NR } \\
\text { Race/ethnicity NR } \\
\text { Pain etiology/location: Renal } \\
\text { colic } 100 \% \\
\text { Pain Classification: Nontraumatic }\end{array}$ & $\begin{array}{l}\text { Any AE } \\
\text { Hypotension } \\
\text { Mental status changes } \\
\text { Nausea or vomiting } \\
\text { Pain severity } \\
\text { Respiratory depression }\end{array}$ \\
\hline $\begin{array}{l}\text { Smith, } 2012^{94} \\
\text { USA } \\
\text { Setting: EMS- } \\
\text { helicopter } \\
\text { transport } \\
\text { Risk of bias: } \\
\text { Medium }\end{array}$ & $\begin{array}{l}\text { 18-65y old transported by helicopter } \\
\text { for evaluation of traumatic injuries, } \\
\text { could report pain and communicate to } \\
\text { the medical crew their pain severity on } \\
\text { NPS } \\
\text { Exclusions: Drug allergy, hypotensive } \\
\text { before receiving the first dose of the } \\
\text { study drug (SBP<100), in custody, } \\
\text { pregnant }\end{array}$ & $\begin{array}{l}\text { A: Morphine } 4 \mathrm{mg} \text { IV every } 5 \mathrm{~min} \\
\text { as needed (max } 5 \text { doses, mean } 3) \\
(n=104) \\
\text { B: Fentanyl } 50 \mathrm{mcg} \text { IV every } 5 \mathrm{~min} \\
\text { as needed (max } 5 \text { doses, mean } \\
\text { 3.3) }(n=100) \\
\text { Rescue: NR }\end{array}$ & $\begin{array}{l}\text { Age A:38(NR) B:39(NR) } \\
\text { Males A:75\% B:76\% } \\
\text { Weight NR } \\
\text { Race/ethnicity A/B: Caucasian } \\
\text { 80.8\%/81\%, African American } \\
\text { 16.4\%/14\%, Other } 2.9 \% / 5 \% \\
\text { Pain etiology/location A/B: Blunt } \\
90 \% / 85 \% \text {, penetration 10\%/15\% } \\
\text { Pain Classification: Traumatic }\end{array}$ & $\begin{array}{l}\text { Hypotension } \\
\text { Pain severity } \\
\text { Presence of pain } \\
\text { Vomiting }\end{array}$ \\
\hline
\end{tabular}




\begin{tabular}{|c|c|c|c|c|}
\hline $\begin{array}{l}\text { Author, year } \\
\text { Country } \\
\text { Setting } \\
\text { Risk of Bias }\end{array}$ & Eligibility & Intervention and Comparator & Population Characteristics & Outcomes \\
\hline $\begin{array}{l}\text { Kariman, } 2011^{83} \\
\text { Iran } \\
\text { Setting: ED } \\
\text { Risk of bias: } \\
\text { Low/medium }\end{array}$ & $\begin{array}{l}\text { 15-85y old w/isolated extremity } \\
\text { trauma, moderate to severe pain per } \\
\text { VAS } \geq 4 / 10 \\
\text { Exclusions: Trauma }>6 \mathrm{~h} \text { ago, } \\
\text { associated injuries including head and } \\
\text { trunk trauma, nonorthopedic limb } \\
\text { injuries, GCS }<15 \text {, abdominal } \\
\text { distension, lung disease, hx of a } \\
\text { recent dive, pneumothorax, } \\
\text { hemothorax, received any form of } \\
\text { prehospital analgesia }\end{array}$ & $\begin{array}{l}\text { A: Fentanyl } 2 \mathrm{mcg} / \mathrm{kg} \text { IV, slow } \\
\text { injection }(n=50) \\
\text { B: Nitrous oxide:oxygen }(50: 50) \\
\text { self-administered until VAS<4/10 } \\
\text { or } 15 \mathrm{~min}(\mathrm{n}=50) \\
\text { Rescue: NR }\end{array}$ & $\begin{array}{l}\text { Age A:35.8(19.9) B:37.0(20.2) } \\
\text { Males A:84\% B:72\% } \\
\text { Weight NR } \\
\text { Race/ethnicity NR } \\
\text { Pain etiology/location A/B: } \\
\text { Fracture } 30 \% / 52 \% \text {, dislocation } \\
70 \% / 48 \% \\
\text { Pain Classification: Traumatic }\end{array}$ & $\begin{array}{l}\text { Any AE } \\
\text { Diastolic blood pressure } \\
\text { Heart rate } \\
\text { Mental status changes } \\
\text { Oxygen saturation } \\
\text { Pain severity } \\
\text { Respiratory rate } \\
\text { Systolic blood pressure }\end{array}$ \\
\hline $\begin{array}{l}\text { Furyk, } 2009^{21} \\
\text { Australia } \\
\text { Setting: ED } \\
\text { Risk of bias: } \\
\text { Medium }\end{array}$ & $\begin{array}{l}\text { 4-13y old w/pain (sufficient to warrant } \\
\text { narcotic analgesia) from a clinically } \\
\text { suspected limb fracture } \\
\text { Exclusions: ASA grade }>1 \text {, chronic } \\
\text { medical condition (e.g. structural heart } \\
\text { disease, hepatic or renal disease), } \\
\text { active asthma (requiring preventers or } \\
\text { current wheeze), concurrent upper } \\
\text { respiratory tract infection or drug } \\
\text { allergy }\end{array}$ & $\begin{array}{l}\text { A: Morphine } 0.1 \mathrm{mg} / \mathrm{kg} \text { IV }(\mathrm{n}=37) \\
\text { B: Fentanyl } 4 \mathrm{mcg} / \mathrm{kg} \text { NEB (max } \\
200 \mathrm{mcg})(\mathrm{n}=35) \\
\text { Rescue: NR }\end{array}$ & $\begin{array}{l}\text { Age A:9.4(2.5) B:8.6(2.8) } \\
\text { Males NR } \\
\text { Weight A:35.1 } \mathrm{kg}(12.6) \\
\text { B:33.6kg(12.7) } \\
\text { Race/ethnicity NR } \\
\text { Pain etiology/location: Limb } \\
\text { fracture } 100 \% \\
\text { Pain Classification: Traumatic }\end{array}$ & $\begin{array}{l}\text { Any AE } \\
\text { Nausea } \\
\text { Pain severity }\end{array}$ \\
\hline $\begin{array}{l}\text { Johansson, } \\
2009^{65} \\
\text { Sweden } \\
\text { Setting: EMS } \\
\text { Risk of bias: } \\
\text { Low/medium }\end{array}$ & $\begin{array}{l}\text { Adults w/bone fractures in acute pain } \\
\text { (NRS }>4 / 10 \text { ) after morphine } 0.1 \mathrm{mg} / \mathrm{kg} \\
\text { IV } \\
\text { Exclusions: Inability to use the rating } \\
\text { scale, long-term use of opioids, hx of } \\
\text { chronic pain, hx of/or acute MI, } \\
\text { unconsciousness }\end{array}$ & $\begin{array}{l}\text { A: Morphine } 0.1 \mathrm{mg} / \mathrm{kg} \text { IV }(\mathrm{n}=11) \\
\text { B: Ketamine } 0.2 \mathrm{mg} / \mathrm{kg} \text { IV }(\mathrm{n}=16) \\
\text { Rescue: NR }\end{array}$ & $\begin{array}{l}\text { Age A:70(16) B:74(14) } \\
\text { Males A:54.5\% B:43.8\% } \\
\text { Weight A:72.9kg (13.6) B:70.1kg } \\
\text { (10.4) } \\
\text { Race/ethnicity NR } \\
\text { Pain etiology/location: Bone } \\
\text { fracture } 100 \% \\
\text { Pain Classification: Traumatic }\end{array}$ & $\begin{array}{l}\text { Heart rate } \\
\text { Mental status changes } \\
\text { Nausea } \\
\text { Oxygen saturation } \\
\text { Pain severity } \\
\text { Respiratory rate } \\
\text { Systolic blood pressure } \\
\text { Vomiting }\end{array}$ \\
\hline
\end{tabular}




\begin{tabular}{|c|c|c|c|c|}
\hline $\begin{array}{l}\text { Author, year } \\
\text { Country } \\
\text { Setting } \\
\text { Risk of Bias }\end{array}$ & Eligibility & Intervention and Comparator & Population Characteristics & Outcomes \\
\hline $\begin{array}{l}\text { Borland, } 2007^{97} \\
\text { Australia } \\
\text { Setting: ED } \\
\text { Risk of bias: Low }\end{array}$ & $\begin{array}{l}\text { 7-15y old w/clinically deformed closed } \\
\text { long-bone fractures } \\
\text { Exclusions: Received narcotic } \\
\text { analgesic within } 4 \mathrm{~h} \text { of ED arrival, head } \\
\text { injury resulting in impaired judgment, } \\
\text { drug allergy, blocked or traumatized } \\
\text { nose, preventing nasal administration; } \\
\text { or were unable to perform pain scoring }\end{array}$ & $\begin{array}{l}\text { A: Morphine } 0.1 \mathrm{mg} / \mathrm{kg} \text { IV once } \\
\text { then } 1.0 \mathrm{mg} \text { every } 5 \mathrm{~min} \text { until relief, } \\
\text { max dose or patient refused } \\
\text { (mean total } 0.11 \mathrm{mg} / \mathrm{kg} \text { ) }(\mathrm{n}=34) \\
\text { B: Fentanyl } 1.4 \mathrm{mcg} / \mathrm{kg} \mathrm{IN} \mathrm{once} \\
\text { then } 15 \mathrm{mcg} \text { every } 5 \mathrm{~min} \text { until } \\
\text { relief, max dose or patient refused } \\
\text { (mean total } 1.7 \mathrm{mcg} / \mathrm{kg} \text { ) ( } \mathrm{n}=33 \text { ) } \\
\text { Rescue: For inadequate pain relief } \\
\text { after } 30 \mathrm{~min}, \text { morphine IV was } \\
\text { offered and titrated }\end{array}$ & $\begin{array}{l}\text { Age A:10.7(6-15) B:11.7(7-15) } \\
\text { Males NR } \\
\text { Weight A:41.9kg(19-80) } \\
\text { B:45.7(26-88) } \\
\text { Race/ethnicity NR } \\
\text { Pain etiology/location: Long bone } \\
\text { fracture } 100 \% \\
\text { Pain Classification: Traumatic }\end{array}$ & $\begin{array}{l}\text { Pain severity } \\
\text { Vomiting }\end{array}$ \\
\hline $\begin{array}{l}\text { Clark, } 2007^{89} \\
\text { Canada } \\
\text { Setting: ED } \\
\text { Risk of bias: Low }\end{array}$ & $\begin{array}{l}\text { 6-17y old presenting to ED w/pain } \\
\text { from a musculoskeletal injury } \\
\text { (extremities, neck, back) in preceding } \\
48 \mathrm{~h} \\
\text { Exclusions: contraindication to a study } \\
\text { drug, required resuscitation, open } \\
\text { fracture, had an IV line in place, } \\
\text { received } 1 \text { of the study drugs in the } \\
\text { preceding } 4 \mathrm{~h} \text { (APAP) or } 6 \mathrm{~h} \text { (IBU), or } \\
\text { had a significant cognitive impairment }\end{array}$ & $\begin{array}{l}\text { A: Ibuprofen } 10 \mathrm{mg} / \mathrm{kg}(\max \\
600 \mathrm{mg}) \text { by mouth once }(\mathrm{n}=112) \\
\text { B: Acetaminophen } 15 \mathrm{mg} / \mathrm{kg}(\max \\
650 \mathrm{mg}) \text { by mouth once }(\mathrm{n}=112) \\
\text { Rescue: } 60 \text { min after study drug } \\
\text { additional pain medication was } \\
\text { allowed, asked every } 30 \mathrm{~min}\end{array}$ & $\begin{array}{l}\text { Age A:11.8(2.8) B:12.0(2.9) } \\
\text { Males A:56.9\% B:66.4\% } \\
\text { Weight NR } \\
\text { Race/ethnicity NR } \\
\\
\text { Pain etiology/location A/B: Soft } \\
\text { tissue } 41.3 \% / 47.7 \% \text {, fracture } \\
58.7 \% / 52.3 \% \\
\text { Pain Classification: Traumatic }\end{array}$ & $\begin{array}{l}\text { Pain severity } \\
\text { Presence of pain }\end{array}$ \\
\hline $\begin{array}{l}\text { Galinski, } 2007^{66} \\
\text { France } \\
\text { Setting: EMS - } \\
\text { considered } \\
\text { "mobile intensive } \\
\text { care units" in } \\
\text { route to ED } \\
\text { Risk of bias: Low }\end{array}$ & $\begin{array}{l}\text { 18-70y old, trauma with severe, acute } \\
\text { pain (VAS } \geq 60 / 100 \text { ) } \\
\text { Exclusions: Respiratory distress, } \\
\text { SBP<90, GCS<15, psychiatric history; } \\
\text { chronic respiratory, renal, or hepatic } \\
\text { failure; drug allergy, treatment of } \\
\text { chronic pain or treatment with opioids; } \\
\text { incapacity to understand the VAS; } \\
\text { pregnancy; indication for local or } \\
\text { regional analgesia, already received } \\
\text { an opioid analgesic }\end{array}$ & $\begin{array}{l}\text { A: Morphine } 0.1 \mathrm{mg} / \mathrm{kg} \mathrm{IV} \mathrm{+} \\
\text { ketamine } 0.2 \mathrm{mg} / \mathrm{kg} \text { IV over } 10 \mathrm{~min} \text {; } \\
\text { then morphine } 3 \mathrm{mg} \text { every } 5 \mathrm{~min} \\
\text { until VAS } \leq 30 / 100(\mathrm{n}=38) \\
\text { B: Morphine } 0.1 \mathrm{mg} / \mathrm{kg} \mathrm{IV} \mathrm{+} \\
\text { placebo over } 10 \mathrm{~min} \text {, then } \\
\text { morphine } 3 \mathrm{mg} \text { every } 5 \mathrm{~min} \text { until } \\
\text { VAS } \leq 30 / 100(\mathrm{n}=35) \\
\text { Rescue: NR }\end{array}$ & $\begin{array}{l}\text { Age A:35(13) B:40(14) } \\
\text { Males A:75.8\% B:71.9\% } \\
\text { Weight NR } \\
\text { Race/ethnicity NR } \\
\\
\text { Pain etiology/location A/B: } \\
\text { Suspicion of bone fracture } \\
58 \% / 75 \% \text {; burns } 6 \% / 6 \% \text {, other } \\
36 \% / 19 \% \\
\text { Pain Classification: Traumatic }\end{array}$ & $\begin{array}{l}\text { Heart rate } \\
\text { Mental status changes } \\
\text { Nausea or vomiting } \\
\text { Oxygen saturation } \\
\text { Pain severity } \\
\text { Presence of pain } \\
\text { Respiratory depression } \\
\text { Respiratory rate } \\
\text { Systolic blood pressure }\end{array}$ \\
\hline
\end{tabular}




\begin{tabular}{|c|c|c|c|c|}
\hline $\begin{array}{l}\text { Author, year } \\
\text { Country } \\
\text { Setting } \\
\text { Risk of Bias }\end{array}$ & Eligibility & Intervention and Comparator & Population Characteristics & Outcomes \\
\hline $\begin{array}{l}\text { Mahar, } 2007^{96} \\
\text { USA } \\
\text { Setting: ED } \\
\text { Risk of bias: } \\
\text { Low/medium }\end{array}$ & $\begin{array}{l}\text { 8-18y old w/extremity deformity and/or } \\
\text { suspected fracture with VAS>50/100 } \\
\text { Exclusions: ASA status }>2, \text { hx of LOC, } \\
\text { altered level of consciousness, } \\
\text { multiple traumatic injuries, received } \\
\text { prior medication for pain control }\end{array}$ & $\begin{array}{l}\text { A: Morphine } 0.1 \mathrm{mg} / \mathrm{kg} \mathrm{IV}(\mathrm{n}=40) \\
\text { B: Fentanyl } 10-15 \mathrm{mcg} / \mathrm{kg} \text {, oral } \\
\text { transmucosal lozenge }(\mathrm{n}=47) \\
\text { Rescue: NR }\end{array}$ & $\begin{array}{l}\text { Age A: } 11.67(\mathrm{NR}) \mathrm{B}: 11.34(\mathrm{NR}) \\
\text { Males A:65\% B:64\% } \\
\text { Weight A:47.6kg(NR) B:43.6kg } \\
\text { Race/ethnicity NR } \\
\text { Pain etiology/location A/B: } \\
\text { Fracture } 87.5 \% / 100 \% \text {, } \\
\text { dislocation } 5 \% / 0 \% \text {, soft tissue } \\
7.5 \% / 0 \% \\
\text { Pain Classification: Traumatic }\end{array}$ & $\begin{array}{l}\text { Any AE } \\
\text { Nausea } \\
\text { Pain severity } \\
\text { Respiratory depression } \\
\text { Vomiting }\end{array}$ \\
\hline $\begin{array}{l}\text { Rickard, } 2007^{95} \\
\text { Australia } \\
\text { Setting: EMS- } 2 \\
\text { ambulance } \\
\text { services } \\
\text { Risk of bias: } \\
\text { Medium }\end{array}$ & $\begin{array}{l}\text { 18-65y old, severe pain }(\mathrm{VRS} \geq 5 / 10 \text { for } \\
\text { cardiac type pain or discomfort } \\
\text { persisting } 5 \text { minutes or more after } \\
\text { glyceryl trinitrate or VRS } \geq 2 / 10 \text { for } \\
\text { noncardiac pain } \\
\text { Exclusions: Hypoxia }(\mathrm{SpO} 2</=85 \%) \text {; } \\
\text { hypotension (SBP }<110) \text {; HR }<50 \text { or } \\
>150, \text { GCS }<15 \text {, vomiting, drug allergy, } \\
\text { opiate use in the past } 24 \mathrm{~h} \text {, unable to } \\
\text { provide a VRS }\end{array}$ & $\begin{array}{l}\text { A: Morphine } 2.5-5 \mathrm{mg} \text { IV, then } 2 \\
\text { more doses of } 2.5-5 \mathrm{mg} \text { at } \\
\text { intervals } \geq 5 \mathrm{~min} \text { if the VRS } \geq 3 / 10 \\
(\mathrm{n}=122) \\
\text { B: Fentanyl } 180 \mathrm{mcg} \text { IN, then } 2 \\
\text { more doses of } 60 \mathrm{mcg} \text { at intervals } \\
\geq 5 \mathrm{~min} \text { if VRS } \geq 3 / 10 \text { ( } \mathrm{n}=136) \\
\text { Rescue: At } 15 \mathrm{~min}, \text { morphine } 2.5 \text { - } \\
5 \mathrm{mg} \text { IV was available if } \\
\text { VRS } \geq 3 / 10 \text {, at } \geq 5 \text { min intervals to a } \\
\text { max of } 20 \mathrm{mg}\end{array}$ & $\begin{array}{l}\text { Age A:41.4(13.6) B:43(13.9) } \\
\text { Males A:70\% B:56\% } \\
\text { Weight A:80.7kg(16.5) B:81.8kg } \\
\text { (14.9) } \\
\text { Race/ethnicity NR } \\
\text { Pain etiology/location A/B: } \\
\text { Fracture/dislocation 37\%/33\%, } \\
\text { chest 15\%/14\%, back 15\%/17\%, } \\
\text { abdomen 13\%/18\%, other } \\
20 \% / 17 \% \\
\text { Pain Classification: Mixed } \\
\end{array}$ & $\begin{array}{l}\text { Any } A E \\
\text { Pain severity }\end{array}$ \\
\hline $\begin{array}{l}\text { Safdar, } 2006^{85} \\
\text { USA } \\
\text { Setting: ED } \\
\text { Risk of Bias: Low }\end{array}$ & $\begin{array}{l}\text { 18-55y old w/clinical diagnosis of renal } \\
\text { colic, VAS } \geq 5 / 10 \text { or at least "moderate" } \\
\text { pain on a 4-category verbal pain scale } \\
\text { Exclusions: pregnancy, breastfeeding, } \\
\text { contraindication to NSAIDs or opiates, } \\
\text { renal dysfunction, analgesics within } \\
6 \mathrm{~h}, \mathrm{hx} \text { of bleeding diathesis, confirmed } \\
\mathrm{hx} \text { of peptic ulcer disease, current use } \\
\text { of warfarin, hx of drug dependence or } \\
\text { current use of methadone, peritonitis } \\
\text { or presence of any peritoneal sign }\end{array}$ & $\begin{array}{l}\text { A: Morphine } 5 \mathrm{mg} \text { IV, then } 5 \mathrm{mg} \mathrm{IV} \\
\text { at } 20 \mathrm{~min} \text { if incomplete relief } \\
(\mathrm{n}=43) \\
\text { B: Ketorolac } 15 \mathrm{mg} \text { IV, then } 15 \mathrm{mg} \\
\text { IV at } 20 \mathrm{~min} \text { if incomplete relief } \\
(\mathrm{n}=43) \\
\text { Rescue: Morphine } 5 \mathrm{mg} \text { IV for } \\
\text { persistent pain at } 40 \mathrm{~min} \text {, titrated } \\
\text { at the discretion of the ED } \\
\text { attending }\end{array}$ & $\begin{array}{l}\text { Age A:37.3(10.0) B:39.3(9.9) } \\
\text { Males A:67\% B:67\% } \\
\text { Weight NR } \\
\text { Race/ethnicity NR } \\
\text { Pain etiology/location: Renal } \\
\text { colic } 100 \% \\
\text { Pain Classification: Nontraumatic }\end{array}$ & $\begin{array}{l}\text { Mental status changes } \\
\text { Nausea } \\
\text { Pain severity } \\
\text { Presence of pain } \\
\text { Vomiting }\end{array}$ \\
\hline
\end{tabular}




\begin{tabular}{|c|c|c|c|c|}
\hline $\begin{array}{l}\text { Author, year } \\
\text { Country } \\
\text { Setting } \\
\text { Risk of Bias }\end{array}$ & Eligibility & Intervention and Comparator & Population Characteristics & Outcomes \\
\hline $\begin{array}{l}\text { Galinski, } 2005^{93} \\
\text { France } \\
\text { Setting: EMS - } 5 \\
\text { prehospital } \\
\text { "mobile intensive } \\
\text { care units" } \\
\text { Risk of bias: Low }\end{array}$ & $\begin{array}{l}\text { 18-70y with severe, acute pain defined } \\
\text { as VAS } \geq 60 / 100 \\
\text { Exclusions: Presence of chronic } \\
\text { respiratory, renal, or hepatic } \\
\text { insufficiency, known opioid allergies, } \\
\text { treatment of chronic pain or treatment } \\
\text { with opioids, incapacity to understand } \\
\text { the VAS, acute hemodynamic, } \\
\text { respiratory, or neurological } \\
\text { compromise, pregnancy, indication for } \\
\text { local or regional analgesia, or patients } \\
\text { who had already received an opioid } \\
\text { analgesic }\end{array}$ & $\begin{array}{l}\text { A: Morphine } 0.1 \mathrm{mg} / \mathrm{kg} \text { IV followed } \\
\text { by additional } 3 \mathrm{mg} \text { doses until } \\
\text { VAS } \leq 30 / 100(\mathrm{n}=26) \\
\text { B: Fentanyl } 1 \mathrm{mcg} / \mathrm{kg} \text { IV followed } \\
\text { by additional } 30 \mathrm{mcg} \text { doses until } \\
\text { VAS } \leq 30 / 100(n=28) \\
\text { Rescue: NR }\end{array}$ & $\begin{array}{l}\text { Age A:40(13) B:45(13) } \\
\text { Males A:88\% B:79\% } \\
\text { Weight NR } \\
\text { Race/ethnicity NR } \\
\text { Pain etiology/location: Trauma } \\
\text { 73\%/50\%, nontrauma } 27 \% / 50 \% \\
\text { Pain Classification: Mixed }\end{array}$ & $\begin{array}{l}\text { Heart rate } \\
\text { Mental status changes } \\
\text { Nausea } \\
\text { Oxygen saturation } \\
\text { Pain severity } \\
\text { Presence of pain } \\
\text { Respiratory rate } \\
\text { Systolic blood pressure } \\
\text { Vomiting }\end{array}$ \\
\hline $\begin{array}{l}\text { Younge, } 1999^{16} \\
\text { Australia } \\
\text { Setting: ED } \\
\text { Risk of bias: } \\
\text { Low/medium }\end{array}$ & $\begin{array}{l}\text { 3-10y old w/limb fracture } \\
\text { Exclusions: patients with head injury, } \\
\text { blocked nose or rhinorrhea, requiring } \\
\text { immediate IV access, intellectual or } \\
\text { visual impairment, hepatic or renal } \\
\text { disease, with known allergy to either } \\
\text { drug or those who had received opioid } \\
\text { analgesia within the previous } 24 \mathrm{~h}\end{array}$ & $\begin{array}{l}\text { A: Morphine } 0.2 \mathrm{mg} / \mathrm{kg} \text { IM ( } \mathrm{n}=23) \\
\text { B: Fentanyl } 1 \mathrm{mcg} / \mathrm{kg} \mathrm{IN} \mathrm{(n=24)} \\
\text { Rescue: Could be given from } \\
20 \mathrm{~min} \text { onwards }\end{array}$ & $\begin{array}{l}\text { Age A:7.1(NR) B:6.6(NR) } \\
\text { Males A:65\% B:62.5\% } \\
\text { Weight NR } \\
\text { Race/ethnicity NR } \\
\text { Pain etiology/location: Limb } \\
\text { fracture } 100 \% \\
\text { Pain Classification: Traumatic }\end{array}$ & $\begin{array}{l}\text { Heart rate } \\
\text { Vomiting }\end{array}$ \\
\hline
\end{tabular}

Abbreviations: APAP=acetaminophen; $\mathrm{ASA}=$ American Society of Anesthesiologists; $\mathrm{COPD}=$ chronic obstructive pulmonary disease; $\mathrm{CVA}=$ cerebrovascular accident;

$\mathrm{CVAT}=$ costovertebral angle tenderness; $\mathrm{ED}=$ emergency department; $\mathrm{EMS}=$ emergency medical services; $\mathrm{GCS}=\mathrm{Glasgow}$ coma scale; $\mathrm{h}=$ hours; HTN=hypertension; hx=history; $\mathrm{IBU}=$ ibuprofen; $\mathrm{IN}=$ intranasal; $\mathrm{IV}=$ intravenous; $\mathrm{LOC}=\mathrm{loss}$ of consciousness; $\mathrm{MAOI}=$ monoamine oxidase inhibitor; $\mathrm{mg}=\mathrm{milligrams}$; $\mathrm{mmHg}=\mathrm{millimeters} \mathrm{of} \mathrm{mercury}$; $\mathrm{NR}=\mathrm{not}$ reported; NSAIDS= nonsteroidal anti-inflammatory drugs; $\mathrm{PID}=$ pelvic inflammatory disease; $\mathrm{SBP}=$ systolic blood pressure; $\mathrm{SSRI}=$ selective serotonin reuptake inhibitors; $\mathrm{TCA}=$ tricyclic antidepressants; VAS=visual analog scale; VNRS=verbal numeric rating scale; VRS=verbal rating scale 
Table C-2. Study and population characteristics, observational studies

\begin{tabular}{|c|c|c|c|c|}
\hline $\begin{array}{l}\text { Author, year } \\
\text { Country } \\
\text { Setting } \\
\text { Risk of Bias }\end{array}$ & Eligibility & Intervention and Comparator & Population Characteristics & Outcomes \\
\hline $\begin{array}{l}\text { Griffioen, } 2019^{105} \\
\text { United States } \\
\text { Setting: ED } \\
\text { Risk of bias: }\end{array}$ & $\begin{array}{l}\text { Adults presenting to ED with lower } \\
\text { extremity fractures } \\
\text { Exclusions: NR }\end{array}$ & $\begin{array}{l}\text { A: Morphine IV }(n=17) \\
\text { B: Fentanyl IV }(n=499) \\
\text { Rescue NR }\end{array}$ & $\begin{array}{l}\text { Age total study } 46(13.6) \\
\text { Males total study } 73 \% \\
\text { Weight NR } \\
\text { Race/ethnicity: total study } \\
\text { Caucasian } 72 \% \\
\text { Pain etiology/location: total study } \\
\text { tibia/fibula } 66 \% \\
\text { Pain classification: Traumatic }\end{array}$ & Presence of pain \\
\hline $\begin{array}{l}\text { Bronsky, } 2018^{61} \\
\text { United States } \\
\text { Setting: EMS } \\
\text { Risk of bias: Low }\end{array}$ & $\begin{array}{l}\geq 18 y \text { old with severe pain }(\geq 7 / 10) \\
\text { Exclusions: Indications other than } \\
\text { severe pain, received a } \\
\text { combination of analgesics, treated } \\
\text { solely by fire department, never } \\
\text { visited ED, or received treatment } \\
\text { through non-IV route }\end{array}$ & $\begin{array}{l}\text { A: Fentanyl } 2 \mathrm{mcg} / \mathrm{kg} \text { IV q10min } \\
\text { prn (max } 2 \text { doses, mean } \\
\text { morphine equivalent } 8.3(2.4)) \\
(\mathrm{n}=79) \\
\text { B: Ketamine } 0.3 \mathrm{mg} / \mathrm{kg} \mathrm{IV} \\
\text { q20min prn (max } 3 \text { doses, } \\
\text { mean morphine equivalent } 8.3 \\
(2.8))(\mathrm{n}=79) \\
\text { Rescue NR }\end{array}$ & $\begin{array}{l}\text { Age A: } 58.1(19.9) \text { B: } 58.4(21.7) \\
\text { Males A: 39\% B: 39\% } \\
\text { Weight: NR } \\
\text { Race/ethnicity A/B: Caucasian } \\
91 \% / 89 \%, \text { Black } 3 \% / 6 \% \text {, American } \\
\text { Indian 0\%/1\%, Other 6\%/4\% } \\
\text { Pain etiology/location A/B: Fall } \\
39 \% / 53 \%, \text { MVC } 11 \% / 6 \% \text {, Assault } \\
3 \% / 3 \%, \text { Medical complication } \\
\text { 10\%/3\%, Other } 20 \% / 28 \% \text {, } \\
\text { Unknown } 16 \% / 8 \% \\
\text { Pain Classification: Mixed }\end{array}$ & $\begin{array}{l}\text { Diastolic blood pressure } \\
\text { Heart rate } \\
\text { Mental status changes } \\
\text { Pain severity } \\
\text { Presence of pain } \\
\text { Respiratory depression } \\
\text { Respiratory rate } \\
\text { Systolic blood pressure }\end{array}$ \\
\hline $\begin{array}{l}\text { Zhang, } 2018^{106} \\
\text { Australia } \\
\text { Setting: EMS } \\
\text { Risk of bias: } \\
\text { Medium }\end{array}$ & $\begin{array}{l}\text { Patients with a traumatic injury, } \\
\text { retrieved from a prehospital site to } \\
\text { the ED } \\
\text { Exclusions: Patient requiring } \\
\text { airway intervention (intubation or } \\
\text { laryngeal mast airway) }\end{array}$ & $\begin{array}{l}\text { A: Ketamine+ morphine }(n=27) \\
\text { B: Ketamine+fentanyl }(n=6) \\
\text { C: Ketamine }(n=4) \\
\text { Rescue NR }\end{array}$ & $\begin{array}{l}\text { Age NR } \\
\text { Males NR } \\
\text { Weight NR } \\
\text { Race/ethnicity NR } \\
\text { Pain etiology/location: NR } \\
\text { Pain Classification: Traumatic }\end{array}$ & Vomiting \\
\hline
\end{tabular}




\begin{tabular}{|c|c|c|c|c|}
\hline $\begin{array}{l}\text { Author, year } \\
\text { Country } \\
\text { Setting } \\
\text { Risk of Bias }\end{array}$ & Eligibility & Intervention and Comparator & Population Characteristics & Outcomes \\
\hline $\begin{array}{l}\text { Oberholzer, } \\
2017^{67} \\
\text { Switzerland } \\
\text { Setting: EMS } \\
\text { Risk of bias: Low }\end{array}$ & $\begin{array}{l}\text { 15y old transported by EMS with } \\
\text { moderate to severe pain } \\
\text { (NRS }>3 / 10) \\
\text { Exclusions: GCS } \leq 12 \text {, NACA score } \\
\geq \mathrm{VI} \text {, patients too unstable or } \\
\text { sedated to determine and verbalize } \\
2 \text { NRS scores (at scene and } \\
\text { hospital arrival) }\end{array}$ & $\begin{array}{l}\text { A: Morphine IV (mean } 7.0 \mathrm{mg} \\
(4.6))(\mathrm{n}=107) \text { OR Fentanyl IV } \\
(\text { mean } 140 \mathrm{mcg}(109))(\mathrm{n}=521) \\
\text { B: Ketamine IV (mean } 58 \mathrm{mg} \\
(37))(n=137) \\
\text { Rescue NR }\end{array}$ & $\begin{array}{l}\text { Age NR } \\
\text { Males NR } \\
\text { Weight NR } \\
\text { Race/ethnicity NR } \\
\text { Pain etiology/location: Trauma } 69 \% \\
\text { Pain Classification: Mixed }\end{array}$ & Presence of pain \\
\hline $\begin{array}{l}\text { Scharonow, } \\
2017^{98} \\
\text { Germany } \\
\text { Setting: EMS } \\
\text { Risk of bias: } \\
\text { Medium }\end{array}$ & $\begin{array}{l}\text { Patients treated with narcotic } \\
\text { analgesics by specially trained } \\
\text { paramedics } \\
\text { Exclusions NR }\end{array}$ & $\begin{array}{l}\text { A: Morphine } 2 \mathrm{mg} / \mathrm{kg} \text { IV every } 3- \\
5 \text { min until NRS<3 or } 10 \mathrm{mg} \\
\text { (mean } 4.38 \mathrm{mg}(2.58))(\mathrm{n}=23) \\
\text { B: Fentanyl } 0.05-0.1 \mathrm{mg} \text { IV } \\
\text { every } 3-5 \text { min until NRS }<3 \text { or } \\
\text { 0.3mg, (mean } 150 \mathrm{mcg}(70)) \\
(\mathrm{n}=53) \\
\text { Rescue: NR }\end{array}$ & $\begin{array}{l}\text { Age total study: } 51.8-66.5 y \\
\text { Males total study: } 51.8 \% \\
\text { Weight NR } \\
\text { Race/ethnicity NR } \\
\text { Pain etiology/location total study: } \\
\text { Trauma } 68.5 \% \text {, abdomen } 20.8 \% \text {, } \\
\text { ACS } 11.7 \% \\
\text { Pain Classification: Mixed }\end{array}$ & $\begin{array}{l}\text { Pain severity } \\
\text { Respiratory depression }\end{array}$ \\
\hline $\begin{array}{l}\text { Schauer, } 2017^{62} \\
\text { Afghanistan } \\
\text { Setting: } \\
\text { Battlefield } \\
\text { Risk of bias: } \\
\text { Medium }\end{array}$ & $\begin{array}{l}23-28 y \text { old with battlefield injury } \\
\text { transported directly from point-of- } \\
\text { injury to enrolling center } \\
\text { Exclusions: NR }\end{array}$ & $\begin{array}{l}\text { A: Morphine }(n=66) \\
\text { B: Fentanyl }(n=85) \\
\text { C: Ketamine }(n=71) \\
\text { Rescue: NR }\end{array}$ & $\begin{array}{l}\text { Age A: } 28(23-33) \text { B: } 26(21-30) \text { C: } \\
23(20-25) \\
\text { Males A: } 98 \% \text { B: } 100 \% \text { C: } 100 \% \\
\text { Weight NR } \\
\text { Race/ethnicity NR } \\
\text { Pain etiology/location A/B/C: Blast } \\
45 \% / 45 \% / 52 \% \text {, penetrating } \\
35 \% / 47 \% / 45 \% \text {, blunt } 15 \% / 8 \% / 4 \% \text {, } \\
\text { burn } 3 \% / 2 \% / 0 \% \\
\text { Pain Classification: Traumatic }\end{array}$ & $\begin{array}{l}\text { Heart rate } \\
\text { Mental status changes } \\
\text { Respiratory rate } \\
\text { Systolic blood pressure }\end{array}$ \\
\hline
\end{tabular}




\begin{tabular}{|c|c|c|c|c|}
\hline $\begin{array}{l}\text { Author, year } \\
\text { Country } \\
\text { Setting } \\
\text { Risk of Bias }\end{array}$ & Eligibility & Intervention and Comparator & Population Characteristics & Outcomes \\
\hline $\begin{array}{l}\text { Daost, } 2015^{99} \\
\text { Canada } \\
\text { Setting: ED } \\
\text { Risk of bias: Low }\end{array}$ & $\begin{array}{l}\geq 16 y \text { old who received an opioid in } \\
\text { the ED } \\
\text { Exclusions: Received } \geq 1 \text { type of } \\
\text { opioid or route of administration, } \\
\text { patients who received opioids for } \\
\text { palliative care, pregnancy, and } \\
\text { patients transferred from or to } \\
\text { another hospital }\end{array}$ & $\begin{array}{l}\text { A: Morphine }(n=N R)^{a} \\
\text { B: Fentanyl }(n=N R) \\
\text { Rescue: NR }\end{array}$ & $\begin{array}{l}\text { Age total study } 55.8(20.5) \\
\text { Males total study } 47 \% \\
\text { Weight NR } \\
\text { Race/ethnicity NR } \\
\text { Pain etiology/location NR } \\
\text { Pain Classification: Mixed }\end{array}$ & $\begin{array}{l}\text { Any adverse event } \\
\text { Hypotension } \\
\text { Respiratory depression }\end{array}$ \\
\hline $\begin{array}{l}\text { Schacherer, } \\
2015^{100} \\
\text { United States } \\
\text { Setting: ED } \\
\text { Risk of bias: High }\end{array}$ & $\begin{array}{l}\text { 3-21y old presenting to ED with } \\
\text { expected long-bone fracture } \\
\text { Exclusions: Prior administration of } \\
\text { narcotics for injury, evidence of } \\
\text { multisystem trauma, hemodynamic } \\
\text { instability, nasal blockage, drug } \\
\text { allergy, patients who received } \\
\text { fentanyl IN without the use of drug } \\
\text { pathway }\end{array}$ & $\begin{array}{l}\text { A: Morphine IV }(\mathrm{n}=71) \\
\text { B: Fentanyl } 1.5 \mathrm{mg} / \mathrm{kg} \text { IN (max } \\
100 \mathrm{mcg}) ; \text { second dose in } 10 \\
\text { min if pain was not relieved } \\
(\mathrm{n}=23) \\
\text { Rescue NR }\end{array}$ & $\begin{array}{l}\text { Age A: } 9(5-12) \text { B: } 8(6-12) \\
\text { Males A: } 72 \% \text { B: } 61 \% \\
\text { Weight NR } \\
\text { Race/ethnicity NR } \\
\text { Pain etiology/location: Long-bone } \\
\text { fracture } 100 \% \\
\text { Pain Classification: Traumatic }\end{array}$ & $\begin{array}{l}\text { Presence of pain } \\
\text { Time to analgesic effect }\end{array}$ \\
\hline $\begin{array}{l}\text { Shackelford, } \\
2015^{63} \\
\text { Afghanistan } \\
\text { Setting: } \\
\text { Battlefield } \\
\text { Risk of bias: High }\end{array}$ & $\begin{array}{l}\text { Report of } 238 \text { traumatic battlefield } \\
\text { casualties } \\
\text { Exclusions NR }\end{array}$ & $\begin{array}{l}\text { A: Morphine IV (mean } 6.9 \text { mg } \\
(2.8)) \text {; Morphine IM (mean } 7.9 \\
\text { mg (3.2)) (n=40) } \\
\text { B: Fentanyl IV (mean } 77 \mathrm{mcg} \\
\text { (38)); fentanyl IM (mean } 75 \mathrm{mcg} \\
(35) \text { ); buccal lozenge } 800 \mathrm{mcg} \\
(\mathrm{n}=117) \\
\text { C: Ketamine IV (mean } 43 \mathrm{mg} \\
(25)) \text {; ketamine IM (mean } 58 \mathrm{mg} \\
(26))(\mathrm{n}=116) \\
\text { Rescue NR }\end{array}$ & $\begin{array}{l}\text { Age NR } \\
\text { Males NR } \\
\text { Weight NR } \\
\text { Race/ethnicity NR } \\
\text { Pain etiology/location NR } \\
\text { Pain Classification: Traumatic }\end{array}$ & $\begin{array}{l}\text { Pain severity } \\
\text { Heart rate } \\
\text { Respiratory depression } \\
\text { Respiratory rate } \\
\text { Systolic blood pressure }\end{array}$ \\
\hline
\end{tabular}




\begin{tabular}{|c|c|c|c|c|}
\hline $\begin{array}{l}\text { Author, year } \\
\text { Country } \\
\text { Setting } \\
\text { Risk of Bias }\end{array}$ & Eligibility & Intervention and Comparator & Population Characteristics & Outcomes \\
\hline $\begin{array}{l}\text { Wenderoth, } \\
2013^{101} \\
\text { United States } \\
\text { Setting: ED } \\
\text { Risk of bias: Low }\end{array}$ & $\begin{array}{l}\text { Consecutive adult trauma patients } \\
\text { with NRS } \geq 4 / 10 \\
\text { Exclusions: Patients which did not } \\
\text { receive one of the opioid/dose } \\
\text { combinations as first opioid in ED, } \\
\text { patients }\end{array}$ & $\begin{array}{l}\text { A: Morphine 4mg IV }(n=84) \\
\text { B: Fentanyl } 50 \text { mcg IV }(n=84) \\
\text { Rescue NR }\end{array}$ & $\begin{array}{l}\text { Age A: } 37(24-51) \text { B: } 38(24-53) \\
\text { Males A: } 67 \% \text { B: } 68 \% \\
\text { Weight A: } 80 \mathrm{~kg}(68-95) \mathrm{B}: 81 \mathrm{~kg} \\
(66-98) \\
\text { Race/ethnicity A/B: White } \\
61 \% / 50 \% \text {, Hispanic } 30 \% / 38 \% \text {, } \\
\text { other } 9 \% / 12 \% \\
\text { Pain etiology/location A/B: Blunt } \\
\text { trauma } 85.9 \% / 83.3 \% \text {, penetrating } \\
\text { trauma } 14.1 \% / 16.7 \% \\
\text { Pain Classification: Traumatic }\end{array}$ & $\begin{array}{l}\text { Hypotension } \\
\text { Nausea } \\
\text { Pain severity } \\
\text { Respiratory depression } \\
\text { Time to analgesic effect }\end{array}$ \\
\hline $\begin{array}{l}\text { Bendall, } 2011^{102} \\
\text { Australia } \\
\text { Setting: EMS } \\
\text { Risk of bias: Low }\end{array}$ & $\begin{array}{l}\text { 5-15y old with moderate to severe } \\
\text { pain (VNRS-11 } \geq 5 / 11 \text { ) } \\
\text { Exclusions NR }\end{array}$ & $\begin{array}{l}\text { A: Morphine IV } \\
5-12 \mathrm{y}: 0.1 \mathrm{mg} / \mathrm{kg} \text { q5min (max } 4 \\
\text { doses) } \\
>12 \mathrm{y}: 2.5 \text { to } 5 \mathrm{mg} \text { initially } \\
\text { followed by } 2.5 \mathrm{mg} \text { q2min (max } \\
\text { dose } 0.5 \mathrm{mg} / \mathrm{kg} \text { ) ( } \mathrm{n}=306) \\
\\
\text { B: Fentanyl IN } \\
\text { 1-5y: } 45-60 \mathrm{mcg} \text { initially } \\
\text { followed by } 30 \mathrm{mcg} \text { q5min prn } \\
6-12 \mathrm{y}: 60-75 \mathrm{mcg} \text { initially } \\
\text { followed by } 30 \mathrm{mcg} \text { q5min prn } \\
\text { 13-15y: } 180 \mathrm{mcg} \text { initially } \\
\text { followed by } 60 \mathrm{mcg} \text { q5min prn } \\
\text { (n=306) }\end{array}$ & $\begin{array}{l}\text { Age A: } 13(12-15) \text { B: } 13(11-14) \\
\text { Males NR } \\
\text { Weight NR } \\
\text { Race/ethnicity NR } \\
\text { Pain etiology/location A/B: Trauma } \\
82 \% / 75 \% \text {, abdominal pain } 5 \% / 5 \% \text {, } \\
\text { back pain } 1 \% / 2 \% \text {, non-specific } \\
5 \% / 7 \% \text {, other } 2 \% / 1 \% \\
\text { Pain Classification: Mixed }\end{array}$ & $\begin{array}{l}\text { Pain severity } \\
\text { Presence of pain }\end{array}$ \\
\hline & & Rescue NR & & \\
\hline
\end{tabular}




\begin{tabular}{|c|c|c|c|c|}
\hline $\begin{array}{l}\text { Author, year } \\
\text { Country } \\
\text { Setting } \\
\text { Risk of Bias }\end{array}$ & Eligibility & Intervention and Comparator & Population Characteristics & Outcomes \\
\hline $\begin{array}{l}\text { Garrick, } 2011^{103} \\
\text { United States } \\
\text { Setting: EMS } \\
\text { Risk of bias: High }\end{array}$ & $\begin{array}{l}\geq 6 \mathrm{~m} \text { old who received fentanyl } \\
\text { during paramedic transport in } \\
\text { moderate to severe pain }(\geq 4 / 10) \\
\text { Exclusions: History of prior renal or } \\
\text { hepatic insufficiency, known opioid } \\
\text { allergies, acute hemodynamic, } \\
\text { respiratory, or neurological } \\
\text { compromise, head trauma, already } \\
\text { received opioids, or protocol } \\
\text { deviations }\end{array}$ & $\begin{array}{l}\text { A: Morphine } 2-5 \mathrm{mg} \text { IV repeat } \\
\text { q2-5min or morphine } 5-10 \mathrm{mg} \\
\text { IM repeat q20min (max } 15 \mathrm{mg}) \\
(\mathrm{n}=66) \\
\text { B: Fentanyl } 1 \mathrm{mcg} / \mathrm{kg} \text { IV/IM } \\
\text { repeat at half initial dose (max } 3 \\
\text { mcg/kg); half-dose used in } \\
\text { patients }>65 y(\mathrm{n}=158) \\
\text { Rescue NR }\end{array}$ & $\begin{array}{l}\text { Age NR } \\
\text { Males NR } \\
\text { Weight NR } \\
\text { Race/ethnicity NR } \\
\text { Pain etiology/location All: Trauma } \\
65 \% \text {, medical 31\%, } \\
\text { cardiac/congestive HF 3\%, burns } \\
1 \% \\
\text { Pain Classification: Mixed }\end{array}$ & $\begin{array}{l}\text { Pain severity } \\
\text { Mental status changes } \\
\text { Nausea }\end{array}$ \\
\hline $\begin{array}{l}\text { Fleischman, } \\
2010^{104} \\
\text { United States } \\
\text { Setting: EMS } \\
\text { Risk of bias: Low }\end{array}$ & $\begin{array}{l}\geq 13 y \text { old transported from the } \\
\text { scene of the injury and received IV } \\
\text { morphine or fentanyl } \\
\text { Exclusions: Interhospital transfers }\end{array}$ & $\begin{array}{l}\text { A: Morphine } 2-5 \mathrm{mg} \text { IV q5min } \\
\text { (max } 20 \mathrm{mg} \text { ); Pediatrics } 0.1 \\
\text { mg/kg doses (morphine } \\
\text { equivalents/kg mean } 0.10) \text { ) } \\
(\mathrm{n}=355) \\
\text { B: Fentanyl } 50 \mathrm{mcg} \text { IV initially, } \\
\text { with } 25-50 \text { mcg q3-5min (max } \\
200 \mathrm{mcg} \text { ); Pediatrics } 1 \mathrm{mcg} / \mathrm{kg} \\
\text { doses (morphine equivalents/kg } \\
\text { mean } 0.12) \text { ) ( } \mathrm{n}=363 \text { ) } \\
\text { Rescue NR }\end{array}$ & $\begin{array}{l}\text { Age A: } 59 \text { (56-61) B: } 61(59-63) \\
\text { Males A: } 42.2 \% \text { B: } 36.6 \% \\
\text { Weight A: } 79.5 \mathrm{~kg}(77-82) \mathrm{B}: 78.3 \mathrm{~kg} \\
\text { (75-81) } \\
\text { Race/ethnicity: NR } \\
\text { Pain etiology/location A/B: } \\
\text { Extremity and hip pain or burns } \\
68 \% / 67 \% \text {, atraumatic abdominal or } \\
\text { pelvic pain } 8.7 \% / 13.8 \% \text {, suspected } \\
\text { ischemic chest pain } 14 \% / 6.3 \% \text {, } \\
\text { back pain } 6.4 \% / 9.1 \%, \text { other chest } \\
\text { pain } 2.5 \% / 2.8 \%, \text { head and neck } \\
\text { pain } 0.6 \% / 0.8 \% \\
\text { Pain Classification: Mixed }\end{array}$ & $\begin{array}{l}\text { Any adverse event } \\
\text { Hypotension } \\
\text { Mental status changes } \\
\text { Nausea } \\
\text { Pain severity } \\
\text { Respiratory depression }\end{array}$ \\
\hline
\end{tabular}

IV=intravenous; $\mathrm{kg}=$ kilogram; $\mathrm{m}=$ month; $\mathrm{mcg}=$ microgram; $\mathrm{mg}=$ milligram; min=minute; $\mathrm{MVC}=$ motor vehicle crash; $\mathrm{n}=$ number; NACA=National Advisory Committee for Aeronautics; $N R=$ not reported; $N R S=$ numerical rating scale; prn=as needed; $q=$ every; VNRS-11=11-point verbal numerical rating score; $y=y e a r$

a Total sample was 31,742 but includes all opioids and no breakdown for each opioid given 
Table C-3. Relative risks, opioids versus ketamine

Outcome

Study Design and Setting: Effect Estimates and 95\% Confidence Intervals

Sample Size

Key Question 1

Pain presence - full resolution $30 \mathrm{~min}$

Pain presence - full resolution 60 min

$3 \operatorname{RCT}(n=172)$

$2 \operatorname{RCT}(n=146)$

Pain presence- partial resolution - $15 \mathrm{~min}$

$5 \operatorname{RCT}(n=369)$

Pain presence- partial resolution - $30 \mathrm{~min}$ $4 \operatorname{RCT}(n=301)$

ED: Meta-analysis of 3 RCTs RR 1.03 (0.32 to 3.36)

Pain presence- partial resolution - $60 \mathrm{~min}$

$3 \operatorname{RCT}(n=208)$

ED: Meta-analysis of 2 RCTs RR 1.07 (0.58 to 1.97)

ED: Meta-analysis of 5 RCTs RR 0.97 (0.65 to 1.45)

Key Question 2 - graded

Any adverse event

$6 \operatorname{RCT}(n=348)$

Hypotension

$4 \operatorname{RCT}(n=508)$

Mental status changes - dizziness

Mental status changes - drowsiness

Mental status changes - sedation

7 RCT $(n=637)$

$4 \operatorname{RCT}(n=356)$

Mental status changes - confusion

1 RCT $(n=22)$

ED: Meta-analysis of 4 RCTs RR 0.98 (0.92 to 1.06)

Mental status changes - difficulty

$1 \operatorname{RCT}(n=75)$

concentrating

Mental status changes - sleepiness/tired

Respiratory depression

$1 \operatorname{RCT}(\mathrm{n}=75)$

Key Question 2- Additional Findings

Dissociation - 15 min

$1 \operatorname{RCT}(n=82)$

ED: Meta-analysis of 3 RCTs RR 1.01 (0.60 to 1.71)

Dissociation - study duration

Emergence delirium

Nausea -15 min

ED: Meta-analysis of 6 RCTs RR $0.63(0.36$ to 1.08$)$

Nausea $-30 \mathrm{~min}$

Nausea $-60 \mathrm{~min}$

Nausea - study period

4 RCT $(n=491) \quad$ ED: Meta-analysis of 4 RCTs RR $3.88(1.76$ to 8.55$)$

ED: Meta-analysis of 4 RCTs RR 3.74 (0.40 to 34.73 )

ED: Meta-analysis of 7 RCTs RR $0.44(0.22$ to 0.88$)$

ED: Meta-analysis of 4 RCTs RR $0.79(0.18$ to 3.42$)$

ED: 1 RCT RR 0.29 (0.08 to 1.08)

ED: One 3-arm trial -morphine IV RR 0.25 (0.08 to 0.78), morphine IM RR 0.37 (0.15 to 0.90)

Nausea and/or vomiting

Vomiting

ED: O 0.83 )

ED: 1 RCT RR $0.94(0.54$ to 1.63$)$

controlled trial; $\mathrm{RD}=$ risk difference 
Table C-4. Relative risks, combination opioids and ketamine versus opioids

Outcome

Study Design and Setting: Effect Estimates and 95\% Confidence Intervals

Key Question 1

Pain presence- partial resolution

Key Question 2- graded

Any adverse event

Hypotension $1 \operatorname{RCT}(n=65)$ EMS: 1 RCT RR 1.49 (0.9 to 2.46)

Mental status changes - dizziness 2 RCT $(n=265)$

Mental status changes - sedation

RCT $(n=265)$

Respiratory depression

$1 \operatorname{RCT}(\mathrm{n}=65)$

$3 \operatorname{RCT}(n=231)$

ED: 1 RCT RR 1.29 (0.53 to 3.12)

ED: 1 RCT RR 0.14 (0.01 to 2.7)

EMS: 1 RCT RR 12.61 (0.74 to 214.93)

ED: 1 RCT RR 0.93 (0.68 to 1.28$)$

EMS: 1 RCT RR 3.39 (0.76 to 15.12)

Key Question 2 - additional findings

Nausea $-60 \mathrm{~min}$

Nausea - study period

Nausea and/or vomiting - $30 \mathrm{~min}$

Nausea and/or vomiting - study period

EMS: 1 RCT RR 0.32 (0.01 to 7.65$)$

ED: Meta-analysis of 2 RCTs RR 0.29 (0.05 to 1.85)

Vomiting -30 min

Vomiting - 60 min

Vomiting - study period

$1 \operatorname{RCT}(n=200)$

$1 \operatorname{RCT}(n=60)$

1 RCT $(n=65)$

ED: 1 RCT RR 0.96 (0.7 to 1.31)

ED: 1 RCT RR 3.00 (0.33 to 27.23$)$

1 RCT $(n=106)$

EMS: 1 RCT RR 1.94 (0.65 to 5.81)

RCT $(n=200) \quad$ ED: 1 RCT RR $0.77(0.19$ to 1.4$)$

Abbreviations: $\mathrm{ED}=$ emergency department; $\mathrm{EMS}=$ emergency medical services; $\mathrm{MD}=$ mean difference; $\mathrm{NR}=$ not reported; $\mathrm{OBS}=\mathrm{observational}$; $\mathrm{RCT}=$ randomized controlled trial

Table C-5. Relative risks, opioids versus acetaminophen

Outcome Study Design and

Key Question 1

Pain presence- partial resolution - $30 \mathrm{~min}$

Key Question 2- graded

Any adverse event

Hypotension

Mental status changes - dizziness

Mental status changes - "mild" sedation Sample Size

Key Question 2 - additional findings

Nausea

Nausea and/or vomiting

Vomiting

$1 \operatorname{RCT}(n=996)$

Setting: Supporting Effect Estimates and 95\% Confidence Intervals

ED: 1 RCT RR 1.05 (0.99 to 1.11)

Abbreviations: $\mathrm{ED}=$ emergency department; $\mathrm{IQR}=$ interquartile range; $\mathrm{MD}=$ mean difference; min=minutes; $\mathrm{NRS}=$ Numeric Rating Scale; $\mathrm{RCT}=$ randomized controlled trial;

$\mathrm{RD}=$ risk difference 
Table C-6. Relative risks, opioids versus nonsteroidal anti-inflammatory drugs

Outcome Study Design and Setting: Supporting Effect Estimates and 95\% Confidence Intervals Sample Size

Key Question 1

Pain presence- partial resolution - $30 \mathrm{~min}$

Pain presence- partial resolution - $60 \mathrm{~min}$ $1 \operatorname{RCT}(n=227)$ 1 RCT $(n=243)$

Pain presence- full resolution -

$1 \operatorname{RCT}(n=86)$

ED: 1 RCT RR 1.05 (0.64 to 1.73)

$30 \mathrm{~min}$

Key Question 2 - graded

Any adverse event

Hypotension

2 RCT $(n=367)$

Mental status changes - drowsiness $\quad 1$ RCT $(n=88)$

$2 \operatorname{RCT}(n=367)$

Mental status changes - dizziness

$1 \operatorname{RCT}(n=86)$

RR $0.89(0.61$ to 1.28$)$

Mental status changes - depression

Key Question 2 - additional findings

Nausea

$3 \mathrm{RCT}(\mathrm{n}=453)$

$2 \operatorname{RCT}(n=174)$

ED: 1 RCT RR 1.4 (0.48 to 4.07 )

Vomiting

ED: Meta-analysis of 2 RCTs RR 3.64 (1.93 to 6.86 )

ED: 1 RCT RR 7 (0.37 to 131.61)

ED: Meta-analysis of 2 RCTs RR 4.90 (0.78 to 30.70$)$

ED: 1 RCT RR 9 (0.5 to 162.16$)$

ED: 1 RCT RR 5 (0.25 to 101.21$)$

: Meta-analysis of 2 RCT RR 2.84 (0.44 to 18.20$)$

Table C-7. Relative risks, acetaminophen versus nonsteroidal anti-inflammatory drugs

Outcome Study Design and Setting: Effect estimates and 95\% Confidence Intervals

Key Question 1

Pain presence - partial resolution $30 \mathrm{~min}$ Sample Size

Pain presence - partial resolution $60 \mathrm{~min}$

$1 \operatorname{RCT}(n=92)$ $2 \operatorname{RCT}(n=340)$

ED: 1 RCT RR 1.05 (0.64 to 1.72)

Key Question 2

Any adverse event

Nausea

$2 \operatorname{RCT}(n=340)$

Vomiting

$1 \operatorname{RCT}(n=140)$

ED: Meta-analysis of 2 RCT RR 0.87 (0.56 to 1.34$)$

ED: Meta-analysis of 2 RCT RR 1.33 (0.47 to 3.77$)$

Abbreviations: $\mathrm{AR}=$ absolute risk; $\mathrm{MD}=$ mean difference; $\mathrm{RCT}=$ randomized controlled trial; $\mathrm{RD}=$ risk difference 
Table C-8. Relative risks, ketamine versus nonsteroidal anti-inflammatory drugs

Outcome Study Design and Setting: Effect estimates and 95\% Confidence Intervals

Key Question 2

Any adverse event Sample Size

Mental status changes - dizziness

$1 \operatorname{RCT}(n=126)$

Nausea

$1 \operatorname{RCT}(n=126)$

ED: 1 RCT RR 52.63 (3.27 to 845.96 )

Nausea

$1 \operatorname{RCT}(\mathrm{n}=126$

ED: 1 RCT RR 0.80 (0.32 to 2.02$)$

Table C-9. Relative risks, morphine versus fentanyl

Outcome Study Design

Key Question 1

and Sample Size Setting: Effect estimates and 95\% Confidence Intervals

Pain presence - partial resolution $15 \mathrm{~min}$

$1 \mathrm{RCT}(\mathrm{n}=54) \quad$ EMS: 1 RCT RR $0.78(0.37$ to 1.64$)$

Pain presence - partial resolution $30 \mathrm{~min}$ $2 \operatorname{RCT}(n=163)$

EMS: Meta-analysis of 2 RCT RR 0.94 (0.76 to 1.16)

Key Question 2

Any adverse event

$3 \operatorname{RCT}(n=391)$

EMS: 1 RCT RR 0.54 (0.32 to 0.93)

Hypotension 3 RCT $(n=419)$

EMS: Meta-analysis of 2 RCT RR 4.44 (0.42 to 47.12)

Mental status changes - lightheadedness,

$1 \operatorname{RCT}(n=90)$

ED: 1 RCT RR 0.33 (0.01 to 7.6)

loss of consciousness

Mental status changes - sedation

Nausea

$1 \operatorname{RCT}(n=54)$

$5 \operatorname{RCT}(n=432)$

:1 RCT RR 5.46 (0.27 to 110.58)

Nausea and/or vomiting

$2 \operatorname{RCT}(n=397)$

EMS: 1 RCT RR 24.74 (1.53 to 399.35)

EMS: Meta-analysis of 2 RCT RR 1.03 (0.41 to 2.60)

ED: Meta-analysis of 3 RCT RR 1.97 (0.41 to 9.39)

Vomiting

$6 \operatorname{RCT}(n=642)$

ED: Meta-analysis of 2 RCT RR 1.75 (1.01 to 3.03)

EMS: Meta-analysis of 3 RCT RR 1.22 (0.36 to 4.09)

Abbreviations: $\mathrm{AR}=$ absolute risk; $\mathrm{ED}=$ emergency department; $\mathrm{EMS}=$ emergency medical services; $\mathrm{MD}=$ mean difference; $\mathrm{RCT}=$ randomized controlled trial; $\mathrm{RD}=$ risk difference

Table C-10. Relative risk, additional opioids versus ketamine, Key Question 4

Outcome

Study Design

Setting: Supporting Effect Estimates and 95\% Confidence Intervals

Key Question 4 - graded

Any adverse event

Hypotension

Mental status changes - GCS $\leq 13$ and Sample Size

Key Question 4 - additional findings

Nausea

$1 \operatorname{RCT}(n=135)$

EMS: 1 RCT RR 0.36 (0.18 to 0.7$)$

EMS: 1 RCT RR $3.23(0.13$ to 77.87$)$

Vomiting

Emergence delirium

$1 \operatorname{RCT}(n=135)$

EMS: 1 RCT RR 0.36 (0.04 to 3.36$)$

EMS: Meta-analysis of 2 RCT RR 1.06 (0.19 to 5.83)

$2 \operatorname{RCT}(n=162)$

1 RCT $(n=135)$

EMS: Meta-analysis of 2 RCT RR 0.24 (0.02 to 2.24) 
Table C-11. Contraindications to analgesics, per package insert ${ }^{112-125}$

\begin{tabular}{|c|c|c|}
\hline Analgesic & Contraindications & Warning/Precautions \\
\hline $\begin{array}{l}\text { Morphine } \\
\text { PO, IV, IM }\end{array}$ & $\begin{array}{l}\text {-Known hypersensitivity } \\
\text {-Significant respiratory depression } \\
\text {-Acute or severe bronchial asthma in an unmonitored setting } \\
\text { or in the absence of resuscitative equipment } \\
\text {-Concurrent use of MAOls or use within the past } 14 \text { days } \\
\text {-Known or suspected GI obstruction, including paralytic ileus }\end{array}$ & $\begin{array}{l}\text {-Life-threatening respiratory depression in patients with chronic pulmonary } \\
\text { disease or in the elderly, cachectic or debilitated patients } \\
\text {-Adrenal insufficiency } \\
\text {-Risks of use in patients with increased intracranial pressure, brain tumors, } \\
\text { head injury, impaired consciousness } \\
\text {-Severe hypotension } \\
\text {-IV/IM only: cardiovascular instability }\end{array}$ \\
\hline $\begin{array}{l}\text { Fentanyl IV, } \\
\text { IM }\end{array}$ & -Hypersensitivity & $\begin{array}{l}\text {-Risk of skeletal muscle rigidity and skeletal muscle movement } \\
\text {-Severe cardiovascular depression } \\
\text {-Serotonin syndrome } \\
\text {-Adrenal insufficiency } \\
\text {-Risks of use in patients with increased intracranial pressure, brain tumors, } \\
\text { head injury, impaired consciousness }\end{array}$ \\
\hline Fentanyl -IN & $\begin{array}{l}\text {-Opioid non-tolerant patients } \\
\text {-Management of acute or postoperative pain including } \\
\text { headache/migraine or dental pain } \\
\text {-Intolerance or hypersensitivity }\end{array}$ & $\begin{array}{l}\text {-Clinically significant respiratory and CNS depression can occur } \\
\text {-Do not convert patients from other fentanyl products on a mcg per mcg } \\
\text { basis, or substitute } \\
\text {-Can be fatal to a child, ensure proper storage and disposal } \\
\text {-Use with other CNS depressants and potent CYP450 3A4 inhibitors may } \\
\text { increase depressant effects } \\
\text {-Titrate cautiously in patients with chronic obstructive pulmonary disease or } \\
\text { preexisting medical conditions predisposing them to respiratory depression } \\
\text { and in patients susceptible to intracranial effects of CO retention }\end{array}$ \\
\hline $\begin{array}{l}\text { Fentanyl - } \\
\text { transmucosal } \\
\text { lozenge }\end{array}$ & $\begin{array}{l}\text {-Opioid non-tolerant patients. } \\
\text {-Significant respiratory depression } \\
\text {-Management of acute or postoperative pain including } \\
\text { headache/migraines and dental pain } \\
\text {-Acute or severe bronchial asthma in an unmonitored setting } \\
\text { or in absence of resuscitative equipment } \\
\text {-Known or suspected gastrointestinal obstruction, including } \\
\text { paralytic ileus } \\
\text {-Known hypersensitivity }\end{array}$ & $\begin{array}{l}\text {-Life-threatening respiratory depression in patients with chronic pulmonary } \\
\text { disease or in elderly, cachectic, or debilitated patients } \\
\text {-Serotonin syndrome } \\
\text {-Adrenal insufficiency } \\
\text {-Severe hypotension } \\
\text {-Risks of use in patients with increased intracranial pressure, brain tumors, } \\
\text { head injury, or impaired consciousness }\end{array}$ \\
\hline Ketamine - IV & $\begin{array}{l}\text {-In those whom a significant elevation of blood pressure would } \\
\text { constitute serious hazard } \\
\text {-Hypersensitivity }\end{array}$ & $\begin{array}{l}\text {-HTN or cardiac decompensation } \\
\text {-Postoperative operative confusion states may occur during recovery period } \\
\text {-Respiratory depression }\end{array}$ \\
\hline Ketamine - IN & -Not FDA approved for pain, no label & -Not FDA approved for pain, no label \\
\hline APAP- IV, PO & $\begin{array}{l}\text {-Known hypersensitivity } \\
\text {-Severe hepatic impairment or severe active liver disease }\end{array}$ & $\begin{array}{l}\text {-Caution in patients with active hepatic impairment or active hepatic } \\
\text { disease, alcoholism, chronic malnutrition, severe hypovolemia, or severe } \\
\text { renal impairment } \\
\text {-Administration in doses higher than recommended may result in hepatic } \\
\text { injury, including the risk of liver failure and death }\end{array}$ \\
\hline
\end{tabular}




\begin{tabular}{|c|c|c|}
\hline Analgesic & Contraindications & Warning/Precautions \\
\hline $\begin{array}{l}\text { Ketorolac - } \\
\text { IV, PO }\end{array}$ & $\begin{array}{l}\text {-Known hypersensitivity } \\
\text {-Active PUD, recent GI bleeding, perforation, history of PUD or } \\
\text { GIB } \\
\text {-Patients who have experienced asthma, urticarial, or allergic } \\
\text { type reactions after taking aspirin or other NSAIDs } \\
\text {-Prophylactic analgesic before any major surgery } \\
\text {-CABG } \\
\text {-Advanced renal impairment or in patients at risk of renal } \\
\text { failure due to volume depletion } \\
\text {-Labor and delivery } \\
\text {-Suspected or confirmed cerebrovascular bleeding, } \\
\text { hemorrhagic diathesis, incomplete hemostasis, and those at } \\
\text { high risk for bleeding } \\
\text {-In patients currently receiving aspirin, NSAIDs, probenecid or } \\
\text { pentoxifylline } \\
\text { IV only: Neuraxial (epidural or intrathecal) administration }\end{array}$ & $\begin{array}{l}\text {-Do not exceed use for } 5 \text { days (combined duration for all routes) } \\
\text {-Not indicated for use in pediatric patients } \\
\text {-Most serious risks include ulceration, bleeding, perforation, hemorrhage, } \\
\text { renal effects, impaired renal function, anaphylactic reactions, cardiovascular } \\
\text { effects, and skin reactions }\end{array}$ \\
\hline $\begin{array}{l}\text { Ibuprofen - } \\
\text { IV, PO }\end{array}$ & $\begin{array}{l}\text {-Known hypersensitivity } \\
\text {-CABG } \\
\text {-History of asthma, urticarial, or allergic type reactions after } \\
\text { taking aspirin or other NSAIDs }\end{array}$ & $\begin{array}{l}\text {-Hypertension } \\
\text {-Heart failure and edema } \\
\text {-Renal toxicity } \\
\text {-Anaphylactic reactions } \\
\text {-Serious skin reactions } \\
\text {-Premature closure of fetal ductus arteriosus } \\
\text {-Hematologic toxicity } \\
\text {-IV only: Hepatotoxicity, exacerbation of asthma related to aspirin sensitivity, } \\
\text { hematologic toxicity }\end{array}$ \\
\hline Nitrous oxide ${ }^{a}$ & $\begin{array}{l}\text {-Known hypersensitivity } \\
\text {-Patients having undergone vitreoretinal surgery and presence } \\
\text { of intraocular gas bubble } \\
\text {-Should not be administered without oxygen }\end{array}$ & $\begin{array}{l}\text {-May be addictive } \\
\text {-Avoid use in pneumothorax, pneumocephalus, middle ear surgery, bowel } \\
\text { obstruction } \\
\text {-Prolonged use may produce neurologic dysfunction } \\
\text {-Do not use in patients who have had intravitreal gas bubbles unless } \\
\text { completely reabsorbed }\end{array}$ \\
\hline
\end{tabular}




\section{Appendix D. Risk of Bias Assessment}

Table D-1. Risk of bias assessment

\begin{tabular}{|c|c|c|c|c|c|c|c|}
\hline Study, Year & $\begin{array}{l}\text { Sequence } \\
\text { Generation }\end{array}$ & $\begin{array}{l}\text { Allocation } \\
\text { concealment }\end{array}$ & $\begin{array}{l}\text { Blinding of } \\
\text { participants, } \\
\text { personnel }\end{array}$ & $\begin{array}{l}\text { Blinding of } \\
\text { Outcome } \\
\text { assessors }\end{array}$ & $\begin{array}{l}\text { Incomplete } \\
\text { outcome data }\end{array}$ & $\begin{array}{l}\text { Selective } \\
\text { outcome } \\
\text { reporting }\end{array}$ & Risk of bias \\
\hline Sotoodehnia, $2019^{90}$ & Unclear & Unclear & Low & Low & Low & Low & Low \\
\hline Vahedi, $2019^{91}$ & Unclear & Unclear & Low & Unclear & Low & Low & Low \\
\hline Verki, $2019^{51}$ & Unclear & Unclear & Low & Unclear & Low & Low & Low \\
\hline Frey, $2019^{17}$ & Low & Low & Low & Unclear & Low & Low & Low \\
\hline Abbasi, $2018^{71}$ & Unclear & Unclear & Low & Low & Low & Low & Low \\
\hline $\mathrm{Al}, 2018^{80}$ & Low & Low & Low & Unclear & Low & Low & Low \\
\hline Cenker, $2018^{87}$ & Unclear & Low & Low & Low & Low & Low & Low \\
\hline Cozzi, $2018^{88}$ & Low & Low & Low & Unclear & Low & Low & Low \\
\hline Hosseininejad, $2018^{68}$ & Low & Low & Low & Low & Low & Low & Low \\
\hline Jahanian, $2018^{60}$ & Low & Low & Low & Low & Low & Low & Low \\
\hline $\begin{array}{l}\text { Mohammadshahi, } \\
2018^{72}\end{array}$ & Low & Low & Low & Unclear & Low & Low & Low \\
\hline Motov, $2018^{55}$ & Low & Unclear & Low & Low & Low & Low & Low \\
\hline Quinn, $2018^{52}$ & Low & Unclear & Low & Low & Low & Low & Low \\
\hline Farina, $2017^{54}$ & Unclear $^{b}$ & Unclear $^{b}$ & Low & Low & Low & Low & Low \\
\hline Mahshidfar, $2017^{56}$ & Unclear & Unclear & Low & Unclear & Low & Low & Low \\
\hline Masoumi, $2017^{84}$ & Highc $^{c}$ & Highc $^{c}$ & Low & Low & Low & Low & Medium \\
\hline Reynolds, $2017^{29}$ & Low & Low & Low & Low & Low & Low & Low \\
\hline Sin, $2017^{69}$ & Low & Low & Low & Low & Low & Low & Low \\
\hline Jalili, $2016^{74}$ & Low & Low & Low & Low & Unclear & Low & Low \\
\hline Mollaei, $2016^{81}$ & Low & Unclear & Low & Low & Unclear & Low & Low \\
\hline Pathan, $2016^{75}$ & Low & Low & Low & Low & Low & Low & Low \\
\hline Serinken, $2016^{76}$ & Low & Low & Low & Low & Low & Low & Low \\
\hline Shimonovich, $2016^{53}$ & High & High & High & High & High & Low & High $^{d}$ \\
\hline Weldon, $2016^{92}$ & Low & Low & Low & Unclear & Low & Low & Low \\
\hline Deaton, $2015^{19}$ & Low & Low & Low & Low & High $^{\mathrm{e}}$ & Low & Medium \\
\hline Graudins, $2015^{30}$ & Low & Unclear & Low & Unclear & Low & Low & Low \\
\hline Miller, $2015^{58}$ & Unclear & Low & Low & Low & Low & Low & Low \\
\hline Motov, $2015^{57}$ & Low & Unclear & Low & Low & Low & Low & Low \\
\hline Beaudoin, $2014^{70}$ & Low & Low & Low & Low & Low & Low & Low \\
\hline Majidinejad, $2014^{59}$ & Unclear & Unclear & Low & Unclear & Unclear & Low & Unclear \\
\hline Masoumi, $2014^{82}$ & Low & Low & Low & Unclear & Low & Low & Low \\
\hline
\end{tabular}

D-1 


\begin{tabular}{|c|c|c|c|c|c|c|c|}
\hline Study, Year & $\begin{array}{l}\text { Sequence } \\
\text { Generation }\end{array}$ & $\begin{array}{l}\text { Allocation } \\
\text { concealment }\end{array}$ & $\begin{array}{l}\text { Blinding of } \\
\text { participants, } \\
\text { personnel }\end{array}$ & $\begin{array}{l}\text { Blinding of } \\
\text { Outcome } \\
\text { assessors }\end{array}$ & $\begin{array}{l}\text { Incomplete } \\
\text { outcome data }\end{array}$ & $\begin{array}{l}\text { Selective } \\
\text { outcome } \\
\text { reporting }\end{array}$ & Risk of bias \\
\hline Vahdati, $2014^{73}$ & Low & Unclear & Low & Unclear & Unclear & Low & Unclear \\
\hline Eken, 201377 & Low & Low & Low & Low & Low & Low & Low \\
\hline Craig, $2012^{79}$ & Unclear & Low & Low & Unclear & Low & Low & Low \\
\hline Jennings, $2012^{64}$ & Low & Low & High & Unclear & Low & Low & Low/Medium $^{\mathrm{i}}$ \\
\hline Serinken, $2012^{78}$ & Unclear & Low & Low & Unclear & Low & Low & Low \\
\hline Smith, $2012^{94}$ & High $^{j}$ & High $^{j}$ & Low & Low & Low & Low & Medium \\
\hline Kariman, $2011^{83}$ & Low & Low & High & High & Low & Low & Low/Medium $^{k}$ \\
\hline Furyk, $2009^{21}$ & Low & Low & High & Unclear & Low & Present $^{\prime}$ & Medium $^{\mathrm{m}}$ \\
\hline Johansson, $2009^{65}$ & Unclear & Unclear & High & High & Low & Low & Low/Medium $^{\text {n }}$ \\
\hline Borland, $2007^{97}$ & Unclear & Low & Low & Unclear & Low & Low & Low \\
\hline Clark, $2007^{89}$ & Low & Low & Low & Unclear & Low & Low & Low \\
\hline Galinksi, $2007^{66}$ & Low & Low & Low & Low & Low & Low & Low \\
\hline Mahar, $2007^{96}$ & Low & Low & High & Unclear & Low & Low & Low/Medium $^{\circ}$ \\
\hline Rickard, $2007^{95}$ & Low & Low & High & High & Low & Low & Medium \\
\hline Safdar, $2006^{85}$ & Unclear & Low & Low & Low & Low & Present $^{p}$ & Low \\
\hline Galinski, $2005^{93}$ & Low & Low & Low & Low & Low & Low & Low \\
\hline
\end{tabular}

${ }^{a}$ Only source of information is the registration in www.clinicaltrials.gov

${ }^{\mathrm{b}}$ Although randomization procedures were not reported thus rated unclear, authors report an imbalance in baseline pain scores thus used and adjusted analysis for this outcome.

Other characteristics were stated to be balanced.

${ }^{\mathrm{C}}$ Despite non-random and lack of allocation concealment (used every other patient), baseline characteristics were similar at the start of the trial.

d Used a personal ID number for randomization which was not concealed, the trial was open-label, high differential attrition between ketamine (30\%) and both morphine arms

(IV 8\%, IM 10\%) that could be related to the study outcomes

'Attrition at $20 \%$ without methods to handle dropouts, didn't use ITT.

${ }^{\mathrm{f}}$ Methods indicate that vitals and oxygenation were collected but the results are not reported

$\mathrm{g}$ Methods indicate that blood pressure and heart rate were collected but the results are not reported.

${ }^{\mathrm{h}}$ Non-random assignment (clustered randomization using every other month) but baseline characteristics are balanced at the start of the trial. Not blinded and all subjective outcomes.

${ }^{\mathrm{i}}$ Low for HR, BP, RR, vomiting, hypotension. Medium for pain, time to analgesic effect, mental status changes, nausea, emergence delirium, any adverse event.

${ }^{\mathrm{j}}$ Despite non-random drug assignment (even and odd calendar day methods) the baseline characteristics were similar at the start of the trial.

${ }^{\mathrm{k}}$ Low for BP, HR, RR, respiratory depression. Medium for pain, any AE, emergence delirium

${ }^{1}$ Methods indicate that heart rate, respiratory rate, GCS and oxygen saturation were collected but the results are not reported.

${ }^{m}$ Patient were aware of drug assignment, no placebos were used. Only subjective outcomes thus all medium

${ }^{\mathrm{n}}$ Low for vomiting, blood pressure, heart rate, respiratory rate, oxygen saturation. Medium for pain, nausea and mental status changes

${ }^{\circ}$ Low for vomiting, blood pressure, heart rate, respiratory rate, oxygen saturation. Medium for pain, nausea and mental status changes

${ }^{\mathrm{p}}$ Methods indicate that blood pressure, heart rate, respiratory rate and oxygen saturation were collected but the results are not reported

${ }^{\mathrm{q}}$ Low for bradycardia and vomiting, medium for pain 
Table D-2. Risk of bias assessment- cohort

\begin{tabular}{|c|c|c|c|c|c|c|c|c|c|}
\hline Study, Year & $\begin{array}{l}\text { Representative } \\
\text {-ness of } \\
\text { exposed } \\
\text { cohort }\end{array}$ & $\begin{array}{l}\text { Selection of } \\
\text { non-exposed } \\
\text { cohort }\end{array}$ & $\begin{array}{l}\text { Ascertainment } \\
\text { of exposure }\end{array}$ & $\begin{array}{l}\text { Outcome of } \\
\text { interest not } \\
\text { present at } \\
\text { start of } \\
\text { study }\end{array}$ & $\begin{array}{l}\text { Comparability } \\
\text { of cohorts }\end{array}$ & $\begin{array}{l}\text { Assessment } \\
\text { of outcome }\end{array}$ & $\begin{array}{l}\text { Follow- } \\
\text { up long } \\
\text { enough }\end{array}$ & $\begin{array}{l}\text { Adequacy } \\
\text { of follow- } \\
\text { up of } \\
\text { cohorts }\end{array}$ & $\begin{array}{l}\text { Risk of } \\
\text { Bias }\end{array}$ \\
\hline $\begin{array}{l}\text { Griffioen, } \\
2019^{105}\end{array}$ & $\begin{array}{l}{ }^{*} \text { Somewhat } \\
\text { representative }\end{array}$ & $\begin{array}{l}{ }^{*} \text { Drawn from } \\
\text { same } \\
\text { community }\end{array}$ & ${ }^{*}$ Secure record & *Yes & Uncontrolled & $\begin{array}{l}{ }^{*} \text { Secure } \\
\text { records }\end{array}$ & ${ }^{*}$ Yes & $\begin{array}{l}\text { No } \\
\text { statement }\end{array}$ & Medium \\
\hline $\begin{array}{l}\text { Bronsky, } \\
2018^{61}\end{array}$ & $\begin{array}{l}{ }^{*} \text { Truly } \\
\text { representative }\end{array}$ & $\begin{array}{l}\text { *Drawn from } \\
\text { same } \\
\text { community }\end{array}$ & ${ }^{*}$ Secure record & *Yes & $\begin{array}{l}{ }^{* *} \text { Controls for } \\
\text { multiple factors }\end{array}$ & $\begin{array}{l}{ }^{*} \text { Secure } \\
\text { records }\end{array}$ & Unknown & $\begin{array}{l}{ }^{*} \text { Complete } \\
\text { follow-up }\end{array}$ & Low \\
\hline $\begin{array}{l}\text { Oberholzer, } \\
2017^{67}\end{array}$ & $\begin{array}{l}{ }^{*} \text { Truly } \\
\text { representative }\end{array}$ & $\begin{array}{l}\text { *Drawn from } \\
\text { same } \\
\text { community }\end{array}$ & ${ }^{*}$ Secure record & ${ }^{*}$ Yes & $\begin{array}{l}{ }^{* *} \text { Controls for } \\
\text { multiple factors }\end{array}$ & $\begin{array}{l}{ }^{*} \text { Secure } \\
\text { records }\end{array}$ & ${ }^{*}$ Yes & $\begin{array}{l}{ }^{*} \text { Complete } \\
\text { follow-up }\end{array}$ & Low \\
\hline $\begin{array}{l}\text { Scharonow, } \\
2017^{98}\end{array}$ & $\begin{array}{l}{ }^{*} \text { Truly } \\
\text { representative }\end{array}$ & $\begin{array}{l}\text { *Drawn from } \\
\text { same } \\
\text { community }\end{array}$ & ${ }^{*}$ Secure record & ${ }^{*}$ Yes & Uncontrolled & $\begin{array}{l}{ }^{*} \text { Secure } \\
\text { records }\end{array}$ & Unknown & $\begin{array}{l}{ }^{*} \text { Complete } \\
\text { follow-up }\end{array}$ & Medium \\
\hline $\begin{array}{l}\text { Schauer, } \\
2017^{62}\end{array}$ & $\begin{array}{l}\text { Selected group } \\
\text { of users }\end{array}$ & $\begin{array}{l}{ }^{*} \text { Drawn from } \\
\text { same } \\
\text { community }\end{array}$ & ${ }^{*}$ Secure record & ${ }^{*}$ Yes & $\begin{array}{l}{ }^{*} \text { Controlled for } \\
\text { single factor }\end{array}$ & $\begin{array}{l}{ }^{*} \text { Secure } \\
\text { records }\end{array}$ & Unknown & $\begin{array}{l}\text { No } \\
\text { statement }\end{array}$ & Medium \\
\hline $\begin{array}{l}\text { Daoust, } \\
2015^{99}\end{array}$ & $\begin{array}{l}{ }^{*} \text { Somewhat } \\
\text { representative }\end{array}$ & $\begin{array}{l}{ }^{*} \text { Drawn from } \\
\text { same } \\
\text { community }\end{array}$ & ${ }^{*}$ Secure record & ${ }^{*}$ Yes & $\begin{array}{l}{ }^{* *} \text { Controls for } \\
\text { multiple factors }\end{array}$ & $\begin{array}{l}{ }^{*} \text { Secure } \\
\text { records }\end{array}$ & *Yes & $\begin{array}{l}{ }^{*} \text { Subjects } \\
\text { lost unlikely } \\
\text { to introduce } \\
\text { bias }\end{array}$ & Low \\
\hline $\begin{array}{l}\text { Shacherer, } \\
2015^{100}\end{array}$ & $\begin{array}{l}{ }^{*} \text { Somewhat } \\
\text { representative }\end{array}$ & $\begin{array}{l}{ }^{*} \text { Drawn from } \\
\text { a different } \\
\text { source }\end{array}$ & ${ }^{*}$ Secure record & *Yes & Uncontrolled & $\begin{array}{l}{ }^{*} \text { Secure } \\
\text { records }\end{array}$ & ${ }^{*}$ Yes & $\begin{array}{l}\text { Not } \\
\text { quantified, } \\
\text { no } \\
\text { explanation }\end{array}$ & High \\
\hline $\begin{array}{l}\text { Shackelford, } \\
2015^{63}\end{array}$ & $\begin{array}{l}\text { Selected group } \\
\text { of users }\end{array}$ & $\begin{array}{l}{ }^{*} \text { Drawn from } \\
\text { same } \\
\text { community }\end{array}$ & ${ }^{*}$ Secure record & ${ }^{*}$ Yes & Uncontrolled & $\begin{array}{l}{ }^{*} \text { Secure } \\
\text { records }\end{array}$ & Unknown & $\begin{array}{l}\text { Inadequate } \\
\text { follow-up } \\
\text { rate }\end{array}$ & High \\
\hline $\begin{array}{l}\text { Wenderoth, } \\
2013^{101}\end{array}$ & $\begin{array}{l}{ }^{*} \text { Somewhat } \\
\text { representative }\end{array}$ & $\begin{array}{l}\text { *Drawn from } \\
\text { same } \\
\text { community }\end{array}$ & ${ }^{*}$ Secure record & ${ }^{*}$ Yes & $\begin{array}{l}{ }^{* *} \text { Controls for } \\
\text { multiple factors }\end{array}$ & $\begin{array}{l}{ }^{*} \text { Secure } \\
\text { records }\end{array}$ & ${ }^{*}$ Yes & $\begin{array}{l}\text { Inadequate } \\
\text { follow-up } \\
\text { rate }\end{array}$ & Low \\
\hline $\begin{array}{l}\text { Bendall, } \\
2011^{102}\end{array}$ & $\begin{array}{l}{ }^{*} \text { Truly } \\
\text { representative }\end{array}$ & $\begin{array}{l}\text { *Drawn from } \\
\text { same } \\
\text { community }\end{array}$ & ${ }^{*}$ Secure record & ${ }^{*}$ Yes & $\begin{array}{l}{ }^{* *} \text { Controls for } \\
\text { multiple factors }\end{array}$ & $\begin{array}{l}{ }^{*} \text { Secure } \\
\text { records }\end{array}$ & *Yes & $\begin{array}{l}\text { Inadequate } \\
\text { follow-up } \\
\text { rate }\end{array}$ & Low \\
\hline $\begin{array}{l}\text { Fleischman, } \\
2010^{104}\end{array}$ & $\begin{array}{l}{ }^{*} \text { Truly } \\
\text { representative }\end{array}$ & $\begin{array}{l}\text { Drawn from a } \\
\text { different } \\
\text { source }\end{array}$ & ${ }^{*}$ Secure record & ${ }^{*}$ Yes & $\begin{array}{l}{ }^{* *} \text { Controls for } \\
\text { multiple factors }\end{array}$ & $\begin{array}{l}{ }^{*} \text { Secure } \\
\text { records }\end{array}$ & ${ }^{*}$ Yes & $\begin{array}{l}{ }^{*} \text { Subjects } \\
\text { lost unlikely } \\
\text { to introduce } \\
\text { bias }\end{array}$ & Low \\
\hline
\end{tabular}




\begin{tabular}{|l|l|l|l|l|l|l|l|}
\hline Study, Year & $\begin{array}{l}\text { Representative } \\
\text {-ness of } \\
\text { exposed } \\
\text { cohort }\end{array}$ & $\begin{array}{l}\text { Selection of } \\
\text { non-exposed } \\
\text { cohort }\end{array}$ & $\begin{array}{l}\text { Ascertainment } \\
\text { of exposure }\end{array}$ & $\begin{array}{l}\text { Outcome of } \\
\text { interest not } \\
\text { present at } \\
\text { start of } \\
\text { study }\end{array}$ & $\begin{array}{l}\text { Comparability } \\
\text { of cohorts }\end{array}$ & $\begin{array}{l}\text { Assessment } \\
\text { of outcome } \\
\text { up long } \\
\text { enough }\end{array}$ & $\begin{array}{l}\text { Follow- } \\
\text { of follow- } \\
\text { up of } \\
\text { cohorts }\end{array}$ \\
\hline $\begin{array}{l}\text { Garrick, } \\
2011^{103}\end{array}$ & $\begin{array}{l}\text { *Truly } \\
\text { representative }\end{array}$ & $\begin{array}{l}\text { Drawn from a } \\
\text { different } \\
\text { source }\end{array}$ & *Secure record & *Yes & $\begin{array}{l}\text { Risk of } \\
\text { Bias }\end{array}$ & $\begin{array}{l}\text { Uncontrolled } \\
\text { records }\end{array}$ \\
\hline
\end{tabular}

Table D-3. Risk of bias assessment- case control

\begin{tabular}{|l|l|l|l|l|l|l|l|}
\hline $\begin{array}{l}\text { Study, } \\
\text { Year }\end{array}$ & $\begin{array}{l}\text { Case } \\
\text { definition }\end{array}$ & $\begin{array}{l}\text { Representative } \\
\text {-ness of the } \\
\text { cases }\end{array}$ & $\begin{array}{l}\text { Selection of } \\
\text { controls }\end{array}$ & $\begin{array}{l}\text { Comparability } \\
\text { of cases and } \\
\text { controls }\end{array}$ & $\begin{array}{l}\text { Ascertainment } \\
\text { of exposure }\end{array}$ & $\begin{array}{l}\text { Same } \\
\text { ascertainment } \\
\text { for cases and } \\
\text { controls }\end{array}$ & $\begin{array}{l}\text { Non- } \\
\text { response } \\
\text { rate }\end{array}$ \\
\hline $\begin{array}{l}\text { Zhang, } \\
2018^{106}\end{array}$ & $\begin{array}{l}{ }^{*} \text { Independent } \\
\text { validation }\end{array}$ & ${ }^{*}$ Consecutive & $\begin{array}{l}{ }^{*} \text { Community } \\
\text { controls } \\
\text { Bias }\end{array}$ & Uncontrolled & ${ }^{*}$ Secure records & ${ }^{*}$ Yes & NA \\
\hline
\end{tabular}

Abbreviations: $\mathrm{NA}=$ not applicable. 


\section{Appendix E. Strength of Evidence Assessments}

Table E-1. Strength of evidence ratings for the comparison of opioids vs. ketamine, Key Questions 1 and 2

\begin{tabular}{|c|c|c|c|c|c|c|c|c|}
\hline Outcome & $\begin{array}{l}\text { Conclusions statement, } \\
\text { rationale }^{\mathrm{a}}\end{array}$ & $\begin{array}{l}\text { Study } \\
\text { Design } \\
\text { and } \\
\text { Sample } \\
\text { Size } \\
\end{array}$ & $\begin{array}{l}\text { Study } \\
\text { Limitations }\end{array}$ & Consistency $^{c}$ & Directness $^{\mathrm{d}}$ & Precision & $\begin{array}{l}\text { Publication } \\
\text { Bias }^{f}\end{array}$ & $\begin{array}{l}\text { Strength of } \\
\text { Evidence }\end{array}$ \\
\hline $\begin{array}{l}\text { Pain severity - } \\
15 \text { min }\end{array}$ & $\begin{array}{l}\text { There is no evidence of a } \\
\text { clinically important difference } \\
\text { between opioids and ketamine } \\
\text { in the change of pain scores in } \\
15 \text { min. } \\
\text { ED: Meta-analysis of } 12 \text { RCTs } \\
\text { found MD } 0.35 \text { (- }-0.36 \text { to } 1.06) \text { at } \\
15 \text { min }\end{array}$ & $\begin{array}{l}12 \text { RCTs } \\
(n=1128)\end{array}$ & Low & Inconsistent & Indirect & Precise & Unsuspected & Low \\
\hline $\begin{array}{l}\text { Pain severity - } \\
30 \text { min }\end{array}$ & $\begin{array}{l}\text { There is no evidence of a } \\
\text { clinically important difference } \\
\text { between opioids and ketamine } \\
\text { in the change of pain scores in } \\
\mathbf{3 0} \text { min. } \\
\\
\text { ED: Meta-analysis of } 12 \text { RCTs } \\
\text { found MD } 0.26(-0.23 \text { to } 0.75) \text { at } \\
30 \text { min }\end{array}$ & $\begin{array}{l}12 \text { RCTs } \\
(\mathrm{n}=1153)\end{array}$ & Low & Inconsistent & Indirect & Precise & Unsuspected & Low \\
\hline
\end{tabular}




\begin{tabular}{|c|c|c|c|c|c|c|c|c|}
\hline Outcome & $\begin{array}{l}\text { Conclusions statement, } \\
\text { rationale }^{\mathrm{a}}\end{array}$ & $\begin{array}{l}\text { Study } \\
\text { Design } \\
\text { and } \\
\text { Sample } \\
\text { Size }\end{array}$ & $\begin{array}{l}\text { Study } \\
\text { Limitations }^{b}\end{array}$ & Consistencyc $^{c}$ & Directness $^{d}$ & Precision $^{\mathrm{e}}$ & $\begin{array}{l}\text { Publication } \\
\text { Bias }^{f}\end{array}$ & $\begin{array}{l}\text { Strength of } \\
\text { Evidence }\end{array}$ \\
\hline $\begin{array}{l}\text { Pain severity - } \\
60 \text { min }\end{array}$ & $\begin{array}{l}\text { There is no evidence of a } \\
\text { clinically important difference } \\
\text { between opioids and ketamine } \\
\text { in the change of pain scores in } \\
60 \text { min. } \\
\text { EMS: } 1 \text { RCT found MD }-0.4(-0.8 \\
\text { to } 0.09) \text { over the prehospital } \\
\text { period. } \\
1 \text { OBS study found the decrease } \\
\text { in pain score to be greater with } \\
\text { ketamine vs. morphine over the } \\
\text { prehospital period [-5.5(3.1) vs. - } \\
2.5 \text { ( } 2.4) \text {, p<0.001] } \\
\text { ED: Meta-analysis of } 11 \text { RCTs } \\
\text { found MD -0.36 (- } 0.94 \text { to } 0.23) \text { at } \\
60 \text { min }\end{array}$ & $\begin{array}{l}12 \text { RCTs } \\
(n=1409) \\
1 \text { OBS } \\
(n=158)\end{array}$ & Low & Inconsistent & Indirect & Precise & Unsuspected & Low \\
\hline $\begin{array}{l}\text { Presence of } \\
\text { pain - full } \\
\text { resolution } 15 \\
\text { min }\end{array}$ & $\begin{array}{l}\text { Inconclusive. } \\
\text { ED: } 1 \text { RCT } \\
\text { AR } 16.7 \% \text { vs. } 50 \% \\
\text { RD }-33 \%(-53 \text { to }-9) \\
\text { Single study with other domain } \\
\text { limitations. }\end{array}$ & $\begin{array}{l}\text { 1 RCT } \\
(n=60)\end{array}$ & Low & Unknown & Indirect & Precise & Unsuspected & Insufficient \\
\hline $\begin{array}{l}\text { Presence of } \\
\text { pain - full } \\
\text { resolution } 30 \\
\text { min }\end{array}$ & $\begin{array}{l}\text { Inconclusive. } \\
\text { ED: Meta-analysis of } 3 \text { RCTs } \\
\text { found } \\
\text { AR } 26.7 \% \text { vs. } 27.9 \% \\
\text { RD }-1 \% \text { (-39 to } 38) \\
\text { Cl includes appreciable harms } \\
\text { and benefit beyond CID in either } \\
\text { direction. }\end{array}$ & $\begin{array}{l}\text { 3 RCT } \\
(n=172)\end{array}$ & Low & Consistent & Indirect & $\begin{array}{l}\text { Very } \\
\text { imprecise }\end{array}$ & Unsuspected & Insufficient \\
\hline
\end{tabular}




\begin{tabular}{|c|c|c|c|c|c|c|c|c|}
\hline Outcome & $\begin{array}{l}\text { Conclusions statement, } \\
\text { rationale }^{\mathrm{a}}\end{array}$ & $\begin{array}{l}\text { Study } \\
\text { Design } \\
\text { and } \\
\text { Sample } \\
\text { Size }\end{array}$ & $\begin{array}{l}\text { Study } \\
\text { Limitations }^{b}\end{array}$ & Consistency $^{c}$ & Directness $^{d}$ & Precision $^{\mathrm{e}}$ & $\begin{array}{l}\text { Publication } \\
\text { Bias }^{f}\end{array}$ & $\begin{array}{l}\text { Strength of } \\
\text { Evidence }\end{array}$ \\
\hline $\begin{array}{l}\text { Presence of } \\
\text { pain - full } \\
\text { resolution } 60 \\
\text { min }\end{array}$ & $\begin{array}{l}\text { Inconclusive. } \\
\text { ED: Meta-analysis of } 2 \text { RCTs } \\
\text { found } \\
\text { AR } 23.3 \% \text { vs. } 21.9 \% \\
\text { RD } 1 \%(-13 \text { to } 14) \\
\text { Cl includes appreciable harms } \\
\text { and benefit beyond CID in either } \\
\text { direction. }\end{array}$ & $\begin{array}{l}2 \mathrm{RCT} \\
(\mathrm{n}=146)\end{array}$ & Low & Consistent & Indirect & $\begin{array}{l}\text { Very } \\
\text { imprecise }\end{array}$ & Unsuspected & Insufficient \\
\hline $\begin{array}{l}\text { Presence of } \\
\text { pain - partial } \\
\text { resolution } 15 \\
\text { min }\end{array}$ & $\begin{array}{l}\text { Inconclusive. } \\
\text { ED: Meta-analysis of } 5 \text { RCTs } \\
\text { found } \\
\text { AR } 76.1 \% \text { vs. } 77.3 \% \\
\text { RD } 2 \%(-25 \text { to } 28) \\
\mathrm{Cl} \text { includes appreciable harms } \\
\text { and benefit beyond CID in either } \\
\text { direction. }\end{array}$ & $\begin{array}{l}5 \mathrm{RCT} \\
(\mathrm{n}=369)\end{array}$ & Low & Inconsistent & Indirect & $\begin{array}{l}\text { Very } \\
\text { imprecise }\end{array}$ & Unsuspected & Insufficient \\
\hline $\begin{array}{l}\text { Presence of } \\
\text { pain - partial } \\
\text { resolution } 30 \\
\text { min }\end{array}$ & $\begin{array}{l}\text { Inconclusive. } \\
\text { ED: Meta-analysis of } 4 \text { RCTs } \\
\text { found } \\
\text { AR } 74.5 \% \text { vs. } 75.7 \% \\
\text { RD }-1 \% \text { (-6 to } 4) \\
\text { CI includes appreciable harms } \\
\text { and benefit beyond CID in either } \\
\text { direction. }\end{array}$ & $\begin{array}{l}4 \mathrm{RCT} \\
(\mathrm{n}=301)\end{array}$ & Low & Consistent & Indirect & Imprecise & Unsuspected & Insufficient \\
\hline
\end{tabular}




\begin{tabular}{|c|c|c|c|c|c|c|c|c|}
\hline Outcome & $\begin{array}{l}\text { Conclusions statement, } \\
\text { rationale }^{\mathrm{a}}\end{array}$ & $\begin{array}{l}\text { Study } \\
\text { Design } \\
\text { and } \\
\text { Sample } \\
\text { Size }\end{array}$ & $\begin{array}{l}\text { Study } \\
\text { Limitations }^{b}\end{array}$ & Consistency $^{c}$ & Directness $^{d}$ & Precision $^{\mathrm{e}}$ & $\begin{array}{l}\text { Publication } \\
\text { Bias }^{f}\end{array}$ & $\begin{array}{l}\text { Strength of } \\
\text { Evidence }\end{array}$ \\
\hline $\begin{array}{l}\text { Presence of } \\
\text { pain - partial } \\
\text { resolution } 60 \\
\text { min }\end{array}$ & $\begin{array}{l}\text { Inconclusive. } \\
\text { EMS: } 1 \text { OBS study found more } \\
\text { patients to have at least } 50 \% \\
\text { improvement in pain scores with } \\
\text { ketamine over the prehospital } \\
\text { period. } \\
\text { ED: Meta-analysis of } 3 \text { RCTs } \\
\text { found } \\
\text { AR } 76.9 \% \text { vs. } 74.0 \% \\
\text { RD } 1 \%(-38 \text { to } 39) \\
\text { Cl includes appreciable harms } \\
\text { and benefit beyond CID in either } \\
\text { direction. }\end{array}$ & $\begin{array}{l}3 \text { RCT } \\
(n=208) \\
1 \text { OBS } \\
(n=158)\end{array}$ & Low & Inconsistent & Indirect & $\begin{array}{l}\text { Very } \\
\text { imprecise }\end{array}$ & Unsuspected & Insufficient \\
\hline $\begin{array}{l}\text { Time to } \\
\text { analgesic effect } \\
\text { - onset }\end{array}$ & $\begin{array}{l}\text { Inconclusive. } \\
\text { ED: } 1 \text { RCT found time to onset } \\
\text { (min) } \\
\text { IN ketamine } 14.3(9.8-18.8) \\
\text { IV morphine } 8.9(6.6-11.2) \\
\text { IM morphine } 26.0(20.3-31.7) \\
\text { IN ketamine } v \text { IV morphine } p=0.3 \\
\text { IN ketamine } v \text { IM morphine } \\
p=0.003 \\
\text { Single trial with high risk of bias } \\
\text { and other domains with } \\
\text { limitation. }\end{array}$ & $\begin{array}{l}\text { 1 RCT } \\
(n=48)\end{array}$ & High & Inconsistent & Indirect & Imprecise & Unsuspected & Insufficient \\
\hline
\end{tabular}




\begin{tabular}{|c|c|c|c|c|c|c|c|c|}
\hline Outcome & $\begin{array}{l}\text { Conclusions statement, } \\
\text { rationale }^{\mathrm{a}}\end{array}$ & $\begin{array}{l}\text { Study } \\
\text { Design } \\
\text { and } \\
\text { Sample } \\
\text { Size }\end{array}$ & $\begin{array}{l}\text { Study } \\
\text { Limitations }^{b}\end{array}$ & Consistency $^{c}$ & Directness $^{d}$ & Precision $^{\mathrm{e}}$ & $\begin{array}{l}\text { Publication } \\
\text { Bias }^{f}\end{array}$ & $\begin{array}{l}\text { Strength of } \\
\text { Evidence }\end{array}$ \\
\hline $\begin{array}{l}\text { Time to } \\
\text { analgesic effect } \\
\text { - max effect }\end{array}$ & $\begin{array}{l}\text { Inconclusive. } \\
\text { ED: } 1 \text { RCT found time to max } \\
\text { effect (min) } \\
\text { IN ketamine } 40.4(33.9-46.9) \\
\text { IV morphine } 33.4(26.2-40.6) \\
\text { IM morphine } 46.7(41.1-52.3) \\
\text { IN ketamine } v \text { IV morphine } \\
p=0.386 \\
\text { IN ketamine } v \text { IM morphine } \\
p=0.441 \\
\text { Single trial with high risk of bias } \\
\text { and other domains with limitation }\end{array}$ & $\begin{array}{l}1 \mathrm{RCT} \\
(\mathrm{n}=48)\end{array}$ & High & Inconsistent & Indirect & Imprecise & Unsuspected & Insufficient \\
\hline $\begin{array}{l}\text { Any adverse } \\
\text { event }\end{array}$ & $\begin{array}{l}\text { Opioids may cause fewer total } \\
\text { adverse events than ketamine. } \\
\text { EMS: No data } \\
\text { ED: Meta-analysis of } 6 \text { RCTs } \\
\text { over the study period } \\
\text { AR } 50.0 \% \text { vs. } 82.4 \% \\
\text { RD }-30 \%(-56 \text { to }-4) \\
\text { Two RCTs reported AEs at } 15 \\
\text { min (pooled: RD -39\% (-53 to - } \\
24) \text { and at } 30 \text { min (pooled: RD - } \\
19 \% \text { (-53 to } 15) \text { are generally in } \\
\text { support of the conclusion. }\end{array}$ & $\begin{array}{l}8 \text { RCTs } \\
(n=398)\end{array}$ & Low & Inconsistent & Indirect & Imprecise & Unsuspected & Low \\
\hline
\end{tabular}




\begin{tabular}{|c|c|c|c|c|c|c|c|c|}
\hline Outcome & $\begin{array}{l}\text { Conclusions statement, } \\
\text { rationale }^{\mathrm{a}}\end{array}$ & $\begin{array}{l}\text { Study } \\
\text { Design } \\
\text { and } \\
\text { Sample } \\
\text { Size }\end{array}$ & $\begin{array}{l}\text { Study } \\
\text { Limitations }^{\mathrm{b}}\end{array}$ & Consistencyc $^{c}$ & Directness $^{d}$ & Precision $^{\mathbf{e}}$ & $\begin{array}{l}\text { Publication } \\
\text { Bias }^{f}\end{array}$ & $\begin{array}{l}\text { Strength of } \\
\text { Evidence }\end{array}$ \\
\hline Hypotension & $\begin{array}{l}\text { Inconclusive. } \\
\text { EMS: No data } \\
\text { ED: Meta-analysis of } 4 \text { RCTs } \\
\text { over the study period } \\
\text { AR } 3.6 \% \text { vs. } 0 \% \\
\text { RD } 8 \% \text { (-20 to } 37) \\
\text { CI includes appreciable harms } \\
\text { and benefit beyond CID in either } \\
\text { direction. }\end{array}$ & $\begin{array}{l}4 \text { RCTs } \\
(n=508)\end{array}$ & Low & Inconsistent & Indirect & $\begin{array}{l}\text { Very } \\
\text { imprecise }\end{array}$ & Unsuspected & Insufficient \\
\hline $\begin{array}{l}\text { Mental status } \\
\text { Changes- } \\
\text { dizziness }\end{array}$ & $\begin{array}{l}\text { Opioids cause less dizziness } \\
\text { than ketamine. } \\
\text { EMS: No data } \\
\text { ED: Meta-analysis of } 7 \text { RCTs } \\
\text { over the study period } \\
\text { AR } 25.4 \% \text { vs. } 43.5 \% \\
\text { RD }-29 \% \text { (-52 to }-6 \text { ) } \\
\text { Two RCTs reported dizziness at } \\
15 \text { min (pooled: RD }-25 \% \text { ( }-40 \text { to } \\
-10 \text { ) and at } 30 \text { min (pooled: RD - } \\
20 \% \text { (-63 to } 23 \text { ) are generally in } \\
\text { support of the conclusion. } 1 \mathrm{RCT} \\
\text { also reported dizziness at } 60 \text { min } \\
\text { (RD - } 13 \% \text { (-34 to } 9 \text { ). }\end{array}$ & $\begin{array}{l}9 \text { RCTs } \\
(n=723)\end{array}$ & Low & Inconsistent & Indirect & Precise & Unsuspected & Low \\
\hline
\end{tabular}




\begin{tabular}{|c|c|c|c|c|c|c|c|c|}
\hline Outcome & $\begin{array}{l}\text { Conclusions statement, } \\
\text { rationale }^{a}\end{array}$ & $\begin{array}{l}\text { Study } \\
\text { Design } \\
\text { and } \\
\text { Sample } \\
\text { Size }\end{array}$ & $\begin{array}{l}\text { Study } \\
\text { Limitations }^{b}\end{array}$ & Consistencyc $^{c}$ & Directness $^{d}$ & Precision $^{\mathrm{e}}$ & $\begin{array}{l}\text { Publication } \\
\text { Bias }^{f}\end{array}$ & $\begin{array}{l}\text { Strength of } \\
\text { Evidence }\end{array}$ \\
\hline $\begin{array}{l}\text { Mental status } \\
\text { changes- } \\
\text { drowsiness }\end{array}$ & $\begin{array}{l}\text { Inconclusive. } \\
\text { EMS: No data } \\
\text { ED: Meta-analysis of } 4 \text { RCTs of } \\
\text { the study period } \\
\text { AR } 8.5 \% \text { vs. } 11.2 \% \\
\text { RD }-2 \%(-19 \text { to } 15) \\
\mathrm{Cl} \text { includes appreciable harms } \\
\text { and benefit beyond CID in either } \\
\text { direction. }\end{array}$ & $\begin{array}{l}4 \text { RCTs } \\
(n=356)\end{array}$ & Low & Consistent & Indirect & $\begin{array}{l}\text { Very } \\
\text { imprecise }\end{array}$ & Unsuspected & Insufficient \\
\hline $\begin{array}{l}\text { Mental status } \\
\text { change - GCS }\end{array}$ & $\begin{array}{l}\text { Inconclusive. } \\
\text { EMS: } 1 \text { OBS study found small } \\
\text { decrease in GCS score in both } \\
\text { groups and no difference in the } \\
\text { change from baseline between } \\
\text { arms [mean (SD) }-0.1(0.8) \text { vs. } \\
0.03(0.4), p=0.16] \\
\text { Single study with unknown } \\
\text { consistency and other domain } \\
\text { limitations. }\end{array}$ & $\begin{array}{l}1 \text { OBS } \\
(n=158)\end{array}$ & Low & Unknown & Direct & Imprecise & Unsuspected & Insufficient \\
\hline $\begin{array}{l}\text { Mental status } \\
\text { changes- } \\
\text { sedation }\end{array}$ & $\begin{array}{l}\text { Inconclusive. } \\
\text { EMS: No data } \\
\text { ED: } 1 \text { RCT found sedation over } \\
\text { the study period in } 18.2 \% \text { vs. } \\
63.6 \% \text { of patients, RD }-45 \%(-70 \\
\text { to }-5) \text {. A second trial found } \\
\text { sedation scores to be similar } \\
\text { between groups. }\end{array}$ & $\begin{array}{l}2 \mathrm{RCT} \\
(\mathrm{n}=95)\end{array}$ & Low & Inconsistent & Indirect & Imprecise & Unsuspected & Insufficient \\
\hline
\end{tabular}




\begin{tabular}{|c|c|c|c|c|c|c|c|c|}
\hline Outcome & $\begin{array}{l}\text { Conclusions statement, } \\
\text { rationale }^{\mathrm{a}}\end{array}$ & $\begin{array}{l}\text { Study } \\
\text { Design } \\
\text { and } \\
\text { Sample } \\
\text { Size }\end{array}$ & $\begin{array}{l}\text { Study } \\
\text { Limitations }^{\mathrm{b}}\end{array}$ & Consistencyc $^{c}$ & Directness $^{d}$ & Precision $^{\mathbf{e}}$ & $\begin{array}{l}\text { Publication } \\
\text { Bias }^{f}\end{array}$ & $\begin{array}{l}\text { Strength of } \\
\text { Evidence }\end{array}$ \\
\hline $\begin{array}{l}\text { Mental status } \\
\text { changes- } \\
\text { confusion }\end{array}$ & $\begin{array}{l}\text { Inconclusive. } \\
\text { EMS: No data } \\
\text { ED: } 1 \text { RCT with } 3 \text { arms ( } 2 \text { opioid, } \\
1 \text { ketamine) found confusion } \\
\text { over the study period in } 33.3 \% \\
\text { vs. } 50 \% \text { of patients. } \\
\text { RD }-38 \%(-58 \text { to }-11) \\
\text { RD }-31 \% \text { ( }-53 \text { to }-5) \\
\text { Single study with high risk of } \\
\text { bias, unknown consistency and } \\
\text { other domain limitations. }\end{array}$ & $\begin{array}{l}1 \mathrm{RCT} \\
(\mathrm{n}=75)\end{array}$ & High & Unknown & Indirect & Precise & Unsuspected & Insufficient \\
\hline $\begin{array}{l}\text { Mental status } \\
\text { changes- } \\
\text { difficulty } \\
\text { concentrating }\end{array}$ & $\begin{array}{l}\text { Inconclusive. } \\
\text { EMS: No data } \\
\text { ED: } 1 \text { RCT with } 3 \text { arms ( } 2 \text { opioid, } \\
1 \text { ketamine) found difficulty } \\
\text { concentrating over the study } \\
\text { period in } 21.6 \% \text { vs. } 58.3 \% \text { of } \\
\text { patients. } \\
\text { RD }-38 \% \text { (-58 to }-10) \\
\text { RD }-36 \%(-57 \text { to }-9) \\
\text { Single study with high risk of } \\
\text { bias, unknown consistency and } \\
\text { other domain limitations. }\end{array}$ & $\begin{array}{l}1 \text { RCT } \\
(n=75)\end{array}$ & High & Unknown & Indirect & Precise & Unsuspected & Insufficient \\
\hline
\end{tabular}




\begin{tabular}{|c|c|c|c|c|c|c|c|c|}
\hline Outcome & $\begin{array}{l}\text { Conclusions statement, } \\
\text { rationale }^{\mathrm{a}}\end{array}$ & $\begin{array}{l}\text { Study } \\
\text { Design } \\
\text { and } \\
\text { Sample } \\
\text { Size }\end{array}$ & $\begin{array}{l}\text { Study } \\
\text { Limitations }^{\mathrm{b}}\end{array}$ & Consistencyc $^{c}$ & Directness $^{d}$ & Precision $^{\mathrm{e}}$ & $\begin{array}{l}\text { Publication } \\
\text { Bias }^{f}\end{array}$ & $\begin{array}{l}\text { Strength of } \\
\text { Evidence }\end{array}$ \\
\hline $\begin{array}{l}\text { Mental status } \\
\text { changes- } \\
\text { sleepiness/tired }\end{array}$ & $\begin{array}{l}\text { Inconclusive. } \\
\text { EMS: No data } \\
\text { ED: } 1 \text { RCT found } \\
\text { sleepiness/tired to occur in } \\
36.6 \% \text { vs. } 46.3 \%, \mathrm{RD}-2 \%(-22 \text { to } \\
18) \\
\mathrm{Cl} \text { includes appreciable harms } \\
\text { and benefit beyond CID in either } \\
\text { direction. }\end{array}$ & $\begin{array}{l}1 \mathrm{RCT} \\
(\mathrm{n}=82)\end{array}$ & Low & Unknown & Indirect & $\begin{array}{l}\text { Very } \\
\text { Imprecise }\end{array}$ & Unsuspected & Insufficient \\
\hline $\begin{array}{l}\text { Mental status } \\
\text { changes - } \\
\text { RAAS }\end{array}$ & $\begin{array}{l}\text { Inconclusive. } \\
\text { EMS: No data } \\
\text { ED: } 1 \text { RCT evaluated RAAS } \\
\text { scores at various times } \\
\text { throughout the trial and found no } \\
\text { significant differences between } \\
\text { groups. Median scores were } 0 \text { in } \\
\text { both arms at all evaluated times. } \\
\text { Single study with unknown } \\
\text { consistency and other domain } \\
\text { limitations. }\end{array}$ & $\begin{array}{l}1 \mathrm{RCT} \\
(\mathrm{n}=36)\end{array}$ & Low & Unknown & Indirect & Imprecise & Unsuspected & Insufficient \\
\hline
\end{tabular}




\begin{tabular}{|c|c|c|c|c|c|c|c|c|}
\hline Outcome & $\begin{array}{l}\text { Conclusions statement, } \\
\text { rationale }^{\mathrm{a}}\end{array}$ & $\begin{array}{l}\text { Study } \\
\text { Design } \\
\text { and } \\
\text { Sample } \\
\text { Size }\end{array}$ & $\begin{array}{l}\text { Study } \\
\text { Limitations }^{b}\end{array}$ & Consistency $^{c}$ & Directness $^{d}$ & Precision $^{\mathrm{e}}$ & $\begin{array}{l}\text { Publication } \\
\text { Bias }^{f}\end{array}$ & $\begin{array}{l}\text { Strength of } \\
\text { Evidence }\end{array}$ \\
\hline $\begin{array}{l}\text { Respiratory } \\
\text { depression }\end{array}$ & $\begin{array}{l}\text { Opioids may cause more } \\
\text { respiratory depression than } \\
\text { ketamine. } \\
\text { EMS: } 1 \text { observational study } \\
\text { ( } n=158 \text { ) found } 2 \text { vs. } 0 \text { cases of } \\
\text { respiratory compromise that } \\
\text { needed oxygen supplementation } \\
\text { - insufficient data, conclusion } \\
\text { based on ED data } \\
\text { ED: Meta-analysis of } 4 \text { RCTs } \\
\text { over the study period } \\
\text { AR } 11.5 \% \text { vs } 2.4 \% \\
\text { RD } 4 \%(-2 \text { to } 11)\end{array}$ & $\begin{array}{l}\begin{array}{l}4 \text { RCTs } \\
(n=491)\end{array} \\
1 \text { OBS } \\
(n=158)\end{array}$ & Low & Inconsistent & Indirect & Imprecise & Unsuspected & Low \\
\hline
\end{tabular}

Abbreviations: $\mathrm{AR}=$ absolute risk; $\mathrm{CID}=$ clinically important difference; $\mathrm{ED}=$ emergency department; $\mathrm{EMS}=$ emergency medical services; $\mathrm{NA}=$ not applicable; $\mathrm{OBS}=\mathrm{observational}$; $\mathrm{RCT}=$ randomized controlled trial; $\mathrm{RD}=$ risk difference

a: Rationale is provided for inconclusive statements (with insufficient strength of evidence).

b: Study limitations were downgraded when the majority of the evidence base came from medium or high risk of bias studies.

c: Consistency was judged using the I2 statistic when meta-analysis was conducted, with values over $50 \%$ considered to be inconsistent. When data were not pooled, we inspected study level results for overall agreement in the direction and magnitude of effects. When evidence was available from trials and observational studies, we considered agreement of direction and magnitude of effect from these sources.

$\mathrm{d}$ : Directness was downgraded when the majority of evidence for the given comparison/outcome came from emergency department studies rather than prehospital studies.

e: Precision was judged using the effect estimate and clinically important difference set for the outcome. Estimates were considered imprecise if the confidence interval crossed the clinically important difference. Estimates were considered very imprecise when the confidence interval spanned the clinically important difference in both directions, thus uninformative.

f: Publication bias was judged using p-value $<0.05$ (when data was meta-analyzed), suggesting presence of publication bias. 
Table E-2. Strength of evidence ratings for the comparison of additional opioid vs. switching to ketamine, Key Questions 3 and 4

\begin{tabular}{|c|c|c|c|c|c|c|c|c|}
\hline Outcome & $\begin{array}{l}\text { Conclusions statement, } \\
\text { rationale }\end{array}$ & $\begin{array}{l}\text { Study } \\
\text { Design and } \\
\text { Sample } \\
\text { Size }\end{array}$ & $\begin{array}{l}\text { Study } \\
\text { Limitations }^{a}\end{array}$ & Consistencyb $^{b}$ & Directness $^{c}$ & Precision $^{d}$ & $\begin{array}{l}\text { Publication } \\
\text { Bias }^{\text {e }}\end{array}$ & $\begin{array}{l}\text { Strength of } \\
\text { Evidence }\end{array}$ \\
\hline Pain severity & $\begin{array}{l}\text { Adding ketamine may reduce } \\
\text { pain more than giving } \\
\text { additional opioids. } \\
\text { EMS: Meta-analysis of } 2 \text { RCTs } \\
\text { found MD } 1.99 \text { ( } 0.95 \text { to } 3.03) \text { over } \\
\text { the prehospital period. }\end{array}$ & $\begin{array}{l}2 \mathrm{RCT} \\
(\mathrm{n}=162)\end{array}$ & Medium & Consistent & Direct & Imprecise & Unsuspected & Low \\
\hline $\begin{array}{l}\text { Presence of } \\
\text { pain }\end{array}$ & $\begin{array}{l}\text { Inconclusive. } \\
\text { No data }\end{array}$ & None & NA & NA & NA & NA & NA & Insufficient \\
\hline $\begin{array}{l}\text { Time to } \\
\text { analgesic } \\
\text { effect }\end{array}$ & $\begin{array}{l}\text { Adding ketamine may be } \\
\text { quicker to reduce pain to a } \\
\text { clinically important difference } \\
\text { compared to giving additional } \\
\text { opioids. } \\
\text { EMS: } 1 \text { RCT found the median } \\
\text { difference in the change of pain } \\
\text { score per minute to be }-2.5 \text { points } \\
\text { per minute }(-3.9 \text { to }-1.1) \text { in favor of } \\
\text { ketamine compared to opioids. }\end{array}$ & $\begin{array}{l}1 \mathrm{RCT} \\
(\mathrm{n}=135)\end{array}$ & Medium & Unknown & Direct & Precise & Unsuspected & Low \\
\hline $\begin{array}{l}\text { Any adverse } \\
\text { event }\end{array}$ & $\begin{array}{l}\text { Inconclusive. } \\
\text { EMS: } 1 \text { RCT found total AEs in } \\
13.8 \% \text { vs. } 38.6 \% \text { of patients. } \\
\text { RD }-25 \%(-38 \text { to }-1) \\
\text { Single study with unknown } \\
\text { consistency and additional domain } \\
\text { limitations. }\end{array}$ & $\begin{array}{l}\text { RCT } \\
(n=135)\end{array}$ & Medium & Unknown & Direct & Imprecise & Unsuspected & Insufficient \\
\hline
\end{tabular}




\begin{tabular}{|c|c|c|c|c|c|c|c|c|}
\hline Outcome & $\begin{array}{l}\text { Conclusions statement, } \\
\text { rationale }\end{array}$ & $\begin{array}{l}\text { Study } \\
\text { Design and } \\
\text { Sample } \\
\text { Size }\end{array}$ & $\begin{array}{l}\text { Study } \\
\text { Limitations }^{a}\end{array}$ & Consistencyb $^{b}$ & Directness $^{\mathrm{c}}$ & Precision $^{d}$ & $\begin{array}{l}\text { Publication } \\
\text { Bias }^{\text {e }}\end{array}$ & $\begin{array}{l}\text { Strength of } \\
\text { Evidence }\end{array}$ \\
\hline Hypotension & $\begin{array}{l}\text { Inconclusive. } \\
\text { EMS: } 1 \text { RCT found hypotension in } \\
1.5 \% \text { vs. } 0 \% \text { of patients. RD } 2 \% \text { (- } \\
40 \text { to } 9) \\
\text { Single study with unknown } \\
\text { consistency and additional domain } \\
\text { limitations. Cl crosses appreciable } \\
\text { differences in either direction. }\end{array}$ & $\begin{array}{l}1 \mathrm{RCT} \\
(n=135)\end{array}$ & Low & Unknown & Direct & $\begin{array}{l}\text { Very } \\
\text { Imprecise }\end{array}$ & Unsuspected & Insufficient \\
\hline $\begin{array}{l}\text { Mental status } \\
\text { Changes - } \\
\text { sedation }\end{array}$ & $\begin{array}{l}\text { Inconclusive. } \\
\text { EMS: } 1 \mathrm{RCT} \text { found no events in } \\
\text { either arm. } \\
\text { Single study with unknown } \\
\text { consistency and additional domain } \\
\text { limitations. }\end{array}$ & $\begin{array}{l}1 \mathrm{RCT} \\
(\mathrm{n}=27)\end{array}$ & Medium & Unknown & Direct & Precise & Unsuspected & Insufficient \\
\hline $\begin{array}{l}\text { Mental status } \\
\text { changes - } \\
\text { GCS score } \\
\leq 13\end{array}$ & $\begin{array}{l}\text { Inconclusive. } \\
\text { EMS: } 1 \text { RCT found reduced GCS } \\
\text { score in } 1.5 \% \text { vs. } 4.3 \% \text { of patients. } \\
\text { RD }-3 \%(-10 \text { to } 5) \\
\text { Single study with unknown } \\
\text { consistency and additional domain } \\
\text { limitations. Cl crosses appreciable } \\
\text { differences in either direction. }\end{array}$ & $\begin{array}{l}\text { 1 RCT } \\
(n=135)\end{array}$ & Medium & Unknown & Direct & $\begin{array}{l}\text { Very } \\
\text { imprecise }\end{array}$ & Unsuspected & Insufficient \\
\hline $\begin{array}{l}\text { Respiratory } \\
\text { depression }\end{array}$ & $\begin{array}{l}\text { Inconclusive. } \\
\text { No data. }\end{array}$ & None & $\mathrm{NA}$ & NA & NA & NA & $\mathrm{NA}$ & Insufficient \\
\hline
\end{tabular}

Abbreviations: $\mathrm{NA}=$ not applicable; $\mathrm{OBS}=$ observational; $\mathrm{RCT}=$ randomized controlled trial

a: Rationale is provided for inconclusive statements (with insufficient strength of evidence).

b: Study limitations were downgraded when the majority of the evidence base came from medium or high risk of bias studies.

c: Consistency was judged using the I2 statistic when meta-analysis was conducted, with values over $50 \%$ considered to be inconsistent. When data were not pooled, we inspected study level results for overall agreement in the direction and magnitude of effects. When evidence was available from trials and observational studies, we considered agreement of direction and magnitude of effect from these sources.

d: Directness was downgraded when the majority of evidence for the given comparison/outcome came from emergency department studies rather than prehospital studies. 
e. Precision was judged using the effect estimate and clinically important difference set for the outcome. Estimates were considered imprecise if the confidence interval crossed the clinically important difference. Estimates were considered very imprecise when the confidence interval spanned the clinically important difference in both directions, thus uninformative.

f: Publication bias was judged using p-value $<0.05$ (when data was meta-analyzed), suggesting presence of publication bias. 
Table E-3. Strength of evidence ratings for the comparison of opioids plus ketamine vs. opioids

\begin{tabular}{|c|c|c|c|c|c|c|c|c|}
\hline Outcome & $\begin{array}{l}\text { Conclusions statement, } \\
\text { rationale }\end{array}$ & $\begin{array}{l}\text { Study } \\
\text { Design and } \\
\text { Sample } \\
\text { Size }\end{array}$ & $\begin{array}{l}\text { Study } \\
\text { Limitations }^{a}\end{array}$ & Consistency $^{\mathbf{b}}$ & Directness $^{c}$ & Precision $^{d}$ & $\begin{array}{l}\text { Publication } \\
\text { Bias }^{\text {e }}\end{array}$ & $\begin{array}{l}\text { Strength of } \\
\text { Evidence }\end{array}$ \\
\hline $\begin{array}{l}\text { Pain severity } \\
-15 \text { min }\end{array}$ & $\begin{array}{l}\text { Combining an opioid and } \\
\text { ketamine may reduce pain more } \\
\text { than an opioid alone at } 15 \text { min. } \\
\text { EMS: } 1 \text { RCT found mean } \\
\text { difference in the change of pain } \\
\text { scores to be MD }-1.3 \text { (-2.6 to } 0.02) \\
\text { at } 15 \text { min. } \\
\text { ED: Meta-analysis of } 3 \text { RCT found } \\
\text { MD }-1.04(-2.55 \text { to } 0.47) \text {. }\end{array}$ & $\begin{array}{c}4 \text { RCT } \\
(n=336)\end{array}$ & Low & Inconsistent & Indirect & Imprecise & Unsuspected & Low \\
\hline $\begin{array}{l}\text { Pain severity } \\
-30 \text { min }\end{array}$ & $\begin{array}{l}\text { Combining an opioid and } \\
\text { ketamine may reduce pain more } \\
\text { than an opioid alone at } 30 \text { min. } \\
\text { EMS: } 1 \text { RCT found mean } \\
\text { difference in the change of pain } \\
\text { scores to be MD }-1(-2.2 \text { to } 0.2) \text { at } \\
30 \text { min. } \\
\text { ED: Meta-analysis of } 4 \text { RCT found } \\
\text { MD }-0.59(-2.24 \text { to } 1.06) \text {. }\end{array}$ & $\begin{array}{l}5 \mathrm{RCT} \\
(\mathrm{n}=545)\end{array}$ & Low & Inconsistent & Indirect & Imprecise & Unsuspected & Low \\
\hline $\begin{array}{l}\text { Pain severity } \\
-60 \text { min }\end{array}$ & $\begin{array}{l}\text { There is no evidence of a } \\
\text { clinically important difference } \\
\text { between combining opioid and } \\
\text { ketamine and opioid alone in } \\
\text { the change of pain scores in } 60 \\
\text { min. } \\
\text { ED: Meta-analysis of } 3 \text { RCT found } \\
\text { MD }-0.07(-1.14 \text { to } 1.00) \text {. }\end{array}$ & $\begin{array}{l}3 \mathrm{RCT} \\
(\mathrm{n}=241)\end{array}$ & Low & Inconsistent & Indirect & Precise & Unsuspected & Low \\
\hline
\end{tabular}




\begin{tabular}{|c|c|c|c|c|c|c|c|c|}
\hline Outcome & $\begin{array}{l}\text { Conclusions statement, } \\
\text { rationale }\end{array}$ & $\begin{array}{l}\text { Study } \\
\text { Design and } \\
\text { Sample } \\
\text { Size }\end{array}$ & $\begin{array}{l}\text { Study } \\
\text { Limitations }^{a}\end{array}$ & Consistencyb $^{b}$ & Directness $^{c}$ & Precision $^{d}$ & $\begin{array}{l}\text { Publication } \\
\text { Bias }^{\text {e }}\end{array}$ & $\begin{array}{l}\text { Strength of } \\
\text { Evidence }\end{array}$ \\
\hline $\begin{array}{l}\text { Presence of } \\
\text { pain - partial } \\
\text { resolution }\end{array}$ & $\begin{array}{l}\text { Inconclusive. } \\
\text { EMS: } 1 \text { RCT found partial } \\
\text { response in } 60.6 \% \text { vs. } 40.6 \% \text { of } \\
\text { patients, RD } 20 \% \text { (-4 to } 41 \text { ). } \\
1 \text { OBS study found the proportion } \\
\text { of sufficient response was } 69 \% \text { vs. } \\
70.9 \% \text {. } \\
\text { Trial alone was insufficient to } \\
\text { conclude, disagreement between } \\
\text { sources of evidence. }\end{array}$ & $\begin{array}{l}1 \text { RCT } \\
(n=65) \\
1 \text { OBS } \\
(n=606)\end{array}$ & Low & Inconsistent & Direct & Imprecise & Unsuspected & Insufficient \\
\hline $\begin{array}{l}\text { Time to } \\
\text { analgesic } \\
\text { effect }\end{array}$ & $\begin{array}{l}\text { Inconclusive. } \\
\text { No data }\end{array}$ & None & $\mathrm{NA}$ & $\mathrm{NA}$ & $\mathrm{NA}$ & $\mathrm{NA}$ & $\mathrm{NA}$ & Insufficient \\
\hline $\begin{array}{l}\text { Any adverse } \\
\text { event }\end{array}$ & $\begin{array}{l}\text { Inconclusive. } \\
\text { ED: } 1 \text { RCT found total AEs to } \\
\text { occur in } 22.5 \% \text { vs. } 17.5 \% \text { of } \\
\text { patients. RD } 5 \% \text { (-13 to } 22) \\
\text { Single study with additional } \\
\text { domain limitations, Cl crosses } \\
\text { appreciable differences in either } \\
\text { direction. }\end{array}$ & $\begin{array}{l}1 \text { RCT } \\
(n=80)\end{array}$ & Low & Unknown & Indirect & $\begin{array}{l}\text { Very } \\
\text { imprecise }\end{array}$ & Unsuspected & Insufficient \\
\hline Hypotension & $\begin{array}{l}\text { Inconclusive. } \\
\text { EMS: No data } \\
\text { ED: } 1 \text { RCT found hypotension to } \\
\text { occur in } 0 \% \text { vs. } 3 \% \text { of patients. } \\
\text { RD }-6 \%(-16 \text { to } 3) \\
\text { Single study with additional } \\
\text { domain limitations. }\end{array}$ & $\begin{array}{l}\text { 1 RCT } \\
(n=106)\end{array}$ & Low & Unknown & Indirect & Imprecise & Unsuspected & Insufficient \\
\hline
\end{tabular}




\begin{tabular}{|c|c|c|c|c|c|c|c|c|}
\hline Outcome & $\begin{array}{l}\text { Conclusions statement, } \\
\text { rationale }\end{array}$ & $\begin{array}{l}\text { Study } \\
\text { Design and } \\
\text { Sample } \\
\text { Size }\end{array}$ & $\begin{array}{l}\text { Study } \\
\text { Limitations }^{a}\end{array}$ & Consistency $^{\mathbf{b}}$ & Directness $^{c}$ & Precision $^{d}$ & $\begin{array}{l}\text { Publication } \\
\text { Bias }^{\mathrm{e}}\end{array}$ & $\begin{array}{l}\text { Strength of } \\
\text { Evidence }\end{array}$ \\
\hline $\begin{array}{l}\text { Mental status } \\
\text { Changes- } \\
\text { dizziness }\end{array}$ & $\begin{array}{l}\text { Inconclusive. } \\
\text { EMS: } 1 \text { RCT found dizziness in } \\
18.2 \% \text { vs. } 0 \% \text { of patients } 30 \text { min } \\
\text { after the dose. RD } 18 \% \text { ( } 3 \text { to } 34 \text { ). } \\
\text { ED: } 1 \text { RCT found dizziness in } 22 \% \\
\text { vs. } 11 \% \text { at } 20 \text { mins [RD } 11 \%(1 \text { to } \\
21)] \text { and } 42 \% \text { vs. } 45 \% \text { at } 40 \text { min } \\
\text { [RD }-3 \% \text { (- }-16 \text { to } 11) \text {. } \\
\text { Cl crosses appreciable differences } \\
\text { in either direction. }\end{array}$ & $\begin{array}{l}2 \text { RCTs } \\
(n=265)\end{array}$ & Low & Inconsistent & Indirect & $\begin{array}{l}\text { Very } \\
\text { imprecise }\end{array}$ & Unsuspected & Insufficient \\
\hline $\begin{array}{l}\text { Mental status } \\
\text { changes- } \\
\text { sedation }\end{array}$ & $\begin{array}{l}\text { Inconclusive. } \\
\text { EMS: } 1 \mathrm{RCT} \text { found sedation in } \\
21.2 \% \text { vs. } 6.3 \% \text { of patients } 30 \text { min } \\
\text { after the dose. RD } 15 \% \text { (-2 to } 32 \text { ) } \\
\text { Single study with other domain } \\
\text { limitations. }\end{array}$ & $\begin{array}{l}\text { 1 RCT } \\
(\mathrm{n}=65)\end{array}$ & Low & Unknown & Direct & Imprecise & Unsuspected & Insufficient \\
\hline $\begin{array}{l}\text { Respiratory } \\
\text { depression }\end{array}$ & $\begin{array}{l}\text { Inconclusive. } \\
\text { EMS: } 1 \text { RCT found respiratory } \\
\text { depression to occur in } 0 \% \text { vs. } \\
3.1 \% \text { of patients. RD }-3 \% \text { (-16 to } \\
9 \text { ) } \\
\text { ED: Meta-analysis of } 2 \text { RCTs } \\
\text { found } \\
\text { AR } 1.2 \% \text { vs. } 6.0 \% \\
\text { RD }-3 \% \text { (-10 to } 4) \\
\text { Both sources of evidence are } \\
\text { uninformative, Cl crosses } \\
\text { appreciable differences in either } \\
\text { direction, other domain limitations. }\end{array}$ & $\begin{array}{l}3 \text { RCTs } \\
(n=231)\end{array}$ & Low & Consistent & Indirect & $\begin{array}{l}\text { Very } \\
\text { imprecise }\end{array}$ & Unsuspected & Insufficient \\
\hline
\end{tabular}

Abbreviations: $\mathrm{NA}=$ not applicable; $\mathrm{OBS}=$ observational; $\mathrm{RCT}=$ randomized controlled trial

a: Rationale is provided for inconclusive statements (with insufficient strength of evidence).

b: Study limitations were downgraded when the majority of the evidence base came from medium or high risk of bias studies. 
c: Consistency was judged using the I2 statistic when meta-analysis was conducted, with values over $50 \%$ considered to be inconsistent. When data were not pooled, we inspected study level results for overall agreement in the direction and magnitude of effects. When evidence was available from trials and observational studies, we considered agreement of direction and magnitude of effect from these sources.

d: Directness was downgraded when the majority of evidence for the given comparison/outcome came from emergency department studies rather than prehospital studies.

e: Precision was judged using the effect estimate and clinically important difference set for the outcome. Estimates were considered imprecise if the confidence interval crossed the clinically important difference. Estimates were considered very imprecise when the confidence interval spanned the clinically important difference in both directions, thus uninformative.

f: Publication bias was judged using p-value $<0.05$ (when data was meta-analyzed), suggesting presence of publication bias. 
Table E-4. Strength of evidence ratings for the comparison of opioids vs. nitrous oxide

\begin{tabular}{|c|c|c|c|c|c|c|c|c|}
\hline Outcome & $\begin{array}{l}\text { Conclusions statement, } \\
\text { rationale }\end{array}$ & $\begin{array}{l}\text { Study } \\
\text { Design and } \\
\text { Sample Size }\end{array}$ & $\begin{array}{l}\text { Study } \\
\text { Limitations }^{a}\end{array}$ & Consistency $^{b}$ & Directness $^{c}$ & Precision $^{d}$ & $\begin{array}{l}\text { Publication } \\
\text { Bias }^{\text {e }}\end{array}$ & $\begin{array}{l}\text { Strength of } \\
\text { Evidence }\end{array}$ \\
\hline $\begin{array}{l}\text { Pain severity } \\
-15 \text { min }\end{array}$ & $\begin{array}{l}\text { Inconclusive. } \\
\text { EMS: } 1 \text { RCT found MD } 0.8 \text { (0.0 to } \\
\text { 1.6) } \\
\text { Single study with additional } \\
\text { domain limitations. }\end{array}$ & $\begin{array}{l}1 \mathrm{RCT} \\
(n=100)\end{array}$ & Medium & Unknown & Direct & Precise & Unsuspected & Insufficient \\
\hline $\begin{array}{l}\text { Pain severity } \\
-60 \text { min }\end{array}$ & $\begin{array}{l}\text { Inconclusive. } \\
\text { EMS: } 1 \text { RCT found MD } 0.1 \text { (-0.6 to } \\
0.8) \\
\text { Single study with additional } \\
\text { domain limitations. }\end{array}$ & $\begin{array}{l}\text { 1 RCT } \\
(n=100)\end{array}$ & Medium & Unknown & Direct & Precise & Unsuspected & Insufficient \\
\hline $\begin{array}{l}\text { Presence of } \\
\text { pain }\end{array}$ & $\begin{array}{l}\text { Inconclusive. } \\
\text { No data }\end{array}$ & None & NA & NA & NA & NA & NA & Insufficient \\
\hline $\begin{array}{l}\text { Time to } \\
\text { analgesic } \\
\text { effect }\end{array}$ & $\begin{array}{l}\text { Inconclusive. } \\
\text { No data }\end{array}$ & None & NA & NA & NA & NA & NA & Insufficient \\
\hline $\begin{array}{l}\text { Any adverse } \\
\text { event }\end{array}$ & $\begin{array}{l}\text { Inconclusive. } \\
\text { EMS: } 1 \text { RCT found total AEs to } \\
\text { occur in } 20 \% \text { vs. } 14 \% \text { of patients. } \\
\text { RD } 6 \% \text { ( }-9 \text { to } 21) \\
\text { Single study with additional } \\
\text { domain limitations, CI crosses } \\
\text { appreciable differences in either } \\
\text { direction. }\end{array}$ & $\begin{array}{l}1 \mathrm{RCT} \\
(n=100)\end{array}$ & Medium & Unknown & Direct & $\begin{array}{l}\text { Very } \\
\text { imprecise }\end{array}$ & Unsuspected & Insufficient \\
\hline Hypotension & $\begin{array}{l}\text { Inconclusive. } \\
\text { No data }\end{array}$ & None & NA & NA & NA & NA & NA & Insufficient \\
\hline
\end{tabular}




\begin{tabular}{|c|c|c|c|c|c|c|c|c|}
\hline Outcome & $\begin{array}{l}\text { Conclusions statement, } \\
\text { rationale }\end{array}$ & $\begin{array}{l}\text { Study } \\
\text { Design and } \\
\text { Sample Size }\end{array}$ & $\begin{array}{l}\text { Study } \\
\text { Limitations }^{a}\end{array}$ & Consistency $^{b}$ & Directness $^{c}$ & Precision $^{d}$ & $\begin{array}{l}\text { Publication } \\
\text { Bias }^{\mathrm{e}}\end{array}$ & $\begin{array}{l}\text { Strength of } \\
\text { Evidence }\end{array}$ \\
\hline $\begin{array}{l}\text { Mental status } \\
\text { Changes- } \\
\text { dizziness }\end{array}$ & $\begin{array}{l}\text { Inconclusive. } \\
\text { EMS: } 1 \text { RCT found dizziness in } \\
8 \% \text { vs. } 4 \% \text { of patients. RD } 4 \% \text { (-7 } \\
\text { to } 15 \text { ) } \\
\text { Single study with additional } \\
\text { domain limitations, } \mathrm{Cl} \text { crosses } \\
\text { appreciable differences in either } \\
\text { direction. }\end{array}$ & $\begin{array}{l}\text { 1 RCT } \\
(n=100)\end{array}$ & Medium & Unknown & Direct & \begin{tabular}{|l|} 
Very \\
imprecise
\end{tabular} & Unsuspected & Insufficient \\
\hline $\begin{array}{l}\text { Respiratory } \\
\text { depression }\end{array}$ & $\begin{array}{l}\text { Inconclusive. } \\
\text { No data }\end{array}$ & None & NA & NA & NA & NA & NA & Insufficient \\
\hline
\end{tabular}

Abbreviations: $\mathrm{NA}=$ not applicable; $\mathrm{OBS}=$ observational; $\mathrm{RCT}=$ randomized controlled trial

a: Rationale is provided for inconclusive statements (with insufficient strength of evidence).

b: Study limitations were downgraded when the majority of the evidence base came from medium or high risk of bias studies.

c: Consistency was judged using the I2 statistic when meta-analysis was conducted, with values over $50 \%$ considered to be inconsistent. When data were not pooled, we inspected study level results for overall agreement in the direction and magnitude of effects. When evidence was available from trials and observational studies, we considered agreement of direction and magnitude of effect from these sources.

d: Directness was downgraded when the majority of evidence for the given comparison/outcome came from emergency department studies rather than prehospital studies.

e: Precision was judged using the effect estimate and clinically important difference set for the outcome. Estimates were considered imprecise if the confidence interval crossed the clinically important difference. Estimates were considered very imprecise when the confidence interval spanned the clinically important difference in both directions, thus uninformative.

f: Publication bias was judged using p-value $<0.05$ (when data was meta-analyzed), suggesting presence of publication bias. 
Table E-5. Strength of evidence ratings for the comparison of opioids vs. acetaminophen

\begin{tabular}{|c|c|c|c|c|c|c|c|c|}
\hline Outcome & $\begin{array}{l}\text { Conclusions statement, } \\
\text { rationale }\end{array}$ & $\begin{array}{l}\text { Study } \\
\text { Design and } \\
\text { Sample Size }\end{array}$ & $\begin{array}{l}\text { Study } \\
\text { Limitations }^{\mathrm{a}}\end{array}$ & Consistency $^{\mathrm{b}}$ & Directness $^{c}$ & Precision $^{\mathrm{d}}$ & $\begin{array}{l}\text { Publication } \\
\text { Bias }^{\text {e }}\end{array}$ & $\begin{array}{l}\text { Strength of } \\
\text { Evidence }\end{array}$ \\
\hline $\begin{array}{l}\text { Pain severity } \\
-15 \text { min }\end{array}$ & $\begin{array}{l}\text { There is no evidence of a } \\
\text { clinically important difference } \\
\text { between opioids and IV APAP in } \\
\text { the change of pain scores in } 15 \\
\text { min. } \\
\text { ED: Meta-analysis of } 7 \text { RCTs } \\
\text { found } \\
\text { MD } 0.19(-1.05 \text { to } 1.42) \text {. }\end{array}$ & $\begin{array}{l}7 \mathrm{RCT} \\
(\mathrm{n}=647)\end{array}$ & Low & Inconsistent & Indirect & Precise & Unsuspected & Low \\
\hline $\begin{array}{l}\text { Pain severity } \\
-30 \text { min }\end{array}$ & $\begin{array}{l}\text { There is no evidence of a } \\
\text { clinically important difference } \\
\text { between opioids and IV APAP in } \\
\text { the change of pain scores in } 30 \\
\text { min. } \\
\text { ED: Meta-analysis of } 9 \text { RCTs } \\
\text { found MD } 0.23 \text { (-0.93 to } 1.38) \text {. }\end{array}$ & $\begin{array}{l}9 \text { RCT } \\
(n=1795)\end{array}$ & Low & Inconsistent & Indirect & Precise & Unsuspected & Low \\
\hline $\begin{array}{l}\text { Pain severity } \\
-60 \text { min }\end{array}$ & $\begin{array}{l}\text { There is no evidence of a } \\
\text { clinically important difference } \\
\text { between opioids and IV APAP in } \\
\text { the change of pain scores in } 60 \\
\text { min. } \\
\text { ED: Meta-analysis of } 3 \text { RCT found } \\
\text { MD } 0.13(-0.72 \text { to } 0.97) \text {. }\end{array}$ & $\begin{array}{l}3 \text { RCT } \\
(n=1260)\end{array}$ & Low & Inconsistent & Indirect & Precise & Unsuspected & Low \\
\hline $\begin{array}{l}\text { Presence of } \\
\text { pain - partial } \\
\text { response } 30 \\
\text { min }\end{array}$ & $\begin{array}{l}\text { Inconclusive. } \\
\text { ED: } 1 \text { RCT found a partial } \\
\text { response in pain score in } 81.8 \% \\
\text { vs. } 78.1 \% \text { of patients, RD } 4 \%(-1 \\
\text { to } 8) \\
\text { Single study with additional } \\
\text { domain limitations. }\end{array}$ & $\begin{array}{l}\text { 1 RCT } \\
(n=996)\end{array}$ & Low & Unknown & Indirect & Imprecise & Unsuspected & Insufficient \\
\hline
\end{tabular}




\begin{tabular}{|c|c|c|c|c|c|c|c|c|}
\hline Outcome & $\begin{array}{l}\text { Conclusions statement, } \\
\text { rationale }\end{array}$ & $\begin{array}{l}\text { Study } \\
\text { Design and } \\
\text { Sample Size }\end{array}$ & $\begin{array}{l}\text { Study } \\
\text { Limitations }\end{array}$ & Consistency $^{b}$ & Directness $^{c}$ & Precision $^{d}$ & $\begin{array}{l}\text { Publication } \\
\text { Bias }^{\text {e }}\end{array}$ & $\begin{array}{l}\text { Strength of } \\
\text { Evidence }\end{array}$ \\
\hline $\begin{array}{l}\text { Time to } \\
\text { analgesic } \\
\text { effect }\end{array}$ & $\begin{array}{l}\text { There is no evidence of a } \\
\text { clinically important difference in } \\
\text { the time to analgesia with } \\
\text { opioids compared with IV APAP } \\
\text { ED: Median time to NRS }<2 \text { was } \\
60 \text { min in both arms, IQR } 30 \text { to } 90 \\
\text { min. }\end{array}$ & $\begin{array}{l}1 \mathrm{RCT} \\
(\mathrm{n}=1097)\end{array}$ & Low & Unknown & Indirect & Precise & Unsuspected & Low \\
\hline $\begin{array}{l}\text { Any adverse } \\
\text { event }\end{array}$ & $\begin{array}{l}\text { Opioids may cause more } \\
\text { adverse events than IV APAP. } \\
\text { ED: Meta-analysis of } 5 \text { RCTs over } \\
\text { the study period found } \\
\text { AR } 35.4 \% \text { vs. } 5.6 \% \\
\text { RD } 30 \% \text { (-1 to } 62) \text {. } \\
1 \text { RCT reporting total AEs "during } \\
\text { acute" management found } 1.3 \% \\
\text { vs. } 3.5 \%, \text { RD }-2 \% \text { (-4 to } 0.00)\end{array}$ & $\begin{array}{l}6 \text { RCTs } \\
(n=1,484)\end{array}$ & Low & Inconsistent & Indirect & Imprecise & Unsuspected & Low \\
\hline Hypotension & $\begin{array}{l}\text { There is no evidence of a } \\
\text { clinically important difference in } \\
\text { hypotension with opioids } \\
\text { compared to IV APAP. } \\
\text { ED: Meta-analysis of } 5 \text { RCTs } \\
\text { found } \\
\text { AR } 2.6 \% \text { vs. } 0 \% \\
\text { RD } 2 \%(0.00 \text { to } 4 \%)\end{array}$ & $\begin{array}{l}5 \text { RCTs } \\
(n=624)\end{array}$ & Low & Consistent & Indirect & Imprecise & Unsuspected & Low \\
\hline $\begin{array}{l}\text { Mental status } \\
\text { Changes- } \\
\text { dizziness }\end{array}$ & $\begin{array}{l}\text { Opioids cause more dizziness } \\
\text { than IV APAP. } \\
\text { ED: Meta-analysis of } 6 \text { RCTs } \\
\text { found } \\
\text { AR } 7.8 \% \text { vs. } 0.3 \% \\
\text { RD } 7 \% \text { (5 to } 9)\end{array}$ & $\begin{array}{l}6 \text { RCTs } \\
(n=539)\end{array}$ & Low & Consistent & Indirect & Precise & Unsuspected & Moderate \\
\hline
\end{tabular}




\begin{tabular}{|c|c|c|c|c|c|c|c|c|}
\hline Outcome & $\begin{array}{l}\text { Conclusions statement, } \\
\text { rationale }\end{array}$ & $\begin{array}{l}\text { Study } \\
\text { Design and } \\
\text { Sample Size }\end{array}$ & $\begin{array}{l}\text { Study } \\
\text { Limitations }\end{array}$ & Consistency $^{b}$ & Directness $^{\mathrm{c}}$ & Precision $^{d}$ & $\begin{array}{l}\text { Publication } \\
\text { Bias }^{\mathrm{e}}\end{array}$ & $\begin{array}{l}\text { Strength of } \\
\text { Evidence }\end{array}$ \\
\hline $\begin{array}{l}\text { Mental status } \\
\text { change - } \\
\text { "mild" } \\
\text { sedation }\end{array}$ & $\begin{array}{l}\text { Inconclusive. } \\
\text { ED: } 1 \text { RCT found mild sedation in } \\
2.2 \% \text { vs. } 0 \% \text { of patients. RD } 2 \% \text { (- } \\
7 \text { to } 12 \text { ). } \\
\text { Single study with additional } \\
\text { domain limitations, CI crosses } \\
\text { appreciable differences in either } \\
\text { direction. }\end{array}$ & $\begin{array}{l}1 \mathrm{RCT} \\
(\mathrm{n}=91)\end{array}$ & Low & Unknown & Indirect & $\begin{array}{l}\text { Very } \\
\text { imprecise }\end{array}$ & Unsuspected & Insufficient \\
\hline $\begin{array}{l}\text { Respiratory } \\
\text { depression }\end{array}$ & $\begin{array}{l}\text { Inconclusive. } \\
\text { ED: } 1 \text { RCT found no cases of } \\
\text { respiratory depression to occur. } \\
\text { Single study with additional } \\
\text { domain limitations. }\end{array}$ & $\begin{array}{l}\text { RCT } \\
(n=73)\end{array}$ & Low & Unknown & Indirect & Precise & Unsuspected & Insufficient \\
\hline
\end{tabular}

Abbreviations: $\mathrm{NA}=$ not applicable; $\mathrm{OBS}=$ observational; $\mathrm{RCT}=$ randomized controlled trial

a: Rationale is provided for inconclusive statements (with insufficient strength of evidence).

b: Study limitations were downgraded when the majority of the evidence base came from medium or high risk of bias studies.

c: Consistency was judged using the I 2 statistic when meta-analysis was conducted, with values over $50 \%$ considered to be inconsistent. When data were not pooled, we inspected study level results for overall agreement in the direction and magnitude of effects. When evidence was available from trials and observational studies, we considered agreement of direction and magnitude of effect from these sources.

d: Directness was downgraded when the majority of evidence for the given comparison/outcome came from emergency department studies rather than prehospital studies.

e: Precision was judged using the effect estimate and clinically important difference set for the outcome. Estimates were considered imprecise if the confidence interval crossed the clinically important difference. Estimates were considered very imprecise when the confidence interval spanned the clinically important difference in both directions, thus uninformative.

f: Publication bias was judged using p-value $<0.05$ (when data was meta-analyzed), suggesting presence of publication bias. 
Table E-6. Strength of evidence ratings for the comparison of opioids vs. nonsteroidal anti-inflammatory drugs

\begin{tabular}{|c|c|c|c|c|c|c|c|c|}
\hline Outcome & $\begin{array}{l}\text { Conclusions statement, } \\
\text { rationale }\end{array}$ & $\begin{array}{l}\text { Study } \\
\text { Design and } \\
\text { Sample Size }\end{array}$ & $\begin{array}{l}\text { Study } \\
\text { Limitations }^{a}\end{array}$ & Consistency $^{b}$ & Directness $^{c}$ & Precision $^{d}$ & $\begin{array}{l}\text { Publication } \\
\text { Bias }^{\text {e }}\end{array}$ & $\begin{array}{l}\text { Strength of } \\
\text { Evidence }\end{array}$ \\
\hline $\begin{array}{l}\text { Pain severity } \\
-15 \text { min }\end{array}$ & $\begin{array}{l}\text { Inconclusive. } \\
\text { ED: } 1 \text { RCT found MD } 0.2 \text { (-0.4 to } \\
0.8) \\
\text { Single study with additional } \\
\text { domain limitations. }\end{array}$ & $\begin{array}{l}1 \mathrm{RCT} \\
(\mathrm{n}=88)\end{array}$ & Medium & Unknown & Indirect & Precise & Unsuspected & Insufficient \\
\hline $\begin{array}{l}\text { Pain severity } \\
-30 \mathrm{~min}\end{array}$ & $\begin{array}{l}\text { There is no evidence of a } \\
\text { clinically important difference } \\
\text { between opioids and NSAIDs in } \\
\text { the change of pain scores in } 30 \\
\text { min. } \\
\text { ED: Meta-analysis of } 3 \text { RCT found } \\
\text { MD } 0.01(-0.29 \text { to } 0.32)\end{array}$ & $\begin{array}{l}3 \mathrm{RCT} \\
(n=453)\end{array}$ & Low & Consistent & Indirect & Precise & Unsuspected & Moderate \\
\hline $\begin{array}{l}\text { Pain severity } \\
-60 \mathrm{~min}\end{array}$ & $\begin{array}{l}\text { There is no evidence of a } \\
\text { clinically important difference } \\
\text { between opioids and NSAIDs in } \\
\text { the change of pain scores in } 60 \\
\text { min. } \\
\text { ED: Meta-analysis of } 3 \text { RCT found } \\
\text { MD } 0.21 \text { (-0.10 to } 0.51)\end{array}$ & $\begin{array}{l}3 \text { RCT } \\
(n=453)\end{array}$ & Low & Consistent & Indirect & Precise & Unsuspected & Moderate \\
\hline $\begin{array}{l}\text { Presence of } \\
\text { pain - partial } \\
\text { response } 30 \\
\text { min }\end{array}$ & $\begin{array}{l}\text { Inconclusive. } \\
\text { ED: } 1 \text { RCT found partial response } \\
\text { in } 20.7 \% \text { vs. } 19.8 \%, \text { RD } 1 \%(-10 \\
\text { to } 10) \\
\text { Single study with additional } \\
\text { domain limitations, Cl crosses } \\
\text { appreciable differences in either } \\
\text { direction. }\end{array}$ & $\begin{array}{l}1 \mathrm{RCT} \\
(\mathrm{n}=227)\end{array}$ & Low & Unknown & Indirect & $\begin{array}{l}\text { Very } \\
\text { imprecise }\end{array}$ & Unsuspected & Insufficient \\
\hline
\end{tabular}




\begin{tabular}{|c|c|c|c|c|c|c|c|c|}
\hline Outcome & $\begin{array}{l}\text { Conclusions statement, } \\
\text { rationale }\end{array}$ & $\begin{array}{l}\text { Study } \\
\text { Design and } \\
\text { Sample Size }\end{array}$ & $\begin{array}{l}\text { Study } \\
\text { Limitations }^{a}\end{array}$ & Consistency $^{b}$ & Directness $^{c}$ & Precision $^{d}$ & $\begin{array}{l}\text { Publication } \\
\text { Bias }^{\text {e }}\end{array}$ & $\begin{array}{l}\text { Strength of } \\
\text { Evidence }\end{array}$ \\
\hline $\begin{array}{l}\text { Presence of } \\
\text { pain - partial } \\
\text { response } 60 \\
\text { min }\end{array}$ & $\begin{array}{l}\text { Inconclusive. } \\
\text { ED: } 1 \text { RCT found partial response } \\
\text { in } 29.3 \% \text { vs. } 33.0 \%, \mathrm{RD}-4 \%(-16 \\
\text { to } 7) \\
\text { Single study with additional } \\
\text { domain limitations, Cl crosses } \\
\text { appreciable differences in either } \\
\text { direction. }\end{array}$ & $\begin{array}{l}1 \mathrm{RCT} \\
(n=243)\end{array}$ & Low & Unknown & Indirect & $\begin{array}{l}\text { Very } \\
\text { imprecise }\end{array}$ & Unsuspected & Insufficient \\
\hline $\begin{array}{l}\text { Presence of } \\
\text { pain - full } \\
\text { resolution } 30 \\
\text { min }\end{array}$ & $\begin{array}{l}\text { Inconclusive. } \\
\text { ED: } 1 \text { RCT found } 16.3 \% \text { vs. } \\
11.6 \%, \text { RD } 5 \%(-11 \text { to } 20) \\
\text { Single study with additional } \\
\text { domain limitations, } \mathrm{Cl} \text { crosses } \\
\text { appreciable differences in either } \\
\text { direction. }\end{array}$ & $\begin{array}{l}\text { 1 RCT } \\
(n=86)\end{array}$ & Low & Unknown & Indirect & $\begin{array}{l}\text { Very } \\
\text { imprecise }\end{array}$ & Unsuspected & Insufficient \\
\hline $\begin{array}{l}\text { Time to } \\
\text { analgesic } \\
\text { effect }\end{array}$ & $\begin{array}{l}\text { Inconclusive. } \\
\text { No data }\end{array}$ & None & $\mathrm{NA}$ & $\mathrm{NA}$ & $\mathrm{NA}$ & $\mathrm{NA}$ & $\mathrm{NA}$ & Insufficient \\
\hline $\begin{array}{l}\text { Any adverse } \\
\text { event }\end{array}$ & $\begin{array}{l}\text { Opioids may cause more } \\
\text { adverse events than NSAIDs } \\
\text { ED: Meta-analysis of } 2 \text { RCTs } \\
\text { found } \\
\text { AR } 24.6 \% \text { vs. } 7.4 \% \text {, RD } 21 \% \text { (4 to } \\
38 \text { ) }\end{array}$ & $\begin{array}{l}2 \text { RCTs } \\
(n=367)\end{array}$ & Low & Inconsistent & Indirect & Imprecise & Unsuspected & Low \\
\hline Hypotension & $\begin{array}{l}\text { Inconclusive. } \\
\text { ED: } 1 \text { RCT found hypotension in } \\
6.8 \% \text { vs. } 0 \% \text { of patients. RD } 7 \% \text { (- } \\
3 \text { to } 18) \\
\text { Single study with additional } \\
\text { domain limitations. }\end{array}$ & $\begin{array}{l}1 \mathrm{RCT} \\
(\mathrm{n}=88)\end{array}$ & Low & Unknown & Indirect & Imprecise & Unsuspected & Insufficient \\
\hline
\end{tabular}




\begin{tabular}{|c|c|c|c|c|c|c|c|c|}
\hline Outcome & $\begin{array}{l}\text { Conclusions statement, } \\
\text { rationale }\end{array}$ & $\begin{array}{l}\text { Study } \\
\text { Design and } \\
\text { Sample Size }\end{array}$ & $\begin{array}{l}\text { Study } \\
\text { Limitations }^{a}\end{array}$ & Consistency $^{b}$ & Directness $^{c}$ & Precision $^{d}$ & $\begin{array}{l}\text { Publication } \\
\text { Bias }^{\text {e }}\end{array}$ & $\begin{array}{l}\text { Strength of } \\
\text { Evidence }\end{array}$ \\
\hline $\begin{array}{l}\text { Mental status } \\
\text { Changes- } \\
\text { drowsiness }\end{array}$ & $\begin{array}{l}\text { Opioids may cause more } \\
\text { drowsiness than NSAIDs } \\
\text { ED: Meta-analysis of } 2 \text { RCTs } \\
\text { found } \\
\text { AR } 3.9 \% \text { vs. } 0.7 \% \text {, RD } 3 \% \text { (0 to } \\
6 \% \text { ) }\end{array}$ & $\begin{array}{l}2 \text { RCTs } \\
(n=367)\end{array}$ & Low & Consistent & Indirect & Imprecise & Unsuspected & Low \\
\hline $\begin{array}{l}\text { Mental status } \\
\text { changes - } \\
\text { Dizziness }\end{array}$ & $\begin{array}{l}\text { Inconclusive. } \\
\text { ED: } 1 \text { RCT found dizziness in } \\
9.3 \% \text { vs. } 0 \% \text { of patients, RD } 9 \% \text { (- } \\
2 \text { to } 22) \\
\text { Single study with additional } \\
\text { domain limitations. }\end{array}$ & $\begin{array}{l}1 \mathrm{RCT} \\
(\mathrm{n}=86)\end{array}$ & Low & Unknown & Indirect & Imprecise & Unsuspected & Insufficient \\
\hline $\begin{array}{l}\text { Mental status } \\
\text { changes- } \\
\text { depression }\end{array}$ & $\begin{array}{l}\text { Inconclusive. } \\
\text { ED: } 1 \text { RCT found depression in } \\
4.5 \% \text { vs. } 0 \% \text { of patients, RD } 4 \% \text { (- } \\
5 \text { to } 15) \\
\text { Single study with additional } \\
\text { domain limitations, Cl crosses } \\
\text { appreciable differences in either } \\
\text { direction. }\end{array}$ & $\begin{array}{l}1 \mathrm{RCT} \\
(\mathrm{n}=88)\end{array}$ & Low & Unknown & Indirect & $\begin{array}{l}\text { Very } \\
\text { imprecise }\end{array}$ & Unsuspected & Insufficient \\
\hline $\begin{array}{l}\text { Respiratory } \\
\text { depression }\end{array}$ & $\begin{array}{l}\text { Inconclusive. } \\
\text { No data }\end{array}$ & None & NA & NA & NA & $\mathrm{NA}$ & NA & Insufficient \\
\hline
\end{tabular}

Abbreviations: $\mathrm{NA}=$ not applicable; $\mathrm{OBS}=$ observational; $\mathrm{RCT}=$ randomized controlled trial

a: Rationale is provided for inconclusive statements (with insufficient strength of evidence).

b: Study limitations were downgraded when the majority of the evidence base came from medium or high risk of bias studies.

c: Consistency was judged using the I2 statistic when meta-analysis was conducted, with values over 50\% considered to be inconsistent. When data were not pooled, we inspected study level results for overall agreement in the direction and magnitude of effects. When evidence was available from trials and observational studies, we considered agreement of direction and magnitude of effect from these sources.

d: Directness was downgraded when the majority of evidence for the given comparison/outcome came from emergency department studies rather than prehospital studies.

e: Precision was judged using the effect estimate and clinically important difference set for the outcome. Estimates were considered imprecise if the confidence interval crossed the clinically important difference. Estimates were considered very imprecise when the confidence interval spanned the clinically important difference in both directions, thus uninformative.

f: Publication bias was judged using p-value $<0.05$ (when data was meta-analyzed), suggesting presence of publication bias. 


\section{Appendix F. Forest Plots}

Figure F-1. Risk difference presence of pain - full resolution at $\mathbf{3 0}$ minutes, opioids versus ketamine

\begin{tabular}{lrr} 
Source & \multicolumn{2}{c}{ Opioid } \\
Events & Total \\
Motov, 2015 & 11 & 45 \\
Motov, 2018 & 4 & 30 \\
Quinn, 2018 & 8 & 11 \\
Random effects model & $\mathbf{2 3}$ & $\mathbf{8 6}$ \\
Heterogeneity: $I^{2}=29 \%, \tau^{2}=0.0099, p=0.25$
\end{tabular}

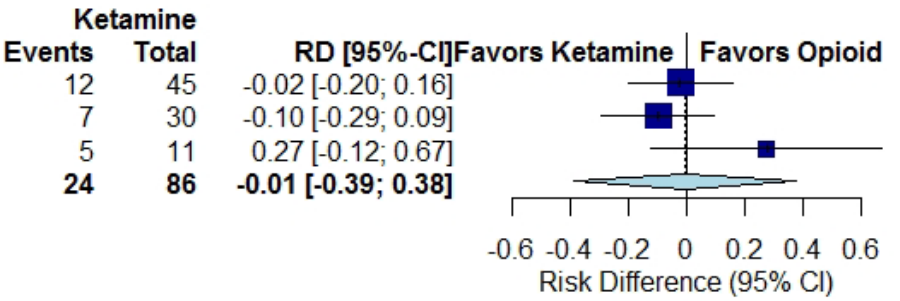

Figure F-2. Risk difference presence of pain - full resolution at 60 minutes, opioids versus ketamine

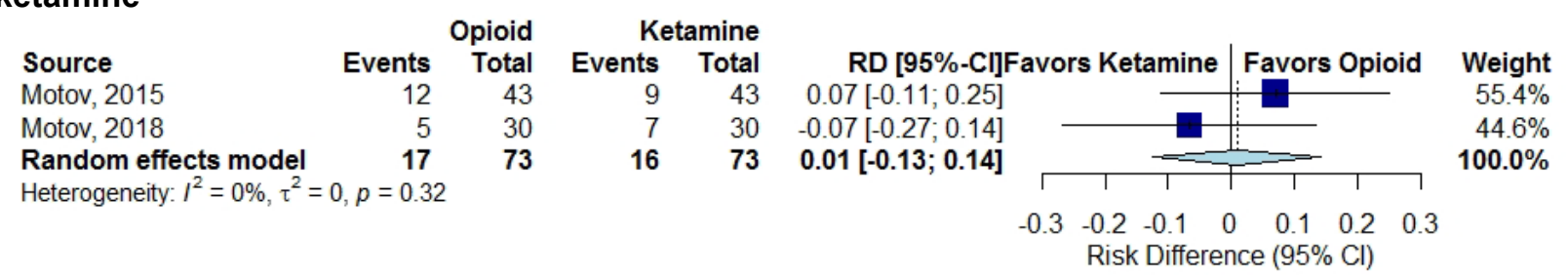

Figure F-3. Risk difference presence of pain - partial resolution at 15 minutes, opioids versus ketamine

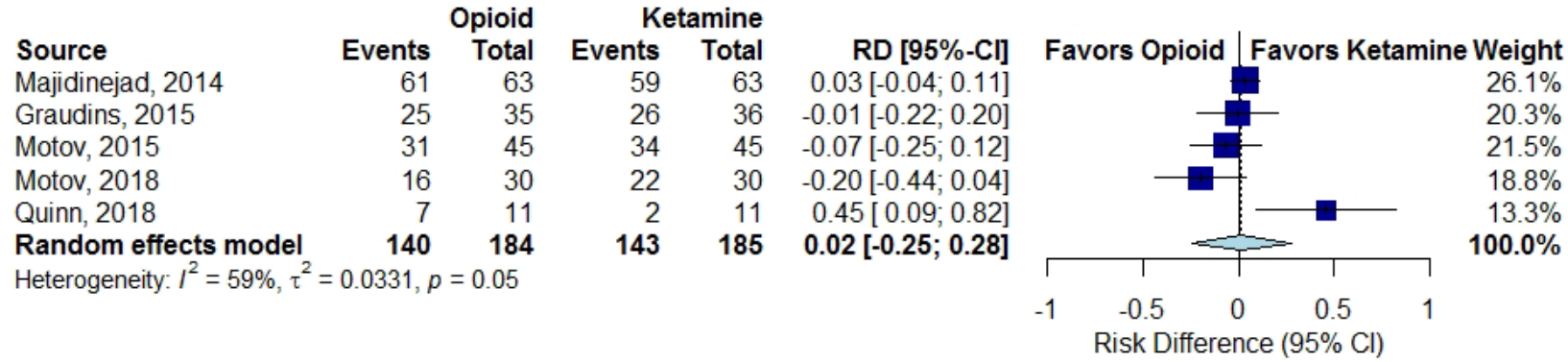

Figure F-4. Risk difference presence of pain - partial resolution at 30 minutes, opioids versus ketamine

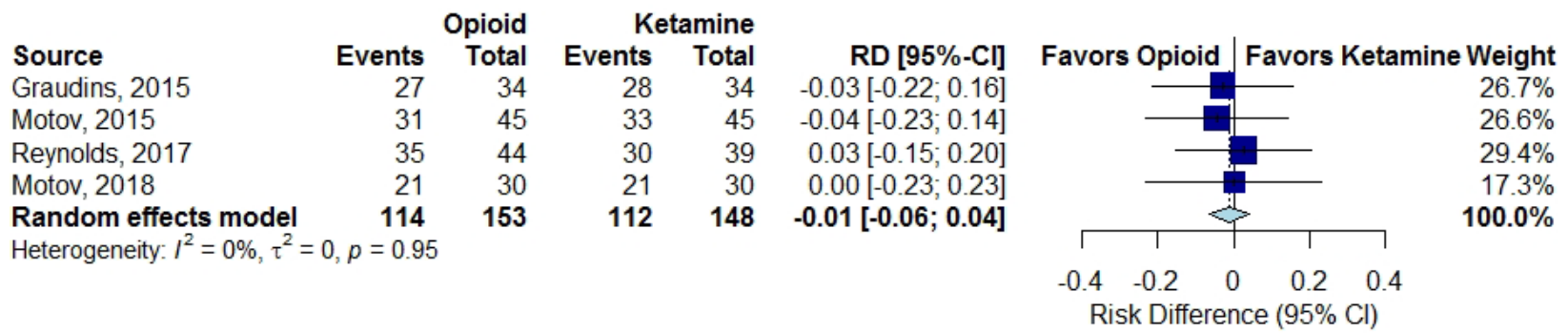

Figure F-5. Risk difference presence of pain - partial resolution at 60 minutes, opioids versus ketamine

\begin{tabular}{|c|c|c|c|c|c|c|c|c|}
\hline \multirow{2}{*}{ Source } & \multicolumn{2}{|r|}{ Opioid } & \multicolumn{2}{|c|}{ Ketamine } & \multirow[b]{2}{*}{$\mathrm{RD}[95 \%-\mathrm{Cl}]$} & \multirow[b]{2}{*}{ Favors Opioid } & \multirow{2}{*}{\multicolumn{2}{|c|}{ Favors Ketamine Weight }} \\
\hline & Events & Total & Events & Total & & & & \\
\hline Graudins, 2015 & 25 & 31 & 28 & 31 & $-0.10[-0.27 ; 0.08]$ & & & $36.1 \%$ \\
\hline Motov, 2015 & 33 & 43 & 25 & 43 & $0.19[-0.01 ; 0.38]$ & & & $33.2 \%$ \\
\hline Motov, 2018 & 22 & 30 & 24 & 30 & $-0.07[-0.28 ; 0.15]$ & & & $30.7 \%$ \\
\hline Random effects model & 80 & 104 & 77 & 104 & $0.01[-0.38 ; 0.39]$ & & $=$ & $100.0 \%$ \\
\hline \multirow{2}{*}{\multicolumn{6}{|c|}{ Heterogeneity: $I^{2}=61 \%, \tau^{2}=0.0146, p=0.08$}} & & I & \\
\hline & & & & & & $\begin{array}{ll}-0.4 & -0.2 \\
\text { Risk Differe }\end{array}$ & $\begin{array}{ccc}0.2 & 0 . \\
0 & 0.2\end{array}$ & \\
\hline
\end{tabular}


Figure F-6. Mean difference change in pain at 15 minutes - subgroup age $<18$ years old, $\geq 18$ years old, opioids versus ketamine

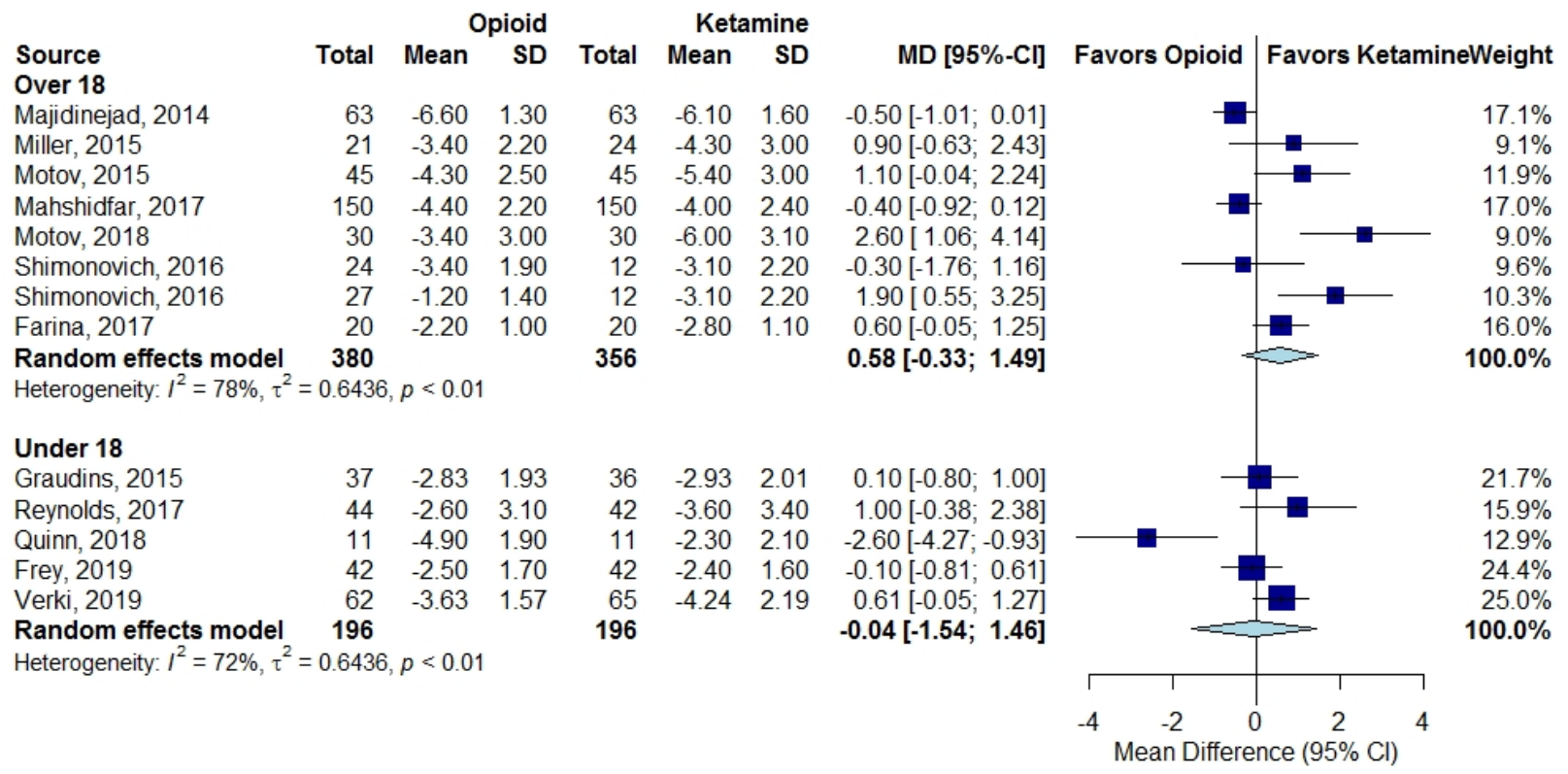

Figure F-7. Mean difference change in pain at 30 minutes - subgroup age $<18$ years old, $\geq 18$ years old, opioids versus ketamine

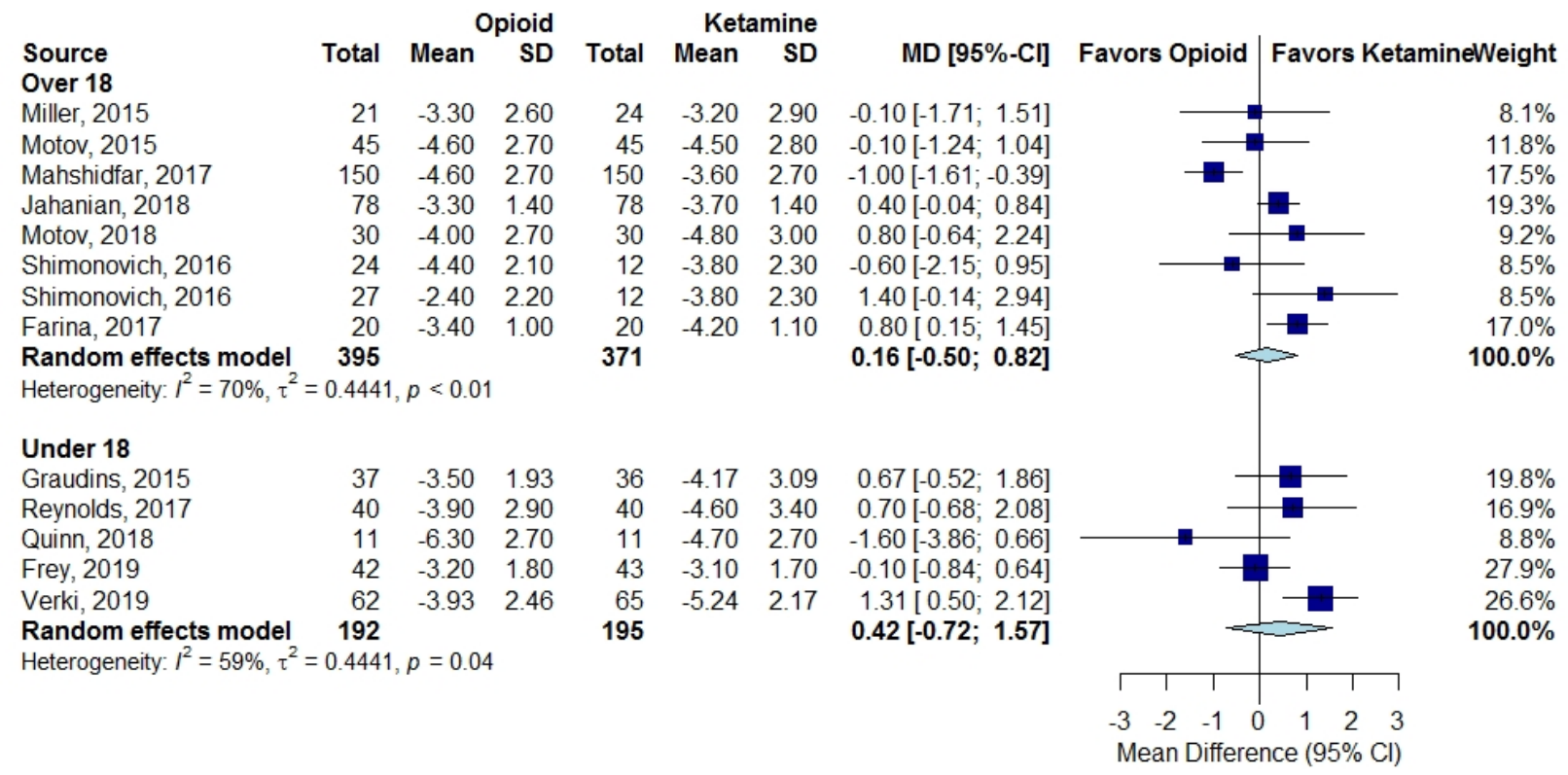


Figure F-8. Mean difference change in pain at 60 minutes - subgroup age $<18$ years old, $\geq 18$ years old, opioids versus ketamine

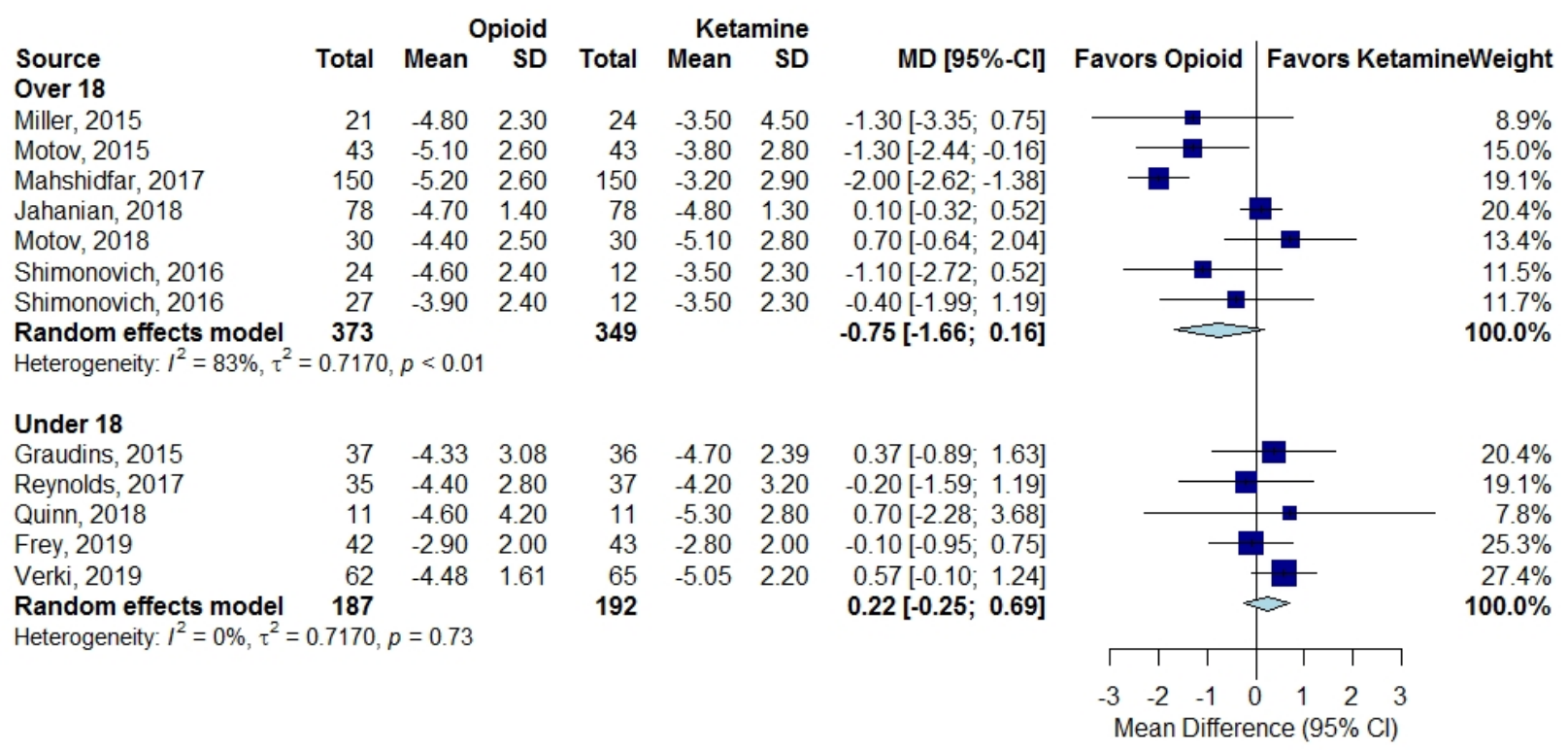

Figure F-9. Mean difference change in pain at 15 minutes - subgroup traumatic pain, opioids versus ketamine

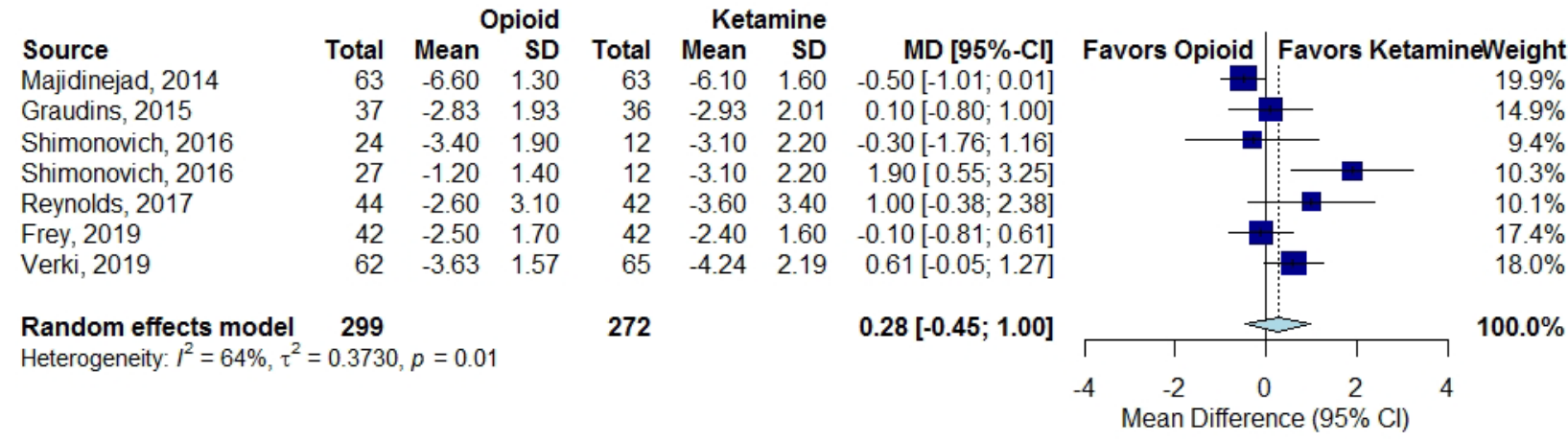

Figure F-10. Mean difference change in pain at $\mathbf{3 0}$ minutes - subgroup traumatic pain, opioids versus ketamine

\begin{tabular}{|c|c|c|c|c|c|c|c|c|c|c|}
\hline \multicolumn{5}{|c|}{ Opioid } & \multicolumn{2}{|c|}{ Ketamine } & \multirow[b]{2}{*}{ MD [95\%-Cl] } & \multirow[b]{2}{*}{ Favors Opioid } & \multirow{2}{*}{\multicolumn{2}{|c|}{ Favors KetamineWeight }} \\
\hline Source & Total & \multicolumn{2}{|c|}{ Mean SD } & Total & Mean & \multirow{2}{*}{$\begin{array}{r}\text { SD } \\
3.09\end{array}$} & & & & \\
\hline Graudins, 2015 & 37 & -3.50 & 1.93 & 36 & -4.17 & & $0.67[-0.52 ; 1.86]$ & & \multicolumn{2}{|c|}{ a $10 \%$} \\
\hline Mahshidfar, 2017 & 150 & -4.60 & 2.70 & 150 & -3.60 & 2.70 & $-1.00[-1.61 ;-0.39]$ & & & $16.1 \%$ \\
\hline Jahanian, 2018 & 78 & -3.30 & 1.40 & 78 & -3.70 & 1.40 & $0.40[-0.04 ; 0.84]$ & & & $17.6 \%$ \\
\hline Shimonovich, 2016 & 24 & -4.40 & 2.10 & 12 & -3.80 & 2.30 & $-0.60[-2.15 ; 0.95]$ & & & $8.4 \%$ \\
\hline Shimonovich, 2016 & 27 & -2.40 & 2.20 & 12 & -3.80 & 2.30 & $1.40[-0.14 ; 2.94]$ & & & $8.4 \%$ \\
\hline Reynolds, 2017 & 40 & -3.90 & 2.90 & 40 & -4.60 & 3.40 & $0.70[-0.68 ; 2.08]$ & & & $9.4 \%$ \\
\hline Frey, 2019 & 42 & -3.20 & 1.80 & 43 & -3.10 & 1.70 & $-0.10[-0.84 ; 0.64]$ & & & $14.9 \%$ \\
\hline Verki, 2019 & 62 & -3.93 & 2.46 & 65 & -5.24 & 2.17 & $1.31[0.50 ; 2.12]$ & & & $14.3 \%$ \\
\hline \multirow{3}{*}{$\begin{array}{l}\text { Random effects model } \\
\text { Heterogeneity: } I^{2}=75 \%, \tau^{2}=\end{array}$} & 460 & & & 436 & & & $0.29[-0.43 ; 1.00]$ & & & \multirow[t]{2}{*}{$100.0 \%$} \\
\hline & $=0.4730$ & $p<0.0$ & & & & & & I & I & \\
\hline & & & & & & & & $\stackrel{-2}{-2}$ & 2 & 4 \\
\hline
\end{tabular}


Figure F-11. Mean difference change in pain at 60 minutes - subgroup traumatic pain, opioids versus ketamine

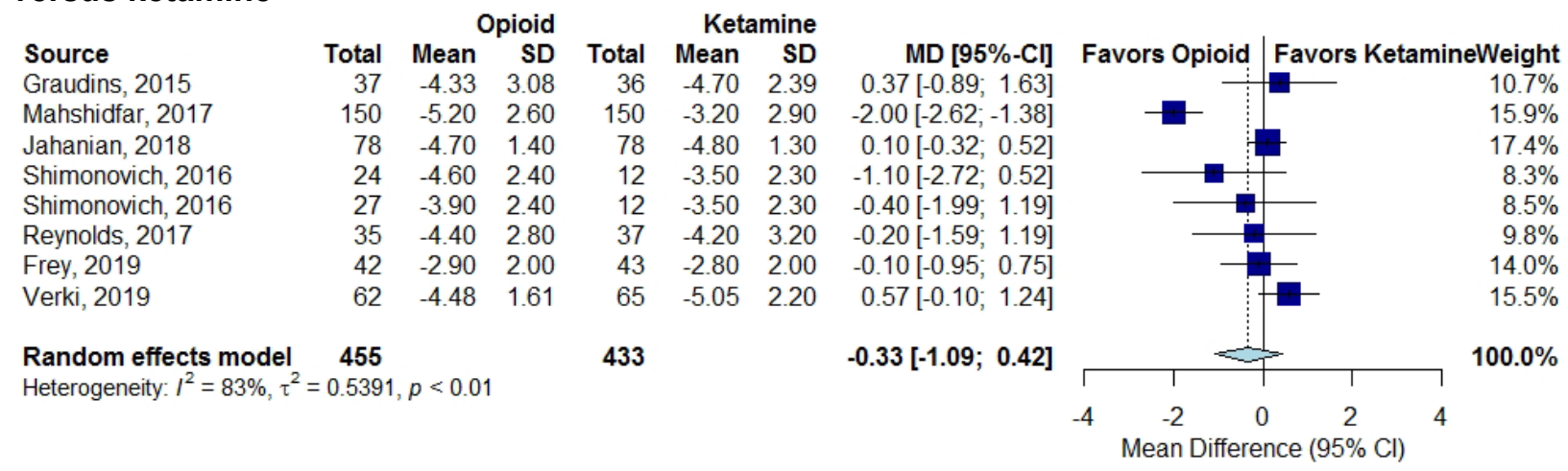

Figure F-12. Mean difference change in pain at 15 minutes - subgroup location of pain, opioids versus ketamine

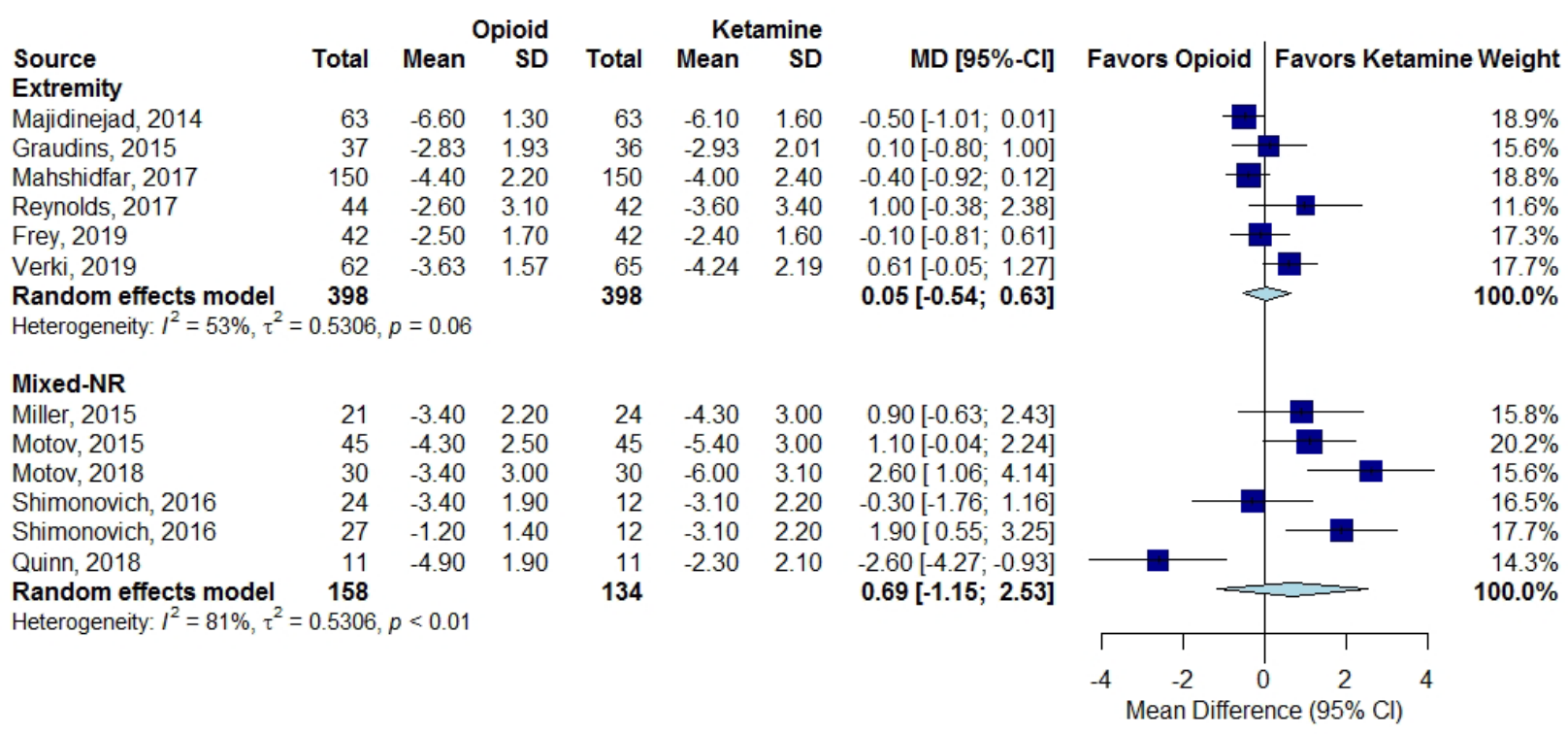


Figure F-13. Mean difference change in pain at $\mathbf{3 0}$ minutes - subgroup location of pain, opioids versus ketamine

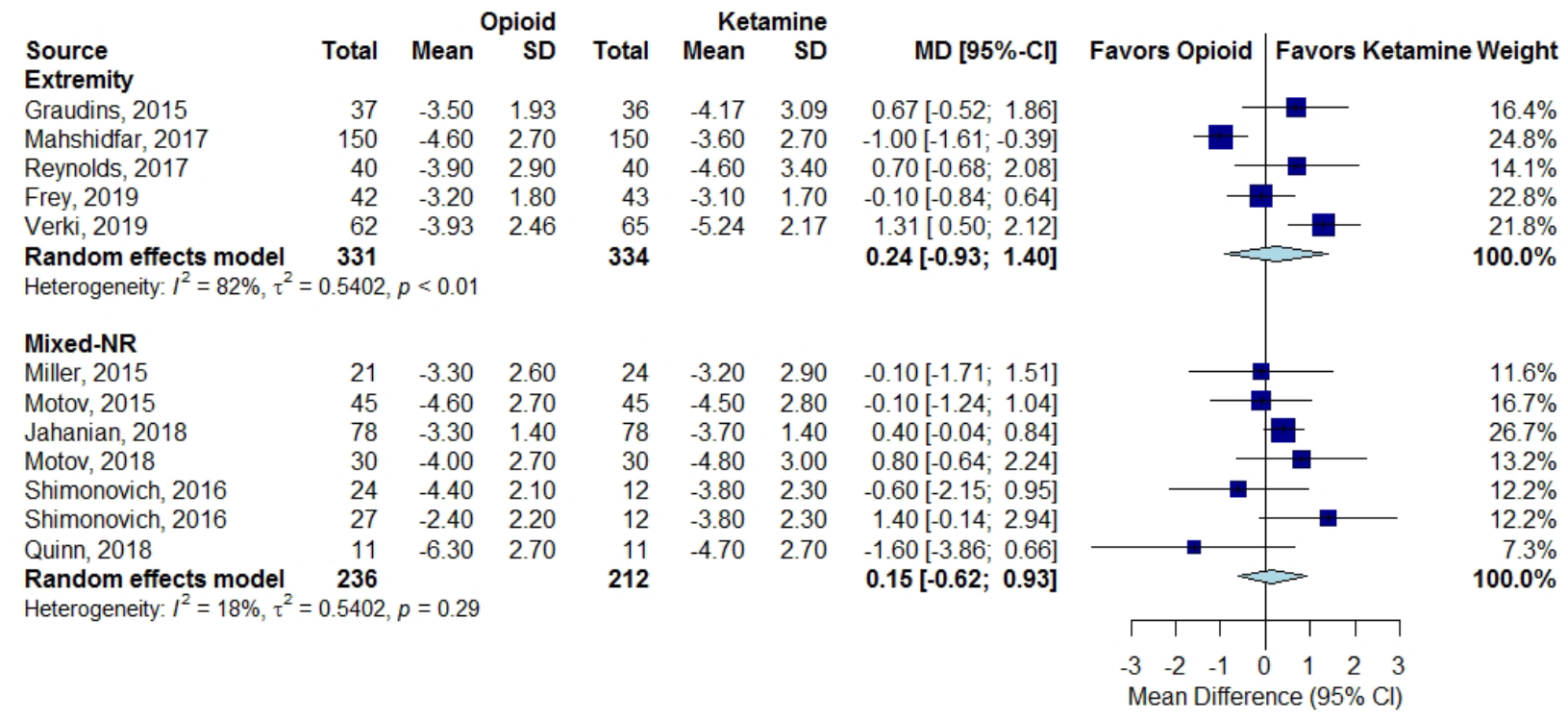

Figure F-14. Mean difference change in pain at 60 minutes - subgroup location of pain, opioids versus ketamine

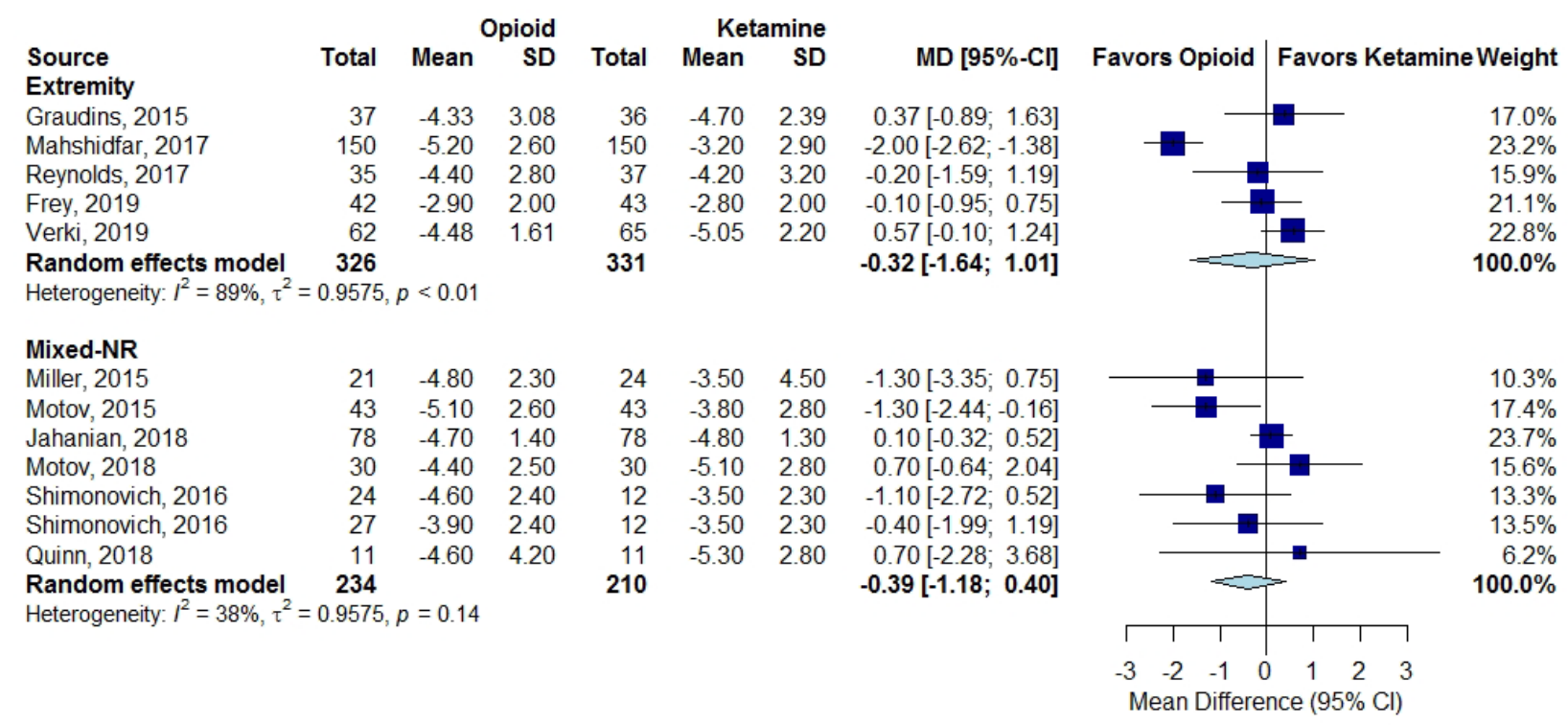


Figure F-15. Mean difference change in pain at 15 minutes - subgroup route of administration, opioids versus ketamine

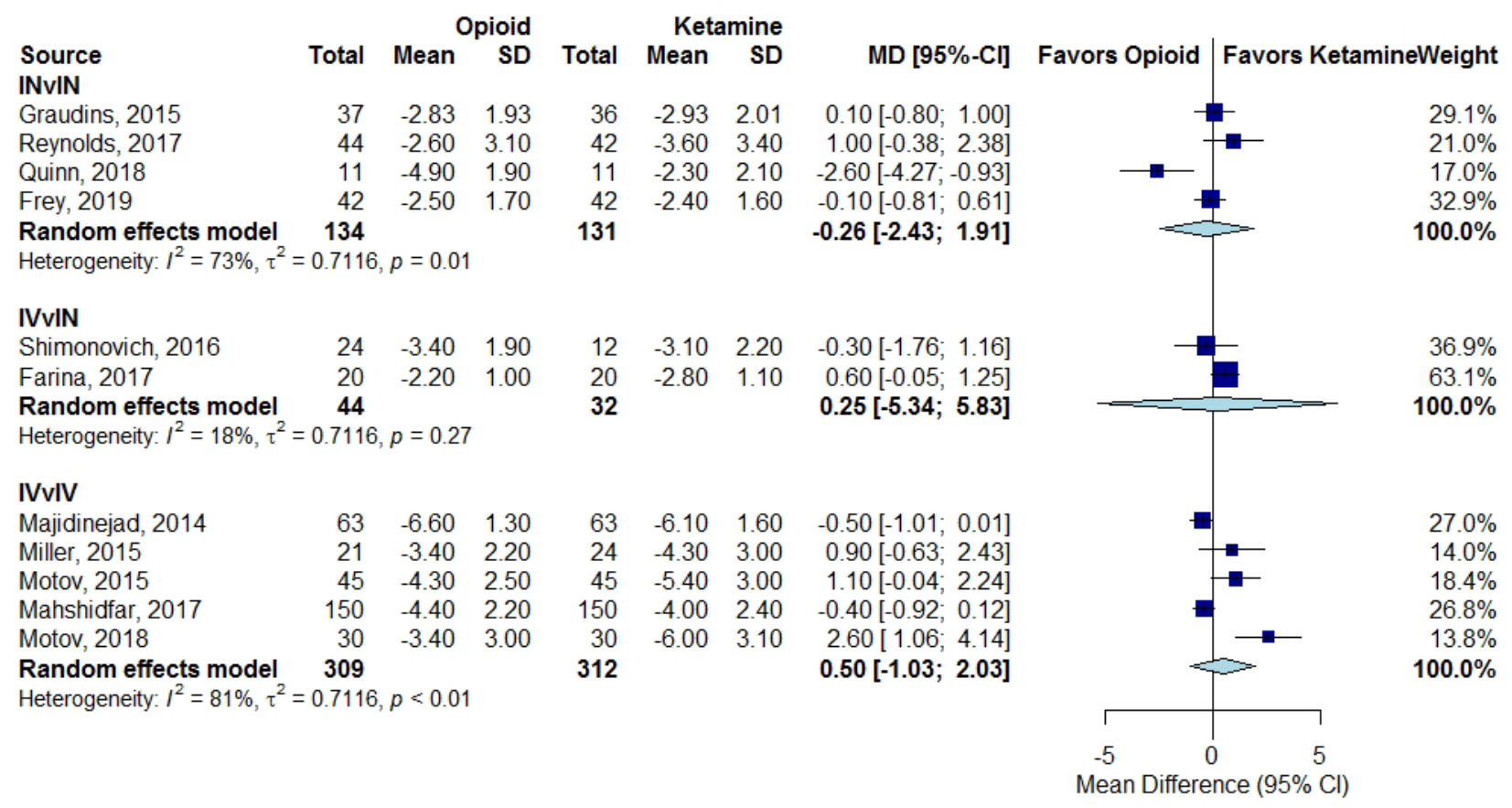

Figure F-16. Mean difference change in pain at 30 minutes - subgroup route of administration, opioids versus ketamine

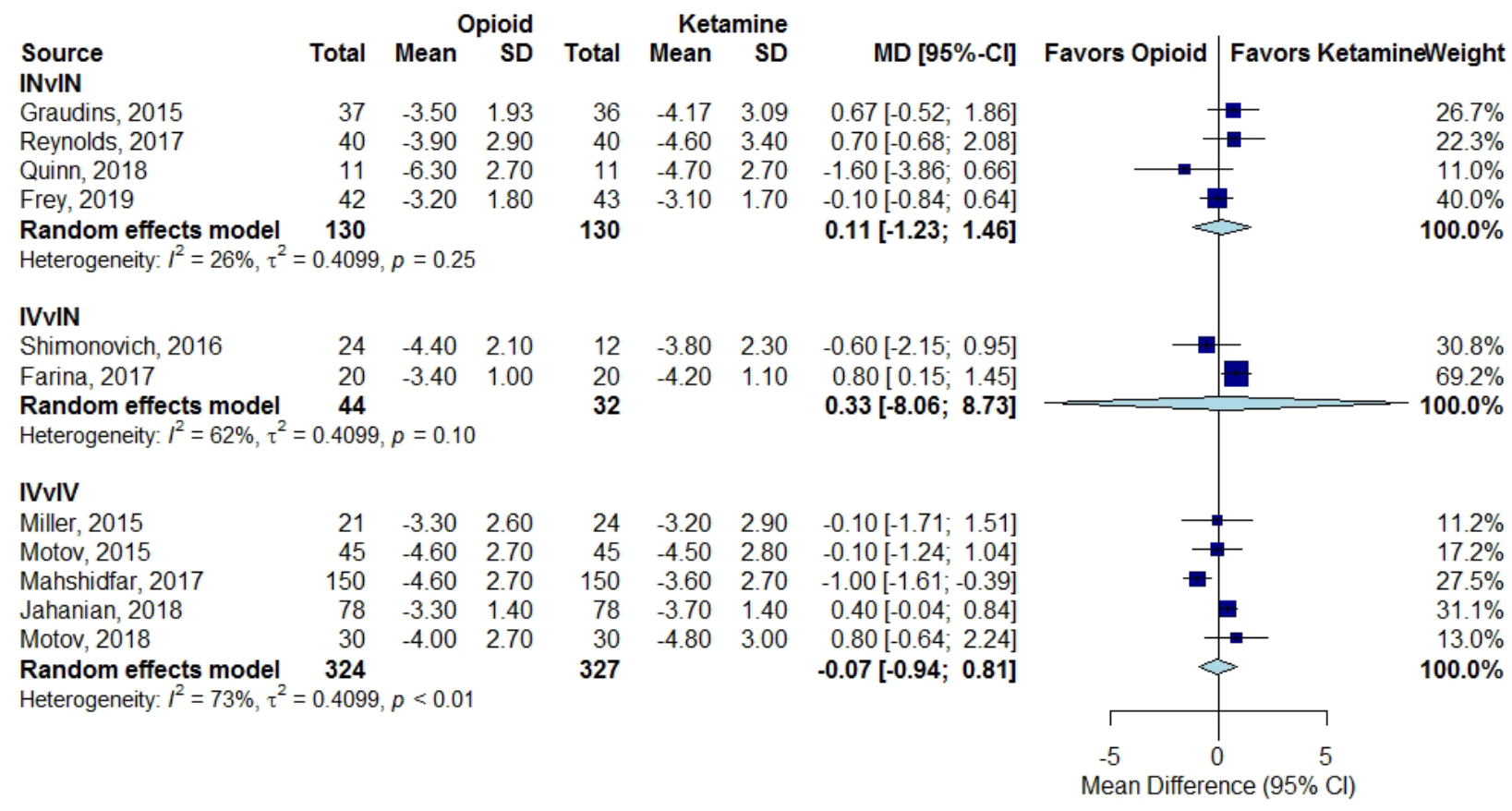


Figure F-17. Mean difference change in pain at 60 minutes - subgroup route of administration, opioids versus ketamine

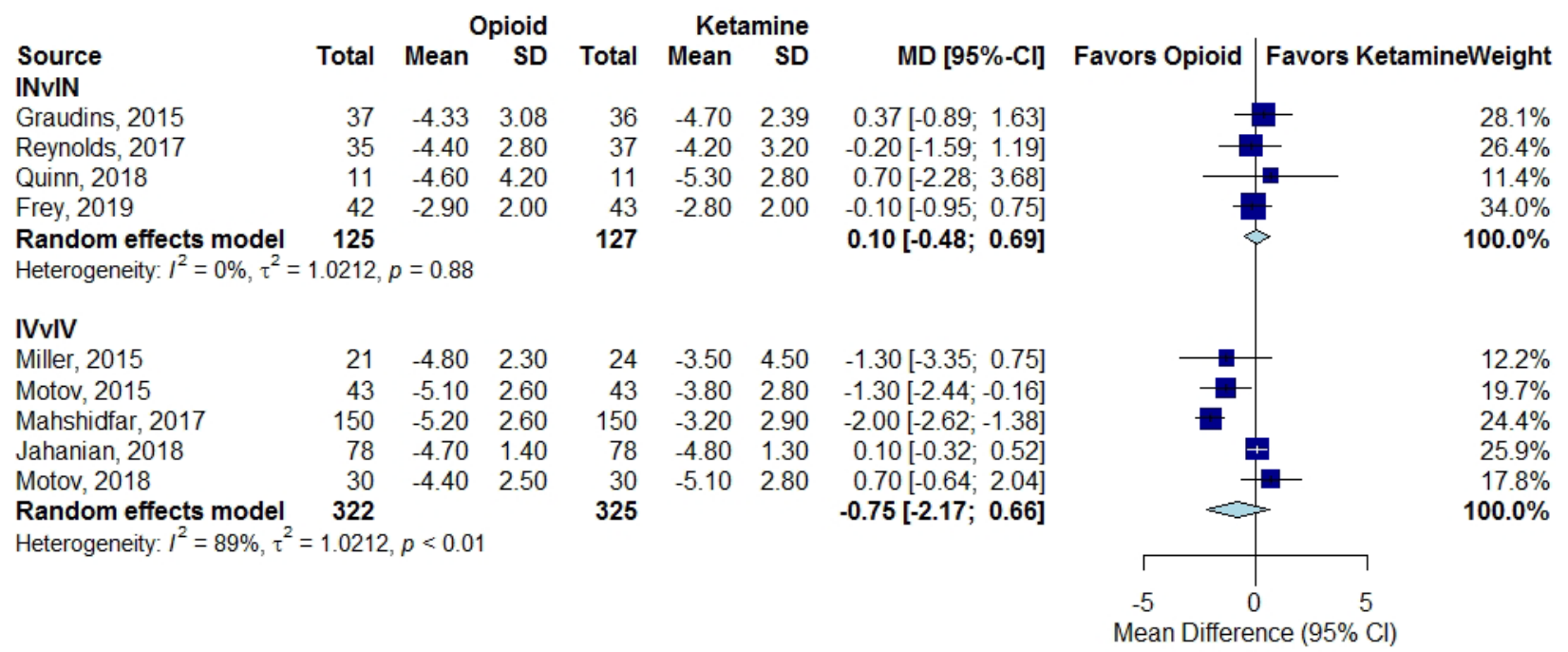

Figure F-18. Mean difference change in pain at 15 minutes - subgroup frequency of administration, opioids versus ketamine

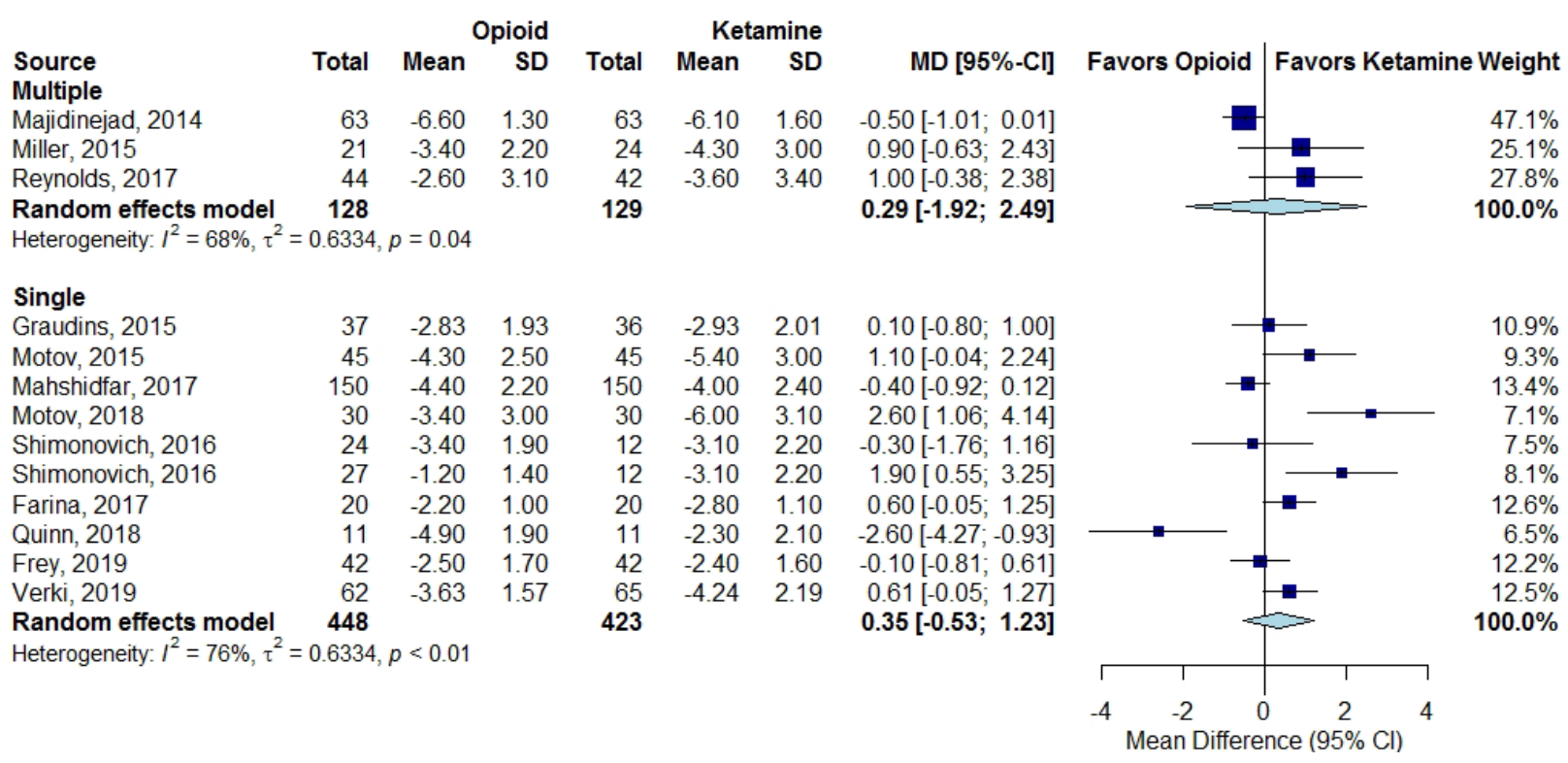


Figure F-19. Mean difference change in pain at 30 minutes - subgroup frequency of administration, opioids versus ketamine

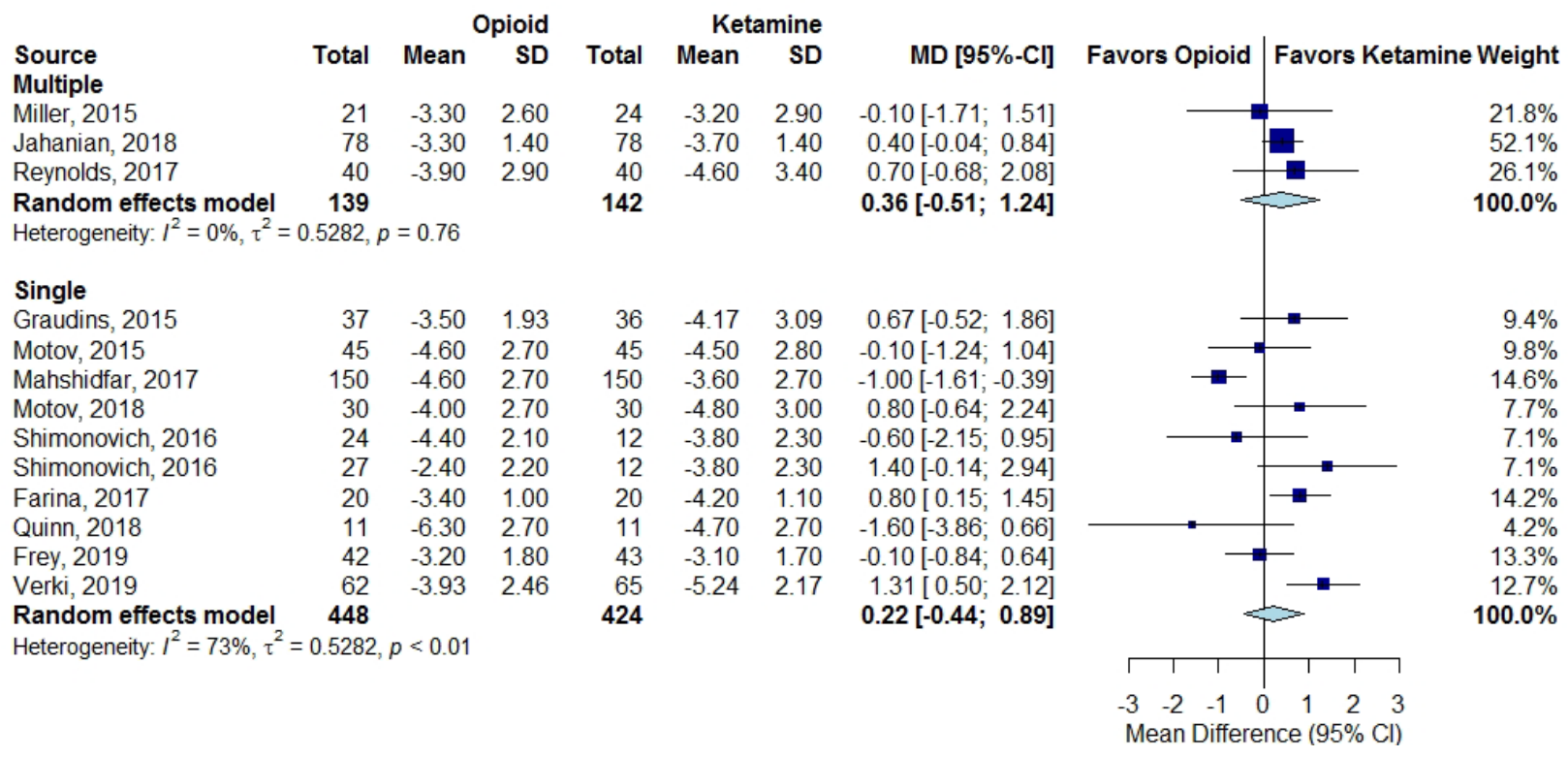

Figure F-20. Mean difference change in pain at 60 minutes - subgroup frequency of administration, opioids versus ketamine

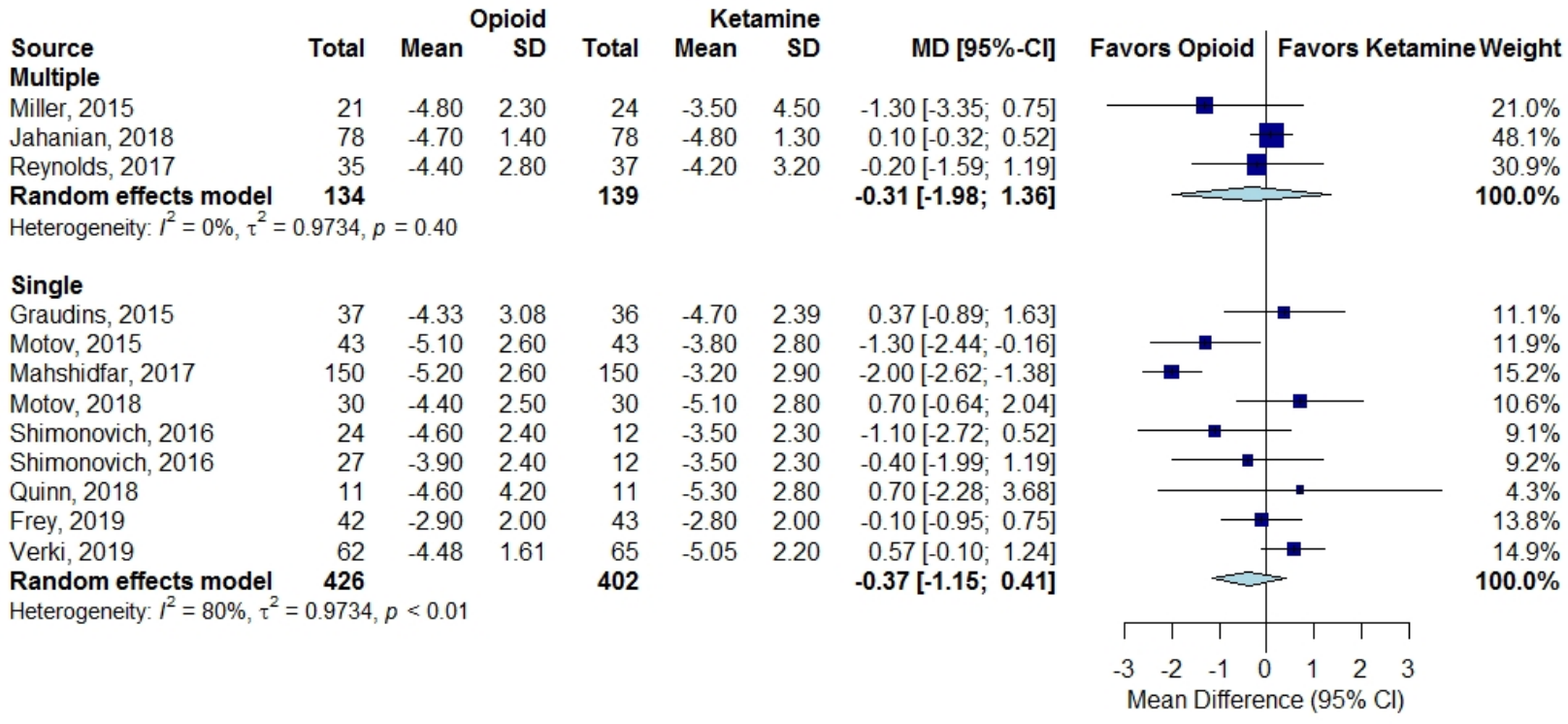


Figure F-21. Mean difference change in pain at 15 minutes - subgroup traumatic pain, opioids versus intravenous acetaminophen

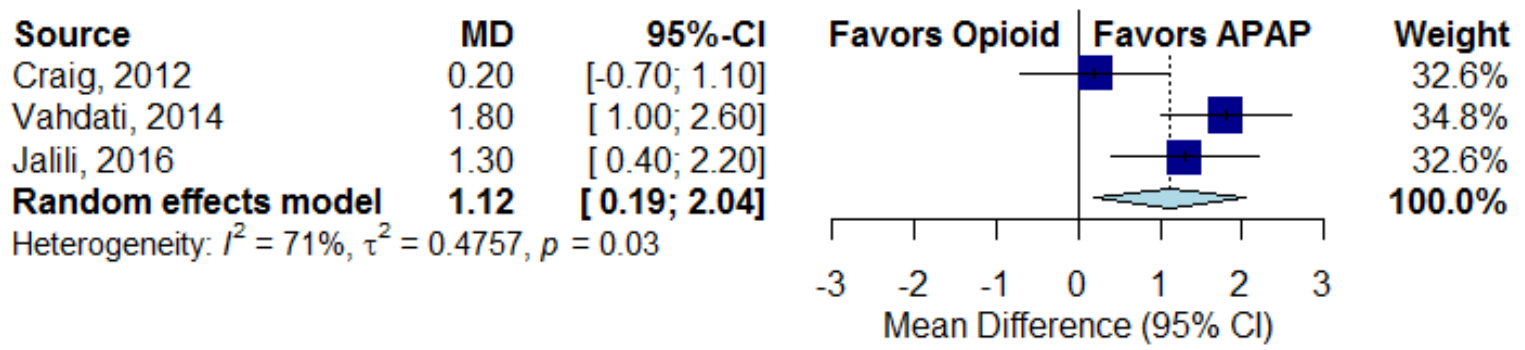

Figure F-22. Mean difference change in pain at $\mathbf{3 0}$ minutes - subgroup traumatic pain, opioids versus acetaminophen

\begin{tabular}{|c|c|c|c|c|c|}
\hline Source & MD & $95 \%-\mathrm{Cl}$ & Favors Opioid & Favors APAP & Weight \\
\hline Craig, 2012 & -0.30 & {$[-1.5 ; 0.9]$} & & & $23.3 \%$ \\
\hline Vahdati, 2014 & 2.30 & {$[1.4 ; 3.2]$} & & & $25.1 \%$ \\
\hline Jalili, 2016 & 1.70 & {$[0.8 ; 2.6]$} & & & $25.1 \%$ \\
\hline Mollaei, 2016 & -0.70 & {$[-1.3 ;-0.1]$} & & & $26.5 \%$ \\
\hline Random effects model & 0.75 & {$[-0.7 ; 2.2]$} & & 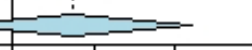 & $100.0 \%$ \\
\hline Heterogeneity: $I^{2}=92 \%, \tau^{2}$ & 1.9732, & $<0.01$ & 「 & 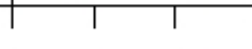 & \\
\hline & & & $\begin{array}{lll}-3 & -2 & -1\end{array}$ & 12 & \\
\hline
\end{tabular}

Figure F-23. Mean difference change in pain at 30 minutes - pain severity, acetaminophen versus nonsteroidal anti-inflammatory drugs

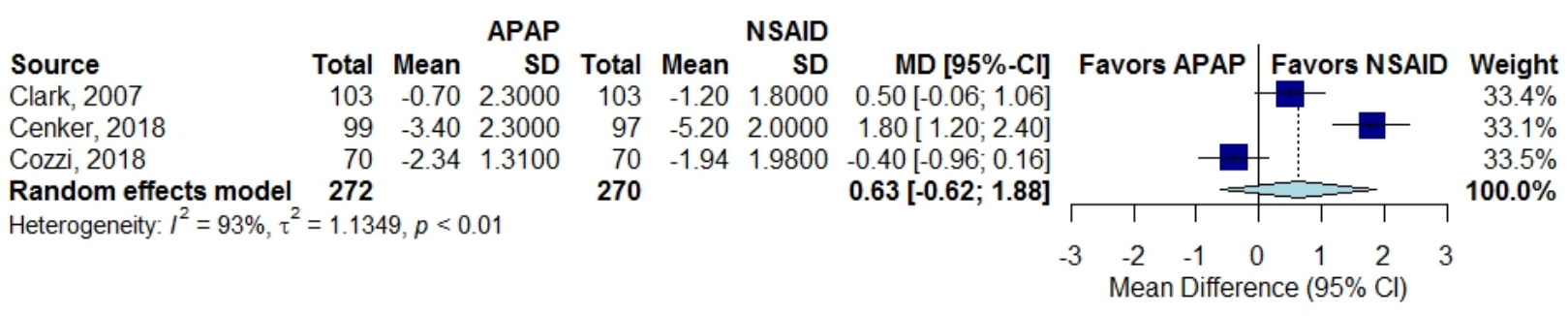

Figure F-24. Mean difference change in pain at 60 minutes - pain severity, acetaminophen versus nonsteroidal anti-inflammatory drugs

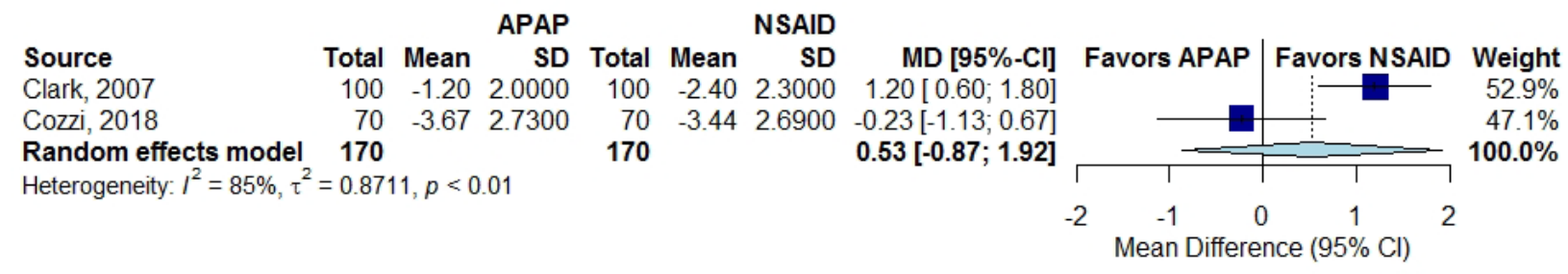


Figure F-25. Risk difference presence of pain - partial resolution at 60 minutes, acetaminophen versus nonsteroidal anti-inflammatory drugs

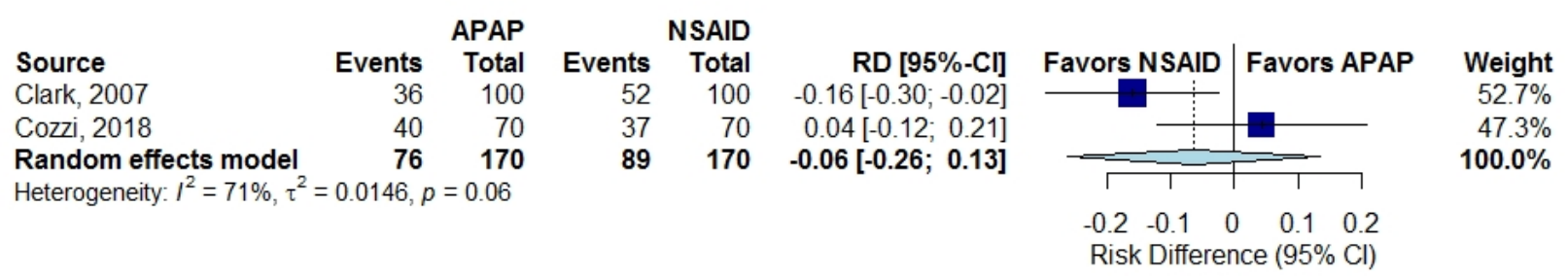

Figure F-26. Mean difference change in pain at 15 minutes - pain severity, morphine versus fentanyl

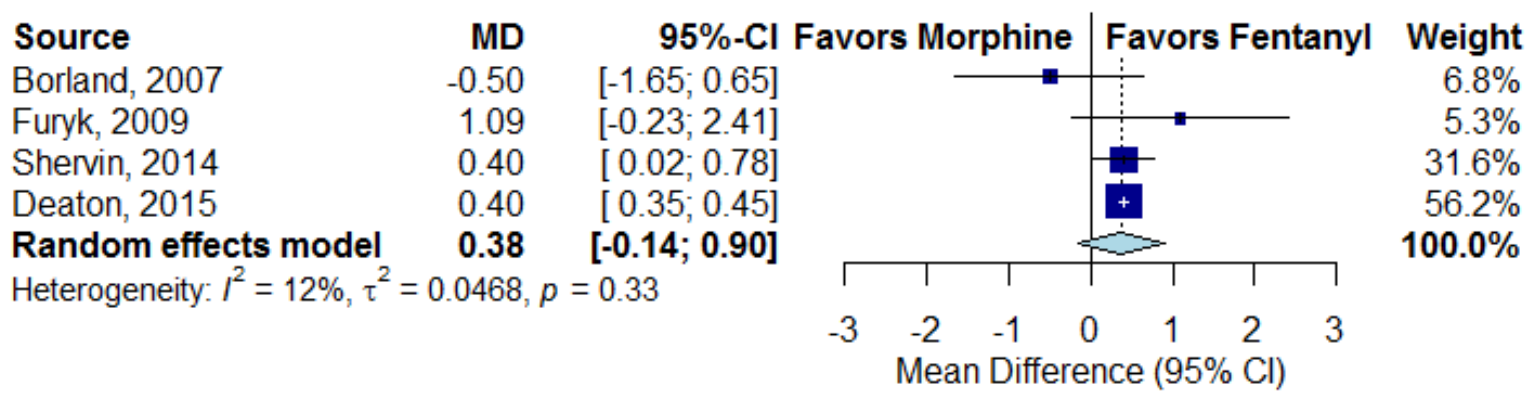

Figure F-27. Mean difference change in pain at 30 minutes - pain severity, morphine versus fentanyl - emergency medical services

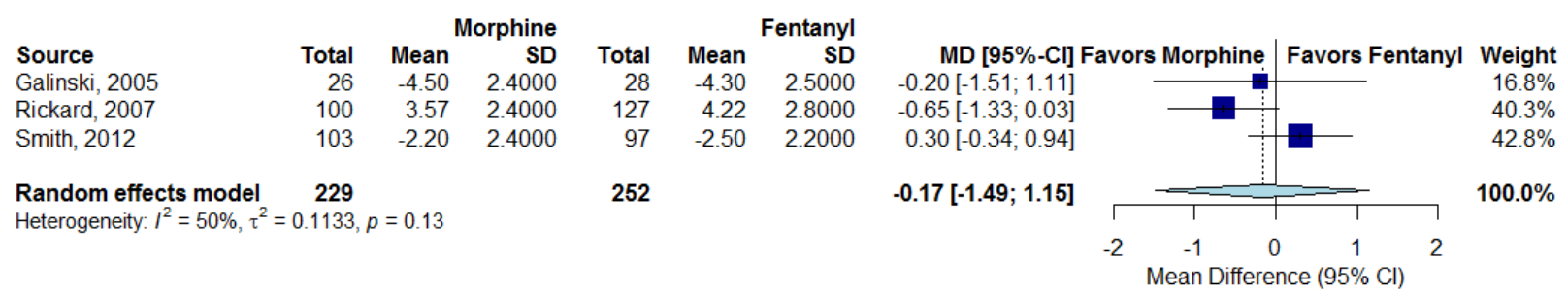

Figure F-28. Mean difference change in pain at 30 minutes - pain severity, morphine versus fentanyl - emergency department

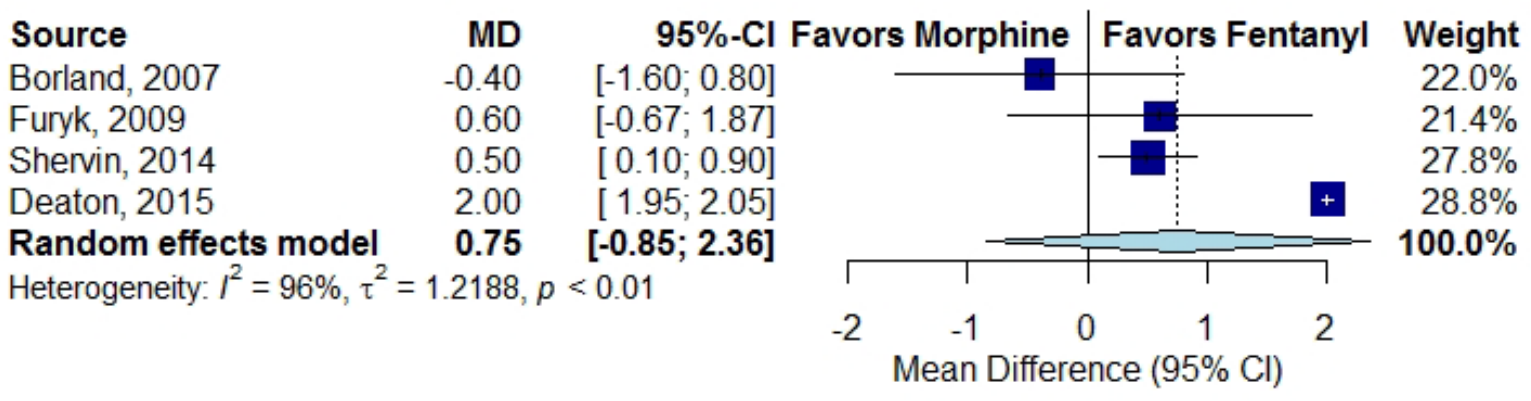


Figure F-29. Mean difference change in pain at 60 minutes - pain severity, morphine versus fentanyl

\begin{tabular}{|c|c|c|c|c|c|c|c|}
\hline Source & MD & $95 \%-\mathrm{Cl}$ & Favors Morphin & & Favors Fent & anyl & Weight \\
\hline Shervin, 2014 & 0.60 & {$[0.20 ; 1.00]$} & & & & & $49.5 \%$ \\
\hline Deaton, 2015 & 2.70 & {$[2.65 ; 2.75]$} & & & + & & $50.5 \%$ \\
\hline Random effects model & 1.66 & {$[-0.40 ; 3.72]$} & & & & & $100.0 \%$ \\
\hline Heterogeneity: $I^{2}=99 \%, \tau^{2}$ & $=2.1838$, & $<0.01$ & 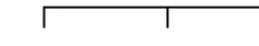 & & T & ᄀ & \\
\hline & & & -4 & & 2 & 4 & \\
\hline
\end{tabular}

Figure F-30. Risk difference presence of pain - partial resolution at $\mathbf{3 0}$ minutes, morphine versus fentanyl-emergency medical services

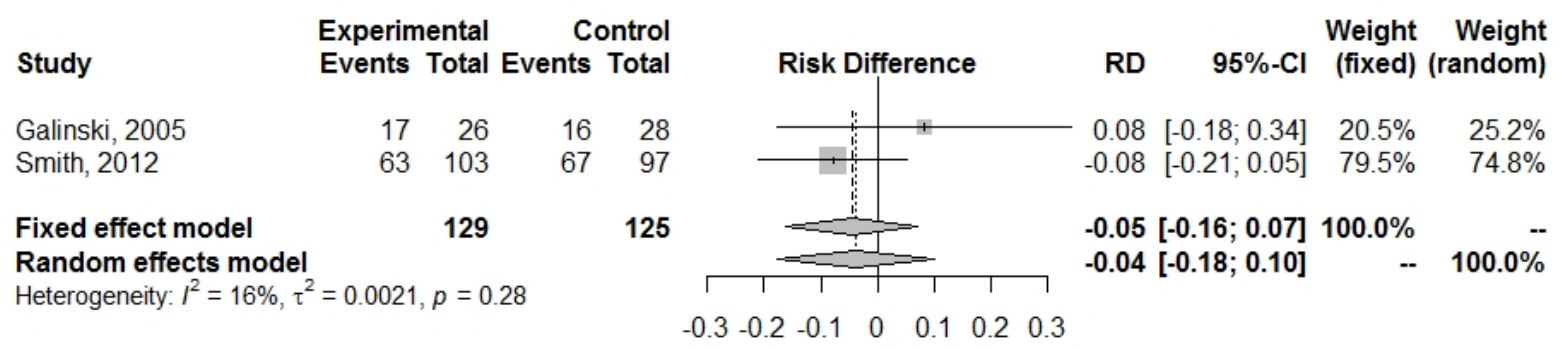

Figure F-31. Risk difference any adverse event, opioids versus ketamine

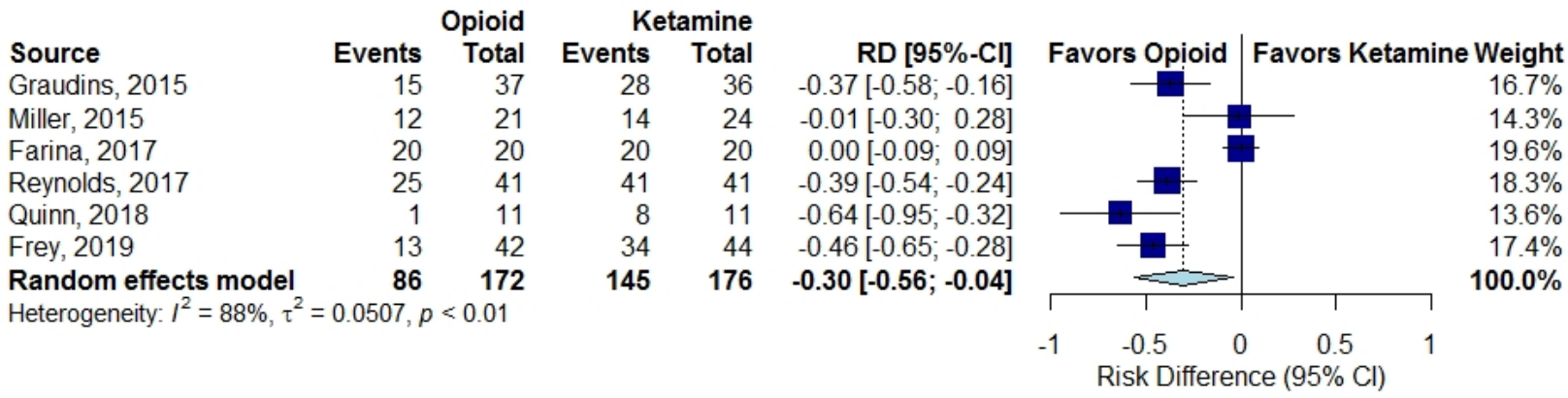

Figure F-32. Risk difference any adverse event at 15 minutes, opioids versus ketamine

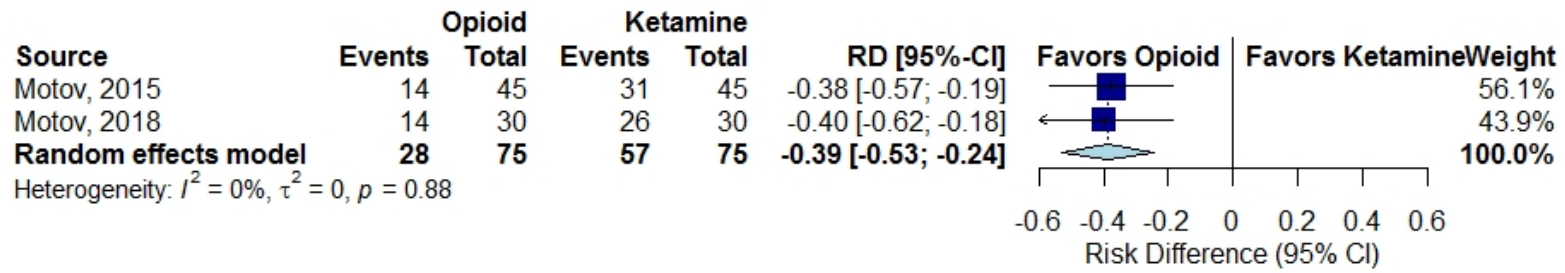


Figure F-33. Risk difference any adverse event at $\mathbf{3 0}$ minutes, opioids versus ketamine

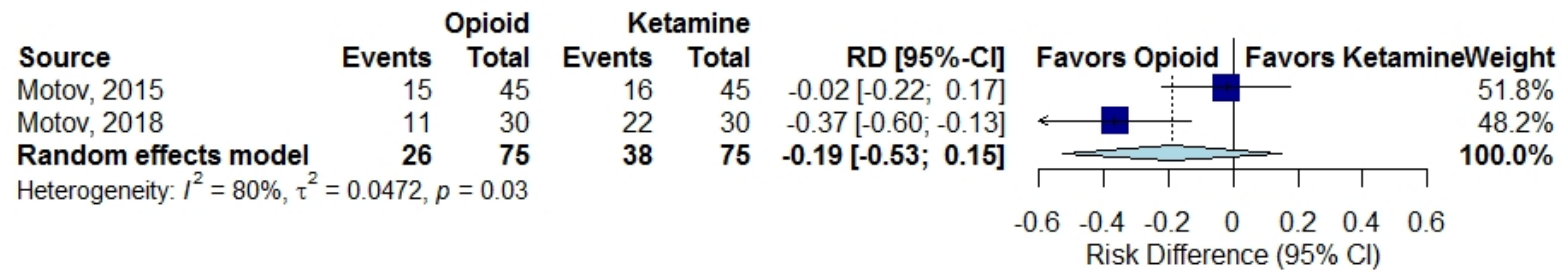

Figure F-34. Risk difference hypotension, opioids versus ketamine

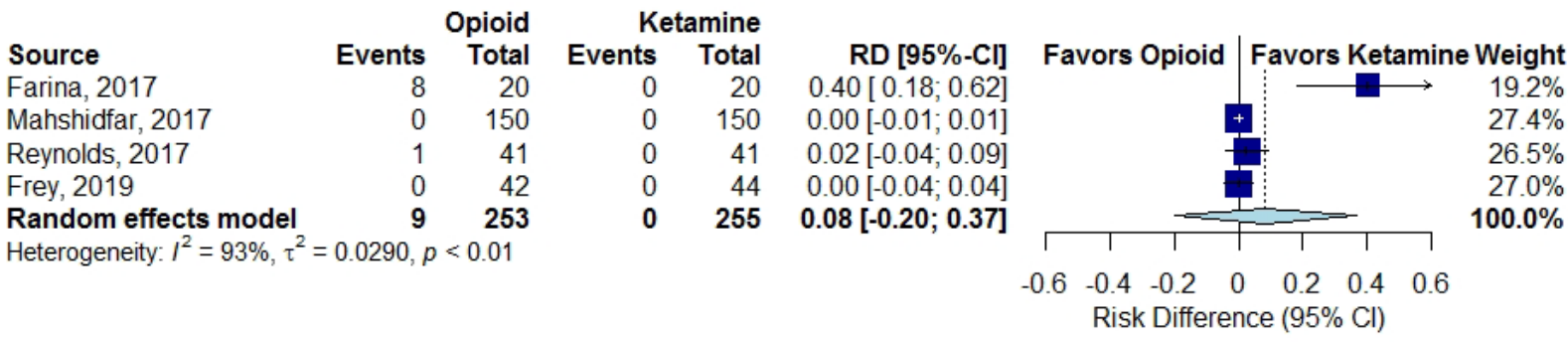

Figure F-35. Risk difference mental status changes dizziness, opioids versus ketamine

\begin{tabular}{|c|c|c|c|c|c|c|c|c|}
\hline \multirow[b]{2}{*}{ Source } & \multicolumn{2}{|c|}{ Opioid } & \multicolumn{2}{|c|}{ Ketamine } & \multirow[b]{2}{*}{$\operatorname{RD}[95 \%-\mathrm{Cl}]$} & \multirow[b]{2}{*}{ Favors Opioid } & \multirow{2}{*}{\multicolumn{2}{|c|}{ Favors Ketamine Weight }} \\
\hline & Events & Total & Events & Total & & & & \\
\hline Graudins, 2015 & 4 & 37 & 20.0 & 36 & $-0.45[-0.64 ;-0.26]$ & & & $13.2 \%$ \\
\hline Miller, 2015 & 1 & 21 & 2.0 & 24 & $-0.04[-0.18 ; 0.11]$ & & & $14.0 \%$ \\
\hline Shimonovich, 2016 & 12 & 24 & 9.5 & 12 & $-0.29[-0.60 ; 0.01]$ & & & $11.0^{\circ}$ \\
\hline Shimonovich, 2016 & 6 & 27 & 9.5 & 12 & $-0.57[-0.85 ;-0.29]$ & & & 11.5 \\
\hline Farina, 2017 & 6 & 20 & 4.0 & 20 & $0.10[-0.17 ; 0.37]$ & & & $11.8^{\circ}$ \\
\hline Mahshidfar, 2017 & 48 & 150 & 51.0 & 150 & $-0.02[-0.13 ; 0.09]$ & & & 14.5 \\
\hline Reynolds, 2017 & 6 & 41 & 30.0 & 41 & $-0.59[-0.76 ;-0.41]$ & & & $13.5^{\circ}$ \\
\hline Quinn, 2018 & 1 & 11 & 7.0 & 11 & $-0.55[-0.88 ;-0.21]$ & & & $10.5 \%$ \\
\hline Random effects model & 84 & 331 & 133.0 & 306 & $-0.29[-0.52 ;-0.06]$ & & & $100.0^{\circ}$ \\
\hline Heterogeneity: $I^{2}=88 \%, \tau^{2}$ & $=0.0645, p$ & $<0.01$ & & & & & 1 & \\
\hline & & & & & & -1 & 0.5 & \\
\hline
\end{tabular}

Figure F-36. Risk difference mental status changes dizziness at 15 minutes, opioids versus ketamine

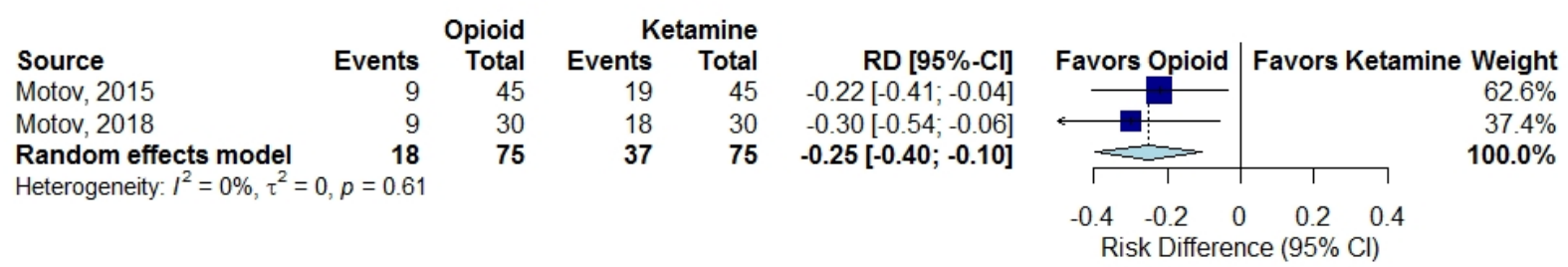

Figure F-37. Risk difference risk mental status changes dizziness 30 minutes, opioids versus ketamine

\begin{tabular}{|c|c|c|c|c|c|c|c|c|}
\hline \multirow{2}{*}{ Source } & \multirow[b]{2}{*}{ Events } & Opioid & \multicolumn{2}{|c|}{ Ketamine } & \multirow[b]{2}{*}{$\mathrm{RD}[95 \%-\mathrm{Cl}]$} & \multirow[b]{2}{*}{ Favors Opioid } & \multirow{2}{*}{\multicolumn{2}{|c|}{ Favors Ketamine Weight }} \\
\hline & & Total & Events & Total & & & & \\
\hline Motov, 2015 & 6 & 45 & 8 & 45 & $-0.04[-0.19 ; 0.11]$ & & & $45.4 \%$ \\
\hline Motov, 2018 & 7 & 30 & 16 & 30 & $-0.30[-0.53 ;-0.07]$ & & & $32.9 \%$ \\
\hline Quinn, 2018 & 1 & 11 & 5 & 11 & $-0.36[-0.70 ;-0.02]$ & & & $21.7 \%$ \\
\hline Random effects model & 14 & 86 & 29 & 86 & $-0.20[-0.63 ; 0.23]$ & & $==$ & $100.0 \%$ \\
\hline \multirow{2}{*}{\multicolumn{6}{|c|}{ Heterogeneity: $I^{2}=62 \%, \tau^{2}=0.0163, p=0.07$}} & & $T$ & \\
\hline & & & & & & $-0.6-0.4$ & $\begin{array}{lll}0.2 & 0.4 & 0.6\end{array}$ & \\
\hline
\end{tabular}


Figure F-38. Risk difference mental status changes drowsiness, opioids versus ketamine

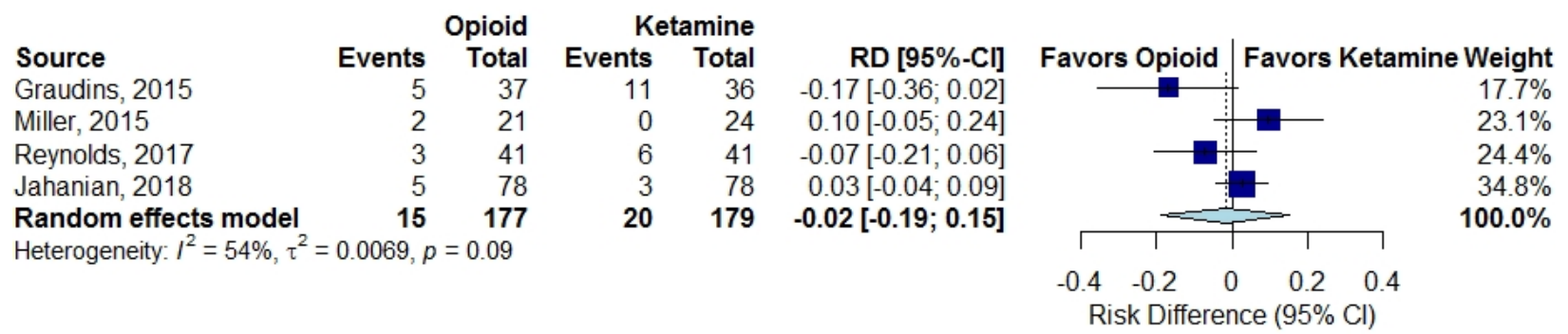

Figure F-39. Risk difference respiratory depression, opioids versus ketamine

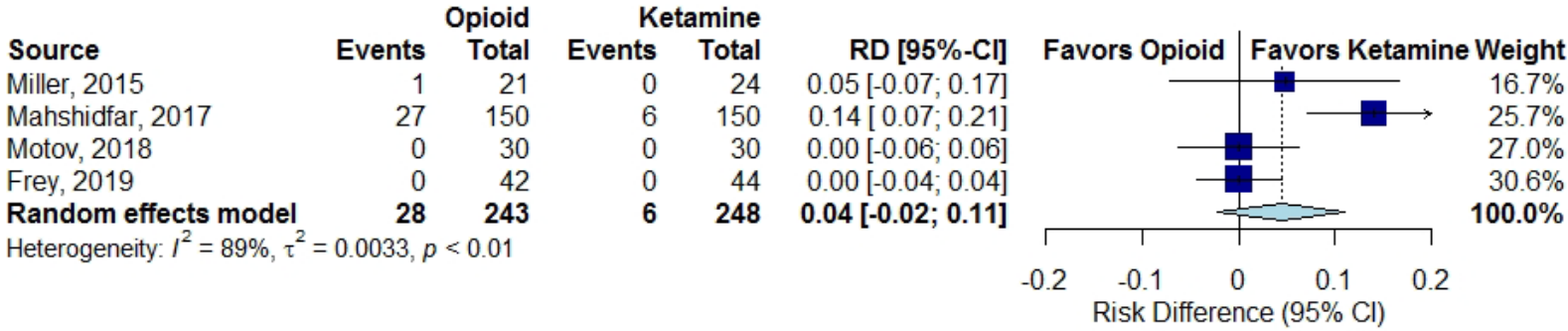

Figure F-40. Risk difference dizziness - subgroup age $<18$ years old, $\geq 18$ years old, opioids versus ketamine

\begin{tabular}{|c|c|c|c|c|c|c|c|c|}
\hline \multirow[b]{2}{*}{ Source } & \multicolumn{2}{|c|}{ Opioid } & \multicolumn{2}{|c|}{ Ketamine } & \multirow[b]{2}{*}{$\mathrm{RD}[95 \%-\mathrm{Cl}]$} & \multirow[b]{2}{*}{ Favors Opioid } & \multirow{2}{*}{\multicolumn{2}{|c|}{ | Favors KetamineWeight }} \\
\hline & Events & Total & Events & Total & & & & \\
\hline Miller, 2015 & 1 & 21 & 2.0 & 24 & $-0.04[-0.18 ; 0.11]$ & & & $22.3 \%$ \\
\hline Shimonovich, 2016 & 12 & 24 & 9.5 & 12 & $-0.29[-0.60 ; 0.01]$ & & & $17.5 \%$ \\
\hline Shimonovich, 2016 & 6 & 27 & 9.5 & 12 & $-0.57[-0.85 ;-0.29]$ & & & $18.4 \%$ \\
\hline Farina, 2017 & 6 & 20 & 4.0 & 20 & $0.10[-0.17 ; 0.37]$ & & & $18.7 \%$ \\
\hline Mahshidfar, 2017 & 48 & 150 & 51.0 & 150 & $-0.02[-0.13 ; 0.09]$ & & & $23.1 \%$ \\
\hline \multirow{2}{*}{\multicolumn{9}{|c|}{ Heterogeneity: $I^{2}=77 \%, \tau^{2}=0.0541, p<0.01$}} \\
\hline & & & & & & & & \\
\hline \multicolumn{9}{|l|}{ Under 18} \\
\hline Graudins, 2015 & 4 & 37 & 20.0 & 36 & $-0.45[-0.64 ;-0.26]$ & & & $35.5 \%$ \\
\hline Reynolds, 2017 & 6 & 41 & 30.0 & 41 & $-0.59[-0.76 ;-0.41]$ & & & $36.3 \%$ \\
\hline Quinn, 2018 & 1 & 11 & 7.0 & 11 & $-0.55[-0.88 ;-0.21]$ & & & $28.2 \%$ \\
\hline Random effects model & 11 & 89 & 57.0 & 88 & $-0.53[-0.72 ;-0.33]$ & & & $100.0 \%$ \\
\hline \multicolumn{9}{|c|}{ Heterogeneity: $I^{2}=0 \%, \tau^{2}=0, p=0.57$} \\
\hline & & & & & & -0.5 & 0.5 & 1 \\
\hline
\end{tabular}


Figure F-41. Risk difference hypotension - subgroup age $<18$ years old, $\geq 18$ years old, opioids versus ketamine

\begin{tabular}{|c|c|c|c|c|c|c|c|c|}
\hline \multirow{3}{*}{$\begin{array}{l}\text { Source } \\
\text { Over } 18 \\
\text { Farina, } 2017\end{array}$} & \multirow[b]{2}{*}{ Events } & Opioid & \multicolumn{2}{|c|}{ Ketamine } & \multirow[b]{2}{*}{$\mathrm{RD}[95 \%-\mathrm{Cl}]$} & \multirow[b]{2}{*}{ Favors Opioid } & \multirow{2}{*}{\multicolumn{2}{|c|}{ Favors Ketamine Weight }} \\
\hline & & Total & Events & Total & & & & \\
\hline & 8 & 20 & 0 & 20 & $0.40[0.18 ; 0.62]$ & & & $41.1 \%$ \\
\hline Mahshidfar, 2017 & 0 & 150 & 0 & 150 & $0.00[-0.01 ; 0.01]$ & & & $58.9 \%$ \\
\hline \multirow{2}{*}{\multicolumn{9}{|c|}{ Heterogeneity: $I^{2}=92 \%, \tau^{2}=0.0737, p<0.01$}} \\
\hline & & & & & & & & \\
\hline \multicolumn{9}{|l|}{ Under 18} \\
\hline Reynolds, 2017 & 1 & 41 & 0 & 41 & $0.02[-0.04 ; 0.09]$ & & & $49.5 \%$ \\
\hline Frey, 2019 & 0 & 42 & 0 & 44 & $0.00[-0.04 ; 0.04]$ & & + & $50.5 \%$ \\
\hline Random effects model & 1 & 83 & 0 & 85 & $0.01[-0.03 ; 0.04]$ & & & $100.0 \%$ \\
\hline \multirow[t]{2}{*}{ Heterogeneity: $I^{2}=0 \%, \tau^{2}$} & $0, p=0.54$ & & & & & $\Gamma$ & $T$ & \\
\hline & & & & & & $\begin{array}{ll}-1 & -0.5 \\
& \text { Risk Differer }\end{array}$ & $\begin{array}{lc}0 & 0.5 \\
\text { nce } & (95 \% \mathrm{Cl})\end{array}$ & \\
\hline
\end{tabular}

Figure F-42. Risk difference dizziness - subgroup traumatic pain, opioids versus ketamine

\begin{tabular}{|c|c|c|c|c|c|c|c|c|}
\hline \multirow[b]{2}{*}{ Source } & \multicolumn{2}{|r|}{ Opioid } & \multicolumn{2}{|c|}{ Ketamine } & \multirow[b]{2}{*}{$\mathrm{RD}[95 \%-\mathrm{Cl}]$} & \multirow[b]{2}{*}{ Favors Opioid } & \multirow{2}{*}{\multicolumn{2}{|c|}{ Favors Ketamine Weight }} \\
\hline & Events & Total & Events & Total & & & & \\
\hline Graudins, 2015 & 4 & 37 & 20.0 & 36 & $-0.45[-0.64 ;-0.26]$ & & & $20.8 \%$ \\
\hline Shimonovich, 2016 & 12 & 24 & 9.5 & 12 & $-0.29[-0.60 ; 0.01]$ & & & $16.6 \%$ \\
\hline Shimonovich, 2016 & 6 & 27 & 9.5 & 12 & $-0.57[-0.85 ;-0.29]$ & & & $17.6 \%$ \\
\hline Mahshidfar, 2017 & 48 & 150 & 51.0 & 150 & $-0.02[-0.13 ; 0.09]$ & & & $23.5 \%$ \\
\hline Reynolds, 2017 & 6 & 41 & 30.0 & 41 & $-0.59[-0.76 ;-0.41]$ & & & $21.5 \%$ \\
\hline Random effects model & 76 & 279 & 120.0 & 251 & $-0.37[-0.68 ;-0.07]$ & & & $100.0 \%$ \\
\hline \multirow{2}{*}{\multicolumn{6}{|c|}{ Heterogeneity: $I^{2}=90 \%, \tau^{2}=0.0481, p<0.01$}} & 1 & T & 7 \\
\hline & & & & & & -0.5 & 0.5 & 1 \\
\hline
\end{tabular}

Figure F-43. Risk difference drowsiness - subgroup traumatic pain, opioids versus ketamine

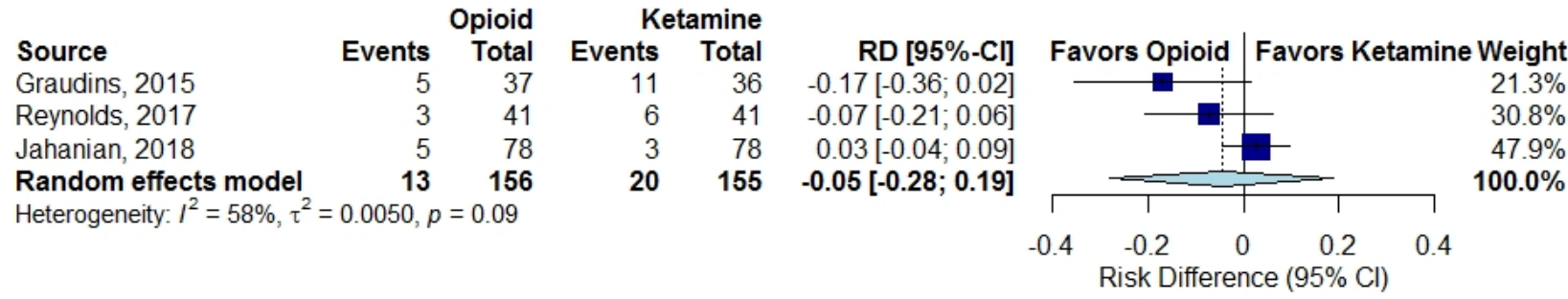

Figure F-44. Risk difference hypotension - subgroup traumatic pain, opioids versus ketamine

\begin{tabular}{lrrrrr} 
& & Opioid & \multicolumn{2}{c}{ Ketamine } & \\
Source & Events & Total & Events & Total & RD [95\%-Cl] \\
Mahshidfar, 2017 & 0 & 150 & 0 & 150 & $0.00[-0.01 ; 0.01]$ \\
Reynolds, 2017 & 1 & 41 & 0 & 41 & $0.02[-0.04 ; 0.09]$ \\
Frey, 2019 & 0 & 42 & 0 & 44 & $0.00[-0.04 ; 0.04]$ \\
Random effects model & $\mathbf{1}$ & $\mathbf{2 3 3}$ & $\mathbf{0}$ & $\mathbf{2 3 5}$ & $\mathbf{0 . 0 0}[-\mathbf{0 . 0 1} ; \mathbf{0 . 0 1}]$
\end{tabular}

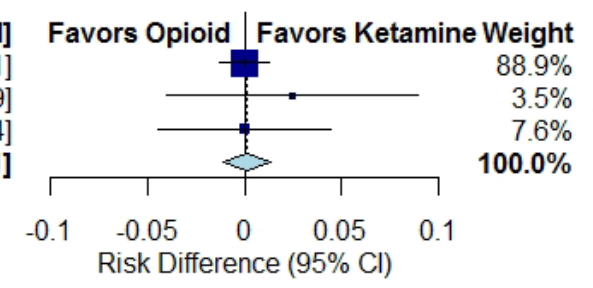


Figure F-45. Risk difference respiratory depression - subgroup traumatic pain, opioids versus ketamine

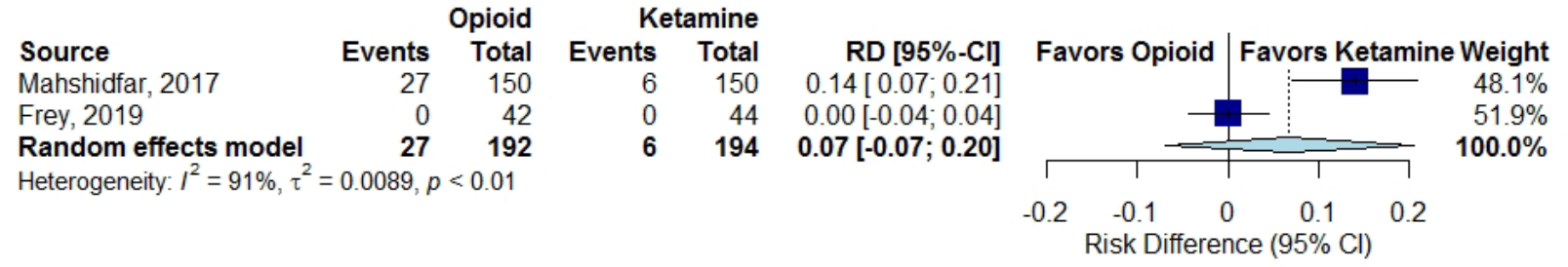

Figure F-46. Risk difference any adverse event - subgroup traumatic pain, opioids versus ketamine

\begin{tabular}{|c|c|c|c|c|c|c|c|c|}
\hline & & Opioid & & amine & & & & \\
\hline Source & Events & Total & Events & Total & $\mathrm{RD}[95 \%-\mathrm{Cl}]$ & Favors Opioid & Favors Ketar & mine Weight \\
\hline Graudins, 2015 & 15 & 37 & 28 & 36 & $-0.37[-0.58 ;-0.16]$ & & & $24.1 \%$ \\
\hline Reynolds, 2017 & 25 & 41 & 41 & 41 & $-0.39[-0.54 ;-0.24]$ & & & $45.8 \%$ \\
\hline Frey, 2019 & 13 & 42 & 34 & 44 & $-0.46[-0.65 ;-0.28]$ & - & & $30.1 \%$ \\
\hline Random effects model & 53 & 120 & 103 & 121 & $-0.41[-0.52 ;-0.30]$ & $\infty$ & & $100.0 \%$ \\
\hline Heterogeneity: $I^{2}=0 \%, \tau^{2}$ & $0, p=0.78$ & & & & & & T & 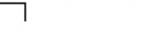 \\
\hline & & & & & & $\begin{array}{c}-0.5 \\
0\end{array}$ & $\begin{array}{l}0.5 \\
5 \%\end{array}$ & 1 \\
\hline
\end{tabular}

Figure F-47. Risk difference any adverse event - subgroup location of pain, opioids versus ketamine

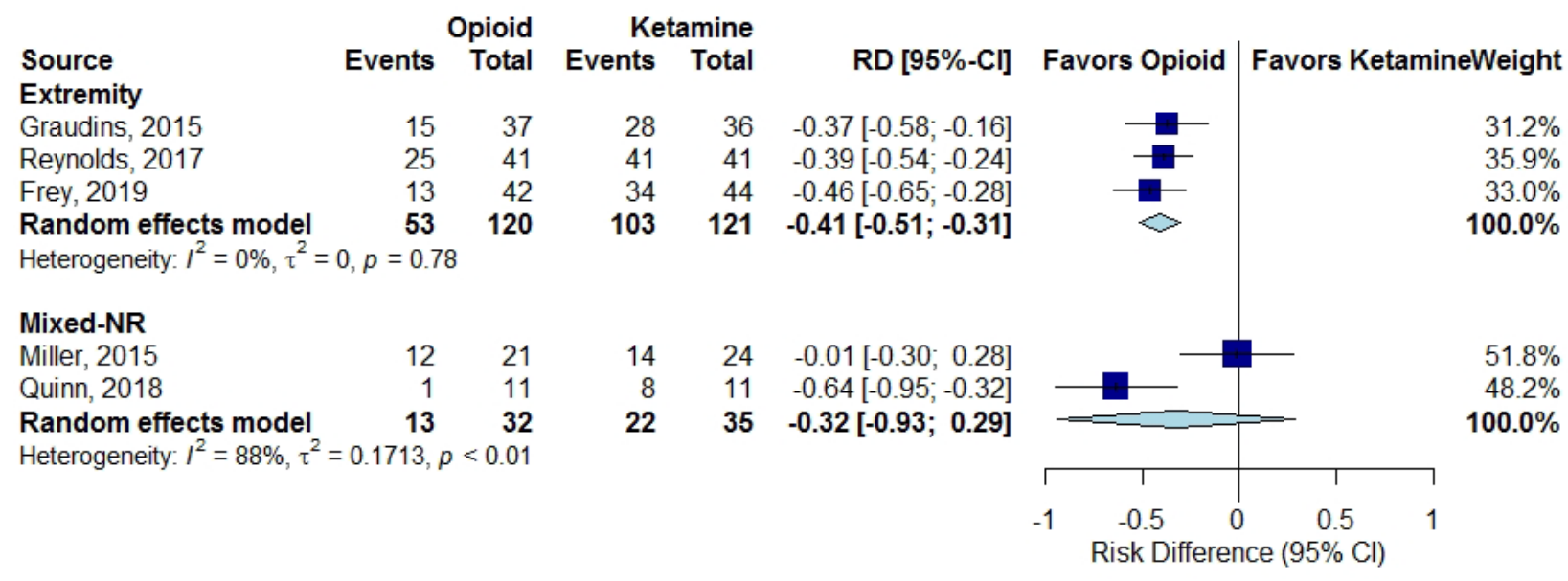


Figure F-48. Risk difference dizziness - subgroup location of pain, opioids versus ketamine

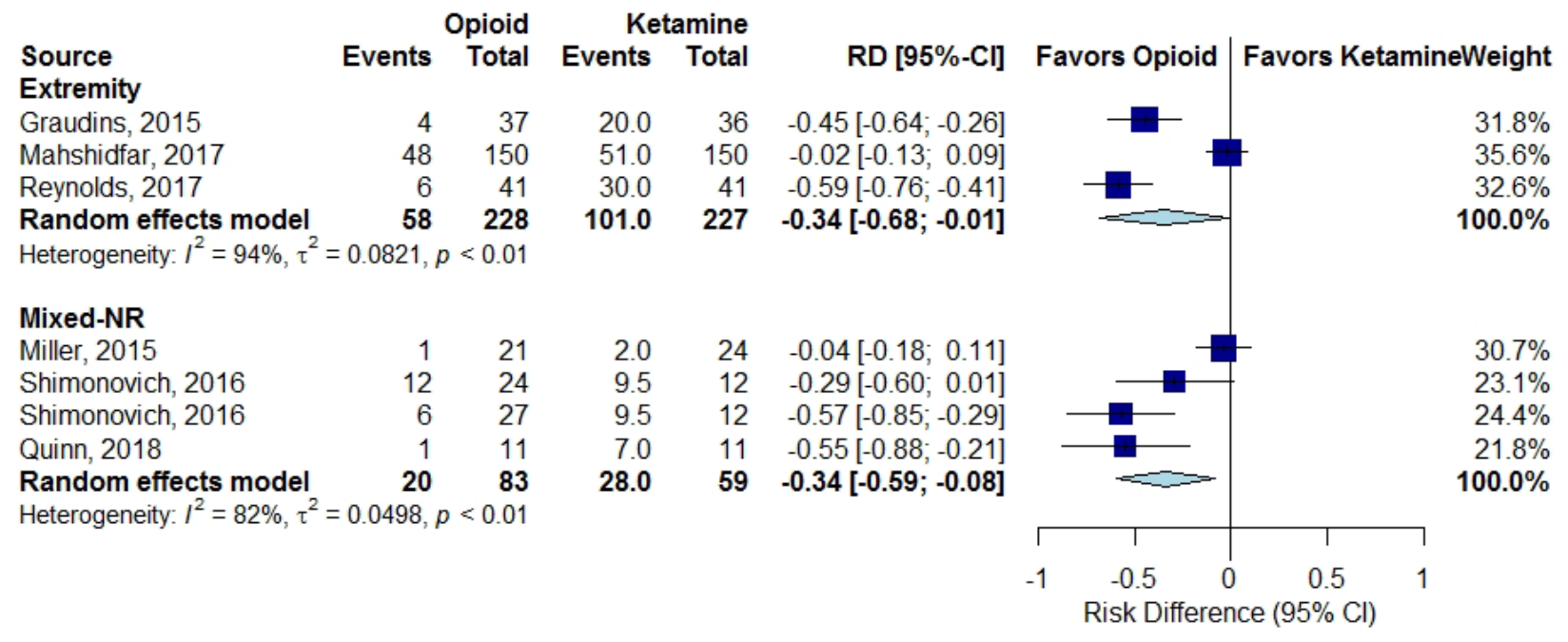

Figure F-49. Risk difference respiratory depression - subgroup location of pain, opioids versus ketamine

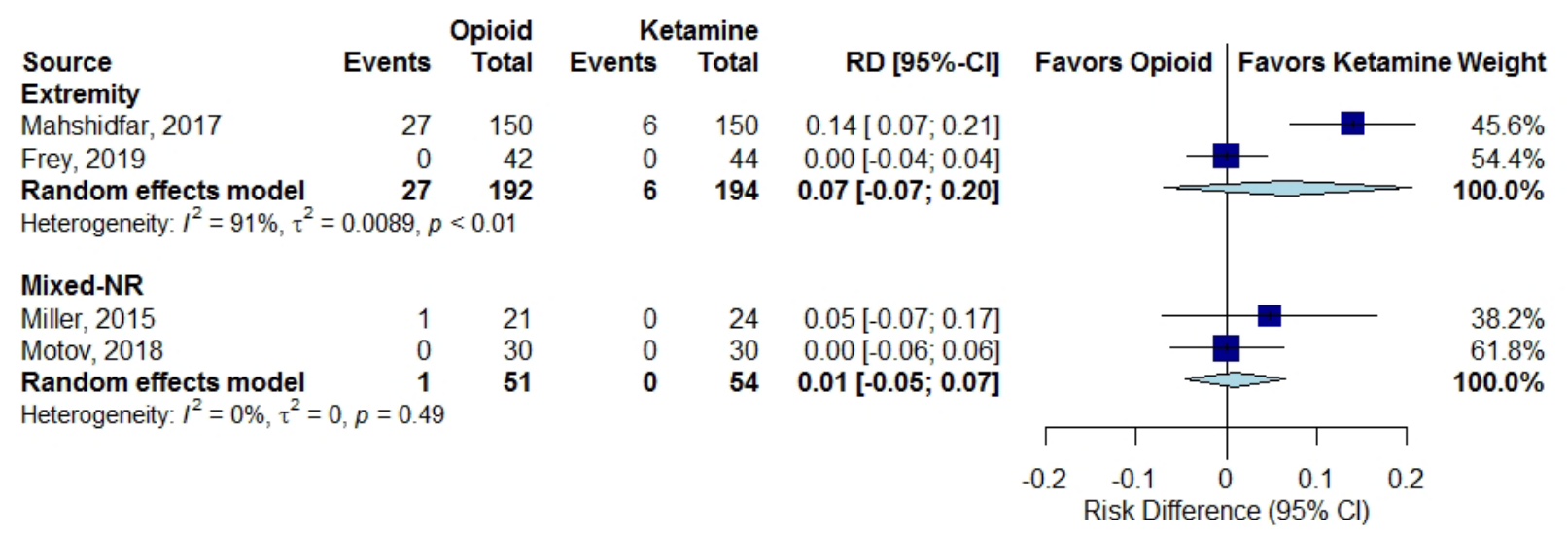


Figure F-50. Risk difference dizziness - subgroup route of administration, opioids versus ketamine

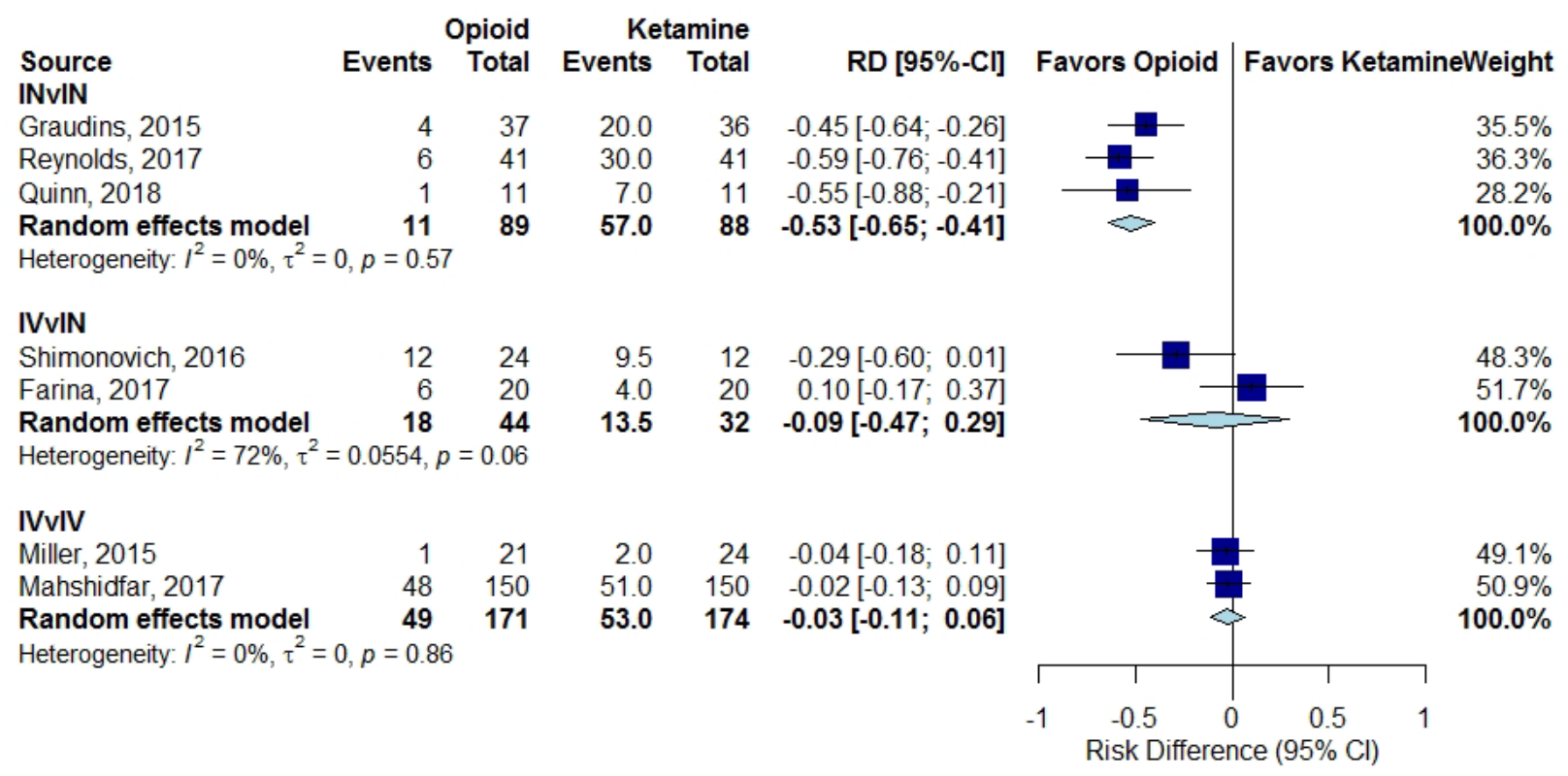

Figure F-51. Risk difference dizziness - subgroup frequency of administration, opioids versus ketamine

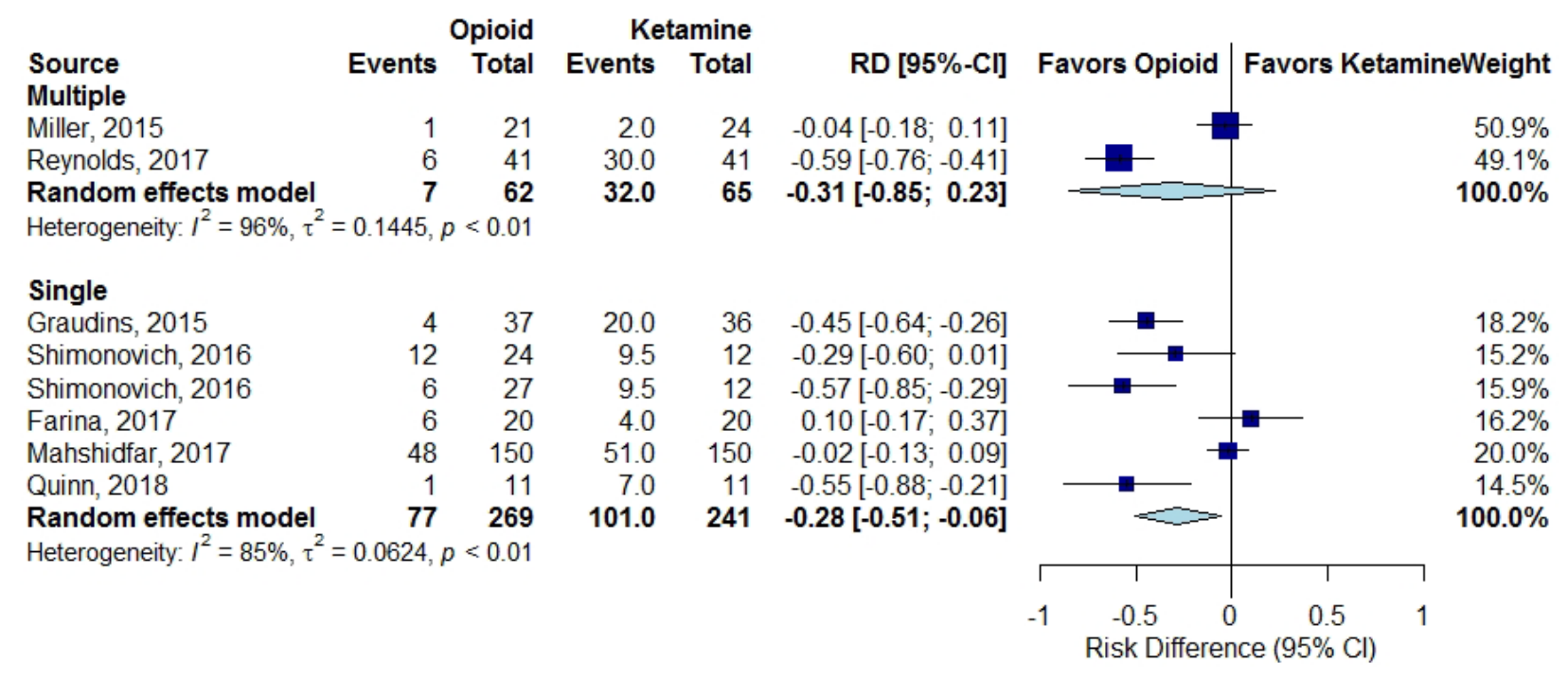


Figure F-52. Risk difference any adverse event - subgroup frequency of administration, opioids versus ketamine

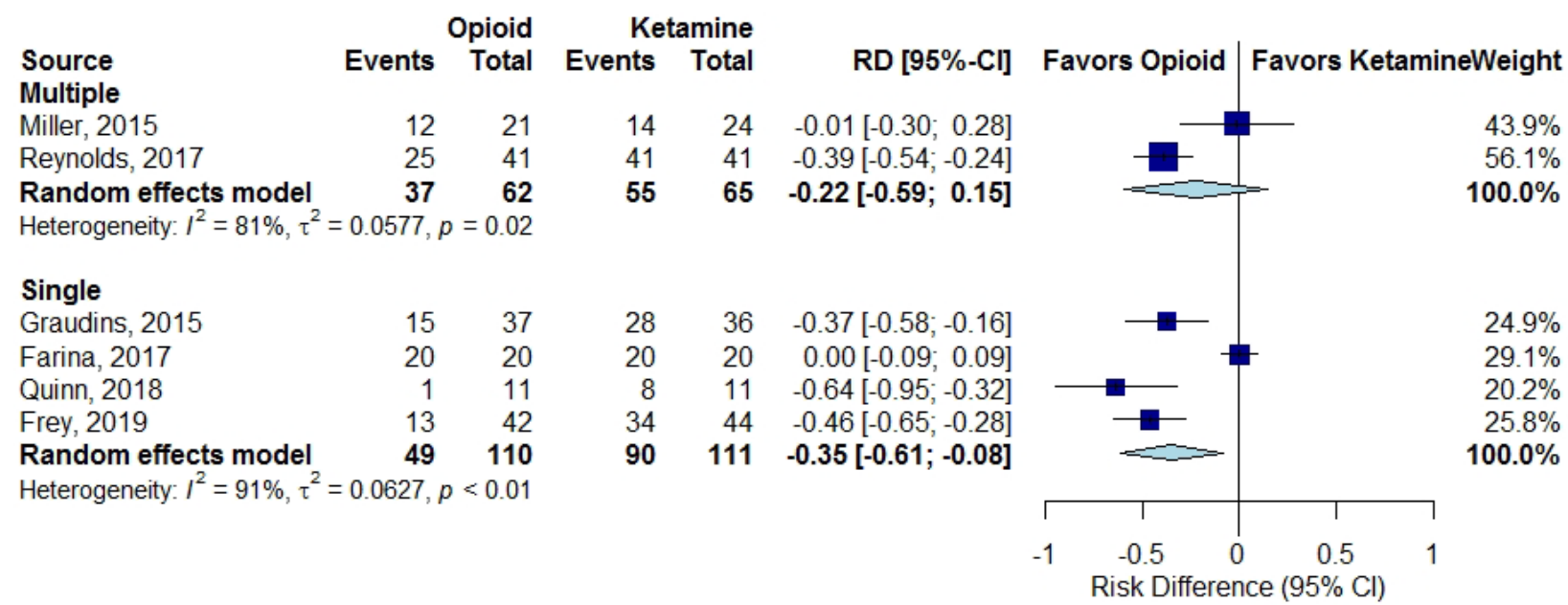

Figure F-53. Mean difference change in diastolic blood pressure at 15 minutes - additional findings, opioids versus ketamine

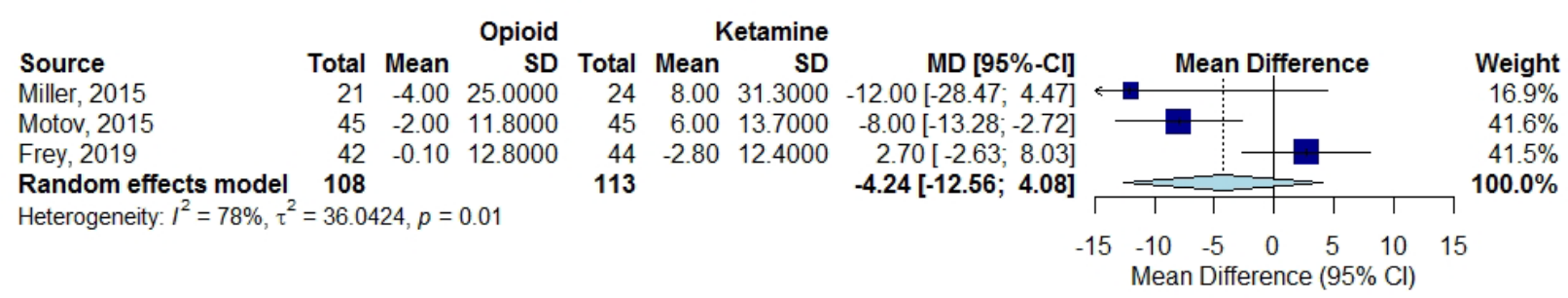

Figure F-54. Mean difference change in diastolic blood pressure at $\mathbf{3 0}$ minutes - additional findings, opioids versus ketamine

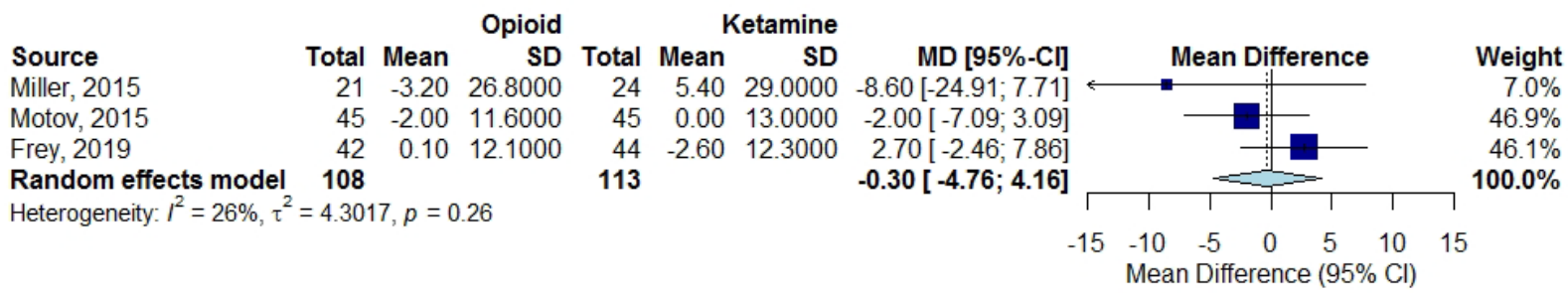

Figure F-55. Mean difference change in diastolic blood pressure at 60 minutes - additional findings, opioids versus ketamine

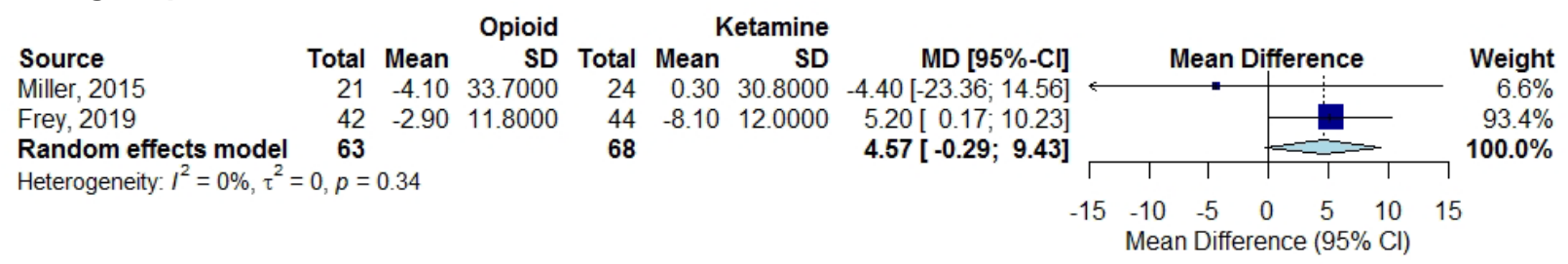


Figure F-56. Risk difference dissociation - additional findings, opioids versus ketamine

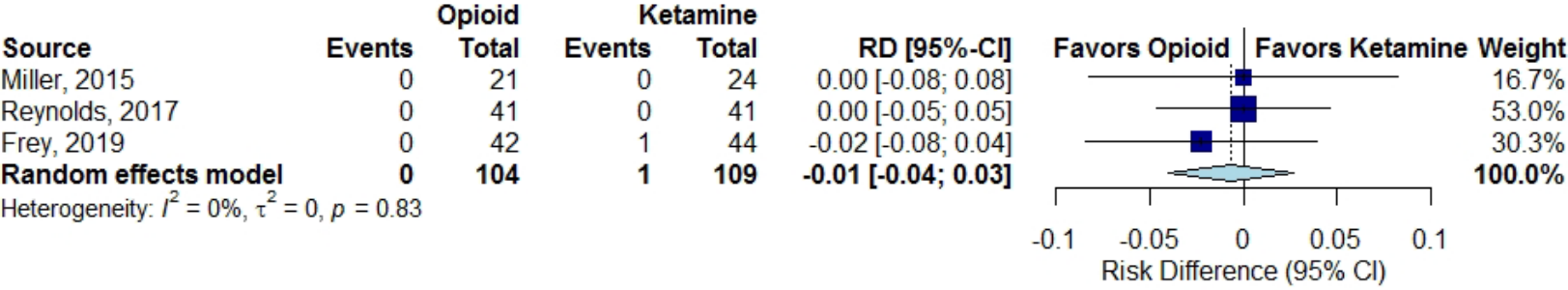

Figure F-57. Risk difference emergence delirium - additional findings, opioids versus ketamine

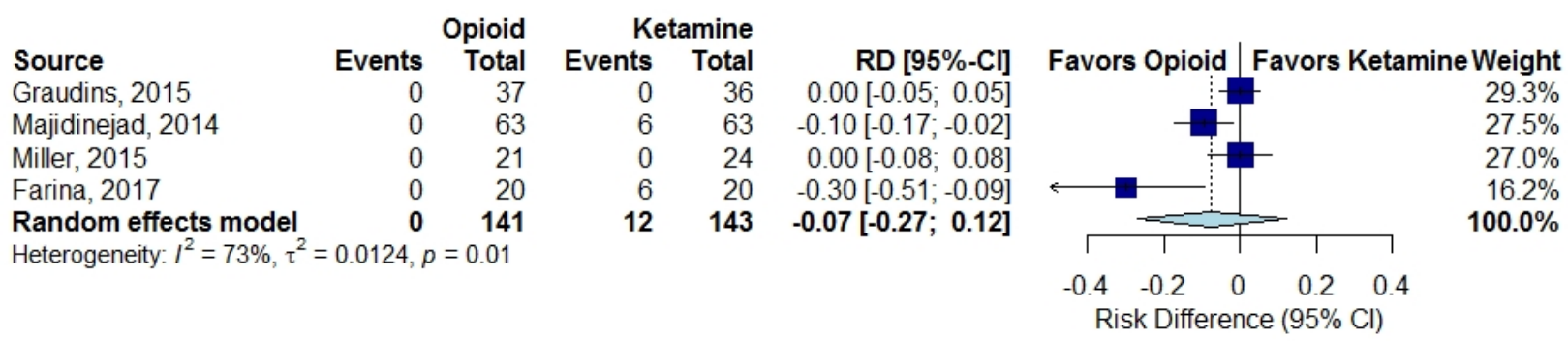

Figure F-58. Mean difference change in heart rate at 15 minutes - additional findings, opioids versus ketamine

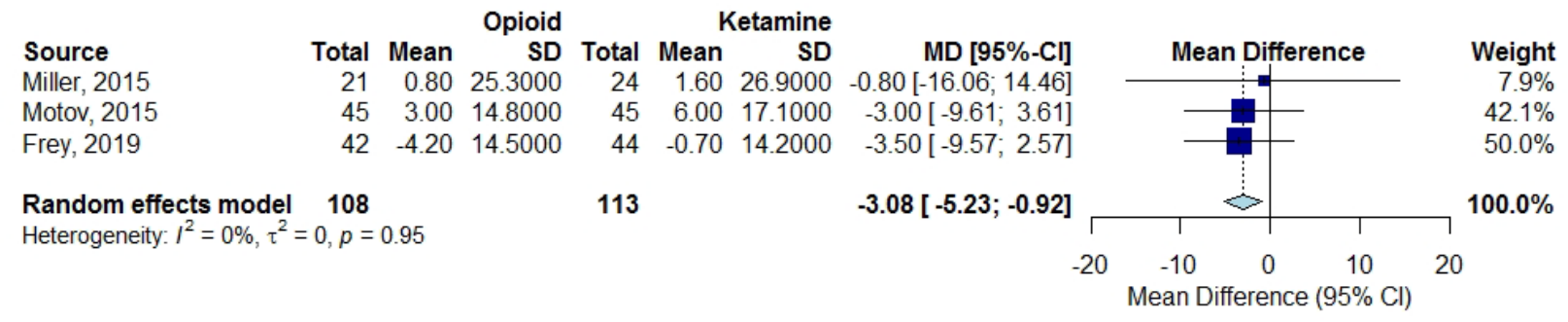

Figure F-59. Mean difference change in heart rate at $\mathbf{3 0}$ minutes - additional findings, opioids versus ketamine

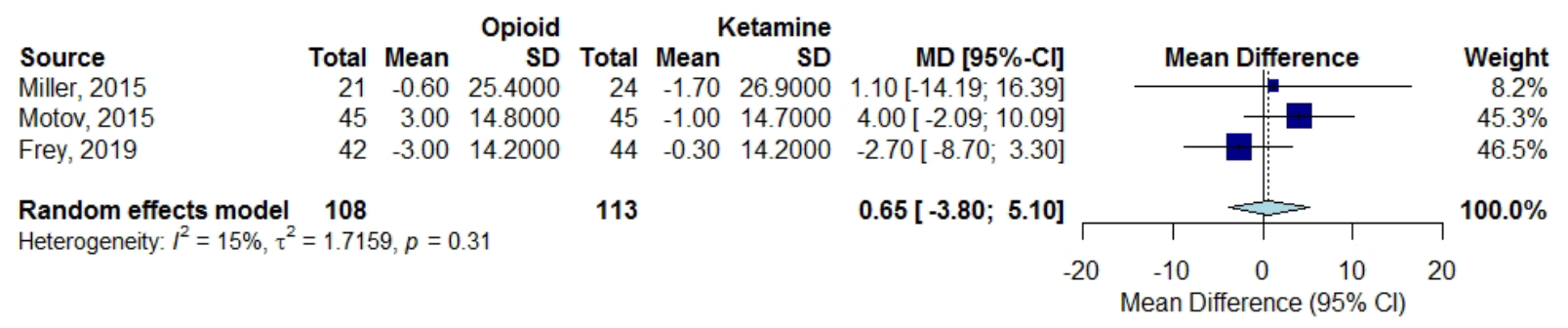

Figure F-60. Mean difference change in heart rate at 60 minutes - additional findings, opioids versus ketamine

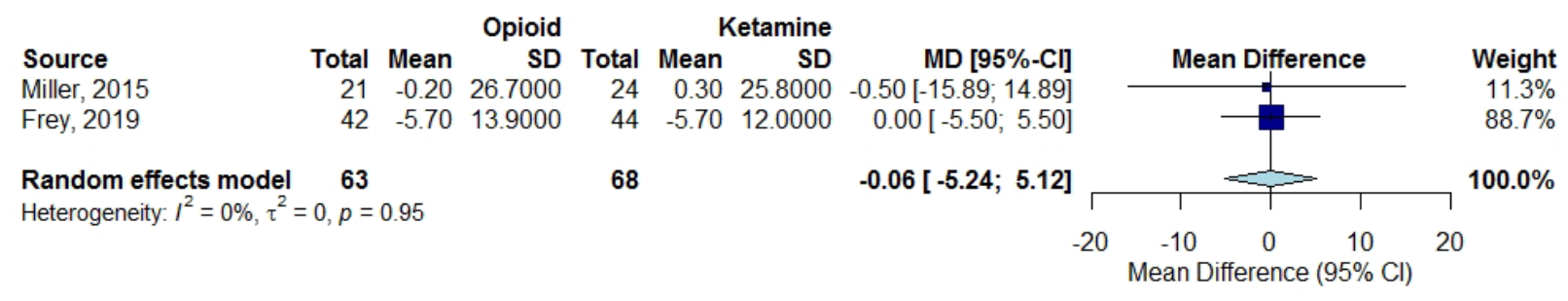


Figure F-61. Risk difference nausea at 15 minutes - additional findings, opioids versus ketamine

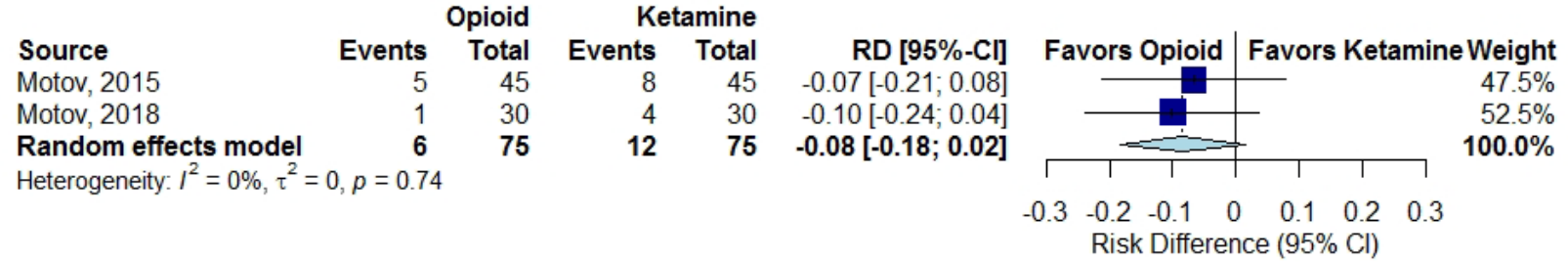

Figure F-62. Risk difference nausea at $\mathbf{3 0}$ minutes - additional findings, opioids versus ketamine

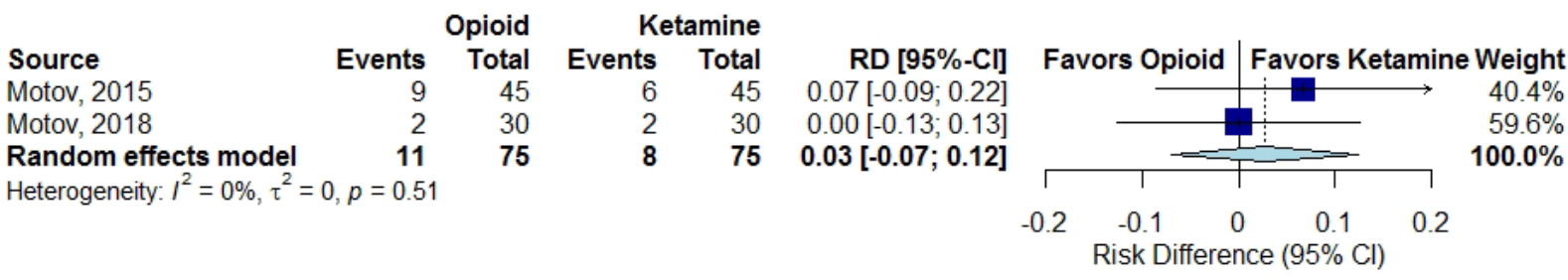

Figure F-63. Risk difference nausea - additional findings, opioids versus ketamine

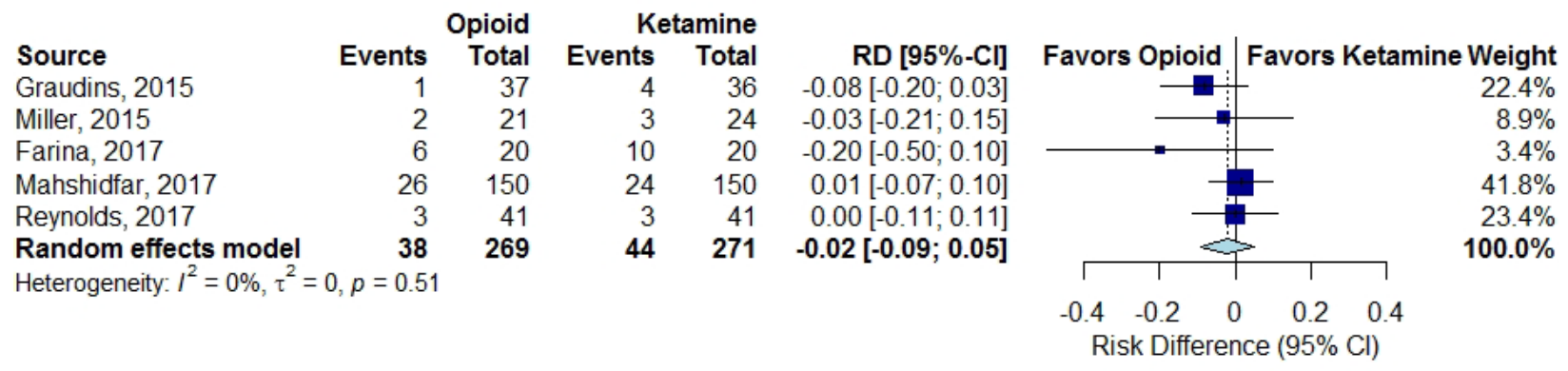

Figure F-64. Mean difference change in oxygen saturation at 15 minutes - additional findings, opioids versus ketamine

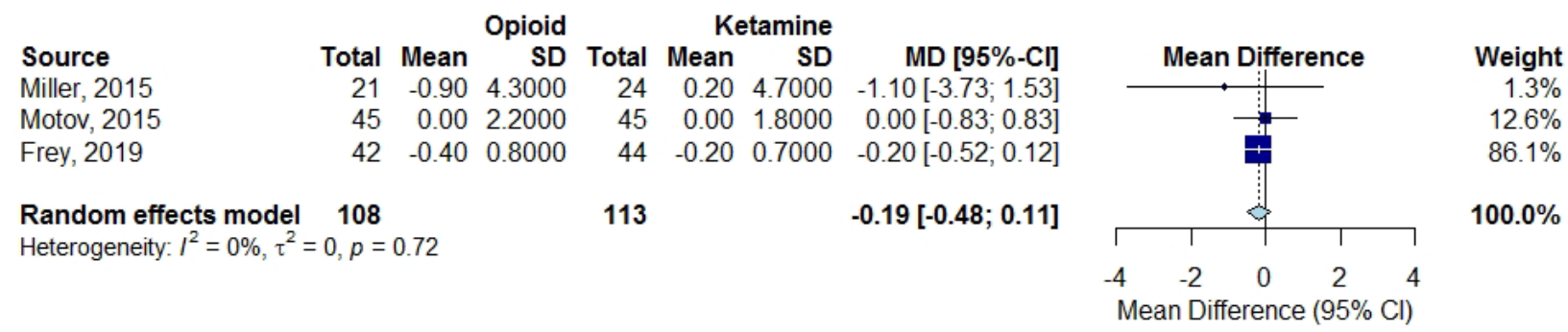

Figure F-65. Mean difference change in oxygen saturation at $\mathbf{3 0}$ minutes - additional findings, opioids versus ketamine

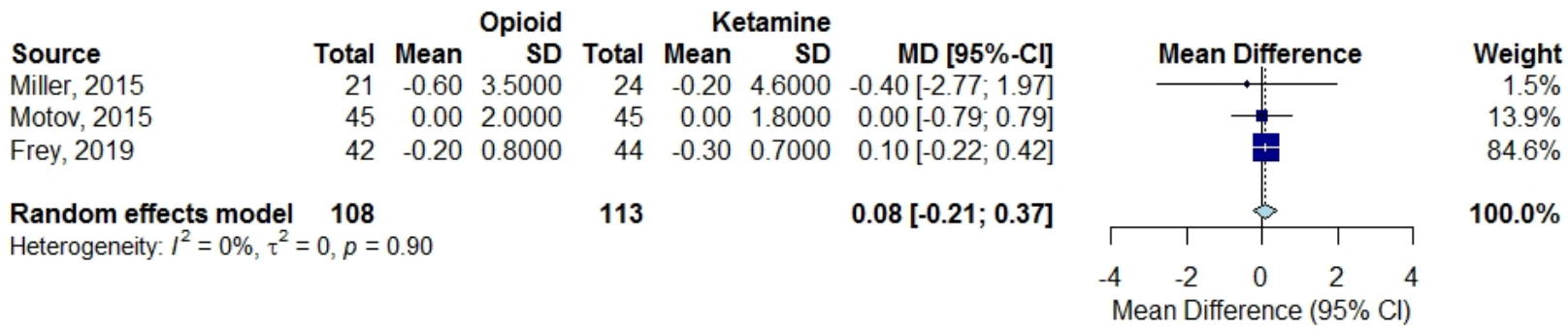


Figure F-66. Mean difference change in oxygen saturation at 60 minutes - additional findings, opioids versus ketamine

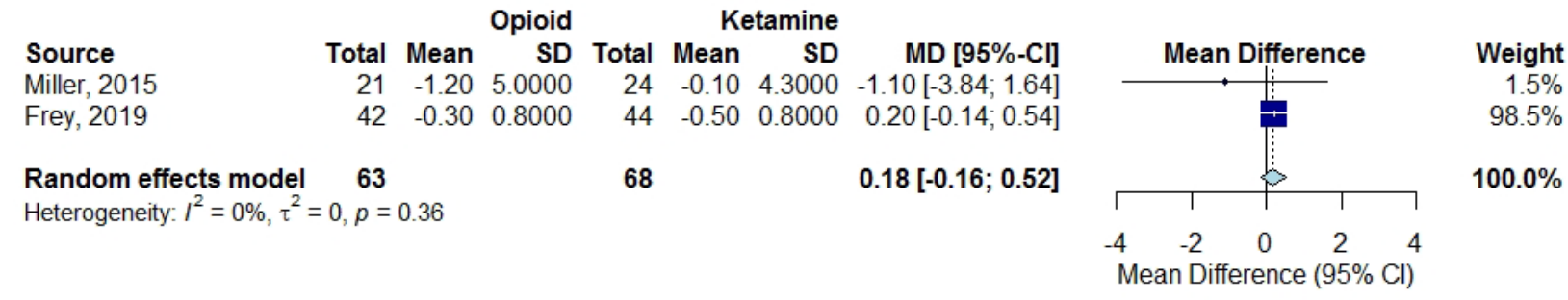

Figure F-67. Mean difference change in respiratory rate at 15 minutes - additional findings, opioids versus ketamine

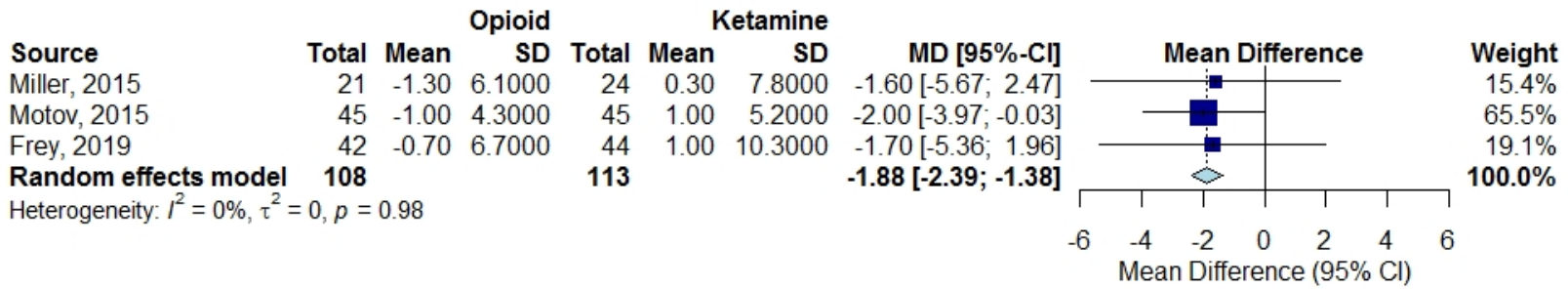

Figure F-68. Mean difference change in respiratory rate at $\mathbf{3 0}$ minutes - additional findings, opioids versus ketamine

\begin{tabular}{|c|c|c|c|c|c|c|c|c|c|}
\hline \multirow{8}{*}{$\begin{array}{l}\text { Source } \\
\text { Miller, } 2015 \\
\text { Motov, } 2015 \\
\text { Frey, } 2019 \\
\text { Random effects model } \\
\text { Heterogeneity: } I^{2}=62 \%, \tau^{2}\end{array}$} & \multirow{3}{*}{$\begin{array}{r}\text { Total } \\
21\end{array}$} & \multirow[b]{2}{*}{ Mean } & \multicolumn{2}{|l|}{ Opioid } & \multicolumn{2}{|c|}{ Ketamine } & \multirow[b]{2}{*}{$\operatorname{MD}[95 \%-\mathrm{Cl}]$} & \multirow[b]{2}{*}{ Mean Difference } & \multirow[b]{2}{*}{ Weight } \\
\hline & & & SD & Total & Mean & SD & & & \\
\hline & & -0.70 & 5.6000 & 24 & 0.00 & 6.4000 & $-0.70[-4.21 ; 2.81]$ & & $27.5 \%$ \\
\hline & 45 & 0.00 & 4.2000 & 45 & 0.00 & 5.4000 & $0.00[-2.00 ; 2.00]$ & & $41.5 \%$ \\
\hline & 42 & -3.10 & 6.7000 & 44 & 1.20 & 7.9000 & $-4.30[-7.39 ;-1.21]$ & & $31.0 \%$ \\
\hline & 108 & & & 113 & & & $-1.52[-4.13 ; 1.08]$ & $==$ & $100.0 \%$ \\
\hline & $=3.223$ & $32, p=0$ & & & & & & & \\
\hline & & & & & & & & 0 & \\
\hline
\end{tabular}

Figure F-69. Mean difference change in respiratory rate at 60 minutes - additional findings, opioids versus ketamine

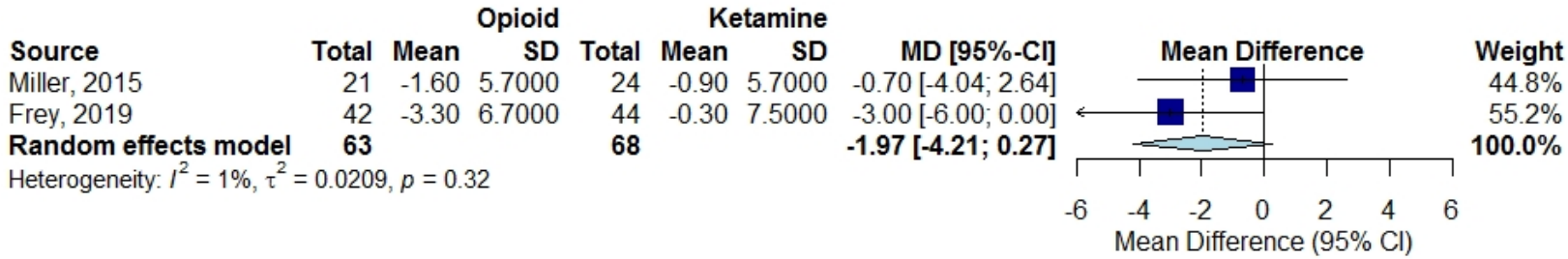


Figure F-70. Mean difference change in systolic blood pressure at 15 minutes - additional findings, opioids versus ketamine

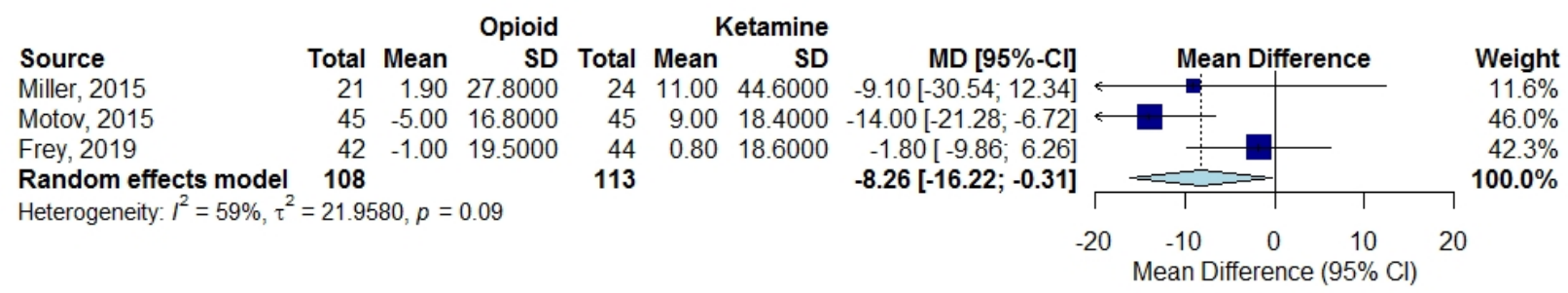

Figure F-71. Mean difference change in systolic blood pressure at 30 minutes - additional findings, opioids versus ketamine

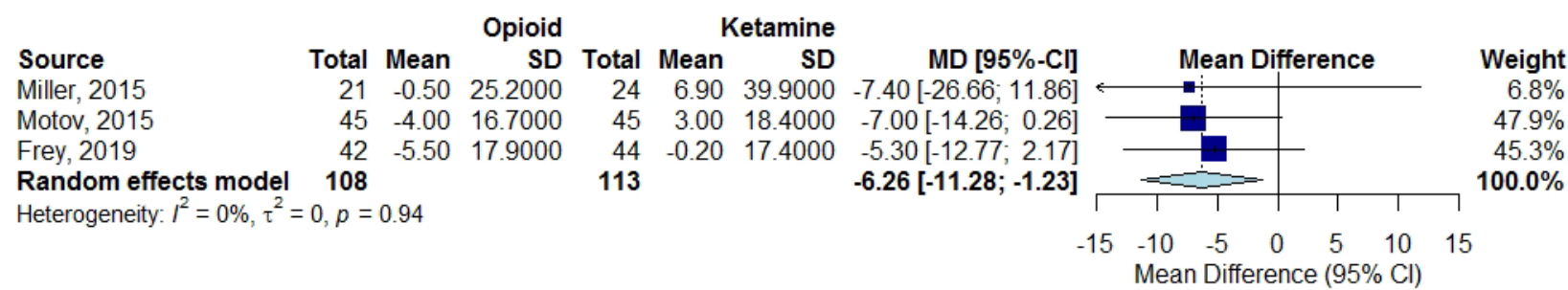

Figure F-72. Mean difference change in systolic blood pressure at 60 minutes - additional findings, opioids versus ketamine

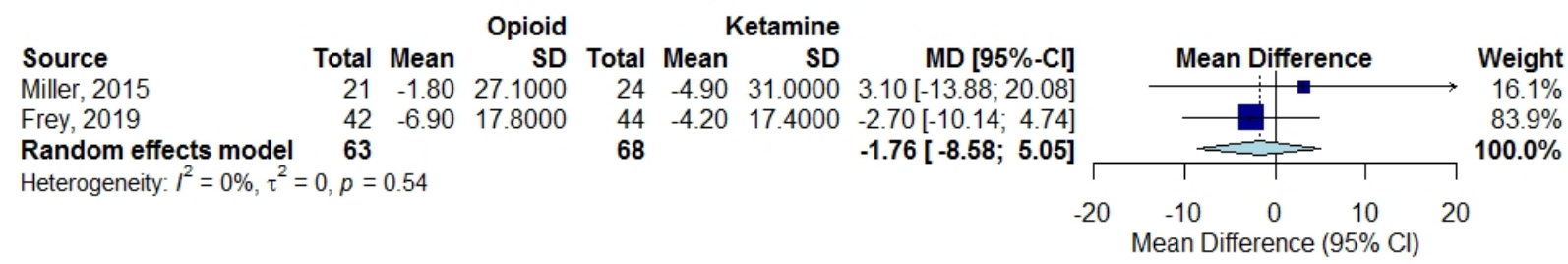

Figure F-73. Risk difference respiratory depression, combination opioids and ketamine versus opioids

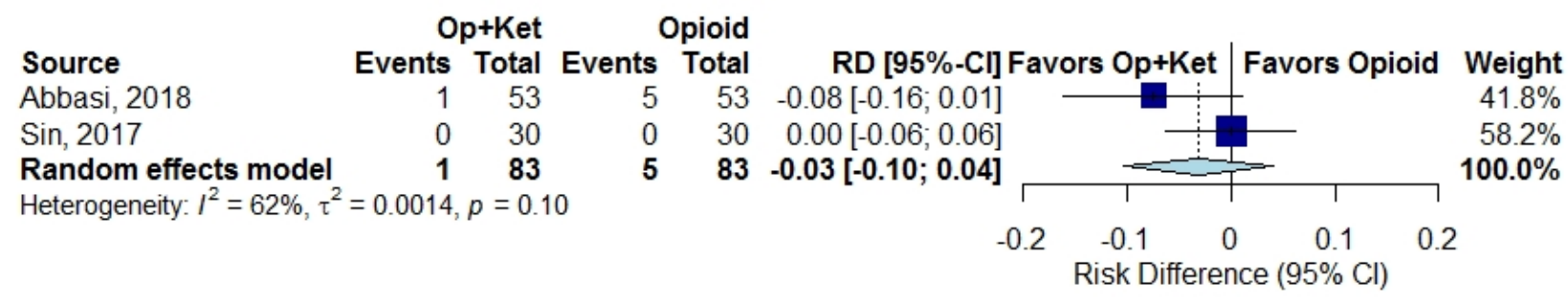


Figure F-74. Mean difference change in systolic blood pressure at 30 minutes - additional findings, combination opioids and ketamine versus opioids

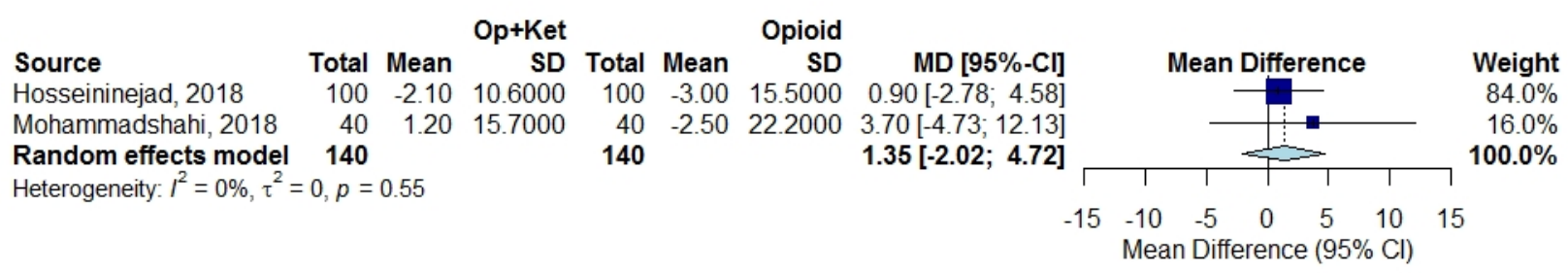

Figure F-75. Mean difference change in systolic blood pressure at 60 minutes - additional findings, combination opioids and ketamine versus opioids

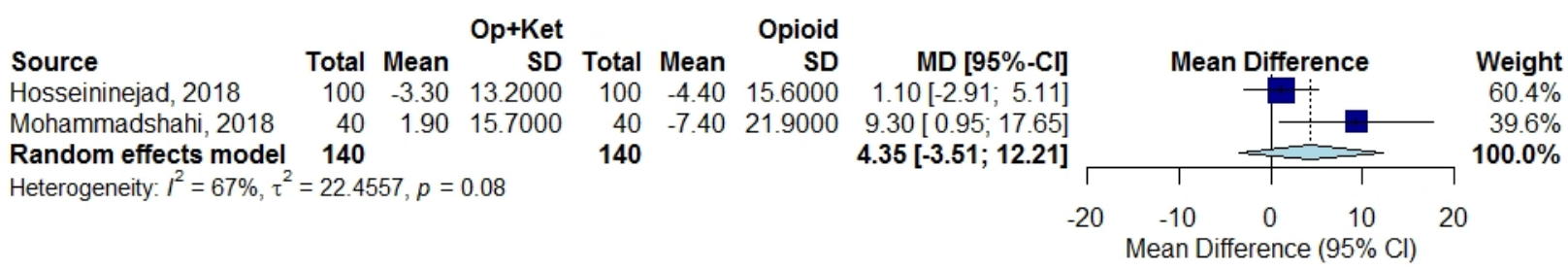

Figure F-76. Risk difference any adverse event, opioids versus acetaminophen

\begin{tabular}{|c|c|c|c|c|c|c|c|c|}
\hline \multirow{2}{*}{ Source } & \multicolumn{2}{|c|}{ Opioid } & \multicolumn{2}{|r|}{ APAP } & \multirow[b]{2}{*}{$\mathrm{RD}[95 \%-\mathrm{Cl}]$} & \multirow[b]{2}{*}{ Favors Opioid } & \multirow[b]{2}{*}{ Favors APAP } & \multirow{3}{*}{ Weight } \\
\hline & Events & Total & Events & Total & & & & \\
\hline Craig, 2012 & 8 & 28 & 2 & 27 & $0.21[0.02 ; 0.41]$ & & & \\
\hline Serinken, 2012 & 5 & 35 & 2 & 38 & $0.09[-0.05 ; 0.23]$ & & & $20.1 \%$ \\
\hline Eken, 2013 & 7 & 45 & 4 & 46 & $0.07[-0.06 ; 0.20]$ & & & $20.1 \%$ \\
\hline Masoumi, 2014 & 14 & 54 & 3 & 54 & $0.20[0.07 ; 0.34]$ & & & $20.1 \%$ \\
\hline Vahdati, 2014 & 28 & 30 & 0 & 30 & $0.93[0.83 ; 1.04]$ & & & $20.4 \%$ \\
\hline \multirow{3}{*}{\multicolumn{6}{|c|}{ Heterogeneity: $I^{2}=98 \%, \tau^{2}=0.1255, p<0.01$}} & & & $100.0 \%$ \\
\hline & & & & & & $\mathrm{T}$ & 1 & \\
\hline & & & & & & -0.5 & 0.5 & \\
\hline
\end{tabular}

Figure F-77. Risk difference hypotension, opioids versus acetaminophen

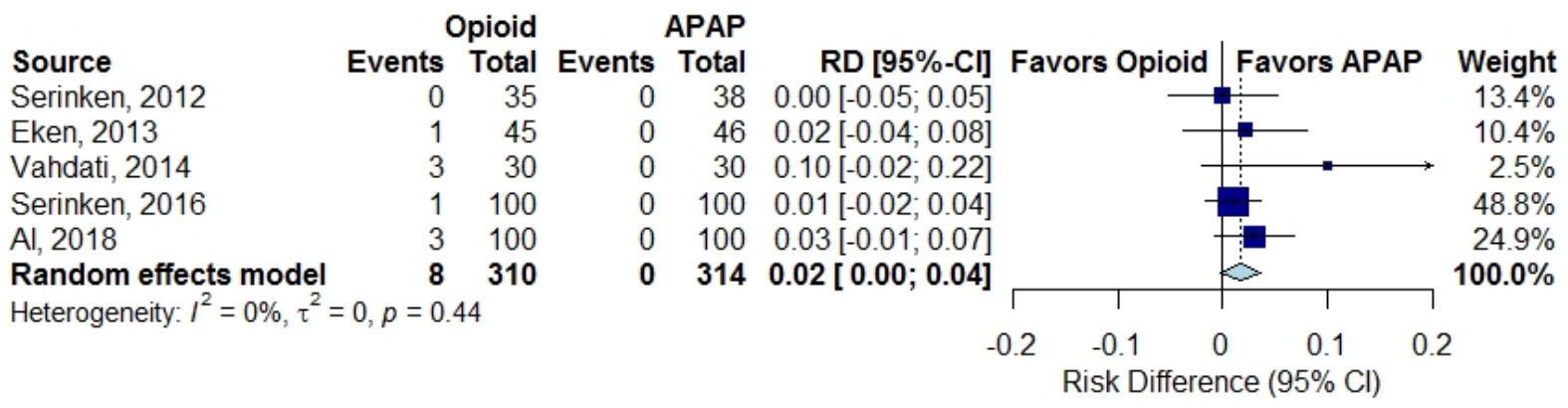


Figure F-78. Risk difference mental status changes dizziness, opioids versus acetaminophen

\begin{tabular}{|c|c|c|c|c|c|c|c|c|}
\hline & & pioid & & APAP & & & & \\
\hline Source & Events & Total & Events & Total & $\mathrm{RD}[95 \%-\mathrm{Cl}]$ & Favors Opioid & Favors APAP & Weight \\
\hline Serinken, 2012 & 3 & 35 & 0 & 38 & $0.09[-0.02 ; 0.19]$ & & & $11.7 \%$ \\
\hline Eken, 2013 & 3 & 45 & 0 & 46 & $0.07[-0.02 ; 0.15]$ & & & $18.4 \%$ \\
\hline Vahdati, 2014 & 1 & 30 & 0 & 30 & $0.03[-0.05 ; 0.12]$ & & & $16.1 \%$ \\
\hline Jalili, 2016 & 2 & 30 & 0 & 30 & $0.07[-0.04 ; 0.17]$ & & & $11.1 \%$ \\
\hline Mollaei, 2016 & 3 & 28 & 0 & 27 & $0.11[-0.02 ; 0.24]$ & & & $7.5 \%$ \\
\hline Al, 2018 & 9 & 100 & 1 & 100 & $0.08[0.02 ; 0.14]$ & & & $35.1 \%$ \\
\hline Random effects model & 21 & 268 & 1 & 271 & $0.07[0.05 ; 0.09]$ & & S & $100.0 \%$ \\
\hline Heterogeneity: $I^{2}=0 \%, \tau^{2}=$ & $=0, p=0$. & & & & & 1 & 1 & \\
\hline & & & & & & -0.1 & 0.1 & 2 \\
\hline
\end{tabular}

Figure F-79. Risk difference any adverse event - subgroup location of pain, opioids versus acetaminophen

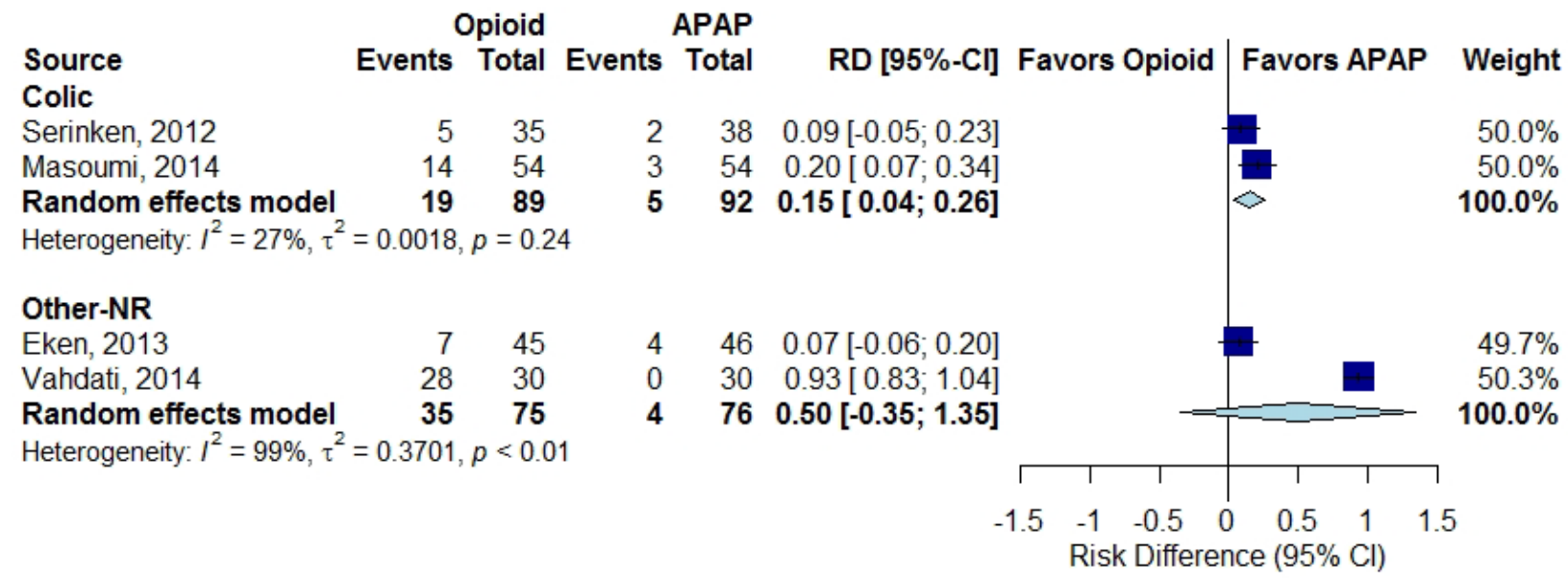

Figure F-80. Risk difference hypotension - subgroup location of pain, opioids versus acetaminophen

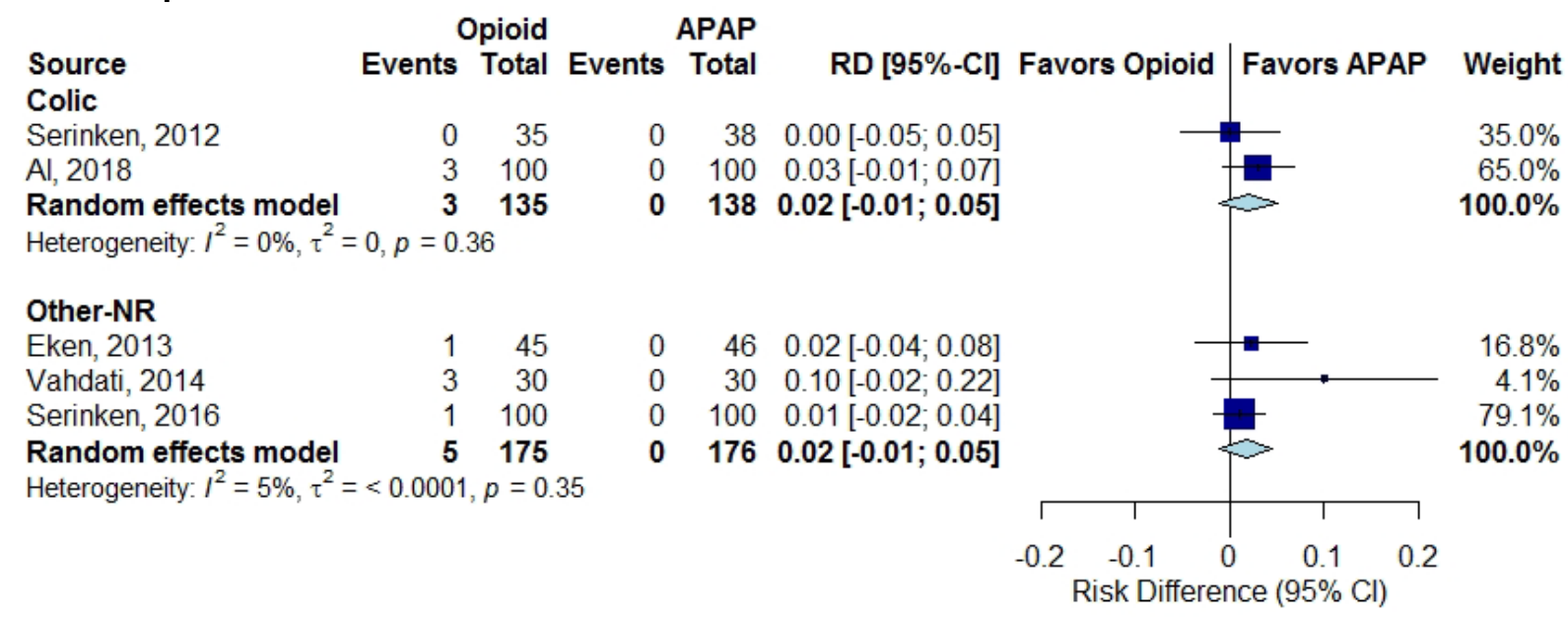


Figure F-81. Risk difference dizziness - subgroup location of pain, opioids versus acetaminophen

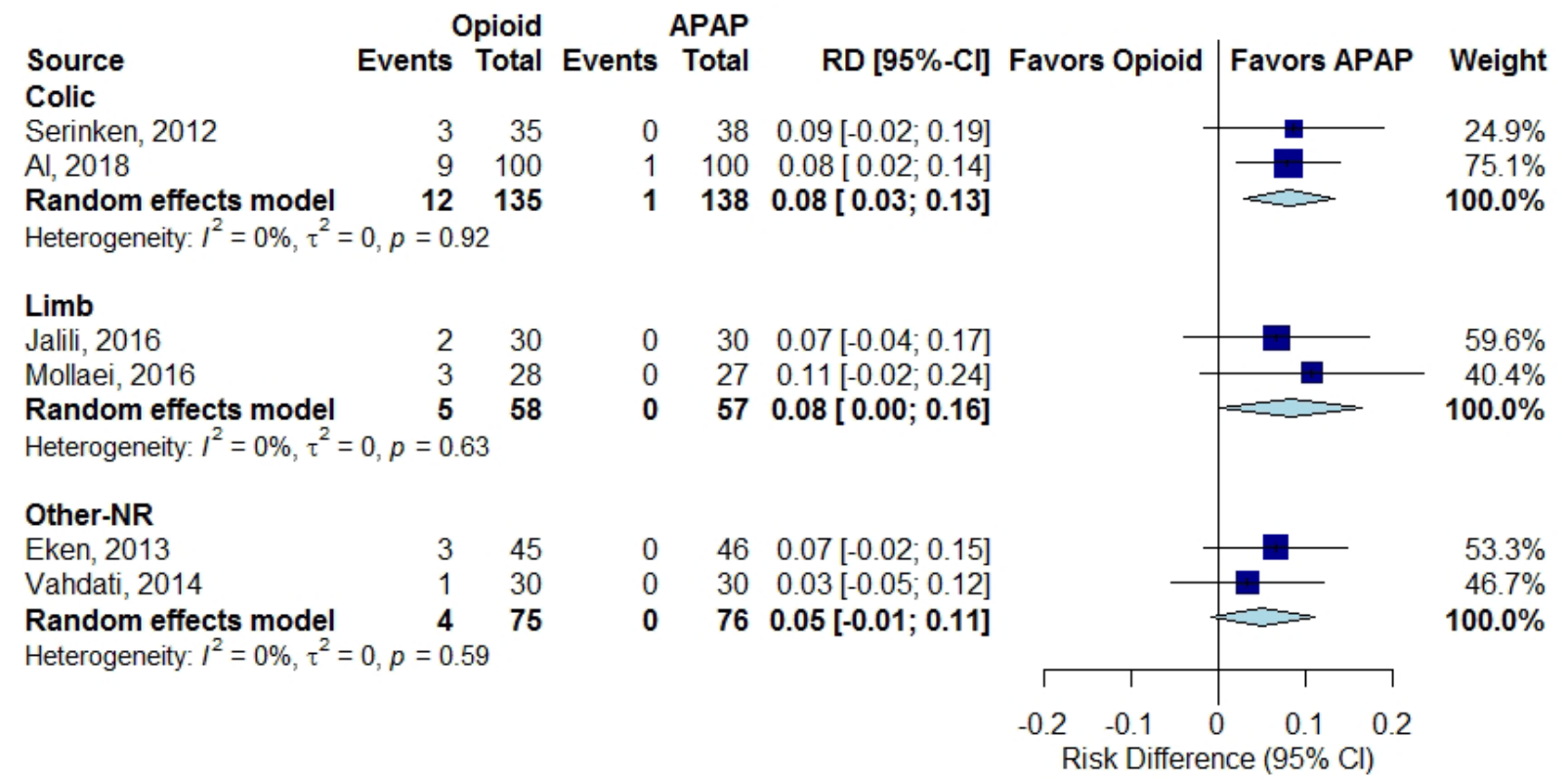

Figure F-82. Risk difference any adverse event - subgroup traumatic pain, opioids versus acetaminophen

\begin{tabular}{|c|c|c|c|c|c|c|c|c|}
\hline \multicolumn{4}{|c|}{ Opioid } & APAP & \multirow[b]{2}{*}{ RD $[95 \%-\mathrm{Cl}]$} & \multirow[b]{2}{*}{ Favors Opioid } & \multirow[b]{2}{*}{ Favors APAP } & \multirow{5}{*}{$\begin{array}{r}\text { Weight } \\
49.3 \% \\
50.7 \% \\
100.0 \%\end{array}$} \\
\hline Source & Events & Total & Events & Total & & & & \\
\hline Craig, 2012 & 8 & 28 & 2 & 27 & $0.21[0.02 ; 0.41]$ & & & \\
\hline Vahdati, 2014 & 28 & 30 & 0 & 30 & $0.93[0.83 ; 1.04]$ & & & \\
\hline Random effects model & 36 & 58 & 2 & 57 & $0.58[-0.13 ; 1.28]$ & & & \\
\hline \multirow{2}{*}{\multicolumn{6}{|c|}{ Heterogeneity: $I^{2}=98 \%, \tau^{2}=0.2541, p<0.01$}} & 「 & $T$ & \\
\hline & & & & & & -2 & 0 & \\
\hline
\end{tabular}

Figure F-83. Risk difference dizziness - subgroup traumatic pain, opioids versus acetaminophen

\begin{tabular}{|c|c|c|c|c|c|c|c|c|}
\hline & & Opioid & & APAP & & & & \\
\hline $\begin{array}{l}\text { Source } \\
\text { Vahdati, } 2014\end{array}$ & $\begin{array}{r}\text { Events } \\
1\end{array}$ & Total & Events & $\begin{array}{r}\text { Total } \\
30\end{array}$ & $\begin{array}{r}\text { RD [95\%-Cl] } \\
0\end{array}$ & Favors Opioid & Favors APAP & $\begin{array}{r}\text { Weight } \\
46.4 \%\end{array}$ \\
\hline Jalili, 2016 & 2 & 30 & 0 & 30 & $0.07[-0.04 ; 0.17]$ & & & $31.9 \%$ \\
\hline Mollaei, 2016 & 3 & 28 & 0 & 27 & $0.11[-0.02 ; 0.24]$ & & & $21.6 \%$ \\
\hline Random effects mode & 6 & 88 & 0 & 87 & $0.06[0.00 ; 0.12]$ & & $=0$ & $100.0 \%$ \\
\hline Heterogeneity: $I^{2}=0 \%, \tau^{2}$ & $=0, p=0$. & & & & & | & 1 & \\
\hline & & & & & & $\begin{array}{ll}-0.2 & -0.1 \\
& \text { Rick }\end{array}$ & 0.2 & \\
\hline
\end{tabular}


Figure F-84. Risk difference nausea - additional findings, opioids versus acetaminophen Opioid APAP

Masoumi, 2014

Vahdati, 2014

Events Total Events Total

Mollaei, 2016

Serinken, 2016

$8 \begin{array}{rr}8 & \text { Total } \\ 8 & 54\end{array}$

Random effects model $\quad 22 \quad 212$

Heterogeneity: $I^{2}=85 \%, \tau^{2}=0.0157, p<0.01$

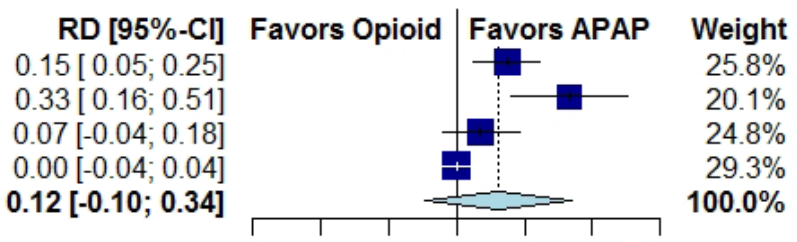

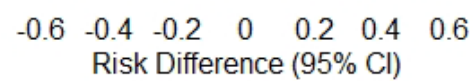

Figure F-85. Risk difference nausea and/or vomiting - additional findings, opioids versus acetaminophen

\begin{tabular}{|c|c|c|c|c|c|c|c|c|c|}
\hline \multirow[b]{2}{*}{ Source } & \multicolumn{2}{|c|}{ Opioid } & \multicolumn{2}{|r|}{ APAP } & \multirow[b]{2}{*}{$\mathrm{RD}[95 \%-\mathrm{Cl}]$} & \multirow[b]{2}{*}{ Favors Opioid } & \multirow{2}{*}{\multicolumn{2}{|c|}{ Favors APAP }} & \multirow{5}{*}{$\begin{array}{r}\text { Weight } \\
39.7 \% \\
60.3 \% \\
\mathbf{1 0 0 . 0 \%}\end{array}$} \\
\hline & Events & Total & Events & Total & & & & & \\
\hline Serinken, 2012 & 1 & 35 & 2 & 38 & $-0.02[-0.11 ; 0.07]$ & & & & \\
\hline Eken, 2013 & 1 & 45 & 2 & 46 & $-0.02[-0.09 ; 0.05]$ & 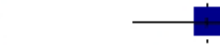 & & & \\
\hline Random effects model & 2 & 80 & 4 & 84 & $-0.02[-0.08 ; 0.03]$ & & $=$ & & \\
\hline \multirow{2}{*}{\multicolumn{6}{|c|}{ Heterogeneity: $I^{2}=0 \%, \tau^{2}=0, p=0.96$}} & & T & & \\
\hline & & & & & & -0.1 & 0.1 & 0.2 & \\
\hline
\end{tabular}

Figure F-86. Risk difference vomiting - additional findings, opioids versus acetaminophen

\begin{tabular}{|c|c|c|c|c|c|c|c|c|}
\hline \multirow{2}{*}{ Source } & \multicolumn{2}{|c|}{ Opioid } & \multicolumn{2}{|c|}{ APAP } & \multirow[b]{2}{*}{$\mathrm{RD}[95 \%-\mathrm{Cl}]$} & \multirow[b]{2}{*}{ Favors Opioid } & \multirow[b]{2}{*}{ Favors APAP } & \multirow{3}{*}{$\begin{array}{r}\text { Weight } \\
33.8 \%\end{array}$} \\
\hline & Events & Total & Events & Total & & & & \\
\hline Masoumi, 2014 & 6 & 54 & 0 & 54 & $0.11[0.02 ; 0.20]$ & & & \\
\hline Vahdati, 2014 & 6 & 30 & 0 & 30 & $0.20[0.05 ; 0.35]$ & & & $24.2 \%$ \\
\hline Al, 2018 & 1 & 100 & 1 & 100 & $0.00[-0.03 ; 0.03]$ & & & $42.0 \%$ \\
\hline Random effects model & 13 & 184 & 1 & 184 & $0.09[-0.03 ; 0.20]$ & & & $100.0 \%$ \\
\hline \multirow{2}{*}{\multicolumn{6}{|c|}{ Heterogeneity: $I^{2}=83 \%, \tau^{2}=0.0075, p<0.01$}} & T & T & \\
\hline & & & & & & -0.2 & 0.2 & 4 \\
\hline
\end{tabular}

Figure F-87. Risk difference any adverse event, opioids versus nonsteroidal anti-inflammatory drugs

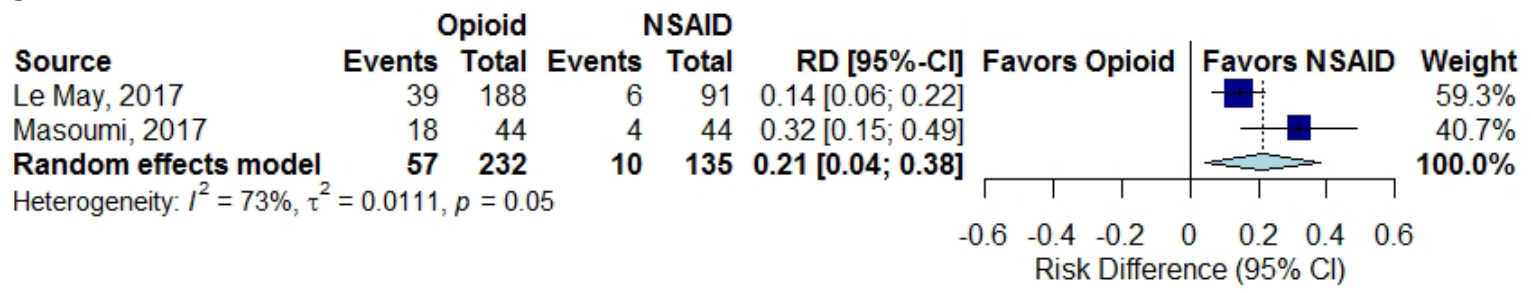

Figure F-88. Risk difference mental status changes drowsiness, opioids versus nonsteroidal antiinflammatory drugs

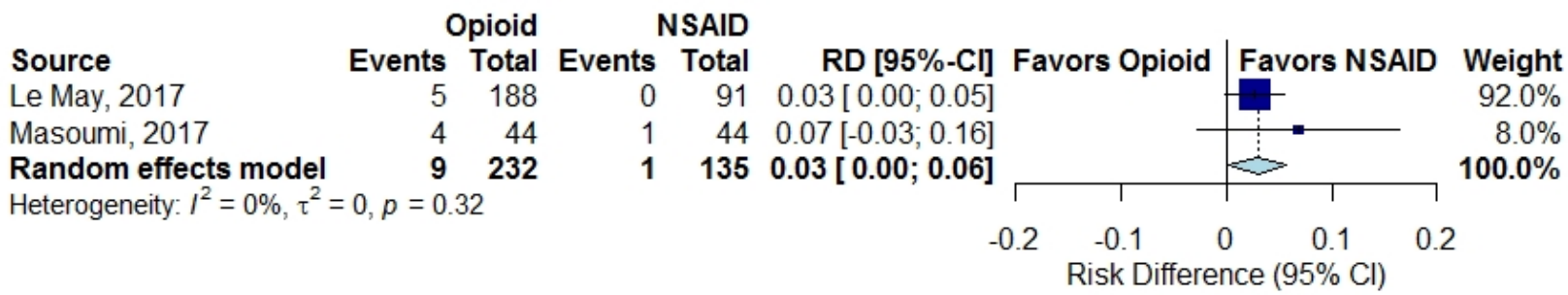


Figure F-89. Risk difference nausea - additional findings, opioids versus nonsteroidal antiinflammatory drugs

\begin{tabular}{|c|c|c|c|c|c|c|c|c|}
\hline \multicolumn{3}{|c|}{ Opioid } & \multicolumn{2}{|c|}{ NSAID } & \multirow[b]{2}{*}{$\mathrm{RD}[95 \%-\mathrm{Cl}]$} & \multirow[b]{2}{*}{ Favors Opioid } & \multirow[b]{2}{*}{ Favors NSAID } & \multirow{3}{*}{$\begin{array}{r}\text { Weight } \\
19.6 \%\end{array}$} \\
\hline Source & Events & Total & Events & Total & & & & \\
\hline Safdar, 2006 & 7 & 43 & 1 & 43 & $0.14[0.02 ; 0.26]$ & & \begin{tabular}{l:l}
0 \\
\hdashline
\end{tabular} & \\
\hline Le May, 2017 & 11 & 188 & 0 & 91 & $0.06[0.02 ; 0.09]$ & & & $64.1 \%$ \\
\hline Masoumi, 2017 & 9 & 44 & 2 & 44 & $0.16[0.02 ; 0.29]$ & & 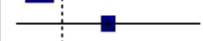 & $16.3 \%$ \\
\hline Random effects model & 27 & 275 & 3 & 178 & $0.09[0.03 ; 0.15]$ & & $\Rightarrow$ & $100.0 \%$ \\
\hline \multirow{2}{*}{\multicolumn{6}{|c|}{ Heterogeneity: $I^{2}=41 \%, \tau^{2}=0.0011, p=0.18$}} & $T$ & 1 & \\
\hline & & & & & & $\begin{array}{lll}-0.3 & -0.2 & -0.1\end{array}$ & $\begin{array}{lll}0.1 & 0.2 & 0\end{array}$ & \\
\hline
\end{tabular}

Figure F-90. Risk difference vomiting - additional findings, opioids versus nonsteroidal antiinflammatory drugs

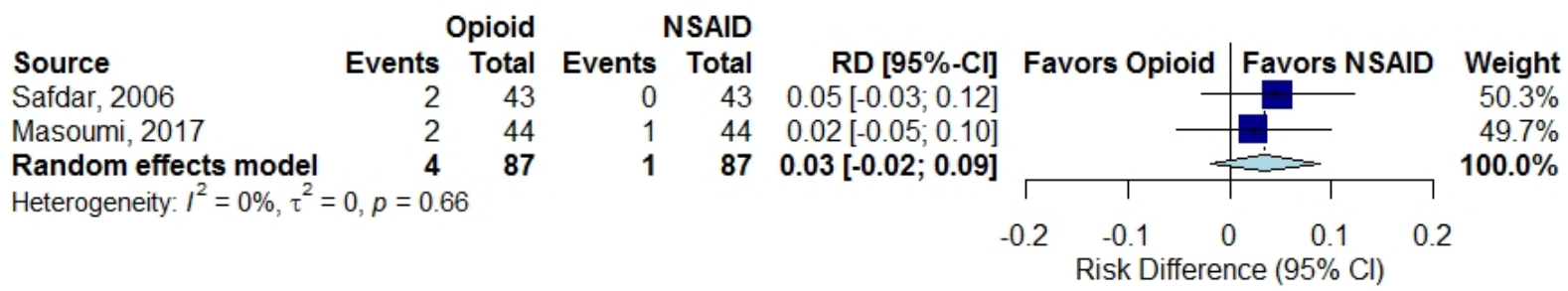

Figure F-91. Risk difference any adverse event, acetaminophen versus nonsteroidal antiinflammatory drugs

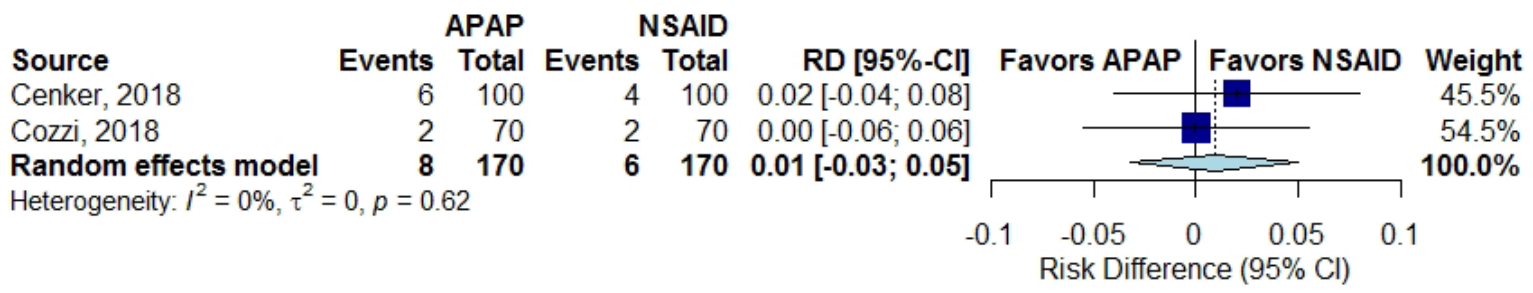

Figure F-92. Risk difference vomiting, acetaminophen versus nonsteroidal anti-inflammatory drugs

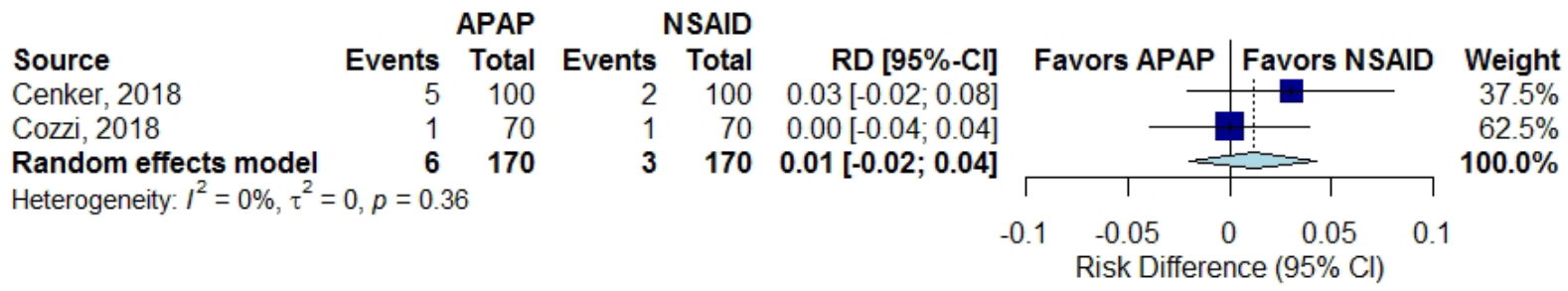

Figure F-93. Risk difference any adverse event, morphine versus fentanyl

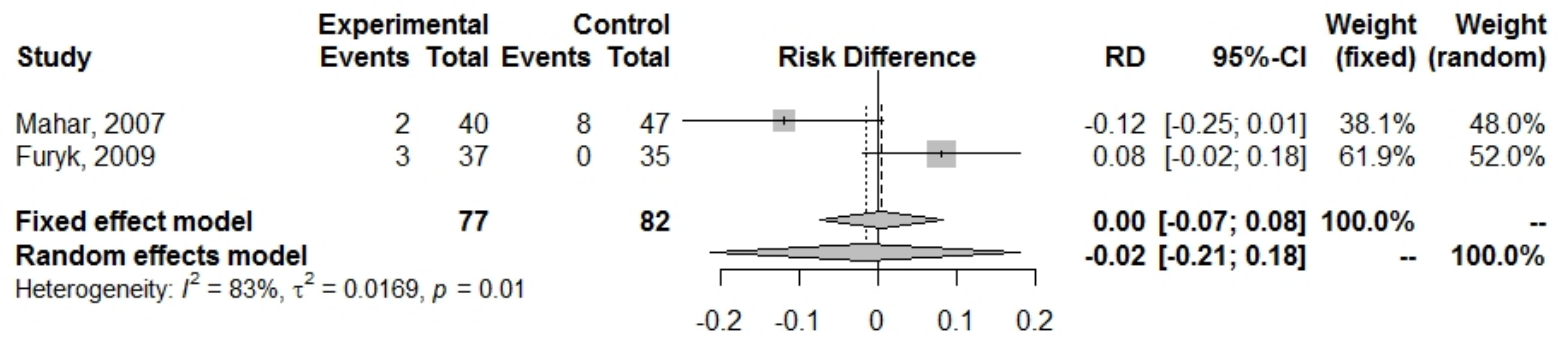


Figure F-94. Mean difference change in heart rate, morphine versus fentanyl

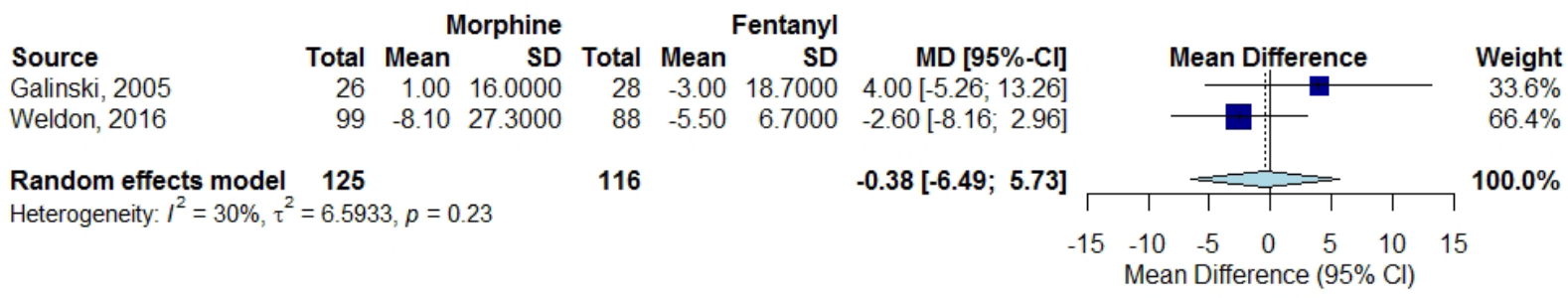

Figure F-95. Risk difference hypotension, morphine versus fentanyl

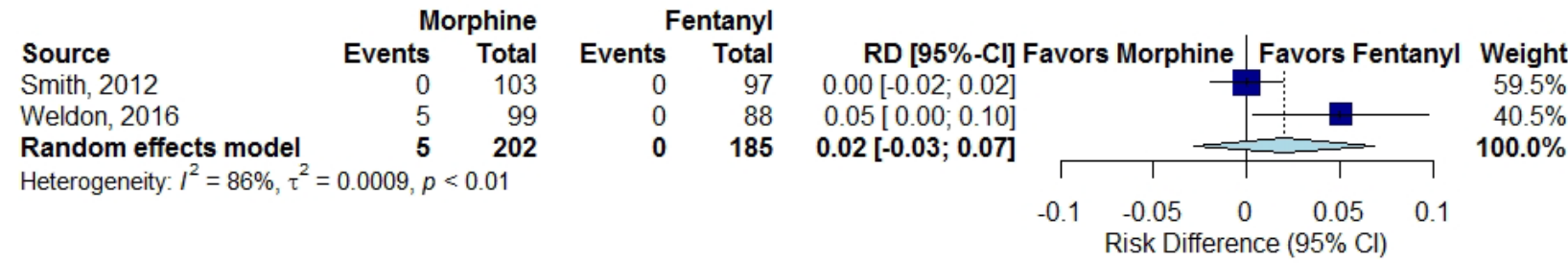

Figure F-96. Risk difference nausea, morphine versus fentanyl - emergency medical services

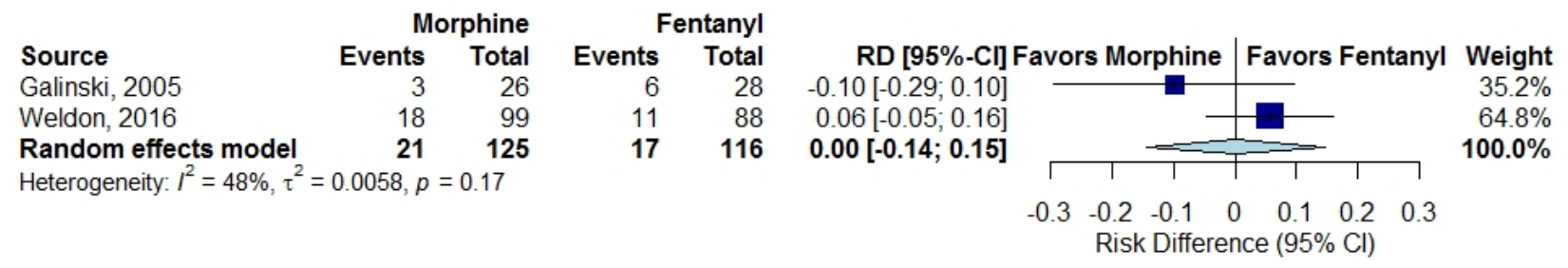

Figure F-97. Risk difference nausea, morphine versus fentanyl - emergency department

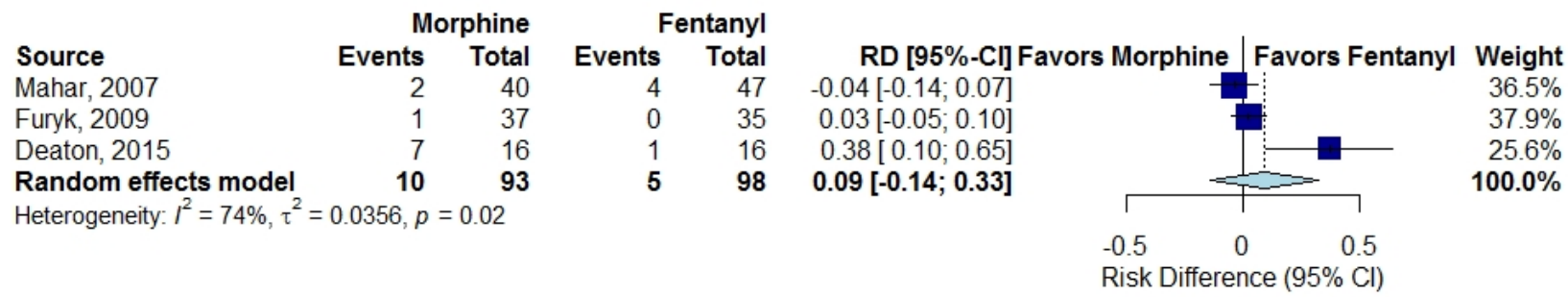

Figure F-98. Risk difference nausea and/or vomiting, morphine versus fentanyl

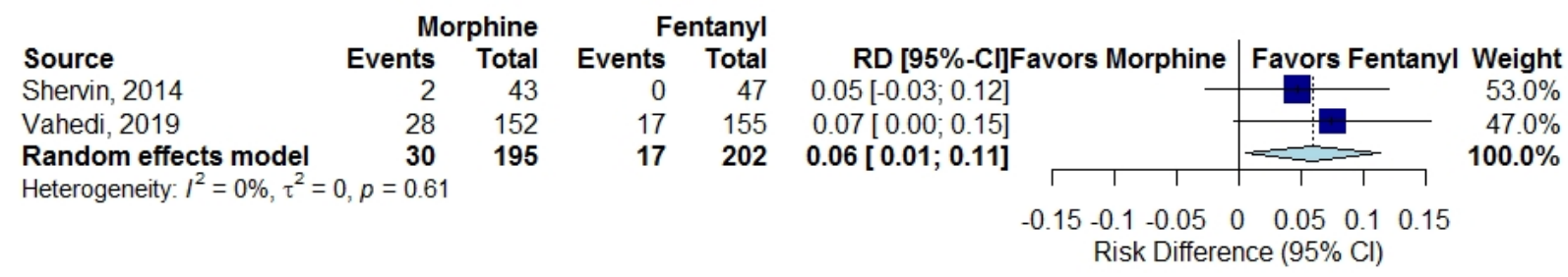


Figure F-99. Mean difference change in respiratory rate, morphine versus fentanyl - emergency medical services

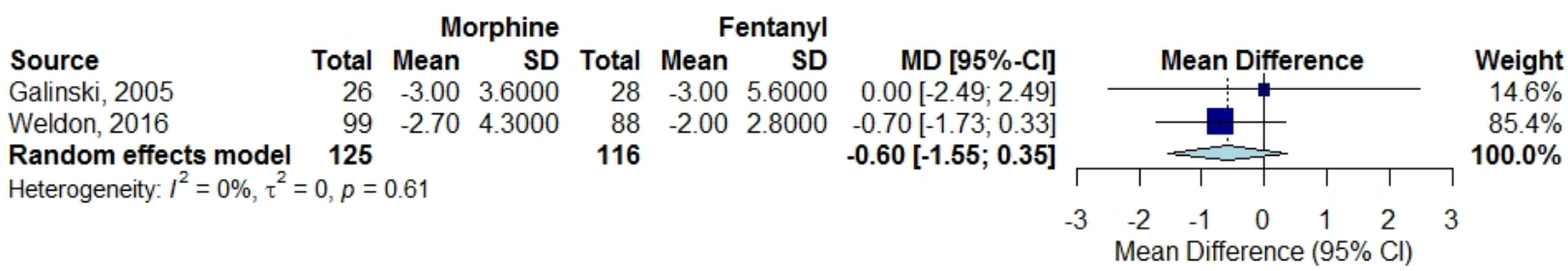

Figure F-100. Risk difference vomiting, morphine versus fentanyl - emergency medical services

\begin{tabular}{|c|c|c|c|c|c|c|c|c|c|}
\hline \multicolumn{3}{|c|}{ Morphine } & \multicolumn{2}{|c|}{ Fentanyl } & \multirow{2}{*}{\multicolumn{2}{|c|}{ RD $[95 \%-\mathrm{Cl}]$ Favors Morphine }} & \multirow{2}{*}{\multicolumn{2}{|c|}{ | Favors Fentanyl }} & \multirow[b]{2}{*}{ Weight } \\
\hline Source & Events & Total & Events & Total & & & & & \\
\hline Galinski, 2005 & 3 & 26 & 3 & 28 & $0.01[-0.16 ; 0.18]$ & & & & $1.0 \%$ \\
\hline Smith, 2012 & 0 & 103 & 0 & 97 & $0.00[-0.02 ; 0.02]$ & & & & $76.3 \%$ \\
\hline Weldon, 2016 & 2 & 99 & 1 & 88 & $0.01[-0.03 ; 0.04]$ & & & & $22.7 \%$ \\
\hline Random effects mode & 5 & 228 & 4 & 213 & $0.00[-0.01 ; 0.02]$ & & & & $100.0 \%$ \\
\hline \multirow{2}{*}{\multicolumn{2}{|c|}{ Heterogeneity: $I^{2}=0 \%, \tau^{2}=0, p=0.91$}} & & & & 年 & 1 & $T$ & 7 & \\
\hline & & & & & -0.2 & $\begin{array}{l}-0.1 \\
\text { Risk Differe }\end{array}$ & $\begin{array}{lc}0 & 0.1 \\
\text { nce } & (95 \% \mathrm{Cl})\end{array}$ & 0.2 & \\
\hline
\end{tabular}

Figure F-101. Risk difference vomiting, morphine versus fentanyl - emergency department

\begin{tabular}{|c|c|c|c|c|c|c|c|c|c|c|c|}
\hline \multicolumn{3}{|c|}{ Morphine } & \multicolumn{2}{|c|}{ Fentanyl } & \multirow[b]{2}{*}{$\operatorname{RD}[95 \%-\mathrm{Cl}]$} & \multirow{2}{*}{\multicolumn{2}{|c|}{ Favors Morphine }} & \multirow{2}{*}{\multicolumn{3}{|c|}{ Favors Fentanyl }} & \multirow[b]{2}{*}{ Weight } \\
\hline Source & Events & Total & Events & Total & & & & & & & \\
\hline Younge, 1999 & 0 & 23 & 1 & 24 & $-0.04[-0.15 ; 0.07]$ & & $-\dot{9}$ & & & & $19.0 \%$ \\
\hline Borland, 2007 & 0 & 34 & 1 & 33 & $-0.03[-0.11 ; 0.05]$ & & & & & & $35.9 \%$ \\
\hline Mahar, 2007 & 0 & 40 & 2 & 47 & $-0.04[-0.11 ; 0.03]$ & & & & . & & $45.0 \%$ \\
\hline Random effects model & 0 & 97 & 4 & 104 & $-0.04[-0.09 ; 0.01]$ & & & - & & & $100.0 \%$ \\
\hline \multirow{2}{*}{\multicolumn{2}{|c|}{ Heterogeneity: $I^{2}=0 \%, \tau^{2}=0, p=0.97$}} & & & & & 1 & $T$ & & $T$ & 1 & \\
\hline & & & & & & -0.2 & -0.1 & 0 & 0.1 & 0.2 & \\
\hline
\end{tabular}

Figure F-102. Mean difference change in pain, additional opioids versus ketamine - emergency medical services

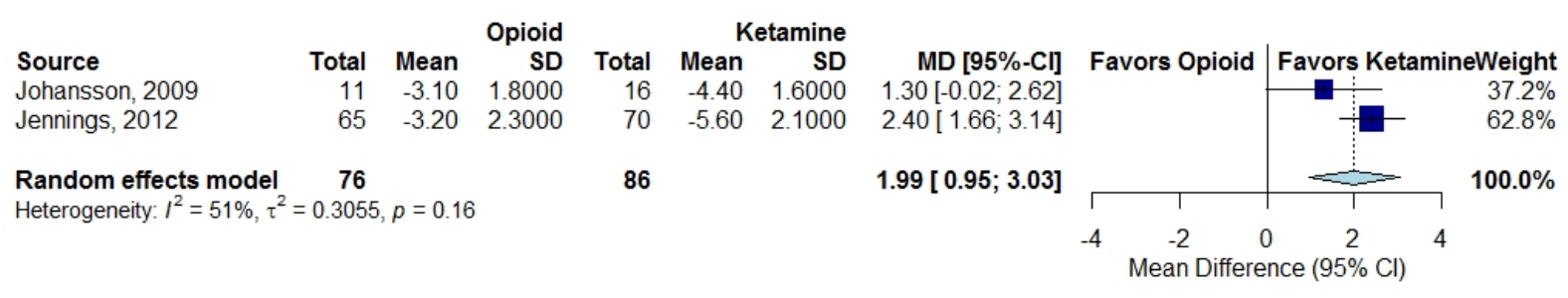


Figure F-103. Mean difference change in heart rate, additional opioids versus ketamine emergency medical services

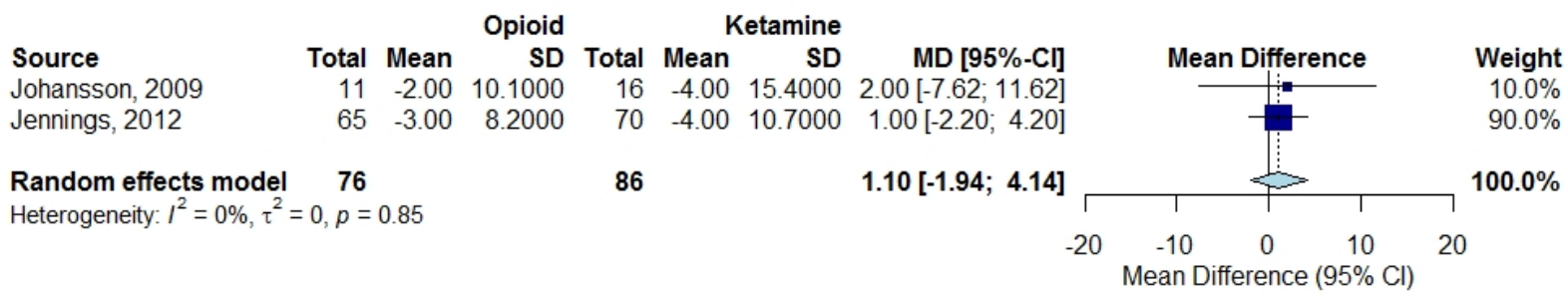

Figure F-104. Mean difference change in respiratory rate, additional opioids versus ketamine emergency medical services

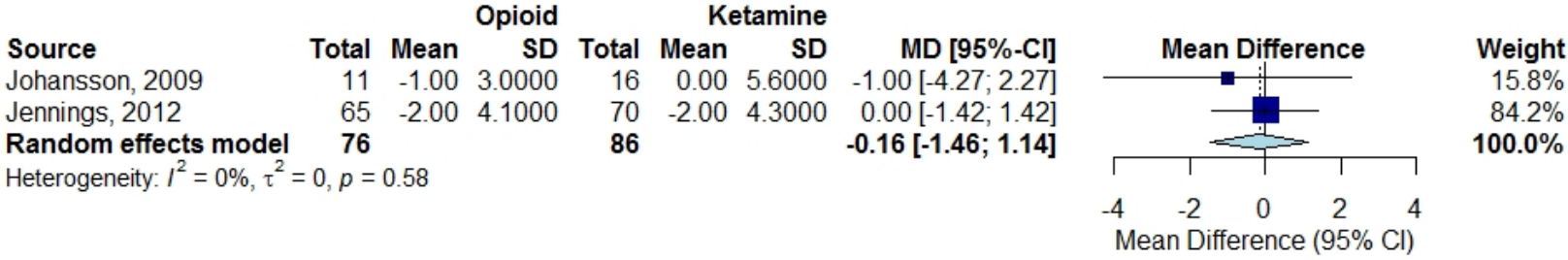

Figure F-105. Mean difference change in systolic blood pressure, additional opioids versus ketamine - emergency medical services

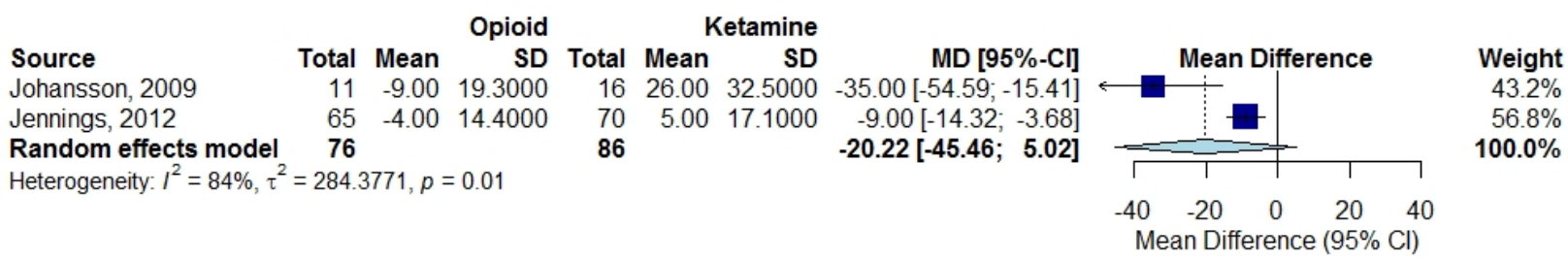

Figure F-106. Risk difference nausea, additional opioids versus ketamine - emergency medical services

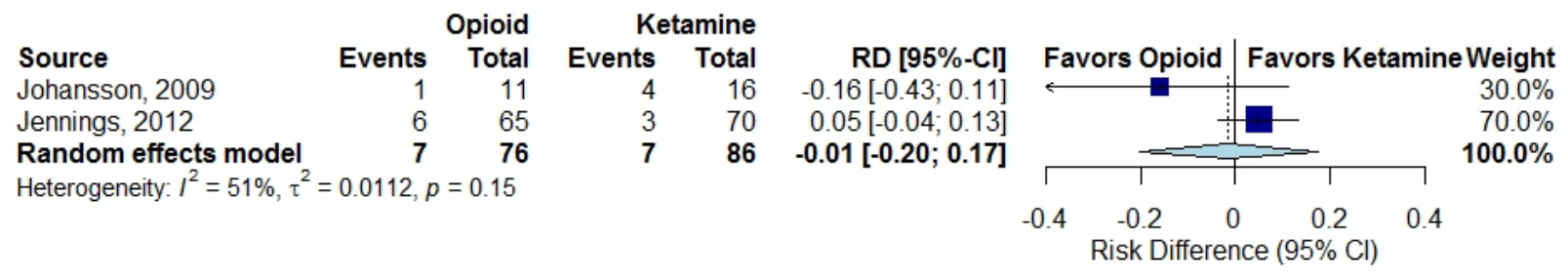


Figure F-107. Risk difference vomiting, additional opioids versus ketamine - emergency medical services

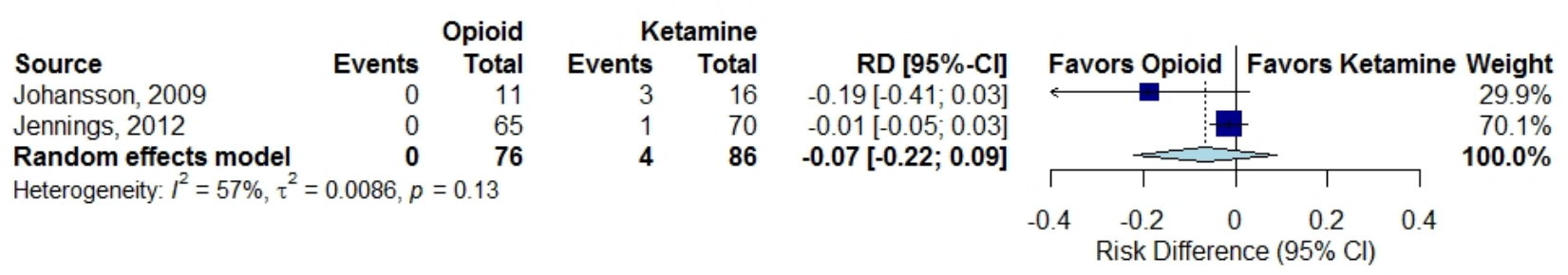

